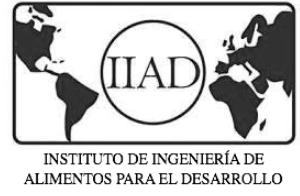

\title{
APROVECHAMIENTO DE SUBPRODUCTOS DE CULTIVOS DE HIGO CHUMBO (Opuntia ficus-indica L.) Y AGUACATE (Persea americana)
}

Tesis doctoral presentada por:

Bruno Melgar Castañeda

Dirigida por:

Esperanza M. García Castelló

Antonio D. Rodríguez López

Valencia Febrero 2019 



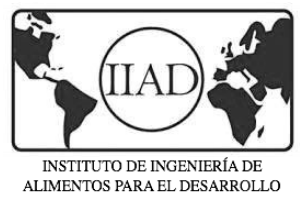

La Dra. Dña. Esperanza M. García Castelló, Investigadora del Instituto Universitario de Ingeniería de Alimentos para el Desarrollo y el Dr. D. Antonio D. Rodríguez López, Investigador del Instituto Universitario de Seguridad Industrial, Radiofísica y Medioambiental.

\section{CERTIFICAN:}

Que el trabajo que presenta Bruno Melgar Castañeda para optar al grado de doctor por la Universidad Politècnica de València, con el título "Aprovechamiento de subproductos de cultivos de higo chumbo (opuntia ficus-indica l.) y aguacate (persea americana)", ha sido realizado bajo nuestra dirección en el Instituto Universitario de Ingeniería de Alimentos para el Desarrollo de la Universidad Politècnica de València.

Y para que conste a los efectos oportunos, firman este certificado en Valencia a 21 de Febrero de 2019.

Esperanza M.

García Castelló
Antonio D.

Rodríguez López 


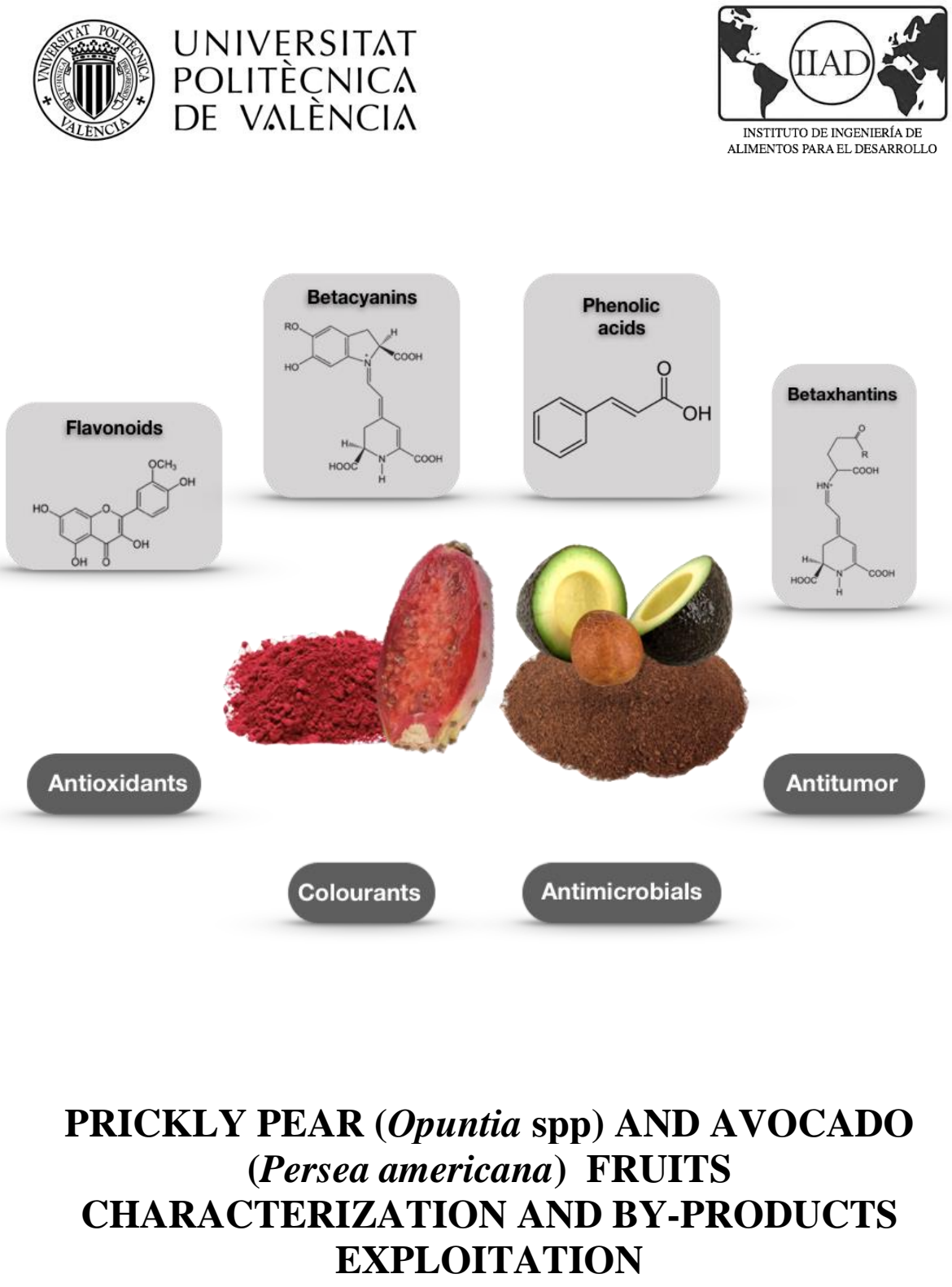



\section{as}

What is not started today is never finished tomorrow.

J.W. Von Goethe 



\section{Agradecimientos}

Siempre he sido persona de pocas palabras, ya que durante todo este tiempo he pensado que solo las cosas importantes merecen ser dichas. Afortunadamente, el realizar esta tesis me ha abierto los ojos y comienzo a observar las cosas desde otra perspectiva.

Este trabajo no es la lucha de una sola persona, sino todo lo contrario, sin el respaldo que he tenido siempre, las cosas hoy serian muy diferentes y lo minimo que puedo hacer es expresar mis gratificaciones a todas y cada una de esas personas tan especiales.

Me gustaría comenzar agradeciendo a mis padres, porque aunque suene trillado, sin ellos no estaría donde estoy ahora, se que no es nada fácil tener un hijo tan lejos y verlo raramente, pero siempre han estado ahí en todo momento.

A mi hermano, a mi tía Inez y a mi abuela Norma, ya que han sido compañeros de camino, me han proporcionado tanto cariño y amor, y han estado muy presentes incondicionalmente en todo momento.

Tambien agradezco a Maite y su familia, por haber sido mi familia en esta travesia europea, llenando los huequitos que faltan cuando tienes a tus seres queridos tan lejos.

Profesionalmente a mis tutores, principal apoyo y modelos a seguir, Esperanza y Antonio, al igual que a mis asesoras en Portugal Isabel y Lillian. A todos aquellos que colaboraron a hacer esto posible, los técnicos de laboratorio, Virginia, Carolina, Mario y especialmente a Milagro por su basta ayuda cromatografica. A los compañeros de laboratorio que siempre estuvieron para ayudar con las técnicas instrumentales, acompañando en la comida o simplemente sacando unas sonrisas, David, Vicky, Cé, Inês, Eliana, Irene y tantos otros que pudimos coincidir en estos tiempos.

No podían faltar los amigos de la Full family, que siempre estuvieron presentes para morir en wods y para una que otra cerveza, Gio, Facu, Hugo, Itahisa, Rolo, Juan Ma, el jabalí y el resto del 
zoológico que es tan extenso que si tuviera que nombrarlos, seguro sería mas difícil que escribir la tésis.

$\mathrm{Y}$ al resto de personas que de alguna forma han hecho de todo este tiempo, un periodo maravilloso lleno de diversión, compañeros de piso, de viajes, y a los erasmus, que me recordaron muchas de las buenas cosas que había olvidado, sobre todo a Andreea por todos los buenos momentos compartidos y a Alexandra por demostrame que en la diversidad y grandeza de este mundo, siempre hay oportunidades de encontrarse.

Y como no podía ser de otra forma, estos agradecimentos los escribo en uno de tantos viajes realízados gracias al apoyo CONACyT.

Muchísimas gracias a todos. 




\section{Resumen}

La industria agro-alimentaria se encuentra en constante evolución, adaptándose a las demandas de los consumidores. Un claro ejemplo es el de la industria frutícola, que ha partido de los productos mínimamente procesados, hacia procesos mucho más complejos como las destilaciones, requiriendo mayores cantidades de materias primas. Estos procesos conllevan a la generación de millones de toneladas de residuos frutícolas al año, produciendo en muchos de los casos grandes problemas con impactos medioambientales. No obstante, la riqueza organoléptica y de compuestos nutraceúticos en estos residuos hacen posible su revalorización, haciendo de manera sostenible un cambio sustancial en el impacto negativo medioambiental y generando nuevos productos con repercusiones económicas.

En este contexto, la presente tesis doctoral explora las características nutricionales, sensoriales y nutraceúticas de dos especies frutícolas (Persea americana y Opuntia spp.) y sus subproductos, con la finalidad de generar una caracterización integral y un aprovechamiento de los residuos generados por los cultivos de ambos frutos en las industrias alimentarias (pieles y semillas), así como de especies de Opuntia no utilizadas comercialmente. Esta exploración ha sido posible usando diferentes técnicas analítica, bioquímicas y microbiológicas para llevar a cabo la detección de las posibles alternativas de uso.

Como resultado a las potenciales propiedades de los frutos de aguacates y de los higos chumbos, se decidió realizar una caracterización nutricional de los principales macronutrientes, y debido a la poca información encontrada en Opuntia spp., se realizó la caracterización lipídica, de los azúcares y ácidos orgánicos de los frutos. Posteriormente se evaluaron las propiedades nutraceúticas, por un lado se evaluaron espectrofotométricamente los compuestos bioactivos de ambos subproductos frutícolas mediante distintas técnicas como Folin-Ciocalteu para la determinación de polifenoles totales, $\mathrm{Al}_{3} \mathrm{Cl}_{3}$ para determinación de flavonoides totales, y poder reductor, ABTS, DPPH, TBARS y $\beta$-caroteno para la determinación de capacidad antioxidante hidrofílica e lipofílica de los extractos, además, en Opuntia spp. se analizó el contenido de los colorantes betaxantinas $\mathrm{y}$ betacianinas. 
Por otro lado, mediante el uso de técnicas cromatográficas HPLCDAD-ESI-MS/MS, se caracterizaron los perfiles polifenólicos (ácidos fenólicos y flavonoides) de ambos subproductos frutícolas, más los perfiles betalainicos de las muestras de higos chumbos. Por último, mediante técnicas microbiológicas y ensayos citotoxicológicos, se comprobó el poder antimicrobiano, antitumoral y hepatotóxico, con ayuda de 16 cepas bacterianas, y fúngicas, 4 líneas celulares tumorales y 1 línea celular sana obtenida a partir de hígado de cerdo, denominada PLP2.

Finalmente, se ha realizado un ensayo de optimización multivariable de extracción de los compuestos bioactivos de Opuntia spp. mediante extracciones asistidas por microondas y ultrasonidos, haciendo uso de un diseño experimental estadístico empleando las herramientas de metodología de respuesta de superficie acopladas a un diseño central compuesto $2^{\wedge} 4$ con 7 puntos centrales, para la obtención de modelizaciones graficas de los parámetros de respuesta, que ayudan a identificar las condiciones óptimas de los factores de extracción empleados.

En definitiva, estos análisis suponen la obtención de información relevante sobre la extracción de compuestos bioactivos con aplicaciones nutraceúticas y colorantes, que pueden ser añadidos a una amplia gama de productos de las industrias farmacéuticas, cosméticas y alimentarias, para reforzar o mejorar las características y funcionalidades de estos. 


\section{Resum}

La indústria agroalimentària es troba en constant evolució, adaptant-se a les demandes dels consumidors. Un clar exemple és el de la indústria fructícola, que ha partit dels productes mínimament processats, cap a processos molt més complexos com les destil·lacions, requerint majors quantitats de matèries primeres. Aquests processos comporten la generació de milions de tones de residus fructícoles a l'any, produint en molts dels casos grans problemes amb impacte mediambientals. No obstant això, la riquesa nutracèutica $i$ organolèptica d'aquests residus fan possible la seua revaloració, fent de manera sostenible un canvi substancial en l'impacte negatiu mediambiental i generant nous productes amb repercussions econòmiques.

En aquest context, la present tesi doctoral explora les característiques nutricionals, sensorials i nutracèutiques de dues espècies fructícoles (Persea americana i Opuntia spp.) i els seus subproductes, amb la finalitat generar una caracterització integral i un aprofitament dels residus generats pels cultius de tots dos fruits en les indústries alimentàries (pells i llavors), així com de les espècies d'Opuntia no utilitzades comercialment. Aquesta exploració ha estat possible usant diferents tècniques analítiques, bioquímiques i microbiològiques per a dur a terme la detecció de les possibles alternatives d'ús.

A causa de les potencials propietats dels fruits d'alvocats i de les figues paleres, es va decidir realitzar una caracterització nutricional dels principals macronutrients, i a causa de la poca informació trobada en Opuntia spp., es va realitzar la caracterització lipídica, dels sucres i àcids orgànics dels fruits. Posteriorment es van avaluar les propietats nutracèutiques, d'una banda es van avaluar espectrofotomètricament els compostos bioactius de tots dos fruits mitjançant diferents tècniques com Folin-Ciocalteu per a la determinació de polifenols totals, $\mathrm{Al}_{3} \mathrm{Cl}_{3}$ per a la determinació de flavonoides totals, i poder reductor, ABTS, DPPH, TBARS i $\beta$-caroteno per a la determinació de capacitat antioxidant hidrofílica i lipofílica dels extractes. A més, en Opuntia spp. es va analitzar el contingut dels colorants betaxantines i betacianines. D'altra banda, mitjançant l'ús de tècniques cromatogràfiques HPLC-DAD-ESI-MS / MS, es van caracteritzar els perfils polifenòlics (àcids fenòlics i flavonoides) de tots dos fruits, més els perfils betalainics de les mostres de figues de moro. Finalment, mitjançant tècniques microbiològiques i assajos citotoxicològics, es va 
comprovar el poder antimicrobià, antitumoral i hepatotòxic, amb ajuda de 8 ceps bacterians, 8 ceps fúngics, 4 línies cel-lulars tumorals i 1 línia cel-lular sana obtinguda a partir de fetge de porc, anomenada PLP2 .

Finalment, s'ha realitzat un assaig d'optimització multivariable d'extracció dels compostos bioactius d'Opuntia spp. mitjançant extraccions assistides per microones i ultrasons, fent ús d'un disseny experimental estadístic emprant les eines de metodologia de resposta de superfície acoplades a un disseny central compost $2^{\wedge} 4$ amb 7 punts centrals, per a l'obtenció de modelitzacions gràfiques dels paràmetres de resposta, que ajuden a identificar les condicions òptimes dels factors d'extracció empleats.

En definitiva, aquestes anàlisis suposen l'obtenció d'informació rellevant sobre l'obtenció de compostos bioactius amb aplicacions nutracèutiques i colorants, que poden ser afegits a una àmplia gamma de productes de les indústries farmacèutiques, cosmètiques i alimentàries, per reforçar o millorar les característiques i funcionalitats d'aquests. 


\section{Abstract}

Agro-alimentary industries are constantly evolving and adapting to their customer needs, for instance, in the fruit industry, the transition between minimum processed products to more complex process such as distillation has been occurring and increasing, thus, demanding higher volumes of raw materials. All this process and operations lead to millions of tons of fruit by-products generated every year, creating deep environmental issues with high impact most of the times. Nevertheless, revalorization of the by-products it possible due to the nutraceutical and organoleptic characteristics, which brings potential benefits in both, environmental protection and positive economic repercussion in a sustainable manner.

According to the previously mentioned background, this doctoral thesis focus on the nutrimental, organoleptic and nutraceutical characteristics of two different fruits (Persea americana and Opuntia spp.) and their by-products, aiming to develop an integral characterization and revalorization of the by-product produced in the food industries (seeds and peels) from both cultivars. Likewise, the exploitation of non-commercial Opuntia species. The whole exploration was possible due to the use of analytic, biochemical and microbiological techniques, which allowed us to elucidate possible alternatives of usage.

As a result of avocado and prickly pears potential functional properties, a nutritional characterization from the principal macronutrients was performed, additionally, due to the lack of information on Opuntia spp., lipid, sugar and organic acids profiling were also analysed on the edible fruits. Afterwards, nutraceutical properties were assessed, on one hand, bioactive compounds from both fruits by-products were spectrophotometric analysed through different procedures such as, total phenolic profile by Folin-Ciocalteu, total flavonoid content through $\mathrm{Al}_{3} \mathrm{Cl}_{3}$ methodology and hydrophilic and lipophilic antioxidant capacity of the extracts via reducing power, ABTS, DPPH, TBARS and $\beta$-carotene bleaching assays, besides, betaxhantins and betacyanins pigments quantification from Opuntia spp. was also performed. 
In the other hand, polyphenolic (phenolic acids and flavonoids) profiling in both fruit by-products was performed throughout chromatographic techniques such as HPLC-DAD-ESI-MS/MS, in the same manner, betalainic profile was also analysed on prickly pears. Lastly, applying microbiological techniques and cytotoxic assays, hepatotoxicity, antimicrobial and antitumor activity was tested using a freshly porcine liver extracted cell line (namely PLP2), 16 bacterial and fungus strains and 4 carcinogenic cell lines respectively.

Finally, multivariable ultrasound and microwave-assisted extractions of Opuntia spp. bioactive compounds were optimized, performing an experimental design using statistical tools such as response surface methodology (RSM) coupled to $2^{\wedge} 4$ central composite design (CCD) with 7 star points, in order to obtain graph modelling of the response parameters, which help to identify the optimal conditions of the extraction factors used.

Summarizing, relevant information on the extraction of bioactive compounds with nutraceutical and colouring applications was achieved through specific analysis, thus, the previously mention phytochemical molecules can then be added to a wide range of products within the pharmaceutical, cosmetic and food industries, to strengthen or improve the characteristics and functionalities of the final products. 


ÍNDICES 

Índice de contenidos

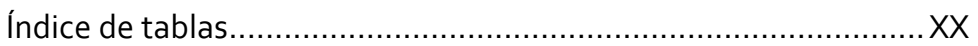

Íindice de figuras ............................................................... XXI

Índice de ecuaciones...................................................................XV

Capítulo 1 Introducción............................................... 1

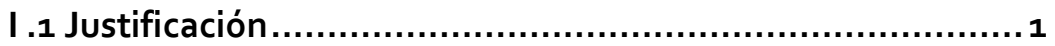

I.2 Aguacate (Persea americana Mill) .................................

I.2.1 Origen, estructuras e hibridaciones …............................. 4

I.2.2 Fisiología, formación del fruto y maduración .................... 5

I.2.3 Temporada de cultivo................................................. 7

I.2.4 Producción anual ......................................................... 7

I.3 Higos chumbos (Opuntia spp.) .......................................

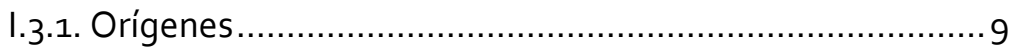

I.3.2. Taxonomía ……....................................................... 10

I.3.3. Variedades cultivadas ................................................... 11

I.3.4. Descripción morfológica............................................... 12

I.3.5. Producción y cultivos de Opuntia spp ............................. 14

I.4 Aprovechamiento de los subproductos frutícolas .............. 16

I.4.1. Perspectiva general .................................................... 16

I.4.2. Identificación de oportunidades ...................................17

I.4.3. Biocompuestos activos en subproductos........................ 19 
I.4.4. Compuestos fenólicos ...................................... 21

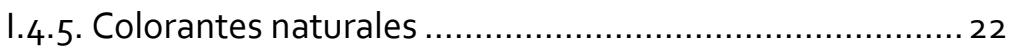

I.5. Contribución de la tesis doctoral............................ 26

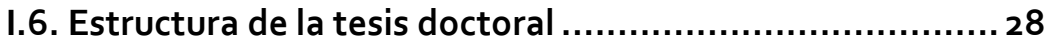

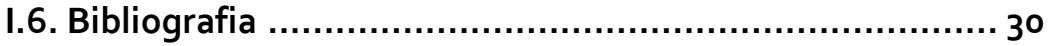

Capítulo 2 Objetivos y plan de trabajo ............................53

II.1 Objetivo General ............................................... 55

II.2 Objetivos Especificos....................................... 56

II.3 Plan de Trabajo................................................. 57

Capítulo 3 Metodología experimental ...........................64 64

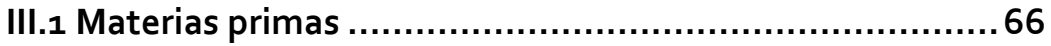

III.1.1 Aguacate (Persea americana Mill) ..........................66

III.1.2 Higos chumbos (Opuntia Spp). ............................66

III.2 Preparación de la muestra.....................................67

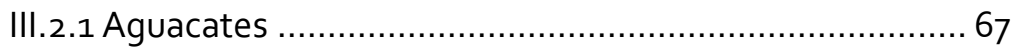

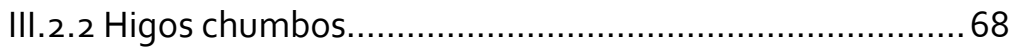

III.2.3 Tratamientos térmicos. .....................................69

III.3 Parametros morfologicos........................................ 70

III.3.1 Dimensiones y peso ....................................... 70

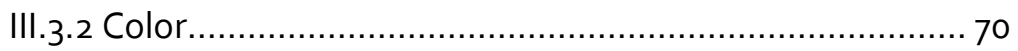

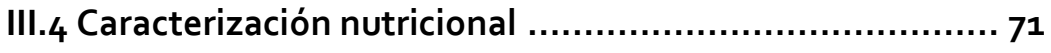

III.4.1 Proteina $\ldots \ldots \ldots \ldots \ldots \ldots \ldots \ldots \ldots \ldots \ldots \ldots \ldots \ldots \ldots \ldots \ldots \ldots \ldots \ldots 71$ 


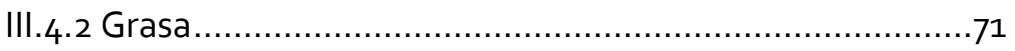

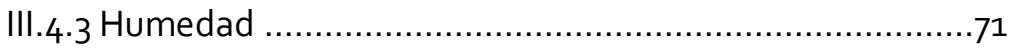

III.4.4 Cenizas...............................................................

III.4.5 Carbohidratos ..................................................... 72

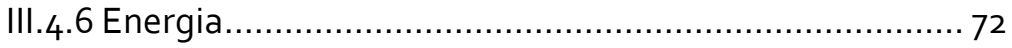

III.5 Compuestos hidrofílicos........................................... 73

III.5.1 Azúcares solubles .................................................... 73

III.5.2 Ácidos orgánicos ................................................... 73

III. 6 Compuestos lipofílicos.................................................. 75

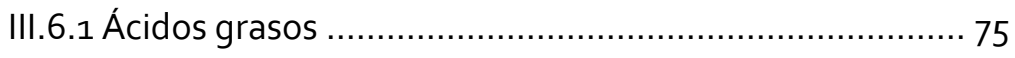

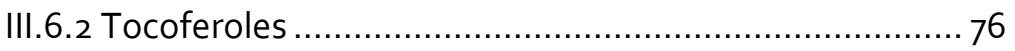

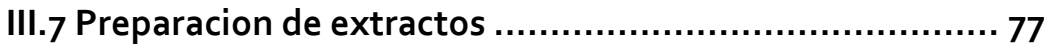

III.7.1 Extracción por agitación ...........................................77

III.7.2 Extracción por Ultrasonidos........................................77

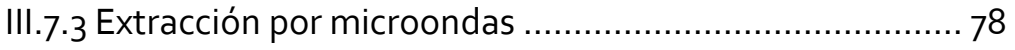

III.7.4 Procesos post-extracción.............................................. 79

III.8 Determinaciónes preliminares de compuestos funcionales 80

III.8.1 Polifenoles por el metodo de Folin-Ciocalteu .................80

III.8.2 Flavonoides por el metodo de tricloro aluminio............. 81

III.8.3 Betalainas por metodo espectrofotometrico ................. 82

III.9 Evaluación de propiedades bioactivas ......................... 84 
III.9.1 Actividad antibacteriana ............................................... 84

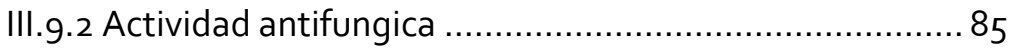

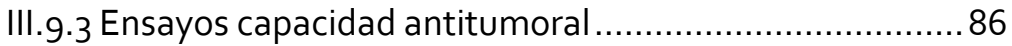

III.9.4 Ensayos de evaluación hepatotoxica ............................ 87

III.9.5 Actividad antioxidante por el método de DPPH ............88

III.9.6 Actividad antioxidante por el metodo del poder reductor

III.9.7 Actividad antioxidante por el método de TBARS ............ 90

III.9.8 Actividad antioxidante por el método de $\beta$-caroteno .... 91

III.9.9 Actividad antioxidante por el método de ABTS............. 91

III.10 Identificación y cuantificación de biocompuestos .......... 93

III.10.1 Polifenoles y Flavonoides............................................. 94

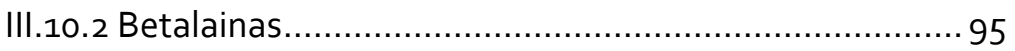

III.11 Determinación y modelización de isotermas de sorción 96

III.12 References.......................................................... 98

Capítulo 4 Caracterización de los frutos y subproductos de Persea americana ..................................................... 122

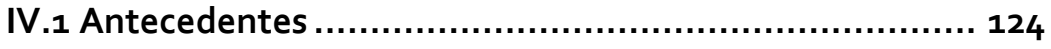

IV.1.1 Características de los frutos de Persea americana ........ 124

IV.1.2 Efecto del secado sobre los compuestos fenólicos ...... 126

IV.2 Caracterización de los compuestos bioactivos de los subproductos de Persea americana mill: Una rica fuente de antioxidantes inherentes.

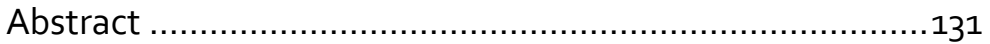


IV.2.1 Introduction ...................................................132

IV.2.2 Material and Methods............................................. 134

IV.2.2.1 Samples preparation ............................................. 134

IV.2.2.2 Extraction procedure ………………………......... 134

IV.2.2.3. Phenolic compounds............................................. 134

IV.2.2.4. Bioactive properties evaluation ............................135

IV.2.2.4.1 Antioxidant activity assays .......................................... 135

IV.2.2.4.2. Antimicrobial activity assays ................................. 135

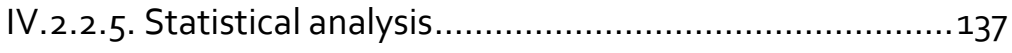

IV.2.3. Results and discussion ......................................... 138

IV.2.3.1. Phenolic profile of $P$. americana by-products.......... 138

IV.2.3.2. Antioxidant capacity of $P$. americana by-products .. 140

IV.2.3.3. Antimicrobial activity of P. americana by-products . 145

IV.2.4. Conclusion................................................... 148

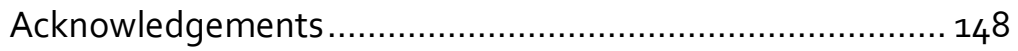

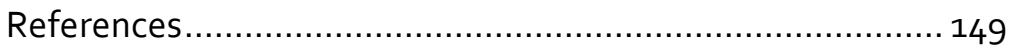

Capítulo 5 Caracterización de los frutos de las especies

Opuntia spp ............................................................. 175

V.1 Antecedentes .........................................................

V.1.1 Metodología rápida de detección de betalaínas .............177

V.2 Caracterización extensiva de tres variedades de frutos de Opuntia spp. para la innovación de ingredientes alimentarios. 
Abstract 183

V.2.1. Introduction ................................................... 184

V.2.2. Material and Methods......................................... 186

V.2.2.1. Sample preparation ............................................. 186

V.2.2.2. Morphological parameters...................................... 186

V.2.2.3. Chemical characterisation ....................................... 186

V.2.2.3.1 Proximal nutritional composition ........................... 186

V.2.2.3.2. Hydrophilic compounds ...................................187

V.2.2.3.3. Lipophilic compounds ......................................... 188

V.2.2.4. Antimicrobial effect of fruit pulp............................ 189

V.2.2.5. Statistical analysis................................................. 190

V.2.3. Results and discussion ....................................... 191

V.2.3.1. Morphological parameters and nutritional composition 191

V.2.3.2. Hydrophilic and lipophilic compounds .................... 194

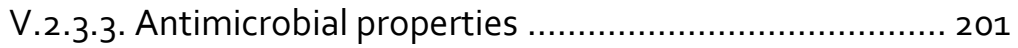

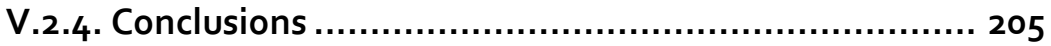

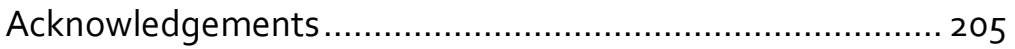

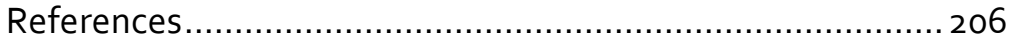

Capítulo 6 Caracterización de los subproductos de Opuntia

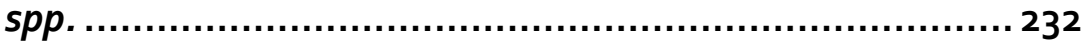

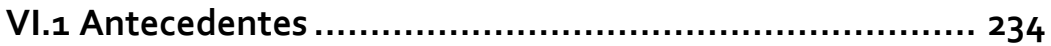

VI.1.1 Efecto del secado en los compuestos fenólicos de las pieles de Opuntia 
VI.1.2 Modelización de isotermas de sorción de las pieles de Opuntia

VI.2 Valorización de los subproductos de Opuntia spp.: Determinación de los perfiles fenolicos, betalainicos y sus propiedades bioactivas.

Abstract 241

VI.2.1. Introduction 242

VI.2.2. Material and Methods 244

VI.2.2.1. Samples preparation 244

VI.2.2.2. Extraction procedure ......................................... 244

VI.2.2.3. Phenolic compounds................................................ 245

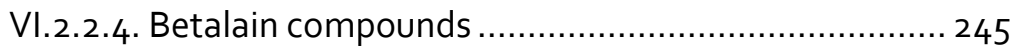

VI.2.2.5. Bioactive properties evaluation............................. 246

VI.2.2.5.1. Antioxidant activity assays ....................................... 246

VI.2.2.5.2. Antimicrobial activity assays ..................................... 247

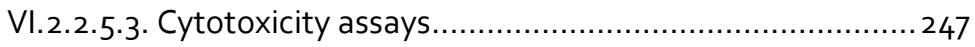

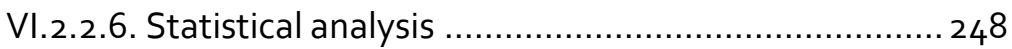

VI.2.3. Results and discussion ................................... 249

VI.2.3.1. Phenolic and betalain composition.......................... 249

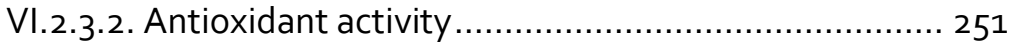

VI.2.3.3. Antibacterial and antifungal activity..................... 256

VI.2.3.4. Cytotoxic activity ................................................. 259

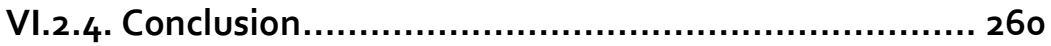


Aknowledgement ........................................................... 260

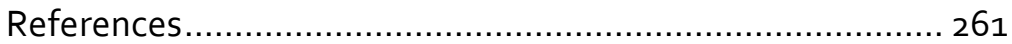

Capítulo 7 Optimización de los extractos de las pieles de Opuntia spp. ..................................................... 287

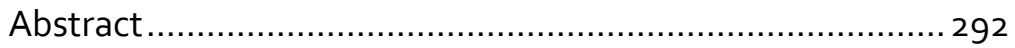

VII.1.1. Introduction ................................................ 293

VII.1.2. Material and Methods............................................ 295

VII.1.2.1. Samples preparation ............................................ 295

VII.1.2.2. Experimental design ........................................... 295

VII.1.2.3. Extraction procedure .............................................. 296

VII.1.2.3.1. Ultrasound-assisted extraction (UAE) ..................... 296

VII.1.2.3.2. Microwave-assisted extraction (MAE) ........................297

VII.1.2.4. Colorimetric determination and extraction yield .... 297

VII.1.2.5. Antioxidant activity evaluation................................ 298

VII.1.2.6. LC-DAD/MS-MS characterization of extracts ......... 298

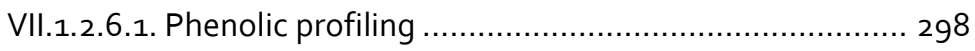

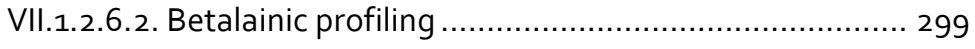

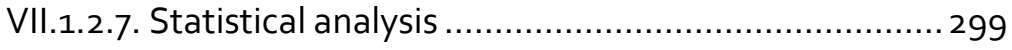

VII.1.3. Results and discussion ...................................301

VII.1.3.1. Tentative identification of bioactive compounds.... 301

VII.1.3..2. Model fitting and technologies used. ................... 305

VII.1.3.3. Effects of independent variables on betacyanins.... 308 VII.1.3.3.1 Ultrasound-assisted extraction. ...................................308 
VII.1.3.3.2. Microwave-assisted extraction 309

VII.1.3.4. Effects of independent variables on phenolic acids and flavonoids

VII.1.3.4.1. Ultrasound-assisted extraction 312

VII.1.3.4.2. Microwave-assisted extraction 313

VII.1.3.5. Effects of independent variables on antioxidant activity.

VII.1.3.5.1. Ultrasound-assisted extraction and microwave-assisted extraction 314

VII.1.3.6. Effects of independent variables on yield and colour. 314

VII.1.3.6.1. Extraction yield on UAE and MAE 314

VII.1.3.7. Colour effect on ultrasonic and microwave extractions

VII.1.3.8. Comparison of UAE and MAE RSM. .315

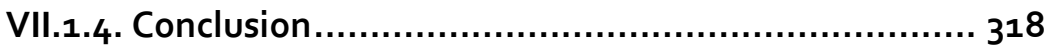

Capítulo 8 Conclusiones......................................... 338

Capítulo g Anexos ............................................... 347

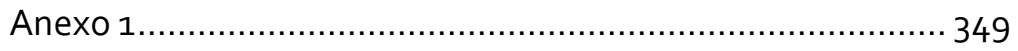

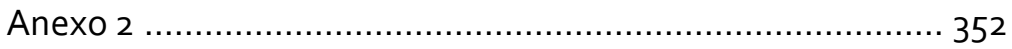

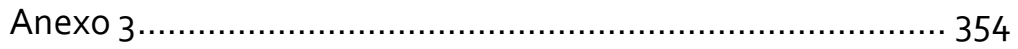




\section{Índice de tablas}

Table 1-1 Publication list presented within this work 27

Table 3-1 GC temperature ramp for fatty acids 75

Table 3-2 Common correlation models of sorption Isotherms 97

Table 4-1 Nutritional and morphological characteristics of avocado fractions

Table 4-2 Tentative identification and quantification of phenolic compounds in the $P$. americana by-products 141

Table 4-3 Antioxidant activity of P. americana by-products 144

Table 4-4 Antibacterial and antifungal activity of $P$. americana by-products

Table 5-1 Morphological parameters of Opuntia spp. 191

Table 5-2 Nutritional value and hydrophilic compounds of the studied Opuntia spp. 192

Table 5-3 Chemical composition in lipophilic compounds, tocopherols and fatty acids of Opuntia spp. 194

Table 5-4 Identification and quantification of betalains detected in Opuntia spp pulp 199

Table 5-5 Antibacterial and antifungal activity of Opuntia samples 202

Table 6-1 Identification and quantification of phenolic compounds in Opuntia peels 252

Table 6-2 Tentative identification and quantification of betalains detected in Opuntia peels 254

Table 6-3 Antioxidant capacity of Opuntia peels 256

Table 6-4 Antibacterial and antifungal activity of Opuntia peels 258

Table 6-5 Cytotoxic activity of Opuntia peel 259

Table 7-1 Tentative identification bioactive compounds in the Opuntia engelmannii cv Valencia peels. 302 
Índice

Table 7-2 Central Composite design and experimental data for 4-level-4-factor response surface analysis 306

Table 7-3 Statistical analysis (ANOVA) of the central composite design 310 


\section{Íindice de figuras}

Figure 1-1 The different parts of the avocado fruit, left avocado var. Fuerte and right var Hass

Figure 1-2 Production quantity of avocados by country (years 2015-2016)__ 8

Figure 1-3 Opuntia spp worldwide distribution of crops 10

Figure 1-4 The different parts of Opuntia plant and fruit 13

Figure 1-5 Main phenolic compounds structures 20

Figure 1-6 Main betalains structures, left OFI var Sangigna, right OFI var

Gialla 24

Figure 1-7 Doctoral thesis estructural scheme 29

Figure -2-1 Approach of experiments in chronological order 58

Figure -2-2 Article 1 experimental work 59

Figure -2-3 Article 2 experimental work 60

Figure -2-4 Article 3 experimental work 61

Figure -2-5 Article 4 experimental work 62

Figure 3-1 Persea americana fruit fractions 67

Figure 3-2 Opuntia spp fruits fractions) 68

Figure 3-3 Conventional extraction 77

Figure 3-4 Ultrasonic extraction system 78

Figure 3-5 Lyophilized powders 79

Figure 3-6 Re-suspended samples) 80

Figure 3-7 Folin-Ciocalteu samples 81

Figure 3-8 $\mathrm{ALCL}_{3}$ colorimetric assay 82

Figure 3-9 SPE extraction of betalains 83 
Figure 3-10 SRB bond cell treated with Opuntia samples 87

Figure 3-11 DPPH colourimetric assay 88

Figure 3-12 Power reduction method chemical reactions 89

Figure 3-13 Power reduction plate reaction 90

Figure 3-14 UPLC-DAD-Esi/MS system employed 93

Figure 3-15 Elution gradient of solvent $B$ in phenolics determination 94

Figure 3-16 Elution gradient of solvent $B$ in betalainic determination 95

Figure 4-4-1 Avocado fruit fraction percentages 125

Figure 4-4-2 Effect of drying and storage on phenolic compounds of avocado peels)

Figure 4-4-3 Effect of drying and storage on phenolic compounds of avocado kernels 128

Figure 4-4-4 Phenolic profile of $P$. americana $(A)$ kernel recorded at $280 \mathrm{~nm}$,

$(B)$ and $(C)$ peels recorded at $280 \mathrm{~nm}$ and $370 \mathrm{~nm}$, respectively 138

Figure 5-1 Screening of betalains in OFI var Gialla 178

Figure 5-2 Screening of betalains in OFI var Sanguigna 178

Figure 5-3 Effect of $\mathrm{pH}$ on betalain extraction 179

Figure 5-4 HPLC chromatograms of (A) OG betaxanthin profile recorded at $484 \mathrm{~nm}$ and (B) OE betacyanin profile recorded at $535 \mathrm{~nm}$ 198

Figure 6-1 Fraction percentage of Opuntia fruits 234

Figure 6-2 Effect of drying and storage in OFI var Sanguigna 236

Figure 6-3 Effect of drying temperatures on flavonoids 236

Figure 6-4 Sorption isotherms of OFI Sanguigna at $20^{\circ} \mathrm{C}$ 237 
Índice de figuras

Figure 6-5 HPLC chromatogram of OG phenolic profile recorded at $370 \mathrm{~nm}(\mathrm{~A})$, betaxanthins profile of OS recorded at $484 \mathrm{~nm}(B)$ and betacyanins profile of OE recorded at $535 \mathrm{~nm}$ (C). 250

Figure 7-1 HPLC chromatogram of Opuntia engelmannii cv. Valencia 304

Figure 7-2 Principal effect graphs of UAE and MAE 316

Figure 8-1 Desorption isotherms of OFI Sanguigna at $20^{\circ} \mathrm{C}$ ) 393

Figure 8-1 Adsorption isotherms of OFI Sanguigna at $20^{\circ} \mathrm{C}$ 394

Figure 8-1 Adsorption isotherms regressions of OFI Sanguigna at $20^{\circ} \mathrm{C}$ 395

Figure 8-1 Desorption isotherms regressions of OFI Sanguigna at $20^{\circ} \mathrm{C}$ 396 


\section{Índice de ecuaciones}

Equation $3-1$ Moisture determination ................................................ 71

Equation 3-2 Total carbohydrates by difference ................................ 72

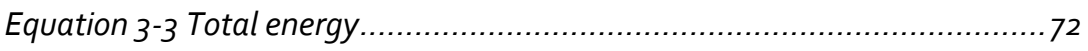

Equation $3-4$ Spectrophotometric betalainic content ............................ 82

Equation $3-5$ Inhibition percentage of DPPH..................................... 88

Equation 3-6 Inhibition percentage of b-carotene ................................. 91

Equation 3-7 Inhibition percentage of ABTS...................................... 92

Equation 3-8 Moisture equilibrium of the sorption isotherms .................... 96

Equation 7-1 Second-order polynomial regression coefficients..................296

Equation 7-2 Second-order polynomial coefficients for betalainic content in the UAE extractions................................................................... 308

Equation 7-3 Second-order polynomial coefficients for betalainic content in the MAE extractions. ................................................................. 312

Equation 7-3 Second-order polynomial coefficients for phenolic acids and flavonoids content in the UAE extractions........................................ 313 



Capítulo 1
INTRODUCCIÓN 





\section{I.1 JUSTIFICACIÓN}

Los estudios en materia de "Ingredientes alimentarios naturales" y "Sostenibilidad" han crecido concomitantemente, ambos inclusive han co-evolucionado para formar un interés particular, relacionándoles de manera positiva y fructífera. Esta simbiosis, se debe principalmente al acelerado aumento de la conciencia social, que ha permitido a la misma sociedad percibir la explotación de fuentes naturales, así como el uso desmedido de aditivos alimentarios sintéticos con un gran impacto negativo en la salud del consumidor. Esto ha conseguido que el enfoque central de interés, se base en la vida saludable y la armonía con el medio ambiente, como lo muestra el aumento de tendencias y oportunidades de mercado alimentario en el estudio realizado por Augustin and Sanguansri (2015).

El crecimiento poblacional, la reducción de zonas de cultivo, así como la utilización de ciertos alimentos con finalidades distintas a la alimentación, como la producción de bioenergéticos, han hecho replantearnos las metodologías agrícolas, el procesado de los alimentos, y nos ha abierto camino en la exploración de los subproductos alimentarios. En consecuencia, la subutilización de los flujos de materia orgánica de los distintos subproductos, conlleva a serias amenazas medioambientales y a la economía del sector agricultura y de la industria alimentaria (Chan et al., 2018), y es por esta razón, que proponemos el estudio de algunos subproductos frutícolas.

Las frutas son componentes importantes dentro de la dieta humana y son consumidas frescas y/o procesadas. Las frutas que crecen en estado salvaje, fueron consumidas por la raza humana desde etapas muy tempranas de la historia, y con la adopción del sedentarismo, podemos disfrutar de la selección de distintos genotipos y variedades de frutas. Además de sus cualidades organolépticas, las frutas, aportan nutrición básica, ya que estas contienen carbohidratos, ácidos orgánicos, vitaminas y minerales.

Además de la importancia estructural y organoléptica de las moléculas mencionadas anteriormente, dentro del sistema celular de las plantas, se sintetizan un sinnúmero de arreglos químicos moleculares, de donde podemos destacar la generación de metabolitos secundarios, 
los cuales cumplen distintos propósitos fisiológicos, como la atracción a través del color y de los compuestos aromáticos, y la protección en contra de patógenos y condiciones medio ambientales (Jimenez-Garcia et al., 2018).

De acuerdo a los tecnólogos alimentarios, la comida se come primero a través de los ojos (Attokaran, 2011). La atracción visual, es responsabilidad de un grupo de moléculas características del tipo y variedad de los frutos. Las antocianinas se encuentran en un gran número de frutas y verduras (moras, cerezas, fresas, uvas, manzanas, col lombarda, maíz y zanahoria morados, etc) aportando colores rojizos y purpuras. Tonalidades amarillas pueden ser aportadas por carotenoides, riboflavina y curcumina, por nombrar algunos. El licopeno aporta el color rojo al tomate, las clorofilas el verde de una amplia gama de alimentos, algas y bacterias (Wrolstad and Culver, 2012). Una de las familias de colorantes que abordaremos en este documento son las betalainas, que cubren un rango de colores entre el purpura y el amarillo, y que además de aporte del color, contribuyen también con propiedades antioxidantes (Kanner et al., 2001).

Los metabolitos secundarios, además de aporte de color, cumplen distintas funciones más complejas como moléculas de señalización, aromas y protección celular. Alcaloides, terpenos, esteres volátiles, aminoácidos no proteicos y muchos más compuestos orgánicos con diversas estructuras, engloban una pequeña parte de éstos compuestos (Bhatia et al., 2015). Últimamente, los compuestos fenólicos y flavonoicos han recibido un creciente interés en sus estructuras, pero sobre todo en sus funciones antioxidantes, debido al rol que juegan en prevención de enfermedades (Maria et al., 2014), aunque la gran mayoría de estos trabajos se enfoca en la parte comestible de los frutos, dejando un importante espacio de estudio para los subproductos y sus posibles propiedades funcionales.

En esta trabajo, se trata principalmente del estudio de algunos subproductos frutícolas (aguacate e higo chumbo), con la finalidad de identificar posibles ingredientes naturales que sean factibles de implementar en las industrias alimentarias, farmacéuticas y/o cosméticas, con énfasis en los colorantes naturales y algunos de los compuestos antioxidantes. Asímismo, las técnicas desarrolladas a lo 
Introducción

largo del trabajo, han sido pensadas para poder ser extrapoladas a distintos tipos de subproductos de la industria, que pudieran llegar a producir particular interés en los sectores mencionados anteriormente. 


\section{I.2 Aguacate (Persea americana Mill)}

\section{I.2.1 Origen, estructuras e hibridaciones}

El aguacate, es una planta dicotiledónea miembro de la familia Lauraceae del orden de los Laurales, una larga familia pantropical de alrededor de 50 géneros y unas 2500 a 3000 especies en su mayoría árboles y arbustos (Rohwer, 1993), y fue clasificada como Persea gratissima por Gaertner, y como Persea americana Mill. por Miller. Este cultivo es originario de Centro América y fue domesticada por los pueblos indígenas de esa zona, hace unos 7000 años, según evidencia arqueológica encontrada en Tehuacán, Puebla (México), se cree que apareció hace alrededor de unos 12000 años (Yahia and Woolf, 2011).

A pesar de que las hojas del árbol del aguacate tienen muy corta longevidad ( $<12$ meses), se caracteriza por su rápido crecimiento, llegando a crecer hasta 20 metros, con raíces superficiales pero con profundidad de hasta $15 \mathrm{~m}$, aunque cuenta con un pobre sistema de conducción de agua, este árbol es capaz de producir muchas flores, aunque solo un bajo porcentaje de ellas producen frutos $(<0,1 \%)$. Esto puede deberse principalmente a tres factores climáticos importantes: (1) la presencia de escarcha durante el invierno; (2) temperaturas medias muy bajas ; y (3) temperaturas muy altas durante la formación de fruto (Carr, 2013).

El nombre botánico del aguacate es Persea america Mill., de las cuales reconocemos 3 razas (conocidas hoy como variedades botánicas o subespecies); Persea americana var. drymifolia (ecotipo Mexicano), Persea americana var. guatemalensis (ecotipo Guatemalteco) y Persea americana var. americana (ecotipo Antillano). Las principales diferencias entre estas razas son dos características fisiológicas y organolépticas: por un lado, (1) la tolerancia al frio, siendo el ecotipo mexicano el que presenta mayor resistencia, mientras que el antillano es el de menor resistencia de los tres (Carr, 2013), por otro lado, (2) el contenido de ácidos grasos en las pulpas, en donde la raza antillana presenta muy bajo contenido $(<8 \%)$ comparado con la raza mexicana (hasta 30\%), haciendo de la raza guatemalteca las deseada en cuanto a términos de ácido grasos, por su característico balance de ellos y su sabor con notas de nuez (Cowan and Wolstenholme, 2003). 
El cruce interracial se ha generado como resultado de la hibridación entre razas en los cultivares de mayor importancia económica, tal es el caso de la variedad Fuerte (raza mexicana y guatemalteca), la cual se originó en México (Atlixco, Puebla) y por muchos años fue la de mayor producción comercial hasta que la variedad Hass (creada y seleccionada en California) la substituyó, en la mayoría de sembradíos con clima mediterráneo (Knight and Campbell, 1999).

\section{I.2.2 Fisiología, formación del fruto y maduración}

Los aguacates son una fruta drupa climatérica subtropical, generalmente de forma oblonga y de piel verde, aunque la variedad comercial predominante Hass, tiene piel púrpura-negra en su estado óptimo de madurez. El nombre proviene de náhuatl "ahuacatl", que significa testículos, esto se refiere al mismo por su forma característica, y era considerada por los aztecas como un afrodisíaco (HurtadoFernández et al., 2018a).

Botánicamente Persea americana es una baya que consiste en una semilla larga central y del pericarpio, que es la suma de la parte comestible (mesocarpio), de la piel (exocarpio) y de la capa interior que rodea a la semilla (endocarpio). La piel varía en texturas y color, la textura puede ir de flexible a lignínica, suave a rígida y el color puede ser verde-amarillento, purpura-rojizo, purpura o negro. La pulpa suele ser amarillo-verdosa o amarillo brillante, y suele tener textura similar a la de la mantequilla, pero variedades de menor calidad presenta mayor fibrosidad. La semilla del fruto es grande y normalmente supone del 10 al $25 \%$ de peso total del fruto. 


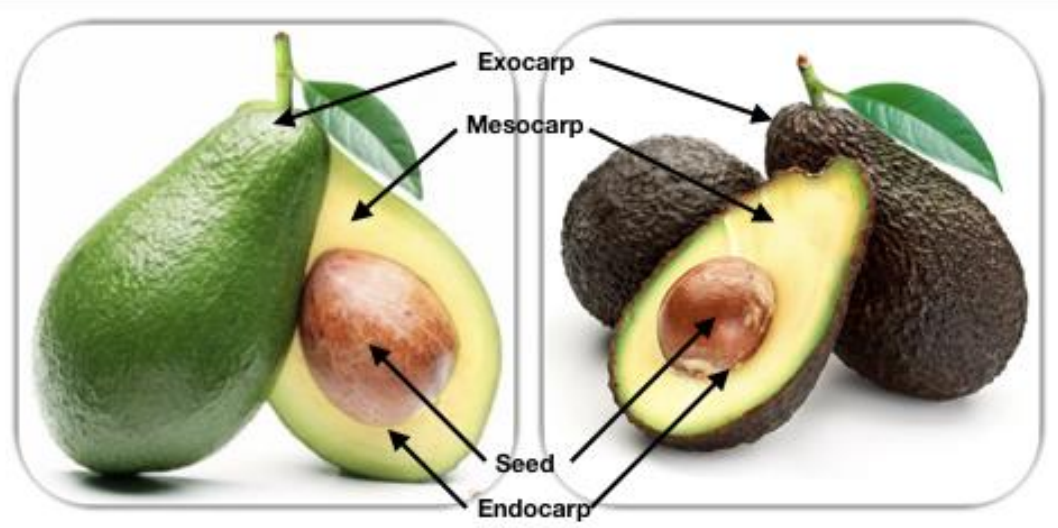

Figure 1-1 The different parts of the avocado fruit, left avocado var. Fuerte and right var Hass (source: private collection)

El desarrollo de la fruta es el resultado de una compleja actividad metabólica, que se ve fácilmente afectada por factores medio ambientales como temperatura, calidad y cantidad de luz, agua disponible, suelo de cultivo y diferentes hormonas de la planta. El crecimiento en la mayoría de los frutos, normalmente está dividido en 3 fases principales: (1) la primera fase (fase lag) incluye la formación del ovario, fertilización y formación del fruto, hay un crecimiento muy lento y alrededor del $90 \%$ de la absición ocurre en este periodo; (2) en la segunda fase (fase de crecimiento) un gran número de células comienzan la división celular, originando también la formación de la semilla y el temprano desarrollo embrionario; y finalmente (3) la tercera fase (fase de maduración fisiológica) se caracteriza por la maduración de la semilla y una disminución de la división celular (Cowan et al., 2001). En general el crecimiento de los frutos de Persea america, dura entre 20 y 60 semanas, dependiendo de la variedad, medioambiente y prácticas de cultivo (Cowan and Wolstenholme, 2003).

A diferencia de otros frutos, el aguacate, es recolectado cuando alcanza la madurez hortícola, ya que estos frutos solo comienzan la madurez comercial, cuando ya no están unidos al árbol (Watada et al., 1984). La madurez comercial es el proceso irreversible mediante el cual se obtienen las propiedades organolépticas deseadas de los frutos, como cuando la pulpa se suaviza, se forman aromas volátiles, se producen cambios de textura y color y el sabor cambia a consecuencia del cambio 
en la composición de azúcares y ácidos orgánicos (Hiwasa-Tanase and Ezure, 2014).

\section{I.2.3 Temporada de cultivo}

E1 árbol del aguacate es muy longevo y con un periodo productivo muy grande, en árboles injertados, la primera cosecha se realiza al quinto año de vida del árbol, antes de llegar a esta edad, el árbol es considerado como joven, y a lo largo de ese año se obtienen en promedio unos 50 frutos, los siguientes 3 años, la producción sube a 150, 300 y 800 frutos en promedio en los años 6, 7 y 8 , respectivamente, y a partir de esta etapa se le considera un árbol adulto y totalmente productivo. En general los árboles son plantados con una distancia entre ellos que va de 7 a 12 metros, y de esta manera se obtiene una hectárea destinada a la plantación de aguacate de 115 a 180 arboles (SAGARPA, 2011).

Este fruto es muy productivo ya que provee aguacates durante todo el año, aunque se pueden separar dos periodos clasificados como de producción máxima y mínima. La máxima que dura 4 meses entre octubre y enero, y la mínima que comprende el resto de los 8 meses entre febrero y septiembre. Cabe destacar que las condiciones medio ambientales siempre tienen un rol muy importante en estos tiempo, pero generalmente el tiempo de madurez hortícola (entre el florecimiento y la cosecha) es de 10 a 18 meses para raza guatemalteca, 6 a 8 meses para la raza antillana y de 5 a 7 meses para la raza mexicana (Crane et al., 2016).

\section{I.2.4 Producción anual}

Aunque el origen del cultivo esta en América, hoy en día, el aguacate es un cultivo de nivel internacional, y aunque es evidente que la mayor explotación de este cultivo esta aún en el continente americano $(73,2 \%$ de la producción mundial), los demás continentes suman sus porcentajes para la producción mundial, África (12,3\%), Asia (11,3\%), Europa $(1,7 \%)$ y Oceanía $(1,6 \%)$. Mientras que los países con mayor producción por continente son: México, Kenia, Indonesia, España y Australia, y a nivel mundial, los líderes en producción son México (1,7 millones de toneladas), seguido por República Dominicana (0,5 
millones), Perú (0,4 millones), Indonesia ( 0,34 millones), Colombia (0,3 millones) y Brasil y Estados Unidos (0,18 millones) (FAO, 2016).

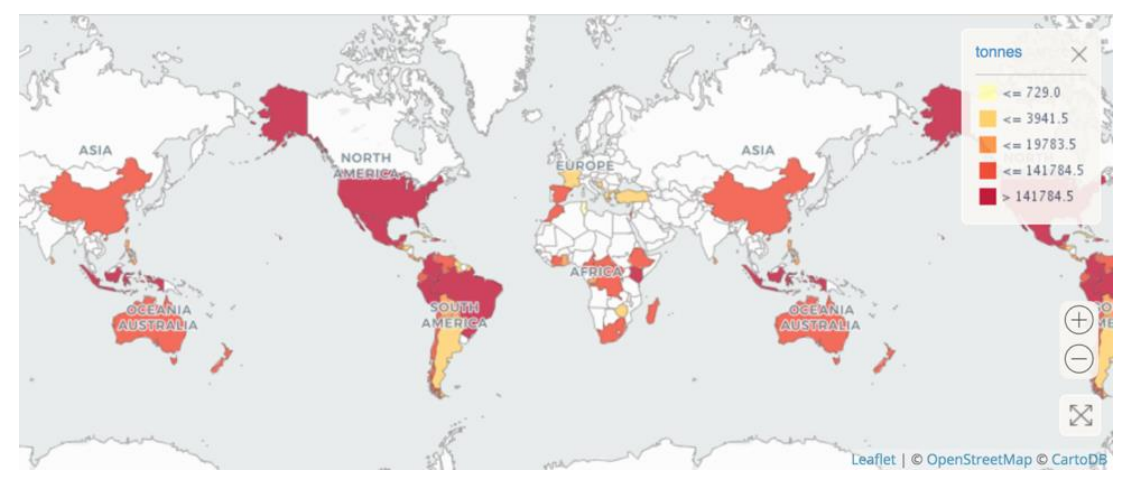

Figure 1-2 Production quantity of avocados by country (years 2015-2016) (source: FAOSTAT)

Generalmente el mayor consumo de los frutos producidos por un país son consumidos por el mismo, sin embargo, en la década pasada, la demanda del aguacate en muchos mercados a nivel mundial creció aceleradamente, causando a su vez un aumento significativo en el volumen de exportación de aguacates, específicamente un incremento de 65,5\% en los últimos 10 años (FAO, 2016). 


\section{I.3 HigOS CHUMbOS (OPUNTIA SPP.)}

\section{I.3.1. Orígenes}

E1 interés por los cactus y sus frutos se remonta a miles de años. Su historia y posible origen se remonta a las antiguas civilizaciones mesoamericanas, concretamente, con el imperio Azteca, en el país que hoy es conocido como México. Existen evidencias arqueológicas en las zonas semiáridas de Mesoamérica, que permiten afirmar que las poblaciones indígenas asentadas en esas zonas iniciaron el cultivo de modo formal (Pimienta, 1990).

Actualmente, los cactus de Opuntia spp. y sus frutos forman parte del panorama natural y de los sistemas de agricultura de un gran número de regiones en el mundo. Esta expansión territorial probablemente comenzó con los muestrarios de plantas llevadas a España por parte de Cristóbal Colón (Donkin, 1977) y debido al gran impacto comercial de sus puertos con el resto de Europa, África, Asia y Oceanía, esta distribución fue posible.

Actualmente estos cultivos se pueden encontrar tanto en forma de explotación comercial o de manera salvaje en países de América como México, Estados Unidos de Norte América, Chile, Perú, Bolivia y Argentina, en África en Argelia, Etiopia, Marruecos, Sudáfrica y Túnez, en países Asiáticos como Jordania, Siria, Líbano, Israel y Yemen, se pueden también encontrar en Australia y en Europa en España, Italia y Portugal. Actualmente el país de mayor producción mundial comercial es México, seguido de Italia y Estados Unidos (Ochoa and Barbera, 2017). 


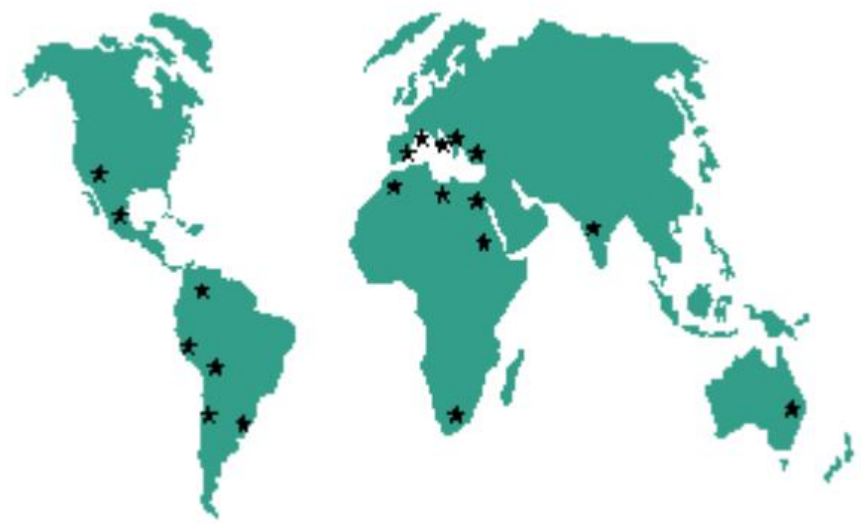

Figure 1-3 Opuntia spp worldwide distribution of crops (source: FAO)

\section{I.3.2. Taxonomía}

E1 género Opuntia es una especie de la familia Cactaceae con gran importancia agronómica, debido a sus frutos y sus tallos, los cuales son empleados en la alimentación humana en ciertas regiones y también como forraje para la producción animal. Estas especies se desarrollan principalmente en regiones áridas y semiáridas, adaptándose fácilmente a condiciones secas, suelos pobres y lluvias erráticas (Reynolds and Arias, 2003)

La taxonomía de las tunas es muy compleja debido a varias razones, entre ellas el hecho de que los fenotipos presentan gran variabilidad según las condiciones ambientales. Además, es frecuente encontrar casos de poliploidía, ya que se reproducen en forma sexual o asexual y existen numerosos híbridos interespecíficos, lo que complica más su clasificación (Sáenz, 2006).

Las características de las especies son variables, y se diferencian en varios parámetros como, forma de los cladodios, tamaño y color de los frutos, presencia o ausencia de gloquidios, tamaño y distribución de las espinas, o en sus características botánicas, como sabores más dulces y pieles más delgadas (Opuntia ficus indica $(\mathrm{OFI})$ ), o sabores más ácidos (Opuntia xoconostle), o pieles más gruesas (O. engelmannii). 
La nomenclatura científica y taxonomía del fruto es la siguiente:

Reino: Plantae

División: Magnoliophyta

Clase: Magnoliopsida

Orden: Caryophyllales

Familia: Cactaceae

Tribu: Opuntiae

Género: Opuntia

Especie: Opuntia ficus-indica Mill.

Las cactus y sus frutos reciben distintos nombres según el país en que se encuentren. El nombre autóctono de los frutos es "nochtli", del náhuatl que significa fruta pera. En México la planta recibe el nombre de nopal mientras que sus frutos se les conoce como "tunas", en España se renombró al nopal con el nombre de chumbera y a la fruta como higo de Indias (hoy "higo chumbo"), en Italia se le conoce como "fico d'India", en Francia se le llama "figue de Barbarie"; en EE.UU. y Sudáfrica "prickly pear", (nombre que está evolucionando a cactus pear, a fin de eliminar el término algo peyorativo de "prickly" que significa "espinoso"); en Israel se conoce como "sabras", que significa espinoso por fuera, pero dulce por dentro. En Brasil, la llaman "palma forrageira", ya que se cultiva principalmente para la producción de forraje (Sáenz, 2006).

\section{I.3.3. Variedades cultivadas}

Actualmente casi 300 especies del género Opuntia son reconocidas, tan solo en México Bravo-Hollis (1978) reporto 104 distintas variedades y especies. La variedad comercial de los frutos proviene de Opuntia ficus-indica (OFI) y sus distintas variedades, aunque existen muchas especies salvajes de igual interés, como $O$. robusta, $O$. streptacantha, O. megacantha, O. xoconostle y O. engelmannii.

Las variedades de $O$. ficus-indica se diferencian de todos los otros miembros del género por presentar distintas combinación de las siguientes características: los cladodios usualmente son elípticos, de gran tamaño y carecen total o casi totalmente de espinas, presentan frutos grandes, dulces y carnosos. Las variedades se diferencian principalmente en cuatro grupos por el color de la cáscara y la pulpa 
del fruto: cáscara verde amarilla y pulpa blanca, cáscara amarilla anaranjada y pulpa naranja, cáscara verde-roja y pulpa roja; y cáscara y pulpa púrpura.

Los nombres comunes de las variedades más populares varían según el país. Así, en México se conocen las variedades Reina, Rojo Pelona, Esmeralda; mientras que en Italia las mismas variedades reciben los nombre de Giallia, Rosso y Bianca y en España las llaman Verdales, Morados, Sanguinos y Blancos. En el mercado internacional las variedades más apetecidas son las de color (distinto al típico color verde), sobre todo las rojas, amarillas, rosadas y púrpuras, atribuyéndose al color atractivo de la fruta y a su bajo contenido de azúcares. Dos variedades muy demandadas son Rosso y Giallia (Álvarez, 2007).

\section{I.3.4. Descripción morfológica}

Los cactus del género Opuntia están conformados por numerosos tallos denominados cladodios (conocidos vulgarmente como paletas o pencas); por frutos, los cuales dependiendo de la latitud, condiciones de cultivo y especies, brotan una o dos veces por año; y por sus flores, que dan inicio a la maduración de los frutos. Los cactus tienen una alta resistencia a las condiciones climatológicas adversas en gran parte debido a sus raíces, las cuales se extienden horizontalmente por varios metros, alcanzando profundidades de alrededor de $80 \mathrm{~cm}$ (Sudzuki et al., 1993).

La chumbera o nopal, es un vegetal arborescente de entre 1 y 5 metros, formado por múltiples cladodios unidos unos a otros, los cuales, en su parte más baja forman un tronco leñoso de entre 20 y 50 centímetros de diámetro, el resto de cladodios en la planta forman estructuras elípticas, oblongas u ovoides que alcanzan longitudes de 18$25 \mathrm{~cm}$, similares a una raqueta de tenis, la coloración de estos de verde pálido a obscuro y dependiendo de la variedad cuenta o no con espinas. Las espinas de los cladodios se encuentran presentes en las numerosas aréolas o yemas y pueden ser de dos tipos: unas pequeñas, agrupadas en gran número denominadas gloquidios, y otras grandes que son hojas modificadas. Las aréolas presentes en toda la superficie de los cladodios tienen la capacidad de desarrollar nuevos cladodios, flores y frutos dependiendo de las condiciones medioambientales. Los nuevos cladodios formados, se posicionan de tal forma con la finalidad de 
optimizar el aprovechamiento máximo de la luminosidad, razón por la cual, los cladodios que crecen en verano, tienen distinta orientación que los desarrollados en invierno (Sáenz, 2006; Sudzuki et al., 1993).

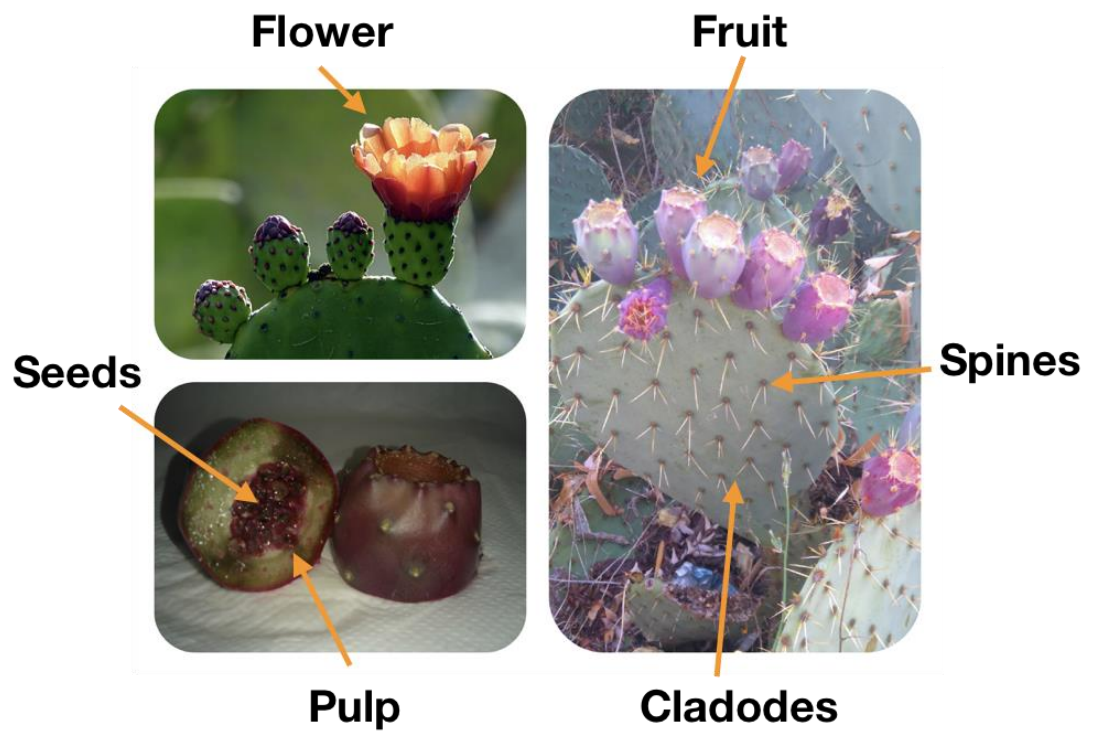

Figure 1-4 The different parts of Opuntia plant and fruit (source: private collection)

Las flores que brotan de las aréolas, son hermafroditas, solitarias y sésiles, de coloraciones amarillo, naranja, rojo, rosa, blanco, entre otros, y suelen tener una longitud de aproximadamente $7 \mathrm{~cm}$, son de antesis diurna y pueden haber más de 10 flores por cladodio, casi siempre en la parte apical del margen del cladodio. Estas florecen entre los 35-45 días desde su aparición en las aréolas y brotan en los cladodios después de los seis meses, necesitando una temperatura mínima de $15^{\circ} \mathrm{C}$ para su optimo desarrollo. Aunque en la mayor parte de latitudes de siembra estas flores sólo aparecen una vez por año, bajo ciertas condiciones, se presenta una segunda floración (Alvarez, 2007; Reyes-Agüero et al., 2005).

Los frutos de Opuntia son una falsa baya con ovario ínfero, uniloculado y carnoso, donde la pulpa corresponde al lóculo desarrollado y la piel corresponde a la envoltura del ovario, es necesario tener en cuenta que son frutos no climatéricos, por lo que es fundamental cosecharlos con madurez de consumo. Como mencionamos anteriormente, las coloraciones de los frutos tanto pieles como frutos son variables respecto a las variedades, con amplia gama de colores que van desde el 
verde, pasando por amarillo y naranja, hasta llegar al rojo-violeta. La epidermis de los frutos comparte sus características con las de los cladodios, presentando aréolas distribuidas en toda la superficie, que cuenta también con gloquidios y espinas, aunque la presencia o ausencia espinas difiere también con las variedades. Otras características variables con respecto a las variedades son: el tamaño y la forma de los frutos (los hay ovoides, redondos, elípticos y oblongos, con los extremos aplanados, cóncavos o convexos). En la pulpa se encuentran también semillas abortivas de 4-4,5 mm de longitud, las cuales son también comestibles, en general, el periodo desde floración hasta la madurez del fruto, se extiende alrededor de los 100 días, aunque esto suele variar dependiendo de las condiciones medioambientales (Alvarez, 2007; Pimienta, 1990; Sáenz, 2006).

\section{I.3.5. Producción y cultivos de Opuntia spp}

Existe poca información a nivel mundial disponible con respecto a las zonas de cultivo de frutas de Opuntia con fines comerciales, y es que aunque este es cultivo presente en los 5 continente, no existen estadísticas disponibles de países productores como es el caso de : Argelia, Brasil, Colombia, Egipto, España, Grecia, Jordania, Marruecos, Perú, Túnez y Turquía (Inglese et al., 2004).

La principal especie cultivada a nivel mundial para la comercialización de sus frutos es Opuntia ficus-indica (OFI), aunque en México otras especies como $O$. streptacantha $O$. lindhemeiri, $O$. amyclaea, $O$. megacantha y $O$. robusta son cultivadas con el mismo fin (Pimiento Barrios and Munoz-Urias, 1999). De hecho, este país es el mayor productor a nivel mundial con el $90 \%$ del total de la superficie de cultivo de higos chumbos a nivel mundial.

Italia mantiene $92 \%$ de sus cultivos en Sicilia, con aproximadamente 3800 hectáreas (ha) de cultivo de tunas, con un rendimiento de frutas de entre 13-17 toneladas (Tn) por hectárea aproximadamente. Timpanaro et al. (2015) reportaron entre los años 2008 y 2011, una producción anual de 75000 Tn de frutos por año. Por otra parte, Flores-Valdez et al. (1995) señalan que en el año 1995 se obtuvo una producción anual de 354000 Tn de higos chumbos en México, siendo este el país, con mayor superficie de siembra para este fruto y consecuentemente el mayor productor de tunas a nivel mundial, aunque comparado con otros países, el rendimiento mencionado en este 
análisis es casi un $50 \%$ inferior que el observado en Italia o en otros países como Chile. En México se estiman unas 50000 ha destinadas al cultivo de los frutos del cactus, lo que representa un rendimiento aproximado de 7 toneladas de fruto por hectárea cultivada.

Entre otros países importantes en el cultivo del higo chumbo destacan: Sudáfrica con una superficie de 1500 ha cultivadas; Chile con unas 1000 ha de chumberas con un rendimiento promedio de 5-20 Tn/ha; Israel y Estados Unidos reportan 300 y 200 hectáreas de chumberas cultivadas, respectivamente. Situados en este punto, es importante destacar que los países con mayor cantidad de toneladas exportadas anualmente son Italia, abarcando el mercado Europeo; y México, que debido al Tratado de Libre Comercio de América del Norte (TLCAN), tiene cubiertas la exportaciones de Estados Unidos y Canadá (Flores-Valdez et al., 1995). 


\section{I.4 APROVECHAMIENTO DE LOS SUBPRODUCTOS FRUTÍCOLAS}

\section{I.4.1. Perspectiva general}

Por mucho tiempo, el desecho de subproductos no era una causa de general interés, sobre todo cuando los productores responsables de estos flujos de desecho incrementaban la producción de alimentos sin un particular interés en el aprovechamiento de los residuos o el impacto medio ambiental que estos producían. Actualmente, la elevada demanda por alimentos procesados en los mercados de consumo, han disparado las alarmas para la identificación de direcciones concretas que minimicen la demanda de energía, reducción de costos, así como la reducción en perdida de alimentos y en generación de desechos.

Por otro lado, la creciente preocupación por los signos de degradación de los recursos naturales (descenso en biodiversidad, campos de cultivo y agua) ha generado un aumento en la concienciación social con miras en satisfacer demandas globales futuras. Es un hecho, que en los próximos años habrá un incremento no sólo de la población mundial, sino de la zonas urbanas, lo que conllevará a la constante generación de nuevas industrias de procesado de alimentos (FAO et al., 2015).

Es por eso que la combinación de ambos planteamientos de aumento en producción de desechos industriales y la preocupación por el medio ambiente, han dado pauta a nuevos planteamientos industriales. En los últimos años la industria alimentaria ha pasado de prestar interés sólo en temas económicos y de mejora en la producción, para enfocarse también en el impacto medioambiental negativo que generan los flujos de desecho, adaptándose a los nuevos temas de interés social (Unilever, 2010).

La sostenibilidad es un nuevo eje de interés global, que brevemente puede ser definido de acuerdo al informe de Brundtland (1987) como la posibilidad de satisfacer necesidades y aspiraciones del presente, sin comprometer la habilidad de las generaciones futuras de disfrutar de las mismas. En este sentido, existen múltiples directrices que se están adoptando dentro de la sociedad y los cuales dependen directamente del consumidor, como el consumo de alimentación local y reducción de desperdicio de alimentos. Aunque en esta índole, las industrias agroalimentarias tiene mucho mayor peso, algunos ejemplos 
importantes son la aplicación de tecnologías de mitigación de producción de gases invernadero, flujos de desecho y uso responsable del agua.

Además de mejoras en las cadenas de producción para disminuir la generación de desechos, actualmente se ha dado mayor importancia al estudio de estos, con la finalidad de convertir el desecho en un subproducto, recordando que el término subproducto se le otorga al residuo de un proceso al que se le puede sacar una segunda utilidad. Atendiendo a esta alternativa de doble utilidad, las tres dimensiones de la sostenibilidad de procesos (medioambiente, social y económico) se cumplen de una manera excepcional, disminuyendo los desechos, demostrando integridad y responsabilidad con los intereses sociales y generando aumento en rentabilidad.

\section{I.4.2. Identificación de oportunidades}

Muchos de los procesos agroalimentarios generan exorbitantes cantidades de subproductos que hoy en día son consideradas fuentes potenciales de moléculas nutritivas, energéticas o con otras capacidades comerciales. Gradualmente los productores industriales son conscientes de las nuevas ofertas comerciales que se pueden generar, y de la mano de investigadores a nivel mundial, se buscan las mejores posibilidades de aprovechamiento de los subproductos y de las fibras vegetales no comestibles.

Análisis como los elaborados en esta tesis doctoral, se hacen necesarios al intentar dilucidar aplicaciones de los subproductos: 1) ensayos de carácter químico enfocados en los macronutrientes son parte importante en la caracterización, y como ejemplo de ello, es la búsqueda industrial por alternativas de obtención de carbohidratos más económicos, 2) ensayos microbiológicos, con la finalidad de extraer moléculas con propiedades antimicrobianas, 3) ensayos inmunológicos donde se prueben capacidades antioxidantes, anticarcinogénicas, entre otras, de los extractos obtenidos, 4) ensayos organolépticos con la finalidad de potenciar posibles alternativas que mejoren las características sensoriales de algunos productos, 5) ensayos enzimáticos con los que se puedan detectar posibles catalizadores de diversas reacciones industriales que mejoren los resultados de procesos específicos, 6) ensayos físico-químicos que permitan detectar polímeros que podrían ser empleados en industrias textiles o de 
bioplásticos. Y estos son sólo parte del abanico de propuestas para el uso de los subproductos.

Algunos investigadores, han dado incluso algunas pautas como estrategias de recuperación, como es el caso de Galanakis (2015), quien propone un proceso de recuperación universal de 5 niveles, brevemente, el primer nivel se centra en las características macroscópicas (agua, solidos, aceites); el segundo nivel en las características de las microestructuras; el tercer nivel se encarga de determinar los grupos que pueden ser extraídos (azúcares, proteínas, fibras, fenoles totales, entre otros) mediante técnicas rápidas de cribado; el cuarto nivel estudia más en detalle las macro y micromoléculas; y el último nivel caracteriza la carga microbiana y enzimática.

Comprendiendo la magnitud de la industria alimentaria y la gran cantidad de subproductos de origen animal y vegetal, es importante destacar que en la industria frutícola existe un gran número de posibilidades a estudiar, como es el caso de los subproductos generados por la industria procesadora frutos tropicales como los aguacate o los higos chumbos.

Aunque los frutos de la chumbera suelen ser consumidos mayoritariamente en fresco como un producto mínimamente procesado, existen compañías agroalimentarias (Ciao bella ${ }^{\circledR}$, Piping Rock $^{\circledR}$, Divine essence ${ }^{\circledR}$, entre otros) que utilizan estos frutos como materia prima para la elaboración de diversos productos como mermeladas, destilados, dulces, helados, bebidas no alcohólicas entre otros, los cuales utilizan en ocasiones las pulpas con semillas o simplemente las pulpas para sus elaboraciones, generando una corriente de subproductos que en este caso particular se centra en las pieles y ocasionalmente las semillas. Dependiendo de la variedad utilizada se obtienen entre 25 y $30 \%$ del peso total del fruto como subproducto (Melgar et al., 2017a).

En el caso del aguacate, este fruto cuenta con una industrialización aún mayor, debido a que es un producto más conocido a nivel mundial y con una comercialización en constante expansión, penetrando en el mercado agroalimentario y cosmético. Añadiendo a las grandes cantidades de aguacates procesados, los porcentajes de subproductos acumulados (alrededor del $14 \%$ y $16 \%$ del peso total en piel y semilla 
respectivamente) (Calderón-Oliver et al., 2016), observamos una buena oportunidad de aprovechamiento y estudio.

\section{I.4.3. Biocompuestos activos en subproductos}

Los subproductos frutícolas son tejidos vegetales, los cuales son una fuente importante de macro y micronutrientes como carbohidratos, proteínas, fibra dietética, vitaminas y minerales, y además, contienen múltiples metabolitos secundarios (ácidos fenólicos, flavonoides, tioles, terpenos, lignanos, betalaínas, carotenoides) que cada vez son más reconocidas por sus posibles beneficios para la salud humana y a los cuales podemos acuñar con los nombres: "fitoquímicos" y "biocompuestos activos".

Para poder seguir adelante en este trabajo, se hace indispensable el definir la terminología que será usada a lo largo de él. Es común utilizar nombres como "alimentos funcionales" o "nutracéuticos" y atribuir ciertas características benéficas en la salud a "fitoquímicos" o "biocompuestos activos", y si bien son términos interrelacionados, cada uno tiene su propia definición.

Los "alimentos funcionales" pueden ser definidos como productos de la dieta, que además de proveer nutrientes y energía, modulan benéficamente una o más funciones específicas en el cuerpo humano, al mejorar ciertas respuestas fisiológicas y/o reducir el riesgo de enfermedades (Nicoletti, 2012). Dentro de este amplio término podemos incluir frutas, vegetales, granos y cereales, alimentos y bebidas fortificadas y algunos suplementos dietéticos.

Aunque un "nutracéutico" cumple también las funciones de mejora de salud, este es un término que es definido según DeFelice (2002) como cualquier substancia que está en los alimentos, o parte de ellos, suplemento dietético o alimento médico, que provee beneficios a la salud, incluyendo prevención y tratamiento de enfermedades. Este nombre se hace mucho más claro al revisar su etimología proveniente de las palabras "nutrición" y "farmacéutico". En contraste a los alimentos funcionales, los nutracéuticos son artículos derivados de los alimentos usados en forma de píldoras, capsulas, ungüentos, polvos y líquidos. 
Los beneficios a la salud de estos ítems, están asociados a las moléculas denominadas fitoquímicos o biocompuestos activos y las principales diferencias se pueden comprender al analizar sus definiciones, y es que aunque ambos moléculas son una variedad de compuestos derivados de las plantas que influencian las actividades celulares y fisiológicas de manera benéfica en la salud de los consumidores, en el caso de los fitoquímicos se hace referencia sólo a metabolitos secundarios, mientras que los biocompuestos activos son un término más extenso al incluir macronutrientes con propiedades benéficas como péptidos o lípidos (Day et al., 2009; McGuire, 2011).

Consecuentemente, la importancia de estos compuestos activos, ha atraído el interés de la industria alimentaria para generar investigación y desarrollo de nuevos productos, con la finalidad de satisfacer las necesidades de los consumidores, los cuales debido a los incrementos en costes de seguridad social, la firme tendencia de incremento en la expectativa de vida y el deseo de la gente adulta de mejorar su calidad de vida, exige constantemente, aumento en la producción de alimentos funcionales (Roberfroid, 2000).

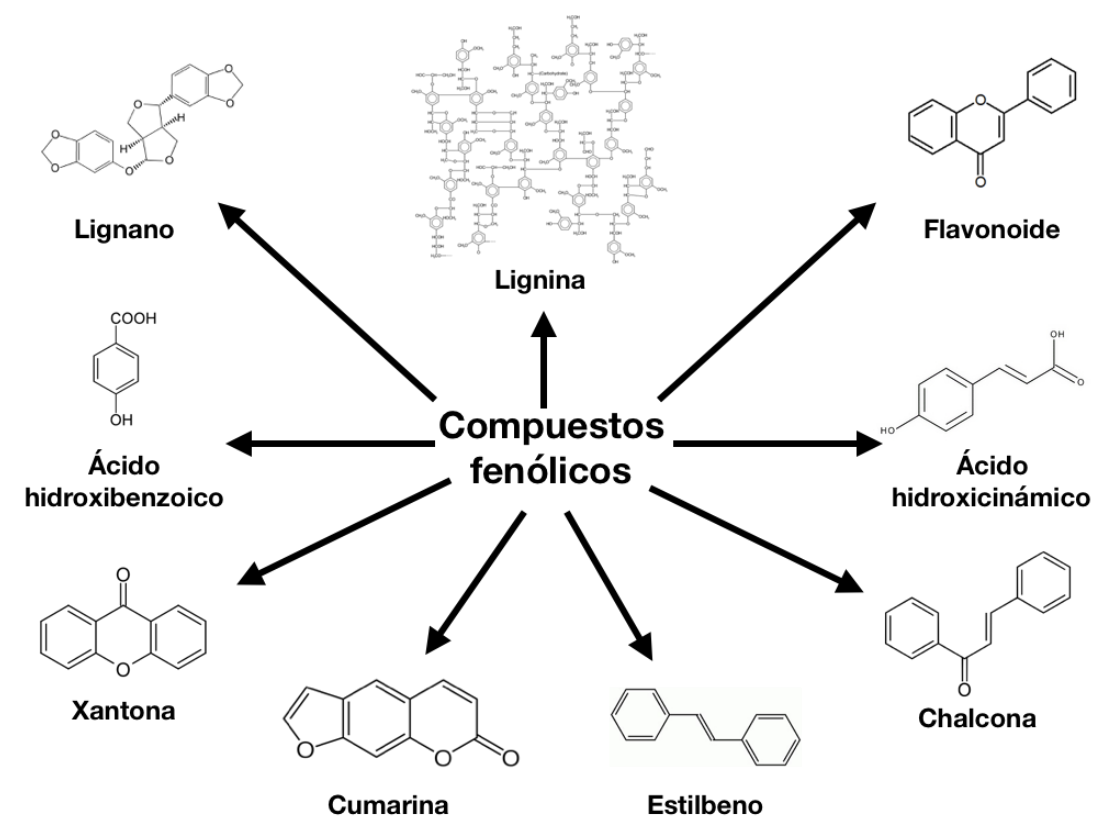

Figure 1-5 Main phenolic compounds structures (source: private collection) 


\section{I.4.4. Compuestos fenólicos}

En general, los subproductos de frutos están compuestos mayoritariamente por agua (80-90\%), seguido por carbohidratos y pequeñas cantidades de lípidos y proteínas (Mirabella et al., 2014). Sin embargo, como mencionamos anteriormente, estos residuos también contienen cantidades significativas de compuestos biológicamente activos como los polifenoles, que pueden ser recuperados y usados en productos para añadir valor agregado.

Incluso a día de hoy no existe un consistente término de uso universal que denote a los polifenoles vegetales, ya que algunos les llaman "fenoles vegetales", mientras que otros usan el término "polifenoles", pero, de acuerdo a Quideau et al. (2011), el uso del término "polifenoles" todavía es preferido principalmente para comunicaciones comerciales.

En cualquier caso, los compuestos fenólicos son un grupo heterogéneo de sustancias que se encuentran ampliamente en todo el reino vegetal, son una clase ubicua de metabolitos secundarios no volátiles de las plantas, y se caracterizan por poseer uno o más grupos hidroxilos unidos a un anillo aromático. Estas estructuras van desde las formas más simples como en el caso del catecol (1,2dihidroxibenceno), hasta la complejidad de las procianidinas oligoméricas que son estructuras poli-hidroxiladas (Lea, 2008).

Actualmente en la bibliografía científica se describen más de 5000 moléculas polifenólicas de forma regular, de las cuales nueve clases diferentes de estos compuestos han sido definidas y son conocidas como: ácidos hidroxibenzoicos, ácidos hidroxicinámicos, xantonas, chalconas, flavonoides, ligninas, lignanos, cumarinas y estilbenos (Figura 1-5). Dentro de estas nueve clases, los flavonoides son los compuestos polifenólicos más comunes y abundantemente esparcidos en la dieta de fuente vegetal humana. Este gran grupo a su vez se divide en 6 subclases: flavonoles, flavonas, flavanonas, flavan-3-oles, isoflavonas y antocianinas (Marais et al., 2006).

Los polifenoles son sintetizados a trevés de la ruta del ácido shikímico, durante el crecimiento normal de los tejidos vegetales, así como en respuesta a ciertas condiciones de estrés (radiación UV, infecciones, heridas, etc.) (Hogervorst-Cvejić et al., 2017). Estos metabolitos secundarios son conocidos por su especificidad en 
funciones y juegan un rol muy importante en la resistencia y respuesta a infecciones por microorganismos patógenos, participan en importantes mecanismos de regulación de las plantas, contribuyen a aspectos organolépticos de los tejidos vegetales, tales como coloración o sabores específicos, además de estar envueltos en mecanismos de reparación de reacciones oxidativas (Moreno and Peinado, 2012).

Los compuestos fenólicos son considerados importantes biomoléculas debido a sus potenciales beneficios en la salud, de hecho, son la fuente más abundante de compuestos antioxidantes presentes en la dieta humana (Kuhnle, 2012). Actualmente, se han llevado a cabo múltiples estudios altamente específicos para confirmar y determinar los mecanismos de acción a partir de los cuales, los polifenoles confieren sus múltiples propiedades: antioxidantes, analgésicas, antitumorales, anti-inflamatorias, ansiolíticas, cardioprotectoras, antimicrobianas, entre otras.

Aunque el número de propiedades atribuidas a estos compuestos es muy extensa, de todos los efectos biológicos mencionados anteriormente, el potencial antioxidante de los compuestos fenólicos es sin lugar a duda el mas estudiado, tanto en extractos de matríces vegetales, cómo en moléculas aisladas. En estos análisis las propuestas más iterativas de mecanismos de acción de la actividad antioxidante, son atribuidas a inhibidores del estrés oxidativo, captación de radicales libres, reducción de intermediarios oxidativos e inhibidores del estrés oxidativo (Ferreira et al., 2017).

\section{I.4.5. Colorantes naturales}

Otra alternativa industrialmente interesante al uso de los subproductos la encontramos en las propiedades organolépticas que estos pueden conferir, como es el caso de los colorantes, ya que los consumidores asocian el color de los productos como un indicador de un buen procesado, calidad e incluso de seguridad. Esto no es ninguna sorpresa, ya que todos como consumidores, antes de probar e incluso oler cualquier producto, el primer sentido que entra en contacto con nuestra compra, es la vista.

El color es la representación de un efecto combinado entre los aspectos químicos y las características físicas. De esta manera, la percepción del color es un proceso en el que se involucran los 
fenómenos físicos como transmisión, refracción, absorción y dispersión, entre otros, y las señales químicas posteriores que involucran las transformaciones neuronales que el cerebro interpreta como color. Este análisis subjetivo del color requiere tres elementos indispensables: luz, objeto y observador.

Las sustancias colorantes se han utilizado para mejorar el atractivo de los alimentos y otros productos desde inicios de la civilización humana, como es el caso de los papiros egipcios que datan del año 1500 a.C., donde se indica que los colorantes naturales como cúrcuma, el azafrán y el pimentón se agregaban a los alimentos para hacerlos más atractivos (Arlt, 2010). Históricamente, los condimentos fueron las primeros utilizados como colorantes, seguidos por pigmentos inorgánicos (silicatos, carbonatos, diferentes metales), los cuales resultaron inductores de potenciales daños a la salud y como resultado, sólo algunos de ellos poseen usos limitados como es el caso del dióxido de titanio.

Posteriormente, la industria sustituyó los colorantes inorgánicos, introduciendo colorantes sintéticos. En las primeras legislaciones, alrededor de 80 de este tipo de compuestos eran permitidos, aunque después de varios estudios esta lista fue reducida a 15, y actualmente, sólo 4 de ellos son ampliamente aceptados a nivel mundial (pigmentos azóicos, tintes xanteno, colorantes de triarilmetano y colorante añil), mientras que el resto poseen ciertas restricciones geográficas debido a los distintos órganos de protección de consumidores y su uso está estrictamente controlado (Delgado-Vargas and Paredes-Lopez, 2003).

Múltiples legislaciones como la ley de pureza de alimentos y medicinas de 1906, la ley federal de alimentos, medicamentos y cosméticos de 1938 y la enmienda de color aditivo de 1960 de la FDA de los Estados Unidos, han sido las regulaciones que han dado forma al uso de colorantes como aditivos en la alimentación. Hoy en día todos los aditivos colorantes deben estar aprobados en listas positivas de uso provenientes de organizaciones mundiales como el Codex Alimentarius o el Comité experto en aditivos alimentarios (JECFA), o regulaciones independientes de los países o regiones de uso (EFSA, FDA, JFCRF).

Actualmente, los aditivos colorantes exentos de certificaciones son aquellos derivados de plantas o minerales (Barrows et al., 2003), y si a esto sumamos la reducción de riesgos para la salud que conlleva la 
ingesta de ciertos colorantes sintéticos, nos encontramos con una excelente alternativa de utilización de los subproductos de tejidos vegetales como colorantes aditivos naturales.

Dentro de los colorantes naturales extraídos a partir de tejidos vegetales encontramos una gran diversidad de grupos moleculares que proporcionan un amplio rango de colores que pueden ser utilizados. Algunos de los ejemplos más destacados son: las antocianinas, carotenoides, clorofilas, oleorresinas tumericas, y betalaínas, entre otros. En esta trabajo nos centramos en las últimas debido a que son los pigmentos presentes en los frutos del genero Opuntia.

Las betalaínas son industrialmente importantes para la coloración de alimentos. Estas moléculas son metabolitos secundario nitrogenados hidrosolubles. Estas estructuras se encuentran depositadas en las vacuolas celulares de plantas pertenecientes al orden Caryophyllales en las familias Caryophyllaceae y Molluginaceae y en algunas familias del género Basidiomycetes. Esta familia de pigmentos se dividen a su vez en dos grandes familias, las betacianinas las cuales presentan coloraciones rojo-violeta y betaxantinas que poseen tonalidades amarillo-naranja, aunque sus pigmentos llegan a ser confundidos con los de las antocianinas, ambas estructuras betalaínas y antocianinas son excluyentes y no se ha encontrado un solo informe sobre aparición simultánea en algún tejido vegetal (Jain and Gould, 2015).

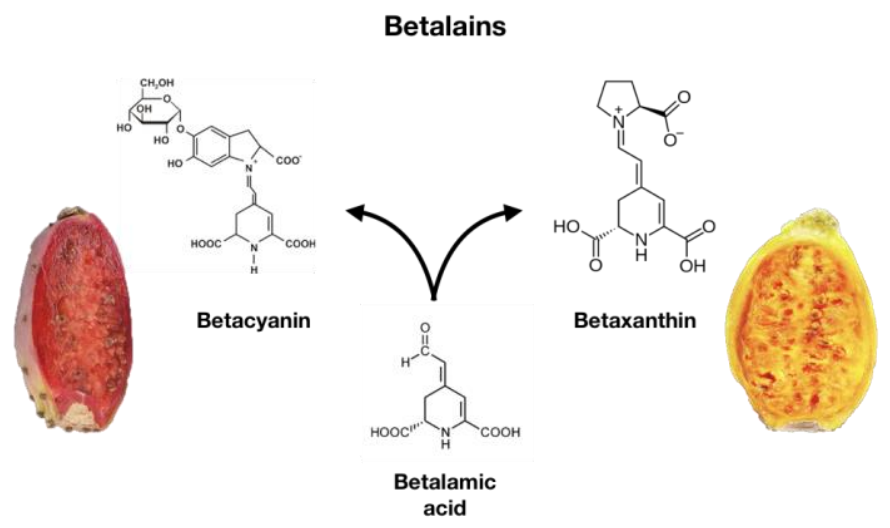

Figure 1-6 Main betalains structures, left OFI var Sangigna, right OFI var Gialla (source: private collection) 
Las distintas betacianinas reportadas en la bibliografía, son glucósidos o acilglicósidos de la betanidina, mientras que las betaxantinas son productos de condensación del ácido betalamico con aminas o aminoácidos. Algunos datos importantes dentro de estas familias son que la betacianina mayormente extendida en la naturaleza es la betanina (betanidin-5-O- $\beta$-glucósido) (Esatbeyoglu et al., 2015a), mientras que la indicaxantina, fue la primer betaxantina aislada e identificada en Opuntia ficus-indica (OFI) (Piattelli et al., 1964).

Debido a que las betalaínas poseen un alto coeficiente de extinción molar, su poder colorante es competitivo de sus alternativas sintéticas (Henry, 1996), además, estas moléculas tienen la capacidad de retener su color sobre un amplio rango de $\mathrm{pH}$ (3-7), lo cual las convierte en una potente alternativa al uso de antocianinas en productos alimenticios con pH bajos (Stintzing et al., 2000). Por último, las betalaínas han sido probadas como captadores de radicales libres, lo que les confiere también, propiedades antioxidantes (Pedreño and Escribano, 2000), que en conjunto con todo lo anterior, les convierte en un prominente promesa de valorización de los subproductos de Opuntia spp. 


\section{I.5. CONTRIBUCIÓN DE LA TESIS DOCTORAL}

Entre las principales contribuciones de esta Tesis Doctoral, pueden destacarse las siguientes:

- La caracterización integral de los frutos de Opuntia spp. y Persea americana, particularmente, sus propiedades nutricionales, organolépticas y funcionales.

- Extracción, identificación y cuantificación de las principales biomoléculas activas presentes en los frutos y subproductos de las especies antes mencionadas.

- Identificación y cuantificación de las moléculas colorantes extraídas de los subproductos de Opuntia spp.

- Optimización de los procesos de extracción de las moléculas con propiedades funcionales obtenidas a partir de los subproductos de Opuntia spp.

Además, y puesto que esta tesis doctoral se presenta como un compendio de publicaciones científicas, la Tabla 1-1 muestra la lista de artículos en revistas científicas a los que este trabajo ha dado lugar. 
Table 1-1 Publication list presented within this work

\begin{tabular}{|c|c|c|c|}
\hline $\begin{array}{l}\text { Publicación } \\
\text { número }\end{array}$ & $\begin{array}{l}\text { Título de la } \\
\text { Publicación }\end{array}$ & $\begin{array}{l}\text { Journal de } \\
\text { publicación }\end{array}$ & $\begin{array}{c}\text { Año de } \\
\text { publicación }\end{array}$ \\
\hline 1 & $\begin{array}{l}\text { By-product recovery } \\
\text { of Opuntia spp. } \\
\text { peels: Betalainic and } \\
\text { phenolic profiles and } \\
\text { bioactive properties }\end{array}$ & $\begin{array}{c}\text { Industrial } \\
\text { Crops and } \\
\text { Products }\end{array}$ & 2017 \\
\hline 2 & $\begin{array}{l}\text { Extensive profiling } \\
\text { of three varieties of } \\
\text { Opuntia spp. fruit } \\
\text { for innovative food } \\
\text { ingredients }\end{array}$ & $\begin{array}{c}\text { Food Research } \\
\text { International }\end{array}$ & 2017 \\
\hline 3 & $\begin{array}{c}\text { Bioactive } \\
\text { characterization of } \\
\text { Persea americana } \\
\text { mill. by-products: A } \\
\text { rich source of } \\
\text { inherent antioxidants }\end{array}$ & $\begin{array}{l}\text { Industrial } \\
\text { Crops and } \\
\text { Products }\end{array}$ & 2018 \\
\hline 4 & $\begin{array}{l}\text { Extraction recovery } \\
\text { optimization through } \\
\text { UAE and MAE of } \\
\text { Opuntia peels } \\
\text { biocompounds: } \\
\text { Avant-garde use of } \\
\text { the byproducts }\end{array}$ & $\begin{array}{l}\text { En proceso de } \\
\text { publicación }\end{array}$ & \\
\hline
\end{tabular}




\section{I.6. ESTRUCTURA DE LA TESIS DOCTORAL}

El presente trabajo se ha dividió en 9 capítulos, de los cuales en el primero (Capítulo 1 - Introducción), se presenta el panorama actual y la revisión bibliográfica llevada a cabo con respecto a las especies frutícolas Opuntia spp. y Persea americana, el aprovechamiento de los subproductos y sugerencias de posibles alternativas de uso, y finalmente, se mencionan las contribuciones y la estructura de la presente tesis doctoral.

En el segundo capítulo (Capítulo 2 - Objetivos y plan de trabajo) se definen los objetivos principales de este trabajo, tanto en términos generales y posteriormente se enlistan los objetivos específicos, así como el orden cronológico a seguir en el plan de trabajo, el cual muestra una figura (Figura 2-1) donde se sintetiza de forma general el trabajo, seguido mediante 4 figuras (Figura 2-2, 2-3, 2-4 y 2-5) donde se resumen los capítulos experimentales.

Consecutivamente, el tercer capítulo (Capítulo 3 - Metodología experimental) es el encargado de describir en profundidad todos los métodos empleados en los ensayos realizado para la obtención de resultados de esta tesis doctoral, dichas metodologías intentan seguir el orden cronológico de ensayos, aunque estas no fueron necesariamente obligatorias en todos los diseños experimentales realizados.

Posteriormente, en los siguientes cuatro capítulos, se exponen los resultados correspondientes a los ensayos realizados y que conforman el eje central de este trabajo.

En el cuarto capítulo (Capítulo 4 - Caracterización de los frutos y subproductos de Persea americana) se desarrollan los resultados obtenidos en los frutos del aguacate y sus subproductos; en el capítulo quinto (Capitulo 5 - Caracterización de los frutos de las especies Opuntia spp.) se recogen los resultados correspondientes a las caracterización de los frutos con la intención de proveer mayor robustez a la bibliografía de estos frutos y para poder diferenciar ciertas características entre los frutos y los subproductos, y en el sexto capítulo (Capítulo 6 - Caracterización de los subproductos de Opuntia spp.) se exhibe información con respecto a los análisis realizados para la identificación de posibles outputs, para la valorización de los subproductos de dichos cultivo frutícola, y para ello se emplean técnicas, físicas, químicas, ópticas, analíticas, microbiológicas e 
inmunológicas, que permiten dilucidar lo que consideramos como mejores opciones de valorización de subproductos.

Como último capítulo de la parte central de esta tesis, se exponen en el séptimo capítulo (Capítulo 7- Optimización de los extractos de las pieles de Opuntia spp.) los resultados obtenidos del diseño experimental de optimización, realizados mediante técnicas estadísticas de sistema central compuesto, utilizando como tecnologías de extracción la extracción asistida por ultrasonidos y por microondas, analizando distintos parámetros de interés.

Finalmente, esta tesis finaliza con un capítulo en el que se recogen las conclusiones más destacadas a lo largo de todo el trabajo (Capítulo 8 - Conclusiones), y otro capítulo (Capítulo 9 - Anexos) donde se presenta información complementaria obtenida durante la realización de dicho trabajo, como lo son presentaciones escritas $u$ orales, originadas a partir de los resultados obtenidos y no publicados en los artículos mencionados anteriormente.

La Figura 1-7 representa de manera esquemática la estructura del trabajo detallado anteriormente.

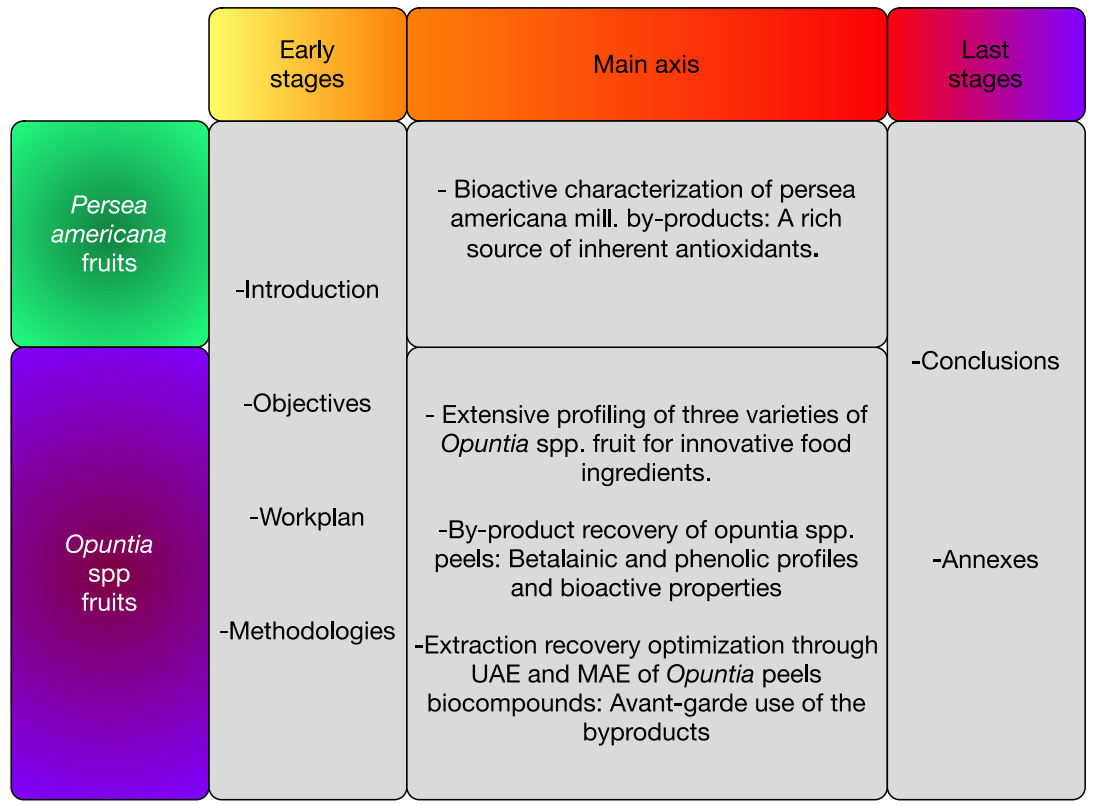

Figure 1-7 Doctoral thesis estructural scheme (source: private collection) 


\section{I.6. BIBLIOGRAFIA}

Ahn, J.H., Jang, Y.-S., Lee, S.Y., 2016. Production of succinic acid by metabolically engineered microorganisms. Curr. Opin. Biotechnol. 42, 54-66. https://doi.org/10.1016/j.copbio.2016.02.034

Al-Farsi, M.A., Lee, C.Y., 2008. Optimization of phenolics and dietary fibre extraction from date seeds. Food Chem. 108, 977-985. https://doi.org/10.1016/j.foodchem.2007.12.009

Albano, C., Negro, C., Tommasi, N., Gerardi, C., Mita, G., Miceli, A., De Bellis, L., Blando, F., 2015. Betalains, Phenols and Antioxidant Capacity in Cactus Pear [Opuntia ficus-indica (L.) Mill.] Fruits from Apulia (South Italy) Genotypes. Antioxidants 4, 269-280. https://doi.org/10.3390/antiox4020269

Albuquerque, T.G., Santos, F., Sanches-Silva, A., Beatriz Oliveira, M., Bento, A.C., Costa, H.S., 2016. Nutritional and phytochemical composition of Annona cherimola Mill. fruits and by-products: Potential health benefits. Food Chem. 193, 187-195. https://doi.org/10.1016/j.foodchem.2014.06.044

Allai, L., Druart, X., Öztürk, M., BenMoula, A., Nasser, B., El Amiri, B., 2016. Protective effects of Opuntia ficus-indica extract on ram sperm quality, lipid peroxidation and DNA fragmentation during liquid storage. Anim. Reprod. Sci. 175, 1-9. https://doi.org/10.1016/j.anireprosci.2016.09.013

Almeida, M.M.B., de Sousa, P.H.M., Arriaga, A.M.C., do Prado, G.M., Magalhães, C.E. de C., Maia, G.A., de Lemos, T.L.G., 2011. Bioactive compounds and antioxidant activity of fresh exotic fruits from northeastern Brazil. Food Res. Int. 44, 2155-2159. https://doi.org/10.1016/j.foodres.2011.03.051

Alvarez, B., 2007. Análisis de factibilidad del cultivo de la tuna en la localidad de Icaño, Departamento La Paz, Dirección provincial de programación del desarrollo, Ministerio de Producción y Desarrollo. Gobierno de la Provincia de Catamarca. Catamarca, Argentina.

Alzate T, L.M., González, D., Hincapié, S., Cardona S, B.L., LondoñoLondoño, J., Jiménez-Cartagena, C., 2016. The profile of bioactive substances in ten vegetable and fruit by-products from a food supply chain in Colombia. Sustain. Prod. Consum. https://doi.org/10.1016/j.spc.2016.07.005

Ammar, I., Ben Salem, M., Harrabi, B., Mzid, M., Bardaa, S., Sahnoun, Z., Attia, H., Ennouri, M., 2018. Anti-inflammatory activity and phenolic composition of prickly pear (Opuntia ficus-indica) 
flowers. Ind. Crops Prod. 112, 313-319. https://doi.org/10.1016/j.indcrop.2017.12.028

Angulo-Bejarano, P.I., Martínez-Cruz, O., Paredes-López, O., 2014.

Phytochemical Content, Nutraceutical Potential and

Biotechnological Applications of an Ancient Mexican Plant:

Nopal (Opuntia ficus-indica). Curr. Nutr. Food Sci. 10, 196-217. https://doi.org/10.2174/157340131003140828121015

Arlt, U., 2010. NATCOL | Foods Colours Legislation.

Aruwa, C.E., Amoo, S.O., Kudanga, T., 2018. Opuntia (Cactaceae) plant compounds, biological activities and prospects - A comprehensive review. Food Res. Int. 112, 328-344. https://doi.org/10.1016/j.foodres.2018.06.047

Association of Official Analytical Chemists, 2016. Official Methods of Analysis of AOAC International, 20th ed. The Association, Gaithersburg, MD, USA.

Attokaran, M., 2011. Natural Food Flavors and Colorants Natural Food Flavors and Colorants, 1st ed. Blackwell Publishing LTD, Iowa.

Augustin, M.A., Sanguansri, L., 2015. Challenges and Solutions to Incorporation of Nutraceuticals in Foods. Annu. Rev. Food Sci. Technol. 6, 463-477. https://doi.org/10.1146/annurev-food022814-015507

Ayala-Zavala, J.F., Vega-Vega, V., Rosas-Domínguez, C., PalafoxCarlos, H., Villa-Rodriguez, J.A., Siddiqui, M.W., Dávila-Aviña, J.E., González-Aguilar, G.A., 2011. Agro-industrial potential of exotic fruit byproducts as a source of food additives. Food Res. Int. 44 , 1866-1874. https://doi.org/10.1016/j.foodres.2011.02.021

Azeredo, H.M.C., 2009. Betalains: Properties, sources, applications, and stability - A review. Int. J. Food Sci. Technol. 44, 2365-2376. https://doi.org/10.1111/j.1365-2621.2007.01668.x

Balouiri, M., Sadiki, M., Ibnsouda, S.K., 2016. Methods for in vitro evaluating antimicrobial activity: A review. J. Pharm. Anal. 6, 71-79. https://doi.org/10.1016/j.jpha.2015.11.005

Barros, L., Calhelha, R.C., Queiroz, M.J.R.P., Santos-Buelga, C., Santos, E.A., Regis, W.C.B., Ferreira, I.C.F.R., 2015. The powerful in vitro bioactivity of Euterpe oleracea Mart. seeds and related phenolic compounds. Ind. Crops Prod. 76, 318-322. https://doi.org/10.1016/j.indcrop.2015.05.086

Barros, L., Pereira, C., Ferreira, I.C.F.R., 2013. Optimized Analysis of Organic Acids in Edible Mushrooms from Portugal by Ultra Fast Liquid Chromatography and Photodiode Array Detection. Food 
Anal. Methods 6. https://doi.org/10.1007/s12161-012-9443-1

Barrows, J.N., Lipman, A.L., Bailey, C.J., Cianci, S., 2003. Color Additives: FDA's Regulatory Process and Historical Perspectives. Food Saf. Mag. https://www.fda.gov/forindustry/coloradditives/regulatoryproces shistoricalperspectives/ (accessed 9.3.18).

Baydar, N.G., Özkan, G., Sağdiç, O., 2004. Total phenolic contents and antibacterial activities of grape (Vitis vinifera L.) extracts. Food Control 15, 335-339. https://doi.org/10.1016/S09567135(03)00083-5

Belščak-Cvitanović, A., Durgo, K., Huđek, A., Bačun-Družina, V., Komes, D., 2018. Metabolism and Health Effects of Polyphenols, in: Galanakis, C.M. (Ed.), Polyphenols: Properties, Recovery, and Applications. Woodhead Publishing, pp. 1-44. https://doi.org/https://doi.org/10.1016/B978-0-12-813572$3.00001-4$

Belwal, T., Dhyani, P., Bhatt, I.D., Rawal, R.S., Pande, V., 2016. Optimization extraction conditions for improving phenolic content and antioxidant activity in Berberis asiatica fruits using response surface methodology (RSM). Food Chem. 207, 115124. https://doi.org/10.1016/j.foodchem.2016.03.081

Bessada, S.M.F., Barreira, J.C.M., Barros, L., Ferreira, I.C.F.R., Oliveira, M.B.P.P., 2016. Phenolic profile and antioxidant activity of Coleostephus myconis (L.) Rchb.f.: An underexploited and highly disseminated species. Ind. Crops Prod. 89, 45-51. https://doi.org/10.1016/j.indcrop.2016.04.065

Betancourt, C., Cejudo-Bastante, M.J., Heredia, F.J., Hurtado, N., 2017. Pigment composition and antioxidant capacity of betacyanins and betaxanthins fractions of Opuntia dillenii (Ker Gawl) Haw cactus fruit. Food Res. Int. 101, 173-179. https://doi.org/10.1016/j.foodres.2017.09.007

Bhatia, S., Bera, T., Dahiya, R., Bera, T., Bhatia, S., Bera, T., 2015. Classical and Nonclassical Techniques for Secondary Metabolite Production in Plant Cell Culture, in: Modern Applications of Plant Biotechnology in Pharmaceutical Sciences. Elsevier, pp. 231291. https://doi.org/10.1016/B978-0-12-802221-4.00007-8

Brand-Williams, W., Cuvelier, M.E., Berset, C., 1995. Use of a free radical method to evaluate antioxidant activity. LWT - Food Sci. Technol. 28, 25-30. https://doi.org/10.1016/S00236438(95)80008-5

Bravo-Hollis, H., 1978. Las cactaceas de Mexico. Universidad 
Nacional Autonoma de Mexico, Mexio. https://doi.org/10.15713/ins.mmj.3

Brundtland, G.H., 1987. Our common future.

Cai, Y., Sun, M., Corke, H., 2003. Antioxidant activity of betalains from plants of the Amaranthaceae. J. Agric. Food Chem. 51, 2288-2294. https://doi.org/10.1021/jf030045u

Calderón-Oliver, M., Escalona-Buendía, H.B., Medina-Campos, O.N., Pedraza-Chaverri, J., Pedroza-Islas, R., Ponce-Alquicira, E., 2016. Optimization of the antioxidant and antimicrobial response of the combined effect of nisin and avocado byproducts. LWT Food Sci. Technol. 65, 46-52. https://doi.org/10.1016/j.lwt.2015.07.048

Cardoso-Ugarte, G.A., Sosa-Morales, M.E., Ballard, T., Liceaga, A., San Martín-González, M.F., 2014. Microwave-assisted extraction of betalains from red beet (Beta vulgaris). LWT - Food Sci. Technol. 59, 276-282. https://doi.org/10.1016/j.lwt.2014.05.025

Carocho, M., Ferreira, I.C.F.R., 2013. A review on antioxidants, prooxidants and related controversy: Natural and synthetic compounds, screening and analysis methodologies and future perspectives. Food Chem. Toxicol. 51, 15-25. https://doi.org/10.1016/j.fct.2012.09.021

Carr, M., 2013. The water relations and irrigation requirements of avocado (Persea americana Mill.): a review. Exp. Agric. 49, 256278. https://doi.org/10.1017/S0014479712001317

Cassano, A., Conidi, C., Timpone, R., D’Avella, M., Drioli, E., 2007. A membrane-based process for the clarification and the concentration of the cactus pear juice. J. Food Eng. 80, 914-921. https://doi.org/10.1016/j.jfoodeng.2006.08.005

Castellanos-Santiago, E., Yahia, E.M., 2008. Identification and quantification of betalains from the fruits of 10 Mexican prickly pear cultivars by high-performance liquid chromatography and electrospray ionization mass spectrometry. J. Agric. Food Chem. 56, 5758-5764. https://doi.org/10.1021/jf800362t

Castellar, R., Obón, J.M., Alacid, M., Fernández-López, J.A., 2003. Color Properties and Stability of Betacyanins from Opuntia Fruits. J. Agric. Food Chem. 51, 2772-2776. https://doi.org/10.1021/jf021045h

Cejudo Bastante, M.J., Chaalal, M., Louaileche, H., Parrado, J., Heredia, F.J., 2014. Betalain Profile, Phenolic Content, and Color Characterization of Different Parts and Varieties of Opuntia ficusindica. J. Agric. Food Chem. 62, 8491-8499. 
https://doi.org/10.1021/jf502465g

Chahdoura, H., Barreira, J.C.M., Barros, L., Santos-Buelga, C., Ferreira, I.C.F.R., Achour, L., 2014. Phytochemical characterization and antioxidant activity of Opuntia microdasys (Lehm.) Pfeiff flowers in different stages of maturity. J. Funct. Foods 9, 27-37. https://doi.org/10.1016/j.jff.2014.04.011

Chahdoura, H., Barreira, J.C.M., Fernández-Ruiz, V., Morales, P., Calhelha, R.C., Flamini, G., Soković, M., Ferreira, I.C.F.R., Achour, L., 2016. Bioactivity, proximate, mineral and volatile profiles along the flowering stages of Opuntia microdasys (Lehm.): defining potential applications. Food Funct. 7, 1458-67. https://doi.org/10.1039/c5fo01536g

Chan, L.G., Cohen, J.L., Maria, J., Nobrega, L., Bell, D.M., 2018. Conversion of Agricultural Streams and Food-Processing ByProducts to Value-Added Compounds using Filamentous Fungi. Annu. Rev. Food Sci. Technol. 9, 1-21. https://doi.org/10.1146/annurev-food-030117-012626

Chougui, N., Djerroud, N., Naraoui, F., Hadjal, S., Aliane, K., Zeroual, B., Larbat, R., 2015. Physicochemical properties and storage stability of margarine containing Opuntia ficus-indica peel extract as antioxidant. Food Chem. 173, 382-90. https://doi.org/10.1016/j.foodchem.2014.10.025

Chougui, N., Tamendjari, A., Hamidj, W., Hallal, S., Barras, A., Richard, T., Larbat, R., 2013. Oil composition and characterisation of phenolic compounds of Opuntia ficus-indica seeds. Food Chem. 139, 796-803. https://doi.org/10.1016/j.foodchem.2013.01.054

Clifford, M.N., Johnston, K.L., Knight, S., Kuhnert, N., 2003. Hierarchical Scheme for LC-MSn Identification of Chlorogenic Acids. J. Agric. Food Chem. 51, 2900-2911. https://doi.org/10.1021/jf026187q

Clifford, M.N., Knight, S., Kuhnert, N., 2005. Discriminating between the six isomers of dicaffeoylquinic acid by LC-MSn. J. Agric. Food Chem. 53, 3821-3832. https://doi.org/10.1021/jf050046h

Cowan, A.K., Cripps, R.F., Richings, E.W., Taylor, N.J., 2001. Fruit size: Towards an understanding of the metabolic control of fruit growth using avocado as a model system. Physiol. Plant. 111, 127-136. https://doi.org/10.1034/j.1399-3054.2001.1110201.x

Cowan, A.K., Wolstenholme, B.N., 2003. AVOCADOS, in: Encyclopedia of Food Sciences and Nutrition. Elsevier, pp. 348353. https://doi.org/10.1016/B0-12-227055-X/00073-0 
Crane, J.H., Balerdi, C.F., Maguire, I., 2016. Avocado Growing in the Florida Home Landscape.

Da-Costa-Rocha, I., Bonnlaender, B., Sievers, H., Pischel, I., Heinrich, M., 2014. Hibiscus sabdariffa L. - A phytochemical and pharmacological review. Food Chem. 165, 424-443. https://doi.org/10.1016/j.foodchem.2014.05.002

da Silva, R.P.F.F., Rocha-Santos, T.A.P., Duarte, A.C., 2016. Supercritical fluid extraction of bioactive compounds. TrAC Trends Anal. Chem. 76, 40-51. https://doi.org/10.1016/j.trac.2015.11.013

Dabas, D., Shegog, R.M., Ziegler, G.R., Lambert, J.D., 2013. Avocado (Persea americana) seed as a source of bioactive phytochemicals. Curr. Pharm. Des. 19, 6133-40. https://doi.org/10.2174/1381612811319340007

Day, L., Seymour, R.B., Pitts, K.F., Konczak, I., Lundin, L., 2009. Incorporation of functional ingredients into foods. Trends Food Sci. Technol. $20, \quad 388-395$. https://doi.org/10.1016/J.TIFS.2008.05.002

DeFelice, S.L., 2002. FIM Rationale And Proposed Guidelines For The Nutraceutical Research \& Education Act - NREA. New York.

Delgado-Vargas, F., Paredes-Lopez, O., 2003. Natural Colorants for Food and Nutraceutical Uses, Trends in Food Science \& Technology. https://doi.org/10.1016/S0924-2244(03)00076-1

Destro dos Santos, C., Külzer Scherer, R., Schilling Cassini, A., Ferreira Marczak, L.D., Tessaro, I.C., 2016. Clarification of red beet stalks extract by microfiltration combined with ultrafiltration. J. Food Eng. 185, 35-41. https://doi.org/10.1016/j.jfoodeng.2016.03.031

Devalaraja, S., Jain, S., Yadav, H., 2011. Exotic fruits as therapeutic complements for diabetes, obesity and metabolic syndrome. Food Res. Int. 44, 1856-1865. https://doi.org/10.1016/j.foodres.2011.04.008

Devasagayam, T.P.A., Boloor, K.K., Ramasarma, T., 2003. Methods for estimating lipid peroxidation: An analysis of merits and demerits. Indian J. Biochem. Biophys. 40, 300-308.

Dias, M.I., Sousa, M.J., Alves, R.C., Ferreira, I.C.F.R., 2016. Exploring plant tissue culture to improve the production of phenolic compounds: A review. Ind. Crops Prod. 82, 9-22. https://doi.org/10.1016/j.indcrop.2015.12.016

Donkin, R.A., 1977. Spanish Red: An Ethnogeographical Study of Cochineal and the Opuntia Cactus. Trans. Am. Philos. Soc. 67, 1- 
84. https://doi.org/10.2307/1006195

Esatbeyoglu, T., Wagner, A.E., Schini-Kerth, V.B., Rimbach, G., 2015a. Betanin a food colorant with biological activity. Mol. Nutr. Food Res. 59, 36-47. https://doi.org/10.1002/mnfr.201400484 Espinel-Ingroff, A., 2001. Comparison of the E-test with the NCCLS

M38-P method for antifungal susceptibility testing of common and emerging pathogenic filamentous fungi. J. Clin. Microbiol. 39 , 1360-1367. https://doi.org/10.1128/JCM.39.4.13601367.2001

Esquivel, P., 2016. Handbook on Natural Pigments in Food and Beverages Industrial Applications for Improving Food Colorl, in: Carle, R., Schweiggert, R.M. (Eds.). Woodhead Publishing, San Pedro, Costa Rica, pp. 81-99.

FAO, 2016. FAOSTAT

URL http://www.fao.org/faostat/en/?\#data/QC/visualize (accessed 5.3.18).

FAO, 2004. AVOCADO: Post-Harvest Operation. Rome.

FAO, IFAD, WFP, 2015. The State of Food Insecurity in the World. Meeting the 2015 international hunger targets: taking stock of uneven progress. Rome.

Farag, M.A., Maamoun, A.A., Ehrlich, A., Fahmy, S., Wesjohann, L.A., 2017. Assessment of sensory metabolites distribution in 3 cactus Opuntia ficus-indica fruit cultivars using UV fingerprinting and GC/MS profiling techniques. LWT - Food Sci. Technol. 80, 145-154. https://doi.org/10.1016/j.lwt.2017.02.014

Fathordoobady, F., Mirhosseini, H., Selamat, J., Manap, M.Y.A., 2016. Effect of solvent type and ratio on betacyanins and antioxidant activity of extracts from Hylocereus polyrhizus flesh and peel by supercritical fluid extraction and solvent extraction. Food Chem. 202, 70-80. https://doi.org/10.1016/j.foodchem.2016.01.121

FDA, 2017. SCOGS (Select Committee on GRAS Substances)]. URL http://www.accessdata.fda.gov/scripts/fdcc/?set=SCOGS (accessed 3.14.17).

FDA, 2007. Guidance for Industry and Other Stakeholders Toxicological Principles for the Safety Assessment of Food Ingredients, Human Studies.

Fernández-López, J. a., Almela, L., 2001. Application of highperformance liquid chromatography to the characterization of the betalain pigments in prickly pear fruits. J. Chromatogr. A 913, 415-420. https://doi.org/10.1016/S0021-9673(00)01224-3

Fernandez-Rojas, B., Ortiz-Moreno, A., Hernandez-Navarro, D., 2010. 
Phenolic Content and its Antioxidant Activity of Persimmon (Dyospiros kaki L.) Cultivated in Mexico. J. Biotechnol. 150. https://doi.org/10.1016/j.jbiotec.2010.09.289

Ferreira, I.C.F.R., Martins, N., Barros, L., 2017. Phenolic Compounds and Its Bioavailability: In Vitro Bioactive Compounds or Health Promoters? Adv. Food Nutr. Res. 82, 1-44. https://doi.org/10.1016/bs.afnr.2016.12.004

Ferreres, F., Grosso, C., Gil-Izquierdo, A., Valentão, P., Mota, A.T., Andrade, P.B., 2017. Optimization of the recovery of high-value compounds from pitaya fruit by-products using microwaveassisted extraction. Food Chem. 230, 463-474. https://doi.org/10.1016/j.foodchem.2017.03.061

Flores-Valdez, C., Luna-Esquivel, J., Ramirez-Moreno, P., 1995. Manejo postcosecha de la tuna para el mercado nacional e internacional y Procesamiento y transformación industrial. Chapingo, Estado de México.

Galanakis, C.M., 2015. Chapter 3 - The universal recovery strategy, Food Waste Recovery. Elsevier Inc. https://doi.org/10.1016/B978-0-12-800351-0.00003-1

Galanakis, C.M., 2012. Recovery of high added-value components from food wastes: Conventional, emerging technologies and commercialized applications. Trends Food Sci. Technol. 26, 6887. https://doi.org/10.1016/j.tifs.2012.03.003

Gandía-herrero, F., Cabanes, J., Escribano, J., García-carmona, F., Jimenez-atienzar, M., Jiménez-atiénzar, M., 2013. Encapsulation of the most antioxidant betalains in edible matrices as powders of different colors Encapsulation of the most antioxidant betalains in edible matrices as powders of different colors. https://doi.org/10.1021/jf400337g

Gandía-Herrero, F., Escribano, J., García-Carmona, F., 2010. Structural implications on color, fluorescence, and antiradical activity in betalains. Planta 232, 449-460. https://doi.org/10.1007/s00425010-1191-0

Garcia-Castello, E.M., Rodriguez-Lopez, A.D., Mayor, L., Ballesteros, R., Conidi, C., Cassano, A., 2015. Optimization of conventional and ultrasound assisted extraction of flavonoids from grapefruit (Citrus paradisi L.) solid wastes. LWT - Food Sci. Technol. 64, 1114-1122. https://doi.org/10.1016/j.lwt.2015.07.024

García-Cruz, L., Dueñas, M., Santos-Buelgas, C., Valle-Guadarrama, S., Salinas-Moreno, Y., 2017. Betalains and phenolic compounds profiling and antioxidant capacity of pitaya (Stenocereus spp.) 
fruit from two species (S. Pruinosus and S. stellatus). Food Chem. 234, 111-118. https://doi.org/10.1016/j.foodchem.2017.04.174

Gebhardt, D., 2018. The Economics of Natural Color Pigments]. URL https://sensientfoodcolors.com/en-us/researchdevelopment/economics-natural-color-pigments/

Ghasemzadeh, A., Ghasemzadeh, N., 2011. Flavonoids and phenolic acids: Role and biochemical activity in plants and human. J. Med. Plants Res. 5, 6697-6703. https://doi.org/10.5897/JMPR11.363

Gomes-Correa, R.C., de Souza, A.H.P., Calhelha, R.C., Barros, L., Glamoclija, J., Sokovic, M., Peralta, R.M., Bracht, A., Ferreira, I.C.F.R., 2015. Bioactive formulations prepared from fruiting bodies and submerged culture mycelia of the Brazilian edible mushroom Pleurotus ostreatoroseus Singer. Food Funct. 6, 21552164. https://doi.org/10.1039/C5FO00465A

Gong, M., Bassi, A., 2016. Carotenoids from microalgae: A review of recent developments. Biotechnol. Adv. 34, 1396-1412. https://doi.org/10.1016/j.biotechadv.2016.10.005

Griffith, M.P., 2004. The origins of an important cactus crop, Opuntia ficus-indica (Cactaceae): New molecular evidence. Am. J. Bot. 91, 1915-1921. https://doi.org/10.3732/ajb.91.11.1915

Guimarães, R., Barros, L., Dueñas, M., Calhelha, R.C., Carvalho, A.M., Santos-Buelga, C., Queiroz, M.J.R.P., Ferreira, I.C.F.R., 2013. Nutrients, phytochemicals and bioactivity of wild Roman chamomile: A comparison between the herb and its preparations. Food Chem. 136, 718-725. https://doi.org/10.1016/j.foodchem.2012.08.025

Guldiken, B., Toydemir, G., Nur Memis, K., Okur, S., Boyacioglu, D., Capanoglu, E., 2016. Home-processed red beetroot (Beta vulgaris L.) products: Changes in antioxidant properties and $\begin{array}{lllll}\text { bioaccessibility. Int. } & \text { J. } & \text { Mol. } & \text { Sci. } & 17 .\end{array}$ https://doi.org/10.3390/ijms 17060858

GVR, 2016. Natural Antioxidants Market Analysis By Product (Vitamin C, Vitamin E, Polyphenols, Carotenoids) And Segment Forecasts To 2022. URL https://www.grandviewresearch.com/industry-analysis/naturalantioxidants-market

Heleno, S.A., Barros, L., Sousa, M.J., Martins, A., Ferreira, I.C.F.R., 2010. Tocopherols composition of Portuguese wild mushrooms with antioxidant capacity. Food Chem. 119, 1443-1450. https://doi.org/10.1016/j.foodchem.2009.09.025

Henry, B.S., 1996. Natural food colours, in: Natural Food Colorants. 
Springer US, Boston, MA, pp. 40-79. https://doi.org/10.1007/978-1-4615-2155-6_2

Herbach, K.M., Stintzing, F.C., Carle, R., 2006. Betalain stability and degradation - Structural and chromatic aspects. J. Food Sci. 71, 41-50. https://doi.org/10.1111/j.1750-3841.2006.00022.x

Herbach, K.M., Stintzing, F.C., Carle, R., 2005. Identification of heatinduced degradation products from purified betanin, phyllocactin and hylocerenin by high-performance liquid chromatography/ electrospray ionization mass spectrometry. Rapid Commun. Mass Spectrom. 19, 2603-2616. https://doi.org/10.1002/rcm.2103

Hiwasa-Tanase, K., Ezure, H., 2014. Climateric and non-climateric ripening, in: Nath, P., Bouzayen, M., Mattoo, A.K., Pech, J.C. (Eds.), Fruit Ripening: Physiology, Signalling and Genomics. CABI International, pp. 151-177. https://doi.org/10.1017/CBO9781107415324.004

Hogervorst-Cvejić, J., Atanacković-Krstonošić, M., Bursać, M., Miljić, U., 2017. Polyphenols, in: Nutraceutical and Functional Food Components. Academic Press, pp. 203-258. https://doi.org/10.1016/B978-0-12-805257-0.00007-7

Hollman, P.C., Bijsman, M.N., van Gameren, Y., Cnossen, E.P., de Vries, J.H., Katan, M.B., 1999. The sugar moiety is a major determinant of the absorption of dietary flavonoid glycosides in man. Free Radic. Res. 31, 569-573. https://doi.org/10.1080/10715769900301141

Hurtado-Fernández, E., Fernandez-Gutierrez, A., Carrasco-Pancorbo, A., 2018a. Avocado fruit, in: Rodrigues, S., de Oliveira, E., Sousa, E. (Eds.), Exotic Fruits. Academic Press, London, pp. 37-46.

Hurtado-Fernández, E., Pacchiarotta, T., Longueira-Suárez, E., Mayboroda, O.A., Fernández-Gutiérrez, A., Carrasco-Pancorbo, A., 2013. Evaluation of gas chromatography-atmospheric pressure chemical ionization-mass spectrometry as an alternative to gas chromatography-electron ionization-mass spectrometry: Avocado fruit as example. J. Chromatogr. A 1313, 228-244. https://doi.org/10.1016/j.chroma.2013.08.084

Hurtado-Fernández, E., Pacchiarotta, T., Mayboroda, O.A., FernándezGutiérrez, A., Carrasco-Pancorbo, A., 2014. Quantitative characterization of important metabolites of avocado fruit by gas chromatography coupled to different detectors (APCI-TOF MS and FID). Food Res. Int. 62, 801-811. https://doi.org/10.1016/j.foodres.2014.04.038

Hussain, Z., Thu, H.E., Amjad, M.W., Hussain, F., Ahmed, T.A., Khan, 
S., 2017. Exploring recent developments to improve antioxidant, anti-inflammatory and antimicrobial efficacy of curcumin: A review of new trends and future perspectives. Mater. Sci. Eng. C. https://doi.org/10.1016/j.msec.2017.03.226

IFIC, FDA, 2010. Overview of Food Ingredients, Additives and Colors. URL

https://www.fda.gov/food/ingredientspackaginglabeling/foodadd itivesingredients/ucm094211.htm

Inglese, P., Giugliuzza, G., Liguori, G., 2004. Cactus pear fruit production: from knowledge to development, in: Esparza-Frausto, G., Valdez-Cepeda, R.D., Méndez- Gallego, S.J. (Eds.), El Nopal.Tópicos de Actualidad. Universidad Autónoma de Chapingo. Colegio de Postgraduados, México, pp. 89-108.

IUPAC, IUPAC-IUB, 1976. Nomenclature of cyclitols. Biochem. J. 153, 23-31. https://doi.org/10.1351/pac197437010283

Jain, G., Gould, K.S., 2015. Are betalain pigments the functional homologues of anthocyanins in plants? Environ. Exp. Bot. 119, 48-53. https://doi.org/10.1016/J.ENVEXPBOT.2015.06.002

Jain, T., Grover, K., Kaur, G., 2016. Effect of processing on nutrients and fatty acid composition of garden cress (Lepidium sativum) seeds. Food Chem. 213, 806-812. https://doi.org/10.1016/j.foodchem.2016.07.034

Jimenez-Garcia, S.N., Vazquez-Cruz, M.A., Garcia-Mier, L., Contreras-Medina, L.M., Guevara-González, R.G., Garcia-Trejo, J.F., Feregrino-Perez, A.A., 2018. Phytochemical and Pharmacological Properties of Secondary Metabolites in Berries, in: Therapeutic Foods. Elsevier, pp. 397-427. https://doi.org/10.1016/B978-0-12-811517-6.00013-1

Kaderides, K., Goula, A.M., 2017. Development and characterization of a new encapsulating agent from orange juice by-products. Food Res. Int. 0-1. https://doi.org/10.1016/j.foodres.2017.07.057

Kanner, J., Harel, S., Granit, R., 2001. Betalains - A new class of dietary cationized antioxidants. J. Agric. Food Chem. 49, 51785185. https://doi.org/10.1021/jf010456f

Karamac, M., Estrella, I., Herna, T., Dykes, G. a., Kosińska, A., Karamać, M., Estrella, I., Hernández, T., Bartolomé, B., Dykes, G. a., 2012. Phenolic compound profiles and antioxidant capacity of Persea americana Mill. peels and seeds of two varieties. J. Agric. Food Chem. 60, 4613-4619. https://doi.org/10.1021/jf300090p

Katsube, T., Tsurunaga, Y., Sugiyama, M., Furuno, T., Yamasaki, Y., 
2009. Effect of air-drying temperature on antioxidant capacity and stability of polyphenolic compounds in mulberry (Morus alba L.) leaves. Food Chem. 113, 964-969. https://doi.org/10.1016/j.foodchem.2008.08.041

Kaur Kala, H., Mehta, R., Tandey, R., Sen, K.K., Mandal, V., 2016. Ten years of research on phenolics (2005-2015): A status report. Pacific Sci. Rev. A Nat. Sci. Eng. https://doi.org/10.1016/j.psra.2016.07.002

Knight, R.J., Campbell, C.W., 1999. Ecological adaptation and the evolution of modern avocado cultivars. Rev. Chapingo Ser. Hortic. 49-54.

Kosińska, A., Karamać, M., Estrella, I., Hernández, T., Bartolomé, B., Dykes, G.A., 2012. Phenolic compound profiles and antioxidant capacity of Persea americana Mill. peels and seeds of two varieties. J. Agric. Food Chem. 60, 4613-4619. https://doi.org/10.1021/jf300090p

Kris-Etherton, P.M., Hecker, K.D., Bonanome, A., Coval, S.M., Binkoski, A.E., Hilpert, K.F., Griel, A.E., Etherton, T.D., 2002. Bioactive compounds in foods: their role in the prevention of cardiovascular disease and cancer. Am. J. Med. 113, 71-88. https://doi.org/10.1016/S0002-9343(01)00995-0

Kuhnle, G.G., 2012. Nutritional biomarkers for objective dietary assessment. J. Sci. Food Agric. 92, 1145-1149. https://doi.org/10.1002/jsfa.5631

Kuti, J.O., 2004. Antioxidant compounds from four Opuntia cactus pear fruit varieties. Food Chem. 85, 527-533. https://doi.org/10.1016/S0308-8146(03)00184-5

Kyriacou, M.C., Emmanouilidou, M.G., Soteriou, G.A., 2016. Asynchronous ripening behavior of cactus pear (Opuntia ficusindica) cultivars with respect to physicochemical and physiological attributes. Food Chem. 211, 598-607. https://doi.org/10.1016/j.foodchem.2016.05.113

Laqui-Vilca, C., Aguilar-Tuesta, S., Mamani-Navarro, W., MontañoBustamante, J., Condezo-Hoyos, L., 2018. Ultrasound-assisted optimal extraction and thermal stability of betalains from colored quinoa (Chenopodium quinoa Willd) hulls. Ind. Crops Prod. 111, 606-614. https://doi.org/10.1016/j.indcrop.2017.11.034

Lea, A., 2008. Analysis of polyphenol antioxidants in fortified foods and supplements. Food Fortif. Suppl. 175-194. https://doi.org/10.1533/9781845694265.2.175

Leardi, R., 2013. Experimental Design, 1st ed, Data Handling in 
Science and Technology. Copyright (C) 2013 Elsevier B.V. All rights reserved. https://doi.org/10.1016/B978-0-444-595287.00002-8

Li, J., Chen, Z., Di, D., 2012. Preparative separation and purification of Rebaudioside A from Stevia rebaudiana Bertoni crude extracts by mixed bed of macroporous adsorption resins. Food Chem. 132, 268-276. https://doi.org/10.1016/j.foodchem.2011.10.077

M. Librán, C., Mayor, L., M. Garcia-Castello, E., Vidal-Brotons, D., 2013. Polyphenol extraction from grape wastes: Solvent and $\mathrm{pH}$ effect. Agric. Sci. 04, 56-62. https://doi.org/10.4236/as.2013.49B010

Madrau, M. a., Piscopo, A., Sanguinetti, A.M., Del Caro, A., Poiana, M., Romeo, F. V., Piga, A., 2009. Effect of drying temperature on polyphenolic content and antioxidant activity of apricots. Eur. Food Res. Technol. 228, 441-448. https://doi.org/10.1007/s00217-008-0951-6

Madunić, J., Madunić, I.V., Gajski, G., Popić, J., Garaj-Vrhovac, V., 2018. Apigenin: A dietary flavonoid with diverse anticancer properties. Cancer Lett. 413, 11-22. https://doi.org/10.1016/j.canlet.2017.10.041

Manach, C., Scalbert, A., Morand, C., Rémésy, C., Jiménez, L., 2004. Bioavailability, Polyphenols: Food sources and. Am. J. Clin. Nutr. 79, 727-747. https://doi.org/10.1038/nature05488

Mandal, S.C., Mandal, V., Das, A.K., 2015. Classification of Extraction Methods, in: Essentials of Botanical Extraction. Academic Press, pp. 83-136. https://doi.org/10.1016/B978-0-12-802325-9.000069

Marais, J.P.J., Deavours, B., Dixon, R.A., Ferreira, D., 2006. The science of flavonoids, The Science of Flavonoids. Springer, Ohio. https://doi.org/10.1007/978-0-387-28822-2

Marco, G.J., 1968. A Rapid Method for Evaluation of Antioxidants. J. Am. oil Chem. Soc. 45, 594-598. https://doi.org/10.1007/BF02668958

Maria, J., Andrade, D.M., Fasolo, D., 2014. Polyphenol Antioxidants from Natural Sources and Contribution to Health Promotion, Polyphenols in Human Health and Disease. Elsevier Inc. https://doi.org/10.1016/B978-0-12-398456-2.00020-7

Martins, N., Roriz, C.L., Morales, P., Barros, L., Ferreira, I.C.F.R., 2016. Food colorants: Challenges, opportunities and current desires of agro-industries to ensure consumer expectations and regulatory practices. Trends Food Sci. Technol. 52, 1-15. 
https://doi.org/10.1016/j.tifs.2016.03.009

Mata, A., Ferreira, J.P., Semedo, C., Serra, T., Duarte, C.M.M., Bronze, M.R., 2016. Contribution to the characterization of Opuntia spp. juices by LC-DAD-ESI-MS/MS. Food Chem. 210, 558-565. https://doi.org/10.1016/j.foodchem.2016.04.033

Mayor, L., Calvo, A., Moreira, R., Fito, P., Garcia-Castello, E. M., 2013. Water sorption isotherms of globe artichoke leaves. Agric. Sci. 04, 63-69. https://doi.org/10.4236/as.2013.49B011

McGuire, S., 2011. U.S. Department of Agriculture and U.S. Department of Health and Human Services, Dietary Guidelines for Americans, 2010. 7th Edition, Washington, DC: U.S. Government Printing Office, January 2011. Adv. Nutr. 2, 293294. https://doi.org/10.3945/an.111.000430

Medina-Meza, I.G., Barbosa-Cánovas, G. V., 2015. Assisted extraction of bioactive compounds from plum and grape peels by ultrasonics and pulsed electric fields. J. Food Eng. 166, 268-275. https://doi.org/10.1016/j.jfoodeng.2015.06.012

Melgar, B., Dias, M.I., Ciric, A., Sokovic, M., Garcia-Castello, E.M., Rodriguez-Lopez, A.D., Barros, L., Ferreira, I.C.R.F., 2017a. Byproduct recovery of Opuntia spp. peels: Betalainic and phenolic profiles and bioactive properties. https://doi.org/10.1016/j.indcrop.2017.06.011

Melgar, B., Pereira, E., Oliveira, M.B.P.P., Garcia-Castello, E.M., Rodriguez-Lopez, A.D., Sokovic, M., Barros, L., Ferreira, I.C.F.R., 2017b. Extensive profiling of three varieties of Opuntia spp. fruit for innovative food ingredients. Food Res. Int. 101, 259265. https://doi.org/10.1016/j.foodres.2017.09.024

Mena, P., Tassotti, M., Andreu, L., Nuncio-Jáuregui, N., Legua, P., Del Rio, D., Hernández, F., 2018. Phytochemical characterization of different prickly pear (Opuntia ficus-indica (L.) Mill.) cultivars and botanical parts: UHPLC-ESI-MSn metabolomics profiles and their chemometric analysis. Food Res. Int. 108, 301-308. https://doi.org/10.1016/j.foodres.2018.03.062

Mirabella, N., Castellani, V., Sala, S., 2014. Current options for the valorization of food manufacturing waste: a review. J. Clean. Prod.

65 , $28-41$. https://doi.org/10.1016/J.JCLEPRO.2013.10.051

Mishra, A., Sharma, A.K., Kumar, S., Saxena, A.K., Pandey, A.K., 2013. Bauhinia variegata leaf extracts exhibit considerable antibacterial, antioxidant, and anticancer activities. Biomed Res. Int. 2013. https://doi.org/10.1155/2013/915436 
Mishra, A.K., Mishra, A., Kehri, H.K., Sharma, B., Pandey, A.K., 2009. Inhibitory activity of Indian spice plant Cinnamomum zeylanicum extracts against Alternaria solani and Curvularia lunata, the pathogenic dematiaceous moulds. Ann. Clin. Microbiol. Antimicrob. 8, 9. https://doi.org/10.1186/1476-07118-9

Monks, A., Scudiero, D., Skehan, P., Shoemaker, R., Paull, K., Vistica, D., Hose, C., Langley, J., Cronise, P., Vaigro-wolff, A., Graygoodrich, M., Campbell, H., Boyd, M., 1991. Feasibility of a High-Flux Anticancer Drug Screen Using a Diverse Panel of Cultured. J. Natl. Cancer Inst. 83, 757-766.

Morales, P., Barros, L., Ramírez-Moreno, E., Santos-Buelga, C., Ferreira, I.C.F.R., 2015. Xoconostle fruit (Opuntia matudae Scheinvar cv. Rosa) by-products as potential functional ingredients. Food Chem. 185, 289-97. https://doi.org/10.1016/j.foodchem.2015.04.012

Morales, P., Barros, L., Ramírez-Moreno, E., Santos-Buelga, C., Ferreira, I.C.F.R., 2014. Exploring xoconostle by-products as sources of bioactive compounds. Food Res. Int. 65, 437-444. https://doi.org/10.1016/j.foodres.2014.05.067

Morales, P., Ramírez-Moreno, E., Sanchez-Mata, M.D.C., Carvalho, A.M., Ferreira, I.C.F.R., 2012. Nutritional and antioxidant properties of pulp and seeds of two xoconostle cultivars (Opuntia joconostle F.A.C. Weber ex Diguet and Opuntia matudae Scheinvar) of high consumption in Mexico. Food Res. Int. 46. https://doi.org/10.1016/j.foodres.2011.12.031

Moreno, J., Peinado, R., 2012. Polyphenols, in: Moreno, J., Peinado, R. (Eds.), Enological Chemistry. Academic Press, pp. 53-76. https://doi.org/10.1016/B978-0-12-388438-1.00005-4

Naik, S.N., Goud, V. V., Rout, P.K., Dalai, A.K., 2010. Production of first and second generation biofuels: A comprehensive review. Renew. Sustain. Energy Rev. 14, 578-597. https://doi.org/10.1016/j.rser.2009.10.003

Nicoletti, M., 2012. Nutraceuticals and botanicals: overview and perspectives. Int. J. Food Sci. Nutr. 63, 2-6. https://doi.org/10.3109/09637486.2011.628012

$\mathrm{NIH}$, 2017. Vitamin E - Fact sheet for Consumer. URL https://ods.od.nih.gov/factsheets/VitaminE-Consumer/ (accessed 3.14.17).

Nobel, P.S., 1998. Los incomparables agaves y cactos. Trillas, México. Novoa, A., Le Roux, J.J., Robertson, M.P., Wilson, J.R.U., Richardson, 
D.M., 2015. Introduced and invasive cactus species: A global review. AoB Plants 7. https://doi.org/10.1093/aobpla/plu078

Ochoa, M. judith, Barbera, G., 2017. History and economic and agroecological importance, in: Crop Ecology, Cultivation and Uses of Catus Pears. FAO, ICARDA, pp. 1-11.

Osborn, S., 2015. 12 - Labelling relating to natural ingredients and additives, in: Advances in Food and Beverage Labelling. pp. 207221. https://doi.org/10.1533/9781782420934.3.207

Paciulli, M., Medina-Meza, I.G., Chiavaro, E., Barbosa-Cánovas, G.V., 2016. Impact of thermal and high pressure processing on quality parameters of beetroot (Beta vulgaris L.). LWT - Food Sci. Technol. 68, 98-104. https://doi.org/10.1016/j.lwt.2015.12.029

Patel, D., Shukla, S., Gupta, S., 2007. Apigenin and cancer chemoprevention: Progress, potential and promise (Review). Int. J. Oncol. 30, 233-245. https://doi.org/10.3892/ijo.30.1.233

Pedreño, M.A., Escribano, J., 2000. Studying the oxidation and the antiradical activity of betalain from beetroot. J. Biol. Educ. 35, 49-51. https://doi.org/10.1080/00219266.2000.9655736

Peláez-Cid, a. a., Velázquez-Ugalde, I., Herrera-González, a. M., García-Serrano, J., 2013. Textile dyes removal from aqueous solution using Opuntia ficus-indica fruit waste as adsorbent and its characterization. J. Environ. Manage. 130, 90-97. https://doi.org/10.1016/j.jenvman.2013.08.059

Pereira, C., Barros, L., Carvalho, A.M., Ferreira, I.C.F.R., 2011. Nutritional composition and bioactive properties of commonly consumed wild greens: Potential sources for new trends in modern diets. Food Res. Int. 44, 2634-2640. https://doi.org/10.1016/j.foodres.2011.05.012

Pereira, E., Barros, L., Calhelha, R.C., Duenas, M., Carvalho, A.M., Santos-Buelga, C., Ferreira, I.C.F.R., 2014. Bioactivity and phytochemical characterization of Arenaria montana L. Food Funct. 5, 1848-1855. https://doi.org/10.1039/c4fo00210e

Pereira, E., Barros, L., Martins, A., Ferreira, I.C.F.R., 2012. Towards chemical and nutritional inventory of Portuguese wild edible mushrooms in different habitats. Food Chem. 130, 394-403. https://doi.org/10.1016/j.foodchem.2011.07.057

Piattelli, M., Minale, L., Prota, G., 1964. Isolation, structure and absolute configuration of indicaxanthin. Tetrahedron 20, 23252329. https://doi.org/10.1016/S0040-4020(01)97621-5

Pimienta, E., 1990. El nopal tunero. Libros de tiempos de ciencia ;5.

Pimiento Barrios, E., Munoz-Urias, A., 1999. Domesticacion de 
nopales tuneros (Opuntis spp.) y descripcion de las principales variedades cultivadas. FAO, Rome (Italy).

Pinela, J., Prieto, M.A., Barreiro, M.F., Carvalho, A.M., Oliveira, M.B.P.P., Vázquez, J.A., Ferreira, I.C.F.R., 2016. Optimization of microwave-assisted extraction of hydrophilic and lipophilic antioxidants from a surplus tomato crop by response surface methodology. Food Bioprod. Process. 98, 283-298. https://doi.org/10.1016/j.fbp.2016.02.002

Primorac, T., Požar, M., Sokolić, F., Zoranić, L., Urbic, T., 2018. A simple two dimensional model of methanol. J. Mol. Liq. 262, 4657. https://doi.org/10.1016/j.molliq.2018.04.055

Quideau, S., Deffieux, D., Douat-Casassus, C., Pouysegu, L., 2011. Plant polyphenols: chemical properties, biological activities, and synthesis. Angew. Chem. Int. Ed. Engl. 50, 586-621. https://doi.org/10.1002/anie.201000044

Rached, W., Calhelha, R.C., Fernandes, Â., Carvalho, A.M., Bennaceur, M., Marouf, A., Barros, L., Santos-Buelga, C., Ferreira, I.C.F.R., 2016. Phytochemical characterization and bioactive properties of Osyris quadripartita Salzm. ex Decne. leaves from Algeria. RSC Adv. 6, 72768-72776. https://doi.org/10.1039/C6RA11787B

Ramos-Jerz, M.D.R., Villanueva, S., Jerz, G., Winterhalter, P., Deters, A.M., 2013. Persea americana Mill. Seed: Fractionation, Characterization, and Effects on Human Keratinocytes and Fibroblasts. Evidence-based Complement. Altern. Med. eCAM 2013, 391247. https://doi.org/10.1155/2013/391247

Rao, G., 2010. Optimization of ultrasound-assisted extraction of cyanidin 3-rutinoside from litchi (Lichi chinensis Sonn.) fruit pericarp. Anal. Methods 2, 1166. https://doi.org/10.1039/c0ay00203h

Ravichandran, K., Saw, N.M.M.T., Mohdaly, A.A.A., Gabr, A.M.M., Kastell, A., Riedel, H., Cai, Z., Knorr, D., Smetanska, I., 2013. Impact of processing of red beet on betalain content and antioxidant activity. Food Res. Int. 50, 670-675. https://doi.org/10.1016/j.foodres.2011.07.002

Raymond Chia, T.W., Dykes, G. a, 2010. Antimicrobial activity of crude epicarp and seed extracts from mature avocado fruit (Persea americana) of three cultivars. Pharm. Biol. 48, 753-756. https://doi.org/10.3109/13880200903273922

Reis, F.S., Barreira, J.C.M., Calhelha, R.C., van Griensven, L.J.I.D., Ćirić, A., Glamočlija, J., Soković, M., Ferreira, I.C.F.R., 2014. 
Chemical characterization of the medicinal mushroom Phellinus linteus (Berkeley \& Curtis) Teng and contribution of different fractions to its bioactivity. LWT - Food Sci. Technol. 58, 478485. https://doi.org/10.1016/j.lwt.2014.04.013

Reyes-Agüero, J.A., Aguirre, J.R., Hernández, H., 2005. Systematyc notes and a Detailed description of Opuntia ficus-indica (L) Mill. (CACTACEAE). Agrociencia 39, 395-408.

Reynolds, S.G., Arias, E., 2003. Opuntia Spp. -A Strategic fodder and efficient tool for combat desertification in the Wana Region, Cactus (Opuntia spp.) as forage. FAO Plant Production and Protection Paper 169.

Roberfroid, M.B., 2000. Concepts and strategy of functional food science: the European perspective. Am. J. Clin. Nutr. 71, 1660S$4 \mathrm{~S}$; discussion 1674S-5S. https://doi.org/10.1093/ajen/71.6.1660S

Rodrigo, D., Martínez-l, A., 2015. Antimicrobial activity of cauli fl ower (Brassica oleracea var . Botrytis) by-product against Listeria monocytogenes 50, 435-440. https://doi.org/10.1016/j.foodcont.2014.09.031

Rodríguez-Carpena, J.G., Morcuende, D., Estévez, M., 2011. Avocado by-products as inhibitors of color deterioration and lipid and protein oxidation in raw porcine patties subjected to chilled storage. Meat Sci. 89, 166-173. https://doi.org/10.1016/j.meatsci.2011.04.013

Rohwer, J.G., 1993. Lauraceae, in: The Families and Genera of Vascular Plants Free Preview, Volume II, Flowering Plants . Dicotyledons. Springer, Berlin, pp. 366-391. https://doi.org/10.1007/978-3-662-02899-5

Roriz, C.L., Barros, L., Prieto, M.A., Morales, P., Ferreira, I.C.F.R., 2017. Floral parts of Gomphrena globosa L. as a novel alternative source of betacyanins: Optimization of the extraction using response surface methodology. Food Chem. 229, 223-234. https://doi.org/10.1016/j.foodchem.2017.02.073

Saavedra, J., Córdova, A., Navarro, R., Díaz-Calderón, P., Fuentealba, C., Astudillo-Castro, C., Toledo, L., Enrione, J., Galvez, L., 2017. Industrial avocado waste: Functional compounds preservation by convective drying process. J. Food Eng. 198, 81-90. https://doi.org/10.1016/j.jfoodeng.2016.11.018

Sáenz, C., 2006. Utilización agroindustrial del nopal. Boletín Serv. Agrícolas La Fao 162, 165.

SAGARPA, 2011. Monografía de cultivos. Aguacate. México city. 
Sansano, S., Rivas, A., Pina-Pérez, M.C., Martinez, A., Rodrigo, D., 2017. Stevia rebaudiana Bertoni effect on the hemolytic potential of Listeria monocytogenes, International Journal of Food Microbiology. https://doi.org/10.1016/j.ijfoodmicro.2017.03.006 SARAVACOS, G.D., 2014. Mass Transfer Properties of Foods 346399. https://doi.org/10.1201/9781420028805-11

Sawicki, T., Wiczkowski, W., 2018. The effects of boiling and fermentation on betalain profiles and antioxidant capacities of red beetroot products. Food Chem. 259, 292-303. https://doi.org/10.1016/j.foodchem.2018.03.143

Shahidi, F., Ambigaipalan, P., 2015. Phenolics and polyphenolics in foods, beverages and spices: Antioxidant activity and health effects - A review. J. Funct. Foods. https://doi.org/10.1016/j.jff.2015.06.018

Sharma, K., Mahato, N., Cho, M.H., Lee, Y.R., 2017. Converting citrus wastes into value-added products: Economic and environmently friendly approaches. Nutrition 34, 29-46. https://doi.org/10.1016/j.nut.2016.09.006

Šiler, B., Živković, S., Banjanac, T., Cvetković, J., Nestorović Živković, J., Ćirić, A., Soković, M., Mišić, D., 2014. Centauries as underestimated food additives: Antioxidant and antimicrobial potential. Food Chem. 147, 367-376. https://doi.org/10.1016/j.foodchem.2013.10.007

Silva, P., Ferreira, S., Nunes, F.M., 2016. Elderberry (Sambucus nigra L.) by-products a source of anthocyanins and antioxidant polyphenols. Ind. Crops Prod. https://doi.org/10.1016/j.indcrop.2016.10.018

Singleton, V.L., Rossi, J.A., 1965. Colorimetry of Total Phenolics with Phosphomolybdic-Phosphotungstic Acid Reagents. Am. J. Enol. Vitic. 16, 144-158. https://doi.org/10.12691/ijebb-2-1-5

Song, F.L., Gan, R.Y., Zhang, Y., Xiao, Q., Kuang, L., Li, H. Bin, 2010. Total phenolic contents and antioxidant capacities of selected chinese medicinal plants. Int. J. Mol. Sci. 11, 2362-2372. https://doi.org/10.3390/ijms11062362

Spórna-Kucab, A., Ignatova, S., Garrard, I., Wybraniec, S., 2013. Versatile solvent systems for the separation of betalains from processed Beta vulgaris L. juice using counter-current chromatography. J. Chromatogr. B Anal. Technol. Biomed. Life Sci. 941, 54-61. https://doi.org/10.1016/j.jchromb.2013.10.001

Stintzing, F., Schieber, A., Carle, R., 2000. Cactus pear-a promising component to functional food. Obs. Kartof. 85, 40-47. 
Stintzing, F.C., Herbach, K.M., Mosshammer, M.R., Carle, R., Yi, W., Sellappan, S., Akoh, C.C., Bunch, R., Felker, P., 2005. Color, betalain pattern, and antioxidant properties of cactus pear (Opuntia spp.) clones. J. Agric. Food Chem. 53, 442-451. https://doi.org/10.1021/jf048751y

Stintzing, F.C., Schieber, A., Carle, R., 2002. Betacyanins in fruits from red-purple pitaya, Hylocereus polyrhizus (Weber) Britton \&amp; Rose. Food Chem. 77, 101-106. https://doi.org/10.1016/S03088146(01)00374-0

Strack, D., Vogt, T., Schliemann, W., 2003. Recent advances in betalain research. Phytochemistry 62, 247-269. https://doi.org/10.1016/S0031-9422(02)00564-2

Sudzuki, F., Muñoz, C., Berger, H., 1993. El cultivo de la tuna (cactus pear)., 1 ed. ed. Departamento de Reproducción Agrícola. Universidad de Chile, Santiago., Santiago, Chile.

Svenson, J., Smallfield, B.M., Joyce, N.I., Sansom, C.E., Perry, N.B., 2008. Betalains in red and yellow varieties of the andean tuber crop ulluco (Ullucus tuberosus). J. Agric. Food Chem. 56, 77307737. https://doi.org/10.1021/jf8012053

Sýs, M., Švecová, B., Švancara, I., Metelka, R., 2017. Determination of vitamin $\mathrm{E}$ in margarines and edible oils using square wave anodic stripping voltammetry with a glassy carbon paste electrode. Food Chem. 229, 621-627. https://doi.org/10.1016/j.foodchem.2017.02.068

Szot, D., Skopińska, A., Wybraniec, S., 2015. Decomposition of 17decarboxy-betanin in selected aqueous-organic solutions induced by $\mathrm{Cu}$ ( II ) cations. PhD Interdiscip. J. Politech. Gdansk Univ. 1, 217-223.

Takshak, S., Agrawal, S.B., 2015. Defence strategies adopted by the medicinal plant Coleus forskohlii against supplemental ultraviolet-B radiation: Augmentation of secondary metabolites and antioxidants. Plant Physiol. Biochem. 97, 124-138. https://doi.org/10.1016/j.plaphy.2015.09.018

Thirugnanasambandham, K., Sivakumar, V., 2017. Microwave assisted extraction process of betalain from dragon fruit and its antioxidant activities. J. Saudi Soc. Agric. Sci. 16, 41-48. https://doi.org/10.1016/j.jssas.2015.02.001

Timilsena, Y.P., Wang, B., Adhikari, R., Adhikari, B., 2017. Advances in microencapsulation of polyunsaturated fatty acids (PUFAs)rich plant oils using complex coacervation: A review. Food Hydrocoll. 
https://doi.org/10.1016/j.foodhyd.2017.03.007

Timpanaro, G., Urso, A., Spampinato, D., Foti, V., 2015. Cactus pear market in Italy: Competitiveness and perspectives. Acta Hortic. 1067.

Torres, M.D., Chenlo, F., Moreira, R., 2018. Structural features and water sorption isotherms of carrageenans: A prediction model for hybrid carrageenans. Carbohydr. Polym. 180, 72-80. https://doi.org/10.1016/J.CARBPOL.2017.10.010

Tretter, L., Patocs, A., Chinopoulos, C., 2016. Succinate, an intermediate in metabolism, signal transduction, ROS, hypoxia, and tumorigenesis. Biochim. Biophys. Acta - Bioenerg. 1857, 1086-1101. https://doi.org/10.1016/j.bbabio.2016.03.012

Tsuchiya, H., Iinuma, M., 2000. Reduction of membrane fluidity by antibacterial sophoraflavanone $\mathrm{G}$ isolated from Sophora exigua. Phytomedicine 7, 161-165. https://doi.org/10.1016/S09447113(00)80089-6

UN DESA, 2015. World Population Prospects: The 2015 Revision. New York.

Unilever, 2010. The Unilever Sustainable Living Plan.

Vieira, V., Barros, L., Martins, A., Ferreira, I., 2016a. Nutritional and Biochemical Profiling of Leucopaxillus candidus (Bres.) Singer Wild Mushroom. Molecules 21, 99. https://doi.org/10.3390/molecules21010099

Vieira, V., Fernandes, Â., Barros, L., Glamočlija, J., Ćirić, A., Stojković, D., Martins, A., Soković, M., Ferreira, I.C.F.R., 2016b. Wild Morchella conica Pers. from different origins: A comparative study of nutritional and bioactive properties. J. Sci. Food Agric. 96, 90-98. https://doi.org/10.1002/jsfa.7063

Vinatoru, M., 2001. An overview of the ultrasonically assisted extraction of bioactive principles from herbs. Ultrason. Sonochem. $\quad 8, \quad 303-313 . \quad$ https://doi.org/10.1016/S13504177(01)00071-2

Wang, W., Bostic, T.R., Gu, L., 2010. Antioxidant capacities, procyanidins and pigments in avocados of different strains and cultivars. Food Chem. 122, 1193-1198. https://doi.org/10.1016/j.foodchem.2010.03.114

Watada, A.E., Herner, R.C., Kader, A.A., Romani, R.J., Staby, G.L., 1984. Terminology for the description of developmental stages of horticultural crops. HortScience.

Weinstein, M.P., 2012. Methods for Dilution Antimicrobial Susceptibility Tests for Bacteria That Grow Aerobically; 
Approved Standard - Ninth Edition, Methods for Dilution Antimicrobial Susceptibility Tests for Bacteria That Grow Aerobically; Approved Standar- Ninth Edition. https://doi.org/10.4103/0976-237X.91790

WHO, 2014. GLOBAL STATUS REPORT on noncommunicable diseases 2014. "Attaining the nine global noncommunicable diseases targets; a shared responsibility"

Wrolstad, R.E., Culver, C.A., 2012. Alternatives to those artificial FD\&C food colorants. Annu. Rev. Food Sci. Technol. 3, 59-77. https://doi.org/10.1146/annurev-food-022811-101118

Wybraniec, S., Starzak, K., Szneler, E., Pietrzkowski, Z., 2016. Separation of chlorinated diastereomers of decarboxybetacyanins in myeloperoxidase catalyzed chlorinated Beta vulgaris L. extract. J. Chromatogr. B Anal. Technol. Biomed. Life Sci. 1036-1037, $20-32$. https://doi.org/10.1016/j.jchromb.2016.09.040

Yahia, E.M., Woolf, A.B., 2011. Avocado (Persea americana Mill), in: Postharvest Biology and Technology of Tropical and Subtropical Fruits: Volume 2: Açai to Citrus. Woodhead Publishing, pp. 125185. https://doi.org/10.1533/9780857092762.125

Yamashita, C., Chung, M.M.S., dos Santos, C., Mayer, C.R.M., Moraes, I.C.F., Branco, I.G., 2017. Microencapsulation of an anthocyanin-rich blackberry (Rubus spp.) by-product extract by freeze-drying. LWT - Food Sci. Technol. 84, 256-262. https://doi.org/10.1016/j.lwt.2017.05.063

Yeddes, N., Chérif, J., Guyot, S., Sotin, H., Ayadi, M., 2013. Comparative Study of Antioxidant Power, Polyphenols, Flavonoids and Betacyanins of the Peel and Pulp of Three Tunisian Opuntia Forms. Antioxidants 2, 37-51. https://doi.org/10.3390/antiox2020037

Zhishen, J., Mengcheng, T., Jianming, W., 1999. The determination of flavonoid contents in mulberry and their scavenging effects on superoxide radicals. Food Chem. https://doi.org/10.1016/S03088146(98)00102-2 



\section{Capítulo 2 \\ OBJETIVOS Y PLAN DE \\ TRABAJO}





\section{II.1 OBJETIVo GENERAL}

El objetivo fundamental de esta tesis fue Identificar y evaluar el potencial bioactivo de los compuestos funcionales obtenidos apartir de los subproductos de la industria frutícola, específicamente de las especies Persea americana y Opuntia spp. y que pueden tener grandes aplicaciones distintas industrias como la alimentaria, farmacéutica, cosmética, entre otras. 
Objetivos y plan de trabajo

\section{II.2 OBJETIVOS ESPECIFICOS}

- Caracterizar desde el punto de vista nutricional las pulpas de los higos chumbos de cultivo y salvaje (Opuntia ficusindica y Opuntia engelmannii, respectivamente) con la finalidad de poder identificar posibles compuestos funcionales.

- Profundizar en el contenido de los compuestos bioactivos, de los subproductos de Opuntia spp y Persea america Mill. Identificar y cuantificar los compuestos presentes en las pieles y semillas mediante técnicas cromatográficas.

- Estudiar los efectos antioxidantes, antimicrobianos y citotóxicos de los compuestos bioactivos extraidos de las distintas fracciones de subproductos estudiadas de los frutos de aguacate e higo chumbo.

- Optimizar el proceso de extracción de los compuestos funcionales de interés de las pieles del higo chumbo (Opunita spp.), con el objetivo de maximizar los rendimientos sin dejar de lado sus propiedades bioactivas. 


\section{II.3 Plan de Trabajo.}

En la Figura 2-1 se sintetizan los principales conceptos de las experimentaciones realizadas durante la presente tesis, en horizontal se sigue la cronología de los experimentales realizados, mientras que verticalmente se mencionan brevemente primero las materias primas utilizadas, posteriormente se enfatiza en el tipo de experimentos realizados y finalmente se presentan los compuestos de interés descritos en los artículos.

Siguiendo con los esquemas presentados en el plan de trabajo, en las Figuras 2-2, 2-3 y 2-4, se presenta en forma vertical los datos más relevantes de los artículos 1, 2 y 3 respectivamente, que posteriormente serán expuestos en detalle en los Capítulos 4,5 y 6 . Comenzando por el nombre del artículo, en el segundo recuadro se menciona cronológicamente la preparación de la muestra, mientras que en el tercer y cuarto recuadro se resumen los análisis realizados a las muestras, a partir de los cuales se obtienen los resultados y conclusiones particulares en sus respectivos capítulos.

Por último en el plan de trabajo, la Figura 2-5, presenta la misma estructura con pequeñas diferencias. Continuando la señalética anterior, el primer recuadro muestra el título del artículo, en el segundo recuadro, al tratarse de un experimental de optimización, se mencionan los factores empleados, decisivos en los modelos estadísticos finales, en el tercer recuadro se sintetizan los pasos experimentales primordiales, y finalmente en el último recuadro, se señalan las respuestas que se quieren optimizar. 
Objetivos y plan de trabajo

Para el desarrollo del trabajo se propuso el siguiente orden cronológico de acuerdo a las experimentaciones realizadas.

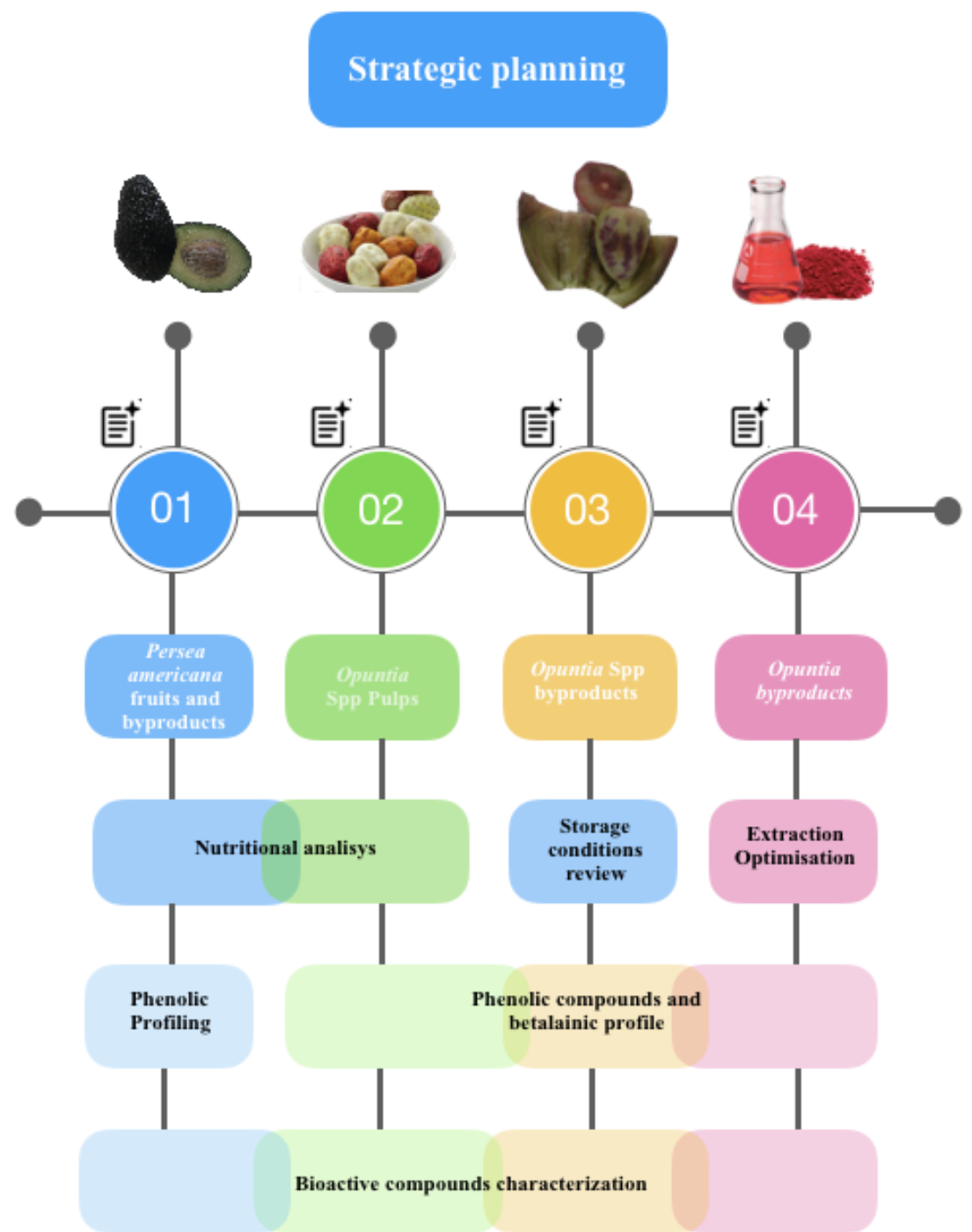

Figure -2-1 Approach of experiments in chronological order (source: private collection) 
Objetivos y plan de trabajo

\section{Bioactive characterization of Persea americana Mill. by-products: A rich source of inherent antioxidants}

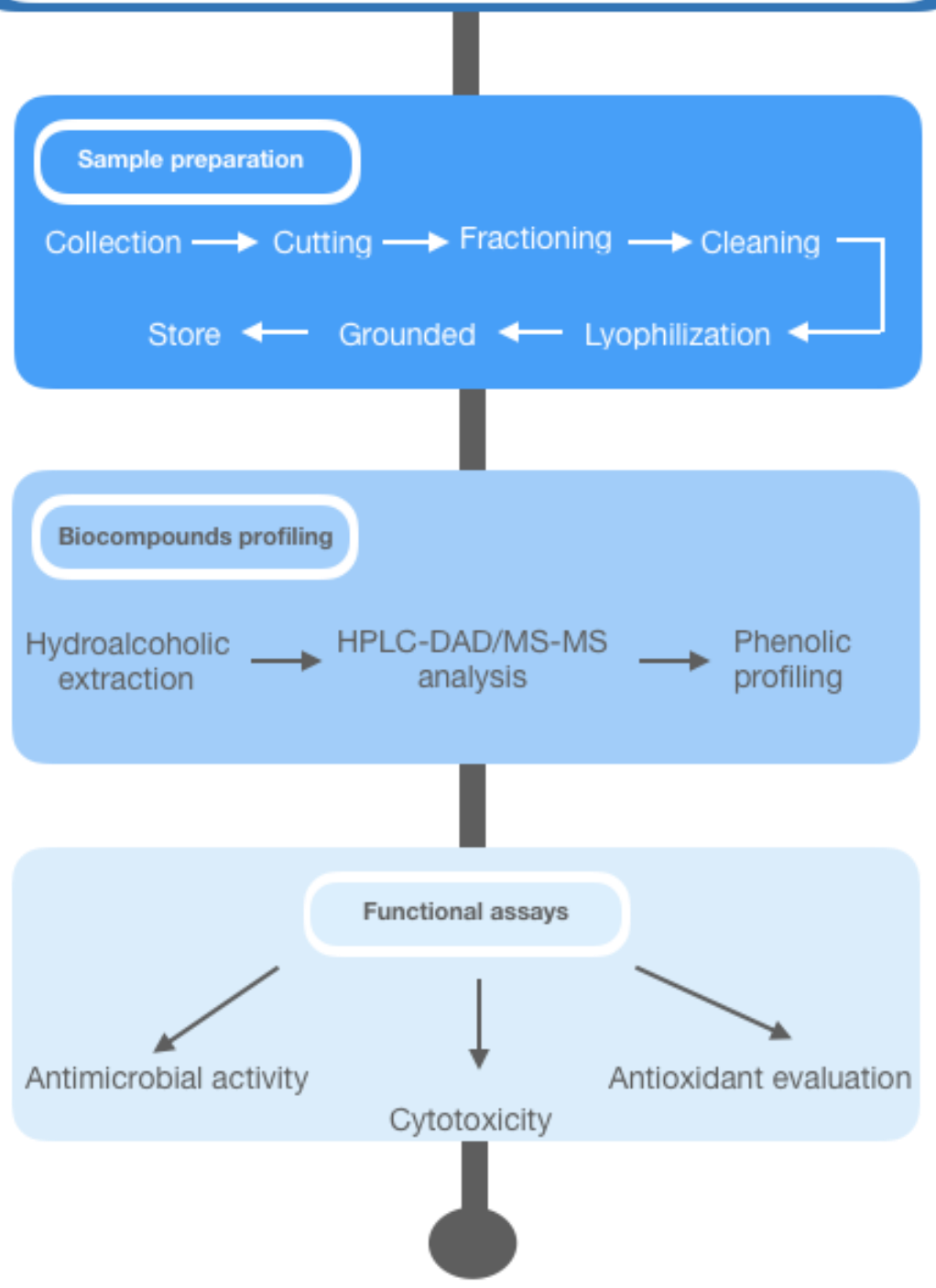

Figure -2-2 Article 1 experimental work (source: private collection) 
Objetivos y plan de trabajo

\section{Extensive profiling of three varieties of Opuntia spp. fruit for innovative food ingredients}

Sample preparation

Collection $\longrightarrow$ Rinse $\longrightarrow$ Air dring $\rightarrow$ Peeling Store $\longleftarrow$ Crushing 4 Lyophilization

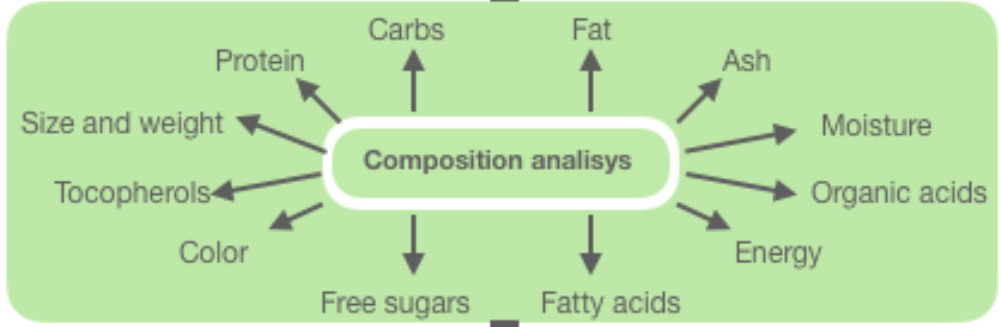

Functional assays
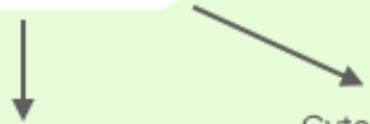

Betalainic content

Antimicrobial activity

Cytotoxicity

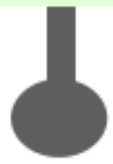

Figure -2-3 Article 2 experimental work (source: private collection) 
Objetivos y plan de trabajo

\section{By-product recovery of Opuntia spp. peels: Betalainic and phenolic profiles and bioactive properties}

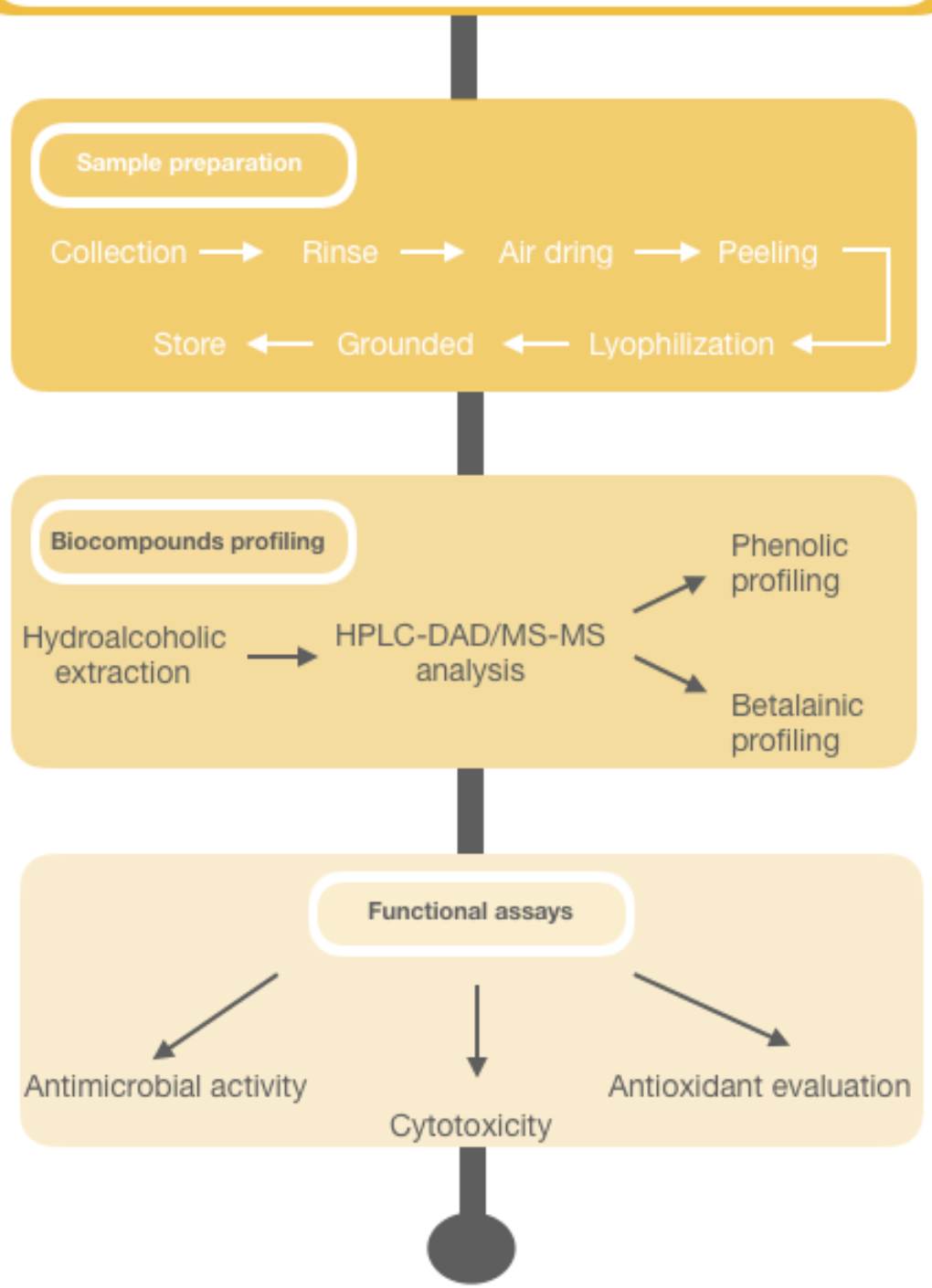

Figure -2-4 Article 3 experimental work (source: private collection) 
Objetivos y plan de trabajo

Extraction recovery optimization through UAE and MAE of Opuntia peels biocompounds: Avant-garde use of the byproducts.

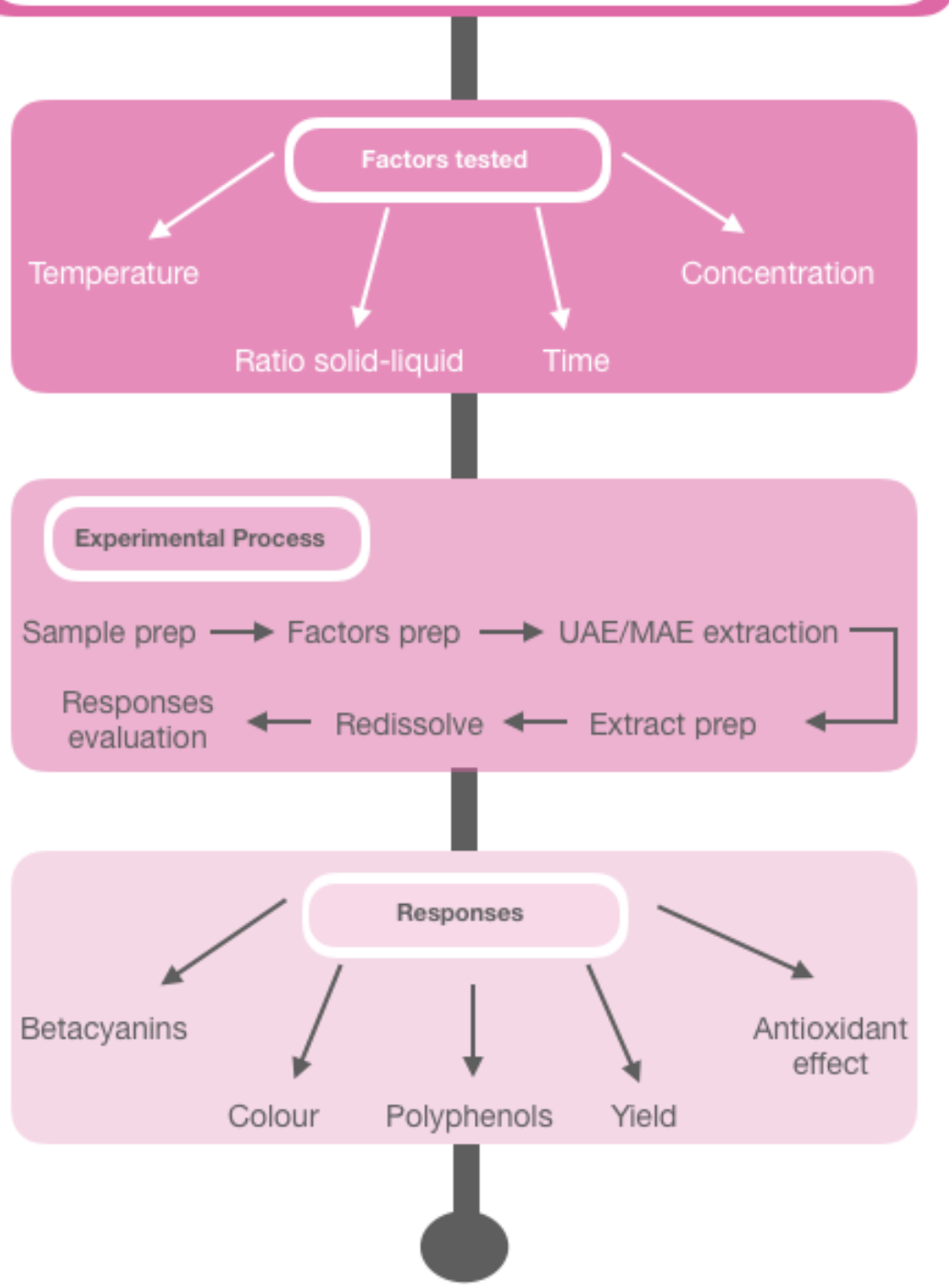

Figure -2-5 Article 4 experimental work (source: private collection) 



\section{Capítulo 3 Metodología EXPERIMENTAL}





\section{III.1 Materias PRIMAS}

Para la realización de los estudios desarrollados se emplearon dos especies frutícolas diferente.

\section{III.1.1 Aguacate (Persea americana Mill)}

Por un lado se estudiaron los residuos (piel y semilla) del aguacate (Persea americana Mill. var. Hass), el cual fue adquirido en estado de madurez comercial. Se utilizaron al menos 25 aguacates de la misma variedad y lote de venta, de tamaño y color homogéneo, exentos de alteraciones fisiológicas perceptibles al ojo. Las muestras se almacenaron a $4{ }^{\circ} \mathrm{C}$ hasta su análisis.

\section{III.1.2 Higos chumbos (Opuntia Spp).}

En las determinaciones de la especie Opuntia se utilizaron diferente variedades, 2 comerciales (Opuntia ficus-indica var. Gialla y Opuntia ficus-indica var. Sanguigna), adquiridas en su estado de maduración comercial, y 2 variedades salvajes (Opuntia engelmannii y Opuntia engelmannii cv. Valencia), ambas fueron recolectadas en los meses de Septiembre, cuando su maduración hortícola era optima, la primer variedad se recolectó en las periferias de Bragança, Portugal, mientras que la segunda variedad fue recolectada en la ciudad de Valencia, España. Siempre se seleccionaron los frutos de tamaño y color homogéneo, excentos de alteraciones fisiológicas perceptibles al ojo. Normalmente se partía de un pool de mas de 30 unidades, de las cuales se seleccionaban aleatoriamente al menos 10 unidades y como minimo para cada una de las determinaciones, se empleaban al menos 3 unidades. Las muestras se almacenaron a $4{ }^{\circ} \mathrm{C}$ hasta su preparación para las determinaciones. 


\section{III.2 PREPARACIÓN DE LA MUESTRA}

Previamente al uso de los frutos para las determinaciones analíticas, estos recibieron distintos tratamientos.

\section{III.2.1 Aguacates}

Los frutos fueron lavados para eliminar cualquier tipo de impureza, secados al aire libre y cortados por la mitad. La semilla fue separada, brevemente lavada y secada al aire libre, mientras que las pieles fueron separadas de las pulpas mediante la ayuda de una espátula y porteriormente lavadas para eliminar los residuos de las pulpas y secadas al aire libre.
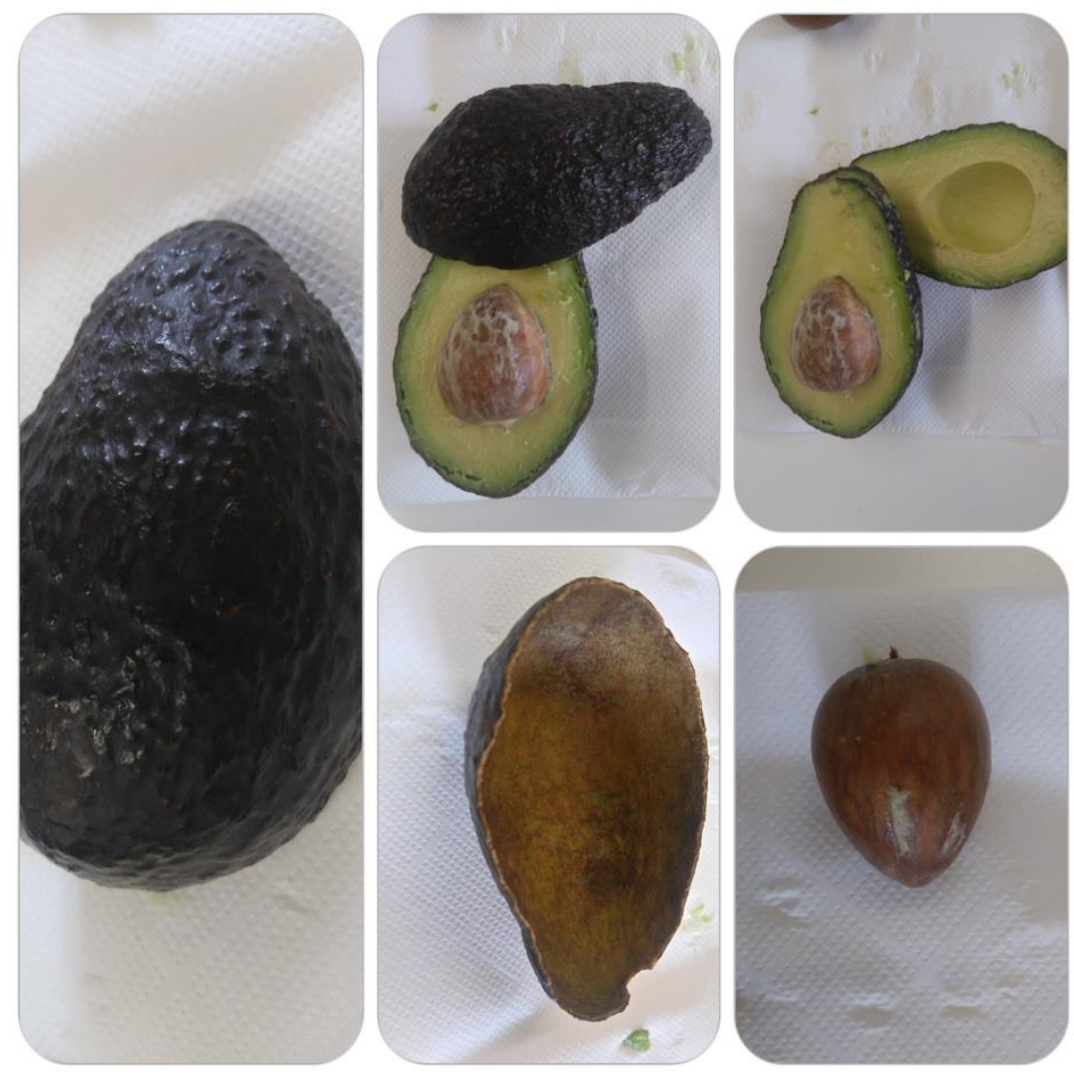

Figure 3-1 Persea americana fruit fractions (source: private collection) 


\section{III.2.2 Higos chumbos}

A diferencia de los frutos de aguacate, los higos chumbos fueron cuidadosamente lavados bajo un chorro de agua con la ayuda de una esponja para remover los gloquidios, y posteriormente secados al aire libre. La separación de las pieles fue hecha realizando 2 cortes verticales en los extremos del fruto y un posterior corte vertical, por donde se realizó la separación. La separación de las semillas (cuando fue necesario) se realizó mediante el uso de una licuadora compacta Moulinex Vitae JU200045, obteniendo por una lado la pulpa y zumo y por otro lado las semillas, que posteriormente son lavadas y secadas al aire libre.
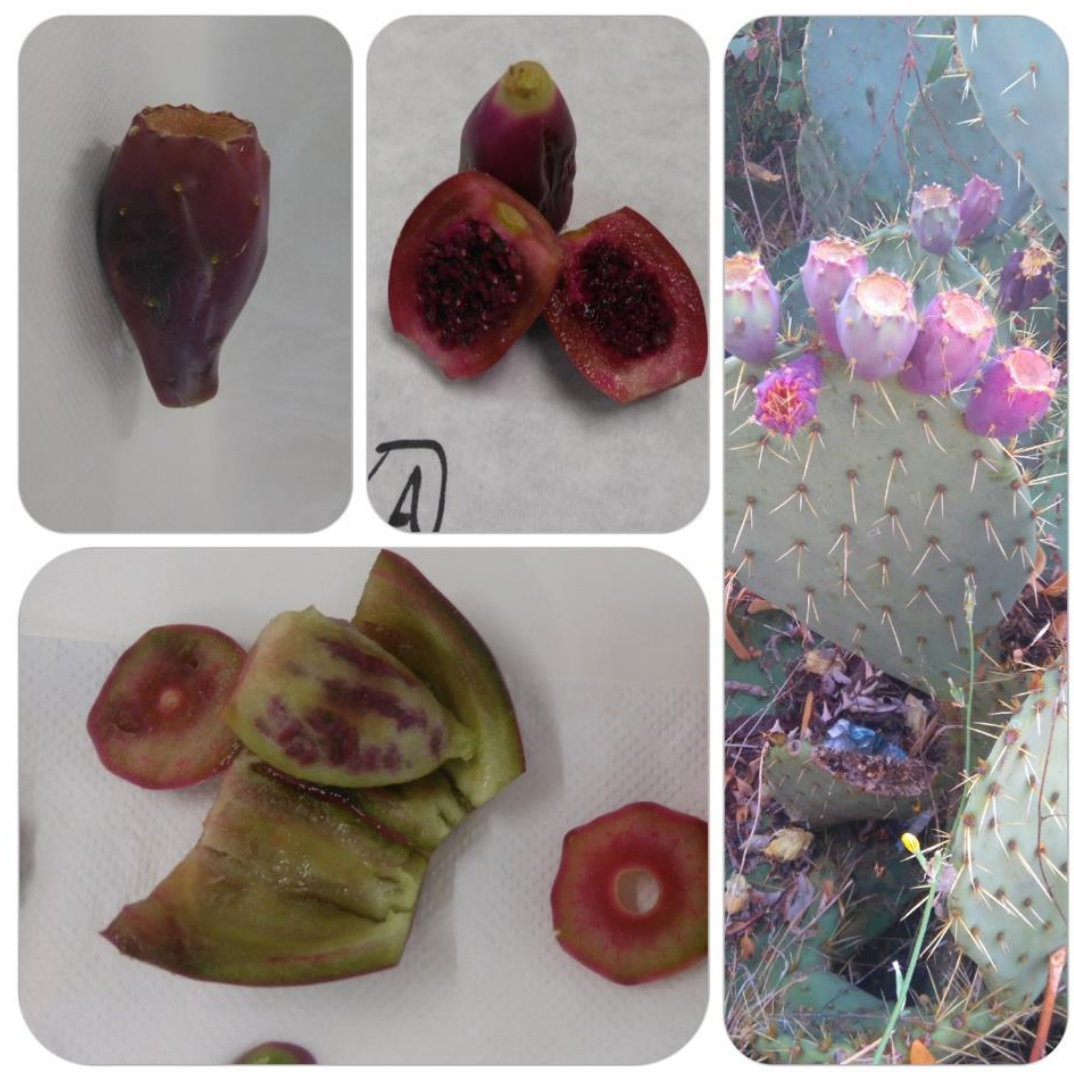

Figure 3-2 Opuntia spp fruits fractions (source: private collection) 


\section{III.2.3 Tratamientos térmicos.}

Las muestras, dependiendo del diseño experimental, fueron usadas frescas, secas o liofilizadas, debido a que estas son las condiciones típicas utilizadas que se citan comunmente en la bibliografía cientifica.

El secado se realizó siempre en dos etapas, la primera, un secado de las distintas fracciones por 24 horas en una estufa de secado por convección modelo Conterm 2000210 (JP Selecta S.A., España) a $60^{\circ}$ $\mathrm{C}$, transcurrido el tiempo necesario, las muestras se secan con una estufa a vacio modelo Vaciotem-Tv (JP Selecta S.A., España) a $60^{\circ} \mathrm{C}$ y un vacío máximo de $0,01 \mathrm{~mm} \mathrm{Hg}$ por 72 horas o hasta que se obtuvo peso constante.

Por otro lado, para conservar mejor la integridad de las muestras biologícas, se utilizó la liofilización como tratamiento de conservación. Las fracciones de los frutos fueron previamente congeladas a $-32^{\circ} \mathrm{C}$ utilizando un congelador convencional durante 24 horas, para posteriormente ser deshidratadas en un liofilizador modelo Telstar Lioalfa-6 (Azbil corp., Japón) con cámara cerrada a vacío por 72 horas a $-50^{\circ} \mathrm{C}$.

Una vez secas las muestras, se disminuyó el tamaño de particula mediante el uso de una picadora Moulinex A320R1 y un posteriror cribado mediante una malla fina. Las muestras fueron después envasadas a vacío hasta su análisis 


\section{III.3 PARAMETROS MORFOLOGICOS}

\section{III.3.1 Dimensiones y peso}

Para la caracterización, los frutos enteros y sus distintas fracciones fueron pesadas en una balanza analítica Secura 224-1S (Secura Lab instruments $\mathrm{GmbH}$, Alemania) y sus dimensiones (alto y ancho) fueron medidas mediante el uso de un calibrador Vernier.

\section{III.3.2 Color}

Las coordenadas de color fueron determinadas en dos formas distintas, las muestras sólidas fueron medidas mediante el uso de un colorímetro Konica Minolta CR-400 (Konica Minolta Sensing Inc, Japón) con el uso del iluminante $\mathrm{C}$ y una apertura del diafragma de $8 \mathrm{~mm}$, midiendo por triplicado en tres puntos distintos elegidos al azar. Las muestras líquidas fueron analizadas mediante el espectrofotómetro Minolta CM3600d (Konica Minolta Sensing Inc, Japón) usando el modo reflactancia con la lente LAV, el componente especular excluido y una difusión de iluminación con el angulo $65 / 10^{\circ}$, midiendo el triplicado de las muestras por tlipicado cada una de ellas. En ambos se utilizó el promedio de cada muestra y se utilizó el software Spectra magic (Version 3.6, CyberChrome Inc, Japón) para reportar las coordenadas cartesianas CIE Lab o las coordenadas cilíndricas CIE L* $\mathrm{C} * \mathrm{~h} *$. 


\section{III.4 CARACTERIZACIÓN NUTRICIONAL}

\section{III.4.1 Proteina}

La determinación proteica se realizó por el método de Kjeldahl de acuerdo a lo indicado en AOAC 991.29 (Association of Official Analytical Chemists, 2016), Utilizando un digestor y destilador automático modelo Pro Nitro A (JP Selecta S.A., España), los valores obtenidos fueron ajustados con el factor de conversión proteica $(\mathrm{N} \mathrm{x}$ $6,25)$

\section{III.4.2 Grasa}

E1 ensayo de grasa total fue hecho por el método de Soxhlet de acuerdo a lo indicado en AOAC 963.15, La extracción fue llevada a cabo con éter de petróleo a $120{ }^{\circ} \mathrm{C}$ por 7 horas.

\section{III.4.3 Humedad}

La determinación de humedad de las muestras se realizó mediante el método gravimétrico indicado en AOAC 930.04, en el cual se emplearon estufas de vacio Vaciotem-Tv (JP Selecta S.A., España), a una temperatura de $60{ }^{\circ} \mathrm{C}$ con la finalidad de evitar la caramelización de los azúcares presentes, expresando el porcentaje de humedad de acuerdo a la siguiente formula.

$$
\text { Humedad }=\left(\frac{\text { Peso fresco }- \text { Peso seco }}{\text { Peso Seco }}\right) \times 100
$$

Equation 3-1 Moisture determination

\section{III.4.4 Cenizas}

Para expresar el porcentaje de cenizas en las muestras, se ha empleado el método gravimétrico 940.26 de la AOAC, removiendo primero la humedad para después incinerar la muestra en un horno mufla Selecthorn-TFT (JP Selecta S.A., España), a $525{ }^{\circ} \mathrm{C}$ durante 5 horas. 
Material y métodos

\section{III.4.5 Carbohidratos}

La determinación de carbohidratos (CHO) totales se calculó por diferencia de los otros constituyentes. La fórmula aplicada se muestra a continuación:

Carbohidratos $\left(\frac{g}{100 g}\right)=100-(g$ Proteina $+g$ Grasa + $g$ Cenizas $+g$ Humedad)

Equation 3-2 Total carbohydrates by difference

\section{III.4.6 Energia}

Los valores de energía son calculados a partir de los gramos de los macronutrientes previamente mencionados.

Energia $\left(\frac{k c a l}{100 g}\right)=4 \times($ Proteina $+g$ CHO $)+9 \times($ Grasa $)$

Equation 3-3 Total energy 


\section{III.5 COMPUESTOS HIDROFÍLICOS}

\section{III.5.1 Azúcares solubles}

Los azúcares (fructosa, glucosa y sacarosa) fueron determinados a partir de las muestras desengrasadas en Soxhlet mediante el método previamente descrito por Pereira et al. (2011). Brevemente, las muestras $(1 \mathrm{~g})$ son adiciondas con el patrón interno melezitosa $(1 \mathrm{~mL}$ [25 mg/mL]), extraídas con etanol $80 \%$ v/v a $80{ }^{\circ} \mathrm{C}$ por $1 \mathrm{~h} 30 \mathrm{~min}$, centrifugadas y evaporadas, para posteriormente ser lavadas 3 veces con éter dietílico; la fase acuosa es recolectada, evaporada, reconstituida en agua $(5 \mathrm{~mL})$ y filtrada a través de un filtro de nylon de $0,2 \mu \mathrm{m}$.

El extracto es posteriormente analizado mediante HPLC acoplado a un detector de índice de refracción (IR) modelo Smartline system 1000 (Knauer, Alemania). La separación se llevó a cabo mediante una columna Eurosphere 100-5 $\mathrm{NH}_{2}(4,6$ x $250 \mathrm{~mm}, 5 \mu \mathrm{m})$ (Knauer, Alemania), y como fase móvil se utilizó una mezcla de acetonitrilo:agua $(70: 30 \mathrm{v} / \mathrm{v})$. Los resultados fueron identificados y comparados con sus respectivos patrones y procesados mediante el software Clarity 2.4 (DataApex, República Checa).

\section{III.5.2 Ácidos orgánicos}

Los ácidos organicos detectados en las muestras (oxálico, quínico, málico, ascórbico, cítrico, succínico y fumárico), se identificaron mediante la metodología descrita por (Barros et al., 2013) utilizando UFLC acoplado a un detector de diodos (DAD) con un equipo Shimadzu 20A series (Shimadzu coorporation, Japon), usando una columna SphereClone $\mathrm{C}_{18}$ en fase reversa (Phenomenex, USA) con tamaño de particula de $5 \mu \mathrm{m}$ y $4,6 \times 250 \mathrm{~mm}$, termostatada a $35^{\circ} \mathrm{C}$ y con elución isocrática de ácido sulfúrico $3,6 \mathrm{mM}$ con un flujo de 0,8 $\mathrm{mL} / \mathrm{min}$. La detección de los compuestos se realizó a $215 \mathrm{~nm}$, excepto para el ácido ascórbico a $245 \mathrm{~nm}$, la identificación y cuantificación se llevó a cabo mediante comparación con patrones usando el software Shimadzu LC solutions (Shimadzu coorporation, Japón).

La extracción de la muestra se realizó usando acído metafosfórico $(25 \mathrm{~mL}[4,5 \% \mathrm{p} / \mathrm{v}])$ a $24{ }^{\circ} \mathrm{C}$ con agitación magnética $(150 \mathrm{rpm})$ y 
Material y métodos

protegido de la luz. A continuación la muestra se filtró a través de papel Whatman No. 4 y posteriormente con un filtro de nylon de $0,2 \mu \mathrm{m}$. 


\section{III.6 COMPUESTOS LIPOFÍLICOS}

\section{III.6.1 Ácidos grasos}

Las muestras extraidas en Soxhlet se derivatizan redisolviendo en una solución de metanol:acído sulfúrico:tolueno $(2: 1: 1 \mathrm{v} / \mathrm{v} / \mathrm{v})$, agitandose en un vortex y otra vez extrayéndose con agitación $(160 \mathrm{rpm})$ durante $12 \mathrm{~h}$ a $50{ }^{\circ} \mathrm{C}$. Posteriormente, se adicionó agua destilada $(3 \mathrm{~mL})$ y se agitó con vortex, después se agregó éter etílico $(3 \mathrm{~mL})$ y vortex nuevamente, se esperó a la separación de fases y mediante una pipeta pasteur se extrajo la fase lipofílica y se añadió a un vial con sulfato de sodio anhídrido para capturar humedad. Por último se filtra con un filtro de nylon de $0,2 \mu \mathrm{m}$.

La detección y cuantificación de ácidos grasos, se realizó mediante Cromatografia de gases en el equipo Dani 1000 con detector de ionización de flama (GC-FID) (Dani Instruments, Switzerland), usando una columna capilar (Macherey-Nagel $\mathrm{GmbH}$, Alemania) (30 $\mathrm{m} \times 0,32 \mathrm{~mm}$ DI $\times 0,25 \mu \mathrm{m} \mathrm{d}_{\mathrm{f}}$ ) dentro de un horno programado con las siguientes rampas de temperatura de acuerdo a lo descrito previamente por Pereira et al. (2012):

Table 3-1 GC temperature ramp for fatty acids

Time (min)

Temperature $\left({ }^{\circ} \mathbf{C}\right)$

\begin{tabular}{|c|c|}
\hline $\mathbf{0}$ & 50 \\
\hline $\mathbf{2}$ & 50 \\
\hline $\mathbf{1 1 , 5}$ & 125 \\
\hline $\mathbf{1 2 , 5}$ & 160 \\
\hline $\mathbf{1 9}$ & 180 \\
\hline $\mathbf{2 0}$ & 200 \\
\hline $\mathbf{3 5}$ & 220 \\
\hline
\end{tabular}

El gas acarreador empleado fue hidrógeno a un flujo de $4 \mathrm{~mL} / \mathrm{min}$ (0,61 bar), y Split injection (1:40) fue realizada a $250{ }^{\circ} \mathrm{C}$. La 
identificación de los ésteres metílicos de ácidos grasos (FAME) se llevó a cabo comparándolos con los tiempos de retención relativos de los patrones empleados, usando el software CSW 1.7 (DataApex, República Checa) y se expresaron en porcentaje relativo.

\section{III.6.2 Tocoferoles}

La extracción de estos compuestos se realizó colocando en un tubo falcon la muestra $(500 \mathrm{mg})$ junto a hidroxitolueno butilado (BHT) (250 $\mu \mathrm{L}[10 \mathrm{mg} / \mathrm{mL}$ en Hexano]), tocol (400 $\mu \mathrm{L}[50 \mu \mathrm{g} / \mathrm{mL}])$ y metanol $(4$ $\mathrm{mL}$ ) y se agitó en el vortex (1 min). A continuación y por duplicado se adicionó hexano $(4 \mathrm{~mL})$, vortex $(1 \mathrm{~min})$, y solución concentrada de $\mathrm{NaCl}(2 \mathrm{~mL})$, Vortex (1 min). Las extracciones se centrifugaron (5 min, $4000 \mathrm{~g}, 10^{\circ} \mathrm{C}$ ) en una centrifuga 5804R, (Eppendorf, Alemania) y se recogieron los sobrenadantes en un vial protegidos de la luz. Sucesivamente se deshidrataron los sobrenadantes agregandó sulfato de sódio anhidrido $(1 \mathrm{~g})$ y se llevaron a sequedad en una corriente de nitrógeno. Por último, el concentrado se redisuelve en hexano $(2 \mathrm{~mL})$ y se filtró con un filtro de nylon de $0,2 \mu \mathrm{m}$.

La determinación cromatográfica se realizó con el método descrito por (Heleno et al., 2010), empleando un cromatógrafo de liquidos Smartline system 1000 (Knauer, Alemania) acoplado a un detector de flourescencia FP-2020 (Jasco, Japón) programado para excitación a 290 nm y emisión a $330 \mathrm{~nm}$. La separación se llevó a cabo con con una columna YMC Polyamide II (Waters, Japón) $(250$ x 4,6 mm x $5 \mu \mathrm{m})$ en fase normal termostatada a $30{ }^{\circ} \mathrm{C}$. La fase móvil utilizada consistió en n-hexano y etil acetato (70:30 v/v) en isocrático con un flujo de 1 $\mathrm{mL} / \mathrm{min}$ y un volumen de inyección de $20 \mu \mathrm{L}$. Los compuestos fueron identificados de acuerdo a la comparación de estándares usando la señal de respuesta de flourescencia mediante el software Clarity 2.4 (DataApex, República Checa). 


\section{III.7 PREPARACION DE EXTRACTOS}

A lo largo del desarrollo de este trabajo, se probaron distintas condiciones y tratamientos de extracción modificando diferentes parámetros, empleando muestras frescas, secas o liofilizadas. A continuación se mencionan sólo los procesos de extracción empleados en las publicaciones que figuran en esta tesis.

\section{III.7.1 Extracción por agitación}

La muestra ( $1 \mathrm{~g})$ se mezcló con $25 \mathrm{~mL}$ de solvente orgánico (variable e indicado en cada capítulo) y se extrajo mediante agitación magnetica $\left(24{ }^{\circ} \mathrm{C}\right.$ y $\left.200 \mathrm{rpm}\right)$ por $1 \mathrm{~h}$, los extractos posteriormente se filtraron a través de un papel Whatman No. 4. Los sobrenadantes se recolectaron y los tejidos vegetales se volvieron a re-extraer como se mencionó anteriormente. Subsecuentemente, los extractos obtenidos se mezclaron y conservaron en refrigeración $\left(4^{\circ} \mathrm{C}\right)$ hasta su posterior uso.

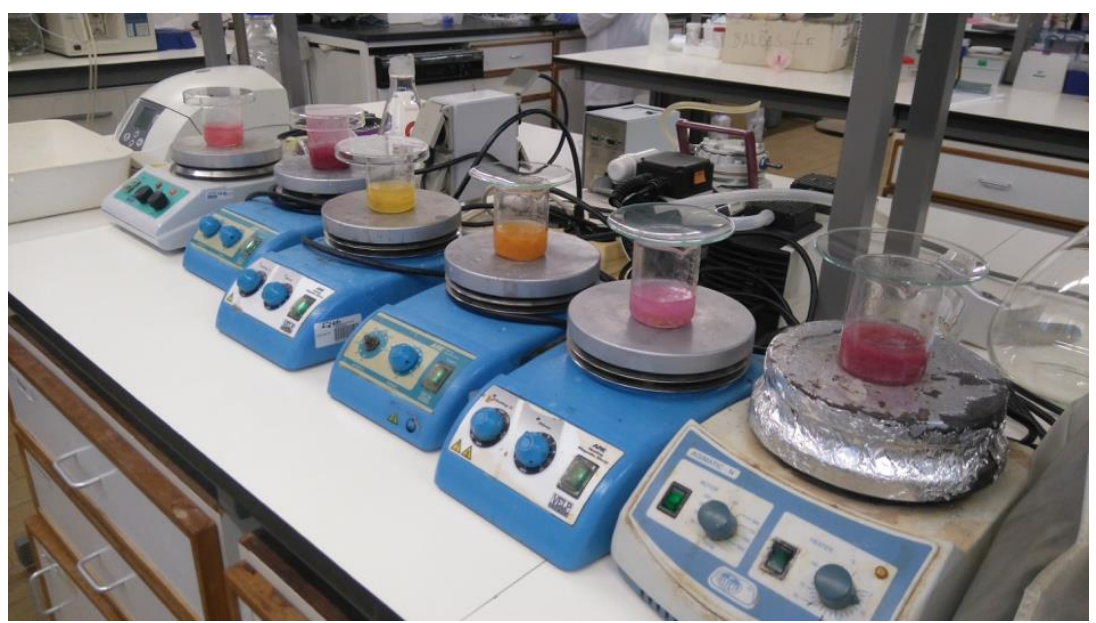

Figure 3-3 Conventional extraction (source: private collection)

\section{III.7.2 Extracción por Ultrasonidos}

Para esta extracción se desarrollo un sistema el cual consiste en un baño de ultrasonidos ATM40-- LCD (Labbox, España) con sistema de control de tiempo y fecuencia $(40 \pm 2 \mathrm{kHz})$ conectado a un baño de enfriamento Frigiterm TFT-30 (JP Selecta S.A., España) unido a un 
termostato de calefacción Tectron bio (JP Selecta S.A., España), para controlar la temperatura de forma precisa, y la recirculación de agua entre la unidad térmica y el baño ultrasónico se realizó con una bomba peristáltica Pumpdrive 5006 (Heidolph, Alemania). Al mismo tiempo se efectuo la agitación de las muestras a través de un agitador de cabezal RZR 2021 (Heidolph, Alemania) a $200 \mathrm{rpm}$. (Las condiciones especificas se mencionan en los capítulos correspondientes).

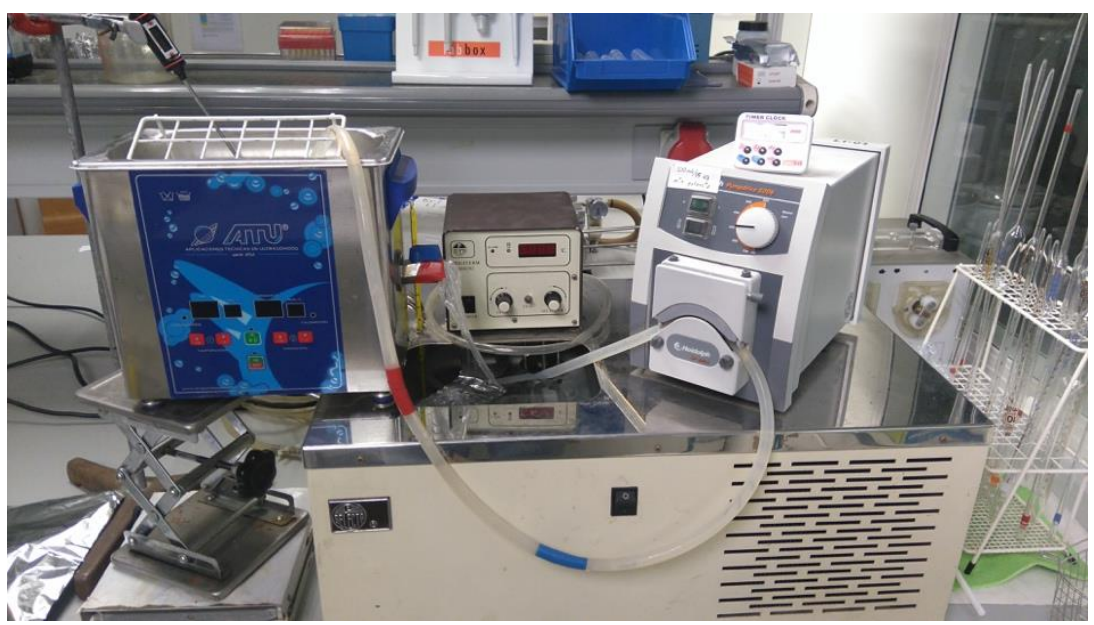

Figure 3-4 Ultrasonic extraction system (source: private collection)

Para las extracciones se pesaron las muestras en matraces Erlen Meyer y se les adicionaron los volúmenes necesarios de solventes, estos se introdujeron en el baño ultrasónico y se comienzó la agitación por 2 minutos con la finalidad de atemperar las muestras con la temperatura del baño. Posteriormente, se realizó la extracción con el tiempo necesario. Los extractos obtenidos se conservaron en refrigeración (4 ${ }^{\circ} \mathrm{C}$ ) hasta su posterior uso.

\section{III.7.3 Extracción por microondas}

Independientemente de los tiempos y temperaturas empleadas empleadas, las muestras siempre se pesaron en tubos de teflón MarsXpress plus (CEM, USA) donde posteriormente se adicionó el volumen necesario del solvente de extracción, estos se cerraron con la válvula de salida de presión y su tapa, montados en el carrusel y llevados al horno de microondas Mars 6 (CEM, USA), equipado con 
sistema de control digital de irradiación (iWave) para asegurar temperatura uniforme en todos los tubos. El horno siempre trabajó a $400 \mathrm{~W}$ de potencia. (Las condiciones especificas se mencionan en los capítulos correspondientes).

\section{III.7.4 Procesos post-extracción}

Los extractos obtenidos por cualquier extracción, se centrifugaron a $15585 \mathrm{~g}$ en una centrifuga 5804-R (Eppendorf, Alemania) por 7 minutos a $10{ }^{\circ} \mathrm{C}$, a continuación, se filtraron a vacío usando un embudo Buchner esmerilado con placa filtrante de porosidad 2 (Labbox, España). En el caso de que el filtrado contuviera además de agua algún alcohol, este se llevaba porsteriormente al rotavapor Hei-Vap Value (Heidolph, Alemania) y se secó a vacío a $40{ }^{\circ} \mathrm{C}$. Por último, el remanente acuoso, se congela a $-32^{\circ} \mathrm{C}$ en un congelador convencional durante 24 horas, y posteriormente se liofilizaba (Telstar Lioalfa-6, Azbil corp.,Japón) durante 72 horas a $-50^{\circ} \mathrm{C}$. Los extractos liofilizados se almaceron a vacío en un ambiente seco y fresco hasta su uso posterior.

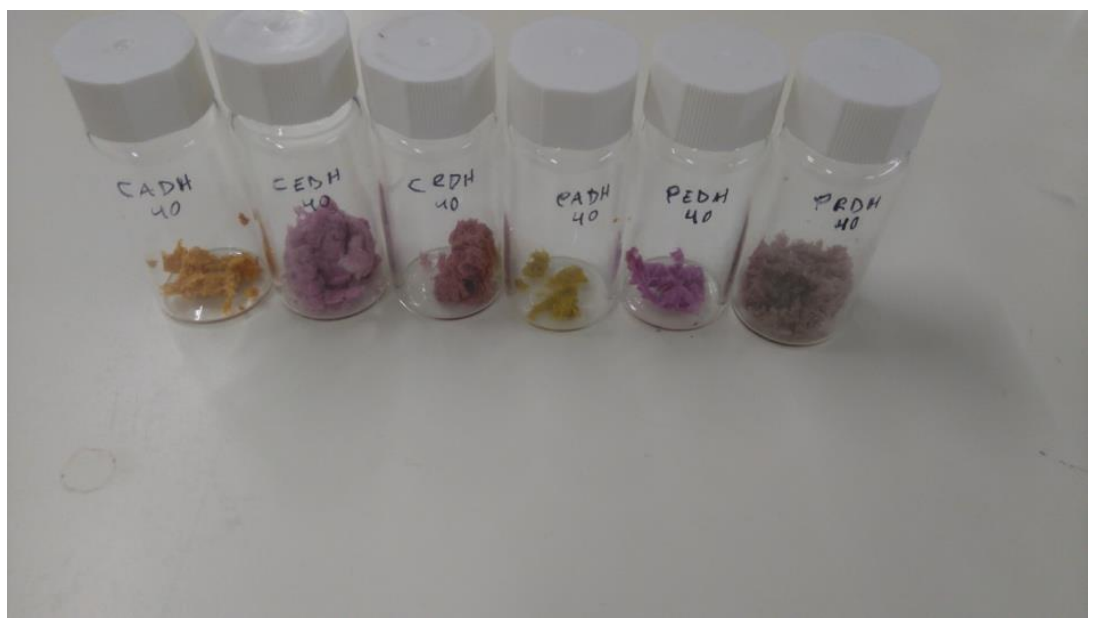

Figure 3-5 Lyophilized powders (source: private collection) 


\section{III.8 DETERMINACIÓNES PRELIMINARES DE COMPUESTOS FUNCIONALES}

Tanto en las determinaciones preliminares como en las determinaciones finales de las propiedades bioactivas, los extractos liofilizados se redisolvieron en una mezcla de etanol ó metanol y agua $(80: 20 \mathrm{v} / \mathrm{v})$ a una concentración conocida a la que posteriormente se le hacieron diluciones sucesivas con el objetivo de poder evaluar el efecto de las distintas concentraciones y poder calcular los valores de concentración de inhibición $\mathrm{IC}_{50}$ de las muestras.

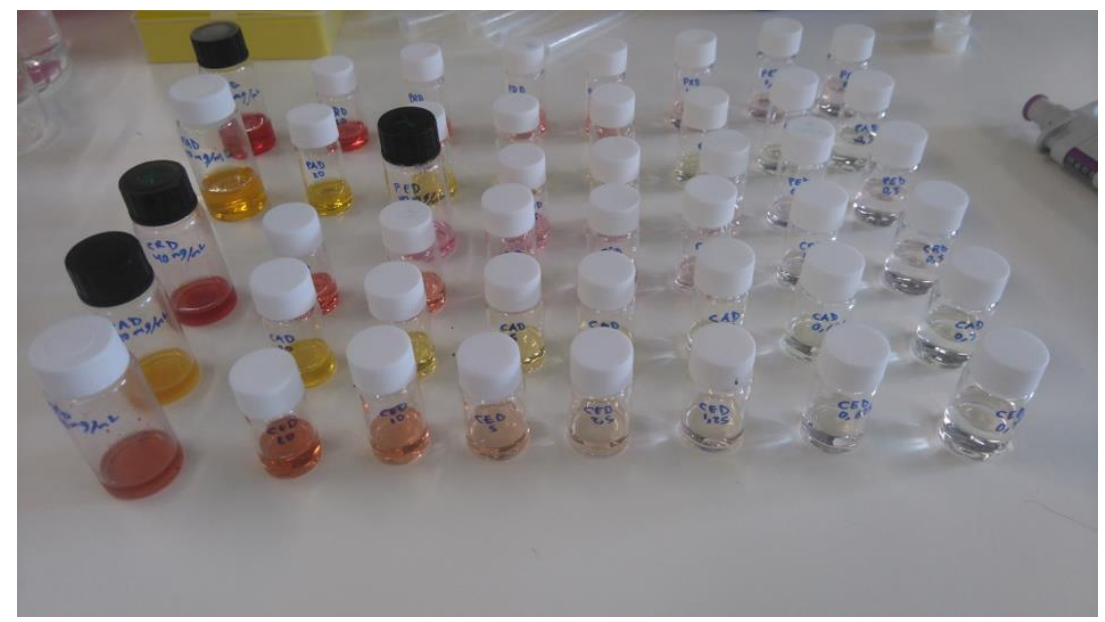

Figure 3-6 Re-suspended samples (source: private collection)

\section{III.8.1 Polifenoles por el metodo de Folin-Ciocalteu}

E1 método descrito por Singleton y Rossi (1965), consiste en oxidar los compuestos fenólicos presentes en la muestra, por medio de una mezcla de ácidos fosfotúngstico y fosfomolíbdico conocida como reactivo de Folin-Ciocalteu, los cuales en presencia de fenoles, son reducidos a óxidos azules de tungsteno y molibdeno.

Para llevar a cabo la reacción se mezclaron el extracto $(200 \mu \mathrm{L})$ con el reactivo de Folin-Ciocalteu $(1 \mathrm{ml}[1: 10 \mathrm{v} / \mathrm{v}])$, se agitó y se dejó reaccionar por 4 minutos, a continuación se añade carbonato de sodio $(800 \mu \mathrm{L})[7,5 \% \mathrm{p} / \mathrm{v}]$ y se dejó reaccionar en obscuridad por $30 \mathrm{~min}$. En paralelo se preparó un blanco con $200 \mu \mathrm{L}$ de agua en lugar de extracto 
y una curva de calibrado (curva patrón) con ácido gálico [0-100 ppm] y una vez transcurrido el tiempo de reacción se mide la absorbancia a $765 \mathrm{~nm}$.

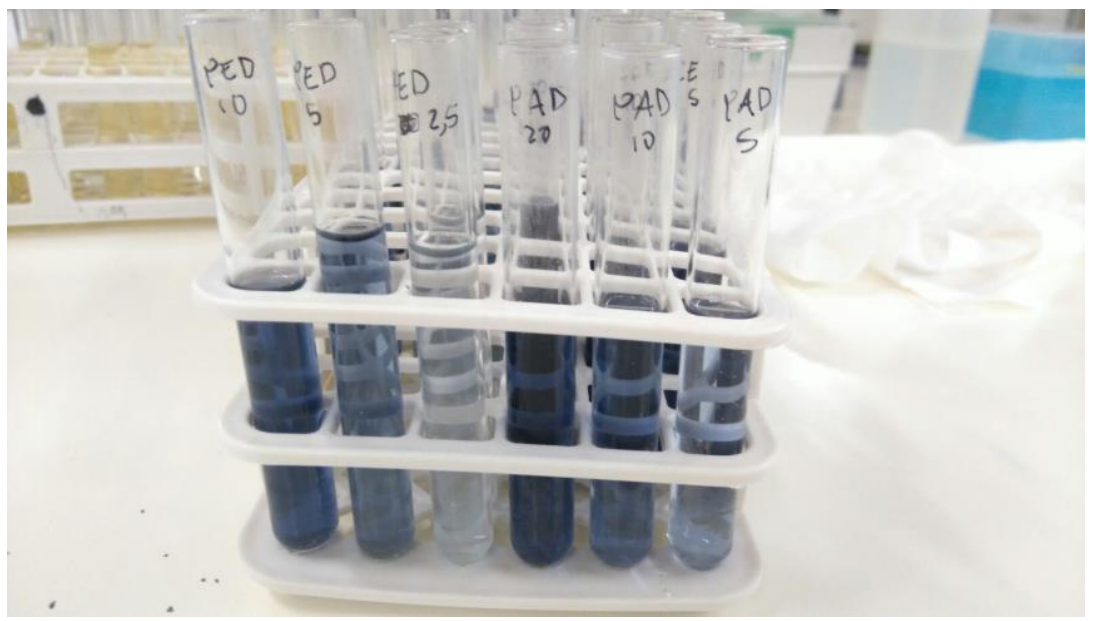

Figure 3-7 Folin-Ciocalteu samples (source: private collection)

\section{III.8.2 Flavonoides por el metodo de tricloro aluminio}

El método colorimétrico descrito por Zhishen et al. (1999) se realizó mezclando el extracto $(1 \mathrm{~mL})$ con agua destilada $(4 \mathrm{~mL})$ y $\mathrm{NaNO}(0,3$ $\mathrm{mL}[5 \% \mathrm{p} / \mathrm{v}])$ el cual se agitó y se dejó reaccionar por 5 minutos, a continuación se adicionó $\mathrm{AlCl}_{3}(0,3 \mathrm{~mL}$ [10 p/v]), se agitó y se dejó reposar por 6 minutos, posteriormente se adicionó $\mathrm{NaOH}(2 \mathrm{~mL}[1 \mathrm{M}])$, se agitó nuevamente y se añadió agua destilada $(2,4 \mathrm{~mL})$ para finalmente leer la absorbancia a $510 \mathrm{~nm}$. La curva de calibración de Rutin y el blanco siguieron las mismas condiciones de reacción. 


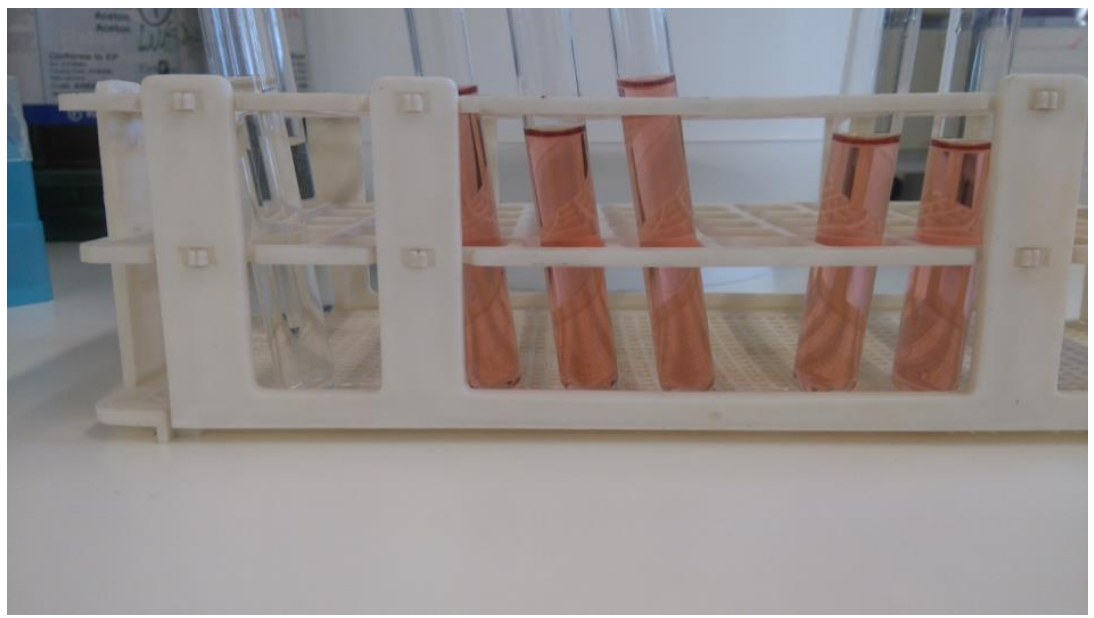

Figure 3-8 $\mathrm{ALCL}_{3}$ colorimetric assay (source: private collection)

\section{III.8.3 Betalainas por metodo espectrofotometrico}

El método rápido para identificación y cuantificación proximal de betalainas se consiguió tras un barrido espectrofotométrico de los extractos de acuerdo a (Cassano et al., 2007), identificando las betacianinas $(\mathrm{Bc})$ a $530 \mathrm{~nm}$ y las betaxantinas $(\mathrm{Bx})$ a $480 \mathrm{~nm}$. Para su cuantificación se utilizó las siguiente formula:

Betalainas $=\left(\frac{A \times F d \times V \times P m}{m \times L \times \varepsilon}\right)$

Equation 3-4 Spectrophotometric betalainic content

Donde $\mathrm{A}=$ absorbancia $(\mathrm{Bx}=480 \mathrm{o} \mathrm{Bc}=530 \mathrm{~nm}) ; \mathrm{Fd}=$ factor de dilución; $\mathrm{V}=$ Volumen del extracto (L); $\mathrm{Pm}=$ peso molecular (betanina $=550 \mathrm{~g} / \mathrm{mol}$, Indicaxantina $=308 \mathrm{~g} / \mathrm{mol}) ; \mathrm{m}=$ masa de muestra $(\mathrm{g}) ; \mathrm{L}=$ longitud de la cuveta $(1 \mathrm{~cm}) ; \varepsilon=$ coeficiente de extinción molar $(\mathrm{Bx}=$ $48000 \mathrm{~L} / \mathrm{mol} \mathrm{cm}, \mathrm{Bc}=60000 \mathrm{~L} / \mathrm{mol} \mathrm{cm}$ ), obteniendo el resultado final de las betalainas en $\mathrm{g}$ de betanina o indicaxantina por gramos de muestra. 


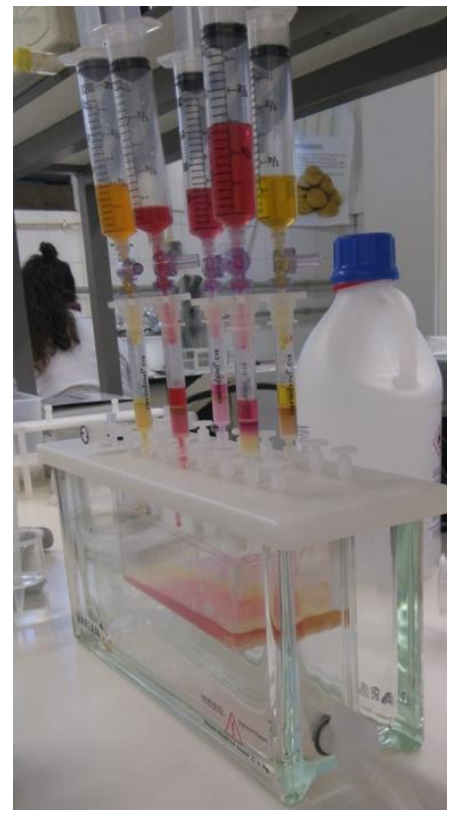

Figure 3-9 SPE extraction of betalains (source: private collection)

Para obtener una mejor resolución del contenido, los extractos se purificaron mediante un sistema de extracción de fase sólida (SPE) en un cartucho C-18 SepPak® Vac 3 cc (Waters, USA). El cartucho se activó con 2 volúmenes de metanol, seguido por 2 volúmenes de agua, inmediatamente el extracto es retenido y posteriormente eluido con agua y finalmente con metanol/ácido trifluoroacético (TFA) (99,9:0,1 $\mathrm{v} / \mathrm{v})$. Ambas freacciones fueron evaporadas y/o liofilizadas, resuspendidas y analizadas por separado espectrofotométricamente. 


\section{III.9 EVALUACIÓN DE PROPIEDADES BIOACTIVAS}

Para determinar la bioactividad de los extractos a continuación se describen los métodos experimentales que fueron realizados. Los resultados son expresados en concentraciones minimas en las actividades antimicrobianas, y para el resto de las pruebas antioxidantes se usarón los valores de concentración efectiva $\mathrm{EC}_{50}$ y concentración de inhibición $\mathrm{IC}_{50}$, que nos proporciona la información de la concentración necesaria de los extractos para tener una bioactividad del $50 \%$.

\section{III.9.1 Actividad antibacteriana}

Se determinaron las concentraciones minimas inhibitorias (MIC) y minimas bactericidas (MBC) utilizando el método de microdilución del comité nacional para estándares de laboratorios clínicos (NCCLS M38P), descrito por Espinel-Ingroff (2001), utilizando microorganismos obtenidos del laboratorio de microbologia del departamento de fisiología vegetal del Instituto para Investigación Biológica "Sinisa Stanković" de la Universidad de Belgrado, Servia. Dichas bacterias fueron, Gram-negativas: Escherichia coli (American Type Culture Collection ATCC 11775), Pseudomonas aeruginosa (ATCC 27853), Salmonella typhimurium (ATCC 13311) y Enterobacter cloacae (ATCC 35030), y Gram-positivas: Bacillus cereus (ATCC) 14579), Staphylococcus aureus (ATCC 6538), Micrococcus flavus (ATCC 10240) y Listeria monocytogenes (aislada clínicamente).

Los extractos se redisolvieron en agua $[10 \mathrm{mg} / \mathrm{mL}]$ y diluidos sucesivamente para el análisis, y los cultivos bacterianos fueron ajustados espectrofotométricamente a una concentración de $1 \times 10^{5}$ Unidades formadoras de Colonias (CFU)/mL. Los extractos se añadieron a los pocillos de las placas espectrofotométricas donde se ha adicionado previamente medio de digerido de soja y caseína (TSB) $(100 \mu \mathrm{L})$ y el inoculo bacterial $(10 \mu \mathrm{L})$. Las placas se incubaron por 24 h a $37{ }^{\circ} \mathrm{C}$. Despues la minima concentración de inhibición (MIC) se determinó por el ensayo de viabilidad colorimétrica basado en la reducción del cloruro de yodonitrotetrazolio (INT) $(40 \mu \mathrm{L}[0,2 \mathrm{mg} / \mathrm{mL}])$ el cual fue adicionado en los pocillos después de la incubación según lo descrito por Weinstein (2012). 
Por otro lado, la minima concetración bactericida (MBC) fue determinada por subcultivo serial de la muestra $(10 \mu \mathrm{L})$ en placas espectrofotométricas que contienen TBS $(100 \mu \mathrm{L})$, La concentración más baja de las diluciones seriales en donde no observa crecimiento es considerada entonces como la MBC. Los controles se trataron de la misma manera que las muestras, utilizando $5 \%$ de dimetilsulfoóxido (DMSO) como control negativo y estreptomicina y ampicilina como controles positivos.

\section{III.9.2 Actividad antifungica}

La capacidad antifúngica fue probada en 8 cepas micóticas igualmente proporcionadas por la Universidad de Belgrado. Estos ensayos se ralizaron en: Aspergillus fumigatus (ATCC 1022), Aspergillus ochraceus (ATCC 12066), Aspergillus versicolor (ATCC 11730), Aspergillus niger (ATCC 6275), Penicillium funiculosum (ATCC 36839), Penicillium ochrochloron (ATCC 9112), Penicillium verrucosum var cyclopium (aislada de alimento) y Trichoderma viride (IAM culture collection 5061).

Los micromicetos se mantienen almacenados en agar de malta (MA) a $4{ }^{\circ} \mathrm{C}$ y se subcultivan una vez por mes, antes de su uso, las esporas fúngicas son lavadas con una solución estéril salina $(0,85 \% \mathrm{p} / \mathrm{v})$ que contiene $0,1 \%$ de Tween $80(\mathrm{v} / \mathrm{v})$. Esta suspensión se ajusta hasta lograr una concentranción aproximada de $1,0 \times 10^{5}$ usando un volumen de $100 \mu \mathrm{L}$ por pocillo.

La MIC se realizó mediante la técnica de dilución serial, los inoculos se mezclan con el extracto redisuelto en DMSO (5\% v/v) y se incubaron por $72 \mathrm{~h}$ a $28{ }^{\circ} \mathrm{C}$. La concentración más baja observada al microscopio fue definida como MIC, mientras que la concentración minima fungicida (MFC) fue determinada por subcultivo serial del extracto (2 $\mu \mathrm{L})$ en los pocillos de las placas conteniendo agar de malta $(100 \mu \mathrm{L})$, se incubó por $72 \mathrm{~h}$ a $28{ }^{\circ} \mathrm{C}$, y la concentración mas baja sin visible crecimiento fue definido como MFC, indicando 99,5\% de aniquilación del inóculo. El control positivo fue el uso de bifonazol y ketokonazol, y DMSO (5\%) como control negativo. 


\section{III.9.3 Ensayos capacidad antitumoral}

Los ensayos de capacidad antitumoral fueron evaluados con 5 líneas celulares tumorales humanas: MCF-7 (adenocarcinoma de mama), NCI-H460 (cáncer de pulmón), HCT-15 (carcinoma de colon), HeLa (carcinoma cervical) y HepG2 (carcinoma hepatocelular).

Las células fueron almacenadas como cultivo adherido de células en medio inRPMI-1640, glutamina $(2 \mathrm{mM})$, conteniendo $10 \%$ de suero fetal bovino (FBS) inactivadas por calor en las líneas MCF-7, NCIH460 y HCT-15. Mientras que las líneas celulares HeLa y HepG2, fueron cultivadas en medio de Eagle modificado de Dulbecco (DMEM) suplemenetado con $10 \%$ FBS, glutamina $(2 \mathrm{mM})$, penicilina (100 $\mathrm{U} / \mathrm{mL})$ y estreptomicina $(100 \mathrm{mg} / \mathrm{mL})$. Todas las líneas fueron almacenadas a $37{ }^{\circ} \mathrm{C}$ en un incubador con aire humidificado con contenido de $5 \%$ de $\mathrm{CO}_{2}$.

La metodología empleada fue la descrita por Monks et al. (1991), dejando las líneas celulares adherirse a las placas por $24 \mathrm{~h}$ con densidad celular de 7,5 x $10^{3}$ celulas/pocillo (MCF-7, NCI-H460 y HCT-15) y $1,0 \times 10^{4}$ celulas/pocillo (HeLa y HepG2). Después de este tiempo, las células fueron adicionadas con las distintas concentraciones de las muestras analizadas por $48 \mathrm{~h}$ en incubación. Una vez transcurrido el periodo anterior, los cultivos fueron adheridos con ácido tricloroacetico (TCA, $100 \mu \mathrm{L}[10 \% \mathrm{v} / \mathrm{v}]$ ) e incubadas por 60 minutos a $4{ }^{\circ} \mathrm{C}$. Posteriormente, las placas fueron lavadas con agua destilada y secadas. Una vez alcanzado el secado, se adicionó la solución de sulforrodamina B (SRB, $100 \mu \mathrm{L}, 0,1 \%$ [1\% v/v de ácido acético]), y se incubó por 30 min a temperatura ambiente. Las células no adheridas con SRB se remueven lavando con ácido acético $(1 \% \mathrm{v} / \mathrm{v})$ y las células adheridas se resolubilizan con solución Tris $(200 \mu \mathrm{L}, \mathrm{pH} 7,4[10 \mathrm{mM}])$ y se mide la obsorvancia a $540 \mathrm{~nm}$ para determinar el valor $\mathrm{GI}_{50}$ (concentración de la muestra con la que se inhibe el $50 \%$ del crecimiento celular total). El control positivo utilizado fue el alkaloide Ellipticina. 


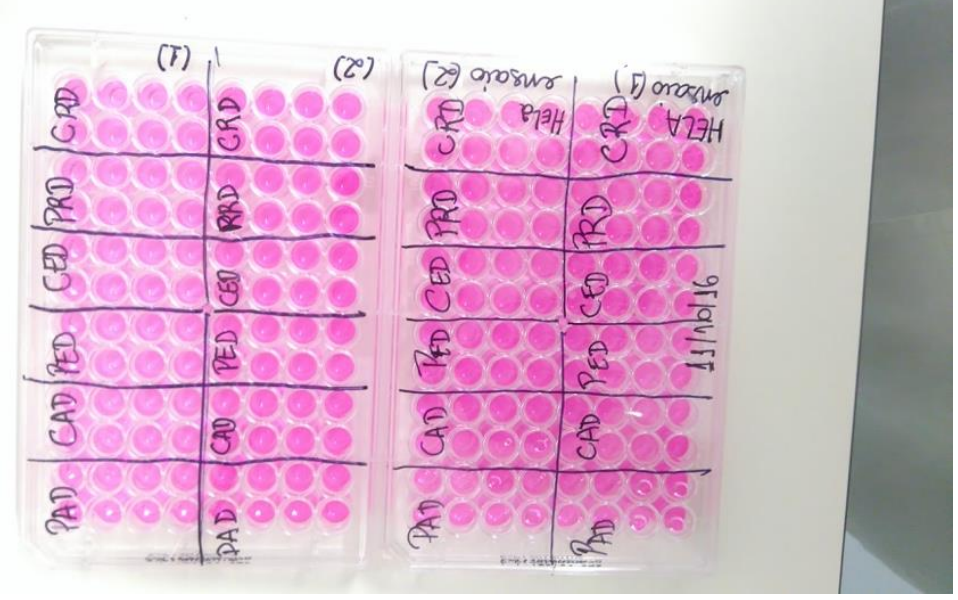

Figure 3-10 SRB bond cell treated with Opuntia samples (source: private collection)

\section{III.9.4 Ensayos de evaluación hepatotoxica}

E1 cultivo celular designado como PLP2, fue preparado a partir de hígado fresco porcino, obtenido localmente. Eal hígado fue enjuagado con solución balanceada salina de Hank, adicionada con suero bovino fetal (FBS) $(10 \% \mathrm{v} / \mathrm{v})$, adicionada con penicilina $(100 \mathrm{U} / \mathrm{mL})$ y estreptomicina $(100 \mu \mathrm{g} / \mathrm{mL})$, el tejido fue posteriormente dividido en dimensiones de $1 \times 1 \mathrm{~mm}^{3}$ del explante, e incubados a $37^{\circ} \mathrm{C}$ en un incubador con aire humidificado con contenido de $5 \%$ de $\mathrm{CO}_{2}$. El medio fue cambiado cada 2-3 dias monitorizándolo con un microscopio de contraste de fases.

Antes de su uso, las células fueron subcultivadas en los pocillos de las placas espectrofotométricas $\left(1,0 \times 10^{4}\right.$ celulas/pocillo) en medio DMEM con FBS $(10 \% \mathrm{v} / \mathrm{v})$, penicilina $(100 \mathrm{u} / \mathrm{mL})$ y estreptomicina $(100 \mu \mathrm{g} / \mathrm{mL})$. Posteriormente las células se tratan con las distintas concentraciones de las muestras por $48 \mathrm{~h}$ y se procede al procedimiento de sulforrodamina $\mathrm{B}$ descrito anteriormente, determinando el valor $\mathrm{GI}_{50}$ y utilizando ellipticina como control positivo. 


\section{III.9.5 Actividad antioxidante por el método de DPPH}

El fundamento consiste en que el radical DPPH tiene un electrón desapareado y es de color azul-violeta, decolorándose hacia amarillo pálido por la reacción en presencia de una sustancia antioxidante, siendo medida espectrofotométricamente a $517 \mathrm{~nm}$. Por diferencia de absorbancia se determina el porcentaje de captación de radical libre DPPH.

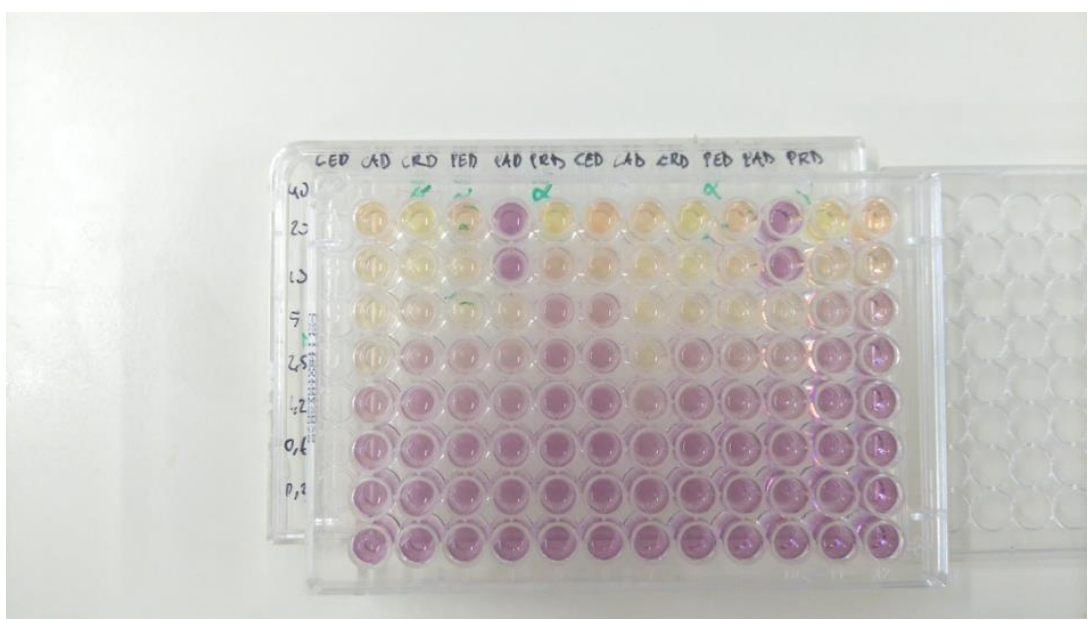

Figure 3-11 DPPH colourimetric assay (source: private collection)

La metodología descrita por Brand-Williams et al. (1995) consiste en confluir el radical DPPH $(60 \mu \mathrm{M}$ en metanol) con las distintas concentraciones de las muestras a evaluar en un ratio 9:1 v/v. Esta mezcla se agita, se mantiene durante 30 minutos reaccionando en obscuridad y se mide su absorbancia a $517 \mathrm{~nm}$. El control negativo es agua y una curva de calibración puede ser utilizada como referencia usando trolox. El resultado se expresa en $\mathrm{IC}_{50}$ y se calcula a partir de la siguiente fórmula interpolando los resultados obtenidos de las distintas concentraciones analizadas.

$$
\% \text { inhibition }=\left(\frac{A B \text { Scontrol }- \text { ABSsample }}{A B S \text { control }}\right) \times 100
$$




\section{III.9.6 Actividad antioxidante por el metodo del poder reductor}

E1 método del poder reductor (ó azul Prusia) descrito por Vieira et al. (2016a), se basa en la capacidad de los compuestos antioxidantes en reducir el $\mathrm{Fe}^{3+}$ en $\mathrm{Fe}^{2+}$, de acuerdo a las siguientes reacciones:

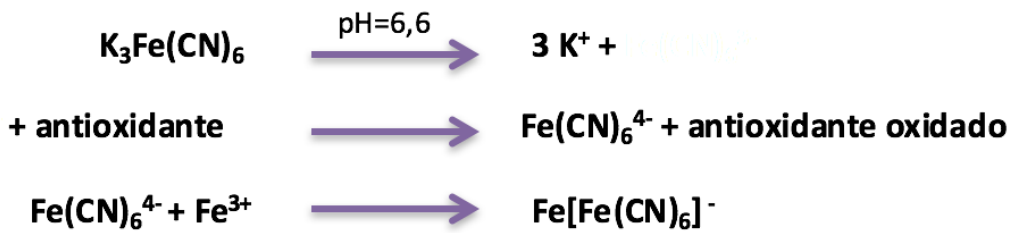

Figure 3-12 Power reduction method chemical reactions (source: private collection)

El procedimiento consiste en mezclar las distintas concentraciones de las muestras $(0,5 \mathrm{~mL})$ con tampón fosfato de sodio $(0,5 \mathrm{~mL}, \mathrm{pH} 6,6$, $200 \mathrm{nM})$, ferrocianato de potasio $(0,5 \mathrm{~mL},[1 \% \mathrm{p} / \mathrm{v}])$ que se incubó a 50 ${ }^{\circ} \mathrm{C}$ durante $20 \mathrm{~min}$.

Posteriormente se detiene la reacción adicionando ácido tricloroacético $(0,5 \mathrm{~mL},[10 \% \mathrm{v} / \mathrm{v}])$, y la mitad del volumen $(0,8 \mathrm{~mL})$ se mezcla con agua $(0,8 \mathrm{~mL})$ y se hace reaccionar adicionando cloruro de hierro $(160 \mu \mathrm{L},[0,1 \% \mathrm{v} / \mathrm{v}])$ y se lee la absorbancia a $690 \mathrm{~nm}$. El control negativo utilizado es agua destilada y el resultado se expresa en $\mathrm{IC}_{50}$. 


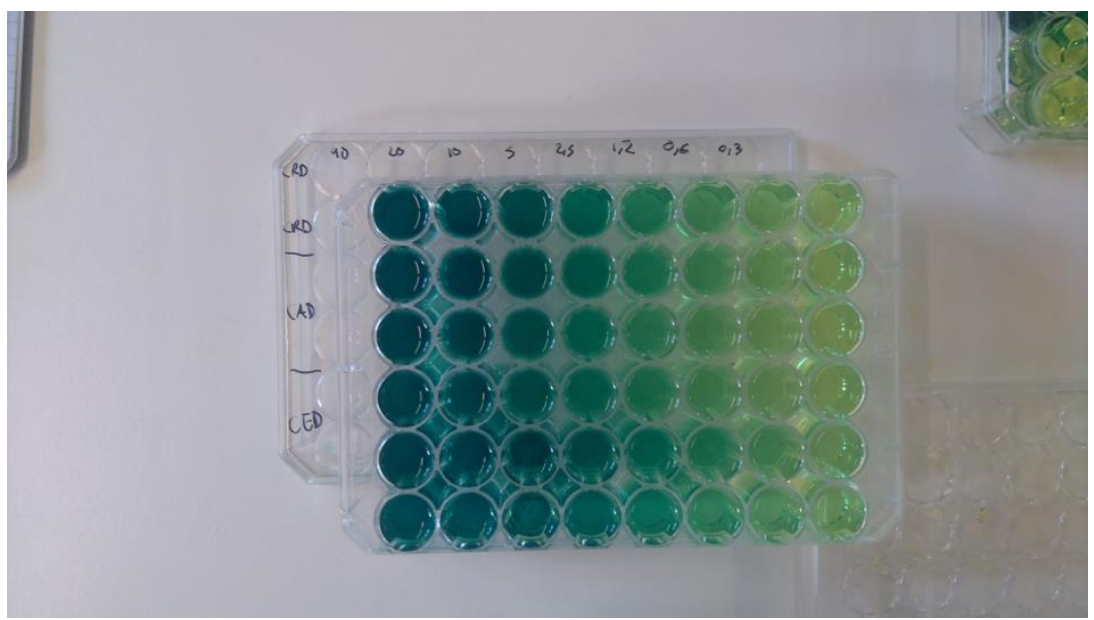

Figure 3-13 Power reduction plate reaction (source: private collection)

\section{III.9.7 Actividad antioxidante por el método de TBARS}

Las sustancias reactivas al ácido tiobarbitúrico (TBARS) es quizá uno de los métodos mas antiguos y utilizados para medir la peroxidación lipídica que termina en malondialdehido (MDA). El MDA forma aductos con 2 moléculas del ácido tiobarbitúrico que produce una especie de color rosado que puede absorbe a $523 \mathrm{~nm}$.

Para obtener este aducto, el método descrito por Devasagayam et al. (2003), indica que para que un espécimen biológico reaccione debe ser calentado. En el laboratorio se utilizó una masa de cerebro de cerdo y el doble de tampón TRIS-HCl $(20$ mM, pH 7,4), y se llevo a agitación. Acto seguido, se centrifugó la suspensión $(3500 \mathrm{~g}, 10 \mathrm{~min})$, de la cual se utilizaron $100 \mu \mathrm{L}$ y se mezcló con las distintas concentraciones de las muestras $(200 \mu \mathrm{L})$, ácido ascórbico $(100 \mu \mathrm{L})$ y sulfato ferroso $(100$ $\mu \mathrm{L}$ ), la mezcla se colocó en un baño a $37,5{ }^{\circ} \mathrm{C}$ durante $1 \mathrm{~h}, \mathrm{y}$ posteriormente se hizo reaccionar con ácido tricloroacético $(500 \mu \mathrm{L}$ $[28 \% \mathrm{v} / \mathrm{v}])$ y ácido tiobarbitúrico $(380 \mu \mathrm{L},[2 \% \mathrm{p} / \mathrm{v}]$ preparado al momento) en un baño a $80^{\circ} \mathrm{C}$ durante $20 \mathrm{~min}$. Esta mezcla se centrifuga $(3500 \mathrm{~g}, 20 \mathrm{~min})$ y se lee la absorbancia a $532 \mathrm{~nm}$.

Para esta determinación se preparan 2 blancos, unos con el solvente de extracción y otro con tampón TRIS-HCl en vez de extracto y se determina el $\mathrm{IC}_{50}$. 


\section{III.9.8 Actividad antioxidante por el método de $\beta$-caroteno}

Esta metodología se basa en los productos formados entre los radicales libres del ácido linoléico y los antioxidantes que protegen al $\beta$-caroteno. El mecanismo de reacción aquí estudiado depende de la decoloración de los carotenoides por calor que induce a la oxidación.

Para la evaluación de la capacidad antioxidante de las muestras se utilizo el método descrito por (Marco, 1968), donde se procede a preparar una emulsión disolviendo el $\beta$-caroteno $(2 \mathrm{mg})$ en $10 \mathrm{~mL}$ de cloroformo, del cual se transfieren solo $2 \mathrm{~mL}$ a un matraz y se evapora el cloroformo a $40{ }^{\circ} \mathrm{C}$, posteriormente se adicionan el ácido linoléico $(40 \mathrm{mg})$, Tween $80(400 \mathrm{mg})$ y agua destilada $(100 \mathrm{~mL})$ y se agita vigorosamente hasta formar la emulsión. De la emulsion obtenida se transfiere $(4,8 \mathrm{~mL})$ a tubos de ensayo donde previamente se adicionaron las distintas concentraciones de las muestras estudiadas ó un blanco (solvente de extracción), se agitan en vortex y se lee la absorbancia a $470 \mathrm{~nm}$. Por último se incuban los tubos en un baño a $50^{\circ} \mathrm{C}$ por $2 \mathrm{~h}$ con agitación constante $(50 \mathrm{rpm})$ y se lee nuevamente la absorbancia una vez transcurrido el tiempo de reacción. El $\mathrm{IC}_{50}$, se calcula apartir de la siguiente formula:

$$
\% \text { inhibition }=\left(\frac{A B S \text { after } 2 h}{A B S \text { initial }}\right) \times 100
$$

Equation 3-6 Inhibition percentage of b-carotene

\section{III.9.9 Actividad antioxidante por el método de ABTS}

Otro método de transferencia de electrón es el brevemente denominado ABTS. En este ensayo el radical catión 2,2'-azino-bis-(3-etilbenzotiazolin-6-ácido-sulfónico) que tiene una coloración azul obscuro, es reducido por la acción del persulfato potásico a incoloro, la oxidación del peroxidisulfato/ABTS sucede de forma estequiometrica 0,5:1, por lo que al combinar ABTS $(7 \mathrm{mM})$ y persulfato $(2,45 \mathrm{mM})$ la reacción no es completada, y la absorbancia de esta reacción es medida a $734 \mathrm{~nm}$. 
Material y métodos

El procedimiento descrito por Devasagayam et al. (2003), comienza con la preparación de la disolución ABTS/persulfato mencionada anteriormente con tampón fosfato ( $\mathrm{pH} 7,4 ;[0,2 \mathrm{M}]$ ) con la finalidad de liberar el radical, por lo que se deja la disolución en obscuridad entre 12-16 h en obscuridad y temperatura ambiente. Después del tiempo necesario, se diluye la solución con tampón fosfato hasta obtener una absorbancia de 0,7 , y a continuación se mezclan $970 \mu \mathrm{L}$ del ABTS con las distintas concentraciones de los extractos $(30 \mu \mathrm{L})$ y se leen las absorbancias a los $6 \mathrm{~min}$ de reacción. El blanco se realiza con el solvente de extracción y el valor $\mathrm{IC}_{50}$, se calcula mediante la siguiente formula:

$$
\% \text { inhibition }=\left(\frac{\text { ABSblank }- \text { ABSsample }}{\text { ABSblank }}\right) \times 100
$$

Equation 3-7 Inhibition percentage of ABTS 


\section{III.10 IDENTIFICACIÓN Y CUANTIFICACIÓN DE BIOCOMPUESTOS}

Para la determinación, identificación y cuantificación de los compuestos con propiedades funcionales, se utilizaron técnicas analíticas, principalmente, cromatografía líquida acoplada a detector de diodos mediante el equipo Dionex Ultimate 3000 UPLC-LTQ XL (ThermoScientific, USA) y a detector de masas de trampa iónica con una fuente de electro-spay (UPLC-DAD-ESI/MS).

Las identificaciones de compuestos se ralizaron mediante la comparación de patrones de fraccionamiento, tiempos de retención y espectros UV-vis de los patrones, siempre que estos eran disponibles, y en caso contrario, comparados con la información científica disponible en la literatura.

La cuantificación fue realizada comparando las curvas de calibración de los patrones disponibles y cuando estos no estaban disponibles, la cuantificación se hizó con los patrones del mismo grupo y los resultados de los compuestos se expresaron en $\mathrm{mg} / \mathrm{g}$ de extracto, mediante el uso del software Xcalibur data system (ThermoFinnigan, USA).

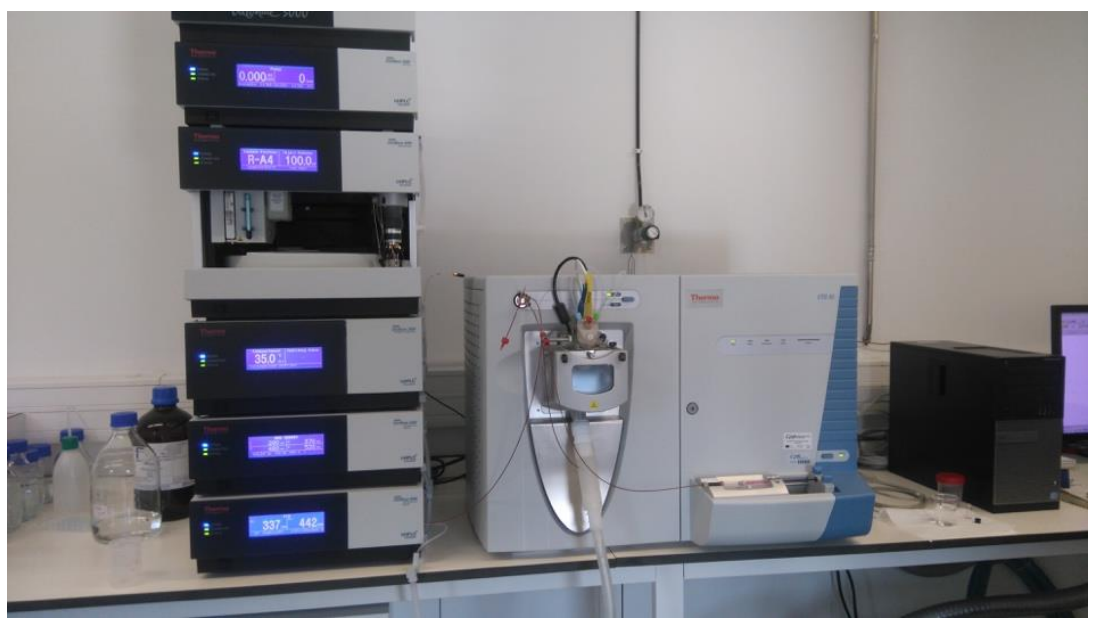

Figure 3-14 UPLC-DAD-Esi/MS system employed (source: private collection) 
El equipo cromatográfico cuenta con bomba cuaternaria, desgasificador y auto-sampler a $5{ }^{\circ} \mathrm{C}$. La separación cromatografica fue llevada a cabo mediante la columan Waters Spherisorb S3 ODS-2C18 (Waters, USA) con tamaño de particula de $3 \mu \mathrm{m}$, diámetro interior de 4,6 $\mathrm{mm}$ y longitud de $150 \mathrm{~mm}$ ó en con una columna Luna C18 (2) con las mismas especificaciones que en la anterior, exceptuando la longitud, la cual en este caso es de $250 \mathrm{~mm}$. Las columnas se mantuvieron en un compartimento termostatado a $35^{\circ} \mathrm{C}$.

\section{III.10.1 Polifenoles y Flavonoides}

Para los compuestos fenólicos se utilizaron las longitudes de onda de 280 y $370 \mathrm{~nm}$ para los polifenoles y flavonoides, respectivamente. Los solventes usados fueron: (A) $0,1 \%$ (v/v) de ácido trifluoroacético (TFA) en agua y (B) acetonitrilo con flujo contante de $0,5 \mathrm{~mL} / \mathrm{min}$, y el gradiente de elución fue el siguiente:

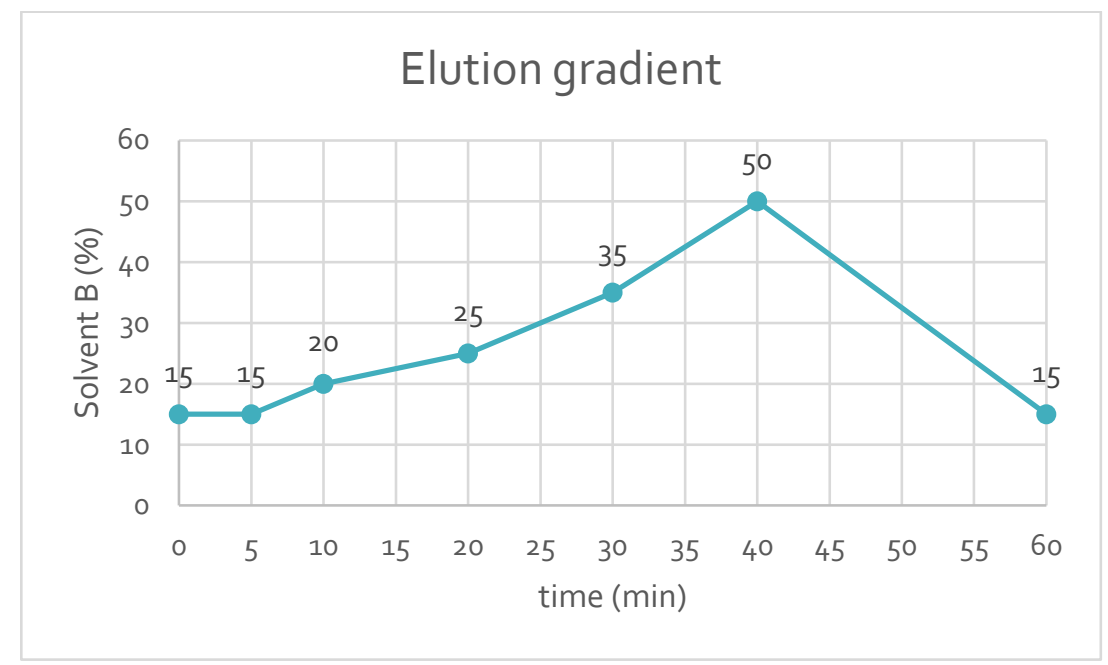

Figure 3-15 Elution gradient of solvent $B$ in phenolics determination (source: private collection)

La detección de masas se realizó en modo negativo, con nitrógeno como gas envolvente (50 psi), el sistema se controló en el voltaje de volatización $(5 \mathrm{kV})$, temperatura $\left(325^{\circ} \mathrm{C}\right)$ y voltaje capilar $(-20 \mathrm{~V})$. El voltaje de las lentes tubulares se mantuvo a $-66 \mathrm{~V}$, la energía de colisión 
usada fue de 35 unidades arbitrarias y el escaneo completo de masas se realizó dentro de los rangos m/z 100-1500.

\section{III.10.2 Betalainas}

Las betalainas se identificaron en las longitudes de onda de 480 y 530 para las betaxantinas y betacianinas, respectivamente, y los solventes empleados fueron: (A) $0,1 \%$ (v/v) de ácido trifluoroacético (TFA) en agua y (B) acetonitrilo a un flujo de $0,5 \mathrm{~mL} / \mathrm{min}$. El gradiente de elución se describe a continuación:

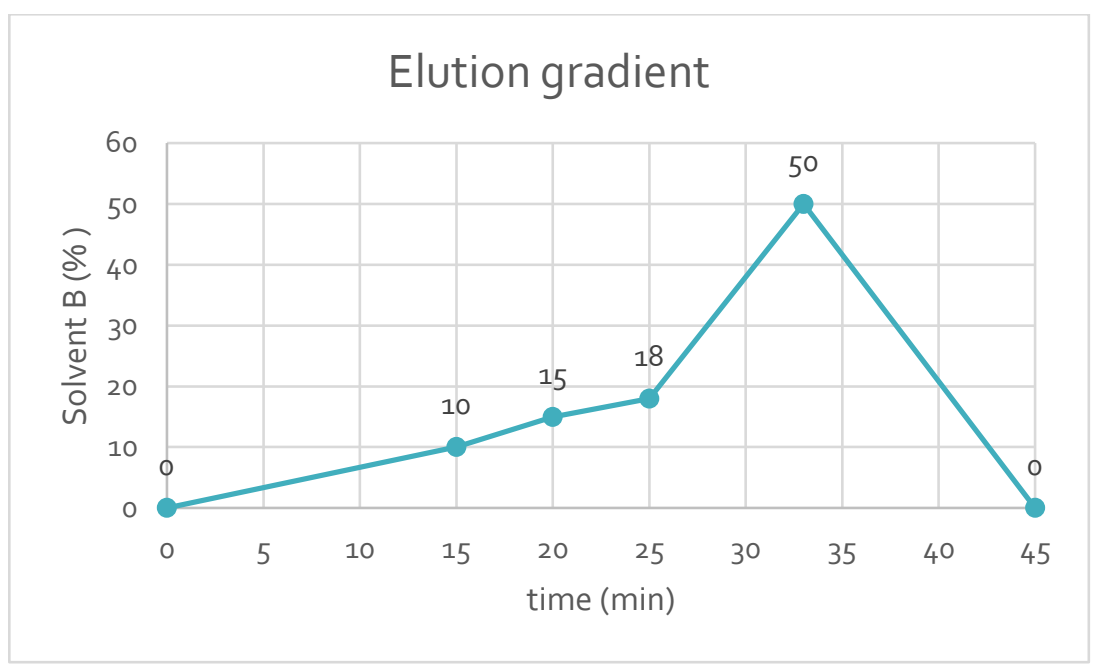

Figure 3-16 Elution gradient of solvent $B$ in betalainic determination (source: private collection)

La detección de masas se realizoó en modo negativo, con nitrógeno como gas envolvente (50 psi), el sistema fue controlado en el voltaje de volatización $(4,8 \mathrm{kV})$, temperatura $\left(320^{\circ} \mathrm{C}\right)$ y voltaje capilar $(39 \mathrm{~V})$. El voltaje de las lentes tubulares se mantuvo a $140 \mathrm{~V}$, la energía de colisión usada fue de 24 unidades arbitrarias y el escaneo completo masas se realizo dentro de los rangos m/z 100-1500 


\section{III.11 DETERMINACIÓN Y MODELIZACIÓN DE ISOTERMAS DE SORCIÓN}

La determinación de las isotermas de adsorción/desorción, se realizó mediante el método estático gravimétrico, el cual consiste en la determinación de la humedad en equilibrio de la muestra en un medioambiente de humedad relativa conocida, lo cual se logra manteniendo las muestras analizadas dentro de una cámara termocontrolada cerrada herméticamente con disoluciones salina saturada de actividad de agua $\left(\mathrm{a}_{\mathrm{w}}\right)$ conocida.

Las sales empleadas utilizadas fueron seleccionadas para cubrir una $\mathrm{a}_{\mathrm{w}}$ en el rango de 0,1 a $0,9\left(\mathrm{LiCl}, \mathrm{MgCl}_{2}, \mathrm{~K}_{2} \mathrm{CO}_{3}, \mathrm{Mg}\left(\mathrm{NO}_{3}\right)_{2}, \mathrm{NaCl}, \mathrm{KCl}\right.$ y $\mathrm{BaCl}_{2}$ ).

Las muestras de adsorción se sometieron a secado a $60{ }^{\circ} \mathrm{C}$ en estufa de vacío para evitar reaciones de caramelización de los azúcares intrínsecos, mientras que para las isotermas de desorción se utilizaron las muestras frescas. La determinación de humedad en equilibrio se llevó a cabo midiendo iterativamente los pesos de las muestras, hasta que estas reportaron peso constante en equilibrio a lo largo del tiempo.

Una vez obtenido el peso constante, se calcula la humedad en equilibrio de los triplicados de las muestras mediante la fórmula:

$$
X b s=\left(\frac{\text { Masa de agua en el equilibrio }}{\text { Masa seca de la muestra }}\right)
$$

Equation 3-8 Moisture equilibrium of the sorption isotherms

Los resultados de Xbs se grafican y modelan. Posteriormente, a través de un software estadístico empleando las expresiones de los modelos de mayor uso y citados en la Tabla 3-2. 
Table 3-2 Common correlation models of sorption Isotherms (Mayor et al., 2013)

\begin{tabular}{|c|c|c|}
\hline Modelo & Expresión & Parámetros \\
\hline BET & $X=\frac{a \cdot b \cdot a_{w}}{\left(1-a_{w}\right) \cdot\left(1+(b-1) \cdot a_{w}\right.}$ & $\begin{array}{l}X \text { : humedad de equilibrio. } \boldsymbol{a} \text { : humedad } \\
\text { del producto correspondiente a una } \\
\text { capa monomolecular de agua } \\
\text { adsorbida. } \boldsymbol{b} \text { : constante característica } \\
\text { del material relacionada con el calor } \\
\text { desprendido en el proceso de sorción }\end{array}$ \\
\hline GAB & $\begin{array}{l}X \\
=\frac{a \cdot b \cdot c \cdot a_{w}}{\left(1-c \cdot a_{w}\right) \cdot\left(1+(b-1) \cdot c \cdot a_{w}\right.}\end{array}$ & $\begin{array}{l}\boldsymbol{X} \text { : humedad de equilibrio. } \boldsymbol{a} \text { : humedad } \\
\text { del producto correspondiente a la } \\
\text { situación en que los puntos de } \\
\text { absorción primarios están saturados } \\
\text { por moléculas de agua b: es la } \\
\text { constante de Guggenheim. } \boldsymbol{c} \text { : factor de } \\
\text { corrección relacionado con el calor de } \\
\text { sorción de la multicapa }\end{array}$ \\
\hline Halsey & $X=\left(-\frac{a}{\ln \left(a_{w}\right)}\right)^{-1 / b}$ & $\begin{array}{l}\text { X: humedad de equilibrio. } \boldsymbol{a} \text { y } \boldsymbol{b} \\
\text { parámetros característicos de cada } \\
\text { isoterma }\end{array}$ \\
\hline Henderson & $X=\left(\frac{\ln \left(1-a_{w}\right)}{a}\right)^{1 / b}$ & $\begin{array}{l}\boldsymbol{X} \text { : humedad de equilibrio. } \boldsymbol{a} \text { y } \boldsymbol{b} \\
\text { parámetros característicos de cada } \\
\text { isoterma }\end{array}$ \\
\hline Oswin & $X=a \cdot \frac{\left(a_{w}\right)^{b}}{1-a_{w}}$ & $\begin{array}{l}\boldsymbol{X} \text { : humedad de equilibrio. } \boldsymbol{a} \text { y } \boldsymbol{b} \\
\text { parámetros característicos de cada } \\
\text { isoterma }\end{array}$ \\
\hline Peleg & $X=a \cdot\left(a_{w}\right)^{b}+c \cdot\left(a_{w}\right)^{d}$ & $\begin{array}{l}\boldsymbol{X} \text { : humedad de equilibrio. } \boldsymbol{a} \text { y } \boldsymbol{b} \\
\text { parámetros característicos de cada } \\
\text { isoterma }\end{array}$ \\
\hline Smith & $X=a-b \cdot \ln \left(1-a_{w}\right)$ & $\begin{array}{l}\boldsymbol{X} \text { : humedad de equilibrio. } \boldsymbol{a} \text { y } \boldsymbol{b} \\
\text { parámetros característicos de cada } \\
\text { isoterma }\end{array}$ \\
\hline
\end{tabular}




\section{III.12 REFERENCES}

Ahn, J.H., Jang, Y.-S., Lee, S.Y., 2016. Production of succinic acid by metabolically engineered microorganisms. Curr. Opin. Biotechnol. 42, 54-66. https://doi.org/10.1016/j.copbio.2016.02.034

Al-Farsi, M.A., Lee, C.Y., 2008. Optimization of phenolics and dietary fibre extraction from date seeds. Food Chem. 108, 977-985. https://doi.org/10.1016/j.foodchem.2007.12.009

Albano, C., Negro, C., Tommasi, N., Gerardi, C., Mita, G., Miceli, A., De Bellis, L., Blando, F., 2015. Betalains, Phenols and Antioxidant Capacity in Cactus Pear [Opuntia ficus-indica (L.) Mill.] Fruits from Apulia (South Italy) Genotypes. Antioxidants 4, 269-280. https://doi.org/10.3390/antiox4020269

Albuquerque, T.G., Santos, F., Sanches-Silva, A., Beatriz Oliveira, M., Bento, A.C., Costa, H.S., 2016. Nutritional and phytochemical composition of Annona cherimola Mill. fruits and by-products: Potential health benefits. Food Chem. 193, 187-195. https://doi.org/10.1016/j.foodchem.2014.06.044

Allai, L., Druart, X., Öztürk, M., BenMoula, A., Nasser, B., El Amiri, B., 2016. Protective effects of Opuntia ficus-indica extract on ram sperm quality, lipid peroxidation and DNA fragmentation during liquid storage. Anim. Reprod. Sci. 175, 1-9. https://doi.org/10.1016/j.anireprosci.2016.09.013

Almeida, M.M.B., de Sousa, P.H.M., Arriaga, Â.M.C., do Prado, G.M., Magalhães, C.E. de C., Maia, G.A., de Lemos, T.L.G., 2011. Bioactive compounds and antioxidant activity of fresh exotic fruits from northeastern Brazil. Food Res. Int. 44, 2155-2159. https://doi.org/10.1016/j.foodres.2011.03.051

Alvarez, B., 2007. Análisis de factibilidad del cultivo de la tuna en la localidad de Icaño, Departamento La Paz, Dirección provincial de programación del desarrollo, Ministerio de Producción y Desarrollo. Gobierno de la Provincia de Catamarca. Catamarca, Argentina.

Alzate T, L.M., González, D., Hincapié, S., Cardona S, B.L., LondoñoLondoño, J., Jiménez-Cartagena, C., 2016. The profile of 
bioactive substances in ten vegetable and fruit by-products from a food supply chain in Colombia. Sustain. Prod. Consum. https://doi.org/10.1016/j.spc.2016.07.005

Ammar, I., Ben Salem, M., Harrabi, B., Mzid, M., Bardaa, S., Sahnoun, Z., Attia, H., Ennouri, M., 2018. Anti-inflammatory activity and phenolic composition of prickly pear (Opuntia ficus-indica) flowers. Ind. Crops Prod. 112, 313-319. https://doi.org/10.1016/j.indcrop.2017.12.028

Angulo-Bejarano, P.I., Martínez-Cruz, O., Paredes-López, O., 2014. Phytochemical Content, Nutraceutical Potential and Biotechnological Applications of an Ancient Mexican Plant: Nopal (Opuntia ficus-indica). Curr. Nutr. Food Sci. 10, 196-217. https://doi.org/10.2174/157340131003140828121015

Arlt, U., 2010. NATCOL | Foods Colours Legislation.

Aruwa, C.E., Amoo, S.O., Kudanga, T., 2018. Opuntia (Cactaceae) plant compounds, biological activities and prospects - A comprehensive review. Food Res. Int. 112, 328-344. https://doi.org/10.1016/j.foodres.2018.06.047

Association of Official Analytical Chemists, 2016. Official Methods of Analysis of AOAC International, 20th ed. The Association, Gaithersburg, MD, USA.

Attokaran, M., 2011. Natural Food Flavors and Colorants Natural Food Flavors and Colorants, 1st ed. Blackwell Publishing LTD, Iowa.

Augustin, M.A., Sanguansri, L., 2015. Challenges and Solutions to Incorporation of Nutraceuticals in Foods. Annu. Rev. Food Sci. Technol. 6, 463-477. https://doi.org/10.1146/annurev-food022814-015507

Ayala-Zavala, J.F., Vega-Vega, V., Rosas-Domínguez, C., PalafoxCarlos, H., Villa-Rodriguez, J.A., Siddiqui, M.W., Dávila-Aviña, J.E., González-Aguilar, G.A., 2011. Agro-industrial potential of exotic fruit byproducts as a source of food additives. Food Res. Int. 44, 1866-1874. https://doi.org/10.1016/j.foodres.2011.02.021

Azeredo, H.M.C., 2009. Betalains: Properties, sources, applications, and stability - A review. Int. J. Food Sci. Technol. 44, 2365-2376. https://doi.org/10.1111/j.1365-2621.2007.01668.x

Balouiri, M., Sadiki, M., Ibnsouda, S.K., 2016. Methods for in vitro evaluating antimicrobial activity: A review. J. Pharm. Anal. 6, 71-79. https://doi.org/10.1016/j.jpha.2015.11.005

Barros, L., Calhelha, R.C., Queiroz, M.J.R.P., Santos-Buelga, C., Santos, E.A., Regis, W.C.B., Ferreira, I.C.F.R., 2015. The 
powerful in vitro bioactivity of Euterpe oleracea Mart. seeds and related phenolic compounds. Ind. Crops Prod. 76, 318-322. https://doi.org/10.1016/j.indcrop.2015.05.086

Barros, L., Pereira, C., Ferreira, I.C.F.R., 2013. Optimized Analysis of Organic Acids in Edible Mushrooms from Portugal by Ultra Fast Liquid Chromatography and Photodiode Array Detection. Food Anal. Methods 6. https://doi.org/10.1007/s12161-012-9443-1

Barrows, J.N., Lipman, A.L., Bailey, C.J., Cianci, S., 2003. Color Additives: FDA's Regulatory Process and Historical Perspectives. Food Saf. Mag. URL https://www.fda.gov/forindustry/coloradditives/regulatoryproces shistoricalperspectives/ (accessed 9.3.18).

Baydar, N.G., Özkan, G., Sağdiç, O., 2004. Total phenolic contents and antibacterial activities of grape (Vitis vinifera L.) extracts. Food Control 15, 335-339. https://doi.org/10.1016/S09567135(03)00083-5

Belščak-Cvitanović, A., Durgo, K., Huđek, A., Bačun-Družina, V., Komes, D., 2018. Metabolism and Health Effects of Polyphenols, in: Galanakis, C.M. (Ed.), Polyphenols: Properties, Recovery, and Applications. Woodhead Publishing, pp. 1-44. https://doi.org/https://doi.org/10.1016/B978-0-12-8135723.00001-4

Belwal, T., Dhyani, P., Bhatt, I.D., Rawal, R.S., Pande, V., 2016. Optimization extraction conditions for improving phenolic content and antioxidant activity in Berberis asiatica fruits using response surface methodology (RSM). Food Chem. 207, 115124. https://doi.org/10.1016/j.foodchem.2016.03.081

Bessada, S.M.F., Barreira, J.C.M., Barros, L., Ferreira, I.C.F.R., Oliveira, M.B.P.P., 2016. Phenolic profile and antioxidant activity of Coleostephus myconis (L.) Rchb.f.: An underexploited and highly disseminated species. Ind. Crops Prod. 89, 45-51. https://doi.org/10.1016/j.indcrop.2016.04.065

Betancourt, C., Cejudo-Bastante, M.J., Heredia, F.J., Hurtado, N., 2017. Pigment composition and antioxidant capacity of betacyanins and betaxanthins fractions of Opuntia dillenii (Ker Gawl) Haw cactus fruit. Food Res. Int. 101, 173-179. https://doi.org/10.1016/j.foodres.2017.09.007

Bhatia, S., Bera, T., Dahiya, R., Bera, T., Bhatia, S., Bera, T., 2015. Classical and Nonclassical Techniques for Secondary Metabolite Production in Plant Cell Culture, in: Modern Applications of Plant Biotechnology in Pharmaceutical Sciences. Elsevier, pp. 231- 
291. https://doi.org/10.1016/B978-0-12-802221-4.00007-8

Brand-Williams, W., Cuvelier, M.E., Berset, C., 1995. Use of a free radical method to evaluate antioxidant activity. LWT - Food Sci. Technol. 28, 25-30. https://doi.org/10.1016/S00236438(95)80008-5

Bravo-Hollis, H., 1978. Las cactaceas de Mexico. Universidad Nacional Autonoma de Mexico, Mexio. https://doi.org/10.15713/ins.mmj.3

Brundtland, G.H., 1987. Our common future.

Cai, Y., Sun, M., Corke, H., 2003. Antioxidant activity of betalains from plants of the Amaranthaceae. J. Agric. Food Chem. 51, 2288-2294. https://doi.org/10.1021/jf030045u

Calderón-Oliver, M., Escalona-Buendía, H.B., Medina-Campos, O.N., Pedraza-Chaverri, J., Pedroza-Islas, R., Ponce-Alquicira, E., 2016. Optimization of the antioxidant and antimicrobial response of the combined effect of nisin and avocado byproducts. LWT Food Sci. Technol. 65, 46-52. https://doi.org/10.1016/j.lwt.2015.07.048

Cardoso-Ugarte, G.A., Sosa-Morales, M.E., Ballard, T., Liceaga, A., San Martín-González, M.F., 2014. Microwave-assisted extraction of betalains from red beet (Beta vulgaris). LWT - Food Sci. Technol. 59, 276-282. https://doi.org/10.1016/j.lwt.2014.05.025

Carocho, M., Ferreira, I.C.F.R., 2013. A review on antioxidants, prooxidants and related controversy: Natural and synthetic compounds, screening and analysis methodologies and future perspectives. Food Chem. Toxicol. 51, 15-25. https://doi.org/10.1016/j.fct.2012.09.021

Carr, M., 2013. The water relations and irrigation requirements of avocado (Persea americana Mill.): a review. Exp. Agric. 49, 256278. https://doi.org/10.1017/S0014479712001317

Cassano, A., Conidi, C., Timpone, R., D’Avella, M., Drioli, E., 2007. A membrane-based process for the clarification and the concentration of the cactus pear juice. J. Food Eng. 80, 914-921. https://doi.org/10.1016/j.jfoodeng.2006.08.005

Castellanos-Santiago, E., Yahia, E.M., 2008. Identification and quantification of betalains from the fruits of 10 Mexican prickly pear cultivars by high-performance liquid chromatography and electrospray ionization mass spectrometry. J. Agric. Food Chem. 56, 5758-5764. https://doi.org/10.1021/jf800362t

Castellar, R., Obón, J.M., Alacid, M., Fernández-López, J.A., 2003. Color Properties and Stability of Betacyanins from Opuntia 
Fruits. J. Agric. Food Chem. 51, 2772-2776. https://doi.org/10.1021/jf021045h

Cejudo Bastante, M.J., Chaalal, M., Louaileche, H., Parrado, J., Heredia, F.J., 2014. Betalain Profile, Phenolic Content, and Color Characterization of Different Parts and Varieties of Opuntia ficusindica. J. Agric. Food Chem. 62, 8491-8499. https://doi.org/10.1021/jf502465g

Chahdoura, H., Barreira, J.C.M., Barros, L., Santos-Buelga, C., Ferreira, I.C.F.R., Achour, L., 2014. Phytochemical characterization and antioxidant activity of Opuntia microdasys (Lehm.) Pfeiff flowers in different stages of maturity. J. Funct. Foods 9, 27-37. https://doi.org/10.1016/j.jff.2014.04.011

Chahdoura, H., Barreira, J.C.M., Fernández-Ruiz, V., Morales, P., Calhelha, R.C., Flamini, G., Soković, M., Ferreira, I.C.F.R., Achour, L., 2016. Bioactivity, proximate, mineral and volatile profiles along the flowering stages of Opuntia microdasys (Lehm.): defining potential applications. Food Funct. 7, 1458-67. https://doi.org/10.1039/c5fo01536g

Chan, L.G., Cohen, J.L., Maria, J., Nobrega, L., Bell, D.M., 2018. Conversion of Agricultural Streams and Food-Processing ByProducts to Value-Added Compounds using Filamentous Fungi. Annu. Rev. Food Sci. Technol. 9, 1-21. https://doi.org/10.1146/annurev-food-030117-012626

Chougui, N., Djerroud, N., Naraoui, F., Hadjal, S., Aliane, K., Zeroual, B., Larbat, R., 2015. Physicochemical properties and storage stability of margarine containing Opuntia ficus-indica peel extract as antioxidant. Food Chem. 173, 382-90. https://doi.org/10.1016/j.foodchem.2014.10.025

Chougui, N., Tamendjari, A., Hamidj, W., Hallal, S., Barras, A., Richard, T., Larbat, R., 2013. Oil composition and characterisation of phenolic compounds of Opuntia ficus-indica seeds. Food Chem. 139, 796-803. https://doi.org/10.1016/j.foodchem.2013.01.054

Clifford, M.N., Johnston, K.L., Knight, S., Kuhnert, N., 2003. Hierarchical Scheme for LC-MSn Identification of Chlorogenic Acids. J. Agric. Food Chem. 51, 2900-2911. https://doi.org/10.1021/jf026187q

Clifford, M.N., Knight, S., Kuhnert, N., 2005. Discriminating between the six isomers of dicaffeoylquinic acid by LC-MSn. J. Agric. Food Chem. 53, 3821-3832. https://doi.org/10.1021/jf050046h

Cowan, A.K., Cripps, R.F., Richings, E.W., Taylor, N.J., 2001. Fruit 
size: Towards an understanding of the metabolic control of fruit growth using avocado as a model system. Physiol. Plant. 111, 127-136. https://doi.org/10.1034/j.1399-3054.2001.1110201.x

Cowan, A.K., Wolstenholme, B.N., 2003. AVOCADOS, in: Encyclopedia of Food Sciences and Nutrition. Elsevier, pp. 348353. https://doi.org/10.1016/B0-12-227055-X/00073-0

Crane, J.H., Balerdi, C.F., Maguire, I., 2016. Avocado Growing in the Florida Home Landscape.

Da-Costa-Rocha, I., Bonnlaender, B., Sievers, H., Pischel, I., Heinrich, M., 2014. Hibiscus sabdariffa L. - A phytochemical and pharmacological review. Food Chem. 165, 424-443. https://doi.org/10.1016/j.foodchem.2014.05.002

da Silva, R.P.F.F., Rocha-Santos, T.A.P., Duarte, A.C., 2016. Supercritical fluid extraction of bioactive compounds. TrAC Trends Anal. Chem. 76, 40-51. https://doi.org/10.1016/j.trac.2015.11.013

Dabas, D., Shegog, R.M., Ziegler, G.R., Lambert, J.D., 2013. Avocado (Persea americana) seed as a source of bioactive phytochemicals. Curr. Pharm. Des. 19, 6133-40. https://doi.org/10.2174/1381612811319340007

Day, L., Seymour, R.B., Pitts, K.F., Konczak, I., Lundin, L., 2009. Incorporation of functional ingredients into foods. Trends Food Sci. Technol. 20 , 388-395. https://doi.org/10.1016/J.TIFS.2008.05.002

DeFelice, S.L., 2002. FIM Rationale And Proposed Guidelines For The Nutraceutical Research \& Education Act - NREA. New York.

Delgado-Vargas, F., Paredes-Lopez, O., 2003. Natural Colorants for Food and Nutraceutical Uses, Trends in Food Science \& Technology. https://doi.org/10.1016/S0924-2244(03)00076-1

Destro dos Santos, C., Külzer Scherer, R., Schilling Cassini, A., Ferreira Marczak, L.D., Tessaro, I.C., 2016. Clarification of red beet stalks extract by microfiltration combined with ultrafiltration. J. Food Eng. 185, 35-41. https://doi.org/10.1016/j.jfoodeng.2016.03.031

Devalaraja, S., Jain, S., Yadav, H., 2011. Exotic fruits as therapeutic complements for diabetes, obesity and metabolic syndrome. Food Res. Int. 44, 1856-1865. https://doi.org/10.1016/j.foodres.2011.04.008

Devasagayam, T.P.A., Boloor, K.K., Ramasarma, T., 2003. Methods for estimating lipid peroxidation: An analysis of merits and demerits. Indian J. Biochem. Biophys. 40, 300-308. 
Dias, M.I., Sousa, M.J., Alves, R.C., Ferreira, I.C.F.R., 2016. Exploring plant tissue culture to improve the production of phenolic compounds: A review. Ind. Crops Prod. 82, 9-22. https://doi.org/10.1016/j.indcrop.2015.12.016

Donkin, R.A., 1977. Spanish Red: An Ethnogeographical Study of Cochineal and the Opuntia Cactus. Trans. Am. Philos. Soc. 67, 184. https://doi.org/10.2307/1006195

Esatbeyoglu, T., Wagner, A.E., Schini-Kerth, V.B., Rimbach, G., 2015a. Betanin--a food colorant with biological activity. Mol. Nutr. Food $\quad$ Res. 59, 36-47. https://doi.org/10.1002/mnfr.201400484

Esatbeyoglu, T., Wagner, A.E., Schini-Kerth, V.B., Rimbach, G., 2015b. Betanin-A food colorant with biological activity. Mol. Nutr. Food $\quad$ Res. 59, 36-47. https://doi.org/10.1002/mnfr.201400484

Espinel-Ingroff, A., 2001. Comparison of the E-test with the NCCLS M38-P method for antifungal susceptibility testing of common and emerging pathogenic filamentous fungi. J. Clin. Microbiol. 39 , 1360-1367. https://doi.org/10.1128/JCM.39.4.13601367.2001

Esquivel, P., 2016. Handbook on Natural Pigments in Food and Beverages Industrial Applications for Improving Food Colorl, in: Carle, R., Schweiggert, R.M. (Eds.), . Woodhead Publishing, San Pedro, Costa Rica, pp. 81-99.

FAO, 2016.

FAOSTAT.

URL http://www.fao.org/faostat/en/?\#data/QC/visualize (accessed 5.3.18).

FAO, 2004. AVOCADO: Post-Harvest Operation. Rome.

FAO, IFAD, WFP, 2015. The State of Food Insecurity in the World. Meeting the 2015 international hunger targets: taking stock of uneven progress. Rome.

Farag, M.A., Maamoun, A.A., Ehrlich, A., Fahmy, S., Wesjohann, L.A., 2017. Assessment of sensory metabolites distribution in 3 cactus Opuntia ficus-indica fruit cultivars using UV fingerprinting and GC/MS profiling techniques. LWT - Food Sci. Technol. 80, 145-154. https://doi.org/10.1016/j.lwt.2017.02.014

Fathordoobady, F., Mirhosseini, H., Selamat, J., Manap, M.Y.A., 2016. Effect of solvent type and ratio on betacyanins and antioxidant activity of extracts from Hylocereus polyrhizus flesh and peel by supercritical fluid extraction and solvent extraction. Food Chem. 202, 70-80. https://doi.org/10.1016/j.foodchem.2016.01.121 
FDA, 2017. SCOGS (Select Committee on GRAS Substances). URL http://www.accessdata.fda.gov/scripts/fdcc/?set=SCOGS (accessed 3.14.17).

FDA, 2007. Guidance for Industry and Other Stakeholders Toxicological Principles for the Safety Assessment of Food Ingredients, Human Studies.

Fernández-López, J. a., Almela, L., 2001. Application of highperformance liquid chromatography to the characterization of the betalain pigments in prickly pear fruits. J. Chromatogr. A 913, 415-420. https://doi.org/10.1016/S0021-9673(00)01224-3

Fernandez-Rojas, B., Ortiz-Moreno, A., Hernandez-Navarro, D., 2010. Phenolic Content and its Antioxidant Activity of Persimmon (Dyospiros kaki L.) Cultivated in Mexico. J. Biotechnol. 150. https://doi.org/10.1016/j.jbiotec.2010.09.289

Ferreira, I.C.F.R., Martins, N., Barros, L., 2017. Phenolic Compounds and Its Bioavailability: In Vitro Bioactive Compounds or Health Promoters? Adv. Food Nutr. Res. 82, 1-44. https://doi.org/10.1016/bs.afnr.2016.12.004

Ferreres, F., Grosso, C., Gil-Izquierdo, A., Valentão, P., Mota, A.T., Andrade, P.B., 2017. Optimization of the recovery of high-value compounds from pitaya fruit by-products using microwaveassisted extraction. Food Chem. 230, 463-474. https://doi.org/10.1016/j.foodchem.2017.03.061

Flores-Valdez, C., Luna-Esquivel, J., Ramirez-Moreno, P., 1995. Manejo postcosecha de la tuna para el mercado nacional e internacional y Procesamiento y transformación industrial. Chapingo, Estado de México.

Galanakis, C.M., 2015. Chapter 3 - The universal recovery strategy, Food Waste Recovery. Elsevier Inc. https://doi.org/10.1016/B978-0-12-800351-0.00003-1

Galanakis, C.M., 2012. Recovery of high added-value components from food wastes: Conventional, emerging technologies and commercialized applications. Trends Food Sci. Technol. 26, 6887. https://doi.org/10.1016/j.tifs.2012.03.003

Gandía-herrero, F., Cabanes, J., Escribano, J., García-carmona, F., Jimenez-atienzar, M., Jiménez-atiénzar, M., 2013. Encapsulation of the most antioxidant betalains in edible matrices as powders of different colors Encapsulation of the most antioxidant betalains in edible matrices as powders of different colors. https://doi.org/10.1021/jf400337g

Gandía-Herrero, F., Escribano, J., García-Carmona, F., 2010. Structural 
implications on color, fluorescence, and antiradical activity in betalains. Planta 232, 449-460. https://doi.org/10.1007/s00425010-1191-0

Garcia-Castello, E.M., Rodriguez-Lopez, A.D., Mayor, L., Ballesteros, R., Conidi, C., Cassano, A., 2015. Optimization of conventional and ultrasound assisted extraction of flavonoids from grapefruit (Citrus paradisi L.) solid wastes. LWT - Food Sci. Technol. 64, 1114-1122. https://doi.org/10.1016/j.lwt.2015.07.024

García-Cruz, L., Dueñas, M., Santos-Buelgas, C., Valle-Guadarrama, S., Salinas-Moreno, Y., 2017. Betalains and phenolic compounds profiling and antioxidant capacity of pitaya (Stenocereus spp.) fruit from two species (S. Pruinosus and S. stellatus). Food Chem. 234, 111-118. https://doi.org/10.1016/j.foodchem.2017.04.174

Gebhardt, D., 2018. The Economics of Natural Color Pigments. URL https://sensientfoodcolors.com/en-us/researchdevelopment/economics-natural-color-pigments/

Ghasemzadeh, A., Ghasemzadeh, N., 2011. Flavonoids and phenolic acids: Role and biochemical activity in plants and human. J. Med. Plants Res. 5, 6697-6703. https://doi.org/10.5897/JMPR11.363

Gomes-Correa, R.C., de Souza, A.H.P., Calhelha, R.C., Barros, L., Glamoclija, J., Sokovic, M., Peralta, R.M., Bracht, A., Ferreira, I.C.F.R., 2015. Bioactive formulations prepared from fruiting bodies and submerged culture mycelia of the Brazilian edible mushroom Pleurotus ostreatoroseus Singer. Food Funct. 6, 21552164. https://doi.org/10.1039/C5FO00465A

Gong, M., Bassi, A., 2016. Carotenoids from microalgae: A review of recent developments. Biotechnol. Adv. 34, 1396-1412. https://doi.org/10.1016/j.biotechadv.2016.10.005

Griffith, M.P., 2004. The origins of an important cactus crop, Opuntia ficus-indica (Cactaceae): New molecular evidence. Am. J. Bot. 91, 1915-1921. https://doi.org/10.3732/ajb.91.11.1915

Guimarães, R., Barros, L., Dueñas, M., Calhelha, R.C., Carvalho, A.M., Santos-Buelga, C., Queiroz, M.J.R.P., Ferreira, I.C.F.R., 2013. Nutrients, phytochemicals and bioactivity of wild Roman chamomile: A comparison between the herb and its preparations. Food Chem. 136, 718-725. https://doi.org/10.1016/j.foodchem.2012.08.025

Guldiken, B., Toydemir, G., Nur Memis, K., Okur, S., Boyacioglu, D., Capanoglu, E., 2016. Home-processed red beetroot (Beta vulgaris L.) products: Changes in antioxidant properties and $\begin{array}{lllll}\text { bioaccessibility. Int. J. } & \text { Mol. } & \text { Sci. } & 17 .\end{array}$ 
https://doi.org/10.3390/ijms 17060858

GVR, 2016. Natural Antioxidants Market Analysis By Product (Vitamin C, Vitamin E, Polyphenols, Carotenoids) And Segment $\begin{array}{llll}\text { Forecasts } & \text { To } 2022 . & \text { URL }\end{array}$ https://www.grandviewresearch.com/industry-analysis/naturalantioxidants-market

Heleno, S.A., Barros, L., Sousa, M.J., Martins, A., Ferreira, I.C.F.R., 2010. Tocopherols composition of Portuguese wild mushrooms with antioxidant capacity. Food Chem. 119, 1443-1450. https://doi.org/10.1016/j.foodchem.2009.09.025

Henry, B.S., 1996. Natural food colours, in: Natural Food Colorants. Springer US, Boston, MA, pp. 40-79. https://doi.org/10.1007/978-1-4615-2155-6_2

Herbach, K.M., Stintzing, F.C., Carle, R., 2006. Betalain stability and degradation - Structural and chromatic aspects. J. Food Sci. 71, 41-50. https://doi.org/10.1111/j.1750-3841.2006.00022.x

Herbach, K.M., Stintzing, F.C., Carle, R., 2005. Identification of heatinduced degradation products from purified betanin, phyllocactin and hylocerenin by high-performance liquid chromatography/ electrospray ionization mass spectrometry. Rapid Commun. Mass Spectrom. 19, 2603-2616. https://doi.org/10.1002/rcm.2103

Hiwasa-Tanase, K., Ezure, H., 2014. Climateric and non-climateric ripening, in: Nath, P., Bouzayen, M., Mattoo, A.K., Pech, J.C. (Eds.), Fruit Ripening: Physiology, Signalling and Genomics. CABI International, pp. 151-177. https://doi.org/10.1017/CBO9781107415324.004

Hogervorst-Cvejić, J., Atanacković-Krstonošić, M., Bursać, M., Miljić, U., 2017. Polyphenols, in: Nutraceutical and Functional Food Components. Academic Press, pp. 203-258. https://doi.org/10.1016/B978-0-12-805257-0.00007-7

Hollman, P.C., Bijsman, M.N., van Gameren, Y., Cnossen, E.P., de Vries, J.H., Katan, M.B., 1999. The sugar moiety is a major determinant of the absorption of dietary flavonoid glycosides in man. Free Radic. Res. 31, 569-573. https://doi.org/10.1080/10715769900301141

Hurtado-Fernández, E., Fernandez-Gutierrez, A., Carrasco-Pancorbo, A., 2018a. Avocado fruit, in: Rodrigues, S., de Oliveira, E., Sousa, E. (Eds.), Exotic Fruits. Academic Press, London, pp. 37-46.

Hurtado-Fernández, E., Pacchiarotta, T., Longueira-Suárez, E., Mayboroda, O.A., Fernández-Gutiérrez, A., Carrasco-Pancorbo, A., 2013. Evaluation of gas chromatography-atmospheric 
pressure chemical ionization-mass spectrometry as an alternative to gas chromatography-electron ionization-mass spectrometry: Avocado fruit as example. J. Chromatogr. A 1313, 228-244. https://doi.org/10.1016/j.chroma.2013.08.084

Hurtado-Fernández, E., Pacchiarotta, T., Mayboroda, O.A., FernándezGutiérrez, A., Carrasco-Pancorbo, A., 2014. Quantitative characterization of important metabolites of avocado fruit by gas chromatography coupled to different detectors (APCI-TOF MS and FID). Food Res. Int. 62, 801-811. https://doi.org/10.1016/j.foodres.2014.04.038

Hussain, Z., Thu, H.E., Amjad, M.W., Hussain, F., Ahmed, T.A., Khan, S., 2017. Exploring recent developments to improve antioxidant, anti-inflammatory and antimicrobial efficacy of curcumin: A review of new trends and future perspectives. Mater. Sci. Eng. C. https://doi.org/10.1016/j.msec.2017.03.226

IFIC, FDA, 2010. Overview of Food Ingredients, Additives and Colors. URL

https://www.fda.gov/food/ingredientspackaginglabeling/foodadd itivesingredients/ucm094211.htm

Inglese, P., Giugliuzza, G., Liguori, G., 2004. Cactus pear fruit production: from knowledge to development, in: Esparza-Frausto, G., Valdez-Cepeda, R.D., Méndez- Gallego, S.J. (Eds.), El Nopal.Tópicos de Actualidad. Universidad Autónoma de Chapingo. Colegio de Postgraduados, México, pp. 89-108.

IUPAC, IUPAC-IUB, 1976. Nomenclature of cyclitols. Biochem. J. 153, 23-31. https://doi.org/10.1351/pac197437010283

Jain, G., Gould, K.S., 2015. Are betalain pigments the functional homologues of anthocyanins in plants? Environ. Exp. Bot. 119, 48-53. https://doi.org/10.1016/J.ENVEXPBOT.2015.06.002

Jain, T., Grover, K., Kaur, G., 2016. Effect of processing on nutrients and fatty acid composition of garden cress (Lepidium sativum) seeds. Food Chem. 213, 806-812. https://doi.org/10.1016/j.foodchem.2016.07.034

Jimenez-Garcia, S.N., Vazquez-Cruz, M.A., Garcia-Mier, L., Contreras-Medina, L.M., Guevara-González, R.G., Garcia-Trejo, J.F., Feregrino-Perez, A.A., 2018. Phytochemical and Pharmacological Properties of Secondary Metabolites in Berries, in: Therapeutic Foods. Elsevier, pp. 397-427. https://doi.org/10.1016/B978-0-12-811517-6.00013-1

Kaderides, K., Goula, A.M., 2017. Development and characterization of a new encapsulating agent from orange juice by-products. Food 
Res. Int. 0-1. https://doi.org/10.1016/j.foodres.2017.07.057

Kanner, J., Harel, S., Granit, R., 2001. Betalains - A new class of dietary cationized antioxidants. J. Agric. Food Chem. 49, 51785185. https://doi.org/10.1021/jf010456f

Karamac, M., Estrella, I., Herna, T., Dykes, G. a., Kosińska, A., Karamać, M., Estrella, I., Hernández, T., Bartolomé, B., Dykes, G. a., 2012. Phenolic compound profiles and antioxidant capacity of Persea americana Mill. peels and seeds of two varieties. J. Agric. Food Chem. 60, 4613-4619. https://doi.org/10.1021/jf300090p

Katsube, T., Tsurunaga, Y., Sugiyama, M., Furuno, T., Yamasaki, Y., 2009. Effect of air-drying temperature on antioxidant capacity and stability of polyphenolic compounds in mulberry (Morus alba L.) leaves. Food Chem. 113, 964-969. https://doi.org/10.1016/j.foodchem.2008.08.041

Kaur Kala, H., Mehta, R., Tandey, R., Sen, K.K., Mandal, V., 2016. Ten years of research on phenolics (2005-2015): A status report. Pacific Sci. Rev. A Nat. Sci. Eng. https://doi.org/10.1016/j.psra.2016.07.002

Knight, R.J., Campbell, C.W., 1999. Ecological adaptation and the evolution of modern avocado cultivars. Rev. Chapingo Ser. Hortic. 49-54.

Kosińska, A., Karamać, M., Estrella, I., Hernández, T., Bartolomé, B., Dykes, G.A., 2012. Phenolic compound profiles and antioxidant capacity of persea americana mill. peels and seeds of two varieties. J. Agric. Food Chem. 60, 4613-4619. https://doi.org/10.1021/jf300090p

Kris-Etherton, P.M., Hecker, K.D., Bonanome, A., Coval, S.M., Binkoski, A.E., Hilpert, K.F., Griel, A.E., Etherton, T.D., 2002. Bioactive compounds in foods: their role in the prevention of cardiovascular disease and cancer. Am. J. Med. 113, 71-88. https://doi.org/10.1016/S0002-9343(01)00995-0

Kuhnle, G.G., 2012. Nutritional biomarkers for objective dietary assessment. J. Sci. Food Agric. 92, 1145-1149. https://doi.org/10.1002/jsfa.5631

Kuti, J.O., 2004. Antioxidant compounds from four Opuntia cactus pear fruit varieties. Food Chem. 85, 527-533. https://doi.org/10.1016/S0308-8146(03)00184-5

Kyriacou, M.C., Emmanouilidou, M.G., Soteriou, G.A., 2016. Asynchronous ripening behavior of cactus pear (Opuntia ficusindica) cultivars with respect to physicochemical and 
physiological attributes. Food Chem. 211, 598-607. https://doi.org/10.1016/j.foodchem.2016.05.113

Laqui-Vilca, C., Aguilar-Tuesta, S., Mamani-Navarro, W., Montaño-

Bustamante, J., Condezo-Hoyos, L., 2018. Ultrasound-assisted optimal extraction and thermal stability of betalains from colored quinoa (Chenopodium quinoa Willd) hulls. Ind. Crops Prod. 111, 606-614. https://doi.org/10.1016/j.indcrop.2017.11.034

Lea, A., 2008. Analysis of polyphenol antioxidants in fortified foods and supplements. Food Fortif. Suppl. 175-194. https://doi.org/10.1533/9781845694265.2.175

Leardi, R., 2013. Experimental Design, 1st ed, Data Handling in Science and Technology. Copyright (C) 2013 Elsevier B.V. All rights reserved. https://doi.org/10.1016/B978-0-444-595287.00002-8

Li, J., Chen, Z., Di, D., 2012. Preparative separation and purification of Rebaudioside A from Stevia rebaudiana Bertoni crude extracts by mixed bed of macroporous adsorption resins. Food Chem. 132, 268-276. https://doi.org/10.1016/j.foodchem.2011.10.077

M. Librán, C., Mayor, L., M. Garcia-Castello, E., Vidal-Brotons, D., 2013. Polyphenol extraction from grape wastes: Solvent and $\mathrm{pH}$ effect. Agric. Sci. 04, 56-62. https://doi.org/10.4236/as.2013.49B010

Madrau, M. a., Piscopo, A., Sanguinetti, A.M., Del Caro, A., Poiana, M., Romeo, F. V., Piga, A., 2009. Effect of drying temperature on polyphenolic content and antioxidant activity of apricots. Eur. Food Res. Technol. 228, 441-448. https://doi.org/10.1007/s00217-008-0951-6

Madunić, J., Madunić, I.V., Gajski, G., Popić, J., Garaj-Vrhovac, V., 2018. Apigenin: A dietary flavonoid with diverse anticancer properties. Cancer Lett. 413, 11-22. https://doi.org/10.1016/j.canlet.2017.10.041

Manach, C., Scalbert, A., Morand, C., Rémésy, C., Jiménez, L., 2004. Bioavailability, Polyphenols: Food sources and. Am. J. Clin. Nutr. 79, 727-747. https://doi.org/10.1038/nature05488

Mandal, S.C., Mandal, V., Das, A.K., 2015. Classification of Extraction Methods, in: Essentials of Botanical Extraction. Academic Press, pp. 83-136. https://doi.org/10.1016/B978-0-12-802325-9.000069

Marais, J.P.J., Deavours, B., Dixon, R.A., Ferreira, D., 2006. The science of flavonoids, The Science of Flavonoids. Springer, Ohio. https://doi.org/10.1007/978-0-387-28822-2 
Marco, G.J., 1968. A Rapid Method for Evaluation of Antioxidants. J. Am. oil Chem. Soc. 45, 594-598. https://doi.org/10.1007/BF02668958

Maria, J., Andrade, D.M., Fasolo, D., 2014. Polyphenol Antioxidants from Natural Sources and Contribution to Health Promotion, Polyphenols in Human Health and Disease. Elsevier Inc. https://doi.org/10.1016/B978-0-12-398456-2.00020-7

Martins, N., Roriz, C.L., Morales, P., Barros, L., Ferreira, I.C.F.R., 2016. Food colorants: Challenges, opportunities and current desires of agro-industries to ensure consumer expectations and regulatory practices. Trends Food Sci. Technol. 52, 1-15. https://doi.org/10.1016/j.tifs.2016.03.009

Mata, A., Ferreira, J.P., Semedo, C., Serra, T., Duarte, C.M.M., Bronze, M.R., 2016. Contribution to the characterization of Opuntia spp. juices by LC-DAD-ESI-MS/MS. Food Chem. 210, 558-565. https://doi.org/10.1016/j.foodchem.2016.04.033

Mayor, L., Calvo, A., Moreira, R., Fito, P., Garcia-Castello, E., 2013. Water sorption isotherms of globe artichoke leaves. Agric. Sci. 04, 63-69. https://doi.org/10.4236/as.2013.49B011

McGuire, S., 2011. U.S. Department of Agriculture and U.S. Department of Health and Human Services, Dietary Guidelines for Americans, 2010. 7th Edition, Washington, DC: U.S. Government Printing Office, January 2011. Adv. Nutr. 2, 293294. https://doi.org/10.3945/an.111.000430

Medina-Meza, I.G., Barbosa-Cánovas, G. V., 2015. Assisted extraction of bioactive compounds from plum and grape peels by ultrasonics and pulsed electric fields. J. Food Eng. 166, 268-275. https://doi.org/10.1016/j.jfoodeng.2015.06.012

Melgar, B., Dias, M.I., Ciric, A., Sokovic, M., Garcia-Castello, E.M., Rodriguez-Lopez, A.D., Barros, L., Ferreira, I., 2017a. Byproduct recovery of Opuntia spp. peels: Betalainic and phenolic profiles and bioactive properties. https://doi.org/10.1016/j.indcrop.2017.06.011

Melgar, B., Pereira, E., Oliveira, M.B.P.P., Garcia-Castello, E.M., Rodriguez-Lopez, A.D., Sokovic, M., Barros, L., Ferreira, I.C.F.R., 2017b. Extensive profiling of three varieties of Opuntia spp. fruit for innovative food ingredients. Food Res. Int. 101, 259265. https://doi.org/10.1016/j.foodres.2017.09.024

Mena, P., Tassotti, M., Andreu, L., Nuncio-Jáuregui, N., Legua, P., Del Rio, D., Hernández, F., 2018. Phytochemical characterization of different prickly pear (Opuntia ficus-indica (L.) Mill.) cultivars 
and botanical parts: UHPLC-ESI-MSnmetabolomics profiles and their chemometric analysis. Food Res. Int. 108, 301-308. https://doi.org/10.1016/j.foodres.2018.03.062

Mirabella, N., Castellani, V., Sala, S., 2014. Current options for the valorization of food manufacturing waste: a review. J. Clean. Prod. 65 , $28-41$. https://doi.org/10.1016/J.JCLEPRO.2013.10.051

Mishra, A., Sharma, A.K., Kumar, S., Saxena, A.K., Pandey, A.K., 2013. Bauhinia variegata leaf extracts exhibit considerable antibacterial, antioxidant, and anticancer activities. Biomed Res. Int. 2013. https://doi.org/10.1155/2013/915436

Mishra, A.K., Mishra, A., Kehri, H.K., Sharma, B., Pandey, A.K., 2009. Inhibitory activity of Indian spice plant Cinnamomum zeylanicum extracts against Alternaria solani and Curvularia lunata, the pathogenic dematiaceous moulds. Ann. Clin. Microbiol. Antimicrob. 8, 9. https://doi.org/10.1186/1476-07118-9

Monks, A., Scudiero, D., Skehan, P., Shoemaker, R., Paull, K., Vistica, D., Hose, C., Langley, J., Cronise, P., Vaigro-wolff, A., Graygoodrich, M., Campbell, H., Boyd, M., 1991. Feasibility of a High-Flux Anticancer Drug Screen Using a Diverse Panel of Cultured. J. Natl. Cancer Inst. 83, 757-766.

Morales, P., Barros, L., Ramírez-Moreno, E., Santos-Buelga, C., Ferreira, I.C.F.R., 2015. Xoconostle fruit (Opuntia matudae Scheinvar cv. Rosa) by-products as potential functional ingredients. Food Chem. 185, 289-97. https://doi.org/10.1016/j.foodchem.2015.04.012

Morales, P., Barros, L., Ramírez-Moreno, E., Santos-Buelga, C., Ferreira, I.C.F.R., 2014. Exploring xoconostle by-products as sources of bioactive compounds. Food Res. Int. 65, 437-444. https://doi.org/10.1016/j.foodres.2014.05.067

Morales, P., Ramírez-Moreno, E., Sanchez-Mata, M.D.C., Carvalho, A.M., Ferreira, I.C.F.R., 2012. Nutritional and antioxidant properties of pulp and seeds of two xoconostle cultivars (Opuntia joconostle F.A.C. Weber ex Diguet and Opuntia matudae Scheinvar) of high consumption in Mexico. Food Res. Int. 46. https://doi.org/10.1016/j.foodres.2011.12.031

Moreno, J., Peinado, R., 2012. Polyphenols, in: Moreno, J., Peinado, R. (Eds.), Enological Chemistry. Academic Press, pp. 53-76. https://doi.org/10.1016/B978-0-12-388438-1.00005-4

Naik, S.N., Goud, V. V., Rout, P.K., Dalai, A.K., 2010. Production of 
first and second generation biofuels: A comprehensive review. Renew. Sustain. Energy Rev. 14, 578-597. https://doi.org/10.1016/j.rser.2009.10.003

Nicoletti, M., 2012. Nutraceuticals and botanicals: overview and perspectives. Int. J. Food Sci. Nutr. 63, 2-6. https://doi.org/10.3109/09637486.2011.628012

$\mathrm{NIH}$, 2017. Vitamin E - Fact sheet for Consumer. URL https://ods.od.nih.gov/factsheets/VitaminE-Consumer/ (accessed 3.14.17).

Nobel, P.S., 1998. Los incomparables agaves y cactos. Trillas, México. Novoa, A., Le Roux, J.J., Robertson, M.P., Wilson, J.R.U., Richardson, D.M., 2015. Introduced and invasive cactus species: A global review. AoB Plants 7. https://doi.org/10.1093/aobpla/plu078

Ochoa, M. judith, Barbera, G., 2017. History and economic and agroecological importance, in: Crop Ecology, Cultivation and Uses of Catus Pears. FAO, ICARDA, pp. 1-11.

Osborn, S., 2015. 12 - Labelling relating to natural ingredients and additives, in: Advances in Food and Beverage Labelling. pp. 207221. https://doi.org/10.1533/9781782420934.3.207

Paciulli, M., Medina-Meza, I.G., Chiavaro, E., Barbosa-Cánovas, G.V., 2016. Impact of thermal and high pressure processing on quality parameters of beetroot (Beta vulgaris L.). LWT - Food Sci. Technol. 68, 98-104. https://doi.org/10.1016/j.lwt.2015.12.029

Patel, D., Shukla, S., Gupta, S., 2007. Apigenin and cancer chemoprevention: Progress, potential and promise (Review). Int. J. Oncol. 30, 233-245. https://doi.org/10.3892/ijo.30.1.233

Pedreño, M.A., Escribano, J., 2000. Studying the oxidation and the antiradical activity of betalain from beetroot. J. Biol. Educ. 35, 49-51. https://doi.org/10.1080/00219266.2000.9655736

Peláez-Cid, a. a., Velázquez-Ugalde, I., Herrera-González, a. M., García-Serrano, J., 2013. Textile dyes removal from aqueous solution using Opuntia ficus-indica fruit waste as adsorbent and its characterization. J. Environ. Manage. 130, 90-97. https://doi.org/10.1016/j.jenvman.2013.08.059

Pereira, C., Barros, L., Carvalho, A.M., Ferreira, I.C.F.R., 2011. Nutritional composition and bioactive properties of commonly consumed wild greens: Potential sources for new trends in modern diets. Food Res. Int. 44, 2634-2640. https://doi.org/10.1016/j.foodres.2011.05.012

Pereira, E., Barros, L., Calhelha, R.C., Duenas, M., Carvalho, A.M., Santos-Buelga, C., Ferreira, I.C.F.R., 2014. Bioactivity and 
phytochemical characterization of Arenaria montana L. Food Funct. 5, 1848-1855. https://doi.org/10.1039/c4fo00210e

Pereira, E., Barros, L., Martins, A., Ferreira, I.C.F.R., 2012. Towards chemical and nutritional inventory of Portuguese wild edible mushrooms in different habitats. Food Chem. 130, 394-403. https://doi.org/10.1016/j.foodchem.2011.07.057

Piattelli, M., Minale, L., Prota, G., 1964. Isolation, structure and absolute configuration of indicaxanthin. Tetrahedron 20, 23252329. https://doi.org/10.1016/S0040-4020(01)97621-5

Pimienta, E., 1990. El nopal tunero. Libros de tiempos de ciencia ;5.

Pimiento Barrios, E., Munoz-Urias, A., 1999. Domesticacion de nopales tuneros (Opuntis spp.) y descripcion de las principales variedades cultivadas. FAO, Rome (Italy).

Pinela, J., Prieto, M.A., Barreiro, M.F., Carvalho, A.M., Oliveira, M.B.P.P., Vázquez, J.A., Ferreira, I.C.F.R., 2016. Optimization of microwave-assisted extraction of hydrophilic and lipophilic antioxidants from a surplus tomato crop by response surface methodology. Food Bioprod. Process. 98, 283-298. https://doi.org/10.1016/j.fbp.2016.02.002

Primorac, T., Požar, M., Sokolić, F., Zoranić, L., Urbic, T., 2018. A simple two dimensional model of methanol. J. Mol. Liq. 262, 4657. https://doi.org/10.1016/j.molliq.2018.04.055

Quideau, S., Deffieux, D., Douat-Casassus, C., Pouysegu, L., 2011. Plant polyphenols: chemical properties, biological activities, and synthesis. Angew. Chem. Int. Ed. Engl. 50, 586-621. https://doi.org/10.1002/anie.201000044

Rached, W., Calhelha, R.C., Fernandes, Â., Carvalho, A.M., Bennaceur, M., Marouf, A., Barros, L., Santos-Buelga, C., Ferreira, I.C.F.R., 2016. Phytochemical characterization and bioactive properties of Osyris quadripartita Salzm. ex Decne. leaves from Algeria. RSC Adv. 6, 72768-72776. https://doi.org/10.1039/C6RA11787B

Ramos-Jerz, M.D.R., Villanueva, S., Jerz, G., Winterhalter, P., Deters, A.M., 2013. Persea americana Mill. Seed: Fractionation, Characterization, and Effects on Human Keratinocytes and Fibroblasts. Evidence-based Complement. Altern. Med. eCAM 2013, 391247. https://doi.org/10.1155/2013/391247

Rao, G., 2010. Optimization of ultrasound-assisted extraction of cyanidin 3-rutinoside from litchi (Lichi chinensis Sonn.) fruit pericarp. Anal. Methods 2, 1166. https://doi.org/10.1039/c0ay00203h 
Ravichandran, K., Saw, N.M.M.T., Mohdaly, A.A.A., Gabr, A.M.M., Kastell, A., Riedel, H., Cai, Z., Knorr, D., Smetanska, I., 2013. Impact of processing of red beet on betalain content and antioxidant activity. Food Res. Int. 50, 670-675. https://doi.org/10.1016/j.foodres.2011.07.002

Raymond Chia, T.W., Dykes, G. a, 2010. Antimicrobial activity of crude epicarp and seed extracts from mature avocado fruit (Persea americana) of three cultivars. Pharm. Biol. 48, 753-756. https://doi.org/10.3109/13880200903273922

Reis, F.S., Barreira, J.C.M., Calhelha, R.C., van Griensven, L.J.I.D., Ćirić, A., Glamočlija, J., Soković, M., Ferreira, I.C.F.R., 2014. Chemical characterization of the medicinal mushroom Phellinus linteus (Berkeley \& Curtis) Teng and contribution of different fractions to its bioactivity. LWT - Food Sci. Technol. 58, 478485. https://doi.org/10.1016/j.lwt.2014.04.013

Reyes-Agüero, J.A., Aguirre, J.R., Hernández, H., 2005. Systematyc notes and a Detailed description of Opuntia ficus-indica (L) Mill. (CACTACEAE). Agrociencia 39, 395-408.

Reynolds, S.G., Arias, E., 2003. Opuntia Spp. -A Strategic fodder and efficient tool for combat desertification in the Wana Region, Cactus (Opuntia spp.) as forage. FAO Plant Production and Protection Paper 169.

Roberfroid, M.B., 2000. Concepts and strategy of functional food science: the European perspective. Am. J. Clin. Nutr. 71, 1660S4S; $\quad$ discussion

1674S-5S. https://doi.org/10.1093/ajen/71.6.1660S

Rodrigo, D., Martínez-1, A., 2015. Antimicrobial activity of cauli fl ower (Brassica oleracea var. Botrytis) by-product against Listeria monocytogenes 50, 435-440. https://doi.org/10.1016/j.foodcont.2014.09.031

Rodríguez-Carpena, J.G., Morcuende, D., Estévez, M., 2011. Avocado by-products as inhibitors of color deterioration and lipid and protein oxidation in raw porcine patties subjected to chilled storage. Meat Sci. 89, 166-173. https://doi.org/10.1016/j.meatsci.2011.04.013

Rohwer, J.G., 1993. Lauraceae, in: The Families and Genera of Vascular Plants Free Preview, Volume II, Flowering Plants . Dicotyledons. Springer, Berlin, pp. 366-391. https://doi.org/10.1007/978-3-662-02899-5

Roriz, C.L., Barros, L., Prieto, M.A., Morales, P., Ferreira, I.C.F.R., 2017. Floral parts of Gomphrena globosa L. as a novel alternative 
source of betacyanins: Optimization of the extraction using response surface methodology. Food Chem. 229, 223-234. https://doi.org/10.1016/j.foodchem.2017.02.073

Saavedra, J., Córdova, A., Navarro, R., Díaz-Calderón, P., Fuentealba, C., Astudillo-Castro, C., Toledo, L., Enrione, J., Galvez, L., 2017. Industrial avocado waste: Functional compounds preservation by convective drying process. J. Food Eng. 198, 81-90. https://doi.org/10.1016/j.jfoodeng.2016.11.018

Sáenz, C., 2006. Utilización agroindustrial del nopal. Boletín Serv. Agrícolas La Fao 162, 165.

SAGARPA, 2011. Monografía de cultivos. Aguacate. México city.

Sansano, S., Rivas, A., Pina-Pérez, M.C., Martinez, A., Rodrigo, D., 2017. Stevia rebaudiana Bertoni effect on the hemolytic potential of Listeria monocytogenes, International Journal of Food Microbiology. https://doi.org/10.1016/j.ijfoodmicro.2017.03.006

SARAVACOS, G.D., 2014. Mass Transfer Properties of Foods 346399. https://doi.org/10.1201/9781420028805-11

Sawicki, T., Wiczkowski, W., 2018. The effects of boiling and fermentation on betalain profiles and antioxidant capacities of red beetroot products. Food Chem. 259, 292-303. https://doi.org/10.1016/j.foodchem.2018.03.143

Shahidi, F., Ambigaipalan, P., 2015. Phenolics and polyphenolics in foods, beverages and spices: Antioxidant activity and health effects - A review. J. Funct. Foods. https://doi.org/10.1016/j.jff.2015.06.018

Sharma, K., Mahato, N., Cho, M.H., Lee, Y.R., 2017. Converting citrus wastes into value-added products: Economic and environmently friendly approaches. Nutrition 34, 29-46. https://doi.org/10.1016/j.nut.2016.09.006

Šiler, B., Živković, S., Banjanac, T., Cvetković, J., Nestorović Živković, J., Ćirić, A., Soković, M., Mišić, D., 2014. Centauries as underestimated food additives: Antioxidant and antimicrobial potential. Food Chem. 147, 367-376. https://doi.org/10.1016/j.foodchem.2013.10.007

Silva, P., Ferreira, S., Nunes, F.M., 2016. Elderberry (Sambucus nigra L.) by-products a source of anthocyanins and antioxidant polyphenols. Ind. Crops Prod. https://doi.org/10.1016/j.indcrop.2016.10.018

Singleton, V.L., Rossi, J.A., 1965. Colorimetry of Total Phenolics with Phosphomolybdic-Phosphotungstic Acid Reagents. Am. J. Enol. Vitic. 16, 144-158. https://doi.org/10.12691/ijebb-2-1-5 
Song, F.L., Gan, R.Y., Zhang, Y., Xiao, Q., Kuang, L., Li, H. Bin, 2010. Total phenolic contents and antioxidant capacities of selected chinese medicinal plants. Int. J. Mol. Sci. 11, 2362-2372. https://doi.org/10.3390/ijms11062362

Spórna-Kucab, A., Ignatova, S., Garrard, I., Wybraniec, S., 2013. Versatile solvent systems for the separation of betalains from processed Beta vulgaris L. juice using counter-current chromatography. J. Chromatogr. B Anal. Technol. Biomed. Life Sci. 941, 54-61. https://doi.org/10.1016/j.jchromb.2013.10.001

Stintzing, F., Schieber, A., Carle, R., 2000. Cactus pear-a promising component to functional food. Obs. Kartof. 85, 40-47.

Stintzing, F.C., Herbach, K.M., Mosshammer, M.R., Carle, R., Yi, W., Sellappan, S., Akoh, C.C., Bunch, R., Felker, P., 2005. Color, betalain pattern, and antioxidant properties of cactus pear (Opuntia spp.) clones. J. Agric. Food Chem. 53, 442-451. https://doi.org/10.1021/jf048751y

Stintzing, F.C., Schieber, A., Carle, R., 2002. Betacyanins in fruits from red-purple pitaya, Hylocereus polyrhizus (Weber) Britton \&amp; Rose. Food Chem. 77, 101-106. https://doi.org/10.1016/S03088146(01)00374-0

Strack, D., Vogt, T., Schliemann, W., 2003. Recent advances in betalain research. Phytochemistry 62, 247-269. https://doi.org/10.1016/S0031-9422(02)00564-2

Sudzuki, F., Muñoz, C., Berger, H., 1993. El cultivo de la tuna (cactus pear)., 1 ed. ed. Departamento de Reproducción Agrícola. Universidad de Chile, Santiago., Santiago, Chile.

Svenson, J., Smallfield, B.M., Joyce, N.I., Sansom, C.E., Perry, N.B., 2008. Betalains in red and yellow varieties of the andean tuber crop ulluco (Ullucus tuberosus). J. Agric. Food Chem. 56, 77307737. https://doi.org/10.1021/jf8012053

Sýs, M., Švecová, B., Švancara, I., Metelka, R., 2017. Determination of vitamin $\mathrm{E}$ in margarines and edible oils using square wave anodic stripping voltammetry with a glassy carbon paste electrode. Food Chem. 229, 621-627. https://doi.org/10.1016/j.foodchem.2017.02.068

Szot, D., Skopińska, A., Wybraniec, S., 2015. Decomposition of 17decarboxy-betanin in selected aqueous-organic solutions induced by $\mathrm{Cu}$ ( II ) cations. PhD Interdiscip. J. Politech. Gdansk Univ. 1, 217-223.

Takshak, S., Agrawal, S.B., 2015. Defence strategies adopted by the medicinal plant Coleus forskohlii against supplemental 
ultraviolet-B radiation: Augmentation of secondary metabolites and antioxidants. Plant Physiol. Biochem. 97, 124-138. https://doi.org/10.1016/j.plaphy.2015.09.018

Thirugnanasambandham, K., Sivakumar, V., 2017. Microwave assisted extraction process of betalain from dragon fruit and its antioxidant activities. J. Saudi Soc. Agric. Sci. 16, 41-48. https://doi.org/10.1016/j.jssas.2015.02.001

Timilsena, Y.P., Wang, B., Adhikari, R., Adhikari, B., 2017. Advances in microencapsulation of polyunsaturated fatty acids (PUFAs)rich plant oils using complex coacervation: A review. Food Hydrocoll. 69 ,

369-381. https://doi.org/10.1016/j.foodhyd.2017.03.007

Timpanaro, G., Urso, A., Spampinato, D., Foti, V., 2015. Cactus pear market in Italy: Competitiveness and perspectives. Acta Hortic. 1067.

Torres, M.D., Chenlo, F., Moreira, R., 2018. Structural features and water sorption isotherms of carrageenans: A prediction model for hybrid carrageenans. Carbohydr. Polym. 180, 72-80. https://doi.org/10.1016/J.CARBPOL.2017.10.010

Tretter, L., Patocs, A., Chinopoulos, C., 2016. Succinate, an intermediate in metabolism, signal transduction, ROS, hypoxia, and tumorigenesis. Biochim. Biophys. Acta - Bioenerg. 1857, 1086-1101. https://doi.org/10.1016/j.bbabio.2016.03.012

Tsuchiya, H., Iinuma, M., 2000. Reduction of membrane fluidity by antibacterial sophoraflavanone $\mathrm{G}$ isolated from Sophora exigua. Phytomedicine 7, 161-165. https://doi.org/10.1016/S09447113(00)80089-6

UN DESA, 2015. World Population Prospects: The 2015 Revision. New York.

Unilever, 2010. The Unilever Sustainable Living Plan.

Vieira, V., Barros, L., Martins, A., Ferreira, I., 2016a. Nutritional and Biochemical Profiling of Leucopaxillus candidus (Bres.) Singer Wild Mushroom. Molecules 21, 99. https://doi.org/10.3390/molecules21010099

Vieira, V., Fernandes, Â., Barros, L., Glamočlija, J., Ćirić, A., Stojković, D., Martins, A., Soković, M., Ferreira, I.C.F.R., 2016 b. Wild Morchella conica Pers. from different origins: A comparative study of nutritional and bioactive properties. J. Sci. Food Agric. 96, 90-98. https://doi.org/10.1002/jsfa.7063

Vinatoru, M., 2001. An overview of the ultrasonically assisted extraction of bioactive principles from herbs. Ultrason. 
Sonochem. $\quad 8, \quad 303-313 . \quad$ https://doi.org/10.1016/S13504177(01)00071-2

Wang, W., Bostic, T.R., Gu, L., 2010. Antioxidant capacities, procyanidins and pigments in avocados of different strains and cultivars. Food Chem. 122, 1193-1198. https://doi.org/10.1016/j.foodchem.2010.03.114

Watada, A.E., Herner, R.C., Kader, A.A., Romani, R.J., Staby, G.L., 1984. Terminology for the description of developmental stages of horticultural crops. HortScience.

Weinstein, M.P., 2012. Methods for Dilution Antimicrobial Susceptibility Tests for Bacteria That Grow Aerobically; Approved Standard - Ninth Edition, Methods for Dilution Antimicrobial Susceptibility Tests for Bacteria That Grow Aerobically; Approved Standar- Ninth Edition. https://doi.org/10.4103/0976-237X.91790

WHO, 2014. GLOBAL STATUS REPORT on noncommunicable diseases 2014. "Attaining the nine global noncommunicable diseases targets; a shared responsibility"

Wrolstad, R.E., Culver, C.A., 2012. Alternatives to those artificial FD\&C food colorants. Annu. Rev. Food Sci. Technol. 3, 59-77. https://doi.org/10.1146/annurev-food-022811-101118

Wybraniec, S., Starzak, K., Szneler, E., Pietrzkowski, Z., 2016. Separation of chlorinated diastereomers of decarboxybetacyanins in myeloperoxidase catalyzed chlorinated Beta vulgaris L. extract. J. Chromatogr. B Anal. Technol. Biomed. Life Sci. $1036-1037$,

$20-32$. https://doi.org/10.1016/j.jchromb.2016.09.040

Yahia, E.M., Woolf, A.B., 2011. Avocado (Persea americana Mill.), in: Postharvest Biology and Technology of Tropical and Subtropical Fruits: Volume 2: Açai to Citrus. Woodhead Publishing, $\quad$ pp.

125-185. https://doi.org/10.1533/9780857092762.125

Yamashita, C., Chung, M.M.S., dos Santos, C., Mayer, C.R.M., Moraes, I.C.F., Branco, I.G., 2017. Microencapsulation of an anthocyanin-rich blackberry (Rubus spp.) by-product extract by freeze-drying. LWT - Food Sci. Technol. 84, 256-262. https://doi.org/10.1016/j.lwt.2017.05.063

Yeddes, N., Chérif, J., Guyot, S., Sotin, H., Ayadi, M., 2013. Comparative Study of Antioxidant Power, Polyphenols, Flavonoids and Betacyanins of the Peel and Pulp of Three Tunisian Opuntia Forms. Antioxidants 2, 37-51. 
Material y métodos

https://doi.org/10.3390/antiox2020037

Zhishen, J., Mengcheng, T., Jianming, W., 1999. The determination of flavonoid contents in mulberry and their scavenging effects on superoxide radicals. Food Chem. https://doi.org/10.1016/S03088146(98)00102-2 
Material y métodos 


\section{Capítulo 4 CARACTERIZACIÓN DE LOS FRUTOS Y SUBPRODUCTOS DE PERSEA AMERICANA}





\section{IV.1 ANTECEDENTES}

Previamente a realizar el trabajo que dio pauta a la segunda publicación incluida en esta Tesis Doctoral y que se centra en los subproductos de Persea americana var Hass, se realizaron 2 estudios que ayudaron a entender con mayor profundidad, los resultados incluidos en dicha publicación.

Por una parte y al igual que en el capítulo 4, se realizó una caracterización morfológica, nutricional y un cribado espectrofotométrico de los compuestos funcionales de todas las fracciones del fruto de aguacate (fruto, piel y semilla). Posteriormente, por otro lado, se evaluó el efecto que ejerce el secado convencional en las biomoléculas activas que poseen los subproductos del aguacate.

\section{IV.1.1 Características de los frutos de Persea americana}

Para poder entender mejor el impacto que pueden representar el flujo de residuos de los frutos de aguacate en los procesos industriales, en la Figura 4-1, hacemos la representación de los porcentajes de cada una de las fracciones dentro de Persea americana var Hass, y claramente podemos observar como alrededor del $30 \%$ del peso total de fruto, lo constituyen los subproductos. Con casi $16 \%$ del total del fruto encontramos a las semillas y con alrededor del $14 \%$ a las pieles, las cuales, más adelante en este capítulo caracterizamos a profundidad para poder sugerir posibles alternativas de aprovechamiento de estos subproductos. 


\section{Avocado fruit fractions percentage}

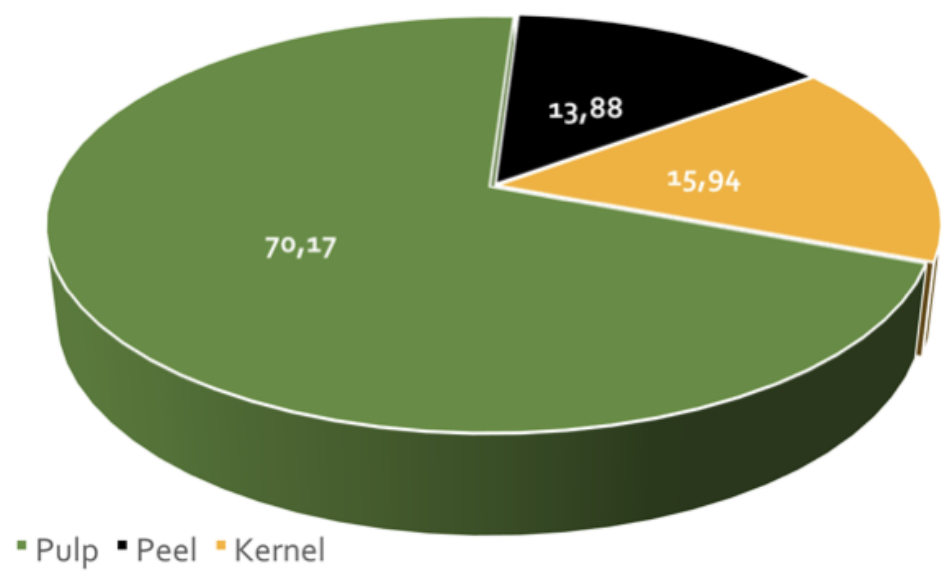

Figure 4-4-1 Avocado fruit fraction percentages (source: private collection)

En la Tabla 4-1 exponemos los valores morfológicos, los porcentajes de macronutrientes, las concentraciones de los compuestos fitoquímicos y la capacidad antioxidante de las tres fracciones del aguacate.

Las características más remarcables obtenidas en esta tabla son: el alto contenido de grasas $(13,14 \%)$ en el fruto. En este punto es importante remarcar que la mayoría de estos lípidos presentes en la pulpa pertenecen a grasa mono y poliinsaturadas, las cuales poseen propiedades buenas para la salud (Hurtado-Fernández et al., 2018b). En las pieles podemos observar un alto porcentaje en fibra $(18,83 \%)$, que nos ayuda a entender mejor la composición estructural de esta fracción, mientras que en las semillas uno de los macronutrientes en mayor proporción, son los carbohidratos totales $(40,33 \%)$, que al igual que en las pieles las fibras dan estructura, en la semilla, los carbohidratos complejos lignificados aportan fuerza a esta fracción (Yahia and Woolf, 2011). 
Table 4-1 Nutritional and morphological characteristics of avocado fractions

\begin{tabular}{|c|c|c|c|}
\hline & Pulp & Peel & Kernel \\
\hline Weight (g) & $90,23 \pm 13,04$ & $17,83 \pm 1,64$ & $20,28 \pm 6,31$ \\
\hline Water activity & $0,99 \pm 0,003$ & $0,98 \pm 0,006$ & $0,98 \pm 0,013$ \\
\hline $\mathrm{pH}$ & 7,45 & - & - \\
\hline $\begin{array}{l}\text { Titratable acidity } \\
(\mathrm{g} \text { citric acid } \\
/ 100 \mathrm{~g})\end{array}$ & $0,15 \pm 0,01$ & $0,2 \pm 0,05$ & $0,27 \pm 0,01$ \\
\hline Moisture(\%) & $74,8 \pm 0,27$ & $69,9 \pm 0,82$ & $54,1 \pm 0,77$ \\
\hline Ashes (\%) & $3,58 \pm 0,56$ & $3,18 \pm 0,39$ & $2,13 \pm 0,93$ \\
\hline Fats $(\%)$ & $13,14 \pm 0,84$ & $1,75 \pm 0,67$ & $0,71 \pm 0,06$ \\
\hline Fiber $(\%)$ & $5,47 \pm 1,17$ & $18,83 \pm 1,05$ & $4,69 \pm 0,77$ \\
\hline Protein (\%) & 3,68 & 4,03 & 2,71 \\
\hline $\begin{array}{l}\text { Carbohydates (by } \\
\text { diference) }(\%)\end{array}$ & 4,76 & 21,11 & 40,33 \\
\hline $\begin{array}{l}\text { Total phenolic } \\
\text { content (mg galic } \\
\text { acid/g D.B.) }\end{array}$ & $3,21 \pm 0,34$ & $25,65 \pm 6,36$ & $21,81 \pm 3,13$ \\
\hline $\begin{array}{l}\text { Scavenging } \\
\text { activity ( } \mu \mathrm{mol} \\
\text { Trolox/g D.B })\end{array}$ & $7,10 \pm 1,19$ & $203,87 \pm 82,8$ & $119,65 \pm 14,15$ \\
\hline
\end{tabular}

Aunque los datos representativos de esta tabla los encontramos al final de ella donde podemos observar claramente y en concordancia con la bibliografía científica (Calderón-Oliver et al., 2016; Dabas et al., 2013; Karamac et al., 2012) como los subproductos de este fruto poseen un contenido total de polifenoles mucho mayor que la parte comestible del fruto, siendo la piel el compuesto con mayor contenido $(25,65 \mathrm{mg}$ equivalente a ácido gálico/ $\mathrm{g}$ de esta fracción en peso seco) en compuestos fenólico. Consecuentemente, la capacidad antioxidante que se encuentra fuertemente ligada a estas biomoléculas activas, muestra de la misma forma a la piel seguida de las semillas, como las fracciones con mejor poder antioxidante in-vitro. Posteriormente en este capítulo, se desarrollaran más ampliamente las implicaciones que esto representa.

\section{IV.1.2 Efecto del secado sobre los compuestos fenólicos}

Una vez realizadas las pruebas de cribado espectrofotométrico en los compuestos fitoquímicos de las fracciones del aguacate, resultó 
pertinente el estudio del efecto que causa el secado convencional a las biomoléculas activas, concretamente a los polifenoles totales en los subproductos de este fruto.

Para poder observar dicho efecto, se realizó un experimental en donde se secaron los subproductos (pieles y semillas) en una estufa de convección a $40{ }^{\circ} \mathrm{C}$, hasta que estos mostraron la máxima sequedad total alcanzando peso constante a lo largo del tiempo. Acto seguido se realizaron las extracciones de las moléculas bioactivas con metanol $80 \%$ y se evaluó su contenido total en polifenoles (CTP) a través del método de Folin-Ciocalteu, comparándolas frente a los subproductos frescos. Además, de esta comparación, los extractos se almacenaron a distintas temperaturas $\left(24,3\right.$ y $\left.-40{ }^{\circ} \mathrm{C}\right)$ por 3 meses para observar mes a mes si existía degradación a lo largo del tiempo. En este experimento se utilizaron las pieles frecas como control.

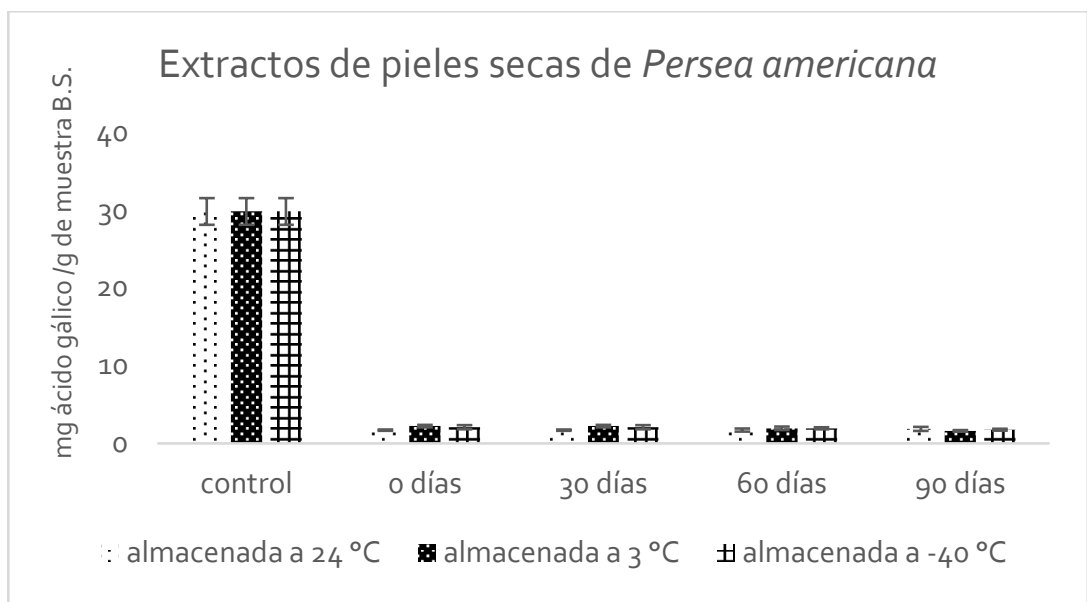

Figure 4-4-2 Effect of drying and storage on phenolic compounds of avocado peels (source: private collection) 


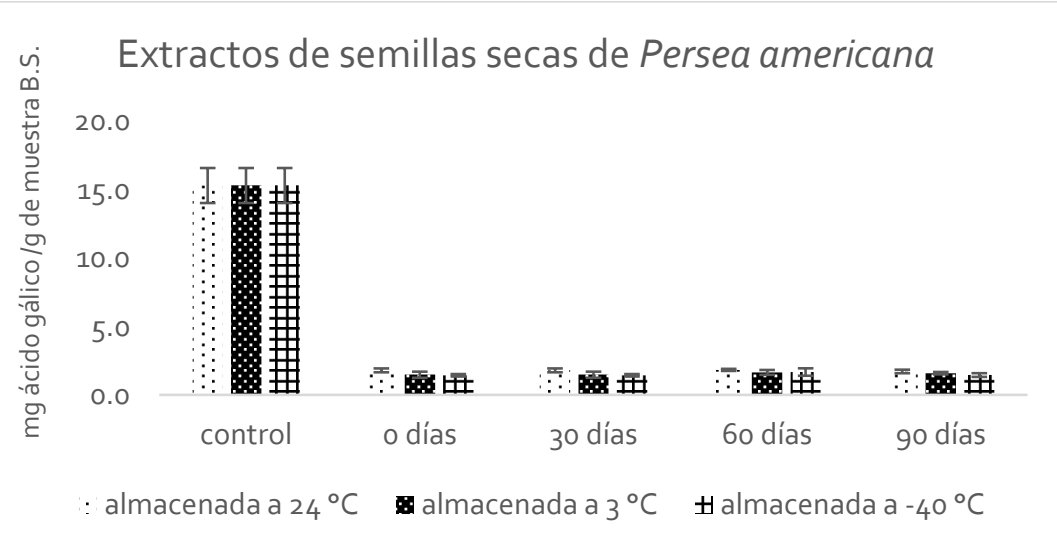

Figure 4-4-3 Effect of drying and storage on phenolic compounds of avocado kernels (source: private collection)

En las Figuras 4-2 y 4-3 observamos el mismo patrón de comportamiento tanto en la piel como en las semillas, donde prácticamente el total de compuestos fenólicos disminuye alrededor de 8 y 17 veces en las semillas y en las pieles, respectivamente. Esta disminución ha sido reportada anteriormente en otros frutos debido a la termolabilidad de estos compuestos (Katsube, Tsurunaga, Sugiyama, Furuno, \& Yamasaki, 2009; Madrau et al., 2009). Podemos observar claramente como los compuestos de la piel fueron afectados con mayor intensidad, probablemente por el tipo de moléculas específicas contenidas en ellas, aunque para tener una propuesta más clara, se deberían de estudiar con mayor profundidad el efecto de cada una las moléculas y no de maneral general, como se realizó en este trabajo.

Por último, podemos observar claramente cómo ni el tiempo ni las temperaturas de almacenaje tuvieron un efecto significativo en las muestras a lo largo del experiental realizado. 


\section{IV.2 CARACTERIZACIÓN DE LOS COMPUESTOS BIOACTIVOS DE LOS SUBPRODUCTOS DE PERSEA AMERICANA MILL: UNA RICA FUENTE DE ANTIOXIDANTES INHERENTES.}

En este capítulo, una adaptación al formato de la tesis doctoral del artículo titulado "Bioactive characterization of persea americana Mill. by-products: A rich source of inherent antioxidants", publicado en la revista Industrial Crops and Products. En él, los subproductos (piel y semilla) de los frutos de aguacate (Persea americana mill) fueron caracterizados en términos funcionales, y la evaluadación de sus propiedades antioxidantes y antimicrobianas. Además, una caracterización completa del perfil polifenolico (ácidos fenólicos y flavonoides) fue llevada a cabo mediante técnicas cromatográficas. Los datos bibliográficos del artículo se destacan a continuación:

Melgar, B., Dias, M. I., Ciric, A., Sokovic, M., Garcia-Castello, E. M., Rodriguez-Lopez, A. D.,Barros, L., Ferreira, I. C. R. F. (2018).

Bioactive characterization of persea americana mill. by-products: A rich source of inherent antioxidants.

Industrial Crops and Products, 111, 212-218. 
Bioactive characterization of Persea americana Mill. by-products: A rich source of inherent antioxidants.

\section{Bruno Melgar ${ }^{a, b}$, Maria Inês Dias ${ }^{\mathrm{a}}$, Ana Ciric ${ }^{\mathrm{c}}$, Marina Sokovic ${ }^{\mathrm{c}}$, Esperanza M. Garcia-Castello ${ }^{b}$, Antonio D. Rodriguez-Lopez ${ }^{d}$, Lillian Barros ${ }^{a}$, Isabel C.F.R. Ferreira ${ }^{a}$,"}

${ }^{a}$ Centro de Investigação de Montanha (CIMO), ESA, Instituto Politécnico de Bragança, Campus de Santa Apolónia, 5300-253 Bragança, Portugal.

${ }^{b}$ Institute of Food Engineering for Development, Universitat Politècnica de València, Camino de Vera, s/n CP, 46022 Valencia, Spain.

${ }^{c}$ University of Belgrade, Department of Plant Physiology, Institute for Biological Research "Siniša Stanković,, Bulevar Despota Stefana 142, 11000 Belgrade, Serbia.

${ }^{d}$ Institute for Industrial, Radiophysical and Environmental Safety (ISIRYM), Universitat Politècnica de València, Camino de Vera, $s / n$ CP, 46022 Valencia, Spain.

*Corresponding author. Tel.+351 273 303219; fax +351 273325405 . E-mail address: iferreira@ipb.pt (I.C.F.R. Ferreira) 


\begin{abstract}
Avocado (Persea americana Mill.) is a worldwide consumed fruit, with great interest for cosmetic and pharmaceutical industries; however, $30 \%$ of avocado fruits are bio-wastes (peels and kernels), converting them into a potential source of bioactive compounds, such as phenolic compounds. Therefore, the hydroethanolic extracts of peels and kernels of Persea america Mill. var. Hass were analysed regarding their individual phenolic profile by HPLC-DAD/ESI-MS and correlated with their antioxidant, antimicrobial and cytotoxic activities. Avocado by-products presented a very distinct phenolic profile, presenting higher concentration in peels ( $227.9 \mathrm{mg} / \mathrm{g}$ of extract), mainly in (epi)catechin derivatives $(175 \mathrm{mg} / \mathrm{g}$ of extract), followed by chlorogenic derivatives $(42,9 \mathrm{mg} / \mathrm{g}$ of extract). In this study hydrophilic and lipophilic antioxidant assays were performed together for first time in $P$. americana by-products and although kernels showed great antioxidant potential ( $\mathrm{IC}_{50}: 220 \mu \mathrm{g} / \mathrm{mL}$ DPPH; $276 \mu \mathrm{g} / \mathrm{mL} \beta$-carotene), peels presented the highest antioxidant activity $\left(\mathrm{IC}_{50}: 149 \mu \mathrm{g} / \mathrm{mL}\right.$ $\mathrm{DPPH} ; 152 \mu \mathrm{g} / \mathrm{mL} \beta$-carotene), mainly due to the presence of phenolic compounds, and an overall better performance in the antibacterial assays. Further studies needs to be conducted to better understand the correlation between the presence of phenolic compounds and bioactivities, however, the main objective is to implement these biocompounds in different products and industries, due to results obtained, $P$. americana peels could be a great alternative to synthetic antioxidants.
\end{abstract}

Keywords: Hass avocado; polyphenols; flavonoids; antimicrobial activity; antioxidant capacity; HPLC-DAD/ESI-MS. 


\section{IV.2.1 INTRODUCTION}

The world population is increasingly higher each year, which can reach 9.7 billion by the year 2050, leading to many concerns about food security issues, especially food inequity in undeveloped countries (UN DESA, 2015). The numbers are alarming, demonstrating great differences between countries, in this sense the Food and Agriculture Organisation report 795 millions of undernourishment people in the world (FAO et al., 2015) and the World Health Organisation published data where more than 1,9 billion adults are overweight (WHO, 2014).

Currently, some food crops are being exploited with purposes other than human feed, like the ones used to produce biofuels (Naik et al., 2010), broadening the food scarcity. Fortunately, food industries and academia have started to play special attention to food by-products in order of their revalorization, keeping a better control of waste management and finding alternatives to the usage of food crops in other applications (Ayala-Zavala et al., 2011; M. Librán et al., 2013; Sharma et al., 2017).

Avocado (Persea americana Mill.) is a dicotyledoneous plant from the Lauraceae family, native from south central Mexico, but with global consumption. It is manly consumed as a fresh fruit, although, food, cosmetic and pharmaceutical industries process its pulp in order to increase commercialisation and give a higher added value to avocado (FAO, 2004). There are several varieties within the $P$. americana species such as Bacon, Hass, Fuerte, Gwen, among many others, being Hass one of the most commercialise varieties. Hass avocados has around $14 \%$ and $16 \%$ of total fruit weight in its peels and kernel, respectively, accounting around $30 \%$ of its weight on by-products (Calderón-Oliver et al., 2016).

The peels and pulps of many fruits, including avocado, contain a large amount of antioxidants that are responsible for the plant defence system, against different types of stresses, such as temperature and light (Ghasemzadeh and Ghasemzadeh, 2011; Manach et al., 2004). They are also known to have effects against some human degenerative diseases (Ghasemzadeh and Ghasemzadeh, 2011; Kaur Kala et al., 2016; Šiler et al., 2014). 
The recovery of bioactive compounds from different waste materials has been the main focus of many scientific studies, since the agro-industries valorise these by-products, generating a large amount of phytochemicals, that can be applied as functional food compounds or as food ingredients, (e.g. colorants, emulsifiers, thickeners, antioxidants, among others) (Azeredo, 2009; Dias et al., 2016; Gong and Bassi, 2016).

Although numerous methodologies can be found in literature for bioactive compounds recovery like ultrafiltration, supercritical fluid extraction, ultrasound extraction, resin adsorption, encapsulation and spray drying among others (da Silva et al., 2016; Destro dos Santos et al., 2016; Kaderides and Goula, 2017; Li et al., 2012; Medina-Meza and Barbosa-Cánovas, 2015; Yamashita et al., 2017), five distinct recovery stages can principally be observed: macroscopic pretreatment, macro and micromolecules separation, extraction, purification and nutraceuticals formation (Galanakis, 2012).

Due to the high volume of by-products generated from the avocado industries and the possibility of extracting functional biomolecules, the main focus of this study was to analyse the waste materials (peels and kernels) of Persea america Mill. var. Hass, concerning their individual phenolic profile, and also evaluate their antioxidant, antimicrobial and cytotoxic potential, in order to acquire better understanding of their intrinsic compounds and functions, which would allow to find an adequate use of these by-products. 


\section{IV.2.2 MATERIAL AND METHODS}

\section{IV.2.2.1 Samples preparation}

Ripen avocado (Persea americana Mill. var. Hass) were purchased from a local market in Bragança, Portugal and stored at $4{ }^{\circ} \mathrm{C}$ until further used. Within 24 hours, fruits were cut, peeled and separated in three fractions (peel, kernel and pulp). Pulp was discarded, peels were carefully cleaned and kernels were frozen. Afterwards, kernels and peels were lyophilized (LabConco, Frezone $-105{ }^{\circ} \mathrm{C}$, $4.5 \mathrm{~L}$ Cascade Benchtop Freeze Dry System, Kansas, MO, USA), grounded ( 20 mesh), and stored in a cool and dry place until further use.

\section{IV.2.2.2 Extraction procedure}

Hydroethanolic extraction (ethanol: water, 80:20 v/v) was performed with $1 \mathrm{~g}$ of lyophilized peels and kernels, by magnetic stirring with 25 $\mathrm{mL}$ of aqueous ethanol $\left(25^{\circ} \mathrm{C}\right.$ at $\left.150 \mathrm{rpm}\right)$ for $1 \mathrm{~h}$ and subsequently filtered through the Whatman no. 4 paper. Supernatants were collected and tissues were re-extracted one more time with the same conditions. The obtained extracts were combined, and the ethanol was evaporated (rotary evaporator Büchi R-210, Flawil, Switzerland), the remaining aqueous phase was frozen and subsequently lyophilized.

The obtained dry extracts were re-dissolved in order to prepare stock solutions in (i) aqueous ethanol solution $80 \%$, for antioxidant activity evaluation (final concentration $40 \mathrm{mg} / \mathrm{mL}$ ) and for phenolic characterization (final concentration $5 \mathrm{mg} / \mathrm{mL}$ ); (ii) water (final concentration $8 \mathrm{mg} / \mathrm{mL}$ ) for cytotoxicity evaluation, and (iii) $5 \%$ DMSO in distilled water (final concentration $10 \mathrm{mg} / \mathrm{mL}$ ) for antimicrobial properties. Stock solutions were further diluted to different concentration for the evaluation of distinct in vitro bioactivity assays.

\section{IV.2.2.3. Phenolic compounds}

For phenolic profile characterization, LC-DAD-ESI/MS analyses were performed using a Dionex Ultimate 3000 UPLC instrument (ThermoScientific, San Jose, CA, USA), coupled to a diode-array detector (using several wavelengths, $280 \mathrm{~nm}, 330 \mathrm{~nm}$ and $370 \mathrm{~nm}$ ) and to a mass detector (Linear Ion Trap LTQ XL mass spectrometer, 
equipped with an ESI source, ThermoFinnigan, San Jose, CA, USA). The elution gradient, chromatographic and mass spectrometer conditions were performed according to the previously described by Bessada et al., (2016), Identification was performed by comparing their fragmentation pattern, retention times and UV-vis spectra with authentic standards, when available, or by comparing the obtained information with available data from literature. The quantification was performed using calibration curves of phenolic standards (chlorogenic acid, epiccatechin, catechin and $\rho$-coumaric acid). When a standard was not available to quantify a phenolic compound, a similar compound of the same phenolic group was used (quercetin 3-O rutinoside and glucoside, kaempferol 3-O rutinoside and isorhamnetin 3-O glucoside). Phenolic compounds quantification results are present in $\mathrm{mg} / \mathrm{g}$ of extract.

\section{IV.2.2.4. Bioactive properties evaluation}

\section{IV.2.2.4.1 Antioxidant activity assays}

Stock solution from $P$. americana by-products were successively diluted and submitted to different in vitro assays (DPPH, Reducing Power, $\beta$-carotene bleaching and TBARS) to evaluate the antioxidant activity of the samples, following the previously described procedure by Vieira et al., (2016a). The results were expressed as $\mathrm{IC}_{50}$ values (sample concentration providing $50 \%$ of antioxidant activity or 0.5 of absorbance in the reducing power assay) for antioxidant activity. Trolox was used as positive control.

\section{IV.2.2.4.2. Antimicrobial activity assays}

Antibacterial activity was assayed using the following, four Grampositive bacteria: Staphylococcus aureus (ATCC 6538), Bacillus cereus (clinical isolate), Micrococcus flavus (ATCC10240), and Listeria monocytogenes (NCTC7973) and four Gram-negative bacteria: Escherichia coli (ATCC 35210), Pseudomonas aeruginosa (ATCC 27853), Salmonella typhimurium (ATCC 13311), and Enterobacter cloacae (ATCC 35030). For the antifungal assays, seven microfungi were used: Aspergillus fumigatus (ATCC1022), Aspergillus ochraceus (ATCC12066), Aspergillus versicolor (ATCC11730), Aspergillus niger (ATCC6275), Penicillium funiculosum (ATCC 36839), Penicillium ochrochloron (ATCC9112), Penicillium 
verrucosum var. cyclopium (food isolate) and Trichoderma viride (IAM 5061).

The minimum inhibitory (MIC), minimum bactericidal concentrations (MBC) and minimum fungicidal concentrations (MFC) were determined by methodologies, described by (Gomes-Correa et al., 2015). The minimum inhibitory (MIC) and minimum bactericidal (MBC) concentrations were determined by the microdilution method. Each fresh overnight culture of bacteria was adjusted spectrophotometrically to a concentration of $1 \times 10^{5} \mathrm{CFU} \mathrm{mL} \mathrm{m}^{-1}$. The

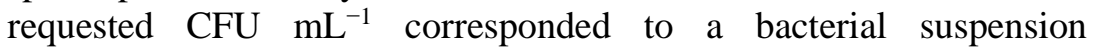
determined in a spectrophotometer at $625 \mathrm{~nm}$ (OD625). Dilutions of inocula were cultured on solid medium to verify the absence of contamination and check the validity of each inoculum. Different solvent dilutions of the ethanolic extract were added to the wells containing $100 \mu \mathrm{L}$ of Tryptic Soy Broth (TSB) and afterwards, $10 \mu \mathrm{L}$ of inoculum was added to all wells.

The microplates were incubated for $24 \mathrm{~h}$ at $37^{\circ} \mathrm{C}$. The MIC of the samples was detected following the addition of $40 \mu \mathrm{L}$ of iodonitrotetrazolium chloride (INT) $\left(0.2 \mathrm{mg} \mathrm{mL}^{-1}\right)$ and incubation at $37^{\circ} \mathrm{C}$ for $30 \mathrm{~min}$. The lowest concentration that produced a significant inhibition (around 50\%) of the growth of the bacteria in comparison with the positive control was identified as the MIC. The minimum inhibitory concentrations (MICs) obtained from the susceptibility testing of various bacteria to tested extracts were determined also by a colorimetric microbial viability assay based on the reduction of the INT color and compared with a positive control for each bacterial strain. MBC was determined by serial sub-cultivation of $10 \mu \mathrm{L}$ into microplates containing $100 \mu \mathrm{L}$ of TSB. The lowest concentration that showed no growth after this sub-culturing was read as the MBC.

The fungal spores were washed from the surface of agar plates with sterile $0.85 \%$ saline containing $0.1 \%$ Tween $80(\mathrm{v} / \mathrm{v})$. The spore suspension was adjusted with sterile saline to a concentration of approximately $1.0 \times 10^{5}$ in a final volume of $100 \mu \mathrm{L}$ per well. The inocula were stored at $4{ }^{\circ} \mathrm{C}$ for further use. Dilutions of each inoculum were cultured on solid MA to verify the absence of contamination and to check the validity of the inoculum. Minimum inhibitory 
concentration (MIC) determination was performed by a serial dilution technique using 96-well microtitre plates.

The investigated extract was dissolved in a 5\% solution of DMSO and added to broth malt medium with a fungal inoculum. The microplates were incubated for $72 \mathrm{~h}$ at $28^{\circ} \mathrm{C}$. The lowest concentrations without visible growth (as assessed using a binocular microscope) were defined as the MICs. The minimum fungicidal concentrations (MFCs) were determined by serial sub-cultivation of $2 \mu \mathrm{L}$ in microtitre plates containing $100 \mu \mathrm{L}$ of malt broth per well and further incubation for 72 $\mathrm{h}$ at $28^{\circ} \mathrm{C}$. The lowest concentration with no visible growth was defined as the MFC, indicating $99.5 \%$ killing of the original inoculum.

Standard drugs, namely streptomycin and ampicillin, bifonazole and ketoconazole were used as positive controls, while 5\% DMSO was used as the negative control. Samples were tested in duplicate and experiments were repeated three times.

Bacterial and fungal organisms were obtained from the Mycological Laboratory, Department of Plant Physiology, Institute for Biological Research "Sinisa Stanković", University of Belgrade, Serbia and the results were expressed in $\mathrm{mg} / \mathrm{mL}$.

\section{IV.2.2.5. Statistical analysis}

All the extractions and assays were performed in triplicate and results were expressed as mean values and standard deviation (SD). Results were analysed using a Student's t-test, in order to determine the significant difference between the two samples, with $p=0.05$. The treatment was carried out using IBM SPSS Statistics for Windows, version 23.0. (IBM Corp., Armonk, New York, USA). 


\section{IV.2.3. RESULTS AND DISCUSSION}

\section{IV.2.3.1. Phenolic profile of $P$. americana by-products}

Table 4-2 presents the peak characteristics (retention time, $\lambda_{\max }$ in the visible region, mass spectral data), tentative identifications and quantification of phenolic compounds in the hydroethanolic extracts from pulp and kernel of $P$. americana. Twenty-nine phenolic compounds were identified, fourteen flavan-3-ols ((epi)catechin derivatives), nine flavonoids (quercetin, kaempferol and isorhamnetin glycoside derivatives) and six phenolic acids (chlorogenic and coumaric acid derivatives). Peels and kernel present a very distinct profile being the only common compounds, peaks 10 and 12 . The phenolic profile of avocado has been previously described by other authors in pulp (Hurtado-Fernández et al., 2014, 2013), peels (Kosińska et al., 2012) and seeds (Kosińska et al., 2012; Ramos-Jerz et al., 2013). However, many of the identified compounds were identified for the first time in avocado by-products. A representative chromatogram of peels and kernel are presented in Figure 4-4.
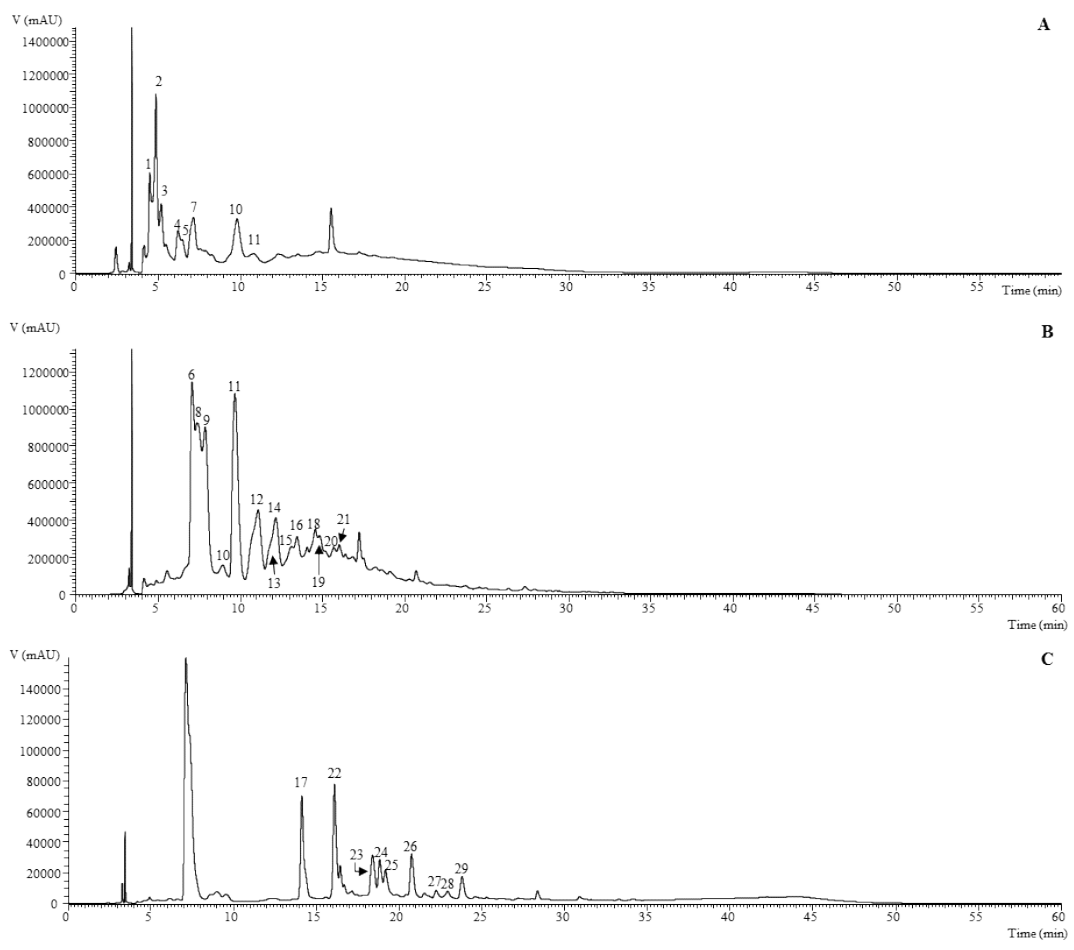

Figure 4-4-4 Phenolic profile of $P$. americana (A) kernel recorded at $280 \mathrm{~nm}$, (B) and (C) peels recorded at $280 \mathrm{~nm}$ and $370 \mathrm{~nm}$, respectively (source: private collection) 
The main family of phenolic compounds found in avocado peels and kernels were (epi)catechin derivatives. Peaks 7 and 10 were positively identified as $(+)$-catechin and (-)-epicatechin, respectively, by comparison with commercial standards taking into account also their retention time, mass and UV-vis characteristics. Peak 7 (catechin) was the major compound found in kernel sample, while epicatechin (peak 10) was the major compound in peel samples. Peaks 3,9 and 21 presented a pseudomolecular ion at $\mathrm{m} / z 577$ and $\mathrm{MS}^{2}$ fragments at $\mathrm{m} / \mathrm{z}$ $451(-126 \mathrm{mu}), 425(-152 \mathrm{mu})$ and $407(-152-18 \mathrm{mu})$ and also $\mathrm{m} / \mathrm{z} 289$ and 287, coherent with the loss of two (epi)catechin units, being for that manner tentatively identified as B-type (epi)catechin dimers. Similarly, peaks 11 and $12\left([\mathrm{M}-\mathrm{H}]^{-}\right.$at $\left.\mathrm{m} / \mathrm{z} 865\right)$, peaks 13 and $14\left([\mathrm{M}-\mathrm{H}]^{-}\right.$at $\mathrm{m} / \mathrm{z}$ 1153), peaks 15 and $16\left([\mathrm{M}-\mathrm{H}]^{-}\right.$at $\mathrm{m} / z$ 1441) and peaks 18,19 and 20( $[\mathrm{M}-\mathrm{H}]^{-}$at $\mathrm{m} / z$ 1729) were assigned as B-type (epi)catechin trimers, tetramers, pentamers and hexamers (Barros et al., 2015; Peláez-Cid et al., 2013; Rached et al., 2016).

The second major family of compounds found in avocado peels samples was flavonoids, mainly quercetin derivatives. Peak 24 was identified as quercetin-3-O-glucoside by comparison of its UV spectrum $\left(\lambda_{\max } 352 \mathrm{~nm}\right)$ and retention time with a commercial standard. Peaks 17, 22, 23, 25, 26 and 28 presented a pseudomolecular ion [M$\mathrm{H}]^{-}$at $\mathrm{m} / z 625,595,477,463,609$ and 579, respectively, and an unique $\mathrm{MS}^{2}$ fragment at $\mathrm{m} / \mathrm{z} 301$, being tentatively identified as quercetindihexoside, quercetin-pentoside-hexoside, quercetin-glucuronide, quercetin-hexoside, quercetin-rhamnoside-hexoside and quercetinrhamnoside-pentoside, respectively. Peaks $27\left([\mathrm{M}-\mathrm{H}]^{-}\right.$at $\left.\mathrm{m} / \mathrm{z} 461\right)$ and $28\left([\mathrm{M}-\mathrm{H}]^{-}\right.$at $\left.\mathrm{m} / \mathrm{z}, 491\right)$ presented a unique $\mathrm{MS}^{2}$ fragments at $\mathrm{m} / \mathrm{z} 285$ and 315 , respectively, corresponding to the loss of a glucuronide unit ($176 \mathrm{mu}$ ), being tentatively identified as kaempferol- and isorhamnetinglucuronide, respectively.

Regarding the phenolic acids, caffeoylquinic acids and $p$-coumaroyl quinic acid isomers were the only compounds found in both samples, being the majority of them found in kernel samples, being peaks 8 and 6 the only phenolic acids found in peels samples. Peaks 1, 2, 6 and 8 were identified as caffeoylquinic acid derivatives according to their UV spectra and pseudomolecular ions, being previously found by Kosińska et al., (2012b) and Ramos-Jerz et al., (2013) in peels and seeds of $P$. americana. Peak assignments of the different caffeoylquinic acids and 
p-coumaroyl quinic acid isomers were made using the recommended IUPAC numbering system (IUPAC, 1976) as also the hierarchical keys previously developed by Clifford et al., (2005, 2003).

By comparison its UV spectrum $\left(\lambda_{\max } 326 \mathrm{~nm}\right)$ and retention time with a commercial standard, peak 8 was identified as 5-Ocaffeoylquinic acid. Peaks 1 and $2\left([\mathrm{M}-\mathrm{H}]^{-}\right.$at $m / z$ 353) were identified as cis 3-O-caffeoylquinic acid and trans 3-O-caffeoylquinic acid, respectively, according to their elution order and also yielding a base peak at $\mathrm{m} / \mathrm{z} 191$ and the ion at $\mathrm{m} / \mathrm{z} 179$ with an intensity $>70 \%$ base peak, characteristic of 3-acylchlorogenic acids (Clifford et al., 2005, 2003). After UV irradiation (366 nm, $24 \mathrm{~h}$ ) of hydroxycinnamic acids in our laboratory, it was possible to observe that the hydroxycinnamoyl cis derivatives elute before the corresponding trans ones and therefore the assignment of cis and trans forms for peaks 1 and 2. Compound 6 was tentatively identified as 4-O-caffeoylquinic acid $\left([\mathrm{M}-\mathrm{H}]^{-}\right.$at $\mathrm{m} / \mathrm{z}$ 353) according to the fragmentation pattern yielding a base peak at $\mathrm{m} / \mathrm{z}$ 173 [quinic acid- $\left.\mathrm{H}_{-} \mathrm{H}_{2} \mathrm{O}\right]^{-}$, accompanied by a secondary fragment ion at $\mathrm{m} / \mathrm{z} 179$ ( $75 \%$ abundance), thus being distinct from the other two isomers (Clifford et al., 2005, 2003).

Taking into account the same findings, peaks 4 and 5 were tentatively identified as cis and trans 3-p-coumarouylquinic acids. (Karamac et al., 2012) have previously identified these compounds in avocado peels.

\section{IV.2.3.2. Antioxidant capacity of $P$. americana by-products}

Polyphenolic content in plants and fruits have been extensively studied due to the good impact these substances has shown as a potential health benefits arising from their biological activity as hepatoprotective, antiinflammatory, antiviral, antimicrobial and antioxidant activities (Carocho and Ferreira, 2013; Dias et al., 2016; Kaur Kala et al., 2016; Shahidi and Ambigaipalan, 2015). From the 29 different compounds found on $P$. americana by-products, 23 of them were found in peels $(227.9 \mathrm{mg} / \mathrm{g}$ of extract) and only 8 in kernels $(72.5 \mathrm{mg} / \mathrm{g}$ of extract), this represent around 3-fold higher polyphenols content in peels, these results obtained proved to be consistent with the other reports (Kosińska et al., 2012; Rodríguez-Carpena et al., 2011). 
Table 4-2 Retention time ( $\mathrm{rt}$ ), waveleghts of maximum absorption in visible region ( $\lambda$ max), mass spectral data, tentative identification and quantification (mg/g of extract) of phenolic compounds in the $P$. americana by-products (peels and kernels)

\begin{tabular}{|c|c|c|c|c|c|c|c|}
\hline Peak & $\begin{array}{c}\text { Tentative } \\
\text { identification }\end{array}$ & $\begin{array}{l}\text { Rt } \\
\text { (min) }\end{array}$ & $\begin{array}{l}\lambda_{\max } \\
(\mathbf{n m})\end{array}$ & $\begin{array}{c}{[\mathrm{M}-\mathrm{H}]^{-}} \\
(\mathrm{m} / \mathrm{z})\end{array}$ & $\begin{array}{l}\mathrm{MS}^{2} \\
(m / z)\end{array}$ & Peel & Kernel \\
\hline 1 & cis 3-O-Caffeoylquinic acid ${ }^{1}$ & 4.7 & 325 & 353 & $191(100), 179(76), 161(5), 135(12)$ & $\mathrm{n} / \mathrm{d}$ & $5.93 \pm 0.04$ \\
\hline 2 & 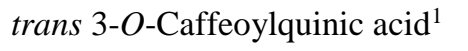 & 4.89 & 325 & 353 & $191(100), 179(75), 161(4), 135(10)$ & $\mathrm{n} / \mathrm{d}$ & $13.6 \pm 0.1$ \\
\hline 3 & B-type (epi)catechin dimer ${ }^{2}$ & 5.22 & 280 & 577 & $\begin{array}{c}451(21), 425(100), 407(26) \\
287(6), \quad 289(5)\end{array}$ & $\mathrm{n} / \mathrm{d}$ & $7.4 \pm 0.1$ \\
\hline 4 & cis 3-p-Coumarouylquinic acid ${ }^{3}$ & 6.4 & 311 & 377 & $\begin{array}{c}191(90), 173(5), 163(100), 155(3) \\
137(5), 119(4)\end{array}$ & $\mathrm{n} / \mathrm{d}$ & $2.6 \pm 0.1$ \\
\hline 5 & cis 3-p-Coumarouylquinic acid ${ }^{3}$ & 6.8 & 311 & 377 & $\begin{array}{c}191(89), 173(5), 163(100), 155(3) \\
137(5), 119(4)\end{array}$ & $\mathrm{n} / \mathrm{d}$ & $1.70 \pm 0.02$ \\
\hline 7 & Catechin $^{4}$ & 7.18 & 280 & 287 & $\begin{array}{c}245(100), 203(5), 187(3) \\
161(3), 137(3)\end{array}$ & $\mathrm{n} / \mathrm{d}$ & $20 \pm 1$ \\
\hline 8 & 5-O-Caffeoylquinic acid ${ }^{1}$ & 7.42 & 325 & 353 & 191(100),179(5),161(3),135(3) & $22.7 \pm 0.1$ & $\mathrm{n} / \mathrm{d}$ \\
\hline 9 & B-type (epi)catechin dimer ${ }^{2}$ & 7.87 & 280 & 577 & $\begin{array}{c}451(19), 425(100), 407(21) \\
289(9), 287(7)\end{array}$ & $34.1 \pm 0.2$ & $\mathrm{n} / \mathrm{d}$ \\
\hline
\end{tabular}




\begin{tabular}{|c|c|c|c|c|c|c|c|}
\hline 10 & Epicatechin $^{2}$ & 9.73 & 280 & 289 & $\begin{array}{c}245(100), 203(5), 187(3) \\
161(3), 137(3)\end{array}$ & $46.5 \pm 0.2 *$ & $15.8 \pm 0.3$ \\
\hline 11 & B-type (epi)catechin trimer ${ }^{2}$ & 10.27 & 280 & 865 & $\begin{array}{c}739(92), 713(59), 695(100), 577(69) \\
575(49), 425(14), 407(10) \\
289(6), 287(12)\end{array}$ & $7.81 \pm 0.01$ & $\mathrm{n} / \mathrm{d}$ \\
\hline 12 & B-type (epi)catechin trimer ${ }^{2}$ & 11.11 & 280 & 865 & $\begin{array}{c}739(89), 713(51), 695(100), 577(8), \\
575(53), 425(13), 407(12) \\
289(5), 287(11)\end{array}$ & $18.4 \pm 0.4^{*}$ & $5.86 \pm 0.05$ \\
\hline 13 & B-type (epi)catechin tetramer ${ }^{2}$ & 11.83 & 280 & 1153 & $\begin{array}{l}865(), 739(16), 713(20), 695(4), 577(10), \\
575(21), 425(10), 407(3), 289(9), 287(12)\end{array}$ & $6.74 \pm 0.04$ & $\mathrm{n} / \mathrm{d}$ \\
\hline 14 & B-type (epi)catechin tetramer ${ }^{2}$ & 12.19 & 280 & 1153 & $\begin{array}{c}865(68) \\
739(27), 713(20), 695(2), 577(22) \\
575(40), 425(5), 407(5), 289(5), 287(10)\end{array}$ & $14.5 \pm 0.3$ & $\mathrm{n} / \mathrm{d}$ \\
\hline 5 & B-type (epi)catechin pentamer ${ }^{2}$ & 13.07 & 280 & 1441 & $\begin{array}{c}1153(27), 865(92), 577(47), 289(25) \\
287(10)\end{array}$ & $7.8 \pm 0.1$ & $\mathrm{n} / \mathrm{d}$ \\
\hline 16 & B-type (epi)catechin pentamer ${ }^{2}$ & 13.45 & 280 & 1441 & $\begin{array}{c}1153(41), 865(29), 577(61), 289(34) \\
287(5)\end{array}$ & $8.8 \pm 0.1$ & $\mathrm{n} / \mathrm{d}$ \\
\hline & Quercetin-dihexoside 5 & 14.11 & 352 & 625 & $301(100)$ & $1.439 \pm 0.001$ & $\mathrm{n} / \mathrm{d}$ \\
\hline
\end{tabular}




\begin{tabular}{|c|c|c|c|c|c|c|c|}
\hline 18 & B-type (epi)catechin hexamer ${ }^{2}$ & 14.59 & 279 & 1729 & $\begin{array}{c}1441(14), 1153(34), 865(14), \\
577(46), 289(20), 287(66)\end{array}$ & $8.89 \pm 0.11$ & $\mathrm{n} / \mathrm{d}$ \\
\hline 19 & B-type (epi)catechin hexamer ${ }^{2}$ & 14.88 & 279 & 1729 & $\begin{array}{c}1441(16), 1153(19), 865(28) \\
577(17), 289(13), 287(41)\end{array}$ & $7.55 \pm 0.01$ & $\mathrm{n} / \mathrm{d}$ \\
\hline 20 & B-type (epi)catechin hexamer ${ }^{2}$ & 15.65 & 280 & 1729 & $\begin{array}{c}1441(12), 1153(10), 865(15) \\
577(37), 289(10), 287(16)\end{array}$ & $6.8 \pm 0.1$ & $\mathrm{n} / \mathrm{d}$ \\
\hline 21 & B-type (epi)catechin dimer ${ }^{2}$ & 16.06 & 280 & 577 & $\begin{array}{c}451(19), 425(100), 407(10) \\
289(6), 287(3)\end{array}$ & $7.13 \pm 0.04$ & $\mathrm{n} / \mathrm{d}$ \\
\hline 22 & Quercetin-pentoside-hexoside ${ }^{5}$ & 16.08 & 352 & 595 & $301(100)$ & $1.521 \pm 0.002$ & $\mathrm{n} / \mathrm{d}$ \\
\hline 23 & Quercetin-glucoronide $^{5}$ & 18.38 & 352 & 477 & $301(100)$ & $1.244 \pm 0.001$ & $\mathrm{n} / \mathrm{d}$ \\
\hline 24 & Quercetin-3-O-glucoside ${ }^{5}$ & 18.5 & 352 & 463 & $301(100)$ & $1.175 \pm 0.002$ & $\mathrm{n} / \mathrm{d}$ \\
\hline 25 & Quercetin-hexoside 5 & 19.2 & 345 & 463 & $301(100)$ & $1.123 \pm 0.004$ & $\mathrm{n} / \mathrm{d}$ \\
\hline 26 & Quercetin-rhamnoside-hexoside ${ }^{5}$ & 20.74 & 348 & 609 & $301(100)$ & $1.21 \pm 0.01$ & $\mathrm{n} / \mathrm{d}$ \\
\hline 27 & Kaempferol-glucuronide ${ }^{6}$ & 22.22 & 352 & 461 & $285(100)$ & $\operatorname{tr}$ & $\mathrm{n} / \mathrm{d}$ \\
\hline 28 & Quercetin-rhamnoside-pentoside ${ }^{5}$ & 22.5 & 350 & 579 & $301(100)$ & $1.015 \pm 0.002$ & $\mathrm{n} / \mathrm{d}$ \\
\hline \multirow[t]{2}{*}{29} & Isorhametin-glucuronide ${ }^{5}$ & 23.79 & 352 & 491 & $315(100)$ & $1.09 \pm 0.01$ & $\mathrm{n} / \mathrm{d}$ \\
\hline & Total phenolic compounds & & & & & $227.9 \pm 0.4^{*}$ & $72.5 \pm 0.1$ \\
\hline
\end{tabular}

n/d- not detected; tr, traces. Standard calibration curves used: $1-$ Chlorogenic acid $\left(y=168823 x-161172, R^{2}=0.9999\right) ; 2-$ epicatechin $\left(y=10314 x+147331, R^{2}=\right.$ $0.9994) ; 3-p$-coumaric acid $\left(y=301950 x+6966.7, R^{2}=0.9999\right) ; 4-$ catechin $\left(y=84950 x-23200, R^{2}=1\right) ; 5-$ quercetin-3-O-glucoside $\left(y=34843 x-160173, R^{2}=\right.$ 0.9998); 6 - kaempferol -3-O-rutinoside $\left(y=11117 x+30861, R^{2}=0.9999\right)$. *Statistical differences $(<0.001)$ were observed when $t$-student test was applied. 
It is also important here to stress, the higher phenolic content in $P$. americana by-products compared with the edible pulp (Wang et al., 2010). This greater polyphenolic content has also displayed higher antioxidant capacity, and as expected $P$. americana peels proof to excel the kernels activity in around 1.5-fold higher in all the antioxidant tests performed and shown in Table 4-3, this result proved to be in concordance with Calderón-Oliver et al., 2016, Kosińska et al., 2012a and Saavedra et al., 2017). Although the differences in the total phenolic content between peels and kernels is 3 times higher, the antioxidant activity observed it is only around half (1.5) greater. This could be explained due to the different degrees of polymerization of the polyphenolic compounds of $P$. american peels. As it was mention before, Epicatechin was the most abundant compound in both byproducts, peels are also majoritarian in different sort of B-type epicatechin dimer, trimer, tetramers and flavonol glycosides.

On one hand Hollman et al., (1999) reports higher antioxidant activity on aglycones compared with glycosides, while Mishra et al., (2013) point out the difference between dimers, trimers, tetramers, heptamers and hexamers specificity on their properties as an antioxidants. These and other interaction could explain the differences obtained in the antioxidant activity between $P$. americana by-products, but in order to obtain better comprehension on this phenomena, more analysis have to be performed.

Table 4-3 Antioxidant activity of $P$. americana by-products (peels and kernels)

\begin{tabular}{lccc}
\hline $\mathrm{IC}_{50}(\mu \mathrm{g} / \mathrm{mL})$ & Peel & Kernel & $\begin{array}{c}t \text {-Students test } \\
p \text {-value }\end{array}$ \\
\hline $\begin{array}{l}\text { DPPH scavenging } \\
\text { activity }\end{array}$ & $149 \pm 5$ & $220 \pm 3$ & $<0.001$ \\
$\begin{array}{l}\text { Reducing power } \\
\begin{array}{l}\beta \text {-carotene bleaching } \\
\text { inhibition }\end{array}\end{array}$ & $152 \pm 1$ & $51 \pm 1$ & $<0.001$ \\
TBARS & $11.7 \pm 0.1$ & $276 \pm 15$ & $<0.001$ \\
\hline
\end{tabular}

In each row different letters mean significant differences $(\mathrm{p}<0.05) . \mathrm{IC}_{50}$ values correspond to the sample concentration achieving $50 \%$ of antioxidant activity or 0.5 of absorbance in reducing power assay. $\mathrm{IC}_{50}$ values for the positive control trolox: $62.98 \mu \mathrm{g} / \mathrm{mL}$ (DDPH), $45.71 \mu \mathrm{g} / \mathrm{mL}$ (reducing power), $10.25 \mu \mathrm{g} / \mathrm{mL}$ ( $\beta$-carotene bleaching inhibition) and $10.83 \mu \mathrm{g} / \mathrm{mL}$ (TBARS inhibition). 


\section{IV.2.3.3. Antimicrobial activity of $P$. americana by- products}

Flavonoids are known to be synthesized by plants in response to microbial infections, thus, it is not surprising this sort of compounds exhibit antimicrobial activity in many in vitro assays. Many flavonoid rich plant and fruits from different species have been reported with antimicrobial activity (Balouiri et al., 2016; Melgar et al., 2017; Rodrigo and Martínez-1, 2015; Sansano et al., 2017; Šiler et al., 2014; Vieira et al., 2016b).

$P$. americana by-products have shown great antibacterial and moderate antifungal activity against the strains tasted Table 4-4. The bactericidal effect of the samples proved to outstand from the controls employed in 7 out of 8 different gram positive and negative strains, although, in this particular assay extracts from kernels displayed better MCB in 6 out of 8 strains, same power in B. cereus strain, and only worst power in E. cloacae strain. The results here exposed shown better performance when compared with the results reported by (CalderónOliver et al., 2016; Raymond Chia and Dykes, 2010).

Contrary to bactericidal effect, fungicidal effect only was shown in 2 strains but only with kernel extracts, from which, the better fungicidal effect was against Trichoderma viride. Comparing the fungistatic effect, both by-product extract were effective against all 8 strains, but only kernel extract did not shown affectivity against $P$. funiculosum. Both peels and kernels extract performed better at fungistastic level in 3 strains (A. ochraceus, $T$. viride and $P$. ochrochloron) when compared with ketoconazole antifungal commercial drug and kernel extract display better fungistastic effect in strain vs bifonazole (stronger control used).

Antibacterial flavonoids might be having multiple cellular targets, rather than one specific site of action. Tsuchiya and Iinuma, (2000) suggested an alteration of membrane fluidity in hydrophilic and hydrophobic regions in this way flavonoids might reduce the fluidity of outer and inner layers of membranes. Mishra et al., (2009) propose that one of the molecular actions of flavonoids is to form complex with proteins through nonspecific forces such as hydrogen bonding and hydrophobic effects, as well as by covalent bond formation, this 
Resultados

interactions have the ability to inactivate microbial adhesions, enzymes, cell envelope transport proteins, and so forth. In this sense, our understanding on the antimicrobial effect of polyphenols agrees with the previous mechanism of action mentioned. 
Table 4-4 Antibacterial and antifungal activity of $P$. americana by-products (peels and kernels)

\begin{tabular}{|c|c|c|c|c|c|c|c|c|}
\hline \multirow{2}{*}{ Antibacterial activity $(\mathrm{mg} / \mathrm{mL})$} & \multicolumn{2}{|c|}{ Peel } & \multicolumn{2}{|c|}{ Kernel } & \multicolumn{2}{|c|}{$\mathrm{C} 1$} & \multicolumn{2}{|c|}{$\mathrm{C} 2$} \\
\hline & MIC & $\mathrm{MBC}$ & MIC & $\mathrm{MBC}$ & MIC & $\mathrm{MBC}$ & MIC & MBC \\
\hline \multicolumn{9}{|l|}{ Gram positive bacteria } \\
\hline Bacillus cereus & 0.015 & 0.030 & 0.020 & 0.030 & 0.10 & 0.20 & 0.25 & 0.40 \\
\hline Listeria monocytogenes & 0.030 & 0.075 & 0.030 & 0.070 & 0.20 & 0.30 & 0.40 & 0.50 \\
\hline Micrococcus flavus & 0.030 & 0.075 & 0.050 & 0.070 & 0.20 & 0.30 & 0.25 & 0.40 \\
\hline Staphylococcus aureus & 0.030 & 0.075 & 0.030 & 0.070 & 0.04 & 0.10 & 0.25 & 0.45 \\
\hline \multicolumn{9}{|l|}{ Gram negative } \\
\hline Enterobacter cloacae & 0.015 & 0.030 & 0.050 & 0.070 & 0.20 & 0.30 & 0.25 & 0.50 \\
\hline Escherichia coli & 0.30 & 0.45 & 0.15 & 0.30 & 0.20 & 0.30 & 0.40 & 0.50 \\
\hline Pseudomonas aeruginosa & 0.030 & 0.075 & 0.030 & 0.070 & 0.20 & 0.30 & 0.75 & 1.20 \\
\hline Salmonella typhimurium & 0.10 & 0.15 & 0.030 & 0.07 & 0.25 & 0.50 & 0.40 & 0.75 \\
\hline \multirow{2}{*}{ Antifungal activity $(\mathrm{mg} / \mathrm{mL})$} & \multicolumn{2}{|c|}{ Peel } & \multicolumn{2}{|c|}{ Kernel } & \multicolumn{2}{|c|}{$\mathrm{C} 3$} & \multicolumn{2}{|c|}{$\mathrm{C} 4$} \\
\hline & MIC & MFC & MIC & MFC & MIC & MFC & MIC & MFC \\
\hline Aspergillus fumigatus & 0.3 & - & 0.3 & - & 0.25 & 0.50 & 0.15 & 0.20 \\
\hline Aspergillus versicolor & 0.3 & - & 0.3 & - & 0.20 & 0.50 & 0.10 & 0.20 \\
\hline Aspergillus ochraceus & 0.3 & - & 0.2 & 0.3 & 1.50 & 2.00 & 0.15 & 0.20 \\
\hline Aspergillus niger & 0.3 & - & 0.3 & - & 0.20 & 0.50 & 0.15 & 0.20 \\
\hline Trichoderma viride & 0.3 & - & 0.02 & 0.03 & 1.00 & 1.00 & 0.15 & 0.20 \\
\hline Penicillium funiculosum & 0.3 & - & - & - & 0.20 & 0.50 & 0.20 & 0.25 \\
\hline Penicillium ochrochloron & 0.3 & - & 0.3 & - & 2.50 & 3.50 & 0.20 & 0.25 \\
\hline Penicillium verrucosum var. cyclopium & 0.3 & - & 0.3 & - & 0.20 & 0.30 & 0.10 & 0.20 \\
\hline
\end{tabular}




\section{IV.2.4. CONCLUSION}

One of the main goals of this research was to revalorize P. americana by-products by characterizing their main bioactive properties. With the assays performed we were able to detect new phenolic compounds in avocado by-products, quantify them and test their hydrophilic and lipophilic antioxidant capacity which shown to be superior to the capacity reported by other authors in the edible pulp.

In the same manner, previous reports about antimicrobial activity were revised and confronted with the data obtained, the results obtained exhibit greater capacity against certain bacterial and fungal strains and wider study of strains tested. All the data recollected is just the begging of a series of experiments that have to be design in order to implement these functional molecules in different products and industries.

The deeper analysis of bioactive compounds performed on $P$. americana by-products, will allow to continue searching the optimum process of extraction, purification and implementation as food ingredients.

\section{Acknowledgements}

The authors are grateful to the Foundation for Science and Technology (FCT, Portugal) and FEDER under Program PT2020 for financial support to CIMO (UID/AGR/00690/2013) and L. Barros contract. B. Melgar thanks CONACyT for his grant (No. 329930). The authors are also grateful to the Serbian Ministry of Education, Science and Technological Development, grant number 173032 for financial support. 


\section{References}

Ahn, J.H., Jang, Y.-S., Lee, S.Y., 2016. Production of succinic acid by metabolically engineered microorganisms. Curr. Opin. Biotechnol. 42, 54-66. https://doi.org/10.1016/j.copbio.2016.02.034

Al-Farsi, M.A., Lee, C.Y., 2008. Optimization of phenolics and dietary fibre extraction from date seeds. Food Chem. 108, 977-985. https://doi.org/10.1016/j.foodchem.2007.12.009

Albano, C., Negro, C., Tommasi, N., Gerardi, C., Mita, G., Miceli, A., De Bellis, L., Blando, F., 2015. Betalains, Phenols and Antioxidant Capacity in Cactus Pear [Opuntia ficus-indica (L.) Mill.] Fruits from Apulia (South Italy) Genotypes. Antioxidants 4, 269-280. https://doi.org/10.3390/antiox4020269

Albuquerque, T.G., Santos, F., Sanches-Silva, A., Beatriz Oliveira, M., Bento, A.C., Costa, H.S., 2016. Nutritional and phytochemical composition of Annona cherimola Mill. fruits and by-products: Potential health benefits. Food Chem. 193, 187-195. https://doi.org/10.1016/j.foodchem.2014.06.044

Allai, L., Druart, X., Öztürk, M., BenMoula, A., Nasser, B., El Amiri, B., 2016. Protective effects of Opuntia ficus-indica extract on ram sperm quality, lipid peroxidation and DNA fragmentation during liquid storage. Anim. Reprod. Sci. 175, 1-9. https://doi.org/10.1016/j.anireprosci.2016.09.013

Almeida, M.M.B., de Sousa, P.H.M., Arriaga, Â.M.C., do Prado, G.M., Magalhães, C.E. de C., Maia, G.A., de Lemos, T.L.G., 2011. Bioactive compounds and antioxidant activity of fresh exotic fruits from northeastern Brazil. Food Res. Int. 44, 2155-2159. https://doi.org/10.1016/j.foodres.2011.03.051

Alvarez, B., 2007. Análisis de factibilidad del cultivo de la tuna en la localidad de Icaño, Departamento La Paz, Dirección provincial de programación del desarrollo, Ministerio de Producción y Desarrollo. Gobierno de la Provincia de Catamarca. Catamarca, Argentina.

Alzate T, L.M., González, D., Hincapié, S., Cardona S, B.L., LondoñoLondoño, J., Jiménez-Cartagena, C., 2016. The profile of bioactive substances in ten vegetable and fruit by-products from a food supply chain in Colombia. Sustain. Prod. Consum. https://doi.org/10.1016/j.spc.2016.07.005 
Ammar, I., Ben Salem, M., Harrabi, B., Mzid, M., Bardaa, S., Sahnoun, Z., Attia, H., Ennouri, M., 2018. Anti-inflammatory activity and phenolic composition of prickly pear (Opuntia ficus-indica) flowers. Ind. Crops Prod. 112, 313-319. https://doi.org/10.1016/j.indcrop.2017.12.028

Angulo-Bejarano, P.I., Martínez-Cruz, O., Paredes-López, O., 2014. Phytochemical Content, Nutraceutical Potential and Biotechnological Applications of an Ancient Mexican Plant: Nopal (Opuntia ficus-indica). Curr. Nutr. Food Sci. 10, 196-217. https://doi.org/10.2174/157340131003140828121015

Arlt, U., 2010. NATCOL | Foods Colours Legislation.

Aruwa, C.E., Amoo, S.O., Kudanga, T., 2018. Opuntia (Cactaceae) plant compounds, biological activities and prospects - A comprehensive review. Food Res. Int. 112, 328-344. https://doi.org/10.1016/j.foodres.2018.06.047

Association of Official Analytical Chemists, 2016. Official Methods of Analysis of AOAC International, 20th ed. The Association, Gaithersburg, MD, USA.

Attokaran, M., 2011. Natural Food Flavors and Colorants Natural Food Flavors and Colorants, 1st ed. Blackwell Publishing LTD, Iowa.

Augustin, M.A., Sanguansri, L., 2015. Challenges and Solutions to Incorporation of Nutraceuticals in Foods. Annu. Rev. Food Sci. Technol. 6, 463-477. https://doi.org/10.1146/annurev-food022814-015507

Ayala-Zavala, J.F., Vega-Vega, V., Rosas-Domínguez, C., PalafoxCarlos, H., Villa-Rodriguez, J.A., Siddiqui, M.W., Dávila-Aviña, J.E., González-Aguilar, G.A., 2011. Agro-industrial potential of exotic fruit byproducts as a source of food additives. Food Res. Int. 44 , 1866-1874. https://doi.org/10.1016/j.foodres.2011.02.021

Azeredo, H.M.C., 2009. Betalains: Properties, sources, applications, and stability - A review. Int. J. Food Sci. Technol. 44, 2365-2376. https://doi.org/10.1111/j.1365-2621.2007.01668.x

Balouiri, M., Sadiki, M., Ibnsouda, S.K., 2016. Methods for in vitro evaluating antimicrobial activity: A review. J. Pharm. Anal. 6, 71-79. https://doi.org/10.1016/j.jpha.2015.11.005

Barros, L., Calhelha, R.C., Queiroz, M.J.R.P., Santos-Buelga, C., Santos, E.A., Regis, W.C.B., Ferreira, I.C.F.R., 2015. The 
powerful in vitro bioactivity of Euterpe oleracea Mart. seeds and related phenolic compounds. Ind. Crops Prod. 76, 318-322. https://doi.org/10.1016/j.indcrop.2015.05.086

Barros, L., Pereira, C., Ferreira, I.C.F.R., 2013. Optimized Analysis of Organic Acids in Edible Mushrooms from Portugal by Ultra Fast Liquid Chromatography and Photodiode Array Detection. Food Anal. Methods 6. https://doi.org/10.1007/s12161-012-9443-1

Barrows, J.N., Lipman, A.L., Bailey, C.J., Cianci, S., 2003. Color Additives: FDA's Regulatory Process and Historical Perspectives. Food Saf. Mag. URL https://www.fda.gov/forindustry/coloradditives/regulatoryproces shistoricalperspectives/ (accessed 9.3.18).

Baydar, N.G., Özkan, G., Sağdiç, O., 2004. Total phenolic contents and antibacterial activities of grape (Vitis vinifera L.) extracts. Food Control 15, 335-339. https://doi.org/10.1016/S09567135(03)00083-5

Belščak-Cvitanović, A., Durgo, K., Huđek, A., Bačun-Družina, V., Komes, D., 2018. Metabolism and Health Effects of Polyphenols, in: Galanakis, C.M. (Ed.), Polyphenols: Properties, Recovery, and Applications. Woodhead Publishing, pp. 1-44. https://doi.org/https://doi.org/10.1016/B978-0-12-8135723.00001-4

Belwal, T., Dhyani, P., Bhatt, I.D., Rawal, R.S., Pande, V., 2016. Optimization extraction conditions for improving phenolic content and antioxidant activity in Berberis asiatica fruits using response surface methodology (RSM). Food Chem. 207, 115124. https://doi.org/10.1016/j.foodchem.2016.03.081

Bessada, S.M.F., Barreira, J.C.M., Barros, L., Ferreira, I.C.F.R., Oliveira, M.B.P.P., 2016. Phenolic profile and antioxidant activity of Coleostephus myconis (L.) Rchb.f.: An underexploited and highly disseminated species. Ind. Crops Prod. 89, 45-51. https://doi.org/10.1016/j.indcrop.2016.04.065

Betancourt, C., Cejudo-Bastante, M.J., Heredia, F.J., Hurtado, N., 2017. Pigment composition and antioxidant capacity of betacyanins and betaxanthins fractions of Opuntia dillenii (Ker Gawl) Haw cactus fruit. Food Res. Int. 101, 173-179. https://doi.org/10.1016/j.foodres.2017.09.007

Bhatia, S., Bera, T., Dahiya, R., Bera, T., Bhatia, S., Bera, T., 2015. Classical and Nonclassical Techniques for Secondary Metabolite 
Production in Plant Cell Culture, in: Modern Applications of Plant Biotechnology in Pharmaceutical Sciences. Elsevier, pp. 231291. https://doi.org/10.1016/B978-0-12-802221-4.00007-8

Brand-Williams, W., Cuvelier, M.E., Berset, C., 1995. Use of a free radical method to evaluate antioxidant activity. LWT - Food Sci. Technol. 28, 25-30. https://doi.org/10.1016/S00236438(95)80008-5

Bravo-Hollis, H., 1978. Las cactaceas de Mexico. Universidad Nacional Autonoma de Mexico, Mexio. https://doi.org/10.15713/ins.mmj.3

Brundtland, G.H., 1987. Our common future.

Cai, Y., Sun, M., Corke, H., 2003. Antioxidant activity of betalains from plants of the Amaranthaceae. J. Agric. Food Chem. 51, 2288-2294. https://doi.org/10.1021/jf030045u

Calderón-Oliver, M., Escalona-Buendía, H.B., Medina-Campos, O.N., Pedraza-Chaverri, J., Pedroza-Islas, R., Ponce-Alquicira, E., 2016. Optimization of the antioxidant and antimicrobial response of the combined effect of nisin and avocado by-products. LWT Food Sci. Technol. 65, 46-52. https://doi.org/10.1016/j.lwt.2015.07.048

Cardoso-Ugarte, G.A., Sosa-Morales, M.E., Ballard, T., Liceaga, A., San Martín-González, M.F., 2014. Microwave-assisted extraction of betalains from red beet (Beta vulgaris). LWT - Food Sci. Technol. 59, 276-282. https://doi.org/10.1016/j.lwt.2014.05.025

Carocho, M., Ferreira, I.C.F.R., 2013. A review on antioxidants, prooxidants and related controversy: Natural and synthetic compounds, screening and analysis methodologies and future perspectives. Food Chem. Toxicol. 51, 15-25. https://doi.org/10.1016/j.fct.2012.09.021

Carr, M., 2013. The water relations and irrigation requirements of avocado (Persea americana Mill.): a review. Exp. Agric. 49, 256278. https://doi.org/10.1017/S0014479712001317

Cassano, A., Conidi, C., Timpone, R., D’Avella, M., Drioli, E., 2007. A membrane-based process for the clarification and the concentration of the cactus pear juice. J. Food Eng. 80, 914-921. https://doi.org/10.1016/j.jfoodeng.2006.08.005

Castellanos-Santiago, E., Yahia, E.M., 2008. Identification and quantification of betalains from the fruits of 10 Mexican prickly 
pear cultivars by high-performance liquid chromatography and electrospray ionization mass spectrometry. J. Agric. Food Chem. 56, 5758-5764. https://doi.org/10.1021/jf800362t

Castellar, R., Obón, J.M., Alacid, M., Fernández-López, J.A., 2003. Color Properties and Stability of Betacyanins from Opuntia Fruits. J. Agric. Food Chem. 51, 2772-2776. https://doi.org/10.1021/jf021045h

Cejudo Bastante, M.J., Chaalal, M., Louaileche, H., Parrado, J., Heredia, F.J., 2014. Betalain Profile, Phenolic Content, and Color Characterization of Different Parts and Varieties of Opuntia ficusindica. J. Agric. Food Chem. 62, 8491-8499. https://doi.org/10.1021/jf502465g

Chahdoura, H., Barreira, J.C.M., Barros, L., Santos-Buelga, C., Ferreira, I.C.F.R., Achour, L., 2014. Phytochemical characterization and antioxidant activity of Opuntia microdasys (Lehm.) Pfeiff flowers in different stages of maturity. J. Funct. Foods 9, 27-37. https://doi.org/10.1016/j.jff.2014.04.011

Chahdoura, H., Barreira, J.C.M., Fernández-Ruiz, V., Morales, P., Calhelha, R.C., Flamini, G., Soković, M., Ferreira, I.C.F.R., Achour, L., 2016. Bioactivity, proximate, mineral and volatile profiles along the flowering stages of Opuntia microdasys (Lehm.): defining potential applications. Food Funct. 7, 1458-67. https://doi.org/10.1039/c5fo01536g

Chan, L.G., Cohen, J.L., Maria, J., Nobrega, L., Bell, D.M., 2018. Conversion of Agricultural Streams and Food-Processing ByProducts to Value-Added Compounds using Filamentous Fungi. Annu. Rev. Food Sci. Technol. 9, 1-21. https://doi.org/10.1146/annurev-food-030117-012626

Chougui, N., Djerroud, N., Naraoui, F., Hadjal, S., Aliane, K., Zeroual, B., Larbat, R., 2015. Physicochemical properties and storage stability of margarine containing Opuntia ficus-indica peel extract as antioxidant. Food Chem. 173, 382-90. https://doi.org/10.1016/j.foodchem.2014.10.025

Chougui, N., Tamendjari, A., Hamidj, W., Hallal, S., Barras, A., Richard, T., Larbat, R., 2013. Oil composition and characterisation of phenolic compounds of Opuntia ficus-indica seeds. Food Chem. 139, 796-803. https://doi.org/10.1016/j.foodchem.2013.01.054

Clifford, M.N., Johnston, K.L., Knight, S., Kuhnert, N., 2003. 
Hierarchical Scheme for LC-MSn Identification of Chlorogenic Acids. J. Agric. Food Chem. 51, 2900-2911. https://doi.org/10.1021/jf026187q

Clifford, M.N., Knight, S., Kuhnert, N., 2005. Discriminating between the six isomers of dicaffeoylquinic acid by LC-MSn. J. Agric. Food Chem. 53, 3821-3832. https://doi.org/10.1021/jf050046h

Cowan, A.K., Cripps, R.F., Richings, E.W., Taylor, N.J., 2001. Fruit size: Towards an understanding of the metabolic control of fruit growth using avocado as a model system. Physiol. Plant. 111, 127-136. https://doi.org/10.1034/j.1399-3054.2001.1110201.x

Cowan, A.K., Wolstenholme, B.N., 2003. AVOCADOS, in: Encyclopedia of Food Sciences and Nutrition. Elsevier, pp. 348353. https://doi.org/10.1016/B0-12-227055-X/00073-0

Crane, J.H., Balerdi, C.F., Maguire, I., 2016. Avocado Growing in the Florida Home Landscape.

Da-Costa-Rocha, I., Bonnlaender, B., Sievers, H., Pischel, I., Heinrich, M., 2014. Hibiscus sabdariffa L. - A phytochemical and pharmacological review. Food Chem. 165, 424-443. https://doi.org/10.1016/j.foodchem.2014.05.002

Da-Silva, R.P.F.F., Rocha-Santos, T.A.P., Duarte, A.C., 2016. Supercritical fluid extraction of bioactive compounds. TrAC Trends Anal. Chem. 76, 40-51. https://doi.org/10.1016/j.trac.2015.11.013

Dabas, D., Shegog, R.M., Ziegler, G.R., Lambert, J.D., 2013. Avocado (Persea americana) seed as a source of bioactive phytochemicals. Current Pharmaceutical Design, 19 (34), 6133-40. https://doi.org/10.2174/1381612811319340007

Day, L., Seymour, R.B., Pitts, K.F., Konczak, I., Lundin, L., 2009. Incorporation of functional ingredients into foods. Trends Food Sci. Technol. 20, 388-395. https://doi.org/10.1016/J.TIFS.2008.05.002

DeFelice, S.L., 2002. FIM Rationale And Proposed Guidelines For The Nutraceutical Research \& Education Act - NREA. New York.

Delgado-Vargas, F., Paredes-Lopez, O., 2003. Natural Colorants for Food and Nutraceutical Uses, Trends in Food Science \& Technology. https://doi.org/10.1016/S0924-2244(03)00076-1

Destro dos Santos, C., Külzer Scherer, R., Schilling Cassini, A., Ferreira Marczak, L.D., Tessaro, I.C., 2016. Clarification of red 
beet stalks extract by microfiltration combined with ultrafiltration. J. Food Eng. 185, 35-41. https://doi.org/10.1016/j.jfoodeng.2016.03.031

Devalaraja, S., Jain, S., Yadav, H., 2011. Exotic fruits as therapeutic complements for diabetes, obesity and metabolic syndrome. Food Res. Int. 44, 1856-1865. https://doi.org/10.1016/j.foodres.2011.04.008

Devasagayam, T.P.A., Boloor, K.K., Ramasarma, T., 2003. Methods for estimating lipid peroxidation: An analysis of merits and demerits. Indian J. Biochem. Biophys. 40, 300-308.

Dias, M.I., Sousa, M.J., Alves, R.C., Ferreira, I.C.F.R., 2016. Exploring plant tissue culture to improve the production of phenolic compounds: A review. Ind. Crops Prod. 82, 9-22. https://doi.org/10.1016/j.indcrop.2015.12.016

Donkin, R.A., 1977. Spanish Red: An Ethnogeographical Study of Cochineal and the Opuntia Cactus. Trans. Am. Philos. Soc. 67, 184. https://doi.org/10.2307/1006195

Esatbeyoglu, T., Wagner, A.E., Schini-Kerth, V.B., Rimbach, G., 2015a. Betanin--a food colorant with biological activity. Mol. Nutr. Food $\quad$ Res. 59, 36-47. https://doi.org/10.1002/mnfr.201400484

Esatbeyoglu, T., Wagner, A.E., Schini-Kerth, V.B., Rimbach, G., 2015b. Betanin-A food colorant with biological activity. Mol. Nutr. Food Res. 59, 36-47. https://doi.org/10.1002/mnfr.201400484

Espinel-Ingroff, A., 2001. Comparison of the E-test with the NCCLS M38-P method for antifungal susceptibility testing of common and emerging pathogenic filamentous fungi. J. Clin. Microbiol. 39, 1360-1367. https://doi.org/10.1128/JCM.39.4.13601367.2001

Esquivel, P., 2016. Handbook on Natural Pigments in Food and Beverages Industrial Applications for Improving Food Colorl, in: Carle, R., Schweiggert, R.M. (Eds.). Woodhead Publishing, San Pedro, Costa Rica, pp. 81-99.

FAO, $2016 . \quad$ FAOSTAT. URL http://www.fao.org/faostat/en/?\#data/QC/visualize (accessed 5.3.18).

FAO, 2004. AVOCADO: Post-Harvest Operation. Rome. 
FAO, IFAD, WFP, 2015. The State of Food Insecurity in the World. Meeting the 2015 international hunger targets: taking stock of uneven progress. Rome.

Farag, M.A., Maamoun, A.A., Ehrlich, A., Fahmy, S., Wesjohann, L.A., 2017. Assessment of sensory metabolites distribution in 3 cactus Opuntia ficus-indica fruit cultivars using UV fingerprinting and GC/MS profiling techniques. LWT - Food Sci. Technol. 80, 145-154. https://doi.org/10.1016/j.lwt.2017.02.014

Fathordoobady, F., Mirhosseini, H., Selamat, J., Manap, M.Y.A., 2016. Effect of solvent type and ratio on betacyanins and antioxidant activity of extracts from Hylocereus polyrhizus flesh and peel by supercritical fluid extraction and solvent extraction. Food Chem. 202, 70-80. https://doi.org/10.1016/j.foodchem.2016.01.121

FDA, 2017. SCOGS (Select Committee on GRAS Substances). URL http://www.accessdata.fda.gov/scripts/fdcc/?set=SCOGS (accessed 3.14.17).

FDA, 2007. Guidance for Industry and Other Stakeholders Toxicological Principles for the Safety Assessment of Food Ingredients, Human Studies.

Fernández-López, J. a., Almela, L., 2001. Application of highperformance liquid chromatography to the characterization of the betalain pigments in prickly pear fruits. J. Chromatogr. A 913, 415-420. https://doi.org/10.1016/S0021-9673(00)01224-3

Fernandez-Rojas, B., Ortiz-Moreno, A., Hernandez-Navarro, D., 2010. Phenolic Content and its Antioxidant Activity of Persimmon (Dyospiros kaki L.) Cultivated in Mexico. J. Biotechnol. 150. https://doi.org/10.1016/j.jbiotec.2010.09.289

Ferreira, I.C.F.R., Martins, N., Barros, L., 2017. Phenolic Compounds and Its Bioavailability: In Vitro Bioactive Compounds or Health Promoters? Adv. Food Nutr. Res. 82, 1-44. https://doi.org/10.1016/bs.afnr.2016.12.004

Ferreres, F., Grosso, C., Gil-Izquierdo, A., Valentão, P., Mota, A.T., Andrade, P.B., 2017. Optimization of the recovery of high-value compounds from pitaya fruit by-products using microwaveassisted extraction. Food Chem. 230, 463-474. https://doi.org/10.1016/j.foodchem.2017.03.061

Flores-Valdez, C., Luna-Esquivel, J., Ramirez-Moreno, P., 1995. Manejo postcosecha de la tuna para el mercado nacional e 
internacional y Procesamiento y transformación industrial ... Chapingo, Estado de México.

Galanakis, C.M., 2015. Chapter 3 - The universal recovery strategy, Food Waste Recovery. Elsevier Inc. https://doi.org/10.1016/B978-0-12-800351-0.00003-1

Galanakis, C.M., 2012. Recovery of high added-value components from food wastes: Conventional, emerging technologies and commercialized applications. Trends Food Sci. Technol. 26, 6887. https://doi.org/10.1016/j.tifs.2012.03.003

Gandía-Herrero, F., Cabanes, J., Escribano, J., García-Carmona, F., Jimenez-Atienzar, M., 2013. Encapsulation of the most antioxidant betalains in edible matrices as powders of different colors Encapsulation of the most antioxidant betalains in edible matrices as powders of different colors. https://doi.org/10.1021/jf400337g

Gandía-Herrero, F., Escribano, J., García-Carmona, F., 2010. Structural implications on color, fluorescence, and antiradical activity in betalains. Planta 232, 449-460. https://doi.org/10.1007/s00425010-1191-0

Garcia-Castello, E.M., Rodriguez-Lopez, A.D., Mayor, L., Ballesteros, R., Conidi, C., Cassano, A., 2015. Optimization of conventional and ultrasound assisted extraction of flavonoids from grapefruit (Citrus paradisi L.) solid wastes. LWT - Food Sci. Technol. 64, 1114-1122. https://doi.org/10.1016/j.1wt.2015.07.024

García-Cruz, L., Dueñas, M., Santos-Buelgas, C., Valle-Guadarrama, S., Salinas-Moreno, Y., 2017. Betalains and phenolic compounds profiling and antioxidant capacity of pitaya (Stenocereus spp.) fruit from two species (S. Pruinosus and S. stellatus). Food Chem. 234, 111-118. https://doi.org/10.1016/j.foodchem.2017.04.174

Gebhardt, D., 2018. The Economics of Natural Color Pigments. URL https://sensientfoodcolors.com/en-us/researchdevelopment/economics-natural-color-pigments/

Ghasemzadeh, A., Ghasemzadeh, N., 2011. Flavonoids and phenolic acids: Role and biochemical activity in plants and human. J. Med. Plants Res. 5, 6697-6703. https://doi.org/10.5897/JMPR11.363

Gomes-Correa, R.C., de Souza, A.H.P., Calhelha, R.C., Barros, L., Glamoclija, J., Sokovic, M., Peralta, R.M., Bracht, A., Ferreira, I.C.F.R., 2015. Bioactive formulations prepared from fruiting 
bodies and submerged culture mycelia of the Brazilian edible mushroom Pleurotus ostreatoroseus Singer. Food Funct. 6, 21552164. https://doi.org/10.1039/C5FO00465A

Gong, M., Bassi, A., 2016. Carotenoids from microalgae: A review of recent developments. Biotechnol. Adv. 34, 1396-1412. https://doi.org/10.1016/j.biotechadv.2016.10.005

Griffith, M.P., 2004. The origins of an important cactus crop, Opuntia ficus-indica (Cactaceae): New molecular evidence. Am. J. Bot. 91, 1915-1921. https://doi.org/10.3732/ajb.91.11.1915

Guimarães, R., Barros, L., Dueñas, M., Calhelha, R.C., Carvalho, A.M., Santos-Buelga, C., Queiroz, M.J.R.P., Ferreira, I.C.F.R., 2013. Nutrients, phytochemicals and bioactivity of wild Roman chamomile: A comparison between the herb and its preparations. Food Chem. 136, 718-725. https://doi.org/10.1016/j.foodchem.2012.08.025

Guldiken, B., Toydemir, G., Nur Memis, K., Okur, S., Boyacioglu, D., Capanoglu, E., 2016. Home-processed red beetroot (Beta vulgaris L.) products: Changes in antioxidant properties and bioaccessibility. Int. J. Mol. Sci. 17. https://doi.org/10.3390/ijms17060858

GVR, 2016. Natural Antioxidants Market Analysis By Product (Vitamin C, Vitamin E, Polyphenols, Carotenoids) And Segment $\begin{array}{llll}\text { Forecasts } & \text { To } 2022 . & \text { URL }\end{array}$ https://www.grandviewresearch.com/industry-analysis/naturalantioxidants-market

Heleno, S.A., Barros, L., Sousa, M.J., Martins, A., Ferreira, I.C.F.R., 2010. Tocopherols composition of Portuguese wild mushrooms with antioxidant capacity. Food Chem. 119, 1443-1450. https://doi.org/10.1016/j.foodchem.2009.09.025

Henry, B.S., 1996. Natural food colours, in: Natural Food Colorants. Springer US, Boston, MA, pp. 40-79. https://doi.org/10.1007/978-1-4615-2155-6_2

Herbach, K.M., Stintzing, F.C., Carle, R., 2006. Betalain stability and degradation - Structural and chromatic aspects. J. Food Sci. 71, 41-50. https://doi.org/10.1111/j.1750-3841.2006.00022.x

Herbach, K.M., Stintzing, F.C., Carle, R., 2005. Identification of heatinduced degradation products from purified betanin, phyllocactin and hylocerenin by high-performance liquid chromatography/ 
electrospray ionization mass spectrometry. Rapid Commun. Mass

Spectrom. 19, 2603-2616. https://doi.org/10.1002/rcm.2103

Hiwasa-Tanase, K., Ezure, H., 2014. Climateric and non-climateric ripening, in: Nath, P., Bouzayen, M., Mattoo, A.K., Pech, J.C. (Eds.), Fruit Ripening: Physiology, Signalling and Genomics. CABI International, pp. 151-177. https://doi.org/10.1017/CBO9781107415324.004

Hogervorst-Cvejić, J., Atanacković-Krstonošić, M., Bursać, M., Miljić, U., 2017. Polyphenols, in: Nutraceutical and Functional Food Components. Academic Press, pp. 203-258. https://doi.org/10.1016/B978-0-12-805257-0.00007-7

Hollman, P.C., Bijsman, M.N., van Gameren, Y., Cnossen, E.P., de Vries, J.H., Katan, M.B., 1999. The sugar moiety is a major determinant of the absorption of dietary flavonoid glycosides in man. Free Radic. Res. 31, 569-573. https://doi.org/10.1080/10715769900301141

Hurtado-Fernández, E., Fernandez-Gutierrez, A., Carrasco-Pancorbo, A., 2018a. Avocado fruit, in: Rodrigues, S., de Oliveira, E., Sousa, E. (Eds.), Exotic Fruits. Academic Press, London, pp. 37-46.

Hurtado-Fernández, E., Pacchiarotta, T., Longueira-Suárez, E., Mayboroda, O.A., Fernández-Gutiérrez, A., Carrasco-Pancorbo, A., 2013. Evaluation of gas chromatography-atmospheric pressure chemical ionization-mass spectrometry as an alternative to gas chromatography-electron ionization-mass spectrometry: Avocado fruit as example. J. Chromatogr. A 1313, 228-244. https://doi.org/10.1016/j.chroma.2013.08.084

Hurtado-Fernández, E., Pacchiarotta, T., Mayboroda, O.A., FernándezGutiérrez, A., Carrasco-Pancorbo, A., 2014. Quantitative characterization of important metabolites of avocado fruit by gas chromatography coupled to different detectors (APCI-TOF MS and FID). Food Res. Int. 62, 801-811. https://doi.org/10.1016/j.foodres.2014.04.038

Hussain, Z., Thu, H.E., Amjad, M.W., Hussain, F., Ahmed, T.A., Khan, S., 2017. Exploring recent developments to improve antioxidant, anti-inflammatory and antimicrobial efficacy of curcumin: A review of new trends and future perspectives. Mater. Sci. Eng. C. https://doi.org/10.1016/j.msec.2017.03.226

IFIC, FDA, 2010. Overview of Food Ingredients, Additives and Colors. URL 
https://www.fda.gov/food/ingredientspackaginglabeling/foodadd itivesingredients/ucm094211.htm

Inglese, P., Giugliuzza, G., Liguori, G., 2004. Cactus pear fruit production: from knowledge to development, in: Esparza-Frausto, G., Valdez-Cepeda, R.D., Méndez- Gallego, S.J. (Eds.), El Nopal.Tópicos de Actualidad. Universidad Autónoma de Chapingo. Colegio de Postgraduados, México, pp. 89-108.

IUPAC, IUPAC-IUB, 1976. Nomenclature of cyclitols. Biochem. J. 153, 23-31. https://doi.org/10.1351/pac197437010283

Jain, G., Gould, K.S., 2015. Are betalain pigments the functional homologues of anthocyanins in plants? Environ. Exp. Bot. 119, 48-53. https://doi.org/10.1016/J.ENVEXPBOT.2015.06.002

Jain, T., Grover, K., Kaur, G., 2016. Effect of processing on nutrients and fatty acid composition of garden cress (Lepidium sativum) seeds. Food Chem. 213, 806-812. https://doi.org/10.1016/j.foodchem.2016.07.034

Jimenez-Garcia, S.N., Vazquez-Cruz, M.A., Garcia-Mier, L., Contreras-Medina, L.M., Guevara-González, R.G., Garcia-Trejo, J.F., Feregrino-Perez, A.A., 2018. Phytochemical and Pharmacological Properties of Secondary Metabolites in Berries, in: Therapeutic Foods. Elsevier, pp. 397-427. https://doi.org/10.1016/B978-0-12-811517-6.00013-1

Kaderides, K., Goula, A.M., 2017. Development and characterization of a new encapsulating agent from orange juice by-products. Food Res. Int. 0-1. https://doi.org/10.1016/j.foodres.2017.07.057

Kanner, J., Harel, S., Granit, R., 2001. Betalains - A new class of dietary cationized antioxidants. J. Agric. Food Chem. 49, 51785185. https://doi.org/10.1021/jf010456f

Karamac, M., Estrella, I., Herna, T., Dykes, G. a., Kosińska, A., Karamać, M., Estrella, I., Hernández, T., Bartolomé, B., Dykes, G. a., 2012. Phenolic compound profiles and antioxidant capacity of Persea americana Mill. peels and seeds of two varieties. J. Agric. Food Chem. 60, 4613-4619. https://doi.org/10.1021/jf300090p

Katsube, T., Tsurunaga, Y., Sugiyama, M., Furuno, T., Yamasaki, Y., 2009. Effect of air-drying temperature on antioxidant capacity and stability of polyphenolic compounds in mulberry (Morus alba L.) leaves.

Food

Chem.

113 ,

964-969. 
https://doi.org/10.1016/j.foodchem.2008.08.041

Kaur Kala, H., Mehta, R., Tandey, R., Sen, K.K., Mandal, V., 2016. Ten years of research on phenolics (2005-2015): A status report. Pacific Sci. Rev. A Nat. Sci. Eng. https://doi.org/10.1016/j.psra.2016.07.002

Knight, R.J., Campbell, C.W., 1999. Ecological adaptation and the evolution of modern avocado cultivars. Rev. Chapingo Ser. Hortic. 49-54.

Kosińska, A., Karamać, M., Estrella, I., Hernández, T., Bartolomé, B., Dykes, G.A., 2012. Phenolic compound profiles and antioxidant capacity of Persea americana Mill. peels and seeds of two varieties. J. Agric. Food Chem. 60, 4613-4619. https://doi.org/10.1021/jf300090p

Kris-Etherton, P.M., Hecker, K.D., Bonanome, A., Coval, S.M., Binkoski, A.E., Hilpert, K.F., Griel, A.E., Etherton, T.D., 2002. Bioactive compounds in foods: their role in the prevention of cardiovascular disease and cancer. Am. J. Med. 113, 71-88. https://doi.org/10.1016/S0002-9343(01)00995-0

Kuhnle, G.G., 2012. Nutritional biomarkers for objective dietary assessment. J. Sci. Food Agric. 92, 1145-1149. https://doi.org/10.1002/jsfa.5631

Kuti, J.O., 2004. Antioxidant compounds from four Opuntia cactus pear fruit varieties. Food Chem. 85, 527-533. https://doi.org/10.1016/S0308-8146(03)00184-5

Kyriacou, M.C., Emmanouilidou, M.G., Soteriou, G.A., 2016. Asynchronous ripening behavior of cactus pear (Opuntia ficusindica) cultivars with respect to physicochemical and physiological attributes. Food Chem. 211, 598-607. https://doi.org/10.1016/j.foodchem.2016.05.113

Laqui-Vilca, C., Aguilar-Tuesta, S., Mamani-Navarro, W., MontañoBustamante, J., Condezo-Hoyos, L., 2018. Ultrasound-assisted optimal extraction and thermal stability of betalains from colored quinoa (Chenopodium quinoa Willd) hulls. Ind. Crops Prod. 111, 606-614. https://doi.org/10.1016/j.indcrop.2017.11.034

Lea, A., 2008. Analysis of polyphenol antioxidants in fortified foods and supplements. Food Fortif. Suppl. 175-194. https://doi.org/10.1533/9781845694265.2.175

Leardi, R., 2013. Experimental Design, 1st ed, Data Handling in 
Science and Technology. Copyright (C) 2013 Elsevier B.V. All rights reserved. https://doi.org/10.1016/B978-0-444-595287.00002-8

Li, J., Chen, Z., Di, D., 2012. Preparative separation and purification of Rebaudioside A from Stevia rebaudiana Bertoni crude extracts by mixed bed of macroporous adsorption resins. Food Chem. 132, 268-276. https://doi.org/10.1016/j.foodchem.2011.10.077

Librán, C. M., Mayor, L., Garcia-Castello, E. M., Vidal-Brotons, D., 2013. Polyphenol extraction from grape wastes: Solvent and $\mathrm{pH}$ effect. Agric. Sci. https://doi.org/10.4236/as.2013.49B010

Madrau, M. a., Piscopo, A., Sanguinetti, A.M., Del Caro, A., Poiana, M., Romeo, F. V., Piga, A., 2009. Effect of drying temperature on polyphenolic content and antioxidant activity of apricots. Eur. Food Res. Technol. 228, 441-448. https://doi.org/10.1007/s00217-008-0951-6

Madunić, J., Madunić, I.V., Gajski, G., Popić, J., Garaj-Vrhovac, V., 2018. Apigenin: A dietary flavonoid with diverse anticancer properties. Cancer Lett. 413, 11-22. https://doi.org/10.1016/j.canlet.2017.10.041

Manach, C., Scalbert, A., Morand, C., Rémésy, C., Jiménez, L., 2004. Bioavailability, Polyphenols: Food sources and. Am. J. Clin. Nutr. 79, 727-747. https://doi.org/10.1038/nature05488

Mandal, S.C., Mandal, V., Das, A.K., 2015. Classification of Extraction Methods, in: Essentials of Botanical Extraction. Academic Press, pp. 83-136. https://doi.org/10.1016/B978-0-12-802325-9.000069

Marais, J.P.J., Deavours, B., Dixon, R.A., Ferreira, D., 2006. The science of flavonoids, The Science of Flavonoids. Springer, Ohio. https://doi.org/10.1007/978-0-387-28822-2

Marco, G.J., 1968. A Rapid Method for Evaluation of Antioxidants. J. Am. oil Chem. Soc. 45, 594-598. https://doi.org/10.1007/BF02668958

Maria, J., Andrade, D.M., Fasolo, D., 2014. Polyphenol Antioxidants from Natural Sources and Contribution to Health Promotion, Polyphenols in Human Health and Disease. Elsevier Inc. https://doi.org/10.1016/B978-0-12-398456-2.00020-7

Martins, N., Roriz, C.L., Morales, P., Barros, L., Ferreira, I.C.F.R., 
2016. Food colorants: Challenges, opportunities and current desires of agro-industries to ensure consumer expectations and regulatory practices. Trends Food Sci. Technol. 52, 1-15. https://doi.org/10.1016/j.tifs.2016.03.009

Mata, A., Ferreira, J.P., Semedo, C., Serra, T., Duarte, C.M.M., Bronze, M.R., 2016. Contribution to the characterization of Opuntia spp. juices by LC-DAD-ESI-MS/MS. Food Chem. 210, 558-565. https://doi.org/10.1016/j.foodchem.2016.04.033

Mayor, L., Calvo, A., Moreira, R., Fito, P., Garcia-Castello, E., 2013. Water sorption isotherms of globe artichoke leaves. Agric. Sci. 04, 63-69. https://doi.org/10.4236/as.2013.49B011

McGuire, S., 2011. U.S. Department of Agriculture and U.S. Department of Health and Human Services, Dietary Guidelines for Americans, 2010. 7th Edition, Washington, DC: U.S. Government Printing Office, January 2011. Adv. Nutr. 2, 293294. https://doi.org/10.3945/an.111.000430

Medina-Meza, I.G., Barbosa-Cánovas, G. V., 2015. Assisted extraction of bioactive compounds from plum and grape peels by ultrasonics and pulsed electric fields. J. Food Eng. 166, 268-275. https://doi.org/10.1016/j.jfoodeng.2015.06.012

Melgar, B., Dias, M.I., Ciric, A., Sokovic, M., Garcia-Castello, E.M., Rodriguez-Lopez, A.D., Barros, L., Ferreira, I., 2017a. Byproduct recovery of Opuntia spp. peels: Betalainic and phenolic profiles and bioactive properties. https://doi.org/10.1016/j.indcrop.2017.06.011

Melgar, B., Pereira, E., Oliveira, M.B.P.P., Garcia-Castello, E.M., Rodriguez-Lopez, A.D., Sokovic, M., Barros, L., Ferreira, I.C.F.R., 2017b. Extensive profiling of three varieties of Opuntia spp. fruit for innovative food ingredients. Food Res. Int. 101, 259265. https://doi.org/10.1016/j.foodres.2017.09.024

Mena, P., Tassotti, M., Andreu, L., Nuncio-Jáuregui, N., Legua, P., Del Rio, D., Hernández, F., 2018. Phytochemical characterization of different prickly pear (Opuntia ficus-indica (L.) Mill.) cultivars and botanical parts: UHPLC-ESI-MSnmetabolomics profiles and their chemometric analysis. Food Res. Int. 108, 301-308. https://doi.org/10.1016/j.foodres.2018.03.062

Mirabella, N., Castellani, V., Sala, S., 2014. Current options for the valorization of food manufacturing waste: a review. J. Clean. Prod.

65 , $28-41$. 
https://doi.org/10.1016/J.JCLEPRO.2013.10.051

Mishra, A., Sharma, A.K., Kumar, S., Saxena, A.K., Pandey, A.K., 2013. Bauhinia variegata leaf extracts exhibit considerable antibacterial, antioxidant, and anticancer activities. Biomed Res. Int. 2013. https://doi.org/10.1155/2013/915436

Mishra, A.K., Mishra, A., Kehri, H.K., Sharma, B., Pandey, A.K., 2009. Inhibitory activity of Indian spice plant Cinnamomum zeylanicum extracts against Alternaria solani and Curvularia lunata, the pathogenic dematiaceous moulds. Ann. Clin. Microbiol. Antimicrob. 8, 9. https://doi.org/10.1186/1476-07118-9

Monks, A., Scudiero, D., Skehan, P., Shoemaker, R., Paull, K., Vistica, D., Hose, C., Langley, J., Cronise, P., Vaigro-wolff, A., Graygoodrich, M., Campbell, H., Boyd, M., 1991. Feasibility of a High-Flux Anticancer Drug Screen Using a Diverse Panel of Cultured. J. Natl. Cancer Inst. 83, 757-766.

Morales, P., Barros, L., Ramírez-Moreno, E., Santos-Buelga, C., Ferreira, I.C.F.R., 2015. Xoconostle fruit (Opuntia matudae Scheinvar cv. Rosa) by-products as potential functional ingredients. Food Chem. 185, 289-97. https://doi.org/10.1016/j.foodchem.2015.04.012

Morales, P., Barros, L., Ramírez-Moreno, E., Santos-Buelga, C., Ferreira, I.C.F.R., 2014. Exploring xoconostle by-products as sources of bioactive compounds. Food Res. Int. 65, 437-444. https://doi.org/10.1016/j.foodres.2014.05.067

Morales, P., Ramírez-Moreno, E., Sanchez-Mata, M.D.C., Carvalho, A.M., Ferreira, I.C.F.R., 2012. Nutritional and antioxidant properties of pulp and seeds of two xoconostle cultivars (Opuntia joconostle F.A.C. Weber ex Diguet and Opuntia matudae Scheinvar) of high consumption in Mexico. Food Res. Int. 46. https://doi.org/10.1016/j.foodres.2011.12.031

Moreno, J., Peinado, R., 2012. Polyphenols, in: Moreno, J., Peinado, R. (Eds.), Enological Chemistry. Academic Press, pp. 53-76. https://doi.org/10.1016/B978-0-12-388438-1.00005-4

Naik, S.N., Goud, V. V., Rout, P.K., Dalai, A.K., 2010. Production of first and second generation biofuels: A comprehensive review. Renew. Sustain. Energy Rev. 14, 578-597. https://doi.org/10.1016/j.rser.2009.10.003 
Nicoletti, M., 2012. Nutraceuticals and botanicals: overview and perspectives. Int. J. Food Sci. Nutr. 63, 2-6. https://doi.org/10.3109/09637486.2011.628012

$\mathrm{NIH}$, 2017. Vitamin E - Fact sheet for Consumer. URL https://ods.od.nih.gov/factsheets/VitaminE-Consumer/ (accessed 3.14.17).

Nobel, P.S., 1998. Los incomparables agaves y cactos. Trillas, México.

Novoa, A., Le Roux, J.J., Robertson, M.P., Wilson, J.R.U., Richardson, D.M., 2015. Introduced and invasive cactus species: A global review. AoB Plants 7. https://doi.org/10.1093/aobpla/plu078

Ochoa, M. judith, Barbera, G., 2017. History and economic and agroecological importance, in: Crop Ecology, Cultivation and Uses of Catus Pears. FAO, ICARDA, pp. 1-11.

Osborn, S., 2015. 12 - Labelling relating to natural ingredients and additives, in: Advances in Food and Beverage Labelling. pp. 207221. https://doi.org/10.1533/9781782420934.3.207

Paciulli, M., Medina-Meza, I.G., Chiavaro, E., Barbosa-Cánovas, G.V., 2016. Impact of thermal and high pressure processing on quality parameters of beetroot (Beta vulgaris L.). LWT - Food Sci. Technol. 68, 98-104. https://doi.org/10.1016/j.lwt.2015.12.029

Patel, D., Shukla, S., Gupta, S., 2007. Apigenin and cancer chemoprevention: Progress, potential and promise (Review). Int. J. Oncol. 30, 233-245. https://doi.org/10.3892/ijo.30.1.233

Pedreño, M.A., Escribano, J., 2000. Studying the oxidation and the antiradical activity of betalain from beetroot. J. Biol. Educ. 35, 49-51. https://doi.org/10.1080/00219266.2000.9655736

Peláez-Cid, A. A., Velázquez-Ugalde, I., Herrera-González, a. M., García-Serrano, J., 2013. Textile dyes removal from aqueous solution using Opuntia ficus-indica fruit waste as adsorbent and its characterization. J. Environ. Manage. 130, 90-97. https://doi.org/10.1016/j.jenvman.2013.08.059

Pereira, C., Barros, L., Carvalho, A.M., Ferreira, I.C.F.R., 2011. Nutritional composition and bioactive properties of commonly consumed wild greens: Potential sources for new trends in modern diets. Food Res. Int. 44, 2634-2640. https://doi.org/10.1016/j.foodres.2011.05.012

Pereira, E., Barros, L., Calhelha, R.C., Duenas, M., Carvalho, A.M., Santos-Buelga, C., Ferreira, I.C.F.R., 2014. Bioactivity and 
phytochemical characterization of Arenaria montana L. Food Funct. 5, 1848-1855. https://doi.org/10.1039/c4fo00210e

Pereira, E., Barros, L., Martins, A., Ferreira, I.C.F.R., 2012. Towards chemical and nutritional inventory of Portuguese wild edible mushrooms in different habitats. Food Chem. 130, 394-403. https://doi.org/10.1016/j.foodchem.2011.07.057

Piattelli, M., Minale, L., Prota, G., 1964. Isolation, structure and absolute configuration of indicaxanthin. Tetrahedron 20, 23252329. https://doi.org/10.1016/S0040-4020(01)97621-5

Pimienta, E., 1990. El nopal tunero. Libros de tiempos de ciencia ;5.

Pimiento Barrios, E., Munoz-Urias, A., 1999. Domesticacion de nopales tuneros (Opuntis spp.) y descripcion de las principales variedades cultivadas. FAO, Rome (Italy).

Pinela, J., Prieto, M.A., Barreiro, M.F., Carvalho, A.M., Oliveira, M.B.P.P., Vázquez, J.A., Ferreira, I.C.F.R., 2016. Optimization of microwave-assisted extraction of hydrophilic and lipophilic antioxidants from a surplus tomato crop by response surface methodology. Food Bioprod. Process. 98, 283-298. https://doi.org/10.1016/j.fbp.2016.02.002

Primorac, T., Požar, M., Sokolić, F., Zoranić, L., Urbic, T., 2018. A simple two dimensional model of methanol. J. Mol. Liq. 262, 4657. https://doi.org/10.1016/j.molliq.2018.04.055

Quideau, S., Deffieux, D., Douat-Casassus, C., Pouysegu, L., 2011. Plant polyphenols: chemical properties, biological activities, and synthesis. Angew. Chem. Int. Ed. Engl. 50, 586-621. https://doi.org/10.1002/anie.201000044

Rached, W., Calhelha, R.C., Fernandes, Â., Carvalho, A.M., Bennaceur, M., Marouf, A., Barros, L., Santos-Buelga, C., Ferreira, I.C.F.R., 2016. Phytochemical characterization and bioactive properties of Osyris quadripartita Salzm. ex Decne. leaves from Algeria. RSC Adv. 6, 72768-72776. https://doi.org/10.1039/C6RA11787B

Ramos-Jerz, M.D.R., Villanueva, S., Jerz, G., Winterhalter, P., Deters, A.M., 2013. Persea americana Mill. Seed: Fractionation, Characterization, and Effects on Human Keratinocytes and Fibroblasts. Evidence-based Complement. Altern. Med. eCAM 2013, 391247. https://doi.org/10.1155/2013/391247

Rao, G., 2010. Optimization of ultrasound-assisted extraction of 
cyanidin 3-rutinoside from litchi (Lichi chinensis Sonn.) fruit pericarp. Anal. Methods 2, 1166. https://doi.org/10.1039/c0ay00203h

Ravichandran, K., Saw, N.M.M.T., Mohdaly, A.A.A., Gabr, A.M.M., Kastell, A., Riedel, H., Cai, Z., Knorr, D., Smetanska, I., 2013. Impact of processing of red beet on betalain content and antioxidant activity. Food Res. Int. 50, 670-675. https://doi.org/10.1016/j.foodres.2011.07.002

Raymond Chia, T.W., Dykes, G. A, 2010. Antimicrobial activity of crude epicarp and seed extracts from mature avocado fruit (Persea americana) of three cultivars. Pharm. Biol. 48, 753-756. https://doi.org/10.3109/13880200903273922

Reis, F.S., Barreira, J.C.M., Calhelha, R.C., van Griensven, L.J.I.D., Ćirić, A., Glamočlija, J., Soković, M., Ferreira, I.C.F.R., 2014. Chemical characterization of the medicinal mushroom Phellinus linteus (Berkeley \& Curtis) Teng and contribution of different fractions to its bioactivity. LWT - Food Sci. Technol. 58, 478485. https://doi.org/10.1016/j.lwt.2014.04.013

Reyes-Agüero, J.A., Aguirre, J.R., Hernández, H., 2005. Systematyc notes and a Detailed description of Opuntia ficus-indica (L) Mill. (CACTACEAE). Agrociencia 39, 395-408.

Reynolds, S.G., Arias, E., 2003. Opuntia Spp. -A Strategic fodder and efficient tool for combat desertification in the Wana Region, Cactus (Opuntia spp.) as forage. FAO Plant Production and Protection Paper 169.

Roberfroid, M.B., 2000. Concepts and strategy of functional food science: the European perspective. Am. J. Clin. Nutr. 71, 1660S4S; $\quad$ discussion https://doi.org/10.1093/ajen/71.6.1660S

1674S-5S.

Rodrigo, D., Martínez-1, A., 2015. Antimicrobial activity of cauli fl ower (Brassica oleracea var . Botrytis) by-product against Listeria monocytogenes 50, 435-440. https://doi.org/10.1016/j.foodcont.2014.09.031

Rodríguez-Carpena, J.G., Morcuende, D., Estévez, M., 2011. Avocado by-products as inhibitors of color deterioration and lipid and protein oxidation in raw porcine patties subjected to chilled storage. Meat Sci. 89, 166-173. https://doi.org/10.1016/j.meatsci.2011.04.013 
Rohwer, J.G., 1993. Lauraceae, in: The Families and Genera of Vascular Plants Free Preview, Volume II, Flowering Plants . Dicotyledons. Springer, Berlin, pp. 366-391. https://doi.org/10.1007/978-3-662-02899-5

Roriz, C.L., Barros, L., Prieto, M.A., Morales, P., Ferreira, I.C.F.R., 2017. Floral parts of Gomphrena globosa L. as a novel alternative source of betacyanins: Optimization of the extraction using response surface methodology. Food Chem. 229, 223-234. https://doi.org/10.1016/j.foodchem.2017.02.073

Saavedra, J., Córdova, A., Navarro, R., Díaz-Calderón, P., Fuentealba, C., Astudillo-Castro, C., Toledo, L., Enrione, J., Galvez, L., 2017. Industrial avocado waste: Functional compounds preservation by convective drying process. J. Food Eng. 198, 81-90. https://doi.org/10.1016/j.jfoodeng.2016.11.018

Sáenz, C., 2006. Utilización agroindustrial del nopal. Boletín Serv. Agrícolas La Fao 162, 165.

SAGARPA, 2011. Monografía de cultivos. Aguacate. México city.

Sansano, S., Rivas, A., Pina-Pérez, M.C., Martinez, A., Rodrigo, D., 2017. Stevia rebaudiana Bertoni effect on the hemolytic potential of Listeria monocytogenes, International Journal of Food Microbiology. https://doi.org/10.1016/j.jifoodmicro.2017.03.006

SARAVACOS, G.D., 2014. Mass Transfer Properties of Foods 346399. https://doi.org/10.1201/9781420028805-11

Sawicki, T., Wiczkowski, W., 2018. The effects of boiling and fermentation on betalain profiles and antioxidant capacities of red beetroot products. Food Chem. 259, 292-303. https://doi.org/10.1016/j.foodchem.2018.03.143

Shahidi, F., Ambigaipalan, P., 2015. Phenolics and polyphenolics in foods, beverages and spices: Antioxidant activity and health effects - A review. J. Funct. Foods. https://doi.org/10.1016/j.jff.2015.06.018

Sharma, K., Mahato, N., Cho, M.H., Lee, Y.R., 2017. Converting citrus wastes into value-added products: Economic and environmently friendly approaches. Nutrition 34, 29-46. https://doi.org/10.1016/j.nut.2016.09.006

Šiler, B., Živković, S., Banjanac, T., Cvetković, J., Nestorović Živković, J., Ćirić, A., Soković, M., Mišić, D., 2014. Centauries as underestimated food additives: Antioxidant and antimicrobial 
potential. Food Chem. 147, 367-376. https://doi.org/10.1016/j.foodchem.2013.10.007

Silva, P., Ferreira, S., Nunes, F.M., 2016. Elderberry (Sambucus nigra L.) by-products a source of anthocyanins and antioxidant polyphenols. Ind. Crops Prod. https://doi.org/10.1016/j.indcrop.2016.10.018

Singleton, V.L., Rossi, J.A., 1965. Colorimetry of Total Phenolics with Phosphomolybdic-Phosphotungstic Acid Reagents. Am. J. Enol. Vitic. 16, 144-158. https://doi.org/10.12691/ijebb-2-1-5

Song, F.L., Gan, R.Y., Zhang, Y., Xiao, Q., Kuang, L., Li, H. Bin, 2010. Total phenolic contents and antioxidant capacities of selected chinese medicinal plants. Int. J. Mol. Sci. 11, 2362-2372. https://doi.org/10.3390/ijms11062362

Spórna-Kucab, A., Ignatova, S., Garrard, I., Wybraniec, S., 2013. Versatile solvent systems for the separation of betalains from processed Beta vulgaris L. juice using counter-current chromatography. J. Chromatogr. B Anal. Technol. Biomed. Life Sci. 941, 54-61. https://doi.org/10.1016/j.jchromb.2013.10.001

Stintzing, F., Schieber, A., Carle, R., 2000. Cactus pear-a promising component to functional food. Obs. Kartof. 85, 40-47.

Stintzing, F.C., Herbach, K.M., Mosshammer, M.R., Carle, R., Yi, W., Sellappan, S., Akoh, C.C., Bunch, R., Felker, P., 2005. Color, betalain pattern, and antioxidant properties of cactus pear (Opuntia spp.) clones. J. Agric. Food Chem. 53, 442-451. https://doi.org/10.1021/jf048751y

Stintzing, F.C., Schieber, A., Carle, R., 2002. Betacyanins in fruits from red-purple pitaya, Hylocereus polyrhizus (Weber) Britton \&amp; Rose. Food Chem. 77, 101-106. https://doi.org/10.1016/S03088146(01)00374-0

Strack, D., Vogt, T., Schliemann, W., 2003. Recent advances in betalain research. Phytochemistry 62, 247-269. https://doi.org/10.1016/S0031-9422(02)00564-2

Sudzuki, F., Muñoz, C., Berger, H., 1993. El cultivo de la tuna (cactus pear)., 1 ed. ed. Departamento de Reproducción Agrícola. Universidad de Chile, Santiago., Santiago, Chile.

Svenson, J., Smallfield, B.M., Joyce, N.I., Sansom, C.E., Perry, N.B., 2008. Betalains in red and yellow varieties of the andean tuber crop ulluco (Ullucus tuberosus). J. Agric. Food Chem. 56, 7730- 
7737. https://doi.org/10.1021/jf8012053

Sýs, M., Švecová, B., Švancara, I., Metelka, R., 2017. Determination of vitamin $\mathrm{E}$ in margarines and edible oils using square wave anodic stripping voltammetry with a glassy carbon paste electrode. Food Chem. 229, 621-627. https://doi.org/10.1016/j.foodchem.2017.02.068

Szot, D., Skopińska, A., Wybraniec, S., 2015. Decomposition of 17decarboxy-betanin in selected aqueous-organic solutions induced by $\mathrm{Cu}$ ( II ) cations. PhD Interdiscip. J. Politech. Gdansk Univ. 1, 217-223.

Takshak, S., Agrawal, S.B., 2015. Defence strategies adopted by the medicinal plant Coleus forskohlii against supplemental ultraviolet-B radiation: Augmentation of secondary metabolites and antioxidants. Plant Physiol. Biochem. 97, 124-138. https://doi.org/10.1016/j.plaphy.2015.09.018

Thirugnanasambandham, K., Sivakumar, V., 2017. Microwave assisted extraction process of betalain from dragon fruit and its antioxidant activities. J. Saudi Soc. Agric. Sci. 16, 41-48. https://doi.org/10.1016/j.jssas.2015.02.001

Timilsena, Y.P., Wang, B., Adhikari, R., Adhikari, B., 2017. Advances in microencapsulation of polyunsaturated fatty acids (PUFAs)rich plant oils using complex coacervation: A review. Food Hydrocoll. 69 , 369-381. https://doi.org/10.1016/j.foodhyd.2017.03.007

Timpanaro, G., Urso, A., Spampinato, D., Foti, V., 2015. Cactus pear market in Italy: Competitiveness and perspectives. Acta Hortic. 1067.

Torres, M.D., Chenlo, F., Moreira, R., 2018. Structural features and water sorption isotherms of carrageenans: A prediction model for hybrid carrageenans. Carbohydr. Polym. 180, 72-80. https://doi.org/10.1016/J.CARBPOL.2017.10.010

Tretter, L., Patocs, A., Chinopoulos, C., 2016. Succinate, an intermediate in metabolism, signal transduction, ROS, hypoxia, and tumorigenesis. Biochim. Biophys. Acta - Bioenerg. 1857, 1086-1101. https://doi.org/10.1016/j.bbabio.2016.03.012

Tsuchiya, H., Iinuma, M., 2000. Reduction of membrane fluidity by antibacterial sophoraflavanone G isolated from Sophora exigua. Phytomedicine 7, 161-165. https://doi.org/10.1016/S0944- 


\section{3(00)80089-6}

UN DESA, 2015. World Population Prospects: The 2015 Revision. New York.

Unilever, 2010. The Unilever Sustainable Living Plan.

Vieira, V., Barros, L., Martins, A., Ferreira, I., 2016a. Nutritional and Biochemical Profiling of Leucopaxillus candidus (Bres.) Singer Wild Mushroom. Molecules 21, 99. https://doi.org/10.3390/molecules21010099

Vieira, V., Fernandes, Â., Barros, L., Glamočlija, J., Ćirić, A., Stojković, D., Martins, A., Soković, M., Ferreira, I.C.F.R., 2016b. Wild Morchella conica Pers. from different origins: A comparative study of nutritional and bioactive properties. J. Sci. Food Agric. 96, 90-98. https://doi.org/10.1002/jsfa.7063

Vinatoru, M., 2001. An overview of the ultrasonically assisted extraction of bioactive principles from herbs. Ultrason. Sonochem. 8, 303-313. https://doi.org/10.1016/S13504177(01)00071-2

Wang, W., Bostic, T.R., Gu, L., 2010. Antioxidant capacities, procyanidins and pigments in avocados of different strains and cultivars. Food Chem. 122, 1193-1198. https://doi.org/10.1016/j.foodchem.2010.03.114

Watada, A.E., Herner, R.C., Kader, A.A., Romani, R.J., Staby, G.L., 1984. Terminology for the description of developmental stages of horticultural crops. HortScience.

Weinstein, M.P., 2012. Methods for Dilution Antimicrobial Susceptibility Tests for Bacteria That Grow Aerobically; Approved Standard - Ninth Edition, Methods for Dilution Antimicrobial Susceptibility Tests for Bacteria That Grow Aerobically; Approved Standar- Ninth Edition. https://doi.org/10.4103/0976-237X.91790

WHO, 2014. GLOBAL STATUS REPORT on noncommunicable diseases 2014. Attaining the nine global noncommunicable diseases targets; a shared responsibility

Wrolstad, R.E., Culver, C.A., 2012. Alternatives to those artificial FD\&C food colorants. Annu. Rev. Food Sci. Technol. 3, 59-77. https://doi.org/10.1146/annurev-food-022811-101118

Wybraniec, S., Starzak, K., Szneler, E., Pietrzkowski, Z., 2016. Separation of chlorinated diastereomers of decarboxy- 
betacyanins in myeloperoxidase catalyzed chlorinated Beta vulgaris L. extract. J. Chromatogr. B Anal. Technol. Biomed. Life Sci. 1036-1037, 20-32. https://doi.org/10.1016/j.jchromb.2016.09.040

Yahia, E.M., Woolf, A.B., 2011. Avocado (Persea americana Mill.), in: Postharvest Biology and Technology of Tropical and Subtropical Fruits: Volume 2: Açai to Citrus. Woodhead Publishing, pp. 125-185. https://doi.org/10.1533/9780857092762.125

Yamashita, C., Chung, M.M.S., dos Santos, C., Mayer, C.R.M., Moraes, I.C.F., Branco, I.G., 2017. Microencapsulation of an anthocyanin-rich blackberry (Rubus spp.) by-product extract by freeze-drying. LWT - Food Sci. Technol. 84, 256-262. https://doi.org/10.1016/j.lwt.2017.05.063

Yeddes, N., Chérif, J., Guyot, S., Sotin, H., Ayadi, M., 2013. Comparative Study of Antioxidant Power, Polyphenols, Flavonoids and Betacyanins of the Peel and Pulp of Three Tunisian Opuntia Forms. Antioxidants 2, 37-51. https://doi.org/10.3390/antiox2020037

Zhishen, J., Mengcheng, T., Jianming, W., 1999. The determination of flavonoid contents in mulberry and their scavenging effects on superoxide radicals. Food Chem. https://doi.org/10.1016/S03088146(98)00102-2 




\section{Capítulo 5 \\ CARACTERIZACIÓN DE LOS FRUTOS DE LAS ESPECIES OPUNTIA SPP}





\section{V.1 ANTECEDENTES}

De la misma manera que en el capítulo 4, antes de realizar el trabajo experimental de los subproductos de Opuntia spp. del cual se publicó el segundo artículo incluido mas adelante en esta Tesis Doctoral, se realizaron algunos análisis que permitieron de una manera más rápida cribar información que permitió seleccionar metodologías óptimas para los posteriores análisis y que de detallan acontinuación.

La información reportada en este apartado consiste básicamente en la descripción rápida de detección de betalaínas.

\section{V.1.1 Metodología rápida de detección de betalaínas}

Con la finalidad de seleccionar rápidamente especies de frutos de Opuntia con concentraciones importantes de betalaínas, se realizó la determinación de ellas mediante el método espectrofotométrico citado en el apartado III.8.3 de la sección de material y métodos.

Para la detección de estas moléculas, se realizaron extracciones de las pieles usando etanol al $20 \%$ como solvente de extracción, agitándolas en un agitador orbital de movimiento alternativo a $190 \mathrm{rpm}$ por $20 \mathrm{~min}$, posteriormente se centrifugaron a $10000 \mathrm{~g}$ y los sobrenadante se filtraron a través de filtros de nylon de $0,45 \mu \mathrm{m}$. Posteriormente, se realizó un barrido espectrofotométrico desde los 400 hasta las $600 \mathrm{~nm}$ y a partir de la Ecuación 3-4 descrita por Cassano et al. (2007) se calcularon los valores estimados de las concentraciones de betacianinas y betaxantinas.

En las Figuras 5-1 y 5-2 se muestran los barridos obtenidos de OFI var Gialla y OFI var Sanguigna respectivamente. Estos barridos resultan de mucha ayuda al ser un método visual por medio del cual se pueden identificar la existencia o ausencia de betacianinas y betaxantinas de una manera muy rápida. Aunque los valores son más del tipo cualitativo que cuantitativo, esta sencilla técnica nos permite seleccionar las variedades de mayor interés a estudiar, antes de realizar extracciones con mayor grado de complejidad y análisis mas específicos. 


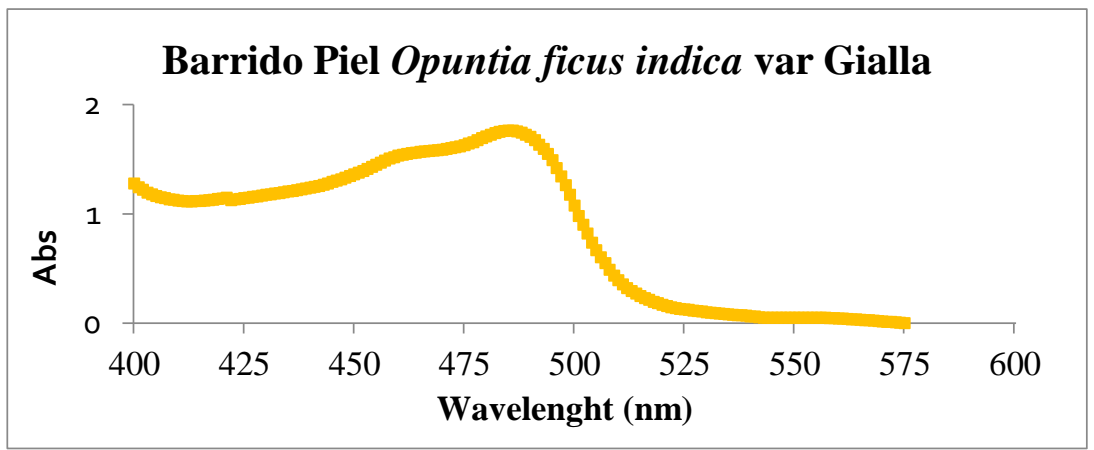

Figure 5-1 Screening of betalains in OFI var Gialla (source: private collection)

En la Figura 5-1 podemos observar una absorción máxima alrededor de los $480 \mathrm{~nm}$, distancia a la cual las betaxantinas absorben mayormente la luz y reflejan su coloración típica amarillenta (Castellar et al., 2003). Por otra parte, en la Figura 5-2 observamos 2 picos de absorción máximos, alrededor de los $480 \mathrm{~nm}$ correspondiente a las betaxantinas, pero además otro alrededor de los $535 \mathrm{~nm}$, que según (Fernández-López and Almela, 2001) representa la distancia de absorción máxima de la betanina, la molécula más abundante y representativa de las betacianinas. Con lo que podemos observar de manera rápida, como las pieles de OFI var Sanguigna, poseen una combinación de ambas moléculas colorantes de la familia de las betalaínas.

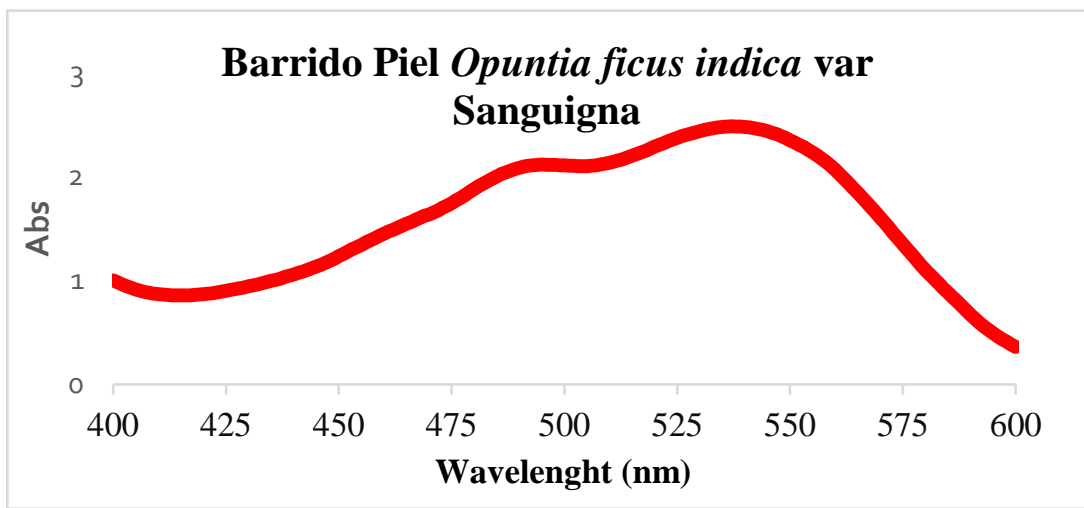

Figure 5-2 Screening of betalains in OFI var Sanguigna (source: private collection) 
Se debe de tener en cuenta que los picos a $480 \mathrm{~nm}$ (representativo de indicaxantina) y a $535 \mathrm{~nm}$ (representativo de betanina), no muestran en ningún caso exclusividad los dos compuestos representativos, sino, un cúmulo de moléculas con estructuras muy similares. Además, se deben de tener muy en cuenta los efectos hipsocrómicos y batcrómicos que presenta la glucosilación, metilación o cualquier otro tipo de anexión de las agliconas (Esquivel, 2016). De acuerdo con lo anterior mencionado, esta metodología es recomendada solo como técnica de cribado, ya que si se precisa de mayor información, entonces se debe de recurrir a técnicas analíticas especializadas como se hace más adelante en este capítulo.

Otro de los usos de esta técnica de cribado, lo demostramos con la Figura 5-3, en donde comparamos de manera rápida el efecto del pH en los solventes de extracción. Como podemos observar en la figura, mientras el $\mathrm{pH}$ sea más básico, mejor será la respuesta y los rendimientos de recuperación del contenido de betalaínas. De la misma forma, podemos probar distintas condiciones de extracción de una manera muy rápida que en pruebas posteriores se podrá refinar. Un ejemplo más complejo de extracción de betalaínas se presenta más adelante en el capítulo 7.

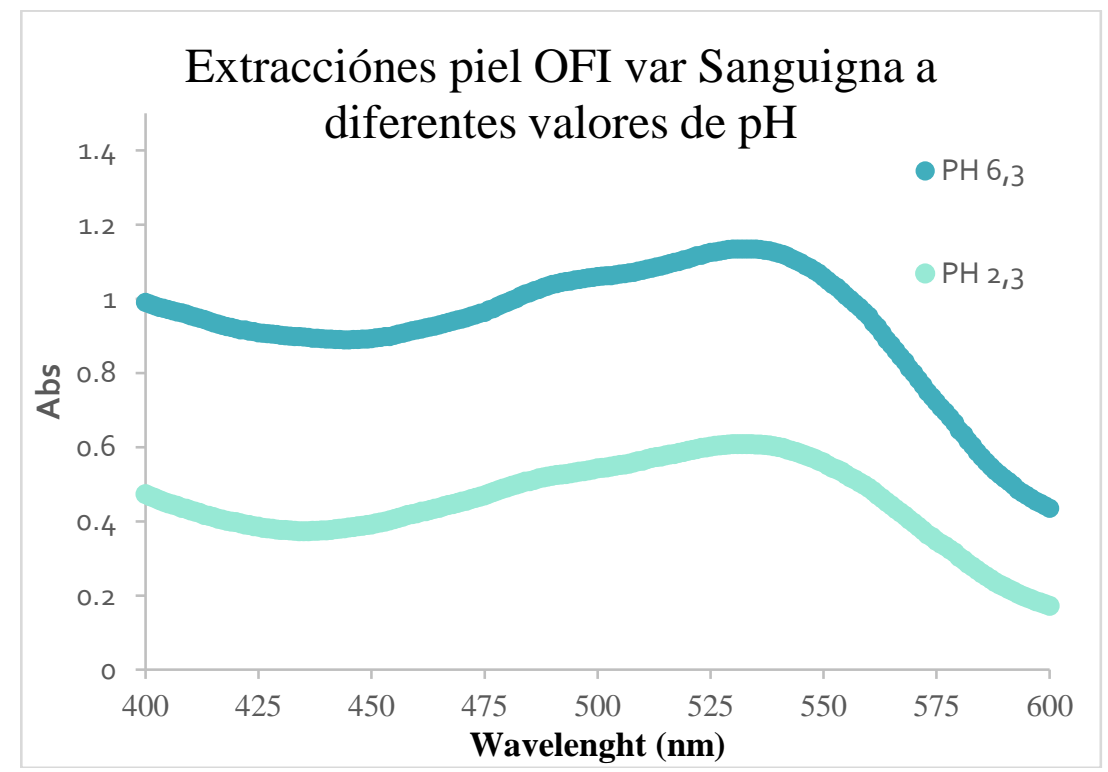

Figure 5-3 Effect of pH on betalain extraction (source: private collection) 


\section{V.2 CARACTERIZACIÓN EXTENSIVA DE TRES VARIEDADES DE FRUTOS DE OPUNTIA SPP. PARA LA INNOVACIÓN DE INGREDIENTES ALIMENTARIOS.}

El presente capítulo consiste en una adaptación al formato de la tesis doctoral del artículo titulado "Extensive profiling of three varieties of Opuntia spp. fruit for innovative food ingredients", publicado en la revista Food Research International. En él, tres especies frutales del genero Opuntia (2 especies de Opuntia ficus-indica y Opuntia engelmannii) fueron caracterizados en términos nutricionales $\mathrm{y}$ funcionales, y evaluadas sus propiedades antimicrobianas, además, una caracterización completa del perfil betalainico fue descrito mediante técnicas cromatográficas. Los datos bibliográficos del artículo se destacan a continuación:

Melgar, B., Pereira, E., Oliveira, M. B. P. P., Garcia-Castello, E. M., Rodriguez-Lopez, A. D., Sokovic, M., Barros, L., Ferreira, I. C. F. R. (2017).

Extensive profiling of three varieties of Opuntia spp. fruit for innovative food ingredients.

Food Research International, 101, 259-265. 
Extensive profiling of three varieties of Opuntia spp. fruit for innovative food ingredients

Bruno Melgar $^{\mathrm{a}, \mathrm{b}}$, Eliana Pereira ${ }^{\mathrm{a}}$, M. Beatriz P.P. Oliveira ${ }^{\mathrm{c}}$, Esperanza M. Garcia-Castello ${ }^{b}$, Antonio D. Rodriguez-Lopez ${ }^{d}$, Marina Sokovic ${ }^{\mathrm{e}}$, Lillian Barros ${ }^{\mathrm{a}}$, Isabel C.F.R. Ferreira ${ }^{\mathrm{a}}$,

${ }^{a}$ Centro de Investigação de Montanha (CIMO), ESA, Instituto Politécnico de Bragança, Campus de Santa Apolónia, 5300-253 Bragança, Portugal

${ }^{b}$ Institute of Food Engineering for Development, Universitat Politècnica de València, Camino de Vera, s/n CP, 46022 Valencia, Spain.

${ }^{c}$ REQUIMTE/LAQV, Science Chemical Department, Faculty of Pharmacy of University of Porto, Rua Jorge Viterbo Ferreira, 228, 4050-313 Porto, Portugal.

${ }^{d}$ Institute for Industrial, Radiophysical and Environmental Safety (ISIRYM), Universitat Politècnica de València, Camino de Vera, $s / n$ CP, 46022 Valencia, Spain.

${ }^{e}$ University of Belgrade, Department of Plant Physiology, Institute for Biological Research "Siniša Stanković", Bulevar Despota Stefana 142, 11000 Belgrade, Serbia.

*Corresponding author. Tel. +351 273 303219; fax +351 273325405 . E-mail address: iferreira@ipb.pt (I.C.F.R. Ferreira) 


\begin{abstract}
Consumer interest in the use of natural ingredients is creating a growing trend in the food industry, leading to research into the development of natural products such as colorants, antimicrobials and antioxidant compounds. This work involves an extensive chemical and microbiological characterization of Opuntia ficus-indica var. Sanguigna, Gialla and Opuntia engelmannii fruits. These species have proved to be a good source of hydrophilic (sugars, organic acids and betalains) and lipophilic (tocopherols and fatty acids) compounds. While Opuntia engelmannii exhibited higher content of betacyanins, Opuntia ficus-indica varieties Sanguigna and Gialla displayed greater sugar and organic acid content. The Sanguigna variety also showed the highest $\alpha$-tocopherol content, enhancing the bioactivity of this variety, which can be observed in its antimicrobial potential, tested in the studied strains too. Results revealed that Opuntia spp. could be used as a nutraceutical and/or food additive, maintaining and promoting health and life quality.
\end{abstract}

Keywords: Opuntia ficus-indica; Opuntia engelmannii; nutritional properties; betalains; antimicrobial activity 


\section{V.2.1. INTRODUCTION}

Consumers, in today's food market, are becoming increasingly conscious of high-quality healthy foods, leading to a demand for the exclusion of synthetic food additives in groceries. These consumers expect to see more familiar ingredients in their food products following the food authorities warnings on the reduction of daily intake levels and the addition of these additives to the Redbook 2000 (FDA, 2007). This provides scientific information about the toxicological effects of the consumption of additives, but often leads to misunderstanding by consumers.

Scientific research is pursuing better alternatives to synthetic food additives, including functional properties. Some researchers like Almeida et al., (2011), directed their investigations towards the revalorization of exotic fruit juices and extracts. These substances contain biomolecules that could be applied as unpurified extracts or isolated molecules, or as a possible substitute for synthetic additives. Thus, by employing these new natural ingredients, consumers will be able to take advantage of these molecules in their role of improving overall well-being, as well as their contribution to the prevention of some diseases (Devalaraja, Jain, \& Yadav, 2011). Additionally, food industries would be able to publish clearer labelling that could have a beneficial impact on their sales (Osborn, 2015).

The prickly pear (Opuntia spp.) is an important crop to study due to its adaptability to difficult growing conditions (arid and semiarid zones). Although this species is native to Mexico, it has spread and been cultivated across the world (Novoa et al., 2015). The genus Opuntia is reported to have almost 300 different varieties (Reynolds and Arias, 2003), between domesticated and wild species. Opuntia ficus-indica is one of the five most cultivated species for fruit production (Griffith, 2004), but there are also other wild species such as Opuntia engelmannii that could be potentially used in the extraction of natural ingredients, such as colorants.

The wide range of colour in prickly pears is due to the presence of betalains, water-soluble, nitrogen-containing pigments present in a limited number of families of the plant order Caryophyllales (Strack et al., 2003). There are two types of betalains, red/violet betacyanins and 
yellow/orange betaxanthins (Esquivel, 2016), creating an interesting palette of natural colouring agents. There is growing interest in betalains, partially due to their good stability between the $\mathrm{pH}$ values of 3 and 7 (Herbach et al., 2006), and their ability to protect against the potential effects of oxidative stress (Azeredo, 2009; Strack et al., 2003). Although, the antixodant properties of betalains could be related to other bioactive molecules such as tocopherols, organic acids, reducing sugars and polyunsaturated fatty acids (PUFA), rather than the effect of just one type of molecule (Pereira et al., 2014).

Therefore, the aim of this research was to carry out an extensive physical, chemical and microbiological characterization of Opuntia ficus-indica var. Sanguigna (OS) and Gialla (OG) and Opuntia engelmannii (OE) fruits, as possible fruit to be used in the food industry as natural ingredients. 


\section{V.2.2. MATERIAL AND MethodS}

\section{V.2.2.1. Sample preparation}

Cactus pear fruits (Opuntia ficus-indica var. Sanguigna -OS and Gialla -OG) were collected in July-August 2016 in Sicily, Italy and were purchased from a local market in Bragança, Portugal. Fruit from these species were separated according to the maturation colour orange-red (pulp and peel) and red-violet, obtaining two different samples. Wild prickly pear fruit (Opuntia engelmannii- OE) were collected in Bragança, Portugal (GPS coordinates: 41.797344, -6.772735) in early September 2016. Dr. Carlos Aguiar of the School of Agriculture, Polytechnic Institute of Bragança (Trás-os-Montes, Portugal), confirmed the botanical identifications and voucher specimens were deposited.

Within 24 hours, the fruit were washed with distilled water in order to remove glochids and then air-dried. Afterwards, all the fruits were peeled and the resulting pulp was lyophilized (LabConco, Frezone -105 ${ }^{\circ} \mathrm{C}$, 4.5 L Cascade Benchtop Freeze Dry System, Kansas, MO, USA) and stored in a cool, dry place until use.

\section{V.2.2.2. Morphological parameters}

Fruit size: the length and width of the entire fruit and pulp were measured with a calliper. The whole fruit, pulp and peel where weighed separately. For colour detection, fresh and lyophilized pulp and peel were measured with a colorimeter (model CR-400; Konica Minolta Sensing Inc., Japan), previously calibrated using the standard white plate. Using illuminant $\mathrm{C}$ and a diaphragm opening of $8 \mathrm{~mm}$, the CIE $\mathrm{L}^{*} \mathrm{a}^{*} \mathrm{~b}^{*}$ colour space values were registered with a computerized system using the colour data software "Spectra Magic Nx" (version CM-S100W 2.03.0006).

\section{V.2.2.3. Chemical characterisation}

\section{V.2.2.3.1 Proximal nutritional composition}

Chemical and nutritional parameters (protein, fat, moisture, ash, carbohydrates and energy) were determined only for the edible part of the fruit (pulp). Samples were analysed according to the AOAC 
procedures (AOAC, 2016) Crude protein content $(\mathrm{N} \times 6.25)$ was determined by the macro-Kjeldahl method (AOAC, 991.02). Crude fat (AOAC, 989.05) was estimated by extracting a known weight of powdered sample with petroleum ether, using a Soxhlet apparatus. Moisture content was determined by the weight difference before and after the drying process (oven at $100{ }^{\circ} \mathrm{C}$ ); the ash content (AOAC, 935.42) was determined by incineration at $550 \pm 15{ }^{\circ} \mathrm{C}$. Total carbohydrates (including fibre) were calculated by difference [total carbohydrates $(\mathrm{g} / 100 \mathrm{~g})=100-(\mathrm{g}$ fat $+\mathrm{g}$ protein $+\mathrm{g}$ ash $)]$. Total energy was calculated according to the following equation: Energy $(\mathrm{kcal} / 100 \mathrm{~g})=4 \times(\mathrm{g}$ proteins $+\mathrm{g}$ carbohydrates $)+9 \times(\mathrm{g}$ fat $)$.

\section{V.2.2.3.2. Hydrophilic compounds}

Soluble sugars. Sugars were determined in defatted samples by high performance liquid chromatography coupled to a refraction index detector (HPLC-RI, Knauer, Smartline system 1000, Berlin, Germany) following a procedure described by Pereira, Barros, Carvalho, \& Ferreira (2011).

Organic acids. Organic acids were determined by an optimised procedure previously described by Barros, Pereira, \& Ferreira (2013) and the analysis was performed using a Shimadzu 20A series UFLC (Shimadzu Coperation, Kyoto, Japan) coupled to a diode array detector (DAD), using 215 and $245 \mathrm{~nm}$ (for ascorbic acid) as the preferred wavelengths. Results were expressed as $\mathrm{g}$ and $\mathrm{mg}$ per $100 \mathrm{~g}$ of pulp fresh weight $(\mathrm{FW})$, for sugars and organic acids, respectively.

The sugars and organic acids were identified by comparing their retention times with standard compounds, and quantification was conducted by comparison with dose-response curves constructed from authentic standards. For sugar determination, melezitose was used as the internal standard. Results were expressed as $\mathrm{g}$ and $\mathrm{mg}$ per $100 \mathrm{~g}$ of pulp fresh weight (FW), for sugars and organic acids, respectively.

Betalains. The profile of these compounds was determined by LCDAD-ESI/MSn (Dionex Ultimate 3000 UPLC, Thermo Scientific, San Jose, CA, USA). The lyophilized pulps were re-dissolved in water at a concentration of $150 \mathrm{mg} / \mathrm{mL}$. Chromatographic separation was 
achieved with a Waters Spherisorb S3 ODS-2 C18 $(3 \mu \mathrm{m}, 4.6 \mathrm{~mm} \times$ $150 \mathrm{~mm}$, Waters, Milford, MA, USA) column working at $35^{\circ} \mathrm{C}$. The solvents used were: (A) $0.1 \%$ trifluoroacetic acid (TFA) in water, and (B) acetonitrile. The gradient elution followed these parameters: from $0 \%$ to $10 \% \mathrm{~B}$ for $15 \mathrm{~min}$, from $10 \%$ to $15 \%$ B for $5 \mathrm{~min}$, from 15 to $18 \% \mathrm{~B}$ for $5 \mathrm{~min}$, from 18 to $50 \% \mathrm{~B}$ for $8 \mathrm{~min}$, and from 50 to $0 \% \mathrm{~B}$ for $12 \mathrm{~min}$.

The resulting total run time was 45 minutes, using a flow rate of 0.5 $\mathrm{mL} / \mathrm{min}$. Double detection was carried out in the DAD using $480 \mathrm{~nm}$ (for betaxanthins) and $530 \mathrm{~nm}$ (for betacyanins), as the preferred wavelengths, and in a mass spectrometer (MS). MS detection was performed using positive mode, with a Linear Ion Trap LTQ XL mass spectrometer (ThermoFinnigan, San Jose, CA, USA) equipped with an ESI source. Nitrogen served as the sheath gas (50 psi); the system was operated with a spray voltage of $4.8 \mathrm{kV}$, a source temperature of 320 ${ }^{\circ} \mathrm{C}$, and a capillary voltage of $39 \mathrm{~V}$. The tube lens offset was kept at a voltage of $140 \mathrm{~V}$. The full scan covered the mass range from $\mathrm{m} / \mathrm{z}, 100$ to 1500 . The collision energy used was 24 (arbitrary units). Data acquisition was carried out with the Xcalibur ${ }^{\circledR}$ data system (ThermoFinnigan, San Jose, CA, USA).

Identification of the betalain compounds (betacyanins and betaxanthins) was performed by comparing the obtained information with available data reported in the literature, providing a tentative identification. For quantitative analysis, a calibration curve using an isolated compound gomphrenin III (isolated from Gomphrena globosa L.) was constructed based on the UV signal ( $\mathrm{y}=14670 \mathrm{x}-19725, R^{2}=$ 0.9997). The results for betacyanins were expressed as $\mathrm{mg}$ per $100 \mathrm{~g}$ of pulp fresh weight $(\mathrm{FW})$, and the results for betaxanthins were expressed as a relative percentage (\%) of the areas recorded at $480 \mathrm{~nm}$.

\section{V.2.2.3.3. Lipophilic compounds}

Fatty acids. Fatty acid determination was achieved via the transesterification procedure described previously by Guimarães et al. (2013). The analysis was performed in gas chromatography (GC DANI 1000; Contone, Switzerland) equipment with flame ionization detection. Results were expressed as relative percentages of each fatty acid. 
Tocopherols. The four isoforms of tocopherols (vitamin E) were determined according to the previously described procedure (Heleno et al., 2010). Analysis was performed using a HPLC system (Knauer, Smartline system 1000, Berlin, Germany), coupled to a fluorescence detector (FP-2020; Jasco, Easton, MD, USA). Quantification was based on the fluorescence signal response of each standard, using the internal standard (tocol) method and using calibration curves obtained from commercial standards of each isoform. The results were expressed in $\mu \mathrm{g}$ per $100 \mathrm{~g}$ of pulp fresh weight (FW).

\section{V.2.2.4. Antimicrobial effect of fruit pulp}

Antibacterial activity was assayed according to Reis et al., (2014) using the following Gram-positive bacteria: Staphylococcus aureus (ATCC 6538), Bacillus cereus (clinical isolate), Micrococcus flavus (ATCC10240), and Listeria monocytogenes (NCTC7973) and Gramnegative bacteria: Escherichia coli (ATCC 35210), Pseudomonas aeruginosa (ATCC 27853), Salmonella typhimurium (ATCC 13311), and Enterobacter cloacae (ATCC 35030).

While for antifungal assays, the following microfungi were used: Aspergillus fumigatus (ATCC1022), Aspergillus ochraceus (ATCC12066), Aspergillus versicolor (ATCC11730), Aspergillus niger (ATCC6275), Penicillium funiculosum (ATCC 36839), Penicillium ochrochloron (ATCC9112), Penicillium verrucosum var. cyclopium (food isolate), and Trichoderma viride (IAM 5061).

The minimum inhibitory (MIC), minimum bactericidal (MBC) and minimum fungicidal concentrations (MFC) were determined by methodologies described previously (Reis et al., 2014; Chahdoura et al., 2016). Bacterial and fungal organisms were obtained from the Mycological Laboratory, Department of Plant Physiology, Institute for Biological Research "Sinisa Stanković", University of Belgrade, Serbia. 
Resultados

\section{V.2.2.5. Statistical analysis}

All the extractions and assays were performed in triplicate. Results were expressed as mean values and standard deviations (SD), analysed using a one-way analysis of variance (ANOVA) followed by Tukey's HSD Test with $p=0.05$. The treatment was carried out using IBM SPSS Statistics for Windows, version 23.0. (IBM Corp., Armonk, New York, USA). 


\section{V.2.3. RESULTS AND DISCUSSION}

\section{V.2.3.1. Morphological parameters and nutritional composition}

According to the data summarized in Table 5-1 (morphologic parameters), the Italian fruit varieties of Opuntia ficus-indica, Gialla (OG) and Sanguigna (OS), are notably heavier in pulp weight compared to the Portuguese species Opuntia engelmannii (OE) and about 5 and 6-fold higher than OG and OS pulps, respectively. The OS variety is around 13\% heavier than fruits of the OG variety, although the pulp's length is reasonably similar these differences can be perceived in the shape of the fruits, the fruit body of OG being more elliptical, while OS has a more oval / rounded shape.

Additionally, in Table 5-1, colour characteristics are described. Positive $\mathrm{a}^{*}$ colour coordinates reflect tendencies to reddish colours, with the highest value for the OS variety, which displays an overall reddish pulp with some deep pink spots. On the other hand, positive values of $b^{*}$ coordinates exhibit yellowish colours, where the OG variety showed the highest values. OG pulp displayed a bright yellow colour in most of the fruit with several shiny orange stains. Finally, OE pulp showed lower values, particularly on the $b^{*}$ coordinates (blueyellow) which mixed with the other coordinates, especially the low lightness, exhibiting a more matte purple colour. Stintzing et al. (2005) found a correlation between the betalains content and the increase in lightness, $\mathrm{L}^{*}$, in general this parameter increased with higher betaxanthins content but decreased when betacyanins were predominant, the same tendency was observed in this assay.

Table 5-1 Morphological parameters of Opuntia spp.

\begin{tabular}{lccc}
\hline & OG & OS & OE \\
\hline Pulp weight $(\mathrm{g})$ & $50 \pm 6^{\mathrm{a}}$ & $58 \pm 5^{\mathrm{a}}$ & $10.0 \pm 0.9^{\mathrm{b}}$ \\
Pulp Length $(\mathrm{cm})$ & $5.9 \pm 0.4^{\mathrm{a}}$ & $5.4 \pm 0.1^{\mathrm{a}}$ & $3.56 \pm 0.18^{\mathrm{b}}$ \\
Pulp Diameter $(\mathrm{cm})$ & $3.8 \pm 0.4^{\mathrm{a}}$ & $4.5 \pm 0.4^{\mathrm{a}}$ & $2.4 \pm 0.1^{\mathrm{b}}$ \\
\hline
\end{tabular}




\section{Color coordinates}

\begin{tabular}{lccc}
\hline $\mathrm{a}^{*}$ & $12 \pm 1^{\mathrm{c}}$ & $36.8 \pm 0.4^{\mathrm{a}}$ & $16 \pm 0.8^{\mathrm{b}}$ \\
$\mathrm{b}^{*}$ & $49 \pm 3^{\mathrm{a}}$ & $19.8 \pm 0.6^{\mathrm{b}}$ & $4.9 \pm 0.7^{\mathrm{c}}$ \\
$\mathrm{L}^{*}$ & $48.9 \pm 0.9^{\mathrm{a}}$ & $33 \pm 1^{\mathrm{b}}$ & $25 \pm 1^{\mathrm{c}}$ \\
$\mathrm{C}^{*}$ & $50 \pm 2^{\mathrm{a}}$ & $41.8 \pm 0.6^{\mathrm{b}}$ & $16.8 \pm 0.5^{\mathrm{c}}$ \\
$\mathrm{h}^{\circ}$ & $1.33 \pm 0.03^{\mathrm{a}}$ & $0.49 \pm 0.01^{\mathrm{b}}$ & $0.30 \pm 0.05^{\mathrm{c}}$ \\
\hline $\begin{array}{l}\text { OG, Opuntia ficus-indica } \text { var Gialla; OS, Opuntia ficus-indica } \text { var } \\
\text { Sanguigna; OE, Opuntia engelmannii. In each row different letters } \\
\text { mean significant differences }(p<0.05) .\end{array}$ \\
\hline
\end{tabular}

The macronutrient composition of Opuntia fruiting bodies is presented in Table 5-2. Opuntia ficus-indica var. Gialla and Sanguigna do not show significant differences in most of the macronutrients, excluding proteins and ash content, which had higher concentrations. Higher percentages in proteins could be due to a greater concentration of pigments in the cell vacuoles, betalainic colorants being water-soluble nitrogen-containing pigments (Azeredo, 2009). Despite the differences shown between proteins and ash, these macronutrients along with moisture, fat and carbohydrates are in accordance with results reported by other authors like Angulo-Bejarano, Martínez-Cruz, \& ParedesLópez (2014).

Table 5-2 Nutritional value and hydrophilic compounds of the studied Opuntia spp.

\begin{tabular}{lccc}
\hline & OG & OS & OE \\
\hline Moisture (\%) & $83.38 \pm$ & $81 \pm 2^{\mathrm{a}}$ & $65 \pm 2^{\mathrm{b}}$ \\
& $0.07^{\mathrm{a}}$ & & \\
Fat (g/100 g FW) & $0.03 \pm$ & $0.06 \pm$ & $0.38 \pm 0.03^{\mathrm{a}}$ \\
& $0.001^{\mathrm{b}}$ & $0.004^{\mathrm{b}}$ & \\
Proteins (g/100 g FW) & $0.52 \pm 0.01^{\mathrm{c}}$ & $0.84 \pm 0.03^{\mathrm{b}}$ & $1.62 \pm 0.06^{\mathrm{a}}$ \\
Ash (g/100 g FW) & $0.34 \pm$ & $0.42 \pm 0.02^{\mathrm{b}}$ & $0.75 \pm 0.02^{\mathrm{a}}$ \\
& $0.004^{\mathrm{c}}$ & & \\
Carbohydrates $\quad(\mathrm{g} / 100$ & $15.68 \pm$ & $18 \pm 2^{\mathrm{b}}$ & $33 \pm 2^{\mathrm{a}}$ \\
g FW) & $0.04^{\mathrm{b}}$ & &
\end{tabular}




\begin{tabular}{|c|c|c|c|}
\hline $\begin{array}{l}\text { Energy } \quad(\mathrm{Kcal} / 100 \mathrm{~g} \\
\mathrm{FW})\end{array}$ & $65.1 \pm 0.1^{\mathrm{b}}$ & $77 \pm 7^{\mathrm{b}}$ & $140 \pm 6^{\mathrm{a}}$ \\
\hline Sugars $(\mathrm{g} / 100 \mathrm{~g} \mathrm{FW})$ & & & \\
\hline Fructose & $4.13 \pm 0.02^{\mathrm{b}}$ & $4.97 \pm 0.07^{\mathrm{a}}$ & $0.53 \pm 0.01^{\mathrm{c}}$ \\
\hline Glucose & $5.53 \pm 0.05^{\mathrm{b}}$ & $6.30 \pm 0.03^{\mathrm{a}}$ & $0.83 \pm 0.01^{\mathrm{c}}$ \\
\hline Sucrose & $\begin{array}{l}0.13 \pm \\
0.005^{c}\end{array}$ & $\begin{array}{l}0.15 \pm \\
0.001^{b}\end{array}$ & $0.31 \pm 0.01^{\mathrm{a}}$ \\
\hline Total sugars & $9.79 \pm 0.07 b$ & $\begin{array}{c}11.43 \pm \\
0.09^{\mathrm{a}}\end{array}$ & $1.68 \pm 0.02^{\mathrm{c}}$ \\
\hline
\end{tabular}

Organic acids $(\mathrm{mg} / 100$

g FW)

\begin{tabular}{|c|c|c|c|}
\hline Oxalic & $26.7 \pm 0.3^{\mathrm{b}}$ & $29.5 \pm 0.6^{\mathrm{a}}$ & $\operatorname{tr}$ \\
\hline Quinic & $28 \pm 1^{*}$ & $35.6 \pm 0.3^{*}$ & nd \\
\hline Malic & $\operatorname{tr}$ & $\operatorname{tr}$ & $\operatorname{tr}$ \\
\hline Ascorbic & $2.3 \pm 0.1^{\mathrm{b}}$ & $2.0 \pm 0.1^{\mathrm{b}}$ & $19.7 \pm 0.1^{\mathrm{a}}$ \\
\hline Citric & $49.3 \pm 0.7^{\mathrm{a}}$ & $46.9 \pm 0.1^{\mathrm{b}}$ & $0.8 \pm 0.01^{\mathrm{c}}$ \\
\hline Succinic & $184 \pm 1 *$ & $131 \pm 2^{*}$ & nd \\
\hline Fumaric & $8.0 \pm 0.1^{*}$ & $6.3 \pm 0.2 *$ & nd \\
\hline Total organic acids & $298.1 \pm 0.8^{\mathrm{a}}$ & $251 \pm 2^{b}$ & $20.5 \pm 0.1^{\mathrm{c}}$ \\
\hline \multicolumn{4}{|c|}{$\begin{array}{l}\text { FW, pulp fresh weight; nd, not detected; tr, traces. OG, Opuntia } \\
\text { ficus-indica var Gialla; OS, Opuntia ficus-indica var Sanguigna; OE, } \\
\text { Opuntia engelmannii. In each row different letters mean significant } \\
\text { differences }(p<0.05) \text {. *Statistical differences }(<0.001) \text { were } \\
\text { observed when t-student test was applied. }\end{array}$} \\
\hline
\end{tabular}

Conversely, OE was statistically different from OG and OS, moisture in $\mathrm{OE}$ was around 17 percent inferior, while protein, ash and carbohydrates were 2-fold higher in $\mathrm{OE}$ and fat content was up to 10fold higher. Once again, high protein content could be related to the greater pigment composition, as will be discussed later on in the betalainic profile of Opuntia spp. 
In addition, fat, ash and carbohydrate content could be superior, and moisture inferior due to a higher ratio of seed/pulp compared to OG or OS. Chougui et al. (2013) have worked on the oil composition and characterization of Opuntia seeds and have shown that a higher ratio of seed/pulp increases the oil yield and the fat content. Likewise Jain, Grover, \& Kaur (2016) reported that seeds are mainly composed of carbohydrates with a considerable amount of minerals and proteins, this information supports our hypothesis on the greater amount of macronutrients found in OE samples. To the best of our knowledge, no reports are available on the nutritional composition of Opuntia engelmannii species.

\section{V.2.3.2. Hydrophilic and lipophilic compounds}

The free sugar content of Opuntia spp. is displayed in Table 5-2, OE has the lowest total sugar content, followed by OG and OS in ascending order. It is worth highlighting that $\mathrm{OE}$ is around 10-fold lower in total sugar concentration compared to Opuntia ficus-indica fruit, this higher concentration is mainly due to the presence of glucose and fructose, the most characteristic sugars in Opuntia ficus-indica (Kyriacou et al., 2016). Although all species were collected in the same period, OE species were probably not at their optimum ripeness. Despite the fact that $\mathrm{OE}$ has higher content in carbohydrates and lower total sugar content compared to OG and OS, this could indicate that the majority of the carbohydrates could be fibres or longer polysaccharide chains like mucilage (Da-Costa-Rocha et al., 2014).

Table 5-3 Chemical composition in lipophilic compounds, tocopherols and fatty acids of Opuntia spp.

OG OS OE

Fatty acids (\%)

\begin{tabular}{lccc}
\hline C6:0 & $0.32 \pm 0.08^{\mathrm{a}}$ & $0.21 \pm 0.02^{\mathrm{b}}$ & $0.09 \pm 0.01^{\mathrm{c}}$ \\
& & $0.044 \pm$ \\
C8:0 & $0.22 \pm 0.06^{\mathrm{a}}$ & $0.07 \pm 0.02^{\mathrm{b}}$ & $0.001^{\mathrm{b}}$ \\
& & $0.097 \pm$ \\
C10:0 & $0.6 \pm 0.2^{\mathrm{a}}$ & $0.18 \pm 0.02^{\mathrm{b}}$ & $0.001^{\mathrm{b}}$ \\
C12:0 & $0.7 \pm 0.2^{\mathrm{a}}$ & $0.23 \pm 0.02^{\mathrm{b}}$ & $0.087 \pm 0.001^{\mathrm{c}}$ \\
C14:0 & $1.4 \pm 0.3^{\mathrm{a}}$ & $0.56 \pm 0.03 \mathrm{~b}$ & $0.234 \pm 0.001^{\mathrm{c}}$
\end{tabular}


C15:0

C16:0

$0.47 \pm 0.01^{\mathrm{a}} \quad 0.16 \pm 0.01^{\mathrm{b}} \quad 0.055 \pm 0.001^{\mathrm{c}}$

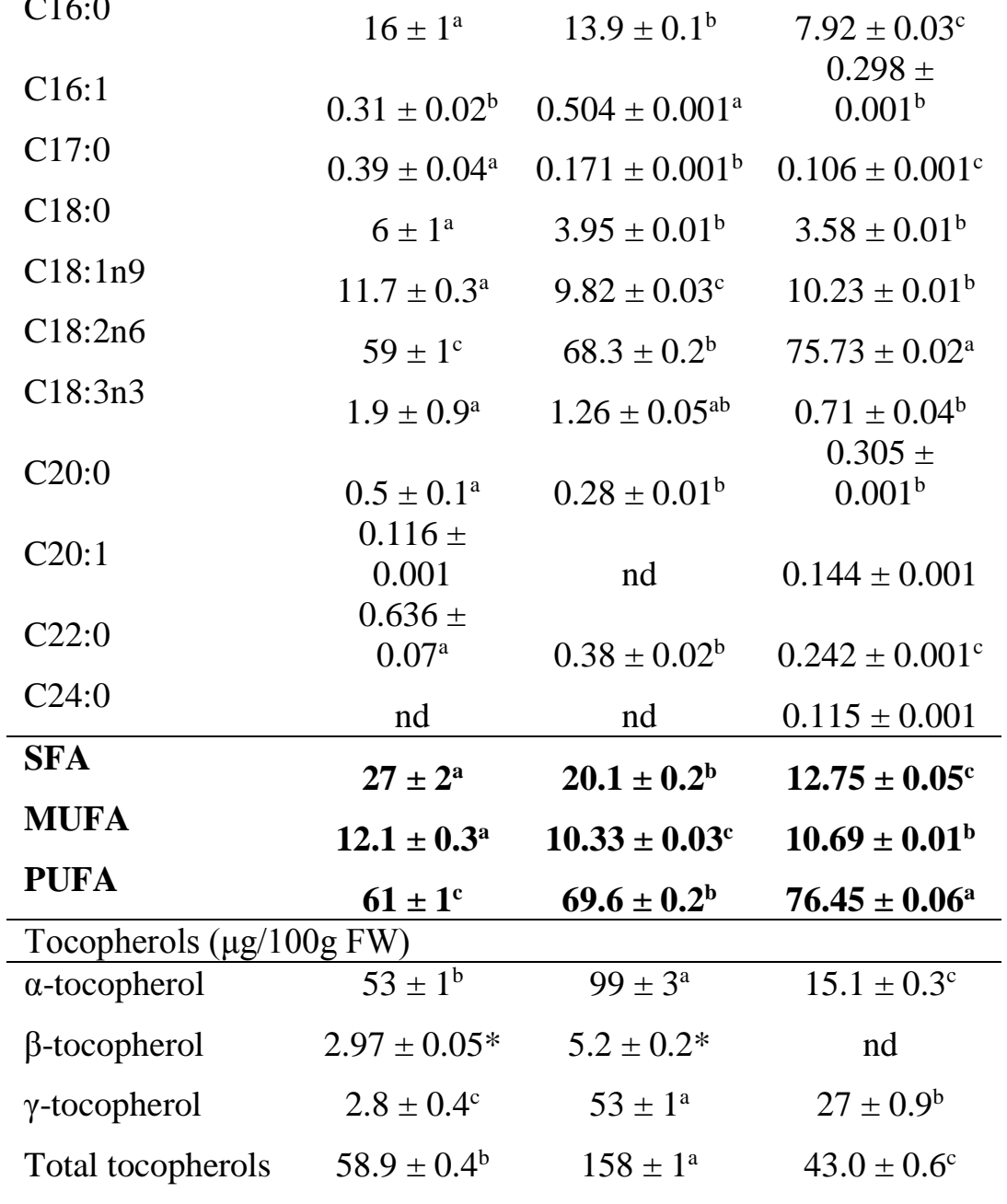

OG, Opuntia ficus-indica var Gialla; OS, Opuntia ficus-indica var Sanguigna; OE, Opuntia engelmannii.

FW, pulp fresh wight; nd, not detected; SFA, saturated fatty acids; MUFA, monounsaturated fatty acids; PUFA, polyunsaturated fatty acids. In each row different letters mean significant differences $(p<$ $0.05)$. *Statistical differences $(<0.001)$ were observed when $t$-student test was applied. 
The total organic acid content of OE is 12 to 15 -fold lower compared to OS and OG, respectively (Table 5-2). The main difference in the total organic acids analysed in Opuntia spp., is due to the succinic acid content, this acid is by far the most abundant in Opuntia ficus-indica fruits, while it was not detected in OE. Farag, Maamoun, Ehrlich, Fahmy, \& Wesjohann (2017), also identified succinic acid as the more abundant organic acid in Italian Opuntia ficus-indica varieties. Succinic acid is an important metabolite involved in several signalling processes, not only in the mitochondria were it is generated, but in the cytoplasm as well as the extracellular space and it is also involved in the elimination of reactive oxygen species (Tretter et al., 2016). Succinic acid is generally recognized as safe (FDA, 2017) and has different applications in the pharmaceutical and food industries, although it is primarily used as an acidity regulator (Ahn et al., 2016). Organic acid profiles are not reported for Opuntia spp. in the literature, although, extensive assays have been performed on ascorbic acid for Opuntia ficus-indica. Variable values are found ranging from 3.5 to $45 \mathrm{mg} / 100$ g edible pulp (Kuti, 2004; Stintzing et al., 2005). OG and OS showed lower levels of vitamin $\mathrm{C}$, compared with reported data, while OE was almost 10 -fold higher than the previously mentioned varieties.

The betalain profiles of OG, OS and OE are shown in Figure 5-4. Data regarding retention time, $\lambda \max$ in the visible region, molecular ion and main fragment ions observed in $\mathrm{MS}^{2}$, obtained by HPLC-DADESI/MS analysis regarding betalains identification and quantification are presented in Table 5-4. Compounds 1-3 were identified as betaxanthin derivatives, and compounds $4-7$ as betacyanin derivatives. All of the identified compounds were previously described in Opuntia spp. (Cejudo Bastante et al., 2014; Mata et al., 2016). Betaxanthins were found in a higher percentage in OG, followed by OS and were not identified in $\mathrm{OE}$. Nevertheless, betacyanidin content was lower in OG (11.32 mg/100 g of FW), followed by OS (215 mg/100 g FW) and the largest amounts were present in OE (total content of 283 $\mathrm{mg} / 100 \mathrm{~g}$ of $\mathrm{FW}$ ), which presented 25 -fold higher quantities then OG and 1.3-fold higher then OS. The hierarchical order observed agrees with the data found by other researchers, were the amount of betalains increased from yellow to red and to purple varieties (Farag et al., 2017).

Saturated fatty acids (SFA), monounsaturated fatty acids (MUFA) and polyunsaturated fatty acids (PUFA) are presented in Table 5-3. 
Samples were richer in PUFA with over $60 \%$ of the total fatty acids, where OE was notably higher than OS and OG. SFA were the second most abundant group followed by MUFA. In all the Opuntia species, linoleic palmitic and oleic acids were the main fatty acids present, respectively.

Although a plethora of information on the seed oils of Opuntia spp are available, few publications have analysed the fatty acid content in the fruit, Farag et al., (2017) also report linoleic, palmitic and oleic acid as the major fatty acids present in the edible portion of Opuntia ficusindica. The essential fatty acids have given rise to great interest due to the health potential of PUFA. According to Timilsena, Wang, Adhikari, \& Adhikari, (2017), PUFA plays a vital role in maintaining health in humans by minimizing the risk of cardiovascular and neurodegenerative disease, arthritis, diabetes and certain types of cancer. Therefore, it is important to stress the possibility of finding richer PUFA matrices in other fruit, vegetables and seeds.

As shown in Table 5-3, OS was the variety that displayed the highest tocopherol content, $\alpha$-tocopherol being the main isoform present, followed by $\gamma$ - and $\beta$-tocopherol. The lowest content in tocopherols was found in OE samples, where only $\alpha$ - and $\gamma$ - isoforms were present, the latter isoform being the one that contributes most to the total content. Regarding OG, $\alpha$-tocopherol was around 18 -fold higher compared with $\beta$ - and $\gamma$-tocopherol. As far as we know, there are no studies related to the tocopherol content in Opuntia ficus-indica, only Farag et al. (2017) describe the relative percentage of $\alpha$-tocopherol in 3 varieties of Opuntia ficus-indica, but do not give concrete amounts with which a comparison could be performed.

The concentration of tocopherols in the same genus, but different species was assayed by Morales et al. (2012), with total tocopherol content ranging between 140 and $220 \mu \mathrm{g} / 100 \mathrm{~g}$ FW in Opuntia joconostle and matudae. Only the values obtained by OS are in concordance with those revealed by Morales et al. (2012), while samples OG and OE only displayed 59 and $43 \mu \mathrm{g} / 100 \mathrm{~g}$, respectively. Vitamin $\mathrm{E}$ is the major lipid-soluble antioxidant in the cell antioxidant defence system, nonetheless, the human body is not able to synthesize these substances using its own metabolic pathways, therefore it has to 


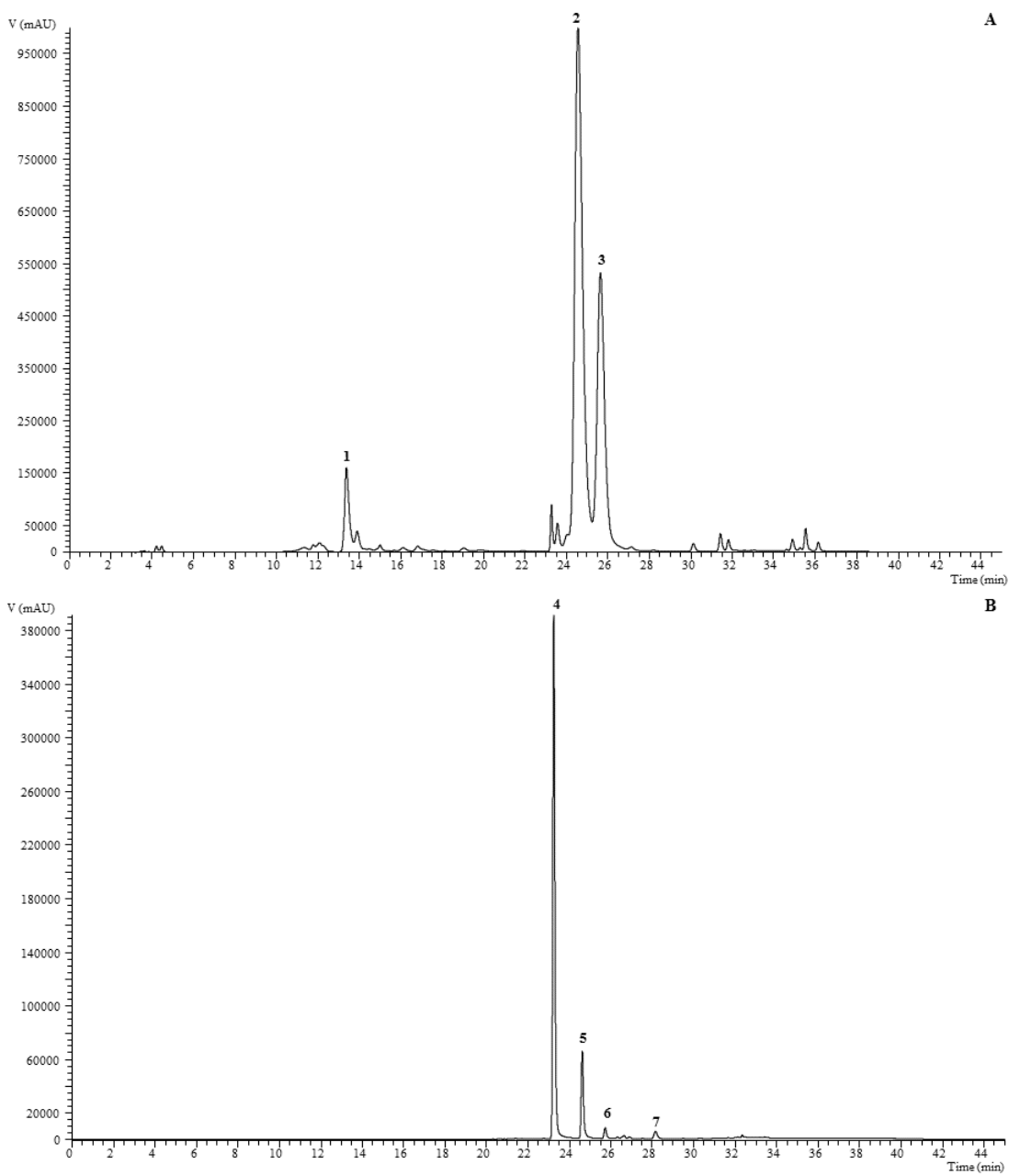

Figure 5-4 HPLC chromatograms of (A) OG betaxanthin profile recorded at $484 \mathrm{~nm}$ and (B) OE betacyanin profile recorded at $535 \mathrm{~nm}$ (source: private collection)

be obtained from the diet (Sýs et al., 2017). Vitamin E functions as a chain-breaking antioxidant, inhibiting the propagation of lipid peroxidation, preventing lipoproteins and cell membranes from oxidative damage by acting as singlet oxygen quencher and stabilizing chloroplast membranes (Takshak and Agrawal, 2015). Although OS has the highest content in total tocopherols, the amount present in 100 $\mathrm{g}$ of fruit only represents around $1 \%$ of the Reference Daily Intake (NIH, 2017). 
Table 5-4 Retention time (rt), waveleghts of maximum absorption in visible region $\left(\lambda_{\max }\right)$, mass spectral data, identification and quantification of betalains detected in Opuntia spp pulp

\begin{tabular}{|c|c|c|c|c|c|c|c|c|}
\hline \multirow[b]{2}{*}{ Peak } & \multirow[b]{2}{*}{ Identification } & \multirow{2}{*}{$\begin{array}{c}\mathbf{R t} \\
(\mathbf{m i n})\end{array}$} & \multirow{2}{*}{$\begin{array}{l}\lambda_{\max } \\
(\mathbf{n m})\end{array}$} & \multirow{2}{*}{$\begin{array}{c}{[\mathbf{M}+\mathbf{H}]^{+}} \\
(m / z)\end{array}$} & \multirow{2}{*}{$\begin{array}{l}\mathbf{M S}^{2} \\
(\mathrm{~m} / \mathrm{z})\end{array}$} & \multicolumn{3}{|c|}{ Quantification } \\
\hline & & & & & & OG & OS & $\mathrm{OE}$ \\
\hline \multicolumn{9}{|c|}{ Betaxanthins } \\
\hline 1 & Muscaaurin & 13.37 & 471 & 349 & $305(100), 124(10)$ & $\begin{array}{c}\mathrm{nq} \\
(5.7)\end{array}$ & nd & nd \\
\hline 2 & Indicaxanthin isomer I & 24.47 & 477 & 309 & $\begin{array}{c}263(100), 219(43) \\
188(15)\end{array}$ & $\begin{array}{c}\mathrm{nq} \\
(60.9)\end{array}$ & $\underset{(46.5)}{\mathrm{nq}}$ & nd \\
\hline 3 & Indicaxanthin isomer II & 25.63 & 477 & 309 & $\begin{array}{c}263(100), 219(21), \\
188(9)\end{array}$ & $\begin{array}{c}\mathrm{nq} \\
(30.1)\end{array}$ & $\begin{array}{c}\mathrm{nq} \\
(7.8)\end{array}$ & nd \\
\hline
\end{tabular}

Betacyanins

\begin{tabular}{|c|c|c|c|c|c|c|c|c|}
\hline 4 & $\begin{array}{l}\text { Betanidin-5-O- } \beta- \\
\text { glucoside (betanin) }{ }^{1}\end{array}$ & 23.26 & 534 & 551 & $\begin{array}{c}389(100), 345(50), \\
150(28)\end{array}$ & $\begin{array}{c}11.32 . \pm \\
0.09^{c}(3.4)\end{array}$ & $\begin{array}{c}195.3 \pm \\
0.9^{\mathrm{b}}(41.6)\end{array}$ & $\begin{array}{l}225 \pm 3^{\mathrm{a}} \\
(80.76)\end{array}$ \\
\hline 5 & Isobetanin ${ }^{1}$ & 24.62 & 534 & 511 & $\begin{array}{c}389(100), 345(73) \\
150(46)\end{array}$ & nd & nd & $\begin{array}{l}43 \pm 1 \\
(15.01)\end{array}$ \\
\hline 6 & Gomphrenin $\mathrm{I}^{1}$ & 25.73 & 535 & 551 & $\begin{array}{c}507(3), 389(38), \\
345(100), 301(21)\end{array}$ & nd & $\begin{array}{c}9.42 \pm \\
0.07^{*} \\
(2.0)\end{array}$ & $\begin{array}{c}7.4 \pm 0.6^{*} \\
(2)\end{array}$ \\
\hline
\end{tabular}


Resultados

\begin{tabular}{|c|c|c|c|c|c|c|c|c|}
\hline 7 & Betanidin $^{1}$ & 28.16 & 523 & 389 & $343(97), 150(91)$ & nd & $\begin{array}{c}9.89 \pm \\
0.03^{*} \\
(2.1)\end{array}$ & $\begin{array}{c}7.5 \pm 0.1^{*} \\
(2.13)\end{array}$ \\
\hline
\end{tabular}

OG, Opuntia ficus-indica var Gialla; OS, Opuntia ficus-indica var Sanguigna; OE, Opuntia engelmannii.

Amounts in samples outside brackets in $\mathrm{mg} / 100 \mathrm{~g}$ pulp FW, amounts inside brackets in relative percentages. FW, Fresh weight; nq, not quantified; nd, not detected. Calibration curve: ${ }^{1}$ gomphrenin III $(\mathrm{y}=14670 \mathrm{x}-19725)$. In each row different letters mean significant differences $(p<0.05)$. *Statistical differences $(<0.001)$ were observed when $\mathrm{t}$-student test was applied. 


\section{V.2.3.3. Antimicrobial properties}

Results showing pathogenic bacteria growth inhibition are presented in Table 5-5. The three varieties of Opuntia spp. showed different levels of antibacterial activity. The Opuntia variety OS and OE displayed activity against all the tested bacterial strains, being more active than the commercial controls ampicillin and streptomycin, for all the MIC values, with the exception of Staphylococcus aureus. When comparing the bactericidal (MBC) potential of OS with the commercial antibiotic streptomycin, only 5 out of the 8 tested strains had better performance (Bacillus cereus, Micrococcus flavus, Escherichia coli, Enterobacter cloacae and Salmonella typhimurium), but in the other three strains, the difference shown was very small. It is important to stress the strong effect of OS samples against Micrococcus flavus, this sample displayed 4-fold stronger inhibition compared to the best antibiotic tested as a positive control (streptomycin).

On the other hand, OE showed higher potential than the commercial antibiotic ampicillin against all 8 strains assayed. When this sample was compared to streptomycin, only 2 strains (Staphylococcus aureus and Listeria monocytogenes) stood out as the species with the highest resistance against the OE sample, otherwise for the remaining 6 strains OE showed a similar or better performance than the mentioned antibiotic.

The sample with the least potential was OG, which only had an effect on 5 out of 8 strains tested. Nevertheless, for 4 of the strains, the OG sample showed the same or better potential compared to the positive antibiotic controls.

The fungi positive controls used in this assay were ketoconazole and bifonazole (Table 5-5), the latter showing overall a stronger effect against the pathogenic fungal strains. Samples of OS, OG and $\mathrm{OE}$ exhibit fungistatic and fungicidal effects against all 8 strains tested. The minimum inhibitory concentrations (MIC) were similar or better than the concentration of ketoconazole control (except in Trichoderma viride, Aspergillus ochraceus and Penicillium ochrochloron), but none of the samples exhibited better performance than bifonazole. 
Table 5-5 Antibacterial and antifungal activity of Opuntia samples

\begin{tabular}{|c|c|c|c|c|c|c|c|c|c|c|}
\hline \multirow[t]{3}{*}{ Bacteria } & \multicolumn{6}{|c|}{ Samples } & \multicolumn{4}{|c|}{ Control } \\
\hline & \multicolumn{2}{|c|}{ OS } & \multicolumn{2}{|c|}{$\mathrm{OG}$} & \multicolumn{2}{|c|}{$\mathrm{OE}$} & \multicolumn{2}{|c|}{$\mathrm{C} 1$} & \multicolumn{2}{|c|}{$\mathrm{C} 2$} \\
\hline & $\mathrm{MIC}$ & $\mathrm{MBC}$ & $\mathrm{MIC}$ & $\mathrm{MBC}$ & MIC & $\mathrm{MBC}$ & MIC & $\mathrm{MBC}$ & MIC & $\mathrm{MBC}$ \\
\hline Bacillus cereus & 0.075 & 0.15 & 0.10 & 0.15 & 0.10 & 0.15 & 0.10 & 0.20 & 0.25 & 0.40 \\
\hline Micrococcus flavus & 0.050 & 0.07 & - & - & 0.20 & 0.30 & 0.20 & 0.30 & 0.25 & 0.40 \\
\hline Staphylococcus aureus & 0.15 & 0.30 & 0.075 & 0.15 & 0.15 & 0.45 & 0.04 & 0.10 & 0.25 & 0.45 \\
\hline Listeria monocytogenes & 0.15 & 0.45 & 0.10 & 0.15 & 0.15 & 0.45 & 0.20 & 0.30 & 0.40 & 0.50 \\
\hline Escherichia coli & 0.10 & 0.15 & - & - & 0.20 & 0.30 & 0.20 & 0.30 & 0.40 & 0.50 \\
\hline Enterobacter cloacae & 0.10 & 0.15 & - & - & 0.075 & 0.30 & 0.20 & 0.30 & 0.25 & 0.50 \\
\hline $\begin{array}{l}\text { Pseudomonas } \\
\text { aeruginosa }\end{array}$ & 0.10 & 0.30 & 0.15 & 0.30 & 0.10 & 0.30 & 0.20 & 0.30 & 0.75 & 1.20 \\
\hline $\begin{array}{l}\text { Salmonella } \\
\text { typhimurium }\end{array}$ & 0.10 & 0.45 & 0.20 & 0.45 & 0.30 & 0.45 & 0.25 & 0.50 & 0.40 & 0.75 \\
\hline
\end{tabular}




\section{Resultados}

\begin{tabular}{|c|c|c|c|c|c|c|c|c|c|c|}
\hline \multirow[t]{3}{*}{ Fungi } & \multicolumn{6}{|c|}{ Samples } & \multicolumn{4}{|c|}{ Control } \\
\hline & \multicolumn{2}{|c|}{ OS } & \multicolumn{2}{|c|}{ OG } & \multicolumn{2}{|c|}{$\mathrm{OE}$} & \multicolumn{2}{|c|}{$\mathrm{C} 3$} & \multicolumn{2}{|c|}{$\mathrm{C} 4$} \\
\hline & MIC & MFC & MIC & MFC & MIC & MFC & MIC & MFC & MIC & MFC \\
\hline Aspergillus fumigatus & 0.30 & 0.60 & 0.30 & 0.60 & 0.30 & 0.45 & 0.25 & 0.50 & 0.15 & 0.20 \\
\hline Aspergillus versicolor & 0.30 & 0.45 & 0.30 & 0.45 & 0.15 & 0.30 & 0.20 & 0.50 & 0.10 & 0.20 \\
\hline Aspergillus ochraceus & 0.20 & 0.45 & 0.30 & 0.45 & 0.20 & 0.30 & 1.50 & 2.00 & 0.15 & 0.20 \\
\hline Aspergillus niger & 0.30 & 0.60 & 0.30 & 0.60 & 0.30 & 0.45 & 0.20 & 0.50 & 0.15 & 0.20 \\
\hline Trichoderma viride & 0.10 & 0.20 & 0.075 & 0.15 & 0.0375 & 0.075 & 1.00 & 1.00 & 0.15 & 0.20 \\
\hline Penicillium funiculosum & 0.30 & 0.45 & 0.30 & 0.45 & 0.30 & 0.45 & 0.20 & 0.50 & 0.20 & 0.25 \\
\hline $\begin{array}{l}\text { Penicillium } \\
\text { ochrochloron }\end{array}$ & 0.50 & 0.75 & 0.075 & 0.15 & 0.30 & 0.45 & 2.50 & 3.50 & 0.20 & 0.25 \\
\hline $\begin{array}{l}\text { Penicillium verrucosum } \\
\text { var. cyclopium }\end{array}$ & 0.30 & 0.60 & 0.30 & 0.60 & 0.30 & 0.60 & 0.20 & 0.30 & 0.10 & 0.20 \\
\hline
\end{tabular}


The minimum fungicidal concentrations (MFC) of the samples against bifonazole were always inferior, except for the $T$. viride strain against all the tested samples and in the $P$. ochrochloron strain against $\mathrm{OG}$. The fungicidal power of $\mathrm{OE}$ against $T$. viride presented 3 -fold lower concentrations (higher potential) than the fungicidal power displayed by bifonazole. Chahdoura et al., (2016), tested the antimicrobial activity from Opuntia microdasys flowers and reported lower effects on their samples compared to OS, OG and OE extracts.

Polyphenols and other biofunctional molecules, such as betalains, have shown the capacity to induce cellular damage in pathogenical microorganisms (Azeredo, 2009; Sansano et al., 2017). Hussain et al. (2017), presented results were curcuminoids distort the cellular architecture, causing cellular edema, followed by lysis and extrusion of cytoplasmic content, this mechanism could also explain the polyphenolic and betalainic antimicrobial effect of $\mathrm{OG}, \mathrm{OS}$ and $\mathrm{OE}$ samples. 


\section{V.2.4. Conclusions}

Overall, fruit from Opuntia ficus indica var Gialla and Sanguigna and Opuntia engelmannii, revealed interesting antimicrobial properties, which might be used to functionalize products in different areas such as cosmetics, pharmaceuticals or food industries, as natural ingredients or as bioactives. An option is the use of betalains as natural colorants, in which the different hues provided from betaxanthins and betacyanins, could be employed, in isolation or mixed in order to obtain a broader range of colours with healthy properties. Opuntia samples have also shown strong antimicrobial activity as well as biomolecules with bioactive potential, which could act positively on the health and well-being of consumers.

\section{Acknowledgements}

The authors are grateful to the Foundation for Science and Technology (FCT, Portugal) and FEDER under Programme PT2020 for financial support to CIMO (UID/AGR/00690/2013) and L. Barros contract. B. Melgar (No. 329930) also thanks CONACyT for his grant. The authors are grateful for a grant from the Serbian Ministry of Education, Sciences and Technological Development (no. 173032). The authors would also like to thank Dr. Carlos Aguiar for the botanical identification of these species. 


\section{References}

Ahn, J.H., Jang, Y.-S., Lee, S.Y., 2016. Production of succinic acid by metabolically engineered microorganisms. Curr. Opin. Biotechnol. 42, 54-66. https://doi.org/10.1016/j.copbio.2016.02.034

Al-Farsi, M.A., Lee, C.Y., 2008. Optimization of phenolics and dietary fibre extraction from date seeds. Food Chem. 108, 977-985. https://doi.org/10.1016/j.foodchem.2007.12.009

Albano, C., Negro, C., Tommasi, N., Gerardi, C., Mita, G., Miceli, A., De Bellis, L., Blando, F., 2015. Betalains, Phenols and Antioxidant Capacity in Cactus Pear [Opuntia ficus-indica (L.) Mill.] Fruits from Apulia (South Italy) Genotypes. Antioxidants 4, 269-280. https://doi.org/10.3390/antiox4020269

Albuquerque, T.G., Santos, F., Sanches-Silva, A., Beatriz Oliveira, M., Bento, A.C., Costa, H.S., 2016. Nutritional and phytochemical composition of Annona cherimola Mill. fruits and by-products: Potential health benefits. Food Chem. 193, 187-195. https://doi.org/10.1016/j.foodchem.2014.06.044

Allai, L., Druart, X., Öztürk, M., BenMoula, A., Nasser, B., El Amiri, B., 2016. Protective effects of Opuntia ficus-indica extract on ram sperm quality, lipid peroxidation and DNA fragmentation during liquid storage. Anim. Reprod. Sci. 175, 1-9. https://doi.org/10.1016/j.anireprosci.2016.09.013

Almeida, M.M.B., de Sousa, P.H.M., Arriaga, Â.M.C., do Prado, G.M., Magalhães, C.E. de C., Maia, G.A., de Lemos, T.L.G., 2011. Bioactive compounds and antioxidant activity of fresh exotic fruits from northeastern Brazil. Food Res. Int. 44, 2155-2159. https://doi.org/10.1016/j.foodres.2011.03.051

Alvarez, B., 2007. Análisis de factibilidad del cultivo de la tuna en la localidad de Icaño, Departamento La Paz, Dirección provincial de programación del desarrollo, Ministerio de Producción y Desarrollo. Gobierno de la Provincia de Catamarca. Catamarca, Argentina.

Alzate T, L.M., González, D., Hincapié, S., Cardona S, B.L., LondoñoLondoño, J., Jiménez-Cartagena, C., 2016. The profile of bioactive substances in ten vegetable and fruit by-products from a food supply chain in Colombia. Sustain. Prod. Consum. https://doi.org/10.1016/j.spc.2016.07.005 
Ammar, I., Ben Salem, M., Harrabi, B., Mzid, M., Bardaa, S., Sahnoun, Z., Attia, H., Ennouri, M., 2018. Anti-inflammatory activity and phenolic composition of prickly pear (Opuntia ficus-indica) flowers. Ind. Crops Prod. 112, 313-319. https://doi.org/10.1016/j.indcrop.2017.12.028

Angulo-Bejarano, P.I., Martínez-Cruz, O., Paredes-López, O., 2014. Phytochemical Content, Nutraceutical Potential and Biotechnological Applications of an Ancient Mexican Plant: Nopal (Opuntia ficus-indica). Curr. Nutr. Food Sci. 10, 196-217. https://doi.org/10.2174/157340131003140828121015

Arlt, U., 2010. NATCOL | Foods Colours Legislation.

Aruwa, C.E., Amoo, S.O., Kudanga, T., 2018. Opuntia (Cactaceae) plant compounds, biological activities and prospects - A comprehensive review. Food Res. Int. 112, 328-344. https://doi.org/10.1016/j.foodres.2018.06.047

Association of Official Analytical Chemists, 2016. Official Methods of Analysis of AOAC International, 20th ed. The Association, Gaithersburg, MD, USA.

Attokaran, M., 2011. Natural Food Flavors and Colorants Natural Food Flavors and Colorants, 1st ed. Blackwell Publishing LTD, Iowa.

Augustin, M.A., Sanguansri, L., 2015. Challenges and Solutions to Incorporation of Nutraceuticals in Foods. Annu. Rev. Food Sci. Technol. 6, 463-477. https://doi.org/10.1146/annurev-food022814-015507

Ayala-Zavala, J.F., Vega-Vega, V., Rosas-Domínguez, C., PalafoxCarlos, H., Villa-Rodriguez, J.A., Siddiqui, M.W., Dávila-Aviña, J.E., González-Aguilar, G.A., 2011. Agro-industrial potential of exotic fruit byproducts as a source of food additives. Food Res. Int. 44 , $1866-1874$. https://doi.org/10.1016/j.foodres.2011.02.021

Azeredo, H.M.C., 2009. Betalains: Properties, sources, applications, and stability - A review. Int. J. Food Sci. Technol. 44, 2365-2376. https://doi.org/10.1111/j.1365-2621.2007.01668.x

Balouiri, M., Sadiki, M., Ibnsouda, S.K., 2016. Methods for in vitro evaluating antimicrobial activity: A review. J. Pharm. Anal. 6, 71-79. https://doi.org/10.1016/j.jpha.2015.11.005

Barros, L., Calhelha, R.C., Queiroz, M.J.R.P., Santos-Buelga, C., Santos, E.A., Regis, W.C.B., Ferreira, I.C.F.R., 2015. The 
powerful in vitro bioactivity of Euterpe oleracea Mart. seeds and related phenolic compounds. Ind. Crops Prod. 76, 318-322. https://doi.org/10.1016/j.indcrop.2015.05.086

Barros, L., Pereira, C., Ferreira, I.C.F.R., 2013. Optimized Analysis of Organic Acids in Edible Mushrooms from Portugal by Ultra Fast Liquid Chromatography and Photodiode Array Detection. Food Anal. Methods 6. https://doi.org/10.1007/s12161-012-9443-1

Barrows, J.N., Lipman, A.L., Bailey, C.J., Cianci, S., 2003. Color Additives: FDA's Regulatory Process and Historical Perspectives. Food Saf. Mag. URL https://www.fda.gov/forindustry/coloradditives/regulatoryproces shistoricalperspectives/ (accessed 9.3.18).

Baydar, N.G., Özkan, G., Sağdiç, O., 2004. Total phenolic contents and antibacterial activities of grape (Vitis vinifera L.) extracts. Food Control 15, 335-339. https://doi.org/10.1016/S09567135(03)00083-5

Belščak-Cvitanović, A., Durgo, K., Huđek, A., Bačun-Družina, V., Komes, D., 2018. Metabolism and Health Effects of Polyphenols, in: Galanakis, C.M. (Ed.), Polyphenols: Properties, Recovery, and Applications. Woodhead Publishing, pp. 1-44. https://doi.org/https://doi.org/10.1016/B978-0-12-8135723.00001-4

Belwal, T., Dhyani, P., Bhatt, I.D., Rawal, R.S., Pande, V., 2016. Optimization extraction conditions for improving phenolic content and antioxidant activity in Berberis asiatica fruits using response surface methodology (RSM). Food Chem. 207, 115124. https://doi.org/10.1016/j.foodchem.2016.03.081

Bessada, S.M.F., Barreira, J.C.M., Barros, L., Ferreira, I.C.F.R., Oliveira, M.B.P.P., 2016. Phenolic profile and antioxidant activity of Coleostephus myconis (L.) Rchb.f.: An underexploited and highly disseminated species. Ind. Crops Prod. 89, 45-51. https://doi.org/10.1016/j.indcrop.2016.04.065

Betancourt, C., Cejudo-Bastante, M.J., Heredia, F.J., Hurtado, N., 2017. Pigment composition and antioxidant capacity of betacyanins and betaxanthins fractions of Opuntia dillenii (Ker Gawl) Haw cactus fruit. Food Res. Int. 101, 173-179. https://doi.org/10.1016/j.foodres.2017.09.007

Bhatia, S., Bera, T., Dahiya, R., Bera, T., Bhatia, S., Bera, T., 2015. Classical and Nonclassical Techniques for Secondary Metabolite 
Production in Plant Cell Culture, in: Modern Applications of Plant Biotechnology in Pharmaceutical Sciences. Elsevier, pp. 231291. https://doi.org/10.1016/B978-0-12-802221-4.00007-8

Brand-Williams, W., Cuvelier, M.E., Berset, C., 1995. Use of a free radical method to evaluate antioxidant activity. LWT - Food Sci. Technol. 28, 25-30. https://doi.org/10.1016/S00236438(95)80008-5

Bravo-Hollis, H., 1978. Las cactaceas de Mexico. Universidad Nacional Autonoma de Mexico, Mexio. https://doi.org/10.15713/ins.mmj.3

Brundtland, G.H., 1987. Our common future.

Cai, Y., Sun, M., Corke, H., 2003. Antioxidant activity of betalains from plants of the Amaranthaceae. J. Agric. Food Chem. 51, 2288-2294. https://doi.org/10.1021/jf030045u

Calderón-Oliver, M., Escalona-Buendía, H.B., Medina-Campos, O.N., Pedraza-Chaverri, J., Pedroza-Islas, R., Ponce-Alquicira, E., 2016. Optimization of the antioxidant and antimicrobial response of the combined effect of nisin and avocado byproducts. LWT Food Sci. Technol. 65, 46-52. https://doi.org/10.1016/j.lwt.2015.07.048

Cardoso-Ugarte, G.A., Sosa-Morales, M.E., Ballard, T., Liceaga, A., San Martín-González, M.F., 2014. Microwave-assisted extraction of betalains from red beet (Beta vulgaris). LWT - Food Sci. Technol. 59, 276-282. https://doi.org/10.1016/j.lwt.2014.05.025

Carocho, M., Ferreira, I.C.F.R., 2013. A review on antioxidants, prooxidants and related controversy: Natural and synthetic compounds, screening and analysis methodologies and future perspectives. Food Chem. Toxicol. 51, 15-25. https://doi.org/10.1016/j.fct.2012.09.021

Carr, M., 2013. The water relations and irrigation requirements of avocado (Persea americana Mill.): a review. Exp. Agric. 49, 256278. https://doi.org/10.1017/S0014479712001317

Cassano, A., Conidi, C., Timpone, R., D’Avella, M., Drioli, E., 2007. A membrane-based process for the clarification and the concentration of the cactus pear juice. J. Food Eng. 80, 914-921. https://doi.org/10.1016/j.jfoodeng.2006.08.005

Castellanos-Santiago, E., Yahia, E.M., 2008. Identification and quantification of betalains from the fruits of 10 Mexican prickly 
pear cultivars by high-performance liquid chromatography and electrospray ionization mass spectrometry. J. Agric. Food Chem. 56, 5758-5764. https://doi.org/10.1021/jf800362t

Castellar, R., Obón, J.M., Alacid, M., Fernández-López, J.A., 2003. Color Properties and Stability of Betacyanins from Opuntia Fruits. J. Agric. Food Chem. 51, 2772-2776. https://doi.org/10.1021/jf021045h

Cejudo Bastante, M.J., Chaalal, M., Louaileche, H., Parrado, J., Heredia, F.J., 2014. Betalain Profile, Phenolic Content, and Color Characterization of Different Parts and Varieties of Opuntia ficusindica. J. Agric. Food Chem. 62, 8491-8499. https://doi.org/10.1021/jf502465g

Chahdoura, H., Barreira, J.C.M., Barros, L., Santos-Buelga, C., Ferreira, I.C.F.R., Achour, L., 2014. Phytochemical characterization and antioxidant activity of Opuntia microdasys (Lehm.) Pfeiff flowers in different stages of maturity. J. Funct. Foods 9, 27-37. https://doi.org/10.1016/j.jff.2014.04.011

Chahdoura, H., Barreira, J.C.M., Fernández-Ruiz, V., Morales, P., Calhelha, R.C., Flamini, G., Soković, M., Ferreira, I.C.F.R., Achour, L., 2016. Bioactivity, proximate, mineral and volatile profiles along the flowering stages of Opuntia microdasys (Lehm.): defining potential applications. Food Funct. 7, 1458-67. https://doi.org/10.1039/c5fo01536g

Chan, L.G., Cohen, J.L., Maria, J., Nobrega, L., Bell, D.M., 2018. Conversion of Agricultural Streams and Food-Processing ByProducts to Value-Added Compounds using Filamentous Fungi. Annu. Rev. Food Sci. Technol. 9, 1-21. https://doi.org/10.1146/annurev-food-030117-012626

Chougui, N., Djerroud, N., Naraoui, F., Hadjal, S., Aliane, K., Zeroual, B., Larbat, R., 2015. Physicochemical properties and storage stability of margarine containing Opuntia ficus-indica peel extract as antioxidant. Food Chem. 173, 382-90. https://doi.org/10.1016/j.foodchem.2014.10.025

Chougui, N., Tamendjari, A., Hamidj, W., Hallal, S., Barras, A., Richard, T., Larbat, R., 2013. Oil composition and characterisation of phenolic compounds of Opuntia ficus-indica seeds. Food Chem. 139, 796-803. https://doi.org/10.1016/j.foodchem.2013.01.054

Clifford, M.N., Johnston, K.L., Knight, S., Kuhnert, N., 2003. 
Hierarchical Scheme for LC-MSn Identification of Chlorogenic Acids. J. Agric. Food Chem. 51, 2900-2911. https://doi.org/10.1021/jf026187q

Clifford, M.N., Knight, S., Kuhnert, N., 2005. Discriminating between the six isomers of dicaffeoylquinic acid by LC-MSn. J. Agric. Food Chem. 53, 3821-3832. https://doi.org/10.1021/jf050046h

Cowan, A.K., Cripps, R.F., Richings, E.W., Taylor, N.J., 2001. Fruit size: Towards an understanding of the metabolic control of fruit growth using avocado as a model system. Physiol. Plant. 111, 127-136. https://doi.org/10.1034/j.1399-3054.2001.1110201.x

Cowan, A.K., Wolstenholme, B.N., 2003. AVOCADOS, in: Encyclopedia of Food Sciences and Nutrition. Elsevier, pp. 348353. https://doi.org/10.1016/B0-12-227055-X/00073-0

Crane, J.H., Balerdi, C.F., Maguire, I., 2016. Avocado Growing in the Florida Home Landscape.

Da-Costa-Rocha, I., Bonnlaender, B., Sievers, H., Pischel, I., Heinrich, M., 2014. Hibiscus sabdariffa L. A phytochemical and pharmacological review. Food Chem. 165, 424-443. https://doi.org/10.1016/j.foodchem.2014.05.002

da Silva, R.P.F.F., Rocha-Santos, T.A.P., Duarte, A.C., 2016. Supercritical fluid extraction of bioactive compounds. TrAC Trends Anal. Chem. 76, 40-51. https://doi.org/10.1016/j.trac.2015.11.013

Dabas, D., Shegog, R.M., Ziegler, G.R., Lambert, J.D., 2013. Avocado (Persea americana) seed as a source of bioactive phytochemicals. Curr. Pharm. Des. 19, 6133-40. https://doi.org/10.2174/1381612811319340007

Day, L., Seymour, R.B., Pitts, K.F., Konczak, I., Lundin, L., 2009. Incorporation of functional ingredients into foods. Trends Food Sci. Technol. $20, \quad 388-395$. https://doi.org/10.1016/J.TIFS.2008.05.002

DeFelice, S.L., 2002. FIM Rationale And Proposed Guidelines For The Nutraceutical Research \& Education Act - NREA. New York.

Delgado-Vargas, F., Paredes-Lopez, O., 2003. Natural Colorants for Food and Nutraceutical Uses, Trends in Food Science \& Technology. https://doi.org/10.1016/S0924-2244(03)00076-1

Destro dos Santos, C., Külzer Scherer, R., Schilling Cassini, A., Ferreira Marczak, L.D., Tessaro, I.C., 2016. Clarification of red 
beet stalks extract by microfiltration combined with ultrafiltration. J. Food Eng. 185, 35-41. https://doi.org/10.1016/j.jfoodeng.2016.03.031

Devalaraja, S., Jain, S., Yadav, H., 2011. Exotic fruits as therapeutic complements for diabetes, obesity and metabolic syndrome. Food Res. Int. 44, 1856-1865. https://doi.org/10.1016/j.foodres.2011.04.008

Devasagayam, T.P.A., Boloor, K.K., Ramasarma, T., 2003. Methods for estimating lipid peroxidation: An analysis of merits and demerits. Indian J. Biochem. Biophys. 40, 300-308.

Dias, M.I., Sousa, M.J., Alves, R.C., Ferreira, I.C.F.R., 2016. Exploring plant tissue culture to improve the production of phenolic compounds: A review. Ind. Crops Prod. 82, 9-22. https://doi.org/10.1016/j.indcrop.2015.12.016

Donkin, R.A., 1977. Spanish Red: An Ethnogeographical Study of Cochineal and the Opuntia Cactus. Trans. Am. Philos. Soc. 67, 184. https://doi.org/10.2307/1006195

Esatbeyoglu, T., Wagner, A.E., Schini-Kerth, V.B., Rimbach, G., 2015a. Betanin--a food colorant with biological activity. Mol. Nutr. Food $\quad$ Res. 59, 36-47. https://doi.org/10.1002/mnfr.201400484

Esatbeyoglu, T., Wagner, A.E., Schini-Kerth, V.B., Rimbach, G., 2015b. Betanin-A food colorant with biological activity. Mol. Nutr. Food Res. 59, 36-47. https://doi.org/10.1002/mnfr.201400484

Espinel-Ingroff, A., 2001. Comparison of the E-test with the NCCLS M38-P method for antifungal susceptibility testing of common and emerging pathogenic filamentous fungi. J. Clin. Microbiol. 39, 1360-1367. https://doi.org/10.1128/JCM.39.4.13601367.2001

Esquivel, P., 2016. Handbook on Natural Pigments in Food and Beverages Industrial Applications for Improving Food Colorl, in: Carle, R., Schweiggert, R.M. (Eds.), . Woodhead Publishing, San Pedro, Costa Rica, pp. 81-99.

FAO, $2016 . \quad$ FAOSTAT. URL http://www.fao.org/faostat/en/?\#data/QC/visualize (accessed 5.3.18).

FAO, 2004. AVOCADO: Post-Harvest Operation. Rome. 
FAO, IFAD, WFP, 2015. The State of Food Insecurity in the World. Meeting the 2015 international hunger targets: taking stock of uneven progress. Rome.

Farag, M.A., Maamoun, A.A., Ehrlich, A., Fahmy, S., Wesjohann, L.A., 2017. Assessment of sensory metabolites distribution in 3 cactus Opuntia ficus-indica fruit cultivars using UV fingerprinting and GC/MS profiling techniques. LWT - Food Sci. Technol. 80, 145-154. https://doi.org/10.1016/j.lwt.2017.02.014

Fathordoobady, F., Mirhosseini, H., Selamat, J., Manap, M.Y.A., 2016. Effect of solvent type and ratio on betacyanins and antioxidant activity of extracts from Hylocereus polyrhizus flesh and peel by supercritical fluid extraction and solvent extraction. Food Chem. 202, 70-80. https://doi.org/10.1016/j.foodchem.2016.01.121

FDA, 2017. SCOGS (Select Committee on GRAS Substances). URL http://www.accessdata.fda.gov/scripts/fdcc/?set=SCOGS (accessed 3.14.17).

FDA, 2007. Guidance for Industry and Other Stakeholders Toxicological Principles for the Safety Assessment of Food Ingredients, Human Studies.

Fernández-López, J. a., Almela, L., 2001. Application of highperformance liquid chromatography to the characterization of the betalain pigments in prickly pear fruits. J. Chromatogr. A 913, 415-420. https://doi.org/10.1016/S0021-9673(00)01224-3

Fernandez-Rojas, B., Ortiz-Moreno, A., Hernandez-Navarro, D., 2010. Phenolic Content and its Antioxidant Activity of Persimmon (Dyospiros kaki L.) Cultivated in Mexico. J. Biotechnol. 150. https://doi.org/10.1016/j.jbiotec.2010.09.289

Ferreira, I.C.F.R., Martins, N., Barros, L., 2017. Phenolic Compounds and Its Bioavailability: In Vitro Bioactive Compounds or Health Promoters? Adv. Food Nutr. Res. 82, 1-44. https://doi.org/10.1016/bs.afnr.2016.12.004

Ferreres, F., Grosso, C., Gil-Izquierdo, A., Valentão, P., Mota, A.T., Andrade, P.B., 2017. Optimization of the recovery of high-value compounds from pitaya fruit by-products using microwaveassisted extraction. Food Chem. 230, 463-474. https://doi.org/10.1016/j.foodchem.2017.03.061

Flores-Valdez, C., Luna-Esquivel, J., Ramirez-Moreno, P., 1995. Manejo postcosecha de la tuna para el mercado nacional e 
internacional y Procesamiento y transformación industrial ... Chapingo, Estado de México.

Galanakis, C.M., 2015. Chapter 3 - The universal recovery strategy, Food Waste Recovery. Elsevier Inc. https://doi.org/10.1016/B978-0-12-800351-0.00003-1

Galanakis, C.M., 2012. Recovery of high added-value components from food wastes: Conventional, emerging technologies and commercialized applications. Trends Food Sci. Technol. 26, 6887. https://doi.org/10.1016/j.tifs.2012.03.003

Gandía-herrero, F., Cabanes, J., Escribano, J., García-carmona, F., Jimenez-atienzar, M., Jiménez-atiénzar, M., 2013. Encapsulation of the most antioxidant betalains in edible matrices as powders of different colors Encapsulation of the most antioxidant betalains in edible matrices as powders of different colors. https://doi.org/10.1021/jf400337g

Gandía-Herrero, F., Escribano, J., García-Carmona, F., 2010. Structural implications on color, fluorescence, and antiradical activity in betalains. Planta 232, 449-460. https://doi.org/10.1007/s00425010-1191-0

Garcia-Castello, E.M., Rodriguez-Lopez, A.D., Mayor, L., Ballesteros, R., Conidi, C., Cassano, A., 2015. Optimization of conventional and ultrasound assisted extraction of flavonoids from grapefruit (Citrus paradisi L.) solid wastes. LWT - Food Sci. Technol. 64, 1114-1122. https://doi.org/10.1016/j.lwt.2015.07.024

García-Cruz, L., Dueñas, M., Santos-Buelgas, C., Valle-Guadarrama, S., Salinas-Moreno, Y., 2017. Betalains and phenolic compounds profiling and antioxidant capacity of pitaya (Stenocereus spp.) fruit from two species (S. Pruinosus and S. stellatus). Food Chem. 234, 111-118. https://doi.org/10.1016/j.foodchem.2017.04.174

Gebhardt, D., 2018. The Economics of Natural Color Pigments. URL https://sensientfoodcolors.com/en-us/researchdevelopment/economics-natural-color-pigments/

Ghasemzadeh, A., Ghasemzadeh, N., 2011. Flavonoids and phenolic acids: Role and biochemical activity in plants and human. J. Med. Plants Res. 5, 6697-6703. https://doi.org/10.5897/JMPR11.363

Gomes-Correa, R.C., de Souza, A.H.P., Calhelha, R.C., Barros, L., Glamoclija, J., Sokovic, M., Peralta, R.M., Bracht, A., Ferreira, I.C.F.R., 2015. Bioactive formulations prepared from fruiting 
bodies and submerged culture mycelia of the Brazilian edible mushroom Pleurotus ostreatoroseus Singer. Food Funct. 6, 21552164. https://doi.org/10.1039/C5FO00465A

Gong, M., Bassi, A., 2016. Carotenoids from microalgae: A review of recent developments. Biotechnol. Adv. 34, 1396-1412. https://doi.org/10.1016/j.biotechadv.2016.10.005

Griffith, M.P., 2004. The origins of an important cactus crop, Opuntia ficus-indica (Cactaceae): New molecular evidence. Am. J. Bot. 91, 1915-1921. https://doi.org/10.3732/ajb.91.11.1915

Guimarães, R., Barros, L., Dueñas, M., Calhelha, R.C., Carvalho, A.M., Santos-Buelga, C., Queiroz, M.J.R.P., Ferreira, I.C.F.R., 2013. Nutrients, phytochemicals and bioactivity of wild Roman chamomile: A comparison between the herb and its preparations. Food Chem. 136, 718-725. https://doi.org/10.1016/j.foodchem.2012.08.025

Guldiken, B., Toydemir, G., Nur Memis, K., Okur, S., Boyacioglu, D., Capanoglu, E., 2016. Home-processed red beetroot (Beta vulgaris L.) products: Changes in antioxidant properties and bioaccessibility. Int. J. Mol. Sci. 17. https://doi.org/10.3390/ijms17060858

GVR, 2016. Natural Antioxidants Market Analysis By Product (Vitamin C, Vitamin E, Polyphenols, Carotenoids) And Segment $\begin{array}{llll}\text { Forecasts } & \text { To } 2022 . & \text { URL }\end{array}$ https://www.grandviewresearch.com/industry-analysis/naturalantioxidants-market

Heleno, S.A., Barros, L., Sousa, M.J., Martins, A., Ferreira, I.C.F.R., 2010. Tocopherols composition of Portuguese wild mushrooms with antioxidant capacity. Food Chem. 119, 1443-1450. https://doi.org/10.1016/j.foodchem.2009.09.025

Henry, B.S., 1996. Natural food colours, in: Natural Food Colorants. Springer US, Boston, MA, pp. 40-79. https://doi.org/10.1007/978-1-4615-2155-6_2

Herbach, K.M., Stintzing, F.C., Carle, R., 2006. Betalain stability and degradation - Structural and chromatic aspects. J. Food Sci. 71, 41-50. https://doi.org/10.1111/j.1750-3841.2006.00022.x

Herbach, K.M., Stintzing, F.C., Carle, R., 2005. Identification of heatinduced degradation products from purified betanin, phyllocactin and hylocerenin by high-performance liquid chromatography/ 
electrospray ionization mass spectrometry. Rapid Commun. Mass

Spectrom. 19, 2603-2616. https://doi.org/10.1002/rcm.2103

Hiwasa-Tanase, K., Ezure, H., 2014. Climateric and non-climateric ripening, in: Nath, P., Bouzayen, M., Mattoo, A.K., Pech, J.C. (Eds.), Fruit Ripening: Physiology, Signalling and Genomics. CABI International, pp. 151-177. https://doi.org/10.1017/CBO9781107415324.004

Hogervorst-Cvejić, J., Atanacković-Krstonošić, M., Bursać, M., Miljić, U., 2017. Polyphenols, in: Nutraceutical and Functional Food Components. Academic Press, pp. 203-258. https://doi.org/10.1016/B978-0-12-805257-0.00007-7

Hollman, P.C., Bijsman, M.N., van Gameren, Y., Cnossen, E.P., de Vries, J.H., Katan, M.B., 1999. The sugar moiety is a major determinant of the absorption of dietary flavonoid glycosides in man. Free Radic. Res. 31, 569-573. https://doi.org/10.1080/10715769900301141

Hurtado-Fernández, E., Fernandez-Gutierrez, A., Carrasco-Pancorbo, A., 2018a. Avocado fruit, in: Rodrigues, S., de Oliveira, E., Sousa, E. (Eds.), Exotic Fruits. Academic Press, London, pp. 37-46.

Hurtado-Fernández, E., Pacchiarotta, T., Longueira-Suárez, E., Mayboroda, O.A., Fernández-Gutiérrez, A., Carrasco-Pancorbo, A., 2013. Evaluation of gas chromatography-atmospheric pressure chemical ionization-mass spectrometry as an alternative to gas chromatography-electron ionization-mass spectrometry: Avocado fruit as example. J. Chromatogr. A 1313, 228-244. https://doi.org/10.1016/j.chroma.2013.08.084

Hurtado-Fernández, E., Pacchiarotta, T., Mayboroda, O.A., FernándezGutiérrez, A., Carrasco-Pancorbo, A., 2014. Quantitative characterization of important metabolites of avocado fruit by gas chromatography coupled to different detectors (APCI-TOF MS and FID). Food Res. Int. 62, 801-811. https://doi.org/10.1016/j.foodres.2014.04.038

Hussain, Z., Thu, H.E., Amjad, M.W., Hussain, F., Ahmed, T.A., Khan, S., 2017. Exploring recent developments to improve antioxidant, anti-inflammatory and antimicrobial efficacy of curcumin: A review of new trends and future perspectives. Mater. Sci. Eng. C. https://doi.org/10.1016/j.msec.2017.03.226

IFIC, FDA, 2010. Overview of Food Ingredients, Additives and Colors. URL 
https://www.fda.gov/food/ingredientspackaginglabeling/foodadd itivesingredients/ucm094211.htm

Inglese, P., Giugliuzza, G., Liguori, G., 2004. Cactus pear fruit production: from knowledge to development, in: Esparza-Frausto, G., Valdez-Cepeda, R.D., Méndez- Gallego, S.J. (Eds.), El Nopal.Tópicos de Actualidad. Universidad Autónoma de Chapingo. Colegio de Postgraduados, México, pp. 89-108.

IUPAC, IUPAC-IUB, 1976. Nomenclature of cyclitols. Biochem. J. 153, 23-31. https://doi.org/10.1351/pac197437010283

Jain, G., Gould, K.S., 2015. Are betalain pigments the functional homologues of anthocyanins in plants? Environ. Exp. Bot. 119, 48-53. https://doi.org/10.1016/J.ENVEXPBOT.2015.06.002

Jain, T., Grover, K., Kaur, G., 2016. Effect of processing on nutrients and fatty acid composition of garden cress (Lepidium sativum) seeds. Food Chem. 213, 806-812. https://doi.org/10.1016/j.foodchem.2016.07.034

Jimenez-Garcia, S.N., Vazquez-Cruz, M.A., Garcia-Mier, L., Contreras-Medina, L.M., Guevara-González, R.G., Garcia-Trejo, J.F., Feregrino-Perez, A.A., 2018. Phytochemical and Pharmacological Properties of Secondary Metabolites in Berries, in: Therapeutic Foods. Elsevier, pp. 397-427. https://doi.org/10.1016/B978-0-12-811517-6.00013-1

Kaderides, K., Goula, A.M., 2017. Development and characterization of a new encapsulating agent from orange juice by-products. Food Res. Int. 0-1. https://doi.org/10.1016/j.foodres.2017.07.057

Kanner, J., Harel, S., Granit, R., 2001. Betalains - A new class of dietary cationized antioxidants. J. Agric. Food Chem. 49, 51785185. https://doi.org/10.1021/jf010456f

Karamac, M., Estrella, I., Herna, T., Dykes, G. a., Kosińska, A., Karamać, M., Estrella, I., Hernández, T., Bartolomé, B., Dykes, G. a., 2012. Phenolic compound profiles and antioxidant capacity of Persea americana Mill. peels and seeds of two varieties. J. Agric. Food Chem. 60, 4613-4619. https://doi.org/10.1021/jf300090p

Katsube, T., Tsurunaga, Y., Sugiyama, M., Furuno, T., Yamasaki, Y., 2009. Effect of air-drying temperature on antioxidant capacity and stability of polyphenolic compounds in mulberry (Morus alba L.) leaves. Food Chem. 113, 964-969. 
https://doi.org/10.1016/j.foodchem.2008.08.041

Kaur Kala, H., Mehta, R., Tandey, R., Sen, K.K., Mandal, V., 2016. Ten years of research on phenolics (2005-2015): A status report. Pacific Sci. Rev. A Nat. Sci. Eng. https://doi.org/10.1016/j.psra.2016.07.002

Knight, R.J., Campbell, C.W., 1999. Ecological adaptation and the evolution of modern avocado cultivars. Rev. Chapingo Ser. Hortic. 49-54.

Kosińska, A., Karamać, M., Estrella, I., Hernández, T., Bartolomé, B., Dykes, G.A., 2012. Phenolic compound profiles and antioxidant capacity of Persea americana Mill. peels and seeds of two varieties. J. Agric. Food Chem. 60, 4613-4619. https://doi.org/10.1021/jf300090p

Kris-Etherton, P.M., Hecker, K.D., Bonanome, A., Coval, S.M., Binkoski, A.E., Hilpert, K.F., Griel, A.E., Etherton, T.D., 2002. Bioactive compounds in foods: their role in the prevention of cardiovascular disease and cancer. Am. J. Med. 113, 71-88. https://doi.org/10.1016/S0002-9343(01)00995-0

Kuhnle, G.G., 2012. Nutritional biomarkers for objective dietary assessment. J. Sci. Food Agric. 92, 1145-1149. https://doi.org/10.1002/jsfa.5631

Kuti, J.O., 2004. Antioxidant compounds from four Opuntia cactus pear fruit varieties. Food Chem. 85, 527-533. https://doi.org/10.1016/S0308-8146(03)00184-5

Kyriacou, M.C., Emmanouilidou, M.G., Soteriou, G.A., 2016. Asynchronous ripening behavior of cactus pear (Opuntia ficusindica) cultivars with respect to physicochemical and physiological attributes. Food Chem. 211, 598-607. https://doi.org/10.1016/j.foodchem.2016.05.113

Laqui-Vilca, C., Aguilar-Tuesta, S., Mamani-Navarro, W., MontañoBustamante, J., Condezo-Hoyos, L., 2018. Ultrasound-assisted optimal extraction and thermal stability of betalains from colored quinoa (Chenopodium quinoa Willd) hulls. Ind. Crops Prod. 111, 606-614. https://doi.org/10.1016/j.indcrop.2017.11.034

Lea, A., 2008. Analysis of polyphenol antioxidants in fortified foods and supplements. Food Fortif. Suppl. 175-194. https://doi.org/10.1533/9781845694265.2.175

Leardi, R., 2013. Experimental Design, 1st ed, Data Handling in 
Science and Technology. Copyright (C) 2013 Elsevier B.V. All rights reserved. https://doi.org/10.1016/B978-0-444-595287.00002-8

Li, J., Chen, Z., Di, D., 2012. Preparative separation and purification of Rebaudioside A from Stevia rebaudiana Bertoni crude extracts by mixed bed of macroporous adsorption resins. Food Chem. 132, 268-276. https://doi.org/10.1016/j.foodchem.2011.10.077

Librán, C. M., Mayor, L., Garcia-Castello, E. M., Vidal-Brotons, D., 2013. Polyphenol extraction from grape wastes: Solvent and $\mathrm{pH}$ $\begin{array}{llll}\text { effect. } & \text { Agric. } & \text { Sci. } & \text { 56, }\end{array}$ https://doi.org/10.4236/as.2013.49B010

Madrau, M. a., Piscopo, A., Sanguinetti, A.M., Del Caro, A., Poiana, M., Romeo, F. V., Piga, A., 2009. Effect of drying temperature on polyphenolic content and antioxidant activity of apricots. Eur. Food Res. Technol. 228, 441-448. https://doi.org/10.1007/s00217-008-0951-6

Madunić, J., Madunić, I.V., Gajski, G., Popić, J., Garaj-Vrhovac, V., 2018. Apigenin: A dietary flavonoid with diverse anticancer properties. Cancer Lett. 413, 11-22. https://doi.org/10.1016/j.canlet.2017.10.041

Manach, C., Scalbert, A., Morand, C., Rémésy, C., Jiménez, L., 2004. Bioavailability, Polyphenols: Food sources and. Am. J. Clin. Nutr. 79, 727-747. https://doi.org/10.1038/nature05488

Mandal, S.C., Mandal, V., Das, A.K., 2015. Classification of Extraction Methods, in: Essentials of Botanical Extraction. Academic Press, pp. 83-136. https://doi.org/10.1016/B978-0-12-802325-9.000069

Marais, J.P.J., Deavours, B., Dixon, R.A., Ferreira, D., 2006. The science of flavonoids, The Science of Flavonoids. Springer, Ohio. https://doi.org/10.1007/978-0-387-28822-2

Marco, G.J., 1968. A Rapid Method for Evaluation of Antioxidants. J. Am. oil Chem. Soc. 45, 594-598. https://doi.org/10.1007/BF02668958

Maria, J., Andrade, D.M., Fasolo, D., 2014. Polyphenol Antioxidants from Natural Sources and Contribution to Health Promotion, Polyphenols in Human Health and Disease. Elsevier Inc. https://doi.org/10.1016/B978-0-12-398456-2.00020-7

Martins, N., Roriz, C.L., Morales, P., Barros, L., Ferreira, I.C.F.R., 
2016. Food colorants: Challenges, opportunities and current desires of agro-industries to ensure consumer expectations and regulatory practices. Trends Food Sci. Technol. 52, 1-15. https://doi.org/10.1016/j.tifs.2016.03.009

Mata, A., Ferreira, J.P., Semedo, C., Serra, T., Duarte, C.M.M., Bronze, M.R., 2016. Contribution to the characterization of Opuntia spp. juices by LC-DAD-ESI-MS/MS. Food Chem. 210, 558-565. https://doi.org/10.1016/j.foodchem.2016.04.033

Mayor, L., Calvo, A., Moreira, R., Fito, P., Garcia-Castello, E., 2013. Water sorption isotherms of globe artichoke leaves. Agric. Sci. 04, 63-69. https://doi.org/10.4236/as.2013.49B011

McGuire, S., 2011. U.S. Department of Agriculture and U.S. Department of Health and Human Services, Dietary Guidelines for Americans, 2010. 7th Edition, Washington, DC: U.S. Government Printing Office, January 2011. Adv. Nutr. 2, 293294. https://doi.org/10.3945/an.111.000430

Medina-Meza, I.G., Barbosa-Cánovas, G. V., 2015. Assisted extraction of bioactive compounds from plum and grape peels by ultrasonics and pulsed electric fields. J. Food Eng. 166, 268-275. https://doi.org/10.1016/j.jfoodeng.2015.06.012

Melgar, B., Dias, M.I., Ciric, A., Sokovic, M., Garcia-Castello, E.M., Rodriguez-Lopez, A.D., Barros, L., Ferreira, I., 2017a. Byproduct recovery of Opuntia spp. peels: Betalainic and phenolic profiles and bioactive properties. https://doi.org/10.1016/j.indcrop.2017.06.011

Melgar, B., Pereira, E., Oliveira, M.B.P.P., Garcia-Castello, E.M., Rodriguez-Lopez, A.D., Sokovic, M., Barros, L., Ferreira, I.C.F.R., 2017b. Extensive profiling of three varieties of Opuntia spp. fruit for innovative food ingredients. Food Res. Int. 101, 259265. https://doi.org/10.1016/j.foodres.2017.09.024

Mena, P., Tassotti, M., Andreu, L., Nuncio-Jáuregui, N., Legua, P., Del Rio, D., Hernández, F., 2018. Phytochemical characterization of different prickly pear (Opuntia ficus-indica (L.) Mill.) cultivars and botanical parts: UHPLC-ESI-MSn metabolomics profiles and their chemometric analysis. Food Res. Int. 108, 301-308. https://doi.org/10.1016/j.foodres.2018.03.062

Mirabella, N., Castellani, V., Sala, S., 2014. Current options for the valorization of food manufacturing waste: a review. J. Clean. Prod.

65 , $28-41$. 
https://doi.org/10.1016/J.JCLEPRO.2013.10.051

Mishra, A., Sharma, A.K., Kumar, S., Saxena, A.K., Pandey, A.K., 2013. Bauhinia variegata leaf extracts exhibit considerable antibacterial, antioxidant, and anticancer activities. Biomed Res. Int. 2013. https://doi.org/10.1155/2013/915436

Mishra, A.K., Mishra, A., Kehri, H.K., Sharma, B., Pandey, A.K., 2009. Inhibitory activity of Indian spice plant Cinnamomum zeylanicum extracts against Alternaria solani and Curvularia lunata, the pathogenic dematiaceous moulds. Ann. Clin. Microbiol. Antimicrob. 8, 9. https://doi.org/10.1186/1476-07118-9

Monks, A., Scudiero, D., Skehan, P., Shoemaker, R., Paull, K., Vistica, D., Hose, C., Langley, J., Cronise, P., Vaigro-wolff, A., Graygoodrich, M., Campbell, H., Boyd, M., 1991. Feasibility of a High-Flux Anticancer Drug Screen Using a Diverse Panel of Cultured. J. Natl. Cancer Inst. 83, 757-766.

Morales, P., Barros, L., Ramírez-Moreno, E., Santos-Buelga, C., Ferreira, I.C.F.R., 2015. Xoconostle fruit (Opuntia matudae Scheinvar cv. Rosa) by-products as potential functional ingredients. Food Chem. 185, 289-97. https://doi.org/10.1016/j.foodchem.2015.04.012

Morales, P., Barros, L., Ramírez-Moreno, E., Santos-Buelga, C., Ferreira, I.C.F.R., 2014. Exploring xoconostle by-products as sources of bioactive compounds. Food Res. Int. 65, 437-444. https://doi.org/10.1016/j.foodres.2014.05.067

Morales, P., Ramírez-Moreno, E., Sanchez-Mata, M.D.C., Carvalho, A.M., Ferreira, I.C.F.R., 2012. Nutritional and antioxidant properties of pulp and seeds of two xoconostle cultivars (Opuntia joconostle F.A.C. Weber ex Diguet and Opuntia matudae Scheinvar) of high consumption in Mexico. Food Res. Int. 46. https://doi.org/10.1016/j.foodres.2011.12.031

Moreno, J., Peinado, R., 2012. Polyphenols, in: Moreno, J., Peinado, R. (Eds.), Enological Chemistry. Academic Press, pp. 53-76. https://doi.org/10.1016/B978-0-12-388438-1.00005-4

Naik, S.N., Goud, V. V., Rout, P.K., Dalai, A.K., 2010. Production of first and second generation biofuels: A comprehensive review. Renew. Sustain. Energy Rev. 14, 578-597. https://doi.org/10.1016/j.rser.2009.10.003 
Nicoletti, M., 2012. Nutraceuticals and botanicals: overview and perspectives. Int. J. Food Sci. Nutr. 63, 2-6. https://doi.org/10.3109/09637486.2011.628012

$\mathrm{NIH}$, 2017. Vitamin E - Fact sheet for Consumer. URL https://ods.od.nih.gov/factsheets/VitaminE-Consumer/ (accessed 3.14.17).

Nobel, P.S., 1998. Los incomparables agaves y cactos. Trillas, México.

Novoa, A., Le Roux, J.J., Robertson, M.P., Wilson, J.R.U., Richardson, D.M., 2015. Introduced and invasive cactus species: A global review. AoB Plants 7. https://doi.org/10.1093/aobpla/plu078

Ochoa, M. judith, Barbera, G., 2017. History and economic and agroecological importance, in: Crop Ecology, Cultivation and Uses of Catus Pears. FAO, ICARDA, pp. 1-11.

Osborn, S., 2015. 12 - Labelling relating to natural ingredients and additives, in: Advances in Food and Beverage Labelling. pp. 207221. https://doi.org/10.1533/9781782420934.3.207

Paciulli, M., Medina-Meza, I.G., Chiavaro, E., Barbosa-Cánovas, G.V., 2016. Impact of thermal and high pressure processing on quality parameters of beetroot (Beta vulgaris L.). LWT - Food Sci. Technol. 68, 98-104. https://doi.org/10.1016/j.lwt.2015.12.029

Patel, D., Shukla, S., Gupta, S., 2007. Apigenin and cancer chemoprevention: Progress, potential and promise (Review). Int. J. Oncol. 30, 233-245. https://doi.org/10.3892/ijo.30.1.233

Pedreño, M.A., Escribano, J., 2000. Studying the oxidation and the antiradical activity of betalain from beetroot. J. Biol. Educ. 35, 49-51. https://doi.org/10.1080/00219266.2000.9655736

Peláez-Cid, a. a., Velázquez-Ugalde, I., Herrera-González, a. M., García-Serrano, J., 2013. Textile dyes removal from aqueous solution using Opuntia ficus-indica fruit waste as adsorbent and its characterization. J. Environ. Manage. 130, 90-97. https://doi.org/10.1016/j.jenvman.2013.08.059

Pereira, C., Barros, L., Carvalho, A.M., Ferreira, I.C.F.R., 2011. Nutritional composition and bioactive properties of commonly consumed wild greens: Potential sources for new trends in modern diets. Food Res. Int. 44, 2634-2640. https://doi.org/10.1016/j.foodres.2011.05.012

Pereira, E., Barros, L., Calhelha, R.C., Duenas, M., Carvalho, A.M., Santos-Buelga, C., Ferreira, I.C.F.R., 2014. Bioactivity and 
phytochemical characterization of Arenaria montana L. Food Funct. 5, 1848-1855. https://doi.org/10.1039/c4fo00210e

Pereira, E., Barros, L., Martins, A., Ferreira, I.C.F.R., 2012. Towards chemical and nutritional inventory of Portuguese wild edible mushrooms in different habitats. Food Chem. 130, 394-403. https://doi.org/10.1016/j.foodchem.2011.07.057

Piattelli, M., Minale, L., Prota, G., 1964. Isolation, structure and absolute configuration of indicaxanthin. Tetrahedron 20, 23252329. https://doi.org/10.1016/S0040-4020(01)97621-5

Pimienta, E., 1990. El nopal tunero. Libros de tiempos de ciencia ;5.

Pimiento Barrios, E., Munoz-Urias, A., 1999. Domesticacion de nopales tuneros (Opuntis spp.) y descripcion de las principales variedades cultivadas. FAO, Rome (Italy).

Pinela, J., Prieto, M.A., Barreiro, M.F., Carvalho, A.M., Oliveira, M.B.P.P., Vázquez, J.A., Ferreira, I.C.F.R., 2016. Optimization of microwave-assisted extraction of hydrophilic and lipophilic antioxidants from a surplus tomato crop by response surface methodology. Food Bioprod. Process. 98, 283-298. https://doi.org/10.1016/j.fbp.2016.02.002

Primorac, T., Požar, M., Sokolić, F., Zoranić, L., Urbic, T., 2018. A simple two dimensional model of methanol. J. Mol. Liq. 262, 4657. https://doi.org/10.1016/j.molliq.2018.04.055

Quideau, S., Deffieux, D., Douat-Casassus, C., Pouysegu, L., 2011. Plant polyphenols: chemical properties, biological activities, and synthesis. Angew. Chem. Int. Ed. Engl. 50, 586-621. https://doi.org/10.1002/anie.201000044

Rached, W., Calhelha, R.C., Fernandes, Â., Carvalho, A.M., Bennaceur, M., Marouf, A., Barros, L., Santos-Buelga, C., Ferreira, I.C.F.R., 2016. Phytochemical characterization and bioactive properties of Osyris quadripartita Salzm. ex Decne. leaves from Algeria. RSC Adv. 6, 72768-72776. https://doi.org/10.1039/C6RA11787B

Ramos-Jerz, M.D.R., Villanueva, S., Jerz, G., Winterhalter, P., Deters, A.M., 2013. Persea americana Mill. Seed: Fractionation, Characterization, and Effects on Human Keratinocytes and Fibroblasts. Evidence-based Complement. Altern. Med. eCAM 2013, 391247. https://doi.org/10.1155/2013/391247

Rao, G., 2010. Optimization of ultrasound-assisted extraction of 
cyanidin 3-rutinoside from litchi (Lichi chinensis Sonn.) fruit pericarp. Anal. Methods 2, 1166. https://doi.org/10.1039/c0ay00203h

Ravichandran, K., Saw, N.M.M.T., Mohdaly, A.A.A., Gabr, A.M.M., Kastell, A., Riedel, H., Cai, Z., Knorr, D., Smetanska, I., 2013. Impact of processing of red beet on betalain content and antioxidant activity. Food Res. Int. 50, 670-675. https://doi.org/10.1016/j.foodres.2011.07.002

Raymond Chia, T.W., Dykes, G. a, 2010. Antimicrobial activity of crude epicarp and seed extracts from mature avocado fruit (Persea americana) of three cultivars. Pharm. Biol. 48, 753-756. https://doi.org/10.3109/13880200903273922

Reis, F.S., Barreira, J.C.M., Calhelha, R.C., van Griensven, L.J.I.D., Ćirić, A., Glamočlija, J., Soković, M., Ferreira, I.C.F.R., 2014. Chemical characterization of the medicinal mushroom Phellinus linteus (Berkeley \& Curtis) Teng and contribution of different fractions to its bioactivity. LWT - Food Sci. Technol. 58, 478485. https://doi.org/10.1016/j.lwt.2014.04.013

Reyes-Agüero, J.A., Aguirre, J.R., Hernández, H., 2005. Systematyc notes and a Detailed description of Opuntia ficus-indica (L) Mill. (CACTACEAE). Agrociencia 39, 395-408.

Reynolds, S.G., Arias, E., 2003. Opuntia Spp. -A Strategic fodder and efficient tool for combat desertification in the Wana Region, Cactus (Opuntia spp.) as forage. FAO Plant Production and Protection Paper 169.

Roberfroid, M.B., 2000. Concepts and strategy of functional food science: the European perspective. Am. J. Clin. Nutr. 71, 1660S$4 \mathrm{~S}$; discussion https://doi.org/10.1093/ajen/71.6.1660S

1674S-5S.

Rodrigo, D., Martínez-1, A., 2015. Antimicrobial activity of cauli fl ower (Brassica oleracea var . Botrytis) by-product against Listeria monocytogenes 50, 435-440. https://doi.org/10.1016/j.foodcont.2014.09.031

Rodríguez-Carpena, J.G., Morcuende, D., Estévez, M., 2011. Avocado by-products as inhibitors of color deterioration and lipid and protein oxidation in raw porcine patties subjected to chilled storage. Meat Sci. 89, 166-173. https://doi.org/10.1016/j.meatsci.2011.04.013 
Rohwer, J.G., 1993. Lauraceae, in: The Families and Genera of Vascular Plants Free Preview, Volume II, Flowering Plants . Dicotyledons. Springer, Berlin, pp. 366-391. https://doi.org/10.1007/978-3-662-02899-5

Roriz, C.L., Barros, L., Prieto, M.A., Morales, P., Ferreira, I.C.F.R., 2017. Floral parts of Gomphrena globosa L. as a novel alternative source of betacyanins: Optimization of the extraction using response surface methodology. Food Chem. 229, 223-234. https://doi.org/10.1016/j.foodchem.2017.02.073

Saavedra, J., Córdova, A., Navarro, R., Díaz-Calderón, P., Fuentealba, C., Astudillo-Castro, C., Toledo, L., Enrione, J., Galvez, L., 2017. Industrial avocado waste: Functional compounds preservation by convective drying process. J. Food Eng. 198, 81-90. https://doi.org/10.1016/j.jfoodeng.2016.11.018

Sáenz, C., 2006. Utilización agroindustrial del nopal. Boletín Serv. Agrícolas La Fao 162, 165.

SAGARPA, 2011. Monografía de cultivos. Aguacate. México city.

Sansano, S., Rivas, A., Pina-Pérez, M.C., Martinez, A., Rodrigo, D., 2017. Stevia rebaudiana Bertoni effect on the hemolytic potential of Listeria monocytogenes, International Journal of Food Microbiology. https://doi.org/10.1016/j.jifoodmicro.2017.03.006

SARAVACOS, G.D., 2014. Mass Transfer Properties of Foods 346399. https://doi.org/10.1201/9781420028805-11

Sawicki, T., Wiczkowski, W., 2018. The effects of boiling and fermentation on betalain profiles and antioxidant capacities of red beetroot products. Food Chem. 259, 292-303. https://doi.org/10.1016/j.foodchem.2018.03.143

Shahidi, F., Ambigaipalan, P., 2015. Phenolics and polyphenolics in foods, beverages and spices: Antioxidant activity and health effects - A review. J. Funct. Foods. https://doi.org/10.1016/j.jff.2015.06.018

Sharma, K., Mahato, N., Cho, M.H., Lee, Y.R., 2017. Converting citrus wastes into value-added products: Economic and environmently friendly approaches. Nutrition 34, 29-46. https://doi.org/10.1016/j.nut.2016.09.006

Šiler, B., Živković, S., Banjanac, T., Cvetković, J., Nestorović Živković, J., Ćirić, A., Soković, M., Mišić, D., 2014. Centauries as underestimated food additives: Antioxidant and antimicrobial 
potential. Food Chem. 147, 367-376. https://doi.org/10.1016/j.foodchem.2013.10.007

Silva, P., Ferreira, S., Nunes, F.M., 2016. Elderberry (Sambucus nigra L.) by-products a source of anthocyanins and antioxidant polyphenols. Ind. Crops Prod. https://doi.org/10.1016/j.indcrop.2016.10.018

Singleton, V.L., Rossi, J.A., 1965. Colorimetry of Total Phenolics with Phosphomolybdic-Phosphotungstic Acid Reagents. Am. J. Enol. Vitic. 16, 144-158. https://doi.org/10.12691/ijebb-2-1-5

Song, F.L., Gan, R.Y., Zhang, Y., Xiao, Q., Kuang, L., Li, H. Bin, 2010. Total phenolic contents and antioxidant capacities of selected chinese medicinal plants. Int. J. Mol. Sci. 11, 2362-2372. https://doi.org/10.3390/ijms11062362

Spórna-Kucab, A., Ignatova, S., Garrard, I., Wybraniec, S., 2013. Versatile solvent systems for the separation of betalains from processed Beta vulgaris L. juice using counter-current chromatography. J. Chromatogr. B Anal. Technol. Biomed. Life Sci. 941, 54-61. https://doi.org/10.1016/j.jchromb.2013.10.001

Stintzing, F., Schieber, A., Carle, R., 2000. Cactus pear-a promising component to functional food. Obs. Kartof. 85, 40-47.

Stintzing, F.C., Herbach, K.M., Mosshammer, M.R., Carle, R., Yi, W., Sellappan, S., Akoh, C.C., Bunch, R., Felker, P., 2005. Color, betalain pattern, and antioxidant properties of cactus pear (Opuntia spp.) clones. J. Agric. Food Chem. 53, 442-451. https://doi.org/10.1021/jf048751y

Stintzing, F.C., Schieber, A., Carle, R., 2002. Betacyanins in fruits from red-purple pitaya, Hylocereus polyrhizus (Weber) Britton \&amp; Rose. Food Chem. 77, 101-106. https://doi.org/10.1016/S03088146(01)00374-0

Strack, D., Vogt, T., Schliemann, W., 2003. Recent advances in betalain research. Phytochemistry 62, 247-269. https://doi.org/10.1016/S0031-9422(02)00564-2

Sudzuki, F., Muñoz, C., Berger, H., 1993. El cultivo de la tuna (cactus pear)., 1 ed. ed. Departamento de Reproducción Agrícola. Universidad de Chile, Santiago., Santiago, Chile.

Svenson, J., Smallfield, B.M., Joyce, N.I., Sansom, C.E., Perry, N.B., 2008. Betalains in red and yellow varieties of the andean tuber crop ulluco (Ullucus tuberosus). J. Agric. Food Chem. 56, 7730- 
7737. https://doi.org/10.1021/jf8012053

Sýs, M., Švecová, B., Švancara, I., Metelka, R., 2017. Determination of vitamin $\mathrm{E}$ in margarines and edible oils using square wave anodic stripping voltammetry with a glassy carbon paste electrode. Food Chem. 229, 621-627. https://doi.org/10.1016/j.foodchem.2017.02.068

Szot, D., Skopińska, A., Wybraniec, S., 2015. Decomposition of 17decarboxy-betanin in selected aqueous-organic solutions induced by $\mathrm{Cu}$ ( II ) cations. PhD Interdiscip. J. Politech. Gdansk Univ. 1, 217-223.

Takshak, S., Agrawal, S.B., 2015. Defence strategies adopted by the medicinal plant Coleus forskohlii against supplemental ultraviolet-B radiation: Augmentation of secondary metabolites and antioxidants. Plant Physiol. Biochem. 97, 124-138. https://doi.org/10.1016/j.plaphy.2015.09.018

Thirugnanasambandham, K., Sivakumar, V., 2017. Microwave assisted extraction process of betalain from dragon fruit and its antioxidant activities. J. Saudi Soc. Agric. Sci. 16, 41-48. https://doi.org/10.1016/j.jssas.2015.02.001

Timilsena, Y.P., Wang, B., Adhikari, R., Adhikari, B., 2017. Advances in microencapsulation of polyunsaturated fatty acids (PUFAs)rich plant oils using complex coacervation: A review. Food Hydrocoll. 69 , 369-381. https://doi.org/10.1016/j.foodhyd.2017.03.007

Timpanaro, G., Urso, A., Spampinato, D., Foti, V., 2015. Cactus pear market in Italy: Competitiveness and perspectives. Acta Hortic. 1067.

Torres, M.D., Chenlo, F., Moreira, R., 2018. Structural features and water sorption isotherms of carrageenans: A prediction model for hybrid carrageenans. Carbohydr. Polym. 180, 72-80. https://doi.org/10.1016/J.CARBPOL.2017.10.010

Tretter, L., Patocs, A., Chinopoulos, C., 2016. Succinate, an intermediate in metabolism, signal transduction, ROS, hypoxia, and tumorigenesis. Biochim. Biophys. Acta - Bioenerg. 1857, 1086-1101. https://doi.org/10.1016/j.bbabio.2016.03.012

Tsuchiya, H., Iinuma, M., 2000. Reduction of membrane fluidity by antibacterial sophoraflavanone G isolated from Sophora exigua. Phytomedicine 7, 161-165. https://doi.org/10.1016/S0944- 


\section{3(00)80089-6}

UN DESA, 2015. World Population Prospects: The 2015 Revision. New York.

Unilever, 2010. The Unilever Sustainable Living Plan.

Vieira, V., Barros, L., Martins, A., Ferreira, I., 2016a. Nutritional and Biochemical Profiling of Leucopaxillus candidus (Bres.) Singer Wild Mushroom. Molecules 21, 99. https://doi.org/10.3390/molecules21010099

Vieira, V., Fernandes, Â., Barros, L., Glamočlija, J., Ćirić, A., Stojković, D., Martins, A., Soković, M., Ferreira, I.C.F.R., 2016b. Wild Morchella conica Pers. from different origins: A comparative study of nutritional and bioactive properties. J. Sci. Food Agric. 96, 90-98. https://doi.org/10.1002/jsfa.7063

Vinatoru, M., 2001. An overview of the ultrasonically assisted extraction of bioactive principles from herbs. Ultrason. Sonochem. 8, 303-313. https://doi.org/10.1016/S13504177(01)00071-2

Wang, W., Bostic, T.R., Gu, L., 2010. Antioxidant capacities, procyanidins and pigments in avocados of different strains and cultivars. Food Chem. 122, 1193-1198. https://doi.org/10.1016/j.foodchem.2010.03.114

Watada, A.E., Herner, R.C., Kader, A.A., Romani, R.J., Staby, G.L., 1984. Terminology for the description of developmental stages of horticultural crops. HortScience.

Weinstein, M.P., 2012. Methods for Dilution Antimicrobial Susceptibility Tests for Bacteria That Grow Aerobically; Approved Standard - Ninth Edition, Methods for Dilution Antimicrobial Susceptibility Tests for Bacteria That Grow Aerobically; Approved Standar- Ninth Edition. https://doi.org/10.4103/0976-237X.91790

WHO, 2014. GLOBAL STATUS REPORT on noncommunicable diseases 2014. "Attaining the nine global noncommunicable diseases targets; a shared responsibility"

Wrolstad, R.E., Culver, C.A., 2012. Alternatives to those artificial FD\&C food colorants. Annu. Rev. Food Sci. Technol. 3, 59-77. https://doi.org/10.1146/annurev-food-022811-101118

Wybraniec, S., Starzak, K., Szneler, E., Pietrzkowski, Z., 2016. Separation of chlorinated diastereomers of decarboxy- 
betacyanins in myeloperoxidase catalyzed chlorinated Beta vulgaris L. extract. J. Chromatogr. B Anal. Technol. Biomed. Life Sci. 1036-1037, 20-32. https://doi.org/10.1016/j.jchromb.2016.09.040

Yahia, E.M., Woolf, A.B., 2011. Avocado (Persea americana Mill.), in: Postharvest Biology and Technology of Tropical and Subtropical Fruits: Volume 2: Açai to Citrus. Woodhead Publishing, pp. 125-185. https://doi.org/10.1533/9780857092762.125

Yamashita, C., Chung, M.M.S., dos Santos, C., Mayer, C.R.M., Moraes, I.C.F., Branco, I.G., 2017. Microencapsulation of an anthocyanin-rich blackberry (Rubus spp.) by-product extract by freeze-drying. LWT - Food Sci. Technol. 84, 256-262. https://doi.org/10.1016/j.lwt.2017.05.063

Yeddes, N., Chérif, J., Guyot, S., Sotin, H., Ayadi, M., 2013. Comparative Study of Antioxidant Power, Polyphenols, Flavonoids and Betacyanins of the Peel and Pulp of Three Tunisian Opuntia Forms. Antioxidants 2, 37-51. https://doi.org/10.3390/antiox2020037

Zhishen, J., Mengcheng, T., Jianming, W., 1999. The determination of flavonoid contents in mulberry and their scavenging effects on superoxide radicals. Food Chem. https://doi.org/10.1016/S03088146(98)00102-2 




\section{Capítulo 6 CARACTERIZACIÓN DE LOS SUBPRODUCTOS DE OPUNTIA SPP.}





\section{VI.1 ANTECEDENTES}

En este apartado nos centramos en otras pruebas importantes que se realizaron para obtener un mejor panorama de los subproductos de los higos chumbos. A continuación se describe el efecto del secado en los compuestos fenólicos de las pieles de Opuntia ficus-indica var Sanguigna y el análisis del modelado de las isotermas de sorción de las pieles de Opuntia.

Es importante resaltar también los porcentajes de subproductos presentes en los frutos de Opuntia, y debido a que más adelante en este capítulo se analizan 3 variedades distintas, nos resulta conveniente mostrar la imagen 6-1 en donde se exhiben la relación piel/pulpa de las variedades OFI var. Gialla, OFI var. Sanguigna y Opuntia engelmannii.

\section{Porcentaje de Piel/Pulpa}

Opuntia engelmannii

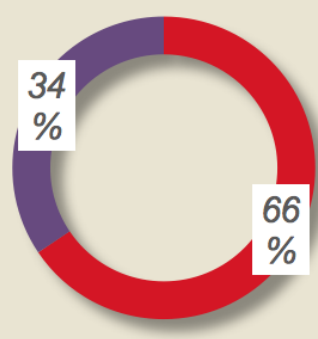

Opuntia ficus-indica Gialla

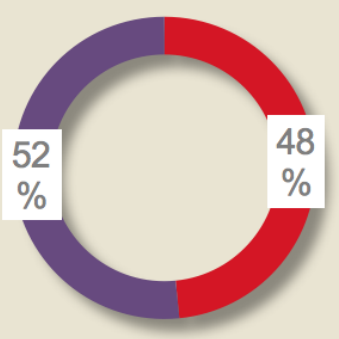

Pulpa

Piel

Opuntia ficus-indica Sanguigna

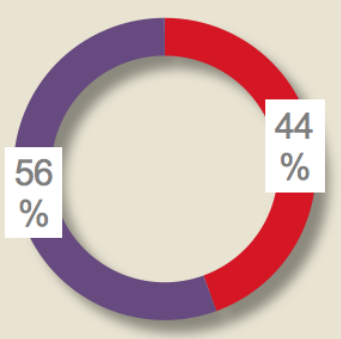

Figure 6-1 Fraction percentage of Opuntia fruits (source: private collection) 


\section{VI.1.1 Efecto del secado en los compuestos fenólicos de las pieles de Opuntia}

En el capítulo anterior de Persea americana se desarrolló el mismo análisis de secado y determinación de compuestos fenólicos, el cual en conjunto con los resultados presentados a continuación, fue presentado como poster en un congreso científico. Dicho poster se encuentra en los anexos al final de este documento. Como se mencionó en el otro capítulo, se realizó un experimento en donde se llevó a sequedad las pieles de OFI var Sanguigna en una estufa de convección a $40{ }^{\circ} \mathrm{C}$, y posteriormente se realizó la extracciones de las compuestos fenólicos con metanol $80 \%$ y se evaluó el contenido total de polifenoles (CTP) de las muestras secas y un control fresco a través del método espectrofotométrico de Folin-Ciocalteu. Acto seguido, se almacenaron los extractos a distintas temperaturas $\left(24,3\right.$ y $\left.-40{ }^{\circ} \mathrm{C}\right)$ por 3 meses con el objetivo de monitorear mes a mes el fenómeno de degradación de los extractos a lo largo del tiempo. Como control para este análisis se utilizaron las pieles frescas sin ningún proceso de secado.

En la Figura 6-2 se presentan los resultados principales, de los cuales, el principal y más claro fue la degradación casi de la mitad de los compuestos fenólicos en las muestras secas comparadas con el CTP en las muestras frescas. Otro de los resultados obtenidos, se presenta en el seguimiento de las muestras secas almacenadas y monitoreadas cada 30 días. En este sentido es importante destacar que no se encontraron diferencias significativas a lo largo del almacenamiento de los extractos. Por lo que podemos destacar, que un correcto almacenamiento de ellos, puede preservar el contenido total fenólico al menos por 3 meses. 


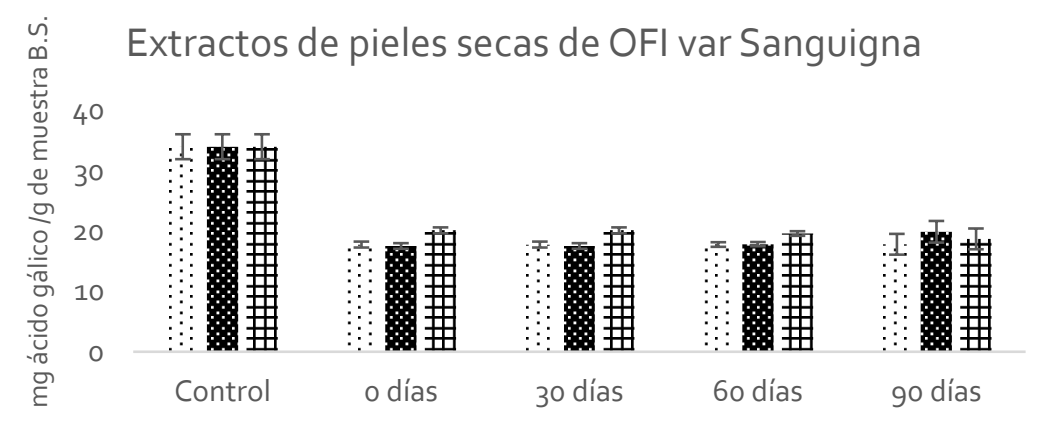

almacenada a $24^{\circ} \mathrm{C} \quad \mathbf{B}$ almacenada a $3{ }^{\circ} \mathrm{C} \quad \mathrm{Halmacenada} a-40^{\circ} \mathrm{C}$

Figure 6-2 Effect of drying and storage in OFI var Sanguigna (source: private collection)

En este caso específico del estudio de degradación de compuestos fenólicos en OFI var. Sanguigna, se quiso ir un paso más allá analizando a 2 temperaturas distintas $\left(40\right.$ y $\left.60{ }^{\circ} \mathrm{C}\right)$ los perfiles cromatográficos de dos flavonoides (isorhamnetina y quercetina -3-Orutinosidos) específicos cuantificados a través de uso de patones específicos $\left(R^{2}=0.998\right.$ en ambos casos), y se muestra en la Figura 6-3 la termolabilidad de estos compuestos dentro de la matriz de OFI var Sanguigna.

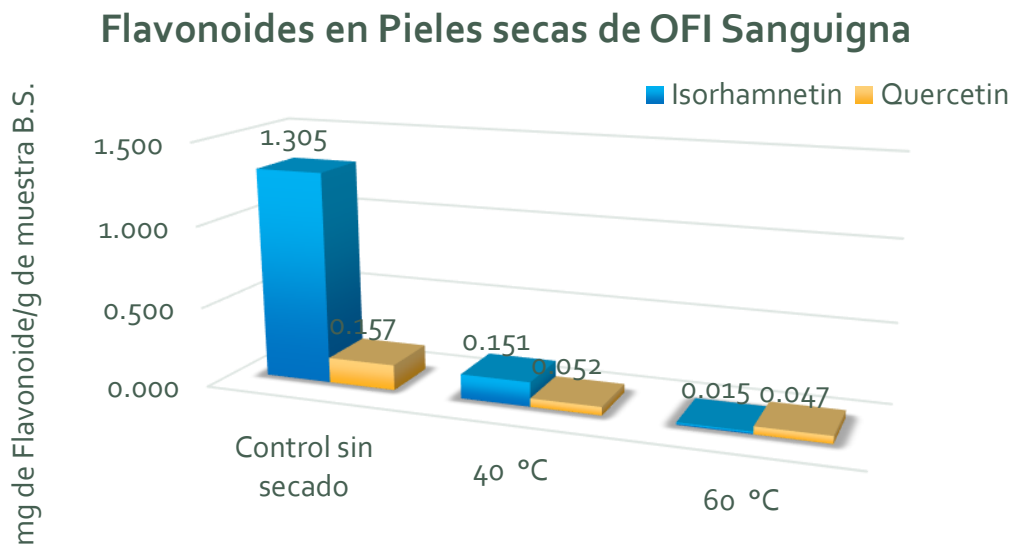

Figure 6-3 Effect of drying temperatures on flavonoids (source: private collection)

La isorhamnetina-3-O-rutinosido se ve extremamente afectado por el proceso de secado, reduciendo su contenido en 9 y hasta 87 veces a las temperaturas de secado de 40 y $60{ }^{\circ} \mathrm{C}$ respectivamente, mientras que 
la querecetin-3-O-rutinosido reduce 3 veces su contenido en ambas temperaturas. Aunque anteriormente Madrau et al. (2009) describiera que el decremento de los polifenoles es inversamente proporcional al aumento de las temperaturas, los resultados mostrados no fueron tan violentos como los presentados en este análisis, donde creemos que la diferencia que ha minimizado tanto el contenido fenólico, fue además de la temperatura la prolongada exposición a ella, ya que para asegurarnos de sequedad total, se extendió el proceso de secado a 10 días.

\section{VI.1.2 Modelización de isotermas de sorción de las pieles de Opuntia}

Aunado al análisis de secado realizado anteriormente, se determinaron experimentalmente las isotermas de adsorción y desorción de las pieles de Opuntia ficus-indica var. Sanguigna a $20{ }^{\circ} \mathrm{C}$. Posteriormente se analizaron los valores de humedad de equilibrio de las distintas sales con $\mathrm{a}_{\mathrm{w}}$ conocida mediante los modelos mencionado en la Tabla 3-2.

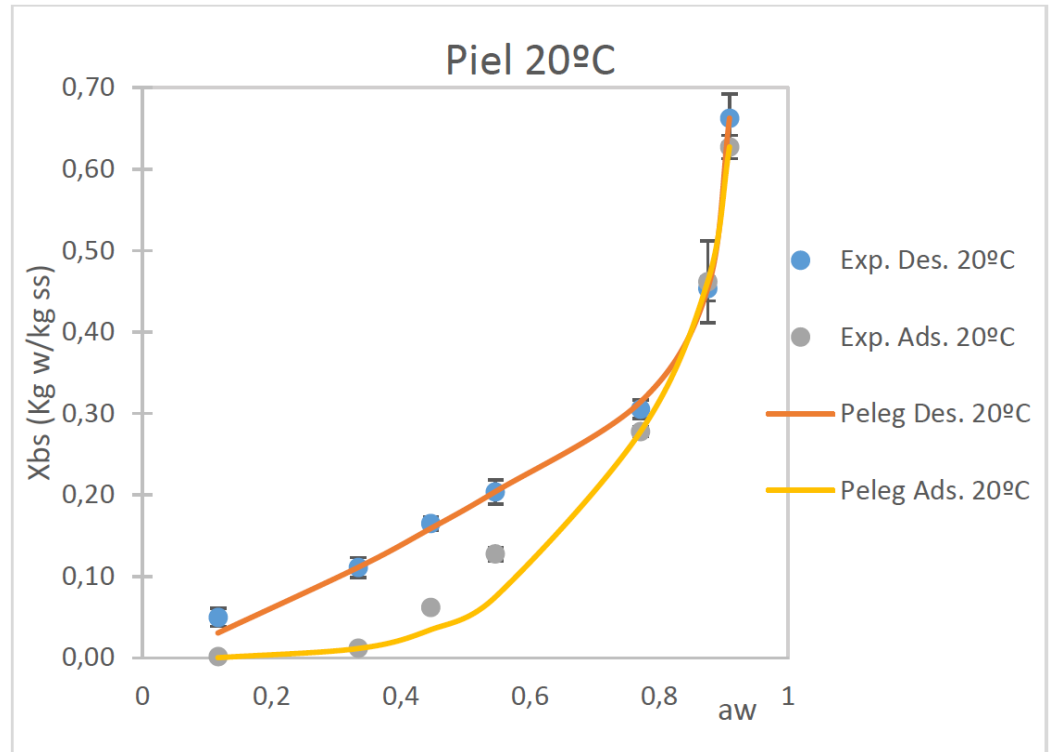

Figure 6-4 Sorption isotherms of OFI Sanguigna at $20^{\circ} \mathrm{C}$ (source: private collection) 
En la Figura 6-4 se puede observar la representación gráfica de ambas isotermas y la representación del modelo descrito por Peleg, que fue el que se acoplo de mejor manera a los datos experimentales. A primera vista podemos observar el fenómeno de desplazamiento entre las isotermas de adsorción y desorción, quedando la última por encima de la primera. A este fenómeno se le conoce como histéresis y es consecuencia de fenómenos irreversibles de reordenamiento conformacional y estructural, los cuales pueden alterar la accesibilidad a sitios polares energéticamente favorables, dificultando la movilidad del agua (Saravacos, 2014). Consecuentemente, podemos mencionar dos cosas importantes: el fenómeno de histéresis es muy común en las matices alimentarias, y estas graficas además nos muestran como las pieles secas no llegan a re-adsorber la misma cantidad de agua contenida en las pieles frescas.

La comprensión de las características de absorción de agua entre los subproductos y la atmósfera es esencial para la selección de las condiciones de proceso adecuadas debido a las características fisicoquímicas, la seguridad microbiana u otras características que dependen de la actividad del agua (Torres et al., 2018).

De esta forma se observa el punto crítico de estas isotermas en una actividad de agua de alrededor de 0,55 , lo que nos indica que para un óptimo almacenamiento de las pieles a la temperatura de $20{ }^{\circ} \mathrm{C}$, debemos de secarlas por debajo de esta $\mathrm{a}_{\mathrm{w}}$.

Con toda la información obtenida anteriormente, determinamos que: 1) el porcentaje de subproductos de las tres variedades de Opuntia, es muy considerable para su revalorización; 2) es necesario reducir la actividad de agua por debajo de 0,55 para su optimo almacenamiento; 3 ) el secado por convección no es nada recomendable como método de secado previo a las extracciones de las biomoléculas activas, debido a la disminución de CTP. Por lo tanto, en los diseños experimentales publicados en esta tesis, recurrimos a técnicas de liofilización como alternativa de secado. 


\title{
VI.2 VALORIZACIÓN DE LOS SUBPRODUCTOS DE OPUNTIA SPP.: DETERMINACIÓN DE LOS PERFILES FENOLICOS, BETALAINICOS Y SUS PROPIEDADES BIOACTIVAS.
}

\begin{abstract}
A continuación se presenta una adaptación al formato de la tesis doctoral del artículo titulado "By-product recovery of Opuntia spp. peels: Betalainic and phenolic profiles and bioactive properties", publicado en la revista Industrial Crops and Products. En él, los subproductos (piel) de los frutos de higos chumbos de tres especies (Opuntia ficus-indica var. Gialla y var. Sanguignea y Opuntia engelmannii) fueron caracterizados en términos funcionales, y la evaluadación sus propiedades antioxidantes, antimicrobianas y citotoxicas fue evaluada, además, una caracterización completa del perfil polifenolico (ácidos fenólicos y flavonoides) y betalainico fue descrito mediante técnicas cromatográficas. Los datos bibliográficos del artículo se destacan a continuación:
\end{abstract}

Melgar, B., Dias, M. I., Ciric, A., Sokovic, M., Garcia-Castello, E. M., Rodriguez-Lopez, A. D., Barros, L., Ferreira, I. C. F. R. (2017).

By-product recovery of Opuntia spp. peels: Betalainic and phenolic profiles and bioactive properties.

Industrial Crops and Products, 107, 353-359. 
Resultados

By-product recovery of Opuntia spp. peels: betalainic and phenolic profiles and bioactive properties

\section{Bruno Melgar $^{\mathrm{a}, \mathrm{c}}$, Maria Inês Dias ${ }^{\mathrm{a}}$, Ana Ciric ${ }^{\mathrm{b}}$, Marina Sokovic ${ }^{\mathrm{b}}$, Esperanza M. Garcia-Castello ${ }^{c}$, Antonio D. Rodriguez-Lopez ${ }^{d}$, Lillian Barros ${ }^{a}$, Isabel C.F.R. Ferreira ${ }^{a}$,*}

${ }^{a}$ Centro de Investigação de Montanha (CIMO), ESA, Instituto Politécnico de Bragança, Campus de Santa Apolónia, 5300-253 Bragança, Portugal.

${ }^{b}$ University of Belgrade, Department of Plant Physiology, Institute for Biological Research "Siniša Stanković", Bulevar Despota Stefana 142, 11000 Belgrade, Serbia.

${ }^{c}$ Institute of Food Engineering for Development, Universitat Politècnica de València, Camino de Vera, s/n CP, 46022 Valencia, Spain.

${ }^{d}$ Institute for Industrial, Radiophysical and Environmental Safety (ISIRYM), Universitat Politècnica de València, Camino de Vera, $s / n$ CP, 46022 Valencia, Spain.

*Corresponding author. Tel.+351 273 303219; fax +351 273325405 . E-mail address: iferreira@ipb.pt (I.C.F.R. Ferreira) 


\begin{abstract}
$\boldsymbol{O}_{\text {puntia spp. are a tropical and subtropical plant that provides both }}$ edible green steams and fruits; however, the processing of this fruits results in the accumulation of enormous amount of by-products that can be a source of bioactive and pigmented compounds. Herein, three cactus pear from the species Opuntia ficus-indica var. Sanguigna (OS) and Gialla (OG) and Opuntia engelmannii (OE) were fully characterized regarding their phenolic and betalain composition and correlated with their antioxidant and antimicrobial activities. The hydroethanolic extracts of $\mathrm{OE}$ gave the highest amount of phenolic compounds (isorhamentin- $O$-(deoxyhexosyl-hexoside) and betacianins (betanin); however, no betaxanthins were identified in this sample. This sample also revealed the lowest $\mathrm{IC}_{50}$ values in all the antioxidant activity assays. Regarding antimicrobial activity, the hydroethanolic extracts of all species revealed to be more active than ampicillin. The pivotal objective of this work was to focus on exploring by-product biocompounds and possible outputs, thus, we could suggest the use of these natural colorants with intrinsic antioxidant and antimicrobial activity, which would grant industries to produce cleaner label products with functional benefits.
\end{abstract}

Keywords: Opuntia ficus-indica; Opuntia engelmannii; by-product; betalains; phenolic compounds; antimicrobial activity. 


\section{VI.2.1. INTRODUCTION}

$\boldsymbol{O}$ puntia spp., including their several varieties, belong to the dicotyledonous angiosperm and are the largest genus within Cactaceae family. Opuntia species are tropical and subtropical plants, able to grow in arid and semi-arid environments, with easy geographic adaptation due to their crassulacean acid metabolism (CAM), which enables the plant to survive to extreme heat, low temperatures $\left(-40^{\circ} \mathrm{C}\right)$ and drought because of their highly efficiency in the use of water (Nobel, 1998; Sudzuki et al., 1993). This plant provides both edible green steams and fruits.

Cactus fruit is also known as prickly pear, cactus fig, Indian fig, cactus pear, Barbary fig, and is available across the 5 continents from early summer until late autumn. Although Opuntia species are native of Mexico, where the steams and fruits are consumed fresh in the local diet, fruits, are also processed and commercialized in numerous countries as jams, sweats, ice cream and alcoholic and not alcoholic beverages (Martins et al., 2016).

The processing of the fruits results in the accumulation of several quantities of by-products, namely prickly pear peels. Proper utilization of this by-product could reduce waste disposal problems and serve as a potential new source of bioactive compounds and pigments. According to several authors (Belwal et al., 2016; Garcia-Castello et al., 2015; Pinela et al., 2016; Rao, 2010), one of the best ways to use this kind of by-products could be the application of an appropriate green solidliquid extraction technology in order to obtain bioactive compounds with different properties and health benefits.

Several studies marked fruits and fruits by-products as a rich source of natural molecules such as polyphenols (i.e. flavonoids), vitamins, colorants like betalains and carotenoids (Albuquerque et al., 2016; Alzate T et al., 2016; Ayala-Zavala et al., 2011; Fernandez-Rojas et al., 2010; Silva et al., 2016), which could have high potential interest in human health, medicine and production of new added-value products.

Scientists have lately reported multiple properties regarding to phenolic compounds as antioxidants endowed with anticancer, anti- 
inflammatory, antimicrobial and antidiabetic activities (Dias et al., 2016; Kaur Kala et al., 2016), among the most cited properties attributed to polyphenols due to their protective effect against damage of the human body caused by reactive oxygen, nitrogen and sulfur species (ROS, RNS and RSS, respectively) (Carocho and Ferreira, 2013; Shahidi and Ambigaipalan, 2015).

Additionally, to phenolic compounds, other relevant components in the cactus pear are the betalains pigments, which are present in most of the Caryophyllales family including the Cactaceae and replace the anthocyanins in flowers and fruits of plants within this family. Betalains are water soluble nitrogen-containing pigments situated in the vacuoles of the plant tissue responsible for the red-violet (betacyanins) and yellow-orange (betaxanthins) colors, showing a stable appearance in the range of $\mathrm{pH} 3$ to 7 (Stintzing et al., 2002). Therefore, betalains could be used as a natural colorant alternative to synthetic dyes used in a broad range of food products.

The present study intends to contribute to the characterization of the bioactive compounds profile, antioxidant and antimicrobial activities of by-products, such as peels, of the cactus pear from the species Opuntia ficus-indica var. Sanguigna (OS) and Gialla (OG) and Opuntia engelmannii $(\mathrm{OE})$. The results of this study might be useful to maximize the potential of the fruits by-products for their colorant and functional added value 


\section{VI.2.2. MATERIAL AND METHODS}

\section{VI.2.2.1. Samples preparation}

Cactus pear fruits (Opuntia ficus-indica var. Sanguigna -OS and Gialla -OG) were collected in July-August 2016 in Sicily, Italy and purchased from a local market in Bragança, Portugal. Fruits from this specie were separated regarding the maturation colour orange-red (Opuntia ficusindica var. Gialla) and red-violet (Opuntia ficus-indica var. Sanguigna), obtaining two different samples. Prickly pear wild fruits (Opuntia engelmannii- OE) were collected in Bragança, Portugal (GPS location: 41.797344, -6.772735) on early September 2016. Dr. Carlos Aguiar of the School of Agriculture, Polytechnic Institute of Bragança (Trás-os-Montes, Portugal), confirmed the botanical identifications and voucher specimens were deposited in a herbarium.

Within 24 hours, fruits were washed with distilled water in order to remove glochids and then further air-dried. Afterwards, all the fruits were peeled and the resulting peel was lyophilized (LabConco, Frezone $-105{ }^{\circ} \mathrm{C}, 4.5 \mathrm{~L}$ Cascade Benchtop Freeze Dry System, Kansas, MO, USA) and stored in a cool and dry place until use.

\section{VI.2.2.2. Extraction procedure}

The hydroethanolic (ethanol: water, 80:20 v/v) extract was obtained from the lyophilized peels. The sample $(1 \mathrm{~g})$ was extracted twice by stirring with $25 \mathrm{~mL}$ of hydro-alcoholic solution $\left(25^{\circ} \mathrm{C}\right.$ at $\left.150 \mathrm{rpm}\right)$ for $1 \mathrm{~h}$ and subsequently filtered through the Whatman no. 4 paper. The obtained extracts were frozen, lyophilized and re-dissolved in: (i) hydroethanolic solution (ethanol: water, 80:20 v/v) for phenolic characterization (final concentration $5 \mathrm{mg} / \mathrm{mL}$ ) and antioxidant activity evaluation (final concentration $40 \mathrm{mg} / \mathrm{mL}$ ); or (ii) water for cytotoxicity evaluation (final concentration $8 \mathrm{mg} / \mathrm{mL}$ ) and betalain characterization (final concentration $30 \mathrm{mg} / \mathrm{mL}$ ); or (iii) $5 \%$ DMSO in distilled water (final concentration $10 \mathrm{mg} / \mathrm{mL}$ ) for antimicrobial assays. The final solutions were further diluted to different concentrations to be submitted for distinct in vitro bioactivity evaluation assays. 


\section{VI.2.2.3. Phenolic compounds}

The lyophilized hydroethanolic extracts were analysed for their content in phenolic compounds, re-dissolve in ethanol:water (80:20, $v / v)$ to a final concentration of $5 \mathrm{mg} / \mathrm{mL}$. LC-DAD-ESI/MSn analyses were performed using a Dionex Ultimate 3000 UPLC instrument (Thermo Scientific, San Jose, CA, USA), coupled to a diode-array detector (using several wavelengths, 280, 330 and $370 \mathrm{~nm}$ ) and to a mass detector (Linear Ion Trap LTQ XL mass spectrometer, equipped with an ESI source, ThermoFinnigan, San Jose, CA, USA). The elution gradient, chromatographic and mass spectrometer conditions were performed according to (Bessada et al., 2016). Identification was performed by comparing their fragmentation pattern, retention times and UV-vis spectra with authentic standards, when available, or by comparing the obtained information with available data from literature. When a standard was not available to quantify a phenolic compound a calibration curve of similar compound from the same phenolic group was used.

\section{VI.2.2.4. Betalain compounds}

The profile in betalain compounds was determined by LC-DADESI/MSn (Dionex Ultimate 3000 UPLC, Thermo Scientific, San Jose, CA, USA). Chromatographic separation was achieved with a Waters Spherisorb S3 ODS-2 C18 (3 $\mu \mathrm{m}, 4.6 \mathrm{~mm} \times 150 \mathrm{~mm}$, Waters, Milford, MA, USA) column working at $35^{\circ} \mathrm{C}$. The solvents used were: (A) $0.1 \%$ trifluoroacetic acid (TFA) in water, (B) acetonitrile. The gradient elution followed these parameters: from $0 \%$ to $10 \%$ B for $15 \mathrm{~min}$, from $10 \%$ to $15 \%$ B for $5 \mathrm{~min}$, from 15 to $18 \%$ B for $5 \mathrm{~min}$, from 18 to $50 \%$ $\mathrm{B}$ for $8 \mathrm{~min}$, and from 50 to $0 \% \mathrm{~B}$ for $12 \mathrm{~min}$. The resulting total run time was 45 minutes, using a flow rate of $0.5 \mathrm{~mL} / \mathrm{min}$. Double detection was carried out in the DAD using $480 \mathrm{~nm}$ (betaxanthins) and $535 \mathrm{~nm}$ (betacyanins), as the preferred wavelength, and in a mass spectrometer (MS).

MS detection was performed using positive mode, with a Linear Ion Trap LTQ XL mass spectrometer (ThermoFinnigan, San Jose, CA, USA) equipped with an ESI source. Nitrogen served as the sheath gas (50 psi); the system was operated with a spray voltage of $4.8 \mathrm{kV}$, a source temperature of $320^{\circ} \mathrm{C}$, a capillary voltage of $39 \mathrm{~V}$. The tube lens offset was kept at a voltage of $140 \mathrm{~V}$. The full scan covered the mass 
range from $\mathrm{m} / \mathrm{z} 100$ to 1500 , collision energy used was 24 (arbitrary units) and data acquisition was carried out with Xcalibur ${ }^{\circledR}$ data system (ThermoFinnigan, San Jose, CA, USA).

The identification of the betalain compounds (betacyanins and betaxanthins) were performed by comparing the obtained information with available data reported in the literature giving a tentative identification. For quantitative analysis, a calibration curve using an isolated compound gomphrenin III (isolated from Gomphrena globosa L.) was constructed based on the UV signal ( $\mathrm{y}=14670 \mathrm{x}-19725, R^{2}=$ 0.9997) (Roriz et al., 2017). The results of betacyanins were expressed as $\mathrm{mg}$ per $100 \mathrm{~g}$ of pulp fresh weight $(\mathrm{FW})$, and the results of betaxanthins were expressed as relative percentage (\%) of their areas recorded at $480 \mathrm{~nm}$.

\section{VI.2.2.5. Bioactive properties evaluation}

\section{VI.2.2.5.1. Antioxidant activity assays}

Successive dilutions were made from the stock solution and submitted to in vitro assays already described by (Heleno et al., 2010) to evaluate the antioxidant activity of the samples. DPPH radical-scavenging activity was evaluated using an ELX800 microplate reader (Bio-Tek Instruments, Inc.; Winooski, VT, USA) and calculated in percentage after $1 \mathrm{~h}$ of reaction in the dark.

The reducing power (RP) assay evaluated the capacity of the extracts to reduce $\mathrm{Fe} 3+$ to $\mathrm{Fe} 2+$, measuring the absorbance at $690 \mathrm{~nm}$. In $\beta$-carotene bleaching assay, the presence of antioxidants in the samples and their capacity to neutralize the linoleate free radicals, avoids $\beta$-carotene bleaching, which can be evaluated measuring the absorbance at $470 \mathrm{~nm}$. Therefore, $\beta$-carotene bleaching inhibition was calculated using the following formula: (Absorbance after $2 \mathrm{~h}$ of assay/initial absorbance) $\times 100$. The results were expressed as $\mathrm{IC}_{50}$ values (sample concentration providing 50\% of antioxidant activity or 0.5 of absorbance in the reducing power assay) for antioxidant activity. Trolox was used as positive control. 


\section{VI.2.2.5.2. Antimicrobial activity assays}

The minimum inhibitory (MIC), minimum bactericidal concentrations (MBC) and minimum fungicidal concentrations (MFC) were determined by methodologies, described by (Vieira et al., 2016b).

Antibacterial activity was assayed using the following, Grampositive bacteria: Staphylococcus aureus (ATCC 6538), Bacillus cereus (clinical isolate), Micrococcus flavus (ATCC10240), and Listeria monocytogenes (NCTC7973) and Gram-negative bacteria: Escherichia coli (ATCC 35210), Pseudomonas aeruginosa (ATCC 27853), Salmonella typhimurium (ATCC 13311), and Enterobacter cloacae (ATCC 35030) were used. Whilst for antifungal assays, the following microfungi were used: Aspergillus fumigatus (ATCC1022), Aspergillus ochraceus (ATCC12066), Aspergillus versicolor (ATCC11730), Aspergillus niger (ATCC6275), Penicillium funiculosum (ATCC 36839), Penicillium ochrochloron (ATCC9112), Penicillium verrucosum var. cyclopium (food isolate), and Trichoderma viride (IAM 5061). Bacterial and fungal organisms were obtained from the Mycological Laboratory, Department of Plant Physiology, Institute for Biological Research "Sinisa Stanković", University of Belgrade, Serbia. Standard drugs, namely streptomycin, ampicillin, bifonazole and ketoconazole were used as positive controls.

\section{VI.2.2.5.3. Cytotoxicity assays}

Both, antitumor activity and hepatotoxicity was evaluated by the Sulphorhodamine B (SRB) assay that has been previously described by (Gomes-Correa et al., 2015; Pereira et al., 2014). Four human tumour cell lines were assayed: HeLa (cervical carcinoma), HepG2 (hepatocellular carcinoma), MCF-7 (breast adenocarcinoma) and NCIH460 (non-small cell lung cancer), while PLP2 cells were used for hepatotoxicity. The five cell cultures were treated for $48 \mathrm{~h}$ with the different diluted sample solutions and assayed according to the SRB colorimetric methodology. Ellipticine was used as positive control and results were expressed in $\mathrm{GI}_{50}$ values in $\mu \mathrm{g} / \mathrm{mL}$ (sample concentration that inhibited $50 \%$ of the net cell growth). 


\section{VI.2.2.6. Statistical analysis}

All the extractions and assays were performed in triplicate. Results were expressed as mean values and standard deviation (SD), being analysed using one-way analysis of variance (ANOVA) followed by Tukey's HSD Test with $p=0.05$. In the case of only existing two samples, the results were analysed using a Student's t-test, in order to determine the significant difference between the two samples, with $p=$ 0.05 . The treatment was carried out using IBM SPSS Statistics for Windows, version 23.0. (IBM Corp., Armonk, New York, USA). 


\section{VI.2.3. RESULTS AND DISCUSSION}

\section{VI.2.3.1. Phenolic and betalain composition}

Tables 6-1 and 6-2 present the peak characteristics (retention time, wavelength of maximum absorption and mass spectral data), tentative identification and quantification of the phenolic compounds and betalains, respectively, present in the hydroethanolic extracts of Opuntia ficus-indica var Gialla (OG), Opuntia ficus-indica var Sanguigna (OS) and Opuntia engelmanniii (OE) peels (Figure 6-8).

Twelve different phenolic compounds (Table 6-1) were found, two phenolic acids, piscid acid (peaks 1) and eucomic acid (peaks 2), and ten flavonoids (isorhamnetin, quercetin and kaempferol derivatives, peaks 3 to 12). All of the compounds have been previously described by other authors in Opuntia spp samples(Chahdoura et al., 2014; Chougui et al., 2015; Mata et al., 2016; Morales et al., 2015, 2014) Overall, OE sample presented higher concentration of phenolic compounds, being peak 11 (isorhamnetin- $O$-(deoxyhexosyl-hexoside)) the major compound found $(5.99 \mathrm{mg} / \mathrm{g})$.

Regarding betalain fractions (Table 6-2), seven compounds were identified; two betaxanthins, indicaxanthin isomer I and II (peaks 1 and 2), previously described by Castellanos-Santiago \& Yahia (2008) in Opuntia spp. cultivars and also by Svenson et al., (2008) in Ullucus tuberosus fruits. Betalain molecules displays wide range of hues, betacyanins have reddish-violet colour while betaxanthins have a general yellow-orange colour (Albano et al., 2015; Esquivel, 2016; Gandía-herrero et al., 2013; Gandía-Herrero et al., 2010), the latter being only identified in OG and OS samples. Five betacyanins were identified, betanidin-5-O- $\beta$-sophoroside, betanidin-5-O- $\beta$-glucoside (betanin), isobetanin, gomphrenin I and betanidin (peaks 3, 4, 5, 6 and 7, respectively), having been previously identified by other authors (Castellanos-Santiago and Yahia, 2008; Morales et al., 2015, 2014; Stintzing et al., 2002; Svenson et al., 2008). 

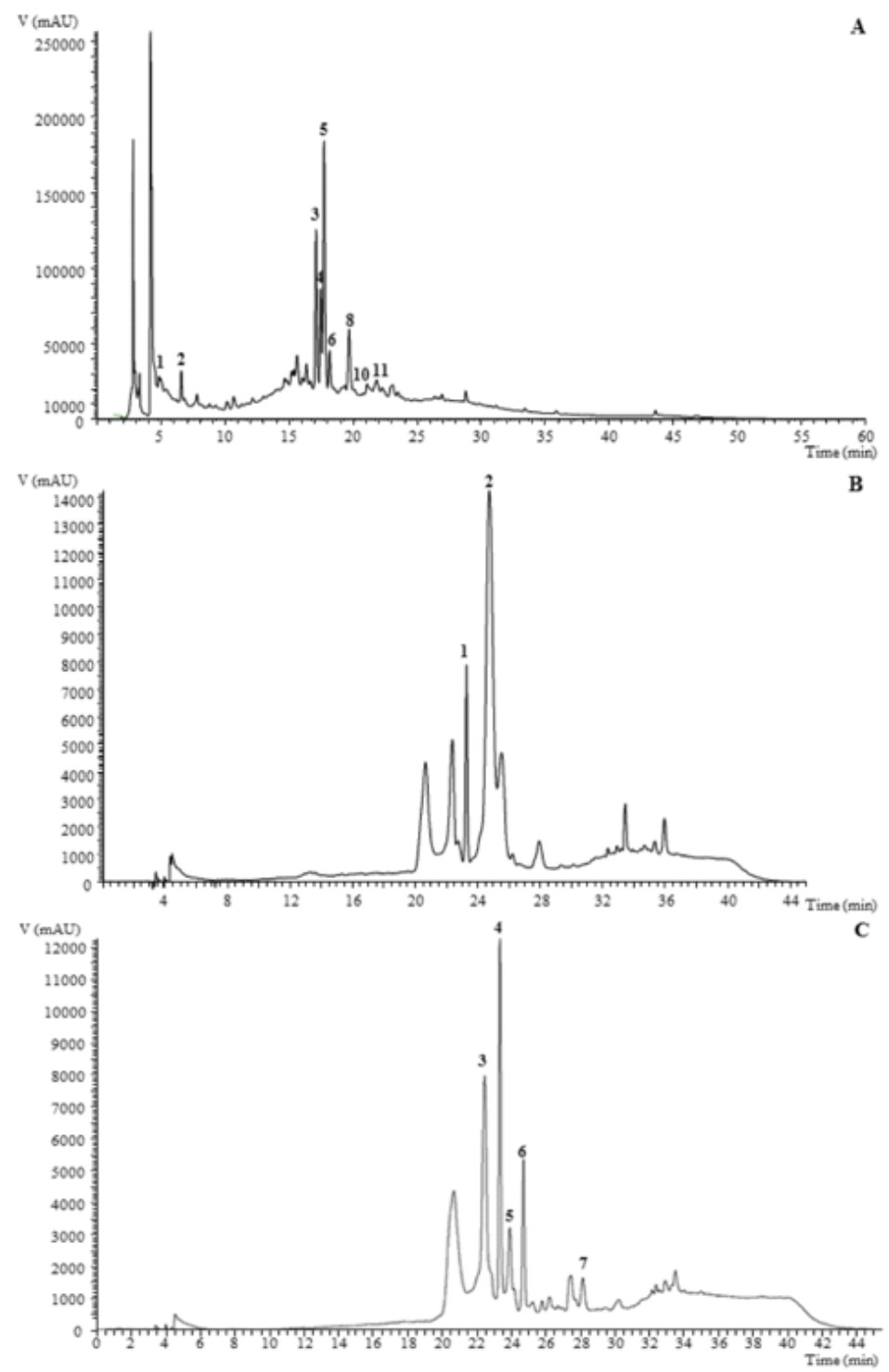

Figure 6-5 HPLC chromatogram of OG phenolic profile recorded at $370 \mathrm{~nm}$ (A), betaxanthins profile of $O S$ recorded at $484 \mathrm{~nm}(B)$ and betacyanins profile of $O E$ recorded at $535 \mathrm{~nm}(\mathrm{C})$. (source: private collection)

On the contrary of betaxanthins, betacianins fraction was found in higher quantities in OE samples, being peak 4 (betanin) the main compound found (14.9 mg/g extract), This characteristic can be easily 
predicted due to the strong violet hue present in $\mathrm{OE}$ and also because betanin (betanidin-5-O- $\beta$-glucoside) is the most widespread betacyanin among plants (Esatbeyoglu et al., 2015b). In this matter, betanin concentration in the analysed samples was in concordance with the previous statement commented. OE displayed differences of around 15 and 5-fold higher than OG and OS, respectively. The second highest concentration of betacyanins was conferred by isobetanin in $\mathrm{OE}$ and OS extracts. Only OE showed other 3 different betacyanins (betanidin, betanidin-5-O- $\beta$-sophoroside and gomphrenin I). Although, OG has this name from the Italian word "yellow", betacyanin molecule betanin, was also present but only around $10 \%$ of the total betalains detected, this pigment can be spotted as a reddish-orange hue intrinsic in $\mathrm{OG}$ peels.

\section{VI.2.3.2. Antioxidant activity}

The results on antioxidant activity of the hydroethanolic extracts are shown in Table 6-3. There is a clear pattern in the antioxidant activity of each Opuntia spp., at first glance, $\mathrm{OE}$ exhibits the best $\mathrm{IC}_{50}$ values, followed by OS and lastly OG, nonetheless, the difference within OE vs OS and OG is around 2-fold higher, while the difference among OS and OG is barely perceptible. At this point, it is worth noting the high $\mathrm{IC}_{50}$ values presented by $\mathrm{OS}$ in the $\beta$-carotene bleaching inhibition our hypothesis on this value could be due to an interference with the sample colour.

Independently of the $\mathrm{IC}_{50}$ values that $\mathrm{OS}$ shown in the and $\beta$ carotene assay, all the antioxidant activities of all samples, can be inversely correlated with the concentration of the betacyanins and phenolic compounds previously described in Table 6-2 and Table 6-1, respectively. The relationship between betacyanins $(\mathrm{Bc})$ or phenolic compounds (PC) exhibited high correlation pattern with DPPH radical scavenging activity $\left(R^{2}=-0.99\right.$ for both $\mathrm{Bc}$ and $\left.\mathrm{PC}\right)$, reducing power $\left(R^{2}=-0.97\right.$ also for $\mathrm{Bc}$ and $\left.\mathrm{PC}\right)$ and $\beta$-carotene bleaching inhibition $\left(R^{2}=-0.75\right.$ for $\mathrm{Bc}$ and $R^{2}=-0.76$ for $\left.\mathrm{PC}\right)$. 
Table 6-1 Retention time (Rt), wavelengths of maximum absorption in visible region ( $\lambda$ max), mass spectral data, tentative identification and quantification of phenolic compounds in Opuntia peels

\begin{tabular}{|c|c|c|c|c|c|c|c|c|c|}
\hline Peak & $\begin{array}{l}\text { Tentative } \\
\text { identification }\end{array}$ & $\underset{(\min )}{\mathbf{R t}}$ & $\begin{array}{l}\lambda \max \\
(\mathbf{n m})\end{array}$ & $\begin{array}{c}{[\mathrm{M}-\mathrm{H}]^{-}} \\
(\mathrm{m} / \mathrm{z})\end{array}$ & $\begin{array}{l}\mathbf{M S}^{2} \\
(m / z)\end{array}$ & OG & OS & OE & $\begin{array}{c}t \text { - } \\
\text { Studen } \\
\mathbf{t} \\
p \text {-value }\end{array}$ \\
\hline 1 & Piscidic acid $^{1}$ & 4.65 & 222 & 255 & $\begin{array}{l}193(34), 179(6) \\
165(100), 149(3)\end{array}$ & $1.061 \pm 0.04$ & nd & nd & - \\
\hline 2 & Eucomic acid ${ }^{1}$ & 6.71 & 223 & 239 & $179(100), 149(62)$ & $1.40 \pm 0.01$ & $2.2 \pm 0.2$ & nd & $<0.001$ \\
\hline 3 & Isorhamnetin- $O$-(di-deoxyhexosyl-hexoside $)^{2}$ & 17.09 & 354 & 769 & $315(100)$ & $0.22 \pm 0.01$ & $0.56 \pm 0.06$ & nd & $<0.001$ \\
\hline 4 & Isorhamnetin- $O$-(di-deoxyhexosyl-hexoside $)^{2}$ & 17.4 & 353 & 769 & $315(100)$ & $\operatorname{tr}$ & $0.21 \pm 0.03$ & nd & - \\
\hline 5 & $\begin{array}{l}\text { Isorhamentin- } O \text {-(deoxyhexosyl-pentosyl-hexoside) } \\
2\end{array}$ & 17.7 & 354 & 755 & $315(100)$ & $0.77 \pm 0.02$ & $1.3 \pm 0.1$ & nd & $<0.001$ \\
\hline 6 & Quercetin-3-O-rutinoside ${ }^{2}$ & 17.98 & 354 & 609 & $301(100)$ & nd & nd & $\operatorname{tr}$ & - \\
\hline 7 & $\begin{array}{l}\text { Isorhamentin- } O \text {-(deoxyhexosyl-pentosyl- } \\
\text { hexoside })^{2}\end{array}$ & 18.14 & 354 & 755 & $315(100)$ & $\operatorname{tr}$ & $\operatorname{tr}$ & nd & - \\
\hline 8 & Isorhamentin- $O$-(pentosyl-hexoside $)^{2}$ & 19.58 & 354 & 609 & $315(100)$ & $0.100 \pm 0.001$ & $0.67 \pm 0.06$ & nd & $<0.001$ \\
\hline
\end{tabular}


11 Isorhamentin- $O$-(deoxyhexosyl-hexoside $)^{2}$

nd

$1.7 \pm 0.1^{\mathrm{b}} \quad 5.99 \pm 0.04^{\mathrm{a}}$

Phenolic compounds were expressed in $\mathrm{mg} / \mathrm{g}$ extract; nd- not detected; Calibration standards: $1-p$-hydroxibenzoic acid $(y=208604 x+173056$, $\left.R^{2}=0.9995\right)$; 2-quercetin-3-O-glucoside $\left(y=34843 x-160173, R^{2}=0.9998\right)$. OG, Opuntia ficus-indica var Gialla; OS, Opuntia ficus-indica var Sanguigna; OE, Opuntia engelmannii; nd, not detected; tr, traces.

In each row different letters mean significant differences $(p<0.05)$. *Statistical differences $(<0.001)$ were observed when t-student test was applied. 
Table 6-2 Retention time (Rt), wavelengths of maximum absorption in visible region ( $\lambda$ max), mass spectral data, tentative identification and quantification (mg/g of extract) of betalains detected in Opuntia peels

\begin{tabular}{|c|c|c|c|c|c|c|c|}
\hline Peak Tentative identification & $\begin{array}{c}\mathrm{Rt} \\
(\mathrm{min}) \\
\end{array}$ & $\begin{array}{l}\lambda \max \\
(\mathrm{nm})\end{array}$ & $\begin{array}{c}{[\mathrm{M}+\mathrm{H}]^{+}} \\
(m / z)\end{array}$ & $\begin{array}{l}\mathrm{MS}^{2} \\
(\mathrm{~m} / \mathrm{z})\end{array}$ & OG & OS & $\mathrm{OE}$ \\
\hline \multicolumn{8}{|l|}{ Betaxanthins } \\
\hline 1 Indicaxanthin isomer I & 24.47 & 477 & 309 & $263(100), 219(43), 188(15)$ & $\begin{array}{c}\mathrm{nq} \\
(25.3 \pm 0.4)\end{array}$ & $\operatorname{nq}_{(56 \pm 6)}$ & nd \\
\hline 2 Indicaxanthin isomer II & 25.63 & 477 & 309 & 263(100),219(43),188(15) & $\begin{array}{l}\mathrm{nq} \\
(64.5 \pm 0.5)\end{array}$ & $\begin{array}{c}\mathrm{nq} \\
(2.8 \pm 0.1)\end{array}$ & nd \\
\hline \multicolumn{8}{|l|}{ Betacyanins } \\
\hline 3 Betanidin-5- $O-\beta$-sophoroside ${ }^{1}$ & 22.76 & 534 & 713 & $551(34), 389(100), 345(3), 150(3)$ & nd & nd & $\begin{array}{l}0.98 \pm 0.02 \\
(4.88 \pm 0.01)\end{array}$ \\
\hline $4 \begin{array}{l}\text { Betanidin-5- } O \text { - } \beta \text {-glucoside } \\
{\text { (betanin })^{1}}^{1}\end{array}$ & 23.26 & 534 & 551 & $389(100), 345(50), 150(28)$ & $\begin{array}{l}1.25 \pm 0.01^{\mathrm{c}} \\
(10.2 \pm 0.1)\end{array}$ & $\begin{array}{l}3.44 \pm 0.03^{b} \\
(36.4)\end{array}$ & $\begin{array}{r}14.9 \pm 0.3^{\mathrm{a}} \\
(77.7 \pm 0.3)\end{array}$ \\
\hline 5 Isobetanin $^{1}$ & 24.62 & 534 & 551 & $389(100), 345(73), 150(46)$ & nd & $\begin{array}{c}0.5439 \pm 0.003 \\
(5.3)\end{array}$ & $\begin{array}{l}1.69 \pm 0.06 * \\
(8.6 \pm 0.1)\end{array}$ \\
\hline 6 Gomphrenin $\mathrm{I}^{1}$ & 25.73 & 535 & 551 & $507(3), 389(38), 345(100), 301(21)$ & nd & nd & $\begin{array}{c}0.423 \pm 0.002 \\
(1.97 \pm 0.05)\end{array}$ \\
\hline 7 Betanidin $^{1}$ & 28.16 & 523 & 389 & 343(97),150(91) & nd & nd & $\begin{array}{c}1.36 \pm 0.07 \\
(6.9 \pm 0.2)\end{array}$ \\
\hline Total betacyanin compounds & & & & & $1.25 \pm 0.01^{\mathrm{c}}$ & $3.97 \pm 0.03^{\mathrm{b}}$ & $19.4 \pm 0.4^{\mathrm{a}}$ \\
\hline
\end{tabular}

Amounts in samples outside brackets in $\mathrm{mg} / \mathrm{g}$ of extract, amounts inside brackets are the relative percentages of both betaxanthins and betacyanins. OG, Opuntia ficus-indica var Gialla; OS, Opuntia ficus-indica var Sanguigna; OE, Opuntia engelmannii. 
nq, not quantified; nd, not detected. Calibration curve: ${ }^{1}$ gomphrenin III $\left(y=14670 x-19725, R^{2}=0.9997\right)$. In each row different letters mean significant differences $(p<0.05)$. *Statistical differences $(<0.001)$ were observed when t-student test was applied. 
Therefore, with these correlation values, very similar among the samples and their composition, can lead to possible synergistic effect between these molecules on the antioxidant activity. Several authors have suggested the positive influence of both betalains and phenolic compounds on the antioxidant activity. Cai et al., (2003) and Gandíaherrero et al., (2013) for instance, have reported that the radical scavenging properties of betalains are increased with the number of hydroxyl and imino groups. Albano et al. (2015) have also provided data related to the antioxidant activity of betalainic colorants. On the other hand, there is plethora of information related with the antioxidant effect and mechanisms of action of the phenolic compounds (Carocho and Ferreira, 2013; Dias et al., 2016; Kaur Kala et al., 2016; Shahidi and Ambigaipalan, 2015).

Table 6-3 Antioxidant capacity of Opuntia peels

\begin{tabular}{lccc}
\hline $\mathrm{IC}_{50}(\mathrm{mg} / \mathrm{mL}$ extract $)$ & OG & OS & OE \\
\hline DPPH scavenging activity & $4.6 \pm 0.1^{\mathrm{a}}$ & $4.1 \pm 0.3^{\mathrm{a}}$ & $1.96 \pm 0.04^{\mathrm{b}}$ \\
Reducing power & $2.65 \pm 0.05^{\mathrm{a}}$ & $2.08 \pm 0.06^{\mathrm{b}}$ & $1.08 \pm 0.04^{\mathrm{c}}$ \\
$\beta$-carotene bleaching inhibition & $3.87 \pm 0.01^{\mathrm{b}}$ & $6.49 \pm 0.02^{\mathrm{a}}$ & $1.73 \pm 0.01^{\mathrm{c}}$
\end{tabular}

$\overline{\mathrm{IC}_{50} \text { values, in } \mathrm{mg} / \mathrm{mL} \text { extract; OG, Opuntia ficus-indica var Gialla; OS, Opuntia ficus- }}$ indica var Sanguigna; OE, Opuntia engelmannii. In each row different letters mean significant differences $(p<0.05$ ). Trolox IC50 values: $62.98 \mu \mathrm{g} / \mathrm{mL}$ (DDPH), 45.71 $\mu \mathrm{g} / \mathrm{mL}$ (reducing power), and $10.25 \mu \mathrm{g} / \mathrm{mL}$ ( $\beta$-carotene bleaching inhibition).

\section{VI.2.3.3. Antibacterial and antifungal activity}

The bacteriostatic and bactericidal effects of Opuntia spp. extracts were tested against 8 different pathogenic strains (Table 6-4). The hydroethanolic extract exhibited effect on 6 of the 8 strains tested, being Micrococcus flavus and Escherichia coli the only resistant strains. The comparison of hydroalcoholic extracts $v s$ commercial antibiotics (streptomycin and ampicillin) were also performed and analysed. It is important to stand out the high efficiency of streptomycin vs $S$. aureus and the better efficiency shown of streptomycin vs ampicillin. Nonetheless, Opuntia extracts display a higher performance against the pathogenic strains when compared with ampicillin. Although, confronting the extract $v s$ streptomycin, it was not possible to notice a good performance shown by the Opuntia extract, OG and OS were better bacteriostatic in 5 of out of 8 , while OE display equal or better 
strength in 3 out of 8 strain tasted. The bactericidal activity of the extracts was equal or higher in 3 out of 8 strains. OG exhibited the best performance against Bacillus cereus, while OE had stronger activity $v s$ Enterobacter cloacae.

Regarding antifungal activity, the results obtained proved to be consistent and reproducible with the hydroethanolic extracts (Table 64). The results revealed an equal or higher performance in 4 (OS extract) and 3 (OG and $\mathrm{OE}$ extract) strains out of the 8 strains tested. All three samples had higher activity on Penicillium ochrochloron compared with the antifungal controls used. However, the fungicidal activity could not improve compared with fungistatic activity mention before. The Opuntia peel extracts showed equal or higher activity regarding ketoconazole or bifonazole drugs. A higher activity performance of the extract was attained on Trichoderma viride and Penicillum ochrochloron strains.

Studies from different authors attributed the inhibitory effect of plant extracts against microbial pathogens to their phenolic composition (Balouiri et al., 2016; Song et al., 2010). The inhibitory effect of these phenolics could be explained by adsorption to cell membranes, interaction with enzymes or deprivation of substrate and metal ions (Baydar et al., 2004). 
Table 6-4 Antibacterial and antifungal activity ( $\mathrm{mg} / \mathrm{mL}$ of extract) of Opuntia peels

\begin{tabular}{|c|c|c|c|c|c|c|c|c|c|c|}
\hline \multirow{2}{*}{ Bacteria } & \multicolumn{2}{|c|}{ OS } & \multicolumn{2}{|c|}{ OG } & \multicolumn{2}{|c|}{$\mathrm{OE}$} & \multicolumn{2}{|c|}{$\mathrm{C} 1$} & \multicolumn{2}{|c|}{$\mathrm{C} 2$} \\
\hline & MIC & MBC & MIC & $\mathrm{MBC}$ & MIC & MBC & MIC & $\mathrm{MBC}$ & MIC & MBC \\
\hline Bacillus cereus & 0.075 & 0.15 & 0.05 & 0.075 & 0.10 & 0.15 & 0.10 & 0.20 & 0.25 & 0.40 \\
\hline Micrococcus flavus & N.A. & N.A. & N.A. & N.A. & N.A. & N.A. & 0.20 & 0.30 & 0.25 & 0.40 \\
\hline Staphylococcus aureus & 0.15 & 0.45 & 0.15 & 0.30 & 0.30 & 0.45 & 0.04 & 0.10 & 0.25 & 0.45 \\
\hline Listeria monocytogenes & 0.15 & 0.60 & 0.15 & 0.45 & 0.30 & 0.45 & 0.20 & 0.30 & 0.40 & 0.50 \\
\hline Escherichia coli & N.A. & N.A. & N.A. & N.A. & N.A. & N.A. & 0.20 & 0.30 & 0.40 & 0.50 \\
\hline Enterobacter cloacae & 0.075 & 0.30 & 0.075 & 0.30 & 0.10 & 0.15 & 0.20 & 0.30 & 0.25 & 0.50 \\
\hline Pseudomonas aeruginosa & 0.15 & 0.45 & 0.15 & 0.45 & 0.30 & 0.45 & 0.20 & 0.30 & 0.75 & 1.20 \\
\hline Salmonella typhimurium & 0.15 & 0.30 & 0.15 & 0.45 & 0.15 & 0.30 & 0.25 & 0.50 & 0.40 & 0.75 \\
\hline \multirow{2}{*}{ Mold } & \multicolumn{2}{|c|}{ OS } & \multicolumn{2}{|c|}{ OG } & \multicolumn{2}{|c|}{$\mathrm{OE}$} & \multicolumn{2}{|c|}{$\mathrm{C} 3$} & \multicolumn{2}{|c|}{$\mathrm{C} 4$} \\
\hline & $\mathrm{MIC}$ & MFC & MIC & MFC & MIC & MFC & MIC & MFC & MIC & MFC \\
\hline Aspergillus fumigatus & 0.30 & 0.45 & 0.30 & 0.60 & 0.30 & 0.60 & 0.25 & 0.50 & 0.15 & 0.20 \\
\hline Aspergillus versicolor & 0.30 & 0.45 & 0.30 & 0.45 & 0.30 & 0.45 & 0.20 & 0.50 & 0.10 & 0.20 \\
\hline Aspergillus ochraceus & 0.10 & 0.15 & 0.15 & 0.30 & 0.15 & 0.30 & 1.50 & 2.00 & 0.15 & 0.20 \\
\hline Aspergillus niger & 0.30 & 0.45 & 0.30 & 0.45 & 0.30 & 0.45 & 0.20 & 0.50 & 0.15 & 0.20 \\
\hline Trichoderma viride & 0.15 & 0.30 & 0.075 & 0.15 & 0.10 & 0.15 & 1.00 & 1.00 & 0.15 & 0.20 \\
\hline Penicillium funiculosum & 0.15 & 0.30 & 0.30 & 0.45 & 0.30 & 0.45 & 0.20 & 0.50 & 0.20 & 0.25 \\
\hline Penicillium ochrochloron & 0.075 & 0.15 & 0.075 & 0.15 & 0.10 & 0.15 & 2.50 & 3.50 & 0.20 & 0.25 \\
\hline Penicillium verrucosum var. cyclopium & 0.30 & 0.45 & 0.30 & 0.45 & 0.30 & 0.60 & 0.20 & 0.30 & 0.10 & 0.20 \\
\hline
\end{tabular}

C1, Streptomycin; C2, Ampicillin; C3, Ketoconazole; C4, Bifonazole; MIC, minimum inhibitory concentration; MBC, minimum bactericidal concentrations; MBC, minimum fungicidal concentrations; N.A., No activity.

OG, Opuntia ficus-indica var Gialla; OS, Opuntia ficus-indica var Sanguigna; OE, Opuntia engelmannii. 


\section{VI.2.3.4. Cytotoxic activity}

Hepatotoxicity analysis were performed on the Opuntia spp. peel extracts treating PLP2 cells in order to guarantee the safety of the extracts and no toxicity was found in none of the extracts $\left(\mathrm{GI}_{50}\right.$ values $>400 \mu \mathrm{g} / \mathrm{mL}$ ). The results obtained will allow to continue studying different application of the by-product extracts in depth. Porcine liver cells were employed as the in vitro model, due to analogous physiological functioning to the human cells. Concurrently, antitumor activity was tested with four different human tumour cell lines (breast adenocarcinoma - MCF-7, non-small cell lung cancer - NCI-H460, cervical carcinoma - HeLa and hepatocellular carcinoma - HepG2), although the extracts displayed beneficial antitumor activity, the strength of the extracts could not overcome the antitumor activity of the ellipticine control tested (data not shown).

Table 6-5 Cytotoxic activity of Opuntia peels; OG: OFI Gialla, OS: OFI Sanguigna, OE: o. engelmannii

\begin{tabular}{lcccc}
\hline & OG & $\begin{array}{r}\text { Peel } \\
\text { OS }\end{array}$ & OE & $\begin{array}{c}\text { Control } \\
\text { Ellipticine }\end{array}$ \\
\hline \multicolumn{2}{l}{ Antitumour activity (GI50 values. $\boldsymbol{\mu g} / \mathbf{m L}$ ) } & & & \\
\hline MCF-7 (breast carcinoma) & $>400$ & $>400$ & $>400$ & $0.91 \pm 0.04$ \\
NCI-H460 (non-small cell lung & $>400$ & $>400$ & $>400$ & $1.03 \pm 0.09$ \\
cancer) & & & & \\
HeLa (cervical carcinoma) & $>400$ & $>400$ & $>400$ & $1.91 \pm 0.06$ \\
HepG2 (hepatocellular carcinoma) & $>400$ & $>400$ & $>400$ & $1.14 \pm 0.21$ \\
\hline Hepatotoxicity (GI50 values. $\boldsymbol{\mu g} / \mathbf{m L})$ & $>400$ & $>400$ & $>400$ & $3.22 \pm 0.67$ \\
\hline PLP2
\end{tabular}




\section{VI.2.4. CONCLUSION}

Overall, Opuntia spp. chemical characterization was able to identify the phenolic and betalainic profile inherent to the by-products (peels) of Opuntia ficus-indica and Opuntia engelmanni. This recompilation of data will bring deeper comprehension on the specific compounds related to the antioxidant and antimicrobial capacity of the extracts analysed and the absence of toxicity. The mentioned benefits make them of huge interest as a new source of functional ingredients. The pivotal objective of this work was focused on exploring by-product biocompounds and possible outputs, thus, we could suggest their use as natural colorants with intrinsic antioxidant and antimicrobial activity, which would grant industries to produce cleaner label products with functional benefits.

\section{Aknowledgement}

The authors are grateful to the Foundation for Science and Technology (FCT, Portugal) and FEDER under Program PT2020 for financial support to CIMO (UID/AGR/00690/2013) and L. Barros contract. B. Melgar thanks CONACyT for his grant (No. 329930). The authors would also like to thank Dr. Carlos Aguiar for the botanical identification of these species. The authors are also grateful to the Serbian Ministry of Education, Science and Technological Development, grant number 173032 for financial support. 


\section{References}

Ahn, J.H., Jang, Y.-S., Lee, S.Y., 2016. Production of succinic acid by metabolically engineered microorganisms. Curr. Opin. Biotechnol. 42, 54-66. https://doi.org/10.1016/j.copbio.2016.02.034

Al-Farsi, M.A., Lee, C.Y., 2008. Optimization of phenolics and dietary fibre extraction from date seeds. Food Chem. 108, 977-985. https://doi.org/10.1016/j.foodchem.2007.12.009

Albano, C., Negro, C., Tommasi, N., Gerardi, C., Mita, G., Miceli, A., De Bellis, L., Blando, F., 2015. Betalains, Phenols and Antioxidant Capacity in Cactus Pear [Opuntia ficus-indica (L.) Mill.] Fruits from Apulia (South Italy) Genotypes. Antioxidants 4, 269-280. https://doi.org/10.3390/antiox4020269

Albuquerque, T.G., Santos, F., Sanches-Silva, A., Beatriz Oliveira, M., Bento, A.C., Costa, H.S., 2016. Nutritional and phytochemical composition of Annona cherimola Mill. fruits and by-products: Potential health benefits. Food Chem. 193, 187-195. https://doi.org/10.1016/j.foodchem.2014.06.044

Allai, L., Druart, X., Öztürk, M., BenMoula, A., Nasser, B., El Amiri, B., 2016. Protective effects of Opuntia ficus-indica extract on ram sperm quality, lipid peroxidation and DNA fragmentation during liquid storage. Anim. Reprod. Sci. 175, 1-9. https://doi.org/10.1016/j.anireprosci.2016.09.013

Almeida, M.M.B., de Sousa, P.H.M., Arriaga, Â.M.C., do Prado, G.M., Magalhães, C.E. de C., Maia, G.A., de Lemos, T.L.G., 2011. Bioactive compounds and antioxidant activity of fresh exotic fruits from northeastern Brazil. Food Res. Int. 44, 2155-2159. https://doi.org/10.1016/j.foodres.2011.03.051

Alvarez, B., 2007. Análisis de factibilidad del cultivo de la tuna en la localidad de Icaño, Departamento La Paz, Dirección provincial de programación del desarrollo, Ministerio de Producción y Desarrollo. Gobierno de la Provincia de Catamarca. Catamarca, Argentina.

Alzate T, L.M., González, D., Hincapié, S., Cardona S, B.L., LondoñoLondoño, J., Jiménez-Cartagena, C., 2016. The profile of bioactive substances in ten vegetable and fruit by-products from a food supply chain in Colombia. Sustain. Prod. Consum. https://doi.org/10.1016/j.spc.2016.07.005 
Ammar, I., Ben Salem, M., Harrabi, B., Mzid, M., Bardaa, S., Sahnoun, Z., Attia, H., Ennouri, M., 2018. Anti-inflammatory activity and phenolic composition of prickly pear (Opuntia ficus-indica) flowers. Ind. Crops Prod. 112, 313-319. https://doi.org/10.1016/j.indcrop.2017.12.028

Angulo-Bejarano, P.I., Martínez-Cruz, O., Paredes-López, O., 2014. Phytochemical Content, Nutraceutical Potential and Biotechnological Applications of an Ancient Mexican Plant: Nopal (Opuntia ficus-indica). Curr. Nutr. Food Sci. 10, 196-217. https://doi.org/10.2174/157340131003140828121015

Arlt, U., 2010. NATCOL | Foods Colours Legislation.

Aruwa, C.E., Amoo, S.O., Kudanga, T., 2018. Opuntia (Cactaceae) plant compounds, biological activities and prospects - A comprehensive review. Food Res. Int. 112, 328-344. https://doi.org/10.1016/j.foodres.2018.06.047

Association of Official Analytical Chemists, 2016. Official Methods of Analysis of AOAC International, 20th ed. The Association, Gaithersburg, MD, USA.

Attokaran, M., 2011. Natural Food Flavors and Colorants Natural Food Flavors and Colorants, 1st ed. Blackwell Publishing LTD, Iowa.

Augustin, M.A., Sanguansri, L., 2015. Challenges and Solutions to Incorporation of Nutraceuticals in Foods. Annu. Rev. Food Sci. Technol. 6, 463-477. https://doi.org/10.1146/annurev-food022814-015507

Ayala-Zavala, J.F., Vega-Vega, V., Rosas-Domínguez, C., PalafoxCarlos, H., Villa-Rodriguez, J.A., Siddiqui, M.W., Dávila-Aviña, J.E., González-Aguilar, G.A., 2011. Agro-industrial potential of exotic fruit byproducts as a source of food additives. Food Res. Int. 44 , 1866-1874. https://doi.org/10.1016/j.foodres.2011.02.021

Azeredo, H.M.C., 2009. Betalains: Properties, sources, applications, and stability - A review. Int. J. Food Sci. Technol. 44, 2365-2376. https://doi.org/10.1111/j.1365-2621.2007.01668.x

Balouiri, M., Sadiki, M., Ibnsouda, S.K., 2016. Methods for in vitro evaluating antimicrobial activity: A review. J. Pharm. Anal. 6, 71-79. https://doi.org/10.1016/j.jpha.2015.11.005 
Barros, L., Calhelha, R.C., Queiroz, M.J.R.P., Santos-Buelga, C., Santos, E.A., Regis, W.C.B., Ferreira, I.C.F.R., 2015. The powerful in vitro bioactivity of Euterpe oleracea Mart. seeds and related phenolic compounds. Ind. Crops Prod. 76, 318-322. https://doi.org/10.1016/j.indcrop.2015.05.086

Barros, L., Pereira, C., Ferreira, I.C.F.R., 2013. Optimized Analysis of Organic Acids in Edible Mushrooms from Portugal by Ultra Fast Liquid Chromatography and Photodiode Array Detection. Food Anal. Methods 6. https://doi.org/10.1007/s12161-012-9443-1

Barrows, J.N., Lipman, A.L., Bailey, C.J., Cianci, S., 2003. Color Additives: FDA's Regulatory Process and Historical Perspectives. Food Saf. Mag. URL https://www.fda.gov/forindustry/coloradditives/regulatoryproces shistoricalperspectives/ (accessed 9.3.18).

Baydar, N.G., Özkan, G., Sağdiç, O., 2004. Total phenolic contents and antibacterial activities of grape (Vitis vinifera L.) extracts. Food Control 15, 335-339. https://doi.org/10.1016/S09567135(03)00083-5

Belščak-Cvitanović, A., Durgo, K., Huđek, A., Bačun-Družina, V., Komes, D., 2018. Metabolism and Health Effects of Polyphenols, in: Galanakis, C.M. (Ed.), Polyphenols: Properties, Recovery, and Applications. Woodhead Publishing, pp. 1-44. https://doi.org/https://doi.org/10.1016/B978-0-12-8135723.00001-4

Belwal, T., Dhyani, P., Bhatt, I.D., Rawal, R.S., Pande, V., 2016. Optimization extraction conditions for improving phenolic content and antioxidant activity in Berberis asiatica fruits using response surface methodology (RSM). Food Chem. 207, 115124. https://doi.org/10.1016/j.foodchem.2016.03.081

Bessada, S.M.F., Barreira, J.C.M., Barros, L., Ferreira, I.C.F.R., Oliveira, M.B.P.P., 2016. Phenolic profile and antioxidant activity of Coleostephus myconis (L.) Rchb.f.: An underexploited and highly disseminated species. Ind. Crops Prod. 89, 45-51. https://doi.org/10.1016/j.indcrop.2016.04.065

Betancourt, C., Cejudo-Bastante, M.J., Heredia, F.J., Hurtado, N., 2017. Pigment composition and antioxidant capacity of betacyanins and betaxanthins fractions of Opuntia dillenii (Ker Gawl) Haw cactus fruit. Food Res. Int. 101, 173-179. https://doi.org/10.1016/j.foodres.2017.09.007 
Bhatia, S., Bera, T., Dahiya, R., Bera, T., Bhatia, S., Bera, T., 2015. Classical and Nonclassical Techniques for Secondary Metabolite Production in Plant Cell Culture, in: Modern Applications of Plant Biotechnology in Pharmaceutical Sciences. Elsevier, pp. 231291. https://doi.org/10.1016/B978-0-12-802221-4.00007-8

Brand-Williams, W., Cuvelier, M.E., Berset, C., 1995. Use of a free radical method to evaluate antioxidant activity. LWT - Food Sci. Technol. 28, 25-30. https://doi.org/10.1016/S00236438(95)80008-5

Bravo-Hollis, H., 1978. Las cactaceas de Mexico. Universidad Nacional Autonoma de Mexico, Mexio. https://doi.org/10.15713/ins.mmj.3

Brundtland, G.H., 1987. Our common future.

Cai, Y., Sun, M., Corke, H., 2003. Antioxidant activity of betalains from plants of the Amaranthaceae. J. Agric. Food Chem. 51, 2288-2294. https://doi.org/10.1021/jf030045u

Calderón-Oliver, M., Escalona-Buendía, H.B., Medina-Campos, O.N., Pedraza-Chaverri, J., Pedroza-Islas, R., Ponce-Alquicira, E., 2016. Optimization of the antioxidant and antimicrobial response of the combined effect of nisin and avocado byproducts. LWT Food Sci. Technol. 65, 46-52. https://doi.org/10.1016/j.lwt.2015.07.048

Cardoso-Ugarte, G.A., Sosa-Morales, M.E., Ballard, T., Liceaga, A., San Martín-González, M.F., 2014. Microwave-assisted extraction of betalains from red beet (Beta vulgaris). LWT - Food Sci. Technol. 59, 276-282. https://doi.org/10.1016/j.lwt.2014.05.025

Carocho, M., Ferreira, I.C.F.R., 2013. A review on antioxidants, prooxidants and related controversy: Natural and synthetic compounds, screening and analysis methodologies and future perspectives. Food Chem. Toxicol. 51, 15-25. https://doi.org/10.1016/j.fct.2012.09.021

Carr, M., 2013. The water relations and irrigation requirements of avocado (Persea americana Mill.): a review. Exp. Agric. 49, 256278. https://doi.org/10.1017/S0014479712001317

Cassano, A., Conidi, C., Timpone, R., D’Avella, M., Drioli, E., 2007. A membrane-based process for the clarification and the concentration of the cactus pear juice. J. Food Eng. 80, 914-921. https://doi.org/10.1016/j.jfoodeng.2006.08.005 
Castellanos-Santiago, E., Yahia, E.M., 2008. Identification and quantification of betalains from the fruits of 10 Mexican prickly pear cultivars by high-performance liquid chromatography and electrospray ionization mass spectrometry. J. Agric. Food Chem. 56, 5758-5764. https://doi.org/10.1021/jf800362t

Castellar, R., Obón, J.M., Alacid, M., Fernández-López, J.A., 2003. Color Properties and Stability of Betacyanins from Opuntia Fruits. J. Agric. Food Chem. 51, 2772-2776. https://doi.org/10.1021/jf021045h

Cejudo Bastante, M.J., Chaalal, M., Louaileche, H., Parrado, J., Heredia, F.J., 2014. Betalain Profile, Phenolic Content, and Color Characterization of Different Parts and Varieties of Opuntia ficusindica. J. Agric. Food Chem. 62, 8491-8499. https://doi.org/10.1021/jf502465g

Chahdoura, H., Barreira, J.C.M., Barros, L., Santos-Buelga, C., Ferreira, I.C.F.R., Achour, L., 2014. Phytochemical characterization and antioxidant activity of Opuntia microdasys (Lehm.) Pfeiff flowers in different stages of maturity. J. Funct. Foods 9, 27-37. https://doi.org/10.1016/j.jff.2014.04.011

Chahdoura, H., Barreira, J.C.M., Fernández-Ruiz, V., Morales, P., Calhelha, R.C., Flamini, G., Soković, M., Ferreira, I.C.F.R., Achour, L., 2016. Bioactivity, proximate, mineral and volatile profiles along the flowering stages of Opuntia microdasys (Lehm.): defining potential applications. Food Funct. 7, 1458-67. https://doi.org/10.1039/c5fo01536g

Chan, L.G., Cohen, J.L., Maria, J., Nobrega, L., Bell, D.M., 2018. Conversion of Agricultural Streams and Food-Processing ByProducts to Value-Added Compounds using Filamentous Fungi. Annu. Rev. Food Sci. Technol. 9, 1-21. https://doi.org/10.1146/annurev-food-030117-012626

Chougui, N., Djerroud, N., Naraoui, F., Hadjal, S., Aliane, K., Zeroual, B., Larbat, R., 2015. Physicochemical properties and storage stability of margarine containing Opuntia ficus-indica peel extract as antioxidant. Food Chem. 173, 382-90. https://doi.org/10.1016/j.foodchem.2014.10.025

Chougui, N., Tamendjari, A., Hamidj, W., Hallal, S., Barras, A., Richard, T., Larbat, R., 2013. Oil composition and characterisation of phenolic compounds of Opuntia ficus-indica seeds.

Food

Chem.

139 ,

796-803. 
https://doi.org/10.1016/j.foodchem.2013.01.054

Clifford, M.N., Johnston, K.L., Knight, S., Kuhnert, N., 2003. Hierarchical Scheme for LC-MSn Identification of Chlorogenic Acids. J. Agric. Food Chem. 51, 2900-2911. https://doi.org/10.1021/jf026187q

Clifford, M.N., Knight, S., Kuhnert, N., 2005. Discriminating between the six isomers of dicaffeoylquinic acid by LC-MSn. J. Agric. Food Chem. 53, 3821-3832. https://doi.org/10.1021/jf050046h

Cowan, A.K., Cripps, R.F., Richings, E.W., Taylor, N.J., 2001. Fruit size: Towards an understanding of the metabolic control of fruit growth using avocado as a model system. Physiol. Plant. 111, 127-136. https://doi.org/10.1034/j.1399-3054.2001.1110201.x

Cowan, A.K., Wolstenholme, B.N., 2003. AVOCADOS, in: Encyclopedia of Food Sciences and Nutrition. Elsevier, pp. 348353. https://doi.org/10.1016/B0-12-227055-X/00073-0

Crane, J.H., Balerdi, C.F., Maguire, I., 2016. Avocado Growing in the Florida Home Landscape.

Da-Costa-Rocha, I., Bonnlaender, B., Sievers, H., Pischel, I., Heinrich, M., 2014. Hibiscus sabdariffa L. - A phytochemical and pharmacological review. Food Chem. 165, 424-443. https://doi.org/10.1016/j.foodchem.2014.05.002

da Silva, R.P.F.F., Rocha-Santos, T.A.P., Duarte, A.C., 2016. Supercritical fluid extraction of bioactive compounds. TrAC Trends Anal. Chem. 76, 40-51. https://doi.org/10.1016/j.trac.2015.11.013

Dabas, D., Shegog, R.M., Ziegler, G.R., Lambert, J.D., 2013. Avocado (Persea americana) seed as a source of bioactive phytochemicals. Curr. Pharm. Des. 19, 6133-40. https://doi.org/10.2174/1381612811319340007

Day, L., Seymour, R.B., Pitts, K.F., Konczak, I., Lundin, L., 2009. Incorporation of functional ingredients into foods. Trends Food Sci. Technol. 20, 388-395. https://doi.org/10.1016/J.TIFS.2008.05.002

DeFelice, S.L., 2002. FIM Rationale And Proposed Guidelines For The Nutraceutical Research \& Education Act - NREA. New York.

Delgado-Vargas, F., Paredes-Lopez, O., 2003. Natural Colorants for Food and Nutraceutical Uses, Trends in Food Science \& Technology. https://doi.org/10.1016/S0924-2244(03)00076-1 
Destro dos Santos, C., Külzer Scherer, R., Schilling Cassini, A., Ferreira Marczak, L.D., Tessaro, I.C., 2016. Clarification of red beet stalks extract by microfiltration combined with ultrafiltration. J. Food Eng. 185, 35-41. https://doi.org/10.1016/j.jfoodeng.2016.03.031

Devalaraja, S., Jain, S., Yadav, H., 2011. Exotic fruits as therapeutic complements for diabetes, obesity and metabolic syndrome. Food Res. Int. 44, 1856-1865. https://doi.org/10.1016/j.foodres.2011.04.008

Devasagayam, T.P.A., Boloor, K.K., Ramasarma, T., 2003. Methods for estimating lipid peroxidation: An analysis of merits and demerits. Indian J. Biochem. Biophys. 40, 300-308.

Dias, M.I., Sousa, M.J., Alves, R.C., Ferreira, I.C.F.R., 2016. Exploring plant tissue culture to improve the production of phenolic compounds: A review. Ind. Crops Prod. 82, 9-22. https://doi.org/10.1016/j.indcrop.2015.12.016

Donkin, R.A., 1977. Spanish Red: An Ethnogeographical Study of Cochineal and the Opuntia Cactus. Trans. Am. Philos. Soc. 67, 184. https://doi.org/10.2307/1006195

Esatbeyoglu, T., Wagner, A.E., Schini-Kerth, V.B., Rimbach, G., 2015a. Betanin a food colorant with biological activity. Mol. Nutr. Food Res. 59, 36-47. https://doi.org/10.1002/mnfr.201400484

Espinel-Ingroff, A., 2001. Comparison of the E-test with the NCCLS M38-P method for antifungal susceptibility testing of common and emerging pathogenic filamentous fungi. J. Clin. Microbiol. 39, 1360-1367. https://doi.org/10.1128/JCM.39.4.13601367.2001

Esquivel, P., 2016. Handbook on Natural Pigments in Food and Beverages Industrial Applications for Improving Food Colorl, in: Carle, R., Schweiggert, R.M. (Eds.). Woodhead Publishing, San Pedro, Costa Rica, pp. 81-99.

FAO, 2016.

FAOSTAT.

URL http://www.fao.org/faostat/en/?\#data/QC/visualize (accessed 5.3.18).

FAO, 2004. AVOCADO: Post-Harvest Operation. Rome.

FAO, IFAD, WFP, 2015. The State of Food Insecurity in the World. Meeting the 2015 international hunger targets: taking stock of uneven progress. Rome. 
Farag, M.A., Maamoun, A.A., Ehrlich, A., Fahmy, S., Wesjohann, L.A., 2017. Assessment of sensory metabolites distribution in 3 cactus Opuntia ficus-indica fruit cultivars using UV fingerprinting and GC/MS profiling techniques. LWT - Food Sci. Technol. 80, 145-154. https://doi.org/10.1016/j.lwt.2017.02.014

Fathordoobady, F., Mirhosseini, H., Selamat, J., Manap, M.Y.A., 2016. Effect of solvent type and ratio on betacyanins and antioxidant activity of extracts from Hylocereus polyrhizus flesh and peel by supercritical fluid extraction and solvent extraction. Food Chem. 202, 70-80. https://doi.org/10.1016/j.foodchem.2016.01.121

FDA, 2017. SCOGS (Select Committee on GRAS Substances). URL http://www.accessdata.fda.gov/scripts/fdcc/?set=SCOGS (accessed 3.14.17).

FDA, 2007. Guidance for Industry and Other Stakeholders Toxicological Principles for the Safety Assessment of Food Ingredients, Human Studies.

Fernández-López, J. a., Almela, L., 2001. Application of highperformance liquid chromatography to the characterization of the betalain pigments in prickly pear fruits. J. Chromatogr. A 913, 415-420. https://doi.org/10.1016/S0021-9673(00)01224-3

Fernandez-Rojas, B., Ortiz-Moreno, A., Hernandez-Navarro, D., 2010. Phenolic Content and its Antioxidant Activity of Persimmon (Dyospiros kaki L.) Cultivated in Mexico. J. Biotechnol. 150. https://doi.org/10.1016/j.jbiotec.2010.09.289

Ferreira, I.C.F.R., Martins, N., Barros, L., 2017. Phenolic Compounds and Its Bioavailability: In Vitro Bioactive Compounds or Health Promoters? Adv. Food Nutr. Res. 82, 1-44. https://doi.org/10.1016/bs.afnr.2016.12.004

Ferreres, F., Grosso, C., Gil-Izquierdo, A., Valentão, P., Mota, A.T., Andrade, P.B., 2017. Optimization of the recovery of high-value compounds from pitaya fruit by-products using microwaveassisted extraction. Food Chem. 230, 463-474. https://doi.org/10.1016/j.foodchem.2017.03.061

Flores-Valdez, C., Luna-Esquivel, J., Ramirez-Moreno, P., 1995. Manejo postcosecha de la tuna para el mercado nacional e internacional y Procesamiento y transformación industrial ... Chapingo, Estado de México. 
Galanakis, C.M., 2015. Chapter 3 - The universal recovery strategy, Food Waste Recovery. Elsevier Inc. https://doi.org/10.1016/B978-0-12-800351-0.00003-1

Galanakis, C.M., 2012. Recovery of high added-value components from food wastes: Conventional, emerging technologies and commercialized applications. Trends Food Sci. Technol. 26, 6887. https://doi.org/10.1016/j.tifs.2012.03.003

Gandía-Herrero, F., Cabanes, J., Escribano, J., García-Carmona, F., Jimenez-Atienzar, M., Jiménez-Atiénzar, M., 2013. Encapsulation of the most antioxidant betalains in edible matrices as powders of different colors Encapsulation of the most antioxidant betalains in edible matrices as powders of different colors. https://doi.org/10.1021/jf400337g

Gandía-Herrero, F., Escribano, J., García-Carmona, F., 2010. Structural implications on color, fluorescence, and antiradical activity in betalains. Planta 232, 449-460. https://doi.org/10.1007/s00425010-1191-0

Garcia-Castello, E.M., Rodriguez-Lopez, A.D., Mayor, L., Ballesteros, R., Conidi, C., Cassano, A., 2015. Optimization of conventional and ultrasound assisted extraction of flavonoids from grapefruit (Citrus paradisi L.) solid wastes. LWT - Food Sci. Technol. 64, 1114-1122. https://doi.org/10.1016/j.lwt.2015.07.024

García-Cruz, L., Dueñas, M., Santos-Buelgas, C., Valle-Guadarrama, S., Salinas-Moreno, Y., 2017. Betalains and phenolic compounds profiling and antioxidant capacity of pitaya (Stenocereus spp.) fruit from two species (S. Pruinosus and S. stellatus). Food Chem. 234, 111-118. https://doi.org/10.1016/j.foodchem.2017.04.174

Gebhardt, D., 2018. The Economics of Natural Color Pigments. URL https://sensientfoodcolors.com/en-us/researchdevelopment/economics-natural-color-pigments/

Ghasemzadeh, A., Ghasemzadeh, N., 2011. Flavonoids and phenolic acids: Role and biochemical activity in plants and human. J. Med. Plants Res. 5, 6697-6703. https://doi.org/10.5897/JMPR11.363

Gomes-Correa, R.C., de Souza, A.H.P., Calhelha, R.C., Barros, L., Glamoclija, J., Sokovic, M., Peralta, R.M., Bracht, A., Ferreira, I.C.F.R., 2015. Bioactive formulations prepared from fruiting bodies and submerged culture mycelia of the Brazilian edible mushroom Pleurotus ostreatoroseus Singer. Food Funct. 6, 21552164. https://doi.org/10.1039/C5FO00465A 
Gong, M., Bassi, A., 2016. Carotenoids from microalgae: A review of recent developments. Biotechnol. Adv. 34, 1396-1412. https://doi.org/10.1016/j.biotechadv.2016.10.005

Griffith, M.P., 2004. The origins of an important cactus crop, Opuntia ficus-indica (Cactaceae): New molecular evidence. Am. J. Bot. 91, 1915-1921. https://doi.org/10.3732/ajb.91.11.1915

Guimarães, R., Barros, L., Dueñas, M., Calhelha, R.C., Carvalho, A.M., Santos-Buelga, C., Queiroz, M.J.R.P., Ferreira, I.C.F.R., 2013. Nutrients, phytochemicals and bioactivity of wild Roman chamomile: A comparison between the herb and its preparations. Food Chem. 136, 718-725. https://doi.org/10.1016/j.foodchem.2012.08.025

Guldiken, B., Toydemir, G., Nur Memis, K., Okur, S., Boyacioglu, D., Capanoglu, E., 2016. Home-processed red beetroot (Beta vulgaris L.) products: Changes in antioxidant properties and $\begin{array}{lllll}\text { bioaccessibility. Int. J. Mol. } & \text { Sci. } 17 .\end{array}$ https://doi.org/10.3390/ijms17060858

GVR, 2016. Natural Antioxidants Market Analysis By Product (Vitamin C, Vitamin E, Polyphenols, Carotenoids) And Segment $\begin{array}{llll}\text { Forecasts } & \text { To } 2022 .\end{array}$ https://www.grandviewresearch.com/industry-analysis/naturalantioxidants-market

Heleno, S.A., Barros, L., Sousa, M.J., Martins, A., Ferreira, I.C.F.R., 2010. Tocopherols composition of Portuguese wild mushrooms with antioxidant capacity. Food Chem. 119, 1443-1450. https://doi.org/10.1016/j.foodchem.2009.09.025

Henry, B.S., 1996. Natural food colours, in: Natural Food Colorants. Springer US, Boston, MA, pp. 40-79. https://doi.org/10.1007/978-1-4615-2155-6_2

Herbach, K.M., Stintzing, F.C., Carle, R., 2006. Betalain stability and degradation - Structural and chromatic aspects. J. Food Sci. 71, 41-50. https://doi.org/10.1111/j.1750-3841.2006.00022.x

Herbach, K.M., Stintzing, F.C., Carle, R., 2005. Identification of heatinduced degradation products from purified betanin, phyllocactin and hylocerenin by high-performance liquid chromatography/ electrospray ionization mass spectrometry. Rapid Commun. Mass Spectrom. 19, 2603-2616. https://doi.org/10.1002/rcm.2103 
Hiwasa-Tanase, K., Ezure, H., 2014. Climateric and non-climateric ripening, in: Nath, P., Bouzayen, M., Mattoo, A.K., Pech, J.C. (Eds.), Fruit Ripening: Physiology, Signalling and Genomics. CABI International, pp. 151-177. https://doi.org/10.1017/CBO9781107415324.004

Hogervorst-Cvejić, J., Atanacković-Krstonošić, M., Bursać, M., Miljić, U., 2017. Polyphenols, in: Nutraceutical and Functional Food Components. Academic Press, pp. 203-258. https://doi.org/10.1016/B978-0-12-805257-0.00007-7

Hollman, P.C., Bijsman, M.N., van Gameren, Y., Cnossen, E.P., de Vries, J.H., Katan, M.B., 1999. The sugar moiety is a major determinant of the absorption of dietary flavonoid glycosides in man. Free Radic. Res. 31, 569-573. https://doi.org/10.1080/10715769900301141

Hurtado-Fernández, E., Fernandez-Gutierrez, A., Carrasco-Pancorbo, A., 2018a. Avocado fruit, in: Rodrigues, S., de Oliveira, E., Sousa, E. (Eds.), Exotic Fruits. Academic Press, London, pp. 37-46.

Hurtado-Fernández, E., Pacchiarotta, T., Longueira-Suárez, E., Mayboroda, O.A., Fernández-Gutiérrez, A., Carrasco-Pancorbo, A., 2013. Evaluation of gas chromatography-atmospheric pressure chemical ionization-mass spectrometry as an alternative to gas chromatography-electron ionization-mass spectrometry: Avocado fruit as example. J. Chromatogr. A 1313, 228-244. https://doi.org/10.1016/j.chroma.2013.08.084

Hurtado-Fernández, E., Pacchiarotta, T., Mayboroda, O.A., FernándezGutiérrez, A., Carrasco-Pancorbo, A., 2014. Quantitative characterization of important metabolites of avocado fruit by gas chromatography coupled to different detectors (APCI-TOF MS and FID). Food Res. Int. 62, 801-811. https://doi.org/10.1016/j.foodres.2014.04.038

Hussain, Z., Thu, H.E., Amjad, M.W., Hussain, F., Ahmed, T.A., Khan, S., 2017. Exploring recent developments to improve antioxidant, anti-inflammatory and antimicrobial efficacy of curcumin: A review of new trends and future perspectives. Mater. Sci. Eng. C. https://doi.org/10.1016/j.msec.2017.03.226

IFIC, FDA, 2010. Overview of Food Ingredients, Additives and Colors. URL https://www.fda.gov/food/ingredientspackaginglabeling/foodadd itivesingredients/ucm094211.htm 
Inglese, P., Giugliuzza, G., Liguori, G., 2004. Cactus pear fruit production: from knowledge to development, in: Esparza-Frausto, G., Valdez-Cepeda, R.D., Méndez- Gallego, S.J. (Eds.), El Nopal.Tópicos de Actualidad. Universidad Autónoma de Chapingo. Colegio de Postgraduados, México, pp. 89-108.

IUPAC, IUPAC-IUB, 1976. Nomenclature of cyclitols. Biochem. J. 153, 23-31. https://doi.org/10.1351/pac197437010283

Jain, G., Gould, K.S., 2015. Are betalain pigments the functional homologues of anthocyanins in plants? Environ. Exp. Bot. 119, 48-53. https://doi.org/10.1016/J.ENVEXPBOT.2015.06.002

Jain, T., Grover, K., Kaur, G., 2016. Effect of processing on nutrients and fatty acid composition of garden cress (Lepidium sativum) seeds. Food Chem. 213, 806-812. https://doi.org/10.1016/j.foodchem.2016.07.034

Jimenez-Garcia, S.N., Vazquez-Cruz, M.A., Garcia-Mier, L., Contreras-Medina, L.M., Guevara-González, R.G., Garcia-Trejo, J.F., Feregrino-Perez, A.A., 2018. Phytochemical and Pharmacological Properties of Secondary Metabolites in Berries, in: Therapeutic Foods. Elsevier, pp. 397-427. https://doi.org/10.1016/B978-0-12-811517-6.00013-1

Kaderides, K., Goula, A.M., 2017. Development and characterization of a new encapsulating agent from orange juice by-products. Food Res. Int. 0-1. https://doi.org/10.1016/j.foodres.2017.07.057

Kanner, J., Harel, S., Granit, R., 2001. Betalains - A new class of dietary cationized antioxidants. J. Agric. Food Chem. 49, 51785185. https://doi.org/10.1021/jf010456f

Karamac, M., Estrella, I., Herna, T., Dykes, G. a., Kosińska, A., Karamać, M., Estrella, I., Hernández, T., Bartolomé, B., Dykes, G. a., 2012. Phenolic compound profiles and antioxidant capacity of Persea americana Mill. peels and seeds of two varieties. J. Agric. Food Chem. 60, 4613-4619. https://doi.org/10.1021/jf300090p

Katsube, T., Tsurunaga, Y., Sugiyama, M., Furuno, T., Yamasaki, Y., 2009. Effect of air-drying temperature on antioxidant capacity and stability of polyphenolic compounds in mulberry (Morus alba L.) leaves. Food Chem. 113, 964-969. https://doi.org/10.1016/j.foodchem.2008.08.041 
Kaur Kala, H., Mehta, R., Tandey, R., Sen, K.K., Mandal, V., 2016. Ten years of research on phenolics (2005-2015): A status report. Pacific Sci. Rev. A Nat. Sci. Eng. https://doi.org/10.1016/j.psra.2016.07.002

Knight, R.J., Campbell, C.W., 1999. Ecological adaptation and the evolution of modern avocado cultivars. Rev. Chapingo Ser. Hortic. 49-54.

Kosińska, A., Karamać, M., Estrella, I., Hernández, T., Bartolomé, B., Dykes, G.A., 2012. Phenolic compound profiles and antioxidant capacity of Persea americana Mill. peels and seeds of two varieties. J. Agric. Food Chem. 60, 4613-4619. https://doi.org/10.1021/jf300090p

Kris-Etherton, P.M., Hecker, K.D., Bonanome, A., Coval, S.M., Binkoski, A.E., Hilpert, K.F., Griel, A.E., Etherton, T.D., 2002. Bioactive compounds in foods: their role in the prevention of cardiovascular disease and cancer. Am. J. Med. 113, 71-88. https://doi.org/10.1016/S0002-9343(01)00995-0

Kuhnle, G.G., 2012. Nutritional biomarkers for objective dietary assessment. J. Sci. Food Agric. 92, 1145-1149. https://doi.org/10.1002/jsfa.5631

Kuti, J.O., 2004. Antioxidant compounds from four Opuntia cactus pear fruit varieties. Food Chem. 85, 527-533. https://doi.org/10.1016/S0308-8146(03)00184-5

Kyriacou, M.C., Emmanouilidou, M.G., Soteriou, G.A., 2016. Asynchronous ripening behavior of cactus pear (Opuntia ficusindica) cultivars with respect to physicochemical and physiological attributes. Food Chem. 211, 598-607. https://doi.org/10.1016/j.foodchem.2016.05.113

Laqui-Vilca, C., Aguilar-Tuesta, S., Mamani-Navarro, W., MontañoBustamante, J., Condezo-Hoyos, L., 2018. Ultrasound-assisted optimal extraction and thermal stability of betalains from colored quinoa (Chenopodium quinoa Willd) hulls. Ind. Crops Prod. 111, 606-614. https://doi.org/10.1016/j.indcrop.2017.11.034

Lea, A., 2008. Analysis of polyphenol antioxidants in fortified foods and supplements. Food Fortif. Suppl. 175-194. https://doi.org/10.1533/9781845694265.2.175

Leardi, R., 2013. Experimental Design, 1st ed, Data Handling in Science and Technology. Copyright (C) 2013 Elsevier B.V. All 
rights reserved. https://doi.org/10.1016/B978-0-444-595287.00002-8

Li, J., Chen, Z., Di, D., 2012. Preparative separation and purification of Rebaudioside A from Stevia rebaudiana Bertoni crude extracts by mixed bed of macroporous adsorption resins. Food Chem. 132, 268-276. https://doi.org/10.1016/j.foodchem.2011.10.077

Librán, C.M., Mayor, L., Garcia-Castello, E.M., Vidal-Brotons, D., 2013. Polyphenol extraction from grape wastes: Solvent and $\mathrm{pH}$ effect. Agric. Sci. 04, 56-62. https://doi.org/10.4236/as.2013.49B010

Madrau, M. a., Piscopo, A., Sanguinetti, A.M., Del Caro, A., Poiana, M., Romeo, F. V., Piga, A., 2009. Effect of drying temperature on polyphenolic content and antioxidant activity of apricots. Eur. Food Res. Technol. 228, 441-448. https://doi.org/10.1007/s00217-008-0951-6

Madunić, J., Madunić, I.V., Gajski, G., Popić, J., Garaj-Vrhovac, V., 2018. Apigenin: A dietary flavonoid with diverse anticancer properties. Cancer Lett. 413, 11-22. https://doi.org/10.1016/j.canlet.2017.10.041

Manach, C., Scalbert, A., Morand, C., Rémésy, C., Jiménez, L., 2004. Bioavailability, Polyphenols: Food sources and. Am. J. Clin. Nutr. 79, 727-747. https://doi.org/10.1038/nature05488

Mandal, S.C., Mandal, V., Das, A.K., 2015. Classification of Extraction Methods, in: Essentials of Botanical Extraction. Academic Press, pp. 83-136. https://doi.org/10.1016/B978-0-12-802325-9.000069

Marais, J.P.J., Deavours, B., Dixon, R.A., Ferreira, D., 2006. The science of flavonoids, The Science of Flavonoids. Springer, Ohio. https://doi.org/10.1007/978-0-387-28822-2

Marco, G.J., 1968. A Rapid Method for Evaluation of Antioxidants. J. Am. oil Chem. Soc. 45, 594-598. https://doi.org/10.1007/BF02668958

Maria, J., Andrade, D.M., Fasolo, D., 2014. Polyphenol Antioxidants from Natural Sources and Contribution to Health Promotion, Polyphenols in Human Health and Disease. Elsevier Inc. https://doi.org/10.1016/B978-0-12-398456-2.00020-7

Martins, N., Roriz, C.L., Morales, P., Barros, L., Ferreira, I.C.F.R., 2016. Food colorants: Challenges, opportunities and current 
desires of agro-industries to ensure consumer expectations and regulatory practices. Trends Food Sci. Technol. 52, 1-15. https://doi.org/10.1016/j.tifs.2016.03.009

Mata, A., Ferreira, J.P., Semedo, C., Serra, T., Duarte, C.M.M., Bronze, M.R., 2016. Contribution to the characterization of Opuntia spp. juices by LC-DAD-ESI-MS/MS. Food Chem. 210, 558-565. https://doi.org/10.1016/j.foodchem.2016.04.033

Mayor, L., Calvo, A., Moreira, R., Fito, P., Garcia-Castello, E.M., 2013. Water sorption isotherms of globe artichoke leaves. Agric. Sci. 04, 63-69. https://doi.org/10.4236/as.2013.49B011

McGuire, S., 2011. U.S. Department of Agriculture and U.S. Department of Health and Human Services, Dietary Guidelines for Americans, 2010. 7th Edition, Washington, DC: U.S. Government Printing Office, January 2011. Adv. Nutr. 2, 293294. https://doi.org/10.3945/an.111.000430

Medina-Meza, I.G., Barbosa-Cánovas, G. V., 2015. Assisted extraction of bioactive compounds from plum and grape peels by ultrasonics and pulsed electric fields. J. Food Eng. 166, 268-275. https://doi.org/10.1016/j.jfoodeng.2015.06.012

Melgar, B., Dias, M.I., Ciric, A., Sokovic, M., Garcia-Castello, E.M., Rodriguez-Lopez, A.D., Barros, L., Ferreira, I., 2017a. Byproduct recovery of Opuntia spp. peels: Betalainic and phenolic profiles and bioactive properties. https://doi.org/10.1016/j.indcrop.2017.06.011

Melgar, B., Pereira, E., Oliveira, M.B.P.P., Garcia-Castello, E.M., Rodriguez-Lopez, A.D., Sokovic, M., Barros, L., Ferreira, I.C.F.R., 2017b. Extensive profiling of three varieties of Opuntia spp. fruit for innovative food ingredients. Food Res. Int. 101, 259265. https://doi.org/10.1016/j.foodres.2017.09.024

Mena, P., Tassotti, M., Andreu, L., Nuncio-Jáuregui, N., Legua, P., Del Rio, D., Hernández, F., 2018. Phytochemical characterization of different prickly pear (Opuntia ficus-indica (L.) Mill.) cultivars and botanical parts: UHPLC-ESI-MSn metabolomics profiles and their chemometric analysis. Food Res. Int. 108, 301-308. https://doi.org/10.1016/j.foodres.2018.03.062

Mirabella, N., Castellani, V., Sala, S., 2014. Current options for the valorization of food manufacturing waste: a review. J. Clean. Prod. 65 , 28-41. https://doi.org/10.1016/J.JCLEPRO.2013.10.051 
Mishra, A., Sharma, A.K., Kumar, S., Saxena, A.K., Pandey, A.K., 2013. Bauhinia variegata leaf extracts exhibit considerable antibacterial, antioxidant, and anticancer activities. Biomed Res. Int. 2013. https://doi.org/10.1155/2013/915436

Mishra, A.K., Mishra, A., Kehri, H.K., Sharma, B., Pandey, A.K., 2009. Inhibitory activity of Indian spice plant Cinnamomum zeylanicum extracts against Alternaria solani and Curvularia lunata, the pathogenic dematiaceous moulds. Ann. Clin. Microbiol. Antimicrob. 8, 9. https://doi.org/10.1186/1476-07118-9

Monks, A., Scudiero, D., Skehan, P., Shoemaker, R., Paull, K., Vistica, D., Hose, C., Langley, J., Cronise, P., Vaigro-wolff, A., Graygoodrich, M., Campbell, H., Boyd, M., 1991. Feasibility of a High-Flux Anticancer Drug Screen Using a Diverse Panel of Cultured. J. Natl. Cancer Inst. 83, 757-766.

Morales, P., Barros, L., Ramírez-Moreno, E., Santos-Buelga, C., Ferreira, I.C.F.R., 2015. Xoconostle fruit (Opuntia matudae Scheinvar cv. Rosa) by-products as potential functional ingredients. Food Chem. 185, 289-97. https://doi.org/10.1016/j.foodchem.2015.04.012

Morales, P., Barros, L., Ramírez-Moreno, E., Santos-Buelga, C., Ferreira, I.C.F.R., 2014. Exploring xoconostle by-products as sources of bioactive compounds. Food Res. Int. 65, 437-444. https://doi.org/10.1016/j.foodres.2014.05.067

Morales, P., Ramírez-Moreno, E., Sanchez-Mata, M.D.C., Carvalho, A.M., Ferreira, I.C.F.R., 2012. Nutritional and antioxidant properties of pulp and seeds of two xoconostle cultivars (Opuntia joconostle F.A.C. Weber ex Diguet and Opuntia matudae Scheinvar) of high consumption in Mexico. Food Res. Int. 46. https://doi.org/10.1016/j.foodres.2011.12.031

Moreno, J., Peinado, R., 2012. Polyphenols, in: Moreno, J., Peinado, R. (Eds.), Enological Chemistry. Academic Press, pp. 53-76. https://doi.org/10.1016/B978-0-12-388438-1.00005-4

Naik, S.N., Goud, V. V., Rout, P.K., Dalai, A.K., 2010. Production of first and second generation biofuels: A comprehensive review. Renew. Sustain. Energy Rev. 14, 578-597. https://doi.org/10.1016/j.rser.2009.10.003

Nicoletti, M., 2012. Nutraceuticals and botanicals: overview and perspectives. Int. J. Food Sci. Nutr. 63, 2-6. 
https://doi.org/10.3109/09637486.2011.628012

NIH, 2017. Vitamin E - Fact sheet for Consumer. URL https://ods.od.nih.gov/factsheets/VitaminE-Consumer/ (accessed 3.14.17).

Nobel, P.S., 1998. Los incomparables agaves y cactos. Trillas, México.

Novoa, A., Le Roux, J.J., Robertson, M.P., Wilson, J.R.U., Richardson, D.M., 2015. Introduced and invasive cactus species: A global review. AoB Plants 7. https://doi.org/10.1093/aobpla/plu078

Ochoa, M. judith, Barbera, G., 2017. History and economic and agroecological importance, in: Crop Ecology, Cultivation and Uses of Catus Pears. FAO, ICARDA, pp. 1-11.

Osborn, S., 2015. 12 - Labelling relating to natural ingredients and additives, in: Advances in Food and Beverage Labelling. pp. 207221. https://doi.org/10.1533/9781782420934.3.207

Paciulli, M., Medina-Meza, I.G., Chiavaro, E., Barbosa-Cánovas, G.V., 2016. Impact of thermal and high pressure processing on quality parameters of beetroot (Beta vulgaris L.). LWT - Food Sci. Technol. 68, 98-104. https://doi.org/10.1016/j.lwt.2015.12.029

Patel, D., Shukla, S., Gupta, S., 2007. Apigenin and cancer chemoprevention: Progress, potential and promise (Review). Int. J. Oncol. 30, 233-245. https://doi.org/10.3892/ijo.30.1.233

Pedreño, M.A., Escribano, J., 2000. Studying the oxidation and the antiradical activity of betalain from beetroot. J. Biol. Educ. 35, 49-51. https://doi.org/10.1080/00219266.2000.9655736

Peláez-Cid, a. a., Velázquez-Ugalde, I., Herrera-González, a. M., García-Serrano, J., 2013. Textile dyes removal from aqueous solution using Opuntia ficus-indica fruit waste as adsorbent and its characterization. J. Environ. Manage. 130, 90-97. https://doi.org/10.1016/j.jenvman.2013.08.059

Pereira, C., Barros, L., Carvalho, A.M., Ferreira, I.C.F.R., 2011. Nutritional composition and bioactive properties of commonly consumed wild greens: Potential sources for new trends in modern diets. Food Res. Int. 44, 2634-2640. https://doi.org/10.1016/j.foodres.2011.05.012

Pereira, E., Barros, L., Calhelha, R.C., Duenas, M., Carvalho, A.M., Santos-Buelga, C., Ferreira, I.C.F.R., 2014. Bioactivity and phytochemical characterization of Arenaria montana L. Food Funct. 5, 1848-1855. https://doi.org/10.1039/c4fo00210e 
Pereira, E., Barros, L., Martins, A., Ferreira, I.C.F.R., 2012. Towards chemical and nutritional inventory of Portuguese wild edible mushrooms in different habitats. Food Chem. 130, 394-403. https://doi.org/10.1016/j.foodchem.2011.07.057

Piattelli, M., Minale, L., Prota, G., 1964. Isolation, structure and absolute configuration of indicaxanthin. Tetrahedron 20, 23252329. https://doi.org/10.1016/S0040-4020(01)97621-5

Pimienta, E., 1990. El nopal tunero. Libros de tiempos de ciencia.

Pimiento Barrios, E., Munoz-Urias, A., 1999. Domesticacion de nopales tuneros (Opuntis spp.) y descripcion de las principales variedades cultivadas. FAO, Rome (Italy).

Pinela, J., Prieto, M.A., Barreiro, M.F., Carvalho, A.M., Oliveira, M.B.P.P., Vázquez, J.A., Ferreira, I.C.F.R., 2016. Optimization of microwave-assisted extraction of hydrophilic and lipophilic antioxidants from a surplus tomato crop by response surface methodology. Food Bioprod. Process. 98, 283-298. https://doi.org/10.1016/j.fbp.2016.02.002

Primorac, T., Požar, M., Sokolić, F., Zoranić, L., Urbic, T., 2018. A simple two dimensional model of methanol. J. Mol. Liq. 262, 4657. https://doi.org/10.1016/j.molliq.2018.04.055

Quideau, S., Deffieux, D., Douat-Casassus, C., Pouysegu, L., 2011. Plant polyphenols: chemical properties, biological activities, and synthesis. Angew. Chem. Int. Ed. Engl. 50, 586-621. https://doi.org/10.1002/anie.201000044

Rached, W., Calhelha, R.C., Fernandes, Â., Carvalho, A.M., Bennaceur, M., Marouf, A., Barros, L., Santos-Buelga, C., Ferreira, I.C.F.R., 2016. Phytochemical characterization and bioactive properties of Osyris quadripartita Salzm. ex Decne. leaves from Algeria. RSC Adv. 6, 72768-72776. https://doi.org/10.1039/C6RA11787B

Ramos-Jerz, M.D.R., Villanueva, S., Jerz, G., Winterhalter, P., Deters, A.M., 2013. Persea americana Mill. Seed: Fractionation, Characterization, and Effects on Human Keratinocytes and Fibroblasts. Evidence-based Complement. Altern. Med. eCAM 2013, 391247. https://doi.org/10.1155/2013/391247

Rao, G., 2010. Optimization of ultrasound-assisted extraction of cyanidin 3-rutinoside from litchi (Lichi chinensis Sonn.) fruit pericarp. Anal. Methods 2, 1166. 
https://doi.org/10.1039/c0ay00203h

Ravichandran, K., Saw, N.M.M.T., Mohdaly, A.A.A., Gabr, A.M.M., Kastell, A., Riedel, H., Cai, Z., Knorr, D., Smetanska, I., 2013. Impact of processing of red beet on betalain content and antioxidant activity. Food Res. Int. 50, 670-675. https://doi.org/10.1016/j.foodres.2011.07.002

Raymond Chia, T.W., Dykes, G. a, 2010. Antimicrobial activity of crude epicarp and seed extracts from mature avocado fruit (Persea americana) of three cultivars. Pharm. Biol. 48, 753-756. https://doi.org/10.3109/13880200903273922

Reis, F.S., Barreira, J.C.M., Calhelha, R.C., van Griensven, L.J.I.D., Ćirić, A., Glamočlija, J., Soković, M., Ferreira, I.C.F.R., 2014. Chemical characterization of the medicinal mushroom Phellinus linteus (Berkeley \& Curtis) Teng and contribution of different fractions to its bioactivity. LWT - Food Sci. Technol. 58, 478485. https://doi.org/10.1016/j.lwt.2014.04.013

Reyes-Agüero, J.A., Aguirre, J.R., Hernández, H., 2005. Systematyc notes and a Detailed description of Opuntia ficus-indica (L) Mill. (CACTACEAE). Agrociencia 39, 395-408.

Reynolds, S.G., Arias, E., 2003. Opuntia Spp. -A Strategic fodder and efficient tool for combat desertification in the Wana Region, Cactus (Opuntia spp.) as forage. FAO Plant Production and Protection Paper 169.

Roberfroid, M.B., 2000. Concepts and strategy of functional food science: the European perspective. Am. J. Clin. Nutr. 71, 1660S$4 \mathrm{~S}$; discussion 1674S-5S. https://doi.org/10.1093/ajen/71.6.1660S

Rodrigo, D., Martínez-l, A., 2015. Antimicrobial activity of cauli fl ower (Brassica oleracea var . Botrytis) by-product against Listeria monocytogenes 50, 435-440. https://doi.org/10.1016/j.foodcont.2014.09.031

Rodríguez-Carpena, J.G., Morcuende, D., Estévez, M., 2011. Avocado by-products as inhibitors of color deterioration and lipid and protein oxidation in raw porcine patties subjected to chilled storage. Meat Sci. 89, 166-173. https://doi.org/10.1016/j.meatsci.2011.04.013

Rohwer, J.G., 1993. Lauraceae, in: The Families and Genera of Vascular Plants Free Preview, Volume II, Flowering Plants · 
Dicotyledons. Springer, Berlin, pp. 366-391. https://doi.org/10.1007/978-3-662-02899-5

Roriz, C.L., Barros, L., Prieto, M.A., Morales, P., Ferreira, I.C.F.R., 2017. Floral parts of Gomphrena globosa L. as a novel alternative source of betacyanins: Optimization of the extraction using response surface methodology. Food Chem. 229, 223-234. https://doi.org/10.1016/j.foodchem.2017.02.073

Saavedra, J., Córdova, A., Navarro, R., Díaz-Calderón, P., Fuentealba, C., Astudillo-Castro, C., Toledo, L., Enrione, J., Galvez, L., 2017. Industrial avocado waste: Functional compounds preservation by convective drying process. J. Food Eng. 198, 81-90. https://doi.org/10.1016/j.jfoodeng.2016.11.018

Sáenz, C., 2006. Utilización agroindustrial del nopal. Boletín Serv. Agrícolas La Fao 162, 165.

SAGARPA, 2011. Monografía de cultivos. Aguacate. México city.

Sansano, S., Rivas, A., Pina-Pérez, M.C., Martinez, A., Rodrigo, D., 2017. Stevia rebaudiana Bertoni effect on the hemolytic potential of Listeria monocytogenes, International Journal of Food Microbiology. https://doi.org/10.1016/j.ijfoodmicro.2017.03.006

SARAVACOS, G.D., 2014. Mass Transfer Properties of Foods 346399. https://doi.org/10.1201/9781420028805-11

Sawicki, T., Wiczkowski, W., 2018. The effects of boiling and fermentation on betalain profiles and antioxidant capacities of red beetroot products. Food Chem. 259, 292-303. https://doi.org/10.1016/j.foodchem.2018.03.143

Shahidi, F., Ambigaipalan, P., 2015. Phenolics and polyphenolics in foods, beverages and spices: Antioxidant activity and health effects - A review. J. Funct. Foods. https://doi.org/10.1016/j.jff.2015.06.018

Sharma, K., Mahato, N., Cho, M.H., Lee, Y.R., 2017. Converting citrus wastes into value-added products: Economic and environmently friendly approaches. Nutrition 34, 29-46. https://doi.org/10.1016/j.nut.2016.09.006

Šiler, B., Živković, S., Banjanac, T., Cvetković, J., Nestorović Živković, J., Ćirić, A., Soković, M., Mišić, D., 2014. Centauries as underestimated food additives: Antioxidant and antimicrobial potential. Food Chem. 147, 367-376. https://doi.org/10.1016/j.foodchem.2013.10.007 
Silva, P., Ferreira, S., Nunes, F.M., 2016. Elderberry (Sambucus nigra L.) by-products a source of anthocyanins and antioxidant polyphenols. Ind. Crops Prod. https://doi.org/10.1016/j.indcrop.2016.10.018

Singleton, V.L., Rossi, J.A., 1965. Colorimetry of Total Phenolics with Phosphomolybdic-Phosphotungstic Acid Reagents. Am. J. Enol. Vitic. 16, 144-158. https://doi.org/10.12691/ijebb-2-1-5

Song, F.L., Gan, R.Y., Zhang, Y., Xiao, Q., Kuang, L., Li, H. Bin, 2010. Total phenolic contents and antioxidant capacities of selected chinese medicinal plants. Int. J. Mol. Sci. 11, 2362-2372. https://doi.org/10.3390/ijms11062362

Spórna-Kucab, A., Ignatova, S., Garrard, I., Wybraniec, S., 2013. Versatile solvent systems for the separation of betalains from processed Beta vulgaris L. juice using counter-current chromatography. J. Chromatogr. B Anal. Technol. Biomed. Life Sci. 941, 54-61. https://doi.org/10.1016/j.jchromb.2013.10.001

Stintzing, F., Schieber, A., Carle, R., 2000. Cactus pear-a promising component to functional food. Obs. Kartof. 85, 40-47.

Stintzing, F.C., Herbach, K.M., Mosshammer, M.R., Carle, R., Yi, W., Sellappan, S., Akoh, C.C., Bunch, R., Felker, P., 2005. Color, betalain pattern, and antioxidant properties of cactus pear (Opuntia spp.) clones. J. Agric. Food Chem. 53, 442-451. https://doi.org/10.1021/jf048751y

Stintzing, F.C., Schieber, A., Carle, R., 2002. Betacyanins in fruits from red-purple pitaya, Hylocereus polyrhizus (Weber) Britton \&amp; Rose. Food Chem. 77, 101-106. https://doi.org/10.1016/S03088146(01)00374-0

Strack, D., Vogt, T., Schliemann, W., 2003. Recent advances in betalain research. Phytochemistry 62, 247-269. https://doi.org/10.1016/S0031-9422(02)00564-2

Sudzuki, F., Muñoz, C., Berger, H., 1993. El cultivo de la tuna (cactus pear)., 1 ed. ed. Departamento de Reproducción Agrícola. Universidad de Chile, Santiago., Santiago, Chile.

Svenson, J., Smallfield, B.M., Joyce, N.I., Sansom, C.E., Perry, N.B., 2008. Betalains in red and yellow varieties of the andean tuber crop ulluco (Ullucus tuberosus). J. Agric. Food Chem. 56, 77307737. https://doi.org/10.1021/jf8012053 
Sýs, M., Švecová, B., Švancara, I., Metelka, R., 2017. Determination of vitamin $\mathrm{E}$ in margarines and edible oils using square wave anodic stripping voltammetry with a glassy carbon paste electrode. Food Chem. 229, 621-627. https://doi.org/10.1016/j.foodchem.2017.02.068

Szot, D., Skopińska, A., Wybraniec, S., 2015. Decomposition of 17decarboxy-betanin in selected aqueous-organic solutions induced by $\mathrm{Cu}$ ( II ) cations. PhD Interdiscip. J. Politech. Gdansk Univ. 1, 217-223.

Takshak, S., Agrawal, S.B., 2015. Defence strategies adopted by the medicinal plant Coleus forskohlii against supplemental ultraviolet-B radiation: Augmentation of secondary metabolites and antioxidants. Plant Physiol. Biochem. 97, 124-138. https://doi.org/10.1016/j.plaphy.2015.09.018

Thirugnanasambandham, K., Sivakumar, V., 2017. Microwave assisted extraction process of betalain from dragon fruit and its antioxidant activities. J. Saudi Soc. Agric. Sci. 16, 41-48. https://doi.org/10.1016/j.jssas.2015.02.001

Timilsena, Y.P., Wang, B., Adhikari, R., Adhikari, B., 2017. Advances in microencapsulation of polyunsaturated fatty acids (PUFAs)rich plant oils using complex coacervation: A review. Food Hydrocoll. 69 ,

369-381. https://doi.org/10.1016/j.foodhyd.2017.03.007

Timpanaro, G., Urso, A., Spampinato, D., Foti, V., 2015. Cactus pear market in Italy: Competitiveness and perspectives. Acta Hortic. 1067.

Torres, M.D., Chenlo, F., Moreira, R., 2018. Structural features and water sorption isotherms of carrageenans: A prediction model for hybrid carrageenans. Carbohydr. Polym. 180, 72-80. https://doi.org/10.1016/J.CARBPOL.2017.10.010

Tretter, L., Patocs, A., Chinopoulos, C., 2016. Succinate, an intermediate in metabolism, signal transduction, ROS, hypoxia, and tumorigenesis. Biochim. Biophys. Acta - Bioenerg. 1857, 1086-1101. https://doi.org/10.1016/j.bbabio.2016.03.012

Tsuchiya, H., Iinuma, M., 2000. Reduction of membrane fluidity by antibacterial sophoraflavanone G isolated from Sophora exigua. Phytomedicine 7, 161-165. https://doi.org/10.1016/S09447113(00)80089-6 
UN DESA, 2015. World Population Prospects: The 2015 Revision. New York.

Unilever, 2010. The Unilever Sustainable Living Plan.

Vieira, V., Barros, L., Martins, A., Ferreira, I., 2016a. Nutritional and Biochemical Profiling of Leucopaxillus candidus (Bres.) Singer Wild Mushroom. Molecules 21, 99. https://doi.org/10.3390/molecules21010099

Vieira, V., Fernandes, Â., Barros, L., Glamočlija, J., Ćirić, A., Stojković, D., Martins, A., Soković, M., Ferreira, I.C.F.R., 2016b. Wild Morchella conica Pers. from different origins: A comparative study of nutritional and bioactive properties. J. Sci. Food Agric. 96, 90-98. https://doi.org/10.1002/jsfa.7063

Vinatoru, M., 2001. An overview of the ultrasonically assisted extraction of bioactive principles from herbs. Ultrason. Sonochem. 8, 303-313. https://doi.org/10.1016/S13504177(01)00071-2

Wang, W., Bostic, T.R., Gu, L., 2010. Antioxidant capacities, procyanidins and pigments in avocados of different strains and cultivars. Food Chem. 122, 1193-1198. https://doi.org/10.1016/j.foodchem.2010.03.114

Watada, A.E., Herner, R.C., Kader, A.A., Romani, R.J., Staby, G.L., 1984. Terminology for the description of developmental stages of horticultural crops. HortScience.

Weinstein, M.P., 2012. Methods for Dilution Antimicrobial Susceptibility Tests for Bacteria That Grow Aerobically; Approved Standard - Ninth Edition, Methods for Dilution Antimicrobial Susceptibility Tests for Bacteria That Grow Aerobically; Approved Standar- Ninth Edition. https://doi.org/10.4103/0976-237X.91790

WHO, 2014. GLOBAL STATUS REPORT on noncommunicable diseases 2014. "Attaining the nine global noncommunicable diseases targets; a shared responsibility"

Wrolstad, R.E., Culver, C.A., 2012. Alternatives to those artificial FD\&C food colorants. Annu. Rev. Food Sci. Technol. 3, 59-77. https://doi.org/10.1146/annurev-food-022811-101118

Wybraniec, S., Starzak, K., Szneler, E., Pietrzkowski, Z., 2016. Separation of chlorinated diastereomers of decarboxybetacyanins in myeloperoxidase catalyzed chlorinated Beta 
vulgaris L. extract. J. Chromatogr. B Anal. Technol. Biomed. Life Sci. 1036-1037,

20-32.

https://doi.org/10.1016/j.jchromb.2016.09.040

Yahia, E.M., Woolf, A.B., 2011. Avocado ( Persea americana Mill.), in: Postharvest Biology and Technology of Tropical and Subtropical Fruits: Volume 2: Açai to Citrus. Woodhead Publishing, pp. 125-185. https://doi.org/10.1533/9780857092762.125

Yamashita, C., Chung, M.M.S., dos Santos, C., Mayer, C.R.M., Moraes, I.C.F., Branco, I.G., 2017. Microencapsulation of an anthocyanin-rich blackberry (Rubus spp.) by-product extract by freeze-drying. LWT - Food Sci. Technol. 84, 256-262. https://doi.org/10.1016/j.lwt.2017.05.063

Yeddes, N., Chérif, J., Guyot, S., Sotin, H., Ayadi, M., 2013. Comparative Study of Antioxidant Power, Polyphenols, Flavonoids and Betacyanins of the Peel and Pulp of Three Tunisian Opuntia Forms. Antioxidants 2, 37-51. https://doi.org/10.3390/antiox2020037

Zhishen, J., Mengcheng, T., Jianming, W., 1999. The determination of flavonoid contents in mulberry and their scavenging effects on superoxide radicals. Food Chem. https://doi.org/10.1016/S03088146(98)00102-2 




\section{Capítulo 7 OPTIMIZACIÓN DE LOS EXTRACTOS DE LAS PIELES DE OPUNTIA SPP.}





\section{VII.1. Optimización de los extractos obtenidos de las pieles de Opuntia spp. a través de las técnicas UAE y MAE: a la vanguardia en uso de subproductos.}

En el capítulo actual se presenta una adaptación al formato de la tesis doctoral del artículo titulado "Extraction recovery optimization through UAE and MAE of Opuntia peels biocompounds: Avant-garde use of the byproducts", que actualmente se encuentra en proceso de revisión de nuestro equipo de investigaciónpara ser publicado. En él, se realiza un análisis multivariable de las extraciones de los subproductos (piel) de los frutos de higos chumbos (Opuntia spp) usando y comparando las tecnologías de extracción asistidas por microondas y ultrasonidos. Para ello, fue necesario emplear un diseño experimental realizado mediante las herramientas estadísticas de metodología de respuesta de superfice (RSM) acoplado a un diseño central compuesto (CCD), con la finalidad de obtener modelizaciones graficas y matemáticas que permitan optimizar las respuestas estudiadas. Los datos bibliográficos del artículo se destacan a continuación:

Melgar, B., Dias, M. I., Barros, L., Ferreira, I. C. F. R. RodriguezLopez, A. D., Garcia-Castello, E. M. (2018)

Extraction recovery optimization through UAE and MAE of Opuntia peels biocompounds: Avant-garde use of the byproducts,.

En proceso de revisión interna para ser publicado. 



\section{Extraction recovery optimization through UAE and MAE of} Opuntia peels biocompounds: avant-garde use of the byproducts.

Bruno Melgar ${ }^{\mathrm{a}}$, Maria Inês Dias ${ }^{\mathrm{b}}$, Lillian Barros ${ }^{\mathrm{b}}$, Isabel C.F.R. Ferreira $^{\mathrm{b}}$, Antonio D. Rodriguez-Lopez ${ }^{\mathrm{c}}$, Esperanza M. GarciaCastello $\mathrm{o}^{\mathrm{a}^{*}}$

${ }^{a}$. Institute of Food Engineering for Development, Universitat Politècnica de València, Camino de Vera, s/n CP, 46022 Valencia, Spain.

${ }^{b}$ Centro de Investigação de Montanha (CIMO), ESA, Instituto Politécnico de Bragança, Campus de Santa Apolónia, 5300-253 Bragança, Portugal

${ }^{c}$ Institute for Industrial, Radiophysical and Environmental Safety (ISIRYM), Universitat Politècnica de València, Camino de Vera, $s / n$ CP, 46022 Valencia, Spain.

*Corresponding author. Tel.+34 687896131. E-mail address: egarcia1@iqn.upv.es 


\begin{abstract}
Utrasound-assisted extraction (UAE) and microwave-assisted extraction (MAE) of bioactive compounds, namely, betalains, phenolic acids and flavonoids from coloured Opuntia engelmannii cultivar (cv.) Valencia peels were optimized by response surface methodology. Thirty-one randomized extraction runs were performed for each of the technologies employed in order to build effective models with maximum (bioactive molecules content and yield) and minimum (antioxidant activity) responses. A 5-level, 4-factor central composite design was used in both UAE and MAE to obtain target responses as a function of extraction time $(t: 0,5-2,5 \mathrm{~min}$ for UAE and 2,5-12,5 min for MAE), solid to liquid ratio $(S / L: 5-45 \mathrm{~g} / \mathrm{L})$, methanol concentration, (MetOH: 0-100\%) and temperature $\left(\boldsymbol{T}: 5-35{ }^{\circ} \mathrm{C}\right.$ for UAE and $25-105$ ${ }^{\circ} \mathrm{C}$ for MAE). Specific response optimization for each technology was analysed and discussed, along with a general optimization from all the responses together was also gather. The optimum values for each factor were $\boldsymbol{t}=2,5$ and $1,4 \mathrm{~min}, \boldsymbol{S} / \boldsymbol{L}=5$ and $5 \mathrm{~g} / \mathrm{L}, \mathbf{M e t} \boldsymbol{O H}=34,6$ and $0,0 \%$ of methanol and $\boldsymbol{T}=30$ and $36,6{ }^{\circ} \mathrm{C}$; yielding 201,6 and $132,9 \mathrm{mg} / \mathrm{g}$ of betalains, 13,9 and $8,0 \mathrm{mg} / \mathrm{g}$ of phenolic acids, 2,4 and $1,5 \mathrm{mg} / \mathrm{g}$ of flavonoids, 71,8 and $79,1 \%$ of extraction yields and $\mathrm{IC}_{50}$ antioxidant values of 2,9 and 3,6, for UAE and MAE, respectively. Opuntia peels are an important by-product with a good source of bioactive compounds, which extractions were optimized to obtain functional ingredients for the food, pharmaceutical, or cosmetic industries.
\end{abstract}

Keywords: Opuntia; by-products; betalains; natural pigments; extraction; optimization; RSM. 


\section{VII.1.1. INTRODUCTION}

Actual market trends, diversification of ingredients, and a growing consciousness in the consumers for healthier and fair trade products, has made an important transformation in the food industries looking beyond than flavour/nutrition balance in their products, extending their awareness on usage of organic products and natural ingredients as part of their new formulations (Gebhardt, 2018; GVR, 2016). Therefore, exponential growth in research and development of new alternatives to synthetic ingredients (such as colourants or bioactive compounds) has been seen in recent years (do Prado et al., 2018). Incorporation of additives can be listed by their important impact on final products, such as 1) maintain or improve safety and freshness, 2) improve or maintain nutritional value and/or 3) improve taste, texture, and appearance (IFIC and FDA, 2010). Furthermore, transversal interest in food security and environmental protection has also encouraged the development in byproducts in by-products recovery and utilization.

Opuntia spp., grows in arid and semiarid environments and belongs to the Cactaceae family. Prickly pear is a meaningful source of the natural pigments betalains and also has been recognized with healthpromoting effects and is considered an interesting source of pharmacologically active phytochemicals (i.e. polyphenols), whose involvement in antimicrobial and antioxidant processes has been demonstrated previously (Aruwa et al., 2018). Despite the potential of these natural biomolecules and their further incorporation into industrial sectors, the development of more efficient processes for their recovery remains challenging and is a current hot topic.

Several studies have been carried out to improve the extraction of these compounds from different plant materials throughout conventional, ultrasound or microwave assisted extraction (CardosoUgarte et al., 2014; Garcia-Castello et al., 2015; Laqui-Vilca et al., 2018; Thirugnanasambandham and Sivakumar, 2017), but a more efficient and robust analysis in Opuntia spp. peels are needed to achieve superior quality phytochemical at lower processing costs and in an environmentally friendly manner. 
Ultrasound and Microwave Assisted Extractions (UAE and MAE, respectively) are emerging technologies increasingly used in extraction industries. UAE is a process that uses acoustic energy (a mechanical energy i.e. it is not absorbed by molecules but is being transmitted throughout the medium) and solvents to extract target compounds from various plant matrices. Ultrasound is transmitted through a medium via pressure waves by inducing vibrational motion of the molecules which alternately compress and stretch the molecular structure of the medium due to a time-varying pressure. While, microwaves, heat up the molecules of any object by a dual mechanism of ionic conduction and dipole rotation, both techniques end up by disrupting the cell walls and releasing the compounds of interest to the extracting solvent (Mandal et al., 2015).

The Conventional optimization technique of changing one variable at a time to study the effects of variables on the responses analysed is an exhausting and expensive task, especially for multivariable systems. Thus, in order to obtain significant models of different variables performing a minimum number of experiments, statistical design of experiments becomes necessary. Central composite design (CCD) along with response surface methodology (RSM) is an efficient and flexible tool, which provides sufficient data on the modelling of multivariable systems, minimizing experimental errors and reducing significantly the number of experiments needed (Leardi, 2013).

To our knowledge, there is scarce information about the recovery of betalains and phenolic compounds from Opuntia spp. peels using UAE and MAE techniques. Therefore, to achieve by-product utilization as natural sources of phytochemical compounds with application in specific industries, the main objective of this study was to optimize UAE and MAE extraction, using RSM methodology in order to identify which of the employed techniques could be potentially established in order to maximize molecules recovery from Opuntia by-products. 


\section{VII.1.2. MATERIAL AND MeTHODS}

\section{VII.1.2.1. Samples preparation}

Cactus pear fruits (Opuntia engelmannii) were manually collected in October 2017 in Valencia, Spain (GPS coordinates: 39²8'34.7'N $0^{\circ} 20^{\prime} 00.4^{\prime \prime} \mathrm{W}$ ). Within 24 hours, fruits were washed with distilled water to remove glochids and then further air-dried. Afterwards, all the fruits were peeled and the resulting peel was lyophilized (Telstar Lioalfa 6, Azbil corp., Tokyo, Japan), grounded and sieved using a fine mesh sieve and stored in a bag under vacuum in a cool and dry place until use.

\section{VII.1.2.2. Experimental design}

In this study, central composite design (CCD) was used for optimization of UAE and MAE of prickly pear peels. The design consisted of 31 randomized runs with seven replicates at the central point. Fixed variables in the designed experiment were defined as $\boldsymbol{X 1}$ : time $(0,5-2,5 \mathrm{~min}), \boldsymbol{X} 2$ : solid to liquid ratio $(5-45 \mathrm{~g} / \mathrm{L}), \boldsymbol{X 3}$ : solvent concentration (0-100\% Methanol/water) and $X 4$ : temperature (3-35 ${ }^{\circ} \mathrm{C}$ ), and each one was tested at five different levels. While for Microwave Assisted Extraction (MAE), the independent variables were the same as in UAE, changing the ranges in time (2,5-12,5 min) and temperature $\left(25-105^{\circ} \mathrm{C}\right)$.

The dependent variable investigated were Response 1: betacyanin content $(\mathrm{mg} / \mathrm{g})$, Response 2: phenolic acids $(\mathrm{mg} / \mathrm{g})$, Response 3: flavonoids (mg/g), Response 4: extraction yield (mg/g), Response 5: antioxidant activity $\mathrm{IC}_{50}(\mathrm{mg} / \mathrm{mL})$ and Response 6: colour (a* coordinate).

The experimental data were fitted to the second-order polynomial model to obtain the regression coefficients (b) using Statgraphics Centurion XVI software (StatPoint Technologies, Inc. Warrenton, VA, USA). The generalized second-order polynomial model used in the response surface analysis as follows: 


$$
Y=b_{0}+\sum_{i=1}^{k} b_{i} X_{i}+\sum_{i=1}^{k} b_{i i} X_{i}^{2}+\sum_{j=i+1}^{k} b_{i j} X_{i} X_{j}
$$

Equation 7-1 Second-order polynomial regression coefficients

Where $\mathrm{Y}$ is the dependent variable (response variable) to be modelled, $\boldsymbol{b}_{0}$ is a constant coefficient (intercept); $\boldsymbol{b}_{\mathrm{i}}, \boldsymbol{b}_{\mathrm{ii}}$ and $\boldsymbol{b}_{\mathrm{ij}}$ are the coefficients of the linear, quadratic, and interactive terms, respectively; $\mathrm{k}$ is the number of tested variables $(\mathrm{k}=4) ; \mathrm{X}_{\mathrm{i}}$ and $\mathrm{X}_{\mathrm{j}}$ are the independent variables.

Parametric estimation responses were collected in the form of Total Betacyanins Content (TBC), Total Phenolic Content (TPC), Total Flavonoid Content (TFC), Power Reduction antioxidant activity (PR), Yield and Colour parameters.

\section{VII.1.2.3. Extraction procedure}

\section{VII.1.2.3.1. Ultrasound-assisted extraction (UAE)}

Ultrasound-assisted extraction of bioactive compounds from Opuntia engelmannii was performed using an ultrasonic bath system (ATM403LCD, Labbox, Barcelona, Spain) connected to a cooled thermal regulation system, consisting of a cooling bath (Frigiterm-TFT-30, JP Selecta, Barcelona, Spain) joined to an immersion thermostat (Tectron bio, JP Selecta, Barcelona, Spain) and linked throughout water recirculation with a peristaltic pump (Pumpdrive 5006, Heidolph, Schwabach, Germany) in order to precisely control the temperature selected. The necessary amount of lyophilized peel with the designed volume of methanol concentration in the required ratio with a constant volume of $20 \mathrm{~mL}$ were placed in an Erlenmeyer flask inside of the ultrasonic bath that was equipped with digital control system for sonication time and frequency $(40 \pm 2 \mathrm{kHz})$, and was agitated with an overhead stirrer (RZR 2021, Heidolph, Schwabach, Germany) at the speed of $200 \mathrm{rpm}$.

Prior to extractions, every methanol concentration employed were taken to pH 7 (S20 SevenEasy pH, Mettler Toledo, Ohio, USA) using 
Mcllvaine buffer solutions. Following the extraction, samples were centrifuged (5804 R centrifuge, Eppendorf, Hamburg, Germany) at $11000 \mathrm{rpm}$ for 7 minutes at $10{ }^{\circ} \mathrm{C}$, filtered through Buchner funnel with fritted disc, pore No. $2(40-90 \mu \mathrm{m})$, dried at $40{ }^{\circ} \mathrm{C}$ using a vacuum rotary evaporator (Hei-VAP Value, Heidolph, Schwabach, Germany) and lyophilized (Telstar Lioalfa 6, Azbil corp., Tokyo, Japan) to obtain the powder extract. The extracts were stored in sealed vaccum bags in a dry place prior to consequent analysis.

\section{VII.1.2.3.2. Microwave-assisted extraction (MAE)}

Samples were prepared according to the experimental design, using the same lyophilized peel and solvents used in UAE assays. Extractions were performed in a microwave digestion system (Mars 6, CEM, North Carolina, USA) using the MARSxpress plus vessels. The microwave was equipped with a digital control system for irradiation (iWave), time and microwave power (the latter was set at $400 \mathrm{~W}$ ). After conditions selected were reached, samples were cooled down to room temperature and centrifuged, filtered, dried, lyophilized and stored as in the UAE extractions.

\section{VII.1.2.4. Colorimetric determination and extraction yield}

A Minolta spectrophotometer (CM-3600d, Konica Minolta Sensing, Inc., Tokyo, Japan) was used to measure re-suspended extracts (methanol 80\%, 7,5 $\mathrm{mg} / \mathrm{ml}$ ) colour. Using the reflectance mode and the LAV lens with diffuse illumination $65 / 10^{\circ}$ viewing angle and specular component excluded. The CIE $L^{*}$ values, Cartesian coordinates $a^{*}$ and $b^{*}$ and cylindrical coordinates $C^{*}$ and $h^{\circ}$ were reported throughout Spectra Magic software (version 3.6, CyberChrome Inc., Tokyo, Japan). In this context each coordinate represents, $L^{*}$ : lightness, $a^{*}$ : chromaticity on a green $(-)$ to red $(+)$ axis, $b^{*}$ : chromaticity on a blue $(-)$ to yellow $(+)$ axis, $C^{*}$ : Chroma or relative saturation and $h^{\circ}$ : the hue angle in the CIELab colour wheel. In the other hand, "Yield" parameter was obtained from separating a portion $(5 \mathrm{~mL})$ of the filtered extraction liquid obtained from UAE and MAE and placed inside of an oven where both parts of the mixture (methanol/water) solvent were evaporated. Afterwards, the dried sample was cooled down and the residue was calculated by difference. 


\title{
VII.1.2.5. Antioxidant activity evaluation
}

\begin{abstract}
A stock solution $(30 \mathrm{mg} / \mathrm{mL})$ was made from each extract with methanol $80 \%$ and successive dilutions were performed (0,9-15 $\mathrm{mg} / \mathrm{mL}$ ) and submitted to the reducing power (RP) assays to evaluate the antioxidant activity of the samples. The reducing power RP assay evaluated the capacity of the extracts to reduce $\mathrm{Fe} 3+$ to $\mathrm{Fe} 2+$, measuring the absorbance at $690 \mathrm{~nm}$. Briefly, different concentration of extracts $0,5 \mathrm{~mL}$ was combined with $0,5 \mathrm{~mL}$ of sodium phosphate tampon $(\mathrm{pH} 6,6)$ and $0,5 \mathrm{~mL}$ of potassium ferrocyanide $(1 \% \mathrm{p} / \mathrm{v})$. The mixture was incubated at $50{ }^{\circ} \mathrm{C}$ for $20 \mathrm{~min}$, the reaction was stopped with $0,5 \mathrm{~mL}$ of trichloroacetic acid $(10 \% \mathrm{v} / \mathrm{v})$. From the latter mixture, $0,8 \mathrm{~mL}$ was taken and diluted with $0,8 \mathrm{~mL}$ of distilled water and then, $160 \mu \mathrm{L}$ of iron chloride $(0,1 \% \mathrm{p} / \mathrm{v})$ was added and the absorbance was measured in the spectrophotometer. The results were expressed as $\mathrm{IC}_{50}$ values (sample concentration providing 50\% of antioxidant activity) for antioxidant activity, Trolox was used as positive control.
\end{abstract}

\section{VII.1.2.6. LC-DAD/MS-MS characterization of extracts}

\section{VII.1.2.6.1. Phenolic profiling}

The profile of these compounds was determined by LC-DAD-ESI/MS (Dionex Ultimate 3000 UPLC, Thermo Scientific, San Jose, CA, USA). The lyophilized extracts were analysed for their phenolic content compounds, re-dissolving in methanol:water $(20: 80, v / v)$ to a final concentration of $30 \mathrm{mg} / \mathrm{mL}$ and filtered through a $0,22-\mu \mathrm{m}$ disposable LC filter disk. Chromatographic separation was achieved with a Waters Spherisorb S3 ODS-2 C18 ( $3 \mu \mathrm{m}, 4,6 \mathrm{~mm} \times 150 \mathrm{~mm}$, Waters, Milford, MA, USA) column working at $35^{\circ} \mathrm{C}$. The solvents used were: (A) $0,1 \%$ trifluoroacetic acid (TFA) in water, and (B) acetonitrile. The gradient elution followed these parameters: isocratic $15 \%$ for $5 \mathrm{~min}$, from $15 \%$ to $20 \%$ B for $5 \mathrm{~min}$, from $20 \%$ to $25 \%$ B for $10 \mathrm{~min}$, from 25 to $35 \%$ B for $10 \mathrm{~min}$, from 35 to $50 \% \mathrm{~B}$ for $10 \mathrm{~min}$, and from 50 to $15 \% \mathrm{~B}$ for $20 \mathrm{~min}$. The resulting total run time was $60 \mathrm{~min}$, using a flow rate of $0,5 \mathrm{~mL} / \mathrm{min}$. Detection was carried out in the DAD using several wavelengths (280, 330 and $370 \mathrm{~nm})$, and in a mass spectrometer (MS). MS detection was performed using negative mode, with a Linear Ion Trap LTQ XL mass spectrometer (ThermoFinnigan, San Jose, CA, USA) equipped with an ESI source. Nitrogen served as the sheath gas (50 psi); the system was operated with a spray voltage of $5 \mathrm{kV}$, a source temperature of $325^{\circ} \mathrm{C}$, and a capillary voltage of $-20 \mathrm{~V}$. The tube lens 
offset was kept at a voltage of $-66 \mathrm{~V}$. The full scan covered the mass range from $\mathrm{m} / \mathrm{z} 100$ to 1500 . The collision energy used was 35 (arbitrary units). Data acquisition was carried out with the Xcalibur® data system (ThermoFinnigan, San Jose, CA, USA).

The phenolic compounds were identified by comparing their retention times, UV-vis and mass spectra with those obtained from standard compounds, when available. Otherwise, compounds were tentatively identified comparing the obtained information with available data reported in the literature. For quantitative analysis, a calibration curve for each available phenolic standard was constructed based on the UV signal. For the identified phenolic compounds for which a commercial standard was not available, the quantification was performed through the calibration curve of the most similar available standard.

\section{VII.1.2.6.2. Betalainic profiling}

The lyophilized extracts were re-dissolved in methanol:water $(20: 80, v / v)$ at a concentration of $30 \mathrm{mg} / \mathrm{mL}$ and filtered through a $0,22-$ $\mu \mathrm{m}$ disposable LC filter disk. LC-DAD-ESI/MS analyses were performed using a Dionex Ultimate 3000 UPLC instrument (Thermo Scientific, San Jose, CA, USA), coupled to a diode-array detector (using different wavelengths, 480 and $530 \mathrm{~nm}$ ) and to a mass detector Linear Ion Trap LTQ XL mass spectrometer, equipped with an ESI source, ThermoFinnigan, San Jose, CA, USA). The elution gradient, chromatographic and mass spectrometer conditions were performed according to (Melgar et al., 2017a). Identification was performed by comparing their fragmentation pattern, retention times and UV-vis spectra with data reported in the literature. For quantitative analysis, a calibration curve was built with an isolated compound gomphrenin III (isolated from Gomphrena globosa L.) ( $\mathrm{y}=14670$ $\mathrm{x}-19725, \mathrm{R}^{2}=0$,9997) (Roriz et al., 2017).

\section{VII.1.2.7. Statistical analysis}

The analysis of variance (ANOVA) was carried out to determine individual linear, quadratic and interaction regression coefficient using Statgraphics Centurion XVI software (StatPoint Technologies, Inc. Warrenton, VA, USA), The significance of all the terms of the 
Resultados

polynomial equation was analysed statistically by computing the $\mathrm{F}$ value at $\mathrm{p}<0,05$. Statgraphics software was used to optimize the conditions of extraction throughout response surface methodology (RSM) with their respective 3D graphs. 


\section{VII.1.3. RESULTS AND DISCUSSION}

\section{VII.1.3.1. Tentative identification of bioactive compounds.}

Table 7-1. present the peak characteristics (Abbreviation used, retention time, the wavelength of maximum absorption, molecular ion, and main fragment ions observed in MS/MS) and tentative identification of the bioactive compounds present in the hydromethanolic extracts of Opuntia engelmannii (cv) Valencia peels (Figure 7-1)

Betalain molecules betacyanins display a wide range of hues between reddish-violet colour (Esquivel, 2016; Melgar et al., 2017a; Szot et al., 2015). In the betalain fractions (Table 7-1), seven betacyanins were identified ( $\mathrm{Bc} 1$ to $\mathrm{Bc} 7)$. Out of the seven betacyanins identified, six common Opuntia spp isomers were found, betanin, isobetanin, 17-decarboxy-betanin, betanidin and isobetanidin (peaks $\mathrm{Bc} 1, \mathrm{Bc} 2, \mathrm{Bc} 5, \mathrm{Bc} 6$, and $\mathrm{Bc} 7$, respectively), having been previously identified by other authors (Betancourt et al., 2017; Mata et al., 2016; Mena et al., 2018). While gomphrenin I (Bc3) have been also previously described in our past works (Melgar et al., 2017b).

Although (Iso)phyllocactin (peak Bc4), have been already described in Cactaceae (Fathordoobady et al., 2016; García-Cruz et al., 2017; Herbach et al., 2005) and in red beets (Spórna-Kucab et al., 2013; Wybraniec et al., 2016), as far as we know, this is the first attempt at tentatively identifying it by HPLC-DAD-ESI-MS in Opuntia engelmannii.

Regarding polyphenolic fraction, twelve different compounds (Table 7-1) were found, four phenolic acids ( $\mathrm{Ph} 1$ to $\mathrm{Ph} 4$ ), and eight flavonoids (Fv1 to Fv8). The main family of flavonoid compounds found in Opuntia engelmanni cv Valencia peels were seven isorhamnetin and only one apigenin derivatives. Peaks Fv1,2,4-8, were positively identified by comparison with commercial standards taking into account also their retention time, mass and UV-vis characteristics. Peaks presented pseudomolecular ions at $\boldsymbol{m} / z$,931, and $\mathrm{MS}^{2}$ fragments at $\boldsymbol{m} / z 769(-162 \mathrm{mu})$, and $315(-454 \mathrm{mu})$ and also pseudomolecular ions at $\boldsymbol{m} / z \mathbf{z} 785,769,623$, and $\mathrm{MS}^{2}$ fragments at $\boldsymbol{m} / z 315(-470,-454$, 308 ), coherent with the loss of hexose or rutinose derivatives, being for 
Table 7-1 Abbreviation, Retention times (Rt), waveleghts of maximum absorption $\left(\lambda_{\max }\right)$, mass spectral data and tentative identification bioactive compounds in the Opuntia engelmannii cv Valencia peels.

\begin{tabular}{|c|c|c|c|c|c|}
\hline Peak & Rt (min) & $\begin{array}{c}\lambda \max \\
(\mathbf{n m})\end{array}$ & $\begin{array}{c}{[\mathrm{M}-\mathrm{H}]^{-}} \\
(\mathrm{m} / \mathrm{z})\end{array}$ & $\operatorname{MS2}(m / z)$ & Tentative identification \\
\hline \multicolumn{6}{|c|}{ Phenolic acids } \\
\hline $\mathrm{Ph} 1$ & 4,19 & 278 & 255 & $193(32), 179(7), 165(100), 149(5)$ & Piscidic acid \\
\hline $\mathrm{Ph} 2$ & 6,47 & 321 & 367 & $\begin{array}{c}193(100), 191(12), 173(13), 149(2 \\
3)\end{array}$ & 3-O-Feruloylquinic acid \\
\hline $\mathrm{Ph} 3$ & 7,68 & 285 & 179 & $161(100), 143(79), 119(32)$ & cis-Caffeic acid \\
\hline $\mathrm{Ph} 4$ & 8,84 & 283 & 355 & $193(100)$ & Ferulic acid hexoside \\
\hline \multicolumn{6}{|c|}{ Flavonoids } \\
\hline Fv1 & 10,48 & 331 & 931 & $769(31), 315(100)$ & $\begin{array}{l}\text { Isorhamnetin- } O \text {-hexoside- } O \text {-(dihexosyl- } \\
\text { hexoside) }\end{array}$ \\
\hline Fv2 & 12,33 & 338 & 785 & $315(100)$ & $\begin{array}{l}\text { Isorhamnetin- } O \text {-hexoside- } \\
\text { (deoxyhexosyl-hexosyde) }\end{array}$ \\
\hline Fv3 & 16,17 & 345 & 431 & $269(100)$ & Apigenin- $O$-hexoside \\
\hline Fv4 & 16,61 & 346 & 931 & $315(100)$ & Isorhamentin-dirutinoside \\
\hline Fv5 & 16,85 & 332 & 931 & $315(100)$ & Isorhamentin-dirutinoside \\
\hline Fv6 & 17,31 & 331 & 769 & $315(100)$ & $\begin{array}{c}\text { Isorhamnetin- } O \text {-(di-deoxyhexosyl- } \\
\text { hexoside) }\end{array}$ \\
\hline
\end{tabular}




$\begin{array}{lllll}\text { Fv7 } & 18,22 & 325 & 785 & 315(100) \\ \text { Fv8 } & 19,04 & 337 & 623 & 315(100)\end{array}$

Isorhamnetin- $O$-hexoside(deoxyhexosyl-hexosyde) Isorhamentin- $O$-(deoxyhexosylhexoside)

\begin{tabular}{cccccc}
\hline & & \multicolumn{5}{c}{ Betalains } \\
\hline $\mathrm{Bc} 1$ & 22,2 & 534 & 551 & $389(100), 345(50), 150(28)$ & Betanin \\
$\mathrm{Bc} 2$ & 23,67 & 534 & 511 & $389(100), 345(73), 150(46)$ & Isobetanin \\
$\mathrm{Bc} 3$ & 23,8 & 535 & 551 & $507(3), 389(38), 345(100)$, & Gomphrenin I \\
& & & & $301(21)$ & (Iso)phyllocactin \\
$\mathrm{Bc} 4$ & 25,2 & 409 & 637 & $551(20), 389(54), 345(100), 1$ & $50(62)$ \\
$\mathrm{Bc} 5$ & 25,43 & 505 & 507 & $345(100), 301(63)$ & 17-Decarboxy-betanin \\
$\mathrm{Bc} 6$ & 26,1 & 523 & 389 & $343(97), 150(91)$ & Betanidin \\
$\mathrm{Bc} 7$ & 28,04 & 534 & 389 & $389(100), 345(73), 150(46)$ & Isobetanidin \\
\hline
\end{tabular}




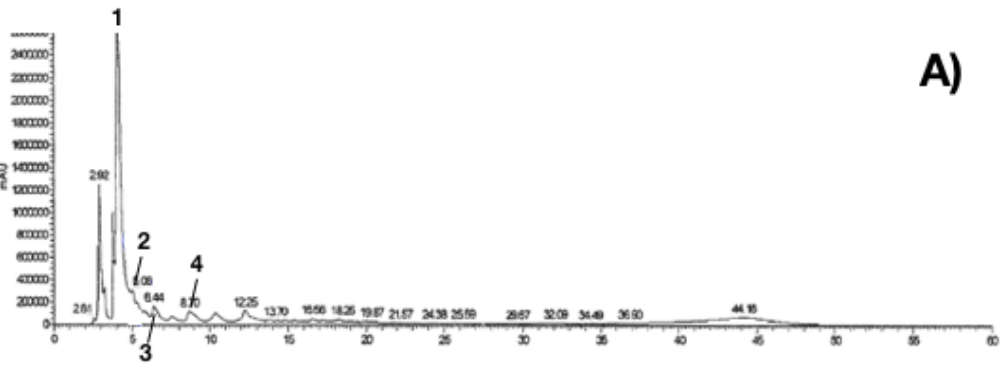

B)

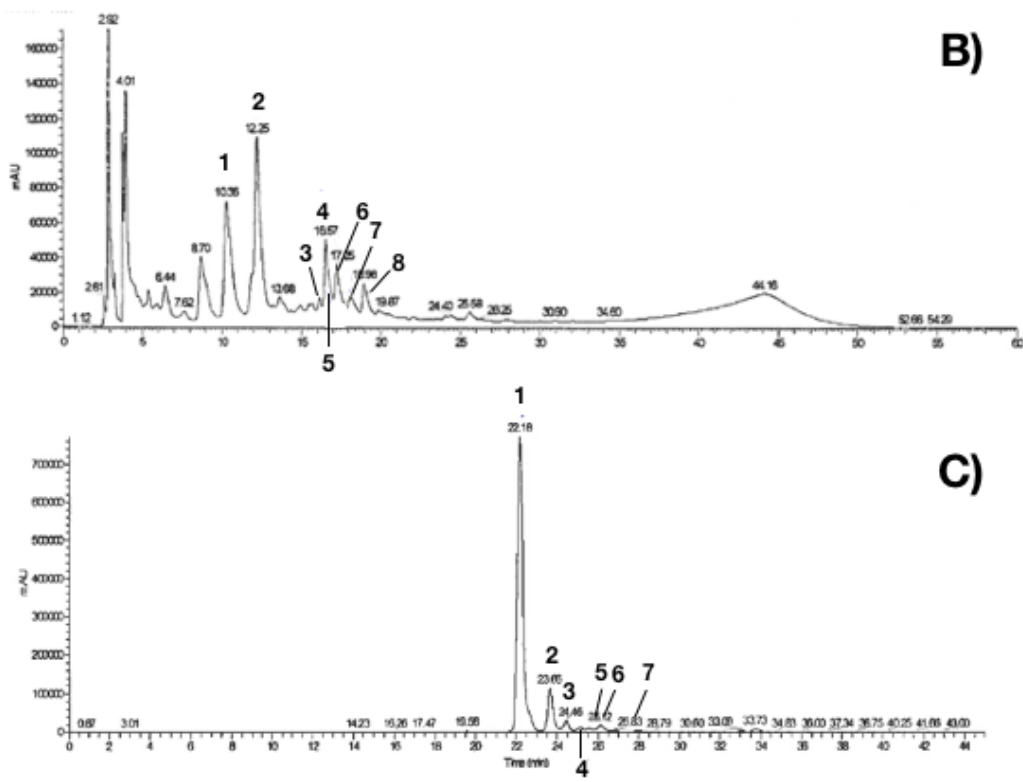

Figure 7-1 HPLC chromatogram of Opuntia engelmannii cv. Valencia, (A) phenolic profile recorded at $370 \mathrm{~nm}$, (B) flavonoid profile recorded at $280 \mathrm{~nm}$ and (C) betacyanins profile recorded at 535 (source: private collection)

that manner tentatively identified as isorhamnetin.

Taking into account the number of compounds identified in prickly pear peels, flavonoids were the most relevant class of phytochemicals, Although, the more abundant out of this 12 compounds was piscidic acid (Figure 7-1). This phenolic acid was previously identified in Opuntia ficus-indica in one of our past works (Melgar et al., 2017a). 
On the other hand, the main family of phenolic compounds found in Opuntia engelmanni peels were ferulic acid derivatives.

All of the compounds have been previously described by other authors in Opuntia spp samples (Chougui et al., 2015; Mena et al., 2018; Yeddes et al., 2013), except for peak Fv3 apigenin- $O$-hexoside, which, to our knowledge, this is the first time this compound has been identified for Opuntia spp. peels. although, apigenin has been founded in Opuntia ficus-indica flowers and cladodes before (Allai et al., 2016; Ammar et al., 2018), this flavone is more abundant in fruits or vegetables, such as, parsley, onion, celery, orange, chamomile, among others (Madunić et al., 2018; Patel et al., 2007).

\section{VII.1.3..2. Model fitting and technologies used.}

To improve the extraction amounts of the different responses, optimization of the process is required. Thus, in order to find out the relationship between the influence factors and the characteristics of the extraction by ultrasound assistance (UAE), we monitored four independent variables (Table 7-2),

For the process of optimization, 31 samples (runs) were prepared for UAE-RSM and 31 runs for MAE-RSM, based on the Central Composite Design (CCD), which the independent and dependent variables are summarized in Table 7-2.

Particular interest was to maximize responses, in order to obtain overall better amounts of "yield" (Res4), natural colourants "betacyanins" (Res1) and bioactive compounds "phenolic acids" and "flavonoids" (Res2 and Res3), which are of particular interest for food, cosmetic and pharmaceutical industries. In the specific case of "antioxidant activity" (Res5) the calculation was performed through power reduction analysis and reported as $\mathrm{IC}_{50}$, consequently, the main interest was to minimize this value. Briefly, as less amount of extract was needed to reduce $50 \%$ of the radical tested, better was the performance and higher interest on those extracts. The other parameter analysed was the a* coordinate of the "colour" extracts (Res 6), this result indicates the qualitative value for the green-red $\left(-a^{*}\right.$ to $+a^{*}$ respectively) colouration of the diluted extract. 
Table 7-2 Central Composite design and experimental data for 4-level-4-factor response surface analysis, X1: Time (min), X2: Ratio (g/L), X3: Concentration (\% methanol), X4: Temperature $\left({ }^{\circ} \mathrm{C}\right)$, and Res1: Betacyanins (mg/g), Res2: Phenolics (mg/g), Res3: Flavonoids (mg/g), Res4: Yield (mg/g), Res5: Antiox activity (mg/mL), Res6: Colour (a* coordinates)

\begin{tabular}{|c|c|c|c|c|c|c|c|c|c|c|c|c|c|c|c|c|c|c|}
\hline $\mathrm{R}$ & & 1 & $\times 2$ & $\mathrm{X} 3$ & $\times 4$ & & & es1 & & es2 & Res & & Res & & Res! & & Res & \\
\hline $\mathrm{u}$ & & & UAE/ & UAE/ & & & & & & & & & & & & & & \\
\hline$n$ & UAE & MAE & MAE & MAE & UAE & MAE & UAE & MAE & UAE & MAE & UAE & MAE & UAE & MAE & UAE & $\mathrm{MAE}$ & UAE & MAE \\
\hline 1 & 1 & 5 & 15 & 25 & 12.5 & 45.0 & 182 & 112 & 8,9 & 6,4 & 1,13 & 0,94 & 62 & 66 & 3,1 & 4,0 & 83,2 & 75,0 \\
\hline 2 & 2 & 10 & 15 & 25 & 12.5 & 45.0 & 149 & 140 & 7,3 & 7,0 & 0,95 & 1,16 & 64 & 67 & 3,4 & 3,8 & 83,6 & 74,4 \\
\hline 3 & 1 & 5 & 35 & 25 & 12.5 & 45.0 & 134 & 112 & 6,4 & 5,7 & 0,77 & 0,80 & 60 & 62 & 3,4 & 4,2 & 83,3 & 74,3 \\
\hline 4 & 2 & 10 & 35 & 25 & 12.5 & 45.0 & 153 & 129 & 7,3 & 6,6 & 0,88 & 0,76 & 61 & 51 & 3,4 & 3,4 & 83,4 & 77,8 \\
\hline 5 & 1 & 5 & 15 & 75 & 12.5 & 45.0 & 109 & 108 & 6,7 & 5,8 & 0,73 & 0,72 & 66 & 73 & 3,6 & 4,5 & 83,1 & 72,3 \\
\hline 6 & 2 & 10 & 15 & 75 & 12.5 & 45.0 & 113 & 113 & 6,4 & 6,2 & 0,96 & 1,09 & 66 & 71 & 3,6 & 3,7 & 85,8 & 72,6 \\
\hline 7 & 1 & 5 & 35 & 75 & 12.5 & 45.0 & 124 & 141 & 7,0 & 7,5 & 0,96 & 1,13 & 66 & 40 & 3,1 & 3,3 & 86,6 & 78,0 \\
\hline 8 & 2 & 10 & 35 & 75 & 12.5 & 45.0 & 128 & 120 & 7,0 & 6,4 & 0,88 & 0,89 & 64 & 65 & 3,7 & 3,5 & 86,3 & 77,3 \\
\hline 9 & 1 & 5 & 15 & 25 & 27.5 & 85.0 & 170 & 83 & 8,6 & 5,6 & 1,14 & 0,90 & 63 & 67 & 3,1 & 3,6 & 83,1 & 73,8 \\
\hline 10 & 2 & 10 & 15 & 25 & 27.5 & 85.0 & 190 & 81 & 13 & 5,6 & 2,06 & 0,88 & 63 & 89 & 3,0 & 4,1 & 83,0 & 73,5 \\
\hline 11 & 1 & 5 & 35 & 25 & 27.5 & 85.0 & 133 & 116 & 6,6 & 6,2 & 0,79 & 1,02 & 44 & 65 & 3,4 & 3,6 & 83,8 & 75,2 \\
\hline 12 & 2 & 10 & 35 & 25 & 27.5 & 85.0 & 139 & 108 & 6,8 & 6,7 & 0,89 & 0,86 & 57 & 55 & 3,4 & 3,7 & 83,3 & 76,3 \\
\hline 13 & 1 & 5 & 15 & 75 & 27.5 & 85.0 & 143 & 54 & 7,7 & 7,2 & 1,13 & 1,03 & 65 & 70 & 3,4 & 2,6 & 85,7 & 59,3 \\
\hline 14 & 2 & 10 & 15 & 75 & 27.5 & 85.0 & 125 & 25 & 7,0 & 4,0 & 0,96 & 0,47 & 66 & 66 & 3,9 & 3,9 & 85,4 & 74,9 \\
\hline
\end{tabular}




\begin{tabular}{ccccccccccccccccccc}
15 & 1 & 5 & 35 & 75 & 27.5 & 85.0 & 116 & 66 & 6,5 & 6,3 & 0,83 & 0,93 & 64 & 67 & 3,6 & 3,4 & 85,3 & 76,4 \\
16 & 2.5 & 10 & 35 & 75 & 27.5 & 85.0 & 119 & 60 & 6,8 & 6,7 & 0,95 & 0,91 & 63 & 65 & 3,7 & 3,9 & 86,4 & 79,0 \\
17 & 0.5 & 2.5 & 25 & 50 & 20 & 65.0 & 159 & 107 & 8,4 & 6,2 & 0,96 & 0,87 & 64 & 56 & 3,4 & 3,6 & 85,2 & 74,0 \\
18 & 2.5 & 12.5 & 25 & 50 & 20 & 65.0 & 174 & 77 & 8,4 & 6,2 & 1,21 & 0,94 & 65 & 68 & 3,1 & 3,7 & 84,7 & 75,5 \\
19 & 1.5 & 7.5 & 5 & 50 & 20 & 65.0 & 198 & 97 & 9,6 & 6,0 & 1,28 & 0,99 & 68 & 72 & 3,5 & 4,1 & 84,8 & 72,9 \\
20 & 1.5 & 7.5 & 45 & 50 & 20 & 65.0 & 160 & 80 & 7,8 & 6,6 & 1,02 & 0,99 & 63 & 53 & 3,0 & 3,6 & 84,8 & 75,3 \\
21 & 1.5 & 7.5 & 25 & 0 & 20 & 65.0 & 175 & 155 & 8,2 & 6,4 & 1,03 & 0,86 & 62 & 59 & 3,1 & 3,3 & 83,2 & 76,1 \\
22 & 1.5 & 7.5 & 25 & 100 & 20 & 65.0 & 72 & 53 & 6,5 & 6,1 & 0,64 & 0,76 & 62 & 65 & 4,0 & 3,8 & 76,3 & 74,0 \\
23 & 1.5 & 7.5 & 25 & 50 & 5 & 25.0 & 134 & 135 & 6,7 & 6,8 & 0,81 & 0,78 & 65 & 69 & 3,0 & 3,1 & 84,9 & 77,7 \\
24 & 1.5 & 7.5 & 25 & 50 & 35 & 105 & 179 & 49 & 8,3 & 6,6 & 1,15 & 0,93 & 65 & 56 & 3,2 & 5,7 & 84,7 & 73,1 \\
25 & 1.5 & 7.5 & 25 & 50 & 20 & 65.0 & 143 & 185 & 7,4 & 6,7 & 0,99 & 1,04 & 63 & 59 & 3,5 & 3,5 & 84,5 & 76,7 \\
26 & 1.5 & 7.5 & 25 & 50 & 20 & 65.0 & 184 & 115 & 9,2 & 6,0 & 1,21 & 0,87 & 64 & 69 & 3,4 & 3,7 & 84,5 & 73,5 \\
27 & 1.5 & 7.5 & 25 & 50 & 20 & 65.0 & 135 & 112 & 6,6 & 5,9 & 0,96 & 0,93 & 64 & 68 & 3,5 & 3,6 & 86,5 & 73,5 \\
28 & 1.5 & 7.5 & 25 & 50 & 20 & 65.0 & 187 & 127 & 9,0 & 6,2 & 1,20 & 0,86 & 64 & 68 & 3,4 & 3,5 & 85 & 74,1 \\
29 & 1.5 & 7.5 & 25 & 50 & 20 & 65.0 & 161 & 126 & 7,7 & 6,2 & 0,98 & 0,90 & 64 & 67 & 3,3 & 3,5 & 85,2 & 74,0 \\
30 & 1.5 & 7.5 & 25 & 50 & 20 & 65.0 & 169 & 115 & 8,6 & 6,8 & 0,95 & 1,09 & 64 & 65 & 2,9 & 3,3 & 84,8 & 73,3 \\
31 & 1.5 & 7.5 & 25 & 50 & 20 & 65.0 & 165 & 112 & 8,0 & 7,0 & 1,03 & 1,08 & 65 & 64 & 3,4 & 3,3 & 84,6 & 74,1 \\
\hline
\end{tabular}




\section{VII.1.3.3. Effects of independent variables on betacyanins.}

\section{VII.1.3.3.1 Ultrasound-assisted extraction.}

The experimental conditions and the values of response from the UAECCD are listed in Table 7-2, which shows the highest betacyanin content $(197,51 \mathrm{mg} / \mathrm{g})$ with the treatment time $(t) 1,5 \mathrm{~min}$, ratio $(S / L) 5$ $\mathrm{g} / \mathrm{L}$, methanol concentration (metOH) $50 \%$ and ultrasound temperature (T) $20{ }^{\circ} \mathrm{C}$ (run No. 19), as well as shows the lowest betacyanin content $(72,01 \mathrm{mg} / \mathrm{g}$ ) with the treatment $(\boldsymbol{t}) 1,5 \mathrm{~min},(\boldsymbol{S} / \mathbf{L}) 25 \mathrm{~g} / \mathrm{L},(\boldsymbol{m e t} \boldsymbol{O H}) 100$ $\%$ and $(\boldsymbol{T}) 20{ }^{\circ} \mathrm{C}$ (run No. 22). The response variables were analysed to fit a regression model. The full quadratic second-order model obtained by multiple regression analysis of the experimental data via using RSM was expressed in Eq. (1) according to values in Table 7-3.

The equation model was used for the prediction of betacyanins content.

$$
\text { (1) Res } 1=\begin{aligned}
& 138,6+8,2 \mathrm{x}_{1}-2,3 \mathrm{x}_{2}+0,5 \mathrm{x}_{3}+5,5 \mathrm{x}_{4}-8,4 \mathrm{x}_{1}^{2} \\
& +0,009 \mathrm{x}_{2}^{2}-0,02 \mathrm{x}_{3}^{2}-0,08 \mathrm{x}_{4}^{2}+0,7 \mathrm{x}_{1} \mathrm{x}_{2} \\
& -0,08 \mathrm{x}_{1} \mathrm{x}_{3}+0,2 \mathrm{x}_{1} \mathrm{x}_{4}+0,03 \mathrm{x}_{2} \mathrm{x}_{3}-0,09 \mathrm{x}_{2} \mathrm{x}_{4} \\
& +0,005 \mathrm{x}_{3} \mathrm{x}_{4}
\end{aligned}
$$

Equation 7-2 Example of statistically and non-statistical values of second-order polynomial coefficients for betalainic content (Res1) in the UAE extractions.

Where Res1 is betacyanin content, $\boldsymbol{x}_{1}$ is time, $\boldsymbol{x}_{2}$ is the ratio, $\boldsymbol{x}_{3}$ is methanol concentration and $\boldsymbol{x}_{4}$ is ultrasound temperature. In order to simplify data in Table 7-3, only ecuation terms are listed and significative $p$-values are only cited on text. Then, the second-order model was significant in the linear coefficients $\boldsymbol{x}_{2}$ and $\boldsymbol{x}_{3}$, and also in the quadratic coefficient $x_{3}^{2}$, respectively, including ratio $\left(x_{2}\right)$ as $\boldsymbol{p}=0,035$, concentration $\left(\boldsymbol{x}_{3}\right)$ as $\boldsymbol{p}=0,0001$ and quadratic concentration value $\left(\boldsymbol{x}_{\mathbf{3}}^{\mathbf{2}}\right)$ as $\boldsymbol{p}=0,0019$, which were quite significant with a very small $\boldsymbol{p}$-value $(<0,05)$ determined by the analysis of variance (ANOVA), while the time $\left(\boldsymbol{x}_{1}\right)$ and temperature $\left(\boldsymbol{x}_{4}\right)$ had no significant effect on betacyanin content $(\boldsymbol{p}=0,7250$ and 0,1602 , respectively); indicating that solid to liquid ratio and solvent concentration were the more important experimental factors for 
ultrasound-assisted extraction. Furthermore, Durbin-Watson coefficient 2,19 with $\boldsymbol{p}=0,6713$ was greater than $\boldsymbol{p}=0,05$ indicating that the residual distribution does not follow any type of autocorrelation from the regression analysis.

From the ANOVA analysis, in the factorial optimization response section, we are able to stand out the importance of the two factors ratio and concentration. The low sample to liquid solvent ratio was explained by (Vinatoru, 2001), which mention, increasing solvent volume with respect to sample provides more surface area for the acoustic wave to form cavitation bubbles and thus increases mass transfer between the solvent and sample. On the other hand, low methanolic concentration could be explained due to betalains polarity, these water-soluble pigments are normally sequestered in the vacuole of the cell (Esquivel, 2016; Strack et al., 2003), so after the breaking up the cell walls through ultrasonic waves, these molecules are more likely to dissolve in more polar solvents like water.

\section{VII.1.3.3.2. Microwave-assisted extraction}

Optimal extraction conditions for maximum total betacyanins were recognized by constructing 3D response surface curves with underlying contour plots (Annex 7-1) and determined by interpolation of experimental values. MAE process variables significantly affected $(\boldsymbol{p}<0.05) \boldsymbol{b} 3$ and $\boldsymbol{b} 4$ as a function of methanol concentration and extraction temperature showed marked decrease, with the increase of methanol concentration and temperature as shown in Figure 7-2. On one hand, the effect of methanol on betalains extraction has been expressed before in section VII.4.3, while on the other hand, according to (Sawicki and Wiczkowski, 2018), betalains are susceptible to a wide range of activities, and thermal treatment could lead to wide ranges of losses, from 6-81\% depending on the process applied or temperature used (Guldiken et al., 2016; Paciulli et al., 2016; Ravichandran et al., 2013), and although (Ferreres et al., 2017; Ravichandran et al., 2013) reports higher betalainic content using MAE, extension of this technique and temperature may also contribute to their degradation. 
Table 7-3 Statistical analysis (ANOVA) of the central composite design including response terms for building the predictive models and optimal response values for the parametric response criteria. Numbers in linear, quadratic and interaction marked with (*) means statistically significant. Terms included: MSE: Minimum Square Error; RMSE Root Minimum Square Error; MAPE: Mean Absolute Percentage Error, DW: Durbin-Watson statistic. Responses are summarized as Res1: Betacyanins (mg/g), Res2: Phenolics (mg/g), Res3: Flavonoids (mg/g), Res4: Yield (mg/g), Res5: Antiox activity (mg/mL), Res6: Colour (a* coordinates). Fixed variables are summarized as $x_{1}=$ time $(\min ) ; x_{2}=$ ratio $(g / L) ; x_{3}=$ methanol concentration $(\%) ; x_{4}=$ temperature $\left({ }^{\circ} C\right)$.

\begin{tabular}{|c|c|c|c|c|c|c|c|c|c|c|c|c|c|}
\hline & & \multicolumn{6}{|c|}{ UAE extraction } & \multicolumn{6}{|c|}{ MAE extraction } \\
\hline & & Res1 & Res2 & Res3 & Res4 & Res5 & Res6 & Res1 & Res2 & Res3 & Res4 & Res5 & Res6 \\
\hline Intercept & b0 & 138,65 & 6,26 & 0,43 & 67,40 & 3,15 & 45,16 & $-37,68$ & 5,74 & 0,03 & 61,48 & 9,38 & 65,60 \\
\hline \multirow[t]{4}{*}{ Linear } & b1 & 8,21 & $-0,23$ & 0,12 & 2,21 & $-0,04$ & 0,02 & 23,64 & 0,50 & 0,16 & 2,66 & $-0,42$ & $*-2,814$ \\
\hline & b2 & $*-2,278$ & $*-0,085$ & $*_{-0,009}$ & $*-0,304$ & 0,00 & $-0,04$ & 1,98 & $-0,11$ & $-0,02$ & $*_{-} 0,720$ & $-0,05$ & 0,21 \\
\hline & b3 & $* 0,501$ & $* 0,017$ & $* 0,006$ & $* 0,067$ & $*-0,008$ & $*-0,069$ & $* 1,514$ & 0,03 & 0,01 & $-0,01$ & $-0,01$ & $*-0,542$ \\
\hline & b4 & 5,60 & 0,32 & $* 0,049$ & $-0,19$ & 0,01 & 0,06 & $* 1,739$ & $-0,02$ & 0,01 & 0,19 & $-0,11$ & $*_{-0,515}$ \\
\hline \multirow[t]{4}{*}{ Quadratic } & b11 & $-8,47$ & 0,01 & 0,03 & $-0,76$ & 0,00 & $-0,27$ & $-0,88$ & $-0,01$ & 0,00 & $-0,07$ & 0,00 & 0,08 \\
\hline & b22 & 0,01 & 0,00 & 0,00 & 0,00 & 0,00 & 0,00 & $*-0,064$ & 0,00 & 0,00 & 0,00 & 0,00 & 0,00 \\
\hline & b33 & $*_{-0,021}$ & 0,00 & 0,00 & 0,00 & 0,00 & $* 0,001$ & 0,00 & 0,00 & 0,00 & 0,00 & 0,00 & $* 0,003$ \\
\hline & b44 & $-0,08$ & 0,00 & 0,00 & 0,00 & 0,00 & 0,00 & $-0,01$ & 0,00 & 0,00 & 0,00 & $* 0,001$ & $* 0,003$ \\
\hline \multirow[t]{5}{*}{ Interaction } & b12 & 0,76 & 0,00 & $-0,01$ & 0,09 & 0,00 & 0,02 & $-0,06$ & 0,01 & 0,00 & $-0,03$ & 0,00 & $-0,01$ \\
\hline & b13 & $-0,09$ & $-0,02$ & 0,00 & $-0,08$ & 0,00 & 0,00 & $-0,08$ & $*-0,005$ & 0,00 & 0,02 & 0,00 & 0,02 \\
\hline & b14 & 0,27 & 0,08 & 0,01 & 0,16 & $-0,01$ & 0,00 & $-0,09$ & 0,00 & 0,00 & $-0,01$ & 0,01 & 0,02 \\
\hline & b23 & 0,03 & $* 0,003$ & $* 0,000$ & 0,01 & 0,00 & 0,00 & 0,01 & 0,00 & 0,00 & 0,00 & 0,00 & 0,00 \\
\hline & b34 & 0,01 & 0,00 & 0,00 & 0,01 & 0,00 & 0,00 & $*-0,021$ & 0,00 & 0,00 & 0,00 & 0,00 & $* 0,003$ \\
\hline
\end{tabular}

Statistical information of the fitting analysis

\begin{tabular}{|c|c|c|c|c|c|c|c|c|c|c|c|c|}
\hline Observations & 31 & 31 & 31 & 31 & 31 & 31 & 31 & 31 & 31 & 31 & 31 & 31 \\
\hline MSE & 18,65 & 0,99 & 0,16 & 2,99 & 0,23 & 0,85 & 13,99 & 0,58 & 0,13 & 8,54 & 0,52 & 2,65 \\
\hline RMSE & 4,32 & 0,99 & 0,40 & 1,73 & 0,48 & 0,92 & 3,74 & 0,76 & 0,36 & 2,92 & 0,72 & 1,63 \\
\hline MAPE & 10,42 & 0,55 & 0,09 & 1,45 & 0,13 & 0,46 & 8,29 & 0,34 & 0,08 & 4,72 & 0,27 & 1,43 \\
\hline
\end{tabular}




\begin{tabular}{|c|c|c|c|c|c|c|c|c|c|c|c|c|}
\hline \multicolumn{12}{|c|}{ Factorial Optimization Response } & 1,68 \\
\hline & $\max$ & $\max$ & $\max$ & $\max$ & $\min$ & $\max$ & $\max$ & $\max$ & $\max$ & $\max$ & $\min$ & $\max$ \\
\hline Optimum value & 227,6 & 17,8 & 3,1 & 73,1 & 2,3 & 87,1 & 144,6 & 8,6 & 1,5 & 84,0 & 1,8 & 73,7 \\
\hline$x_{1}$ & 1,2 & 2,5 & 2,5 & 2,5 & 2,2 & 2,1 & 8,8 & 2,5 & 12,5 & 11,9 & 12,5 & 12,4 \\
\hline$x_{2}$ & 5,0 & 5,0 & 5,0 & 5,3 & 5,0 & 44,3 & 20,3 & 34,0 & 5,0 & 5,0 & 44,3 & 16,2 \\
\hline$x_{3}$ & 17,7 & 0,1 & 0,0 & 30,2 & 0,0 & 56,3 & 54,8 & 100,0 & 25,1 & 46,8 & 0,0 & 100,0 \\
\hline $\mathbf{x}_{4}$ & 33,9 & 34,1 & 33,8 & 34,7 & 35,0 & 5,0 & 25,0 & 103,6 & 25,0 & 25,0 & 25,0 & 105,0 \\
\hline \multicolumn{13}{|c|}{ General Optimization } \\
\hline $\bar{i}$ & $\max$ & $\max$ & $\max$ & $\max$ & $\min$ & $\max$ & $\max$ & $\max$ & $\max$ & $\max$ & $\min$ & $\max$ \\
\hline \multicolumn{13}{|l|}{ Optimum } \\
\hline response & 201,6 & 13,9 & 2,4 & 71,8 & 2,9 & 85,7 & 132,9 & 8,0 & 1,5 & 79,1 & 3,6 & 78,7 \\
\hline Deseability & 0,985 & & & & & & 0,871 & & & & & \\
\hline Optimum value & & & $x_{1}=2,5$ & $x_{2}=5$ & $x_{3}=34,6$ & $x_{4}=30,0$ & & $x_{1}=12,4$ & $x_{2}=5,0$ & $x_{3}=0,0$ & $x_{4}=36,6$ & \\
\hline
\end{tabular}


(1) $\operatorname{Res} 1=-37,7+1,5 \mathrm{x}_{3}+1,7 \mathrm{x}_{4}-0,06 \mathrm{x}_{2}^{2}-0,02 \mathrm{x}_{3} \mathrm{x}_{4}$

Equation 7-3 Statistically values of second-order polynomial coefficients for betalainic content (Res1) in the MAE extractions.

In Table 7-3 has been also exposed 2 different optimization values, 1) the factorial optimization response, which determine the optimal value of a single response in case of being interested only in maximizing the colorant extraction in a single process, in this case betalainic content of 144,6 mg/g correspondent with factorial values of $\boldsymbol{x}_{1}=8,8 \mathrm{~min} ; \boldsymbol{x}_{2}=20,3 \mathrm{~g} / \mathrm{L} ; \boldsymbol{x}_{3}=54,8 \%$ of methanol and $\boldsymbol{x}_{4}=25^{\circ} \mathrm{C}$ the general optimization response, which determines the optimal value for all the responses in the same batch, in this case, the max value for betalains was $132,9 \mathrm{mg} / \mathrm{g}$ lower than the one obtained in the factorial optimization response, but at the same contemplating maximization from the other responses, in order to achieve this optimization factorial values, factors are meant to be $\boldsymbol{x}_{1}=12,4 \mathrm{~min} ; \boldsymbol{x}_{2}=5 \mathrm{~g} / \mathrm{L} ; \boldsymbol{x}_{3}=0$ methanol $\%$ and $\boldsymbol{x}_{4}=36,6^{\circ} \mathrm{C}$.

\section{VII.1.3.4. Effects of independent variables on phenolic acids and flavonoids.}

\section{VII.1.3.4.1. Ultrasound-assisted extraction}

Based on Table 7-3, Total Phenolic Content (TPC) and Total Flavonoid Content (TFC) under ultrasonic extraction were significantly $(\boldsymbol{p}<0.05)$ affected by the linear effect of ratio and solvent concentration for TPC and TFC, being temperature extraction significant only for the flavonoid content, and time non-significant for any of both. Significant interaction values were also present on ratio-concentration for both TPC and TFC, although, the last mentioned response, was also significant on ratio-temperature interaction Remaining factors did not show any significant $(\boldsymbol{p}<0.05)$ effect on TPC or TFC. Removing all non-significant terms, the polynomial Equation (2) and (3) for TPC (Res2) and TFC (Res3) respectively, comes as: 
(2) $\operatorname{Res} 2=6,263-0,08 \mathrm{x}_{2}+0,01 \mathrm{x}_{3}+0,003 \mathrm{x}_{2} \mathrm{x}_{3}$

(3) Res3 $=0,434+0,009 \mathrm{x}_{2}+0,006 \mathrm{x}_{3}+0,049 \mathrm{x}_{4}+0,0001 \mathrm{x}_{2} \mathrm{x}_{3}$ $-0,001 x_{2} x_{4}$

Equation 7-4 Statistically values of second-order polynomial coefficients for phenolic acids (Res2) and flavonoids content (Res3) in the UAE extractions

Previously, we had proposed a concise response about the sample/solvent ratio in the extraction, which gave us a clue as to why lower ratios rendered better yields. On the precise case of solvent concentration, observing Figure 7-2, clearly, the best yield for these bioactive compounds are achieved by using high concentrations of water rather than methanol. A possible explanation could be due the to interaction of both bioactive compounds with water-soluble molecules like carbohydrates or by their carboxylic acid terminations (BelščakCvitanović et al., 2018). Most certainly, extraction conditions used, are not strong enough to split the aglycones from the original glucides, forcing the glucides to bond more efficiently to low methanolic solvents. Additionally, with the increasing temperature the solubility of both bioactive compounds increases due to penetration of solvent into the plant matrix and higher mass transfer rate (Al-Farsi and Lee, 2008).

\section{VII.1.3.4.2. Microwave-assisted extraction}

From Annex 7-2 and Annex 7-3 we were able to stood out piscidic acid, as the maximum extracted molecule, being at least 20 -fold higher than the rest of the compounds detected, followed by the $2^{\text {nd }}, 3^{\text {rd }}$ and $4^{\text {th }}$ more abundant flavonoid molecules, apigenin-O-hexoside, Isorhamnetin-O-hexoside-O-(dihexosyl-hexoside) and isorhamnetinO-(di-deoxyhexosyl-hexoside), respectively, while the other eight molecules got similar percentages of recovery between them.

The data obtained in both TPC (Res2) and TFC (Res3) for MAE did not show significant statistical differences for the linear or quadratic terms, and only showed significance $(\boldsymbol{p}<0,05)$ for the timeconcentration interaction in the response 2 (TPC), for these reasons, polynomial coefficient ecuations of Res 2 and Res3 of MAE extraction are not shown. The fact of the terms being non-significant could be due to insufficient time or power employed on the MAE for these particular compounds (Phenolic acids and flavonoids). 


\section{VII.1.3.5. Effects of independent variables on antioxidant activity.}

\section{VII.1.3.5.1. Ultrasound-assisted extraction and microwave- assisted extraction}

Our main goal was to minimize the $\mathrm{IC}_{50}$ value in Response 5 (antioxidant effect). Briefly, lower concentration of antioxidant molecules that reduce $50 \%$ of the oxidation process, means better phytochemicals quality.

Betalains and polyphenolics have shown a wide range physiological properties, such as antimicrobial, anti-inflammatory, cardioprotective and antioxidant among others (Melgar et al., 2017a; Strack et al., 2003; Yeddes et al., 2013). Fom Table 7-3 and Figure 7-2 we were able to identify solvent concentration (b3), as the only linear effect with statistical significance in UAE and MAE, both cases exhibit better antioxidant effect on highly aqueous concentration, which is in concordance with data analysed, previously, we exposed in this essay how betalains, phenolic acids and flavonoids concentrations were higher on low methanolic solvents, providing a clear synergistic effect from the bioactive compounds on the antioxidant effect tested.

\section{VII.1.3.6. Effects of independent variables on yield and colour.}

\section{VII.1.3.6.1. Extraction yield on UAE and MAE}

From Figure 7-2, we can clearly stand out, first, how ratio effect $\left(\boldsymbol{x}_{2}\right)$ affect negatively while this increases in both types of extractions, second, in UAE, solvent concentration effect $\left(\boldsymbol{x}_{3}\right)$ also played an important role, which is confirmed with the statistical significance in Table 7-3, in this particular case, observing higher yields with higher methanolic concentration, achieving an optimum value for $\boldsymbol{x}_{3}$ in Response 4 of $30,2 \%$ of methanol.

The effect of ratio on yielding of phytochemical compounds was mentioned before on section VII.4.3, so no further comments on this matter will be mention in this section. On the other hand, solvent concentration yielding could be explained as a polarity effect, we 
pointed out how our interest phytochemicals have been better extracted with low methanolic concentration, perhaps, this little increase on methanol helps also to extract various unidentified polar compounds, and due to its amphiphilic properties, also some non-polar ones (Primorac et al., 2018).

\section{VII.1.3.7. Colour effect on ultrasonic and microwave extractions}

The colour properties of Opuntia peels, ranging in colour from pink to violet, were measured by colourimetric analysis. Statistics from Table 7-3, stands out solvent concentration $\left(\boldsymbol{x}_{3}\right)$ in both extraction technologies employed, and time $\left(\boldsymbol{x}_{1}\right)$ and temperature $\left(\boldsymbol{x}_{4}\right)$ only on microwave extractions. Even though, the statistical analysis focused only on coordinate $\mathrm{a}^{*}$, to better understand the total colour perspective, table Annex 7-8, exhibits the complementary parameters $\mathrm{L}^{*}, \mathrm{~b}^{*}$ and chroma. From all this data brighter (chroma) and lighter colour intensity $\left(\mathrm{L}^{*}\right)$ but reddish tone $\left(\mathrm{a}^{*}\right)$ can be noted in every single run of UAE compared to MAE, and the possible explanation for this effect could be due to small oxidation of sugar attached to betalains caused by employment of higher temperatures on the microwave extraction technique.

\section{VII.1.3.8. Comparison of UAE and MAE RSM}

Ultrasound and microwave are both common extraction technologies used for the recovery of bioactive compounds, on the bibliography, plethora of information about different plants and by-products can be found, mainly oriented to improve specific conditions, although these technologies have different mechanism of action, both are used cited on extraction procedures, microwave assisted extraction essentially heat up the molecules by dual mechanism of ionic conduction and dipole rotation, while ultrasound assisted extraction relies on the uses of acoustic energy inducing vibrational motion (cavitation) of the molecules (Mandal et al., 2015).

On this assay, we have already described the effects of every single factor and the influence of the different levels on the responses analysed, now as a brief summary, a comparison between these two technologies and their results is discussed. 


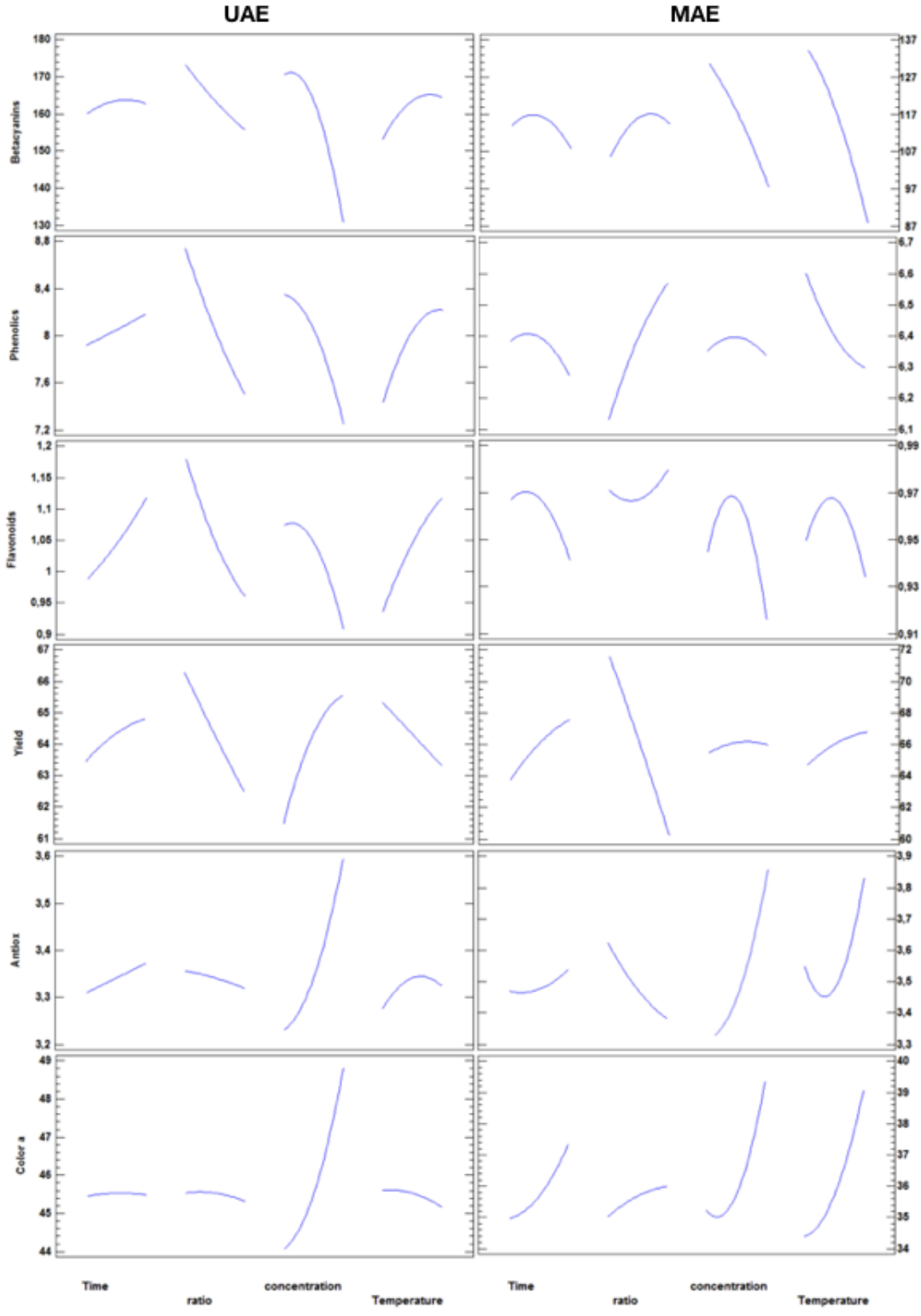

Figure 7-2 Principal effect graphs of UAE and MAE, representing responses values, acquire from the independent variables employed on the CCD-RMS (source: private collection) 
All the phytochemical compounds were identified using both technologies, varying the percentages and the concentrations of these molecules. Considering maximums obtained in each different extraction (Table 7-2), all the maximum amounts of bioactive compounds (betalains, phenolic acids and flavonoids) was achieved by ultrasonic assisted extraction.

In betalains for instance, almost 22\% more was achieved, 197,51 $\mathrm{mg} / \mathrm{g}$ of UAE vs $151,11 \mathrm{mg} / \mathrm{g}$ of MAE; for phenolic acids and flavonoids this differences went up to about $43 \%, 12,99 \mathrm{mg} / \mathrm{g}$ of UAE vs $7,46 \mathrm{mg} / \mathrm{g}$ of MAE and 2,06 mg/g of UAE vs $1,16 \mathrm{mg} / \mathrm{g}$ of MAE, respectively. Differences in the means of specific compounds did not exceed the $2 \%$ for betacyanins, 5,3\% for flavonoids and $5 \%$ for phenolic acids, in this last one mentioned, piscidic acid (Ph1) for instance changed from $93,3 \%$ on UAE to $98,3 \%$ on MAE, compensating those differences on cis-caffeic acid, where $4,1 \%$ was achieved on UAE compared to the $0,3 \%$ of the MAE. As far as we know, there has not been performed any other comparison of this type in which we could compare our results.

In the antioxidant activity effect (Table 7-2), although lower $\mathrm{IC}_{50}$ response was obtained on the MAE 2,6 $\mathrm{mg} / \mathrm{mL}$ vs 2,9 from the UAE, the majority of data in the 31 runs was always lower for the UAE extracts. Two possible explanations for this unexpected result could be due to a colorimetric interference while performing the assay or an operational error, either way, UAE has shown also an overall better antioxidant performance, which is in concordance with the maximum amounts of biomolecules obtained also by UAE. Table 7-3, also shows optimum responses values of $2,9 \mathrm{mg} / \mathrm{mL}$ for UAE and $3,6 \mathrm{mg} / \mathrm{mL}$ for MAE, which agrees with the aforementioned.

On the other hand, the percentage of yield (Table 7-2) was in the opposite way, where MAE exhibits the best results almost in every run. 


\section{VII.1.4. CONCLUSION}

The present work has described the use of ultrasound-assisted extraction and microwave-assisted extraction techniques in order to extract bioactive compounds of interest, namely betacyanins, phenolic acids, flavonoid, as well as their antioxidant profiling. In this essay, the interaction of four different factors (time, solid to solvent ratio, methanol concentration and temperature) were investigated using the RSM model for predicting variables. From the data obtained, we are able to stand out:

I. The identification through HPLC-DAD-ESI-MS/MS of 7 different betacyanins, 4 phenolic acids and 8 flavonoids, from the Opuntia engelmaannii peels, reporting their respective tentative names, retention times and identification patterns.

II. By using the CCD-RSM modelling, principal effect and 3D graphs, the recognition of each independent variable impact on the studied responses was highlighted, indicating the factorial optimisation responses and proposing how to build the equation models for the prediction of the different responses.

III. Compiling all of the previous information, a comparison of the different techniques of extraction was mentioned, based on the singular responses of each UAE and MAE, the most suitable technique for this particular by product and conditions was proposed.

Finally, a general response optimization of both types of extractions was also performed statistically, involving all the responses analysed at the same time. With a deseability response of 0,985 , the optimum values for each factor in UAE was $\boldsymbol{x}_{I}=2,5 \mathrm{~min}, \boldsymbol{x}_{2}=5 \mathrm{~g} / \mathrm{L}$, $\boldsymbol{x}_{3}=34,6 \%$ of methanol and $\boldsymbol{x}_{4}=30{ }^{\circ} \mathrm{C}$. In the same manner, with a deseability response of 0,871 , the optimum values for each factor in MAE was $\boldsymbol{x}_{1}=1,4 \mathrm{~min}, \boldsymbol{x}_{2}=5 \mathrm{~g} / \mathrm{L}, \boldsymbol{x}_{3}=0,0 \%$ of methanol and $\boldsymbol{x}_{4}=36,6$ ${ }^{\circ} \mathrm{C}$. These conditions will produce 201,6 and $132,9 \mathrm{mg} / \mathrm{g}$ of betalains, 13,9 and $8,0 \mathrm{mg} / \mathrm{g}$ of phenolic acids, 2,4 and $1,5 \mathrm{mg} / \mathrm{g}$ of flavonoids, 71,8 and $79,1 \%$ of yields and $\mathrm{IC}_{50}$ antioxidant values of 2,9 and 3,6 , for $\mathrm{UAE}$ and MAE respectively.

Concluding, the present study suggests the use of ultrasoundassisted extraction in order to maximize recovery of bioactive 
compounds such as betalains, phenolic acids and flavonoids under the conditions previously mentioned, which also provide better antioxidant activity.

The main recommendation is to work at temperatures lower than $37^{\circ} \mathrm{C}$, with the minimum solid to solvent ratio used $(5 \mathrm{~g} / \mathrm{L})$ and low concentrations of methanol $(<35 \%)$.

\section{Acknowledgements}

The authors are grateful to CONACyT for supporting B. Melgar with his doctoral grant (No. 329930). The authors specially thanks to Maria Luisa Ruiz and the "Laboratorio Agroalimentario de la Comunitat Valenciana" for allow us to use the microwave for the extractions. 


\section{References}

Al-Farsi, M.A., Lee, C.Y., 2008. Optimization of phenolics and dietary fibre extraction from date seeds. Food Chem. 108, 977-985. https://doi.org/10.1016/j.foodchem.2007.12.009

Allai, L., Druart, X., Öztürk, M., BenMoula, A., Nasser, B., El Amiri, B., 2016. Protective effects of Opuntia ficus-indica extract on ram sperm quality, lipid peroxidation and DNA fragmentation during liquid storage. Anim. Reprod. Sci. 175, 1-9. https://doi.org/10.1016/j.anireprosci.2016.09.013

Ammar, I., Ben Salem, M., Harrabi, B., Mzid, M., Bardaa, S., Sahnoun, Z., Attia, H., Ennouri, M., 2018. Anti-inflammatory activity and phenolic composition of prickly pear (Opuntia ficus-indica) flowers. Ind. Crops Prod. 112, 313-319. https://doi.org/10.1016/j.indcrop.2017.12.028

Aruwa, C.E., Amoo, S.O., Kudanga, T., 2018. Opuntia (Cactaceae) plant compounds, biological activities and prospects - A comprehensive review. Food Res. Int. 112, 328-344. https://doi.org/10.1016/j.foodres.2018.06.047

Belščak-Cvitanović, A., Durgo, K., Huđek, A., Bačun-Družina, V., Komes, D., 2018. Metabolism and Health Effects of Polyphenols, in: Galanakis, C.M. (Ed.), Polyphenols: Properties, Recovery, and Applications. Woodhead Publishing, pp. 1-44. https://doi.org/https://doi.org/10.1016/B978-0-12-813572$3.00001-4$

Betancourt, C., Cejudo-Bastante, M.J., Heredia, F.J., Hurtado, N., 2017. Pigment composition and antioxidant capacity of betacyanins and betaxanthins fractions of Opuntia dillenii (Ker Gawl) Haw cactus fruit. Food Res. Int. 101, 173-179. https://doi.org/10.1016/j.foodres.2017.09.007

Cardoso-Ugarte, G.A., Sosa-Morales, M.E., Ballard, T., Liceaga, A., San Martín-González, M.F., 2014. Microwave-assisted extraction of betalains from red beet (Beta vulgaris). LWT - Food Sci. Technol. 59, 276-282. https://doi.org/10.1016/j.lwt.2014.05.025

Chougui, N., Djerroud, N., Naraoui, F., Hadjal, S., Aliane, K., Zeroual, B., Larbat, R., 2015. Physicochemical properties and storage stability of margarine containing Opuntia ficus-indica peel extract as antioxidant. Food Chem. 173, 382-90. https://doi.org/10.1016/j.foodchem.2014.10.025 
do Prado, D. Z., Capoville, B. L., Delgado, C. H. O., Heliodoro, J. C. A., Pivetta, M. R., Pereira, M. S., ... Fleuri, L. F. (2018). Nutraceutical food: composition, biosynthesis, therapeutic properties, and applications. Alternative and Replacement Foods, 95-140. https://doi.org/10.1016/B978-0-12-811446-9.00004-6

Esquivel, P., 2016. Handbook on Natural Pigments in Food and Beverages Industrial Applications for Improving Food Colorl, in: Carle, R., Schweiggert, R.M. (Eds.), . Woodhead Publishing, San Pedro, Costa Rica, pp. 81-99.

Fathordoobady, F., Mirhosseini, H., Selamat, J., Manap, M.Y.A., 2016. Effect of solvent type and ratio on betacyanins and antioxidant activity of extracts from Hylocereus polyrhizus flesh and peel by supercritical fluid extraction and solvent extraction. Food Chem. 202, 70-80. https://doi.org/10.1016/j.foodchem.2016.01.121

Ferreres, F., Grosso, C., Gil-Izquierdo, A., Valentão, P., Mota, A.T., Andrade, P.B., 2017. Optimization of the recovery of high-value compounds from pitaya fruit by-products using microwaveassisted extraction. Food Chem. 230, 463-474. https://doi.org/10.1016/j.foodchem.2017.03.061

Garcia-Castello, E. M., Rodriguez-Lopez, A. D., Mayor, L., Ballesteros, R., Conidi, C., \& Cassano, A. (2015). Optimization of conventional and ultrasound assisted extraction of flavonoids from grapefruit (Citrus paradisi L.) solid wastes. LWT - Food Science and Technology, 64(2), 1114-1122. https://doi.org/10.1016/j.lwt.2015.07.024

García-Cruz, L., Dueñas, M., Santos-Buelgas, C., Valle-Guadarrama, S., Salinas-Moreno, Y., 2017. Betalains and phenolic compounds profiling and antioxidant capacity of pitaya (Stenocereus spp.) fruit from two species (S. Pruinosus and S. stellatus). Food Chem. 234, 111-118. https://doi.org/10.1016/j.foodchem.2017.04.174

Gebhardt, D., 2018. The Economics of Natural Color Pigments. URL https://sensientfoodcolors.com/en-us/researchdevelopment/economics-natural-color-pigments/

Guldiken, B., Toydemir, G., Nur Memis, K., Okur, S., Boyacioglu, D., Capanoglu, E., 2016. Home-processed red beetroot (Beta vulgaris L.) products: Changes in antioxidant properties and bioaccessibility. Int. J. Mol. Sci. 17. https://doi.org/10.3390/ijms17060858

GVR, 2016. Natural Antioxidants Market Analysis By Product 
(Vitamin C, Vitamin E, Polyphenols, Carotenoids) And Segment $\begin{array}{llll}\text { Forecasts } & \text { To } 2022 . & \text { URL }\end{array}$ https://www.grandviewresearch.com/industry-analysis/naturalantioxidants-market

Herbach, K.M., Stintzing, F.C., Carle, R., 2005. Identification of heatinduced degradation products from purified betanin, phyllocactin and hylocerenin by high-performance liquid chromatography/ electrospray ionization mass spectrometry. Rapid Commun. Mass Spectrom. 19, 2603-2616. https://doi.org/10.1002/rcm.2103

IFIC, FDA, 2010. Overview of Food Ingredients, Additives and Colors. URL

https://www.fda.gov/food/ingredientspackaginglabeling/foodadd itivesingredients/ucm094211.htm

Laqui-Vilca, C., Aguilar-Tuesta, S., Mamani-Navarro, W., MontañoBustamante, J., Condezo-Hoyos, L., 2018. Ultrasound-assisted optimal extraction and thermal stability of betalains from colored quinoa (Chenopodium quinoa Willd) hulls. Ind. Crops Prod. 111, 606-614. https://doi.org/10.1016/j.indcrop.2017.11.034

Leardi, R., 2013. Experimental Design, 1st ed, Data Handling in Science and Technology. Copyright (C) 2013 Elsevier B.V. All rights reserved. https://doi.org/10.1016/B978-0-444-595287.00002-8

Madunić, J., Madunić, I.V., Gajski, G., Popić, J., Garaj-Vrhovac, V., 2018. Apigenin: A dietary flavonoid with diverse anticancer properties. Cancer Lett. 413, 11-22. https://doi.org/10.1016/j.canlet.2017.10.041

Mandal, S.C., Mandal, V., Das, A.K., 2015. Classification of Extraction Methods, in: Essentials of Botanical Extraction. Academic Press, pp. 83-136. https://doi.org/10.1016/B978-0-12-802325-9.000069

Mata, A., Ferreira, J.P., Semedo, C., Serra, T., Duarte, C.M.M., Bronze, M.R., 2016. Contribution to the characterization of Opuntia spp. juices by LC-DAD-ESI-MS/MS. Food Chem. 210, 558-565. https://doi.org/10.1016/j.foodchem.2016.04.033

Melgar, B., Dias, M.I., Ciric, A., Sokovic, M., Garcia-Castello, E.M., Rodriguez-Lopez, A.D., Barros, L., Ferreira, I., 2017a. Byproduct recovery of Opuntia spp. peels: Betalainic and phenolic profiles and bioactive properties. https://doi.org/10.1016/j.indcrop.2017.06.011 
Melgar, B., Pereira, E., Oliveira, M.B.P.P., Garcia-Castello, E.M., Rodriguez-Lopez, A.D., Sokovic, M., Barros, L., Ferreira, I.C.F.R., 2017b. Extensive profiling of three varieties of Opuntia spp. fruit for innovative food ingredients. Food Res. Int. 101, 259265. https://doi.org/10.1016/j.foodres.2017.09.024

Mena, P., Tassotti, M., Andreu, L., Nuncio-Jáuregui, N., Legua, P., Del Rio, D., Hernández, F., 2018. Phytochemical characterization of different prickly pear (Opuntia ficus-indica (L.) Mill.) cultivars and botanical parts: UHPLC-ESI-MSn metabolomics profiles and their chemometric analysis. Food Res. Int. 108, 301-308. https://doi.org/10.1016/j.foodres.2018.03.062

Paciulli, M., Medina-Meza, I.G., Chiavaro, E., Barbosa-Cánovas, G.V., 2016. Impact of thermal and high pressure processing on quality parameters of beetroot (Beta vulgaris L.). LWT - Food Sci. Technol. 68, 98-104. https://doi.org/10.1016/j.lwt.2015.12.029

Patel, D., Shukla, S., Gupta, S., 2007. Apigenin and cancer chemoprevention: Progress, potential and promise (Review). Int. J. Oncol. 30, 233-245. https://doi.org/10.3892/ijo.30.1.233

Primorac, T., Požar, M., Sokolić, F., Zoranić, L., Urbic, T., 2018. A simple two dimensional model of methanol. J. Mol. Liq. 262, 4657. https://doi.org/10.1016/j.molliq.2018.04.055

Ravichandran, K., Saw, N.M.M.T., Mohdaly, A.A.A., Gabr, A.M.M., Kastell, A., Riedel, H., Cai, Z., Knorr, D., Smetanska, I., 2013. Impact of processing of red beet on betalain content and antioxidant activity. Food Res. Int. 50, 670-675. https://doi.org/10.1016/j.foodres.2011.07.002

Roriz, C.L., Barros, L., Prieto, M.A., Morales, P., Ferreira, I.C.F.R., 2017. Floral parts of Gomphrena globosa L. as a novel alternative source of betacyanins: Optimization of the extraction using response surface methodology. Food Chem. 229, 223-234. https://doi.org/10.1016/j.foodchem.2017.02.073

Sawicki, T., Wiczkowski, W., 2018. The effects of boiling and fermentation on betalain profiles and antioxidant capacities of red beetroot products. Food Chem. 259, 292-303. https://doi.org/10.1016/j.foodchem.2018.03.143

Spórna-Kucab, A., Ignatova, S., Garrard, I., Wybraniec, S., 2013. Versatile solvent systems for the separation of betalains from processed Beta vulgaris L. juice using counter-current chromatography. J. Chromatogr. B Anal. Technol. Biomed. Life 
Sci. 941, 54-61. https://doi.org/10.1016/j.jchromb.2013.10.001

Strack, D., Vogt, T., Schliemann, W., 2003. Recent advances in betalain research. Phytochemistry 62, 247-269. https://doi.org/10.1016/S0031-9422(02)00564-2

Szot, D., Skopińska, A., Wybraniec, S., 2015. Decomposition of 17decarboxy-betanin in selected aqueous-organic solutions induced by $\mathrm{Cu}$ ( II ) cations. PhD Interdiscip. J. Politech. Gdansk Univ. 1, 217-223.

Thirugnanasambandham, K., Sivakumar, V., 2017. Microwave assisted extraction process of betalain from dragon fruit and its antioxidant activities. J. Saudi Soc. Agric. Sci. 16, 41-48. https://doi.org/10.1016/j.jssas.2015.02.001

Vinatoru, M., 2001. An overview of the ultrasonically assisted extraction of bioactive principles from herbs. Ultrason. Sonochem. 8, 303-313. https://doi.org/10.1016/S13504177(01)00071-2

Wybraniec, S., Starzak, K., Szneler, E., Pietrzkowski, Z., 2016. Separation of chlorinated diastereomers of decarboxybetacyanins in myeloperoxidase catalyzed chlorinated Beta vulgaris L. extract. J. Chromatogr. B Anal. Technol. Biomed. Life Sci. 1036-1037, $20-32$. https://doi.org/10.1016/j.jchromb.2016.09.040

Yeddes, N., Chérif, J., Guyot, S., Sotin, H., Ayadi, M., 2013. Comparative Study of Antioxidant Power, Polyphenols, Flavonoids and Betacyanins of the Peel and Pulp of Three Tunisian Opuntia Forms. Antioxidants 2, 37-51. https://doi.org/10.3390/antiox2020037 


\begin{tabular}{|c|c|c|c|c|c|c|c|c|c|c|c|c|c|c|c|c|}
\hline \multirow[t]{3}{*}{ Run } & \multirow{2}{*}{\multicolumn{2}{|c|}{$\begin{array}{l}\text { Peak } 1 \\
\text { Betanin }\end{array}$}} & \multirow{2}{*}{\multicolumn{2}{|c|}{$\begin{array}{c}\text { Peak } 2 \\
\text { Isobetanin }\end{array}$}} & \multirow{2}{*}{\multicolumn{2}{|c|}{$\begin{array}{c}\text { Peak } 3 \\
\text { iomphrenin I }\end{array}$}} & \multirow{2}{*}{\multicolumn{2}{|c|}{$\begin{array}{c}\text { Peak } 4 \\
\text { (Iso)phyllocactin }\end{array}$}} & \multirow{2}{*}{\multicolumn{2}{|c|}{$\begin{array}{c}\text { Peak } 5 \\
17 \text { decarboxy- } \\
\text { betanin }\end{array}$}} & \multirow{2}{*}{\multicolumn{2}{|c|}{$\begin{array}{c}\text { Peak } 6 \\
\text { Betanidin }\end{array}$}} & \multirow{2}{*}{\multicolumn{2}{|c|}{$\begin{array}{c}\text { Peak } 7 \\
\text { Isobetanidin }\end{array}$}} & \multirow{2}{*}{\multicolumn{2}{|c|}{$\begin{array}{l}\text { Total } \\
\mathrm{mg} / \mathrm{g}\end{array}$}} \\
\hline & & & & & & & & & & & & & & & & \\
\hline & UAE & MAE & UAE & MAE & UAE & MAE & UAE & MAE & UAE & MAE & UAE & MAE & UAE & MAE & UAE & MAE \\
\hline 1 & 144,0 & 90,4 & 21,6 & 12,6 & 4,8 & 1,7 & 2,2 & 0,4 & 2,0 & 0,6 & 3,3 & 1,2 & 3,7 & 5,4 & 181,5 & 112,3 \\
\hline 2 & 118,7 & 111,9 & 18,0 & 16,0 & 4,1 & 3,0 & 1,7 & 1,2 & 1,6 & 0,9 & 2,3 & 1,5 & 2,5 & 5,7 & 148,8 & 140,1 \\
\hline 3 & 107,6 & 95,2 & 16,2 & 13,0 & 3,3 & 1,8 & 1,6 & 1,0 & 1,3 & 0,7 & 1,8 & 0,7 & 2,6 & 0,0 & 134,3 & 112,5 \\
\hline 4 & 123,7 & 104,8 & 17,7 & 15,1 & 3,9 & 2,3 & 1,9 & 0,6 & 1,6 & 0,2 & 2,3 & 2,0 & 1,9 & 4,2 & 152,9 & 129,3 \\
\hline 5 & 91,0 & 91,5 & 11,1 & 12,2 & 2,8 & 2,0 & 1,0 & 1,0 & 0,9 & 0,8 & 0,9 & 0,3 & 1,5 & 0,0 & 109,3 & 107,9 \\
\hline 6 & 92,2 & 91,7 & 12,4 & 14,2 & 2,9 & 2,2 & 1,4 & 0,3 & 1,0 & 0,6 & 1,2 & 0,9 & 1,3 & 3,5 & 112,5 & 113,5 \\
\hline 7 & 100,4 & 117,1 & 13,4 & 17,2 & 3,2 & 2,5 & 1,4 & 0,4 & 1,1 & 0,5 & 1,3 & 0,3 & 2,7 & 3,3 & 123,6 & 141,3 \\
\hline 8 & 103,6 & 96,1 & 13,8 & 15,6 & 3,2 & 2,1 & 1,5 & 0,9 & 1,1 & 0,6 & 1,8 & 2,0 & 2,8 & 2,5 & 127,8 & 119,7 \\
\hline 9 & 135,2 & 67,6 & 20,8 & 10,0 & 4,5 & 1,0 & 1,8 & 0,2 & 1,8 & 0,4 & 2,8 & 0,1 & 3,5 & 3,4 & 170,3 & 82,7 \\
\hline 10 & 150,2 & 65,3 & 22,7 & 9,6 & 5,2 & 1,0 & 2,2 & 0,2 & 2,3 & 0,4 & 3,2 & 0,8 & 3,7 & 3,1 & 189,5 & 80,5 \\
\hline 11 & 107,5 & 92,4 & 16,6 & 16,4 & 3,3 & 1,6 & 1,2 & 0,1 & 1,2 & 0,6 & 1,8 & 1,0 & 1,6 & 4,1 & 133,2 & 116,4 \\
\hline 12 & 111,5 & 83,0 & 16,5 & 14,4 & 3,7 & 1,7 & 1,5 & 0,2 & 1,4 & 0,1 & 2,2 & 3,7 & 1,7 & 4,4 & 138,6 & 107,6 \\
\hline 13 & 116,1 & 43,1 & 16,0 & 7,5 & 4,1 & 1,0 & 1,8 & 0,2 & 1,5 & 0,1 & 2,1 & 0,1 & 1,8 & 1,5 & 143,2 & 53,5 \\
\hline 14 & 102,6 & 18,8 & 13,4 & 3,3 & 3,3 & 0,3 & 1,2 & 0,1 & 1,1 & 0,2 & 1,3 & 0,3 & 1,8 & 2,0 & 124,7 & 25,1 \\
\hline 15 & 94,8 & 52,1 & 12,7 & 10,6 & 2,9 & 1,2 & 1,1 & 0,7 & 0,9 & 0,4 & 1,6 & 1,2 & 1,6 & 0,0 & 115,7 & 66,3 \\
\hline
\end{tabular}




\begin{tabular}{|c|c|c|c|c|c|c|c|c|c|c|c|c|c|c|c|c|}
\hline 16 & 97,1 & 44,2 & 13,4 & 10,0 & 3,0 & 1,2 & 1,4 & 0,2 & 1,0 & 0,2 & 1,1 & 0,7 & 2,4 & 3,1 & 119,3 & 59,6 \\
\hline 17 & 126,3 & 88,7 & 19,1 & 14,8 & 3,9 & 1,8 & 1,8 & 0,5 & 1,3 & 0,2 & 2,2 & 0,6 & 4,4 & 0,0 & 159,1 & 106,6 \\
\hline 18 & 136,3 & 60,9 & 21,3 & 10,8 & 4,6 & 1,5 & 2,1 & 0,1 & 1,8 & 0,2 & 3,3 & 2,3 & 4,5 & 1,3 & 173,9 & 77,1 \\
\hline 19 & 156,1 & 78,6 & 23,6 & 11,5 & 5,1 & 1,4 & 2,3 & 0,4 & 2,0 & 0,4 & 3,7 & 0,5 & 4,6 & 4,0 & 197,5 & 96,8 \\
\hline 20 & 126,6 & 55,9 & 18,8 & 16,5 & 4,4 & 2,2 & 2,3 & 0,9 & 1,6 & 0,7 & 2,6 & 1,5 & 3,5 & 2,2 & 159,7 & 79,8 \\
\hline 21 & 139,0 & 127,0 & 21,4 & 18,2 & 4,6 & 3,4 & 2,1 & 1,2 & 2,4 & 0,9 & 2,8 & 1,3 & 2,2 & 3,2 & 174,5 & 155,1 \\
\hline 22 & 58,6 & 16,7 & 7,2 & 30,8 & 1,8 & 5,0 & 0,8 & 0,1 & 0,6 & 0,6 & 0,9 & 0,0 & 2,1 & 0,0 & 72,0 & 53,2 \\
\hline 23 & 108,0 & 113,3 & 15,2 & 15,8 & 3,4 & 2,5 & 1,7 & 1,6 & 1,3 & 1,2 & 2,0 & 0,8 & 2,1 & 0,0 & 133,8 & 135,1 \\
\hline 24 & 140,6 & 25,8 & 21,8 & 16,5 & 5,1 & 4,8 & 2,5 & 0,9 & 1,7 & 0,3 & 3,4 & 1,2 & 4,1 & 0,0 & 179,2 & 49,4 \\
\hline 25 & 116,3 & 92,1 & 16,1 & 12,5 & 3,7 & 1,5 & 1,4 & 0,5 & 1,2 & 0,2 & 1,7 & 0,7 & 2,6 & 0,0 & 143,0 & 107,6 \\
\hline 26 & 144,9 & 95,1 & 23,2 & 14,9 & 5,3 & 2,1 & 2,3 & 1,3 & 1,9 & 0,9 & 3,1 & 0,5 & 3,6 & 0,0 & 184,3 & 114,8 \\
\hline 27 & 106,8 & 93,0 & 16,9 & 14,4 & 3,6 & 1,8 & 1,5 & 0,8 & 1,3 & 0,8 & 2,2 & 1,0 & 2,3 & 0,0 & 134,7 & 111,8 \\
\hline 28 & 149,9 & 102,8 & 22,8 & 16,1 & 5,1 & 2,4 & 2,4 & 0,2 & 1,8 & 0,7 & 2,8 & 0,8 & 2,7 & 4,1 & 187,4 & 127,1 \\
\hline 29 & 128,8 & 101,6 & 19,7 & 15,9 & 4,3 & 1,8 & 2,0 & 0,3 & 1,6 & 0,7 & 2,2 & 1,3 & 2,6 & 4,6 & 161,2 & 126,3 \\
\hline 30 & 134,7 & 94,1 & 19,4 & 14,4 & 4,8 & 1,6 & 2,3 & 0,3 & 1,7 & 0,5 & 2,5 & 0,3 & 3,6 & 3,4 & 169,0 & 114,7 \\
\hline 31 & 131,6 & 90,4 & 19,6 & 12,6 & 4,4 & 1,7 & 2,1 & 0,4 & 1,7 & 0,6 & 2,5 & 1,2 & 3,2 & 5,4 & 165,0 & 112,3 \\
\hline
\end{tabular}


Annex 7-2 Amount in mg/g of the specific phenolic acids identified in every single run and the sum of all to obtained the total phenolic content

\begin{tabular}{|c|c|c|c|c|c|c|c|c|c|c|}
\hline \multirow[t]{2}{*}{ Run } & \multicolumn{2}{|c|}{$\begin{array}{c}\text { Peak } 1 \\
\text { Piscidic acid }\end{array}$} & \multicolumn{2}{|c|}{$\begin{array}{c}\text { Peak } 2 \\
\text { 3-O-Feruloylquinic } \\
\text { acid }\end{array}$} & \multicolumn{2}{|c|}{$\begin{array}{c}\text { Peak } 3 \\
\text { cis-Caffeic acid }\end{array}$} & \multicolumn{2}{|c|}{$\begin{array}{l}\text { Peak } 4 \\
\text { Ferulic acid } \\
\text { hexoside }\end{array}$} & \multicolumn{2}{|c|}{$\begin{array}{l}\text { Total } \\
\mathrm{mg} / \mathrm{g}\end{array}$} \\
\hline & UAE & MAE & UAE & MAE & UAE & MAE & UAE & MAE & UAE & MAE \\
\hline 1 & 8,46 & 6,30 & $\mathrm{n} / \mathrm{d}$ & 0,03 & 0,38 & 0,02 & 0,07 & 0,07 & 8,91 & 6,41 \\
\hline 2 & 6,85 & 6,89 & $\mathrm{n} / \mathrm{d}$ & 0,02 & 0,36 & 0,02 & 0,06 & 0,08 & 7,26 & 7,01 \\
\hline 3 & 6,00 & 5,57 & 0,08 & 0,02 & 0,25 & 0,01 & 0,05 & 0,07 & 6,39 & 5,66 \\
\hline 4 & 6,86 & 6,51 & $\mathrm{n} / \mathrm{d}$ & 0,02 & 0,37 & 0,03 & 0,06 & 0,07 & 7,29 & 6,62 \\
\hline 5 & 6,34 & 5,71 & 0,09 & 0,02 & 0,21 & 0,00 & 0,05 & 0,06 & 6,69 & 5,80 \\
\hline 6 & 6,03 & 6,12 & 0,08 & 0,02 & 0,24 & 0,01 & 0,05 & 0,08 & 6,40 & 6,23 \\
\hline 7 & 6,59 & 7,32 & $\mathrm{n} / \mathrm{d}$ & 0,03 & 0,34 & 0,02 & 0,06 & 0,09 & 6,98 & 7,46 \\
\hline 8 & 6,62 & 6,33 & $\mathrm{n} / \mathrm{d}$ & 0,02 & 0,35 & 0,01 & 0,06 & 0,06 & 7,04 & 6,42 \\
\hline 9 & 8,11 & 5,52 & $\mathrm{n} / \mathrm{d}$ & 0,01 & 0,43 & 0,01 & 0,07 & 0,07 & 8,61 & 5,60 \\
\hline 10 & 12,13 & 5,50 & 0,71 & 0,01 & 0,06 & 0,01 & 0,09 & 0,07 & 12,99 & 5,59 \\
\hline 11 & 6,23 & 6,07 & 0,07 & 0,03 & 0,24 & 0,02 & 0,05 & 0,08 & 6,60 & 6,20 \\
\hline 12 & 6,44 & 6,54 & $\mathrm{n} / \mathrm{d}$ & 0,01 & 0,32 & 0,04 & 0,05 & 0,07 & 6,81 & 6,65 \\
\hline 13 & 7,28 & 7,14 & 0,00 & 0,01 & 0,36 & 0,02 & 0,07 & 0,06 & 7,71 & 7,23 \\
\hline 14 & 6,60 & 3,95 & $\mathrm{n} / \mathrm{d}$ & 0,01 & 0,34 & 0,01 & 0,06 & 0,04 & 7,00 & 4,01 \\
\hline 15 & 6,13 & 6,22 & 0,09 & 0,03 & 0,25 & 0,00 & 0,06 & 0,07 & 6,52 & 6,32 \\
\hline
\end{tabular}




\begin{tabular}{lllrlllllll}
16 & 6,33 & 6,59 & $\mathrm{n} / \mathrm{d}$ & 0,04 & 0,36 & 0,02 & 0,06 & 0,07 & 6,75 & 6,73 \\
17 & 7,93 & 6,08 & 0,10 & 0,02 & 0,28 & 0,01 & 0,06 & 0,06 & 8,37 & 6,18 \\
18 & 7,92 & 6,12 & $\mathrm{n} / \mathrm{d}$ & 0,02 & 0,40 & 0,01 & 0,07 & 0,07 & 8,39 & 6,22 \\
19 & 9,05 & 5,94 & $\mathrm{n} / \mathrm{d}$ & 0,01 & 0,45 & 0,01 & 0,08 & 0,07 & 9,58 & 6,03 \\
20 & 7,33 & 6,48 & $\mathrm{n} / \mathrm{d}$ & 0,01 & 0,35 & 0,02 & 0,06 & 0,07 & 7,75 & 6,57 \\
21 & 7,78 & 6,34 & $\mathrm{n} / \mathrm{d}$ & 0,01 & 0,38 & 0,03 & 0,06 & 0,06 & 8,22 & 6,43 \\
22 & 6,21 & 5,99 & $\mathrm{n} / \mathrm{d}$ & 0,04 & 0,28 & 0,01 & 0,05 & 0,06 & 6,53 & 6,10 \\
23 & 6,28 & 6,70 & 0,12 & 0,01 & 0,21 & 0,01 & 0,05 & 0,06 & 6,66 & 6,78 \\
24 & 7,83 & 6,48 & $\mathrm{n} / \mathrm{d}$ & 0,02 & 0,41 & 0,02 & 0,06 & 0,07 & 8,31 & 6,60 \\
25 & 7,00 & 6,61 & 0,10 & 0,04 & 0,28 & 0,02 & 0,06 & 0,07 & 7,44 & 6,74 \\
26 & 8,61 & 5,93 & $\mathrm{n} / \mathrm{d}$ & 0,00 & 0,49 & 0,01 & 0,07 & 0,07 & 9,17 & 6,02 \\
27 & 6,17 & 5,76 & $\mathrm{n} / \mathrm{d}$ & 0,02 & 0,34 & 0,02 & 0,05 & 0,08 & 6,56 & 5,87 \\
28 & 8,41 & 6,07 & 0,19 & 0,03 & 0,30 & 0,04 & 0,07 & 0,06 & 8,97 & 6,20 \\
29 & 7,19 & 6,06 & 0,12 & 0,02 & 0,29 & 0,01 & 0,06 & 0,08 & 7,66 & 6,18 \\
30 & 8,00 & 6,68 & 0,13 & 0,02 & 0,35 & 0,02 & 0,07 & 0,09 & 8,55 & 6,81 \\
31 & 7,57 & 6,84 & $\mathrm{n} / \mathrm{d}$ & 0,02 & 0,35 & 0,01 & 0,06 & 0,08 & 7,98 & 6,95 \\
\hline
\end{tabular}




\begin{tabular}{|c|c|c|c|c|c|c|c|c|c|c|c|c|c|c|c|c|c|c|}
\hline \multirow[t]{2}{*}{ Run } & \multicolumn{2}{|c|}{$\begin{array}{c}\text { Peak } 1 \\
\text { Isorhamnetin- } \\
\text { O-hexoside-O- } \\
\text { (dihexosyl- } \\
\text { hexoside) }\end{array}$} & \multicolumn{2}{|c|}{$\begin{array}{c}\text { Peak } 2 \\
\text { Isorhamnetin- } \\
\text { O-hexoside- } \\
\text { (deoxyhexosyl- } \\
\text { hexosyde) }\end{array}$} & \multicolumn{2}{|c|}{$\begin{array}{l}\text { Peak } 3 \\
\text { Apigenin-O- } \\
\text { hexoside }\end{array}$} & \multicolumn{2}{|c|}{ Peak 4} & \multicolumn{2}{|c|}{ Peak 5} & \multicolumn{2}{|c|}{$\begin{array}{c}\text { Peak } 6 \\
\text { Isorhamnetin- } \\
\text { O-(di- } \\
\text { deoxyhexosyl- } \\
\text { hexoside) }\end{array}$} & \multicolumn{2}{|c|}{$\begin{array}{c}\text { Peak } 7 \\
\text { Isorhamnetin- } \\
\text { O-hexoside- } \\
\text { (deoxyhexosyl- } \\
\text { hexosyde) }\end{array}$} & \multicolumn{2}{|c|}{$\begin{array}{c}\text { Peak } 8 \\
\text { Isorhamentin- } \\
\text { O- } \\
\text { (deoxyhexosyl } \\
\text {-hexoside) }\end{array}$} & \multicolumn{2}{|c|}{$\begin{array}{l}\text { Total } \\
\mathrm{mg} / \mathrm{g}\end{array}$} \\
\hline & UAE & MAE & UAE & MAE & UAE & MAE & UAE & MAE & UAE & MAE & UAE & MAE & UAE & MAE & UAE & MAE & UAE & $\mathrm{MAE}$ \\
\hline 1 & 0,38 & 0,23 & 0,09 & 0,06 & 0,31 & 0,29 & 0,11 & 0,08 & 0,03 & 0,03 & 0,13 & 0,14 & 0,08 & 0,10 & 0,00 & 0,02 & 1,13 & 0,94 \\
\hline 2 & 0,34 & 0,29 & 0,03 & 0,10 & 0,30 & 0,35 & 0,09 & 0,09 & 0,02 & 0,03 & 0,11 & 0,18 & 0,06 & 0,09 & 0,01 & 0,03 & 0,95 & 1,16 \\
\hline 3 & 0,22 & 0,22 & 0,04 & 0,04 & 0,25 & 0,25 & 0,08 & 0,06 & 0,02 & 0,02 & 0,10 & 0,13 & 0,06 & 0,06 & 0,00 & 0,01 & 0,77 & 0,80 \\
\hline 4 & 0,31 & 0,20 & 0,03 & 0,03 & 0,24 & 0,26 & 0,09 & 0,07 & 0,02 & 0,03 & 0,10 & 0,11 & 0,06 & 0,06 & 0,02 & 0,01 & 0,88 & 0,76 \\
\hline 5 & 0,25 & 0,23 & 0,03 & 0,07 & 0,20 & 0,18 & 0,09 & 0,02 & 0,02 & 0,02 & 0,08 & 0,13 & 0,05 & 0,06 & 0,01 & 0,03 & 0,73 & 0,72 \\
\hline 6 & 0,30 & 0,24 & 0,05 & 0,10 & 0,28 & 0,36 & 0,10 & 0,09 & 0,03 & 0,04 & 0,11 & 0,16 & 0,07 & 0,09 & 0,01 & 0,03 & 0,96 & 1,09 \\
\hline 8 & 0,29 & 0,22 & 0,03 & 0,08 & 0,27 & 0,29 & 0,08 & 0,07 & 0,02 & 0,03 & 0,11 & 0,13 & 0,06 & 0,06 & 0,01 & 0,01 & 0,88 & 0,89 \\
\hline 9 & 0,35 & 0,20 & 0,06 & 0,05 & 0,37 & 0,30 & 0,09 & 0,07 & 0,03 & 0,03 & 0,14 & 0,15 & 0,09 & 0,09 & 0,01 & 0,02 & 1,14 & 0,90 \\
\hline 10 & 0,55 & 0,20 & 0,28 & 0,05 & 0,59 & 0,29 & 0,19 & 0,07 & 0,07 & 0,03 & 0,23 & 0,15 & 0,13 & 0,09 & 0,02 & 0,01 & 2,06 & 0,88 \\
\hline 11 & 0,21 & 0,28 & 0,07 & 0,09 & 0,25 & 0,31 & 0,07 & 0,08 & 0,02 & 0,03 & 0,09 & 0,15 & 0,06 & 0,08 & 0,00 & 0,02 & 0,79 & 1,02 \\
\hline 12 & 0,31 & 0,21 & 0,04 & 0,08 & 0,27 & 0,27 & 0,09 & 0,07 & 0,02 & 0,03 & 0,09 & 0,12 & 0,06 & 0,06 & 0,00 & 0,01 & 0,89 & 0,86 \\
\hline 13 & 0,35 & 0,29 & 0,06 & 0,12 & 0,34 & 0,26 & 0,12 & 0,01 & 0,03 & 0,05 & 0,14 & 0,19 & 0,08 & 0,10 & 0,01 & 0,02 & 1,13 & 1,03 \\
\hline
\end{tabular}




\begin{tabular}{|c|c|c|c|c|c|c|c|c|c|c|c|c|c|c|c|c|c|c|}
\hline 14 & 0,30 & 0,13 & 0,05 & 0,02 & 0,30 & 0,15 & 0,09 & 0,05 & 0,02 & 0,01 & 0,11 & 0,07 & 0,07 & 0,04 & 0,02 & 0,00 & 0,96 & 0,47 \\
\hline 15 & 0,29 & 0,24 & 0,03 & 0,06 & 0,24 & 0,31 & 0,08 & 0,09 & 0,02 & 0,03 & 0,10 & 0,14 & 0,06 & 0,07 & 0,01 & 0,02 & 0,83 & 0,93 \\
\hline 16 & 0,32 & 0,23 & 0,05 & 0,06 & 0,29 & 0,30 & 0,10 & 0,07 & 0,02 & 0,03 & 0,10 & 0,14 & 0,06 & 0,08 & 0,01 & 0,02 & 0,95 & 0,91 \\
\hline 17 & 0,23 & 0,24 & 0,10 & 0,06 & 0,31 & 0,27 & 0,08 & 0,06 & 0,03 & 0,03 & 0,13 & 0,13 & 0,06 & 0,06 & 0,01 & 0,02 & 0,96 & 0,87 \\
\hline 18 & 0,37 & 0,22 & 0,06 & 0,09 & 0,37 & 0,31 & 0,12 & 0,07 & 0,03 & 0,04 & 0,15 & 0,13 & 0,09 & 0,07 & 0,01 & 0,01 & 1,21 & 0,94 \\
\hline 19 & 0,40 & 0,25 & 0,05 & 0,06 & 0,41 & 0,33 & 0,13 & 0,08 & 0,04 & 0,02 & 0,15 & 0,15 & 0,09 & 0,08 & 0,01 & 0,01 & 1,28 & 0,99 \\
\hline 20 & 0,34 & 0,26 & 0,04 & 0,11 & 0,30 & 0,29 & 0,13 & 0,08 & 0,02 & 0,03 & 0,12 & 0,13 & 0,07 & 0,06 & 0,01 & 0,02 & 1,02 & 0,99 \\
\hline 21 & 0,32 & 0,21 & 0,05 & 0,06 & 0,35 & 0,29 & 0,08 & 0,07 & 0,03 & 0,03 & 0,13 & 0,12 & 0,07 & 0,07 & 0,01 & 0,01 & 1,03 & 0,86 \\
\hline 22 & 0,21 & 0,20 & 0,03 & 0,04 & 0,19 & 0,25 & 0,04 & 0,05 & 0,03 & 0,02 & 0,09 & 0,12 & 0,04 & 0,06 & 0,01 & 0,01 & 0,64 & 0,76 \\
\hline 23 & 0,27 & 0,13 & 0,04 & 0,07 & 0,24 & 0,27 & 0,08 & 0,07 & 0,02 & 0,03 & 0,09 & 0,13 & 0,05 & 0,06 & 0,01 & 0,01 & 0,81 & 0,78 \\
\hline 24 & 0,37 & 0,26 & 0,05 & 0,06 & 0,35 & 0,30 & 0,12 & 0,07 & 0,04 & 0,03 & 0,13 & 0,13 & 0,08 & 0,06 & 0,01 & 0,02 & 1,15 & 0,93 \\
\hline 25 & 0,32 & 0,28 & 0,05 & 0,08 & 0,28 & 0,33 & 0,11 & 0,07 & 0,02 & 0,03 & 0,11 & 0,16 & 0,08 & 0,08 & 0,02 & 0,02 & 0,99 & 1,04 \\
\hline 26 & 0,38 & 0,20 & 0,06 & 0,04 & 0,38 & 0,30 & 0,11 & 0,08 & 0,03 & 0,03 & 0,14 & 0,14 & 0,09 & 0,06 & 0,01 & 0,02 & 1,21 & 0,87 \\
\hline 27 & 0,30 & 0,20 & 0,05 & 0,08 & 0,31 & 0,30 & 0,09 & 0,07 & 0,02 & 0,03 & 0,11 & 0,15 & 0,07 & 0,08 & 0,01 & 0,02 & 0,96 & 0,93 \\
\hline 28 & 0,41 & 0,24 & 0,05 & 0,10 & 0,36 & 0,23 & 0,12 & 0,01 & 0,03 & 0,03 & 0,13 & 0,14 & 0,08 & 0,08 & 0,01 & 0,03 & 1,20 & 0,86 \\
\hline 29 & 0,31 & 0,20 & 0,06 & 0,07 & 0,30 & 0,29 & 0,10 & 0,08 & 0,02 & 0,03 & 0,12 & 0,14 & 0,07 & 0,07 & 0,01 & 0,02 & 0,98 & 0,90 \\
\hline 30 & 0,24 & 0,27 & 0,10 & 0,07 & 0,29 & 0,36 & 0,10 & 0,09 & 0,03 & 0,02 & 0,12 & 0,17 & 0,06 & 0,08 & 0,01 & 0,04 & 0,95 & 1,09 \\
\hline 31 & 0,30 & 0,29 & 0,07 & 0,07 & 0,32 & 0,34 & 0,10 & 0,10 & 0,04 & 0,03 & 0,13 & 0,16 & 0,07 & 0,08 & 0,01 & 0,02 & 1,03 & 1,08 \\
\hline
\end{tabular}


Betalains response surface graphs

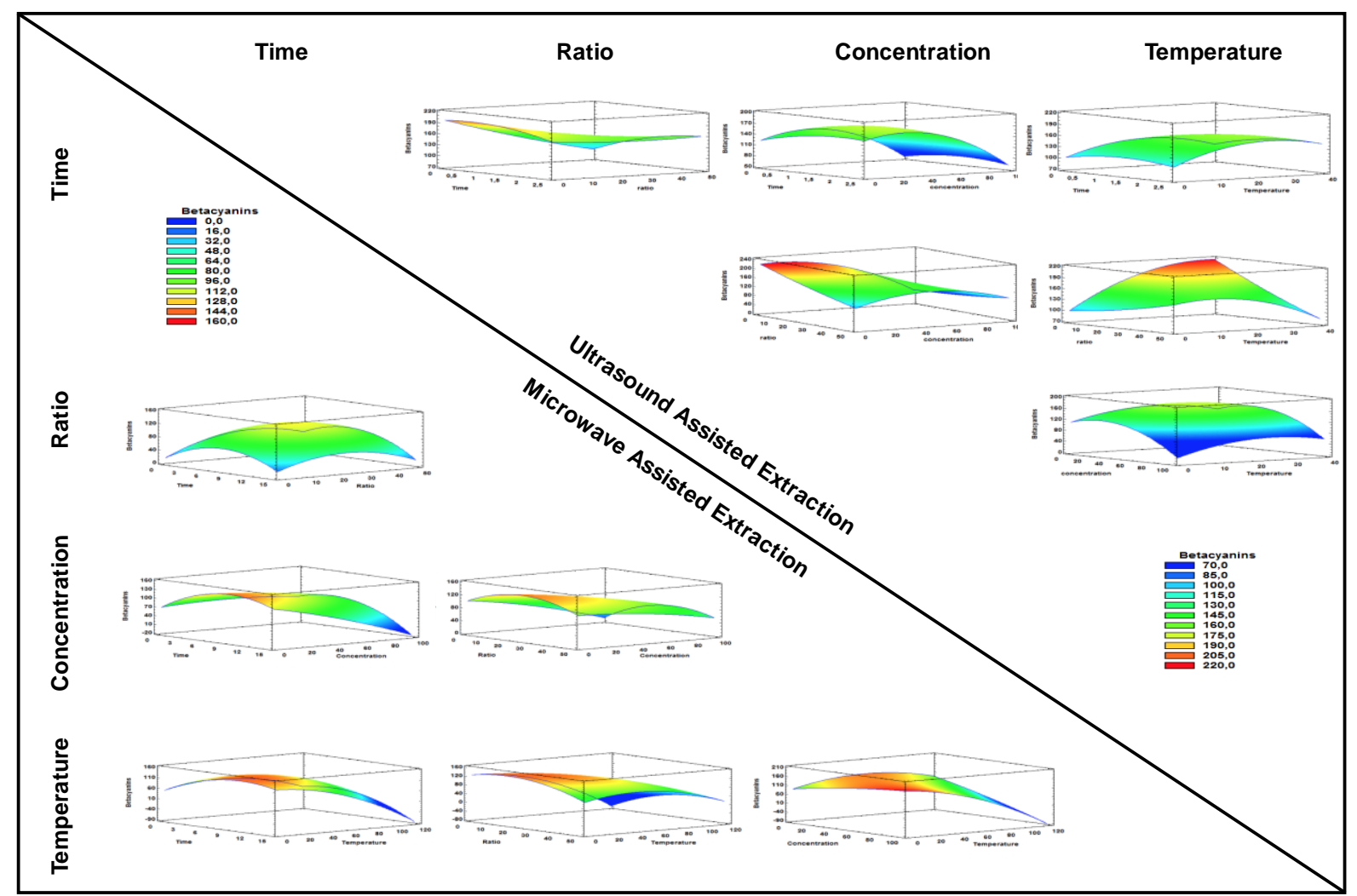

Annex 7-4 Total betacyanin content 3d response surface plots of UAE and MAE for the parametric responses. For representation purposes, the 2 variable which are not confronted, were positioned at the centre of their experimental domain. 
Phenolic compounds response surface graphs

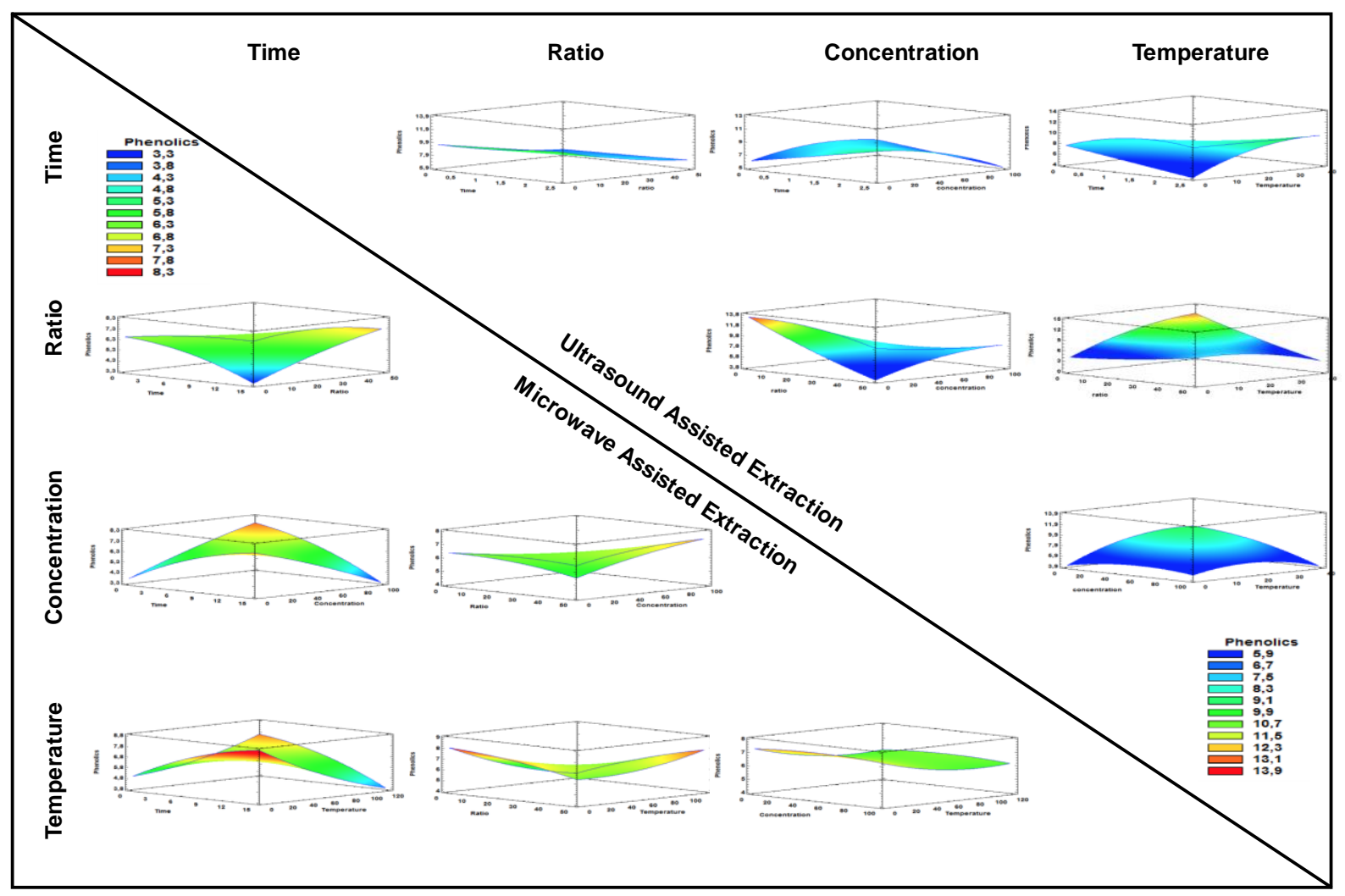

Annex 7-5 Total phenolic content 3d response surface plots of UAE and MAE for the parametric responses. For representation purposes, the 2 variable which are not confronted, were positioned at the centre of their experimental domain. 
Flavonoids response surface graphs

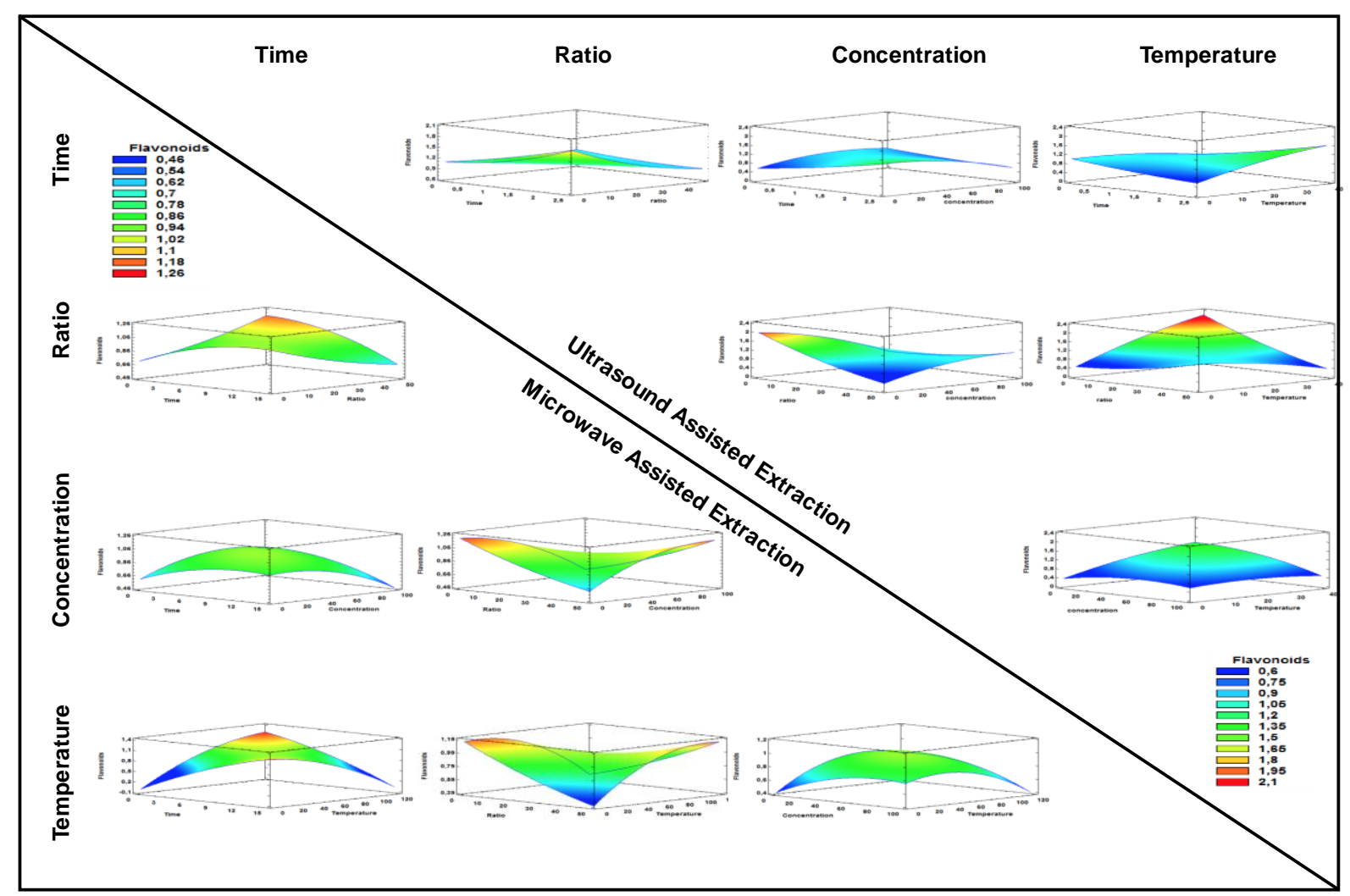

Annex 7-6 Total flavonoid content 3d response surface plots of UAE and MAE for the parametric responses. For representation purposes, the 2 variable which are not confronted, were positioned at the centre of their experimental domain. 
Antioxidant activity response surface graphs

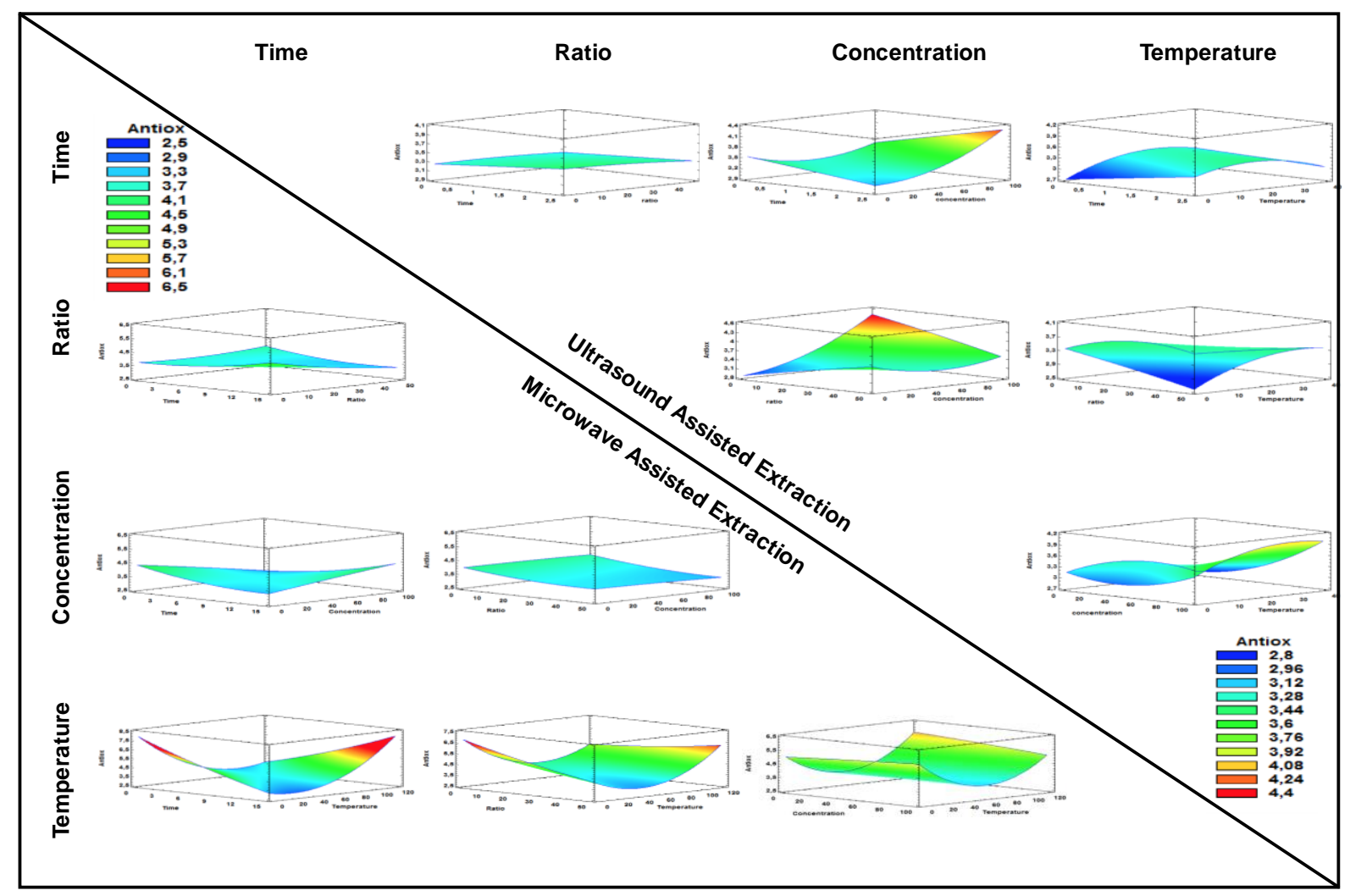

Annex 7-7 Antioxidant activity 3d response surface plots of UAE and MAE for the parametric responses. For representation purposes, the 2 variable which are not confronted, were positioned at the centre of their experimental domain. 
Annex 7-8 Colour coordinates acquired in the 31 runs of ultrasound-assisted and microwave-assisted extraction. Terms used include: $L^{*}$ : lightness; $a^{*}$ : green-red colour component; $\mathbf{b}^{*}$ : blue-yellow colour component and C: Chroma

\begin{tabular}{|c|c|c|c|c|c|c|c|c|}
\hline \multirow[t]{3}{*}{ Run } & \multicolumn{8}{|c|}{ Colour coordinates } \\
\hline & \multicolumn{2}{|c|}{$L^{*}$} & \multicolumn{2}{|c|}{$a^{*}$} & \multicolumn{2}{|c|}{$b^{*}$} & \multicolumn{2}{|c|}{ Chroma } \\
\hline & UAE & MAE & UAE & MAE & UAE & MAE & UAE & MAE \\
\hline 1 & 43,82 & 36,12 & 83,84 & 76,12 & $-22,35$ & $-0,99$ & 86,77 & 76,12 \\
\hline 2 & 45,36 & 49,71 & 84,50 & 74,89 & $-23,90$ & 26,47 & 87,82 & 79,43 \\
\hline 3 & 47,39 & 46,89 & 85,33 & 78,96 & $-26,95$ & 18,42 & 89,49 & 81,08 \\
\hline 4 & 48,17 & 37,51 & 83,07 & 77,84 & $-24,19$ & $-3,40$ & 86,52 & 77,92 \\
\hline 5 & 45,50 & 38,62 & 84,51 & 76,27 & $-22,47$ & 4,67 & 87,44 & 76,41 \\
\hline 6 & 47,70 & 50,57 & 85,37 & 74,00 & $-24,99$ & 24,80 & 88,95 & 78,05 \\
\hline 7 & 43,99 & 37,31 & 83,30 & 74,05 & $-21,97$ & 11,04 & 86,15 & 74,87 \\
\hline 8 & 46,60 & 38,17 & 86,48 & 76,71 & $-25,64$ & 3,88 & 90,20 & 76,80 \\
\hline 9 & 45,84 & 45,24 & 85,24 & 73,07 & $-23,82$ & 25,69 & 88,51 & 77,46 \\
\hline 10 & 45,60 & 36,20 & 84,99 & 75,34 & $-23,10$ & 3,32 & 88,08 & 75,41 \\
\hline 11 & 45,93 & 38,43 & 85,18 & 73,83 & $-24,28$ & 8,39 & 88,57 & 75,01 \\
\hline 12 & 48,44 & 40,32 & 86,35 & 75,52 & $-26,97$ & 13,48 & 90,46 & 76,72 \\
\hline 13 & 48,81 & 37,01 & 86,25 & 77,75 & $-27,53$ & 0,38 & 90,54 & 77,75 \\
\hline 14 & 55,56 & 34,01 & 76,34 & 72,32 & $-23,63$ & 0,36 & 79,91 & 72,33 \\
\hline 15 & 44,73 & 36,78 & 83,56 & 77,28 & $-22,94$ & $-1,61$ & 86,65 & 77,30 \\
\hline 16 & 48,48 & 35,41 & 86,56 & 73,50 & $-27,00$ & 5,64 & 90,67 & 73,72 \\
\hline 17 & 44,76 & 35,11 & 84,74 & 73,47 & $-22,46$ & 6,12 & 87,66 & 73,73 \\
\hline 18 & 43,87 & 35,24 & 83,12 & 74,33 & $-21,03$ & 1,23 & 85,74 & 74,34 \\
\hline 19 & 43,14 & 41,82 & 83,22 & 76,36 & $-21,64$ & 16,74 & 85,99 & 78,18 \\
\hline 20 & 44,36 & 35,54 & 84,80 & 74,08 & $-21,43$ & 5,65 & 87,47 & 74,30 \\
\hline 21 & 45,24 & 34,86 & 84,83 & 74,35 & $-22,22$ & 0,36 & 87,69 & 74,36 \\
\hline 22 & 43,76 & 34,09 & 83,32 & 72,65 & $-20,83$ & 1,82 & 85,89 & 72,67 \\
\hline 23 & 48,05 & 36,70 & 85,75 & 75,18 & $-24,05$ & 3,41 & 89,06 & 75,26 \\
\hline 24 & 45,35 & 35,46 & 84,89 & 73,99 & $-21,61$ & 4,10 & 87,60 & 74,10 \\
\hline 25 & 47,51 & 36,19 & 85,71 & 72,86 & $-22,68$ & 8,00 & 88,65 & 73,29 \\
\hline 26 & 44,18 & 37,42 & 83,35 & 73,53 & $-20,70$ & 8,36 & 85,88 & 74,00 \\
\hline 27 & 44,96 & 36,78 & 84,71 & 77,95 & $-21,22$ & $-5,64$ & 87,32 & 78,16 \\
\hline 28 & 44,50 & 34,71 & 84,58 & 73,31 & $-20,55$ & 5,84 & 87,04 & 73,54 \\
\hline 29 & 46,12 & 34,93 & 84,76 & 59,35 & $-23,37$ & 26,34 & 87,93 & 64,99 \\
\hline 30 & 43,67 & 35,31 & 83,03 & 75,06 & $-19,85$ & $-0,79$ & 85,37 & 75,07 \\
\hline 31 & 44,40 & 35,39 & 83,24 & 74,07 & $-19,78$ & 5,28 & 85,56 & 74,26 \\
\hline
\end{tabular}






\section{Capítulo 8 CONCLUSIONES}



Las principales conclusiones obtenidas de los resultados en estas tesis son:

\section{Frutos higos chumbos (Opuntia)}

1) La diferencia entre especies y variedades de la misma familia Opuntia son muy claras en términos morfológicos, en donde los pesos y las medidas axiales de los frutos varían drásticamente, encontrando diferencias de hasta 6 veces el peso y 2 veces el diámetro de Opuntia engelmannii comparado con Opuntia ficus-indica var Sanguigna. Incluso pudimos identificar diferencias nutricionales significativas dentro de la misma especie, como es el caso de las concentraciones proteicas entre OFI Sanguigna y OFI Gialla, en donde la primera variedad contiene hasta $40 \%$ más de contenido proteico y lo cual atribuimos al aumento en pigmentos betalainicos los cuales contienen estructuras nitrogenadas, y es debido a estos pigmentos que observamos la diferencia más clara que les atribuye sus características distintivas entre cada variedad, las diferentes coloraciones en los frutos.

2) Los perfiles en compuestos lipofílicos e hidrofílicos muestran también diferencias muy marcadas, sobre todo entre especies, el total de ácidos orgánicos presentes en Opuntia engelmannii (OE), comparados con los frutos de OFI var. Sanguigna y var. Gialla, son hasta 10 veces menores, valores que se repiten en las concentraciones de azúcares libres, en donde observamos como los valores de fructosa en OE $(0,53 \mathrm{~g} / 100 \mathrm{~g}$ PS) son extremamente bajos comparados con OFI var Gialla y Sanguigna (4,13 y 4,97 g/100 g PS respectivamente). Debido a que los valores de carbohidratos totales son inversos y $\mathrm{OE}$ llega a duplicar a los valores de las variedades de OFI, propusimos que mientras los frutos de OFI son favorecidos en cuestiones organolépticas debido al alto contenido de azúcares libres, su contraparte OE, contiene arreglos de fibras y carbohidratos complejos como el mucilago, el cual tiene propiedades potenciales para su uso como aditivo en las industrias de alimentación, farmacia y cosmética.

3) Se identificaron 7 betalaínas, de las cuales 3 pertenecen al grupo de las betaxantinas y 4 al de las betacianinas. Las moléculas mayoritarias de cada grupo son también las más abundantes en la naturaleza según la bibliografía científica, por parte de las betacianinas encontramos la betanina e indicaxantina como la más abundante betaxantina. Su distribución dentro de las especies estudiadas es muy 
heterogénea, aunque los perfiles betalainicos de cada variedad nos describe muy bien sus características visuales, en OE se encuentran solo betacianinas con lo que obtenemos una tonalidad violeta muy intensa. OFI Sanguigna presenta una mayoría y alto contenido en betacianinas, aunque también contiene betaxantinas, lo que ayuda a modificar la tonalidad del fruto a un rojo más vibrante. Por ultimo OFI Gialla predomina en betaxantinas aunque también tiene un bajo contenido en betanin, lo cual proporciona las motas rojas que se combinan para dar tonalidades más naranjas.

4) Los frutos de todas las variedades estudiadas, presentaron potencial antimicrobiológico. Todos los frutos mostraron poder antifúngico contra las 9 cepas probadas, mientras que el poder bactericida testado en 8 cepas fue efectivo en los 3 frutos, con excepción en 3 cepas, donde OFI Gialla no mostró efecto alguno (Micrococcus aureus, Escherichia coli y Enterobacter cloacae). El poder inhibidor, bactericida y fungicida de los frutos fue comparado contra antibióticos comerciales y en muchos de los casos, las concentraciones necesarias de inhibición o aniquilación de microorganismos fueron menores en los frutos y por tanto mejores.

\section{Subproductos Aguacate (Persea americana)}

5) De acuerdo a los estudios realizados preliminarmente en los frutos del aguacate, se ha determinado que la capacidad antioxidante de los subproductos, son mucho mejores que la de los fruto, lo que resalta la importancia del aprovechamiento de estos residuos, cuando comparamos ambos subproductos, y como era de esperar, observamos una mejor capacidad en las pieles comparadas con las semillas tanto en las metodologías experimentales hidrofílicas como en las lipofílicas.

\section{Subproductos Aguacate (Persea americana)}

6) Los subproductos de Persea americana var Hass, presentaron en conjunto 29 compuestos fenólicos, 14 flavan-3-oles (derivados de epicatequinas), 9 flavonoides (derivados de Quercetina, Kaempferol e isorhamnetina) y 6 ácidos fenólicos (derivados de ácidos cloragénico y cumárico). De estos 23 compuestos, se encontraron 18 en las pieles y 8 en las semillas, de los cuales solo 2 compuestos coincidieron en ambos 
subproductos (Epicatequina y un trímero de epicatequina de tipo B). Las semillas son ricas en ácidos fenólicos, contienen solo una molécula flavan-3-oles y carecen de flavonoides, mientras que las pieles contienen mayoritariamente flavan-3-oles, flavonoides y solo 2 ácidos fenólicos derivados del ácido clorogénico. Debido a la mayor cantidad de compuestos fenólicos, las pieles contienen hasta 3 veces más de estos compuestos comparados con las semillas $(227,9$ y $72,5 \mathrm{mg} / \mathrm{g}$ extracto respectivamente).

7) Es importante remarcar que aunque en el contenido total de compuestos fenólicos en las pieles triplica la cantidad total obtenida en las semillas, la actividad antioxidante es ligeramente menor, las pieles son 1,5 veces mejores en este sentido que las semillas, lo que atribuimos a la complejidad de las estructuras de los flavan-3-oles, ya que de acuerdo a otras investigaciones en la bibliografía, la especificidad de los antioxidantes disminuye conforme aumentan los números de moléculas agregadas, en este caso, en los dímeros, trímeros, tetrámeros, y así sucesivamente.

8) Debido a los compuestos fenólicos son metabolitos secundarios generados en el metabolismo vegetal como respuesta a diferentes tipos de estrés, entre ellos el combatir infecciones, en este trabajo hemos observado en las 8 cepas testadas alta eficiencia de los extractos de los subproductos para inhibir y destruir tanto bacterias Gram positivas como negativas, destacando ambas capacidades en bacterias Gram negativas como Enterobacter cloacae, Pseudomonas aeruginosa y Salmonella typhimurium, incluso mejor que los antibióticos usados como control positivo. Por otro lado, su capacidad antifúngica testada de los subproductos contra 8 cepas patógenas comunes, mostró una eficiencia media-buena como inhibidor, y solo las semillas exhibieron una capacidad excelente antifúngica ante 2 cepas (Aspergillus ochraceus y Trichoderma viride), superando por mucho a los antimicóticos comerciales.

\section{Subproductos higos chumbos (Opuntia spp.)}

9) El perfil fenólico de los extractos de los subproductos de Opuntia obtenido, corresponde a 12 compuestos fenólicos, de los cuales 10 de ellos son flavonoides 8 derivados de Isorhamnetina, 1 derivado de Quercetina y 1 derivado de Kaempferol, además de 2 ácidos fenólicos (ácido piscidico y eucomino). El extracto de $\mathrm{OE}$ es el que se encuentra 
en mayor concentración, casi el doble comparado con los extractos de OFI Gialla y Sanguigna. Aunque en OE solo se detectaron 5 de los 12 compuestos, solo 2 de ellos se pudieron cuantificar mientras que los otros tres, solo se pudieron detectar trazas, pero aun así, el contenido en Isorhamnetina-O-(deoxihexosil-hexosido) $\quad(5,99 \mathrm{mg} / \mathrm{g}$ extracto), dispara el contenido total de fenoles totales.

10) Se detectaron 7 betalaínas en total en los tres extractos, 2 isómeros de indicaxantina pertenecientes a las betaxantinas y 5 betacianinas. Al igual que en los frutos, betanin e indicaxantina, fueron los compuestos mayoritarios de cada grupo y estos se encontraron distribuidos de distintas manera en los tres subproductos. Las betaxantinas fueron solo detectadas en las variedades de OFI, mientras que OE predomina en el contenido de betacianinas hasta 5 y 15 veces más que los extractos de OFI Sanguigna y OFI Gialla respectivamente.

11) La capacidad antioxidante de los extractos de los subproductos analizados, se corresponde inversamente al contenido de compuestos y betalaínas. De esta forma que apreciamos que $\mathrm{OE}$ es 2,3 y 2 más veces eficaz que OG y OS respectivamente, en los análisis de capacidad antioxidante de compuestos hidrofílicos. En el caso de la capacidad antioxidante de los compuestos lipofílicos, solo el análisis de $\beta$ caroteno se pudo realizar despreciando los valores obtenidos en OS, lo que atribuimos a que los valores fueron erróneos debido a una posible interferencia del color en este análisis espectrofotométrico especifico, lo que comprobamos al obtener datos totalmente erróneos en el análisis TBARS, el cual fue descartado de la publicación.

12) La capacidad antioxidante, al igual que el poder antimicrobiano, se atribuye en este caso a un posible efecto sinérgico entre los compuestos fenólicos y las betalaínas. Estrictamente hablando del poder antibacteriano, observamos una eficiencia media alta, ya que dentro de las 8 cepas patógenas analizadas, en 2 de ellas los 3 extractos no mostraron efecto alguno, aunque por otro lado, se comprobó que en otras tres cepas (Bacillus cereus, Enterobacter cloacae y Salmonella typhimurium), estos poseen una mejor eficacia cuando se les compara con el control comercial utilizado. En cualquiera de los casos, ningún extracto demostró ser mejor que los otros en términos generales, debido 
a que cada uno de ellos actúa de forma distinta con respecto a las cepa bacteriana analizada.

A diferencia del poder bactericida, el poder fungicida muestra una alta eficacia en las tres variedades. De las 8 cepas estudias, en 2 de ellas (Penicillium ochrochloron y Trichoderma viride para OG y OE y Penicillium ochrochloron y Aspergillus ochraceus en OS) los tres extractos de los subproductos de Opuntia, probaron ser mejores que el fungicida comercial utilizado como control positivo. En este apartado si se observa un mejor efecto protector frente a patógenos fúngicos en OS seguido por OE y por último en OG.

Los efectos de los extractos se evaluaron in-vitro en cultivos celulares PLP2 para poder garantizar la seguridad de cada uno de los extractos y ninguno de estos mostro toxicidad a estas células testadas. Además, se comprobó en las 4 líneas celulares tumorales su efecto antitumoral, y a pesar de demostrar esta capacidad benéfica, las concentraciones necesarias para observar dicho efecto fueron mayores que las utilizadas en el control positivo de elipticina. Por lo que podemos corroborar la seguridad de los extractos además de su capacidad antitumoral.

\section{Optimización de extraciones}

13) El perfil fenólico de los extractos de las pieles de Opuntia engelmannii obtenidos mediante extracciones asistidas por microondas y ultrasonidos, corresponde a 12 compuestos fenólicos, 8 de ellos con estructuras flavonoides derivados casi en totalidad de isorhamnetina, exceptuando un solo derivado de Apigenina, compuesto que ha sido identificado por primera vez en las pieles de frutos de Opuntia. Además, se detectaron 4 ácidos fenólicos (ácido piscidico, ácido cafeico y 2 derivados del ácido ferúlico). Los ácidos fenólicos fueron los que se encontraron en mayor concentración y esto se debe sobre todo a que el ácido piscidico fue el compuesto mayoritario en todas las extracciones con concentraciones muy por encima del resto de los compuestos fenólicos.

14) En los subproductos de Opuntia engelmannii, se identificaron 7 betalaínas correspondientes todas al grupo de las betacianinas, 6 de 
ellas previamente documentadas en nuestros y otros trabajos, y una de ellas, (iso)-phyllocactina, a pesar de haber sido descrita antes en la familia Cactaceae, es la primera vez que se describe en esta variedad. Las betacianinas mayoritarias fueron betanina, seguidas de su isómero, isobetanina, gomphrenina, betanidina, isobetanidina, (iso)phyllocactina y por ultimo 17 decarboxi-betanina.

15) Mediante el uso del diseño experimental de respuesta de superficie acompañado del diseño central compuesto, pudimos determinar dentro de los rangos estudiados, las variables significativas de acuerdo a la tecnología de extracción empleada y a la respuesta analizada. Por un lado, siendo el ratio solido-líquido y la concentración de solvente las variables que más influencia tienen sobre las respuestas usando tanto la extracción asistida por microondas como por ultrasonidos. Mientras que por otro lado, las variables temperatura y tiempo de extracción solo afectaron a las extracciones realizadas en el microondas, concretamente, la temperatura afecto significativamente a las extracciones de betalaínas, y la variables temperatura y tiempo afectaron también significativamente al parámetro de color.

16) También, a través del uso de estos diseños experimentales hemos sido capaces de obtener los coeficientes polinomiales de segundo orden, a partir de los cuales podemos hacer tanto la representación gráfica de las extracciones, como poder inferir los valores óptimos de cada una de las respuesta analizadas. Adicionalmente, determinamos la optimización general del cumulo de repuestas, mediante el cual obtuvimos un mayor factor de deseabilidad $(0,985)$ y mejores concentraciones en las respuestas de las extracciones asistidas mediante microondas y por lo cual nos declinamos a su elección como metodología de extracción recomendada, ya que utilizando los valores de 2,5 minutos, $5 \mathrm{~g} / \mathrm{L}, 34,6 \%$ de metanol en agua y una temperatura de $30{ }^{\circ} \mathrm{C}$, obtuvimos los mejores valores de cada respuesta, en este caso: 201,6 mg de betalaínas/ g de piel seca, 13,9 mg de ácidos fenólicos/g, $2,4 \mathrm{mg}$ de flavonoides/g, 85,7 \% de rendimiento de extracción y un valor de $2,9 \mathrm{mg}$ de extracto/ $\mathrm{mL}$ para poder obtener el valor $\mathrm{IC}_{50}$ 

Capítulo 9

ANEXOS 

Anexo 1

Poster 4ta edición del "ISEKI Food conference" (Julio 2016) Viena, Austria. ISBN 978-3-900932-34-3

\title{
Effect of drying temperatures and stored conditions on bioactive compound of prickly pear (Opuntia spp.) peels.
}

\author{
Bruno Melgar $^{1 *}$, Esperanza M. Garcia-Castello ${ }^{1}$, Luis Mayor ${ }^{?}$ \\ and Antonio Rodriguez-Lopez ${ }^{3}$.
}

1. Institute of Food Engineering for Development (IIAD), Universitat Politècnica de València, Spain.

2. Department2, College or Institute2, University2, Country2

3. Dpt. Of Chemical and Nuclear Engineering, Universitat Politècnica de València, Spain.

* Corresponding author: $\quad$ bruno.melgarc@gmail.com; anrodlo@iqn.upv.es

Prickly pear has become an important fruit crop in many semi-arid lands of the world. The cactus pear is often marketed as a raw peeled fruit, juice, marmalades and other different products. These transformations produce considerable amounts of by-products (peels and seeds).

Peels represent a large proportion of the whole fruit and constitute an important source of bioactive compounds, especially polyphenols, flavonoids and betalains which are the characteristic colorants of this fruit. Polyphenols are present in a higher concentration on the peels compared to the edible portion of the fruit, which makes it a great source of extraction for this type of bioactive compound.

These phenolic compounds have been recognized as a potential nutraceutical target for the food and pharmaceutical industries. Due to 
their wide range of bioactivities, there is a growing interest in developing of methods for their recovery and for the optimal storage of the by-products.

Storing these by-products to prevent the microbial spoilage and to preserve them in optimal conditions until their use could be expensive and might be considered irrational. Therefore, the purpose is to look for alternatives to reduce the cost of storage without sacrificing the bioactive compounds.

The aim of the current investigation was to evaluate changes on the phenolic compounds of the dried peels of prickly pear at different temperatures $\left(40,60\right.$ and $\left.70{ }^{\circ} \mathrm{C}\right)$ and to follow their behavior once they are dried and stored at room temperature (15, 60 and 90 days) by HPLC-DAD and spectrophotometric methods.

For the different drying temperatures we detected a decrease of up to $58 \%\left(70{ }^{\circ} \mathrm{C}\right)$ of the phenolic compounds, which also has negative influence on the antioxidant capacity. On the other hand, stored dry peel did not show any important changes through time.

Keywords: Food by-products, Bioactive compounds, Prickly pear, Drying. 
Bruno Melgar', Esperanza M. Garcia-Castello', Luis Mayor ${ }^{2}$, Antonio D. Rodriguez-Lopez ${ }^{3}$

1. Universitat Politènica de València - Institute of food engineering for development (IIAD), Valencia, Spain.

2. ISEKI-Food Association (IFA), Austria.

Effect of drying temperatures on bioactive compounds of Opuntia ficus-indica and Persea

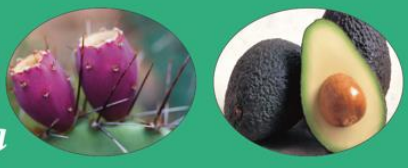
america byproducts

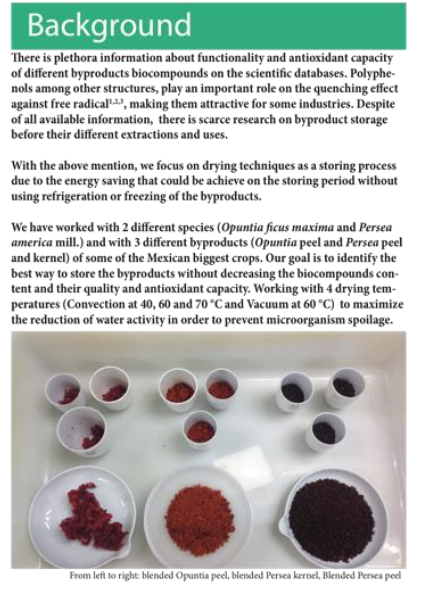

Methods

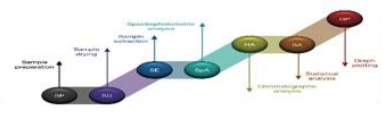

\section{Extraction setup}

$$
\text { (1) }
$$

\section{Conclusions}

- Persea peels contains lower concentration of total polyphenols content (TPC) compared with our other 2 byproducts, although, it shows a con-
siderable antioxidant capacity, greater than Persea kernel and almost the same as Opuntia peel, which shows higher TPC
sation

cosect on the antionidnt pacity as well as 'TPC of our 3 sample. This could be explained due to the yphenol oxidase (PPO)', which has been reported to have higher activity at $55^{\circ} \mathrm{C}$

- Almost in all cases, vacuum drying has decreased more the TPC and the antioxidant capacity of our byproduct compered with the convection dry ing apuntio peels has the

ity compared with the Persea byprod reduction of TPC and antioxidant capain mind the different sample drying conditions.

che also tornd hrough HPLC Tediniques, a detrimental content or certain flavonoids with all our drying temperatures which in addition to our spectrophotom

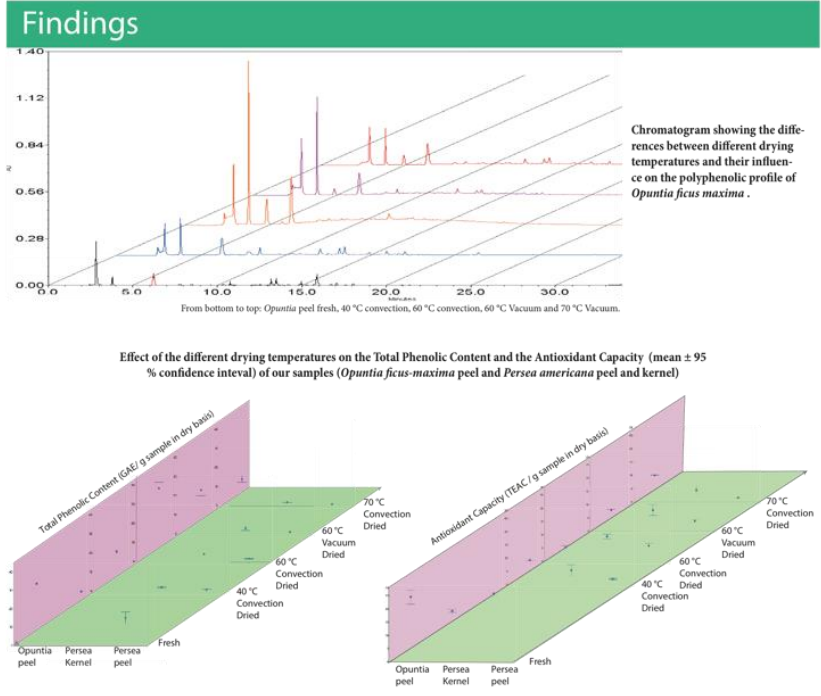

Decreased percentages of Total Polyphenol Content (TPC) and Antioxidant Activity (AA) in the samples

IPC

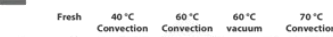

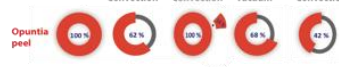

$\therefore=0$

을 (1) 00

\section{Future directions}

- The HPLC chromatogram reveal the increase of certain peaks at the beginning of the analysis that could not be determined. Currently we are
working on the identification of this peaks through Q-Tof HPIC-MS/MS Te. working on the
chniques.

- Future research on storing conditions will be carried out in order to develop an efficient technique, able to keep unspoiled the byproducts and as well as to preserve their TPC content and antioxidant capacity.

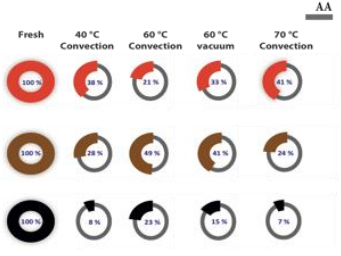

\section{Literature cited}

Del Caro, A, Piga, A, Pinna, 1., Fenu, P. M., \& Agabbio, M. (2004). Effect of drying conditions and storage period on polyphenolic content, antioxidant capaci4780-4784. http://doi.org/10.1021/jifo49889;

Kosiáska, A, Karamać, M., Estrella, L., Hernaindec, T., Bartolomé, B., \& Dykes G. a. (2012). Phenoilic compound proiles and antionidant capacity of persea ame. mistry, 60(18), 4613-4619, http://doi.org/10.1021/j300090p

M. Lbrian, C, Mayor, L, M. Garcia-Castello, E, \& Vidal-Brotons, D. (2013). Polyphenol extraction from grape wastes: Solvent and pH effect. Agricultural Sci

Mayor, L, Galvo, A, Morecira, R., Fito, P., \& Garcia-Castello, E. (2013), Water sorption isotherms of globe artichoke le,

\section{UNIVERSITAT POLITĖCNICA DE VALÈNCIA}

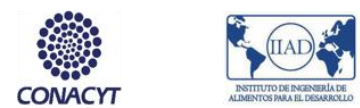

CONACYT

\section{Further info:}

brumelca@doctor.upv.es (+34) 684327458

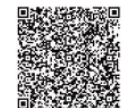




\title{
Anexo 2
}

Presentación oral en el "6to Simposio de becarios CONACyT en Europa" disponible en https://goo.gl/Xbz3aW

\section{Extraction of natural colorants obtained from prickly pear fruit by-products.}

\author{
Bruno Melgar Castañedaa, , Esperanza M. Garcia-Castelloa, Antonio \\ D. Rodriguez-Lopez .
}

anstituto Universitario de Ingeniería de Alimentos para el Desarrollo, Universitat Politècnica de València, Valencia, Spain

${ }^{b}$ Institute for Industrial, Radiophysical and Environmental Safety (ISIRYM), Universitat Politècnica de València, Valencia, Spain 'Speaker (bruno.melgarc@gmail.com)

Color perception has been crucial on the selection and ingestion of food products. Since the beginning of the mankind, color parameters were related primarily to food quality and safety.

Food industry has employed several synthetic colorants obtained from mineral or chemical resources, the advantage of those colorants are their high stability in the food matrixes and the low concentrations needed to give the desired color.

In the other hand, due to the constant research and improvement on the food safety field, some drawback has emerged, arising the awareness of the consumers, who constantly demands to the food industries for minimal processed food and synthetic additives free, opening new research lines focused on the replacement of synthetic for natural obtained colorants.

In addition, food chain productions generate humongous quantities of food by-products, which according to their origin and composition might been used in different applications, from simple fodder until more refined process for recovery of different biomolecules with 
functional properties, called thickeners, acidity regulators, foaming or antifoaming agents, antioxidants, colorants, among others.

The research ongoing, works in the utilization of food by-products from Opuntia spp. fruits for the obtention of natural colorants with antioxidant properties, which could be used as an alternative to synthetic colorants helping at the same time on scavenging of free radical that could prevent many diseases caused by oxidative stress. 


\section{Anexo 3}

En el capitulo VI en la sección 1.2 se menciona la elaboración de curvas de adsorción y desorción de Opuntia ficus-indica var. Sanguignea así como el uso de 7 modelos distintos, los cuales por simplificación de resultados, se expone en esa sección solo el modelo que major se adapto a los datos experimentales, pero acontinuación se presentan la comparativa del resto de los modelos y las tablas con las regresiones correspondientes.

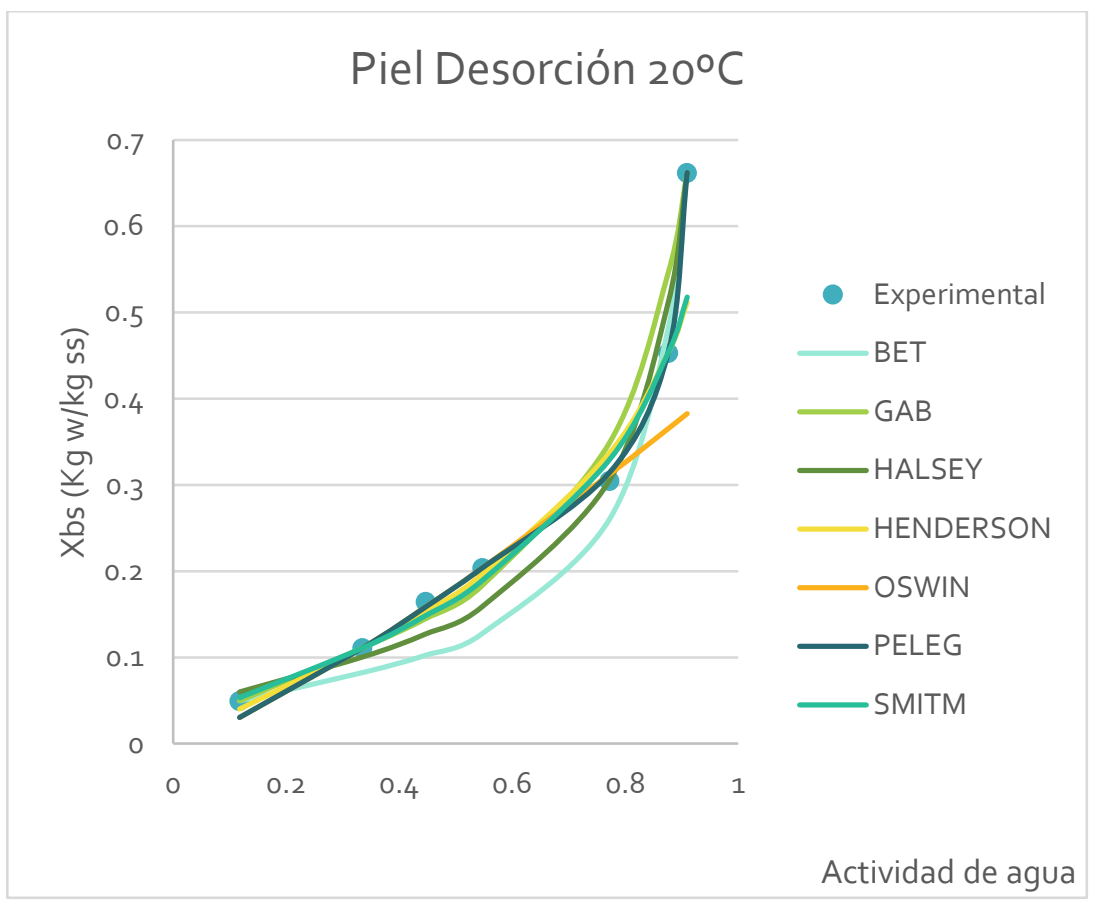

Figure 8-1 Desorption isotherms of $\mathrm{OFI}$ Sanguigna at $20^{\circ} \mathrm{C}$ (source: private collection) 


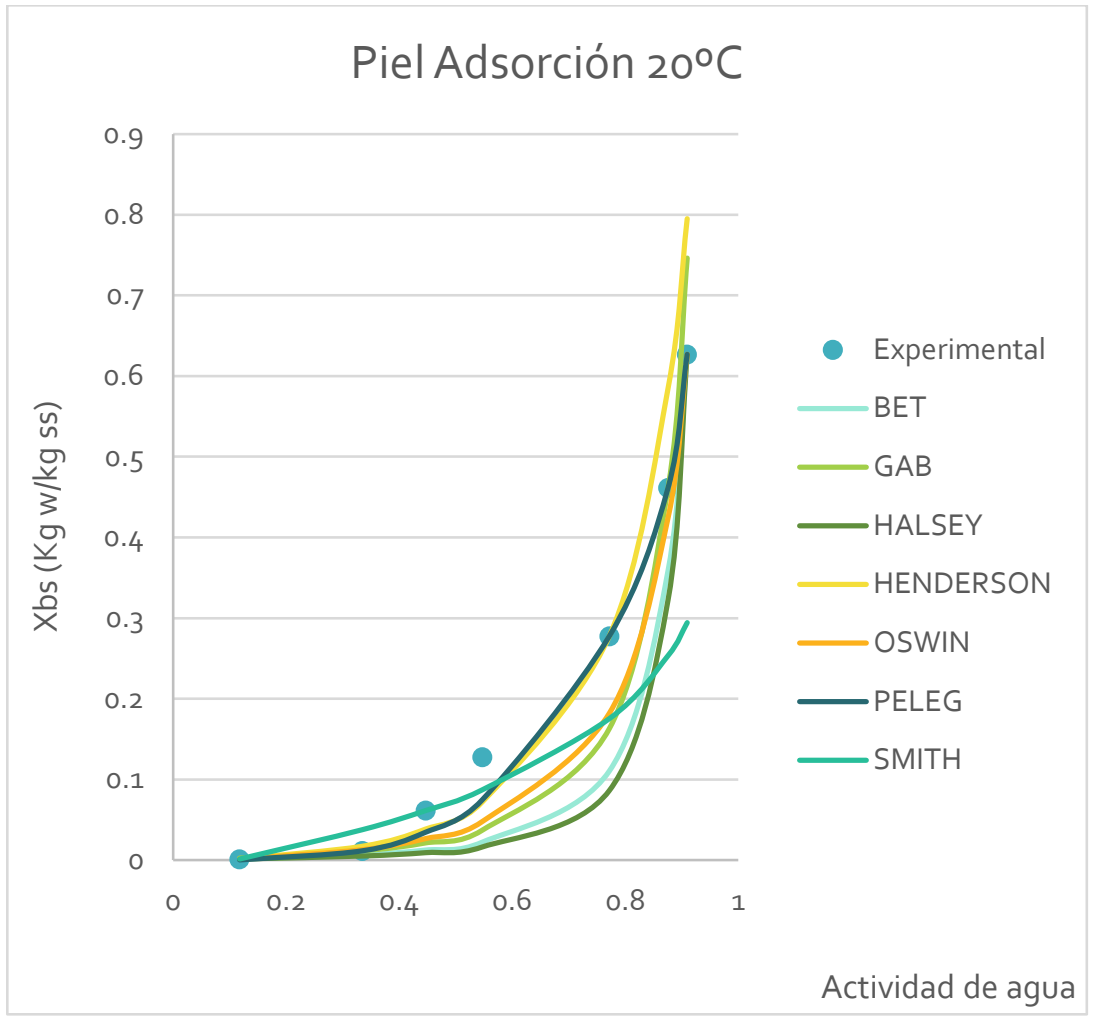

Figure 8-2 Adsorption isotherms of $\mathrm{OFI}$ Sanguigna at $20^{\circ} \mathrm{C}$ (source: private collection) 


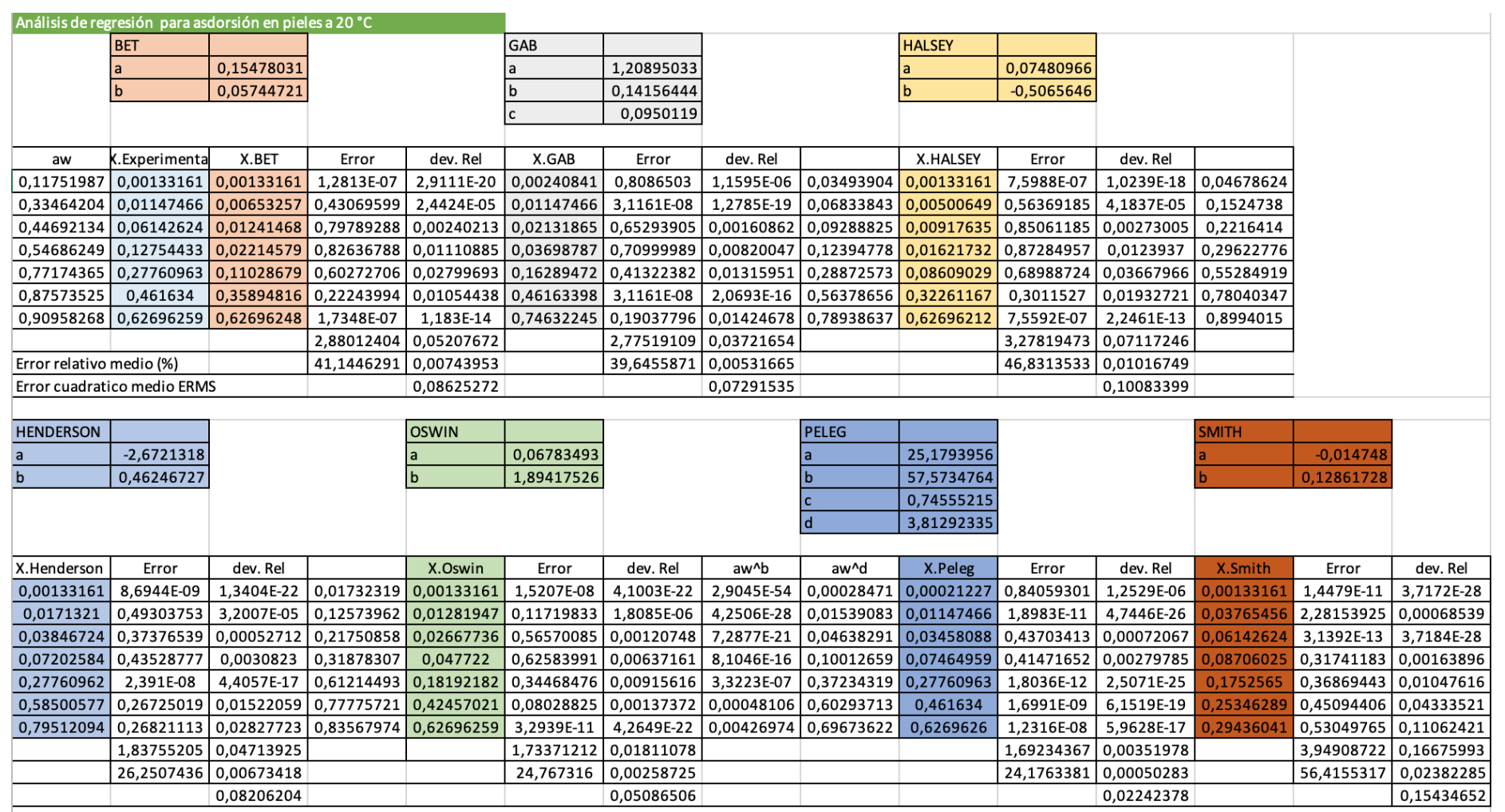

Figure 8-3 Adsorption isotherms regressions of $O F I$ Sanguigna at $20^{\circ} \mathrm{C}$ (source: private collection) 


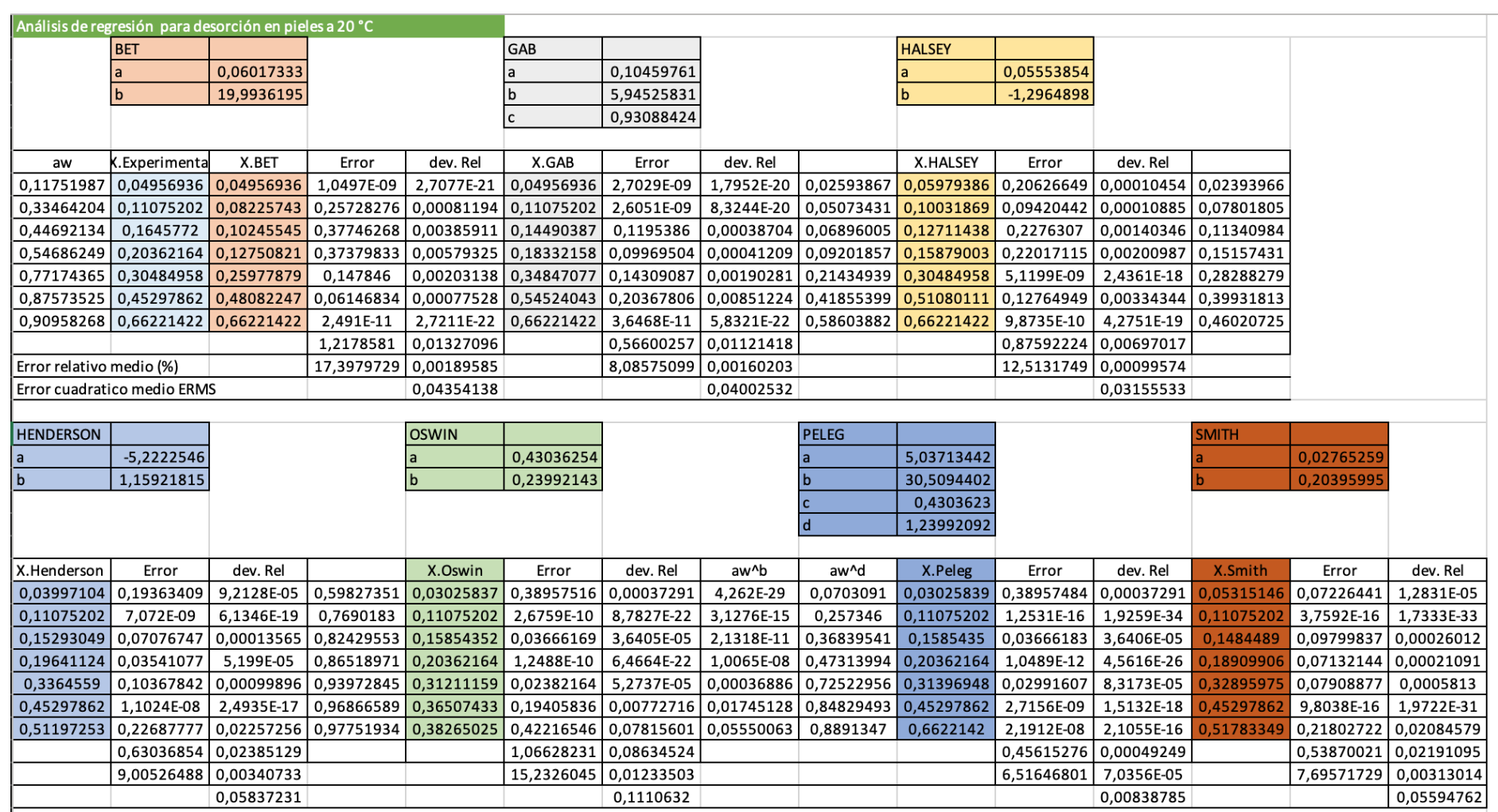

Figure 8-4 Dessorption isotherms regressions of $O F I$ Sanguigna at $2{ }^{\circ} \mathrm{C}$ (source: private collection) 